\title{
Diuncrivg
}

\section{Le Caire}

Dessiné et photographié au XIXe siècle

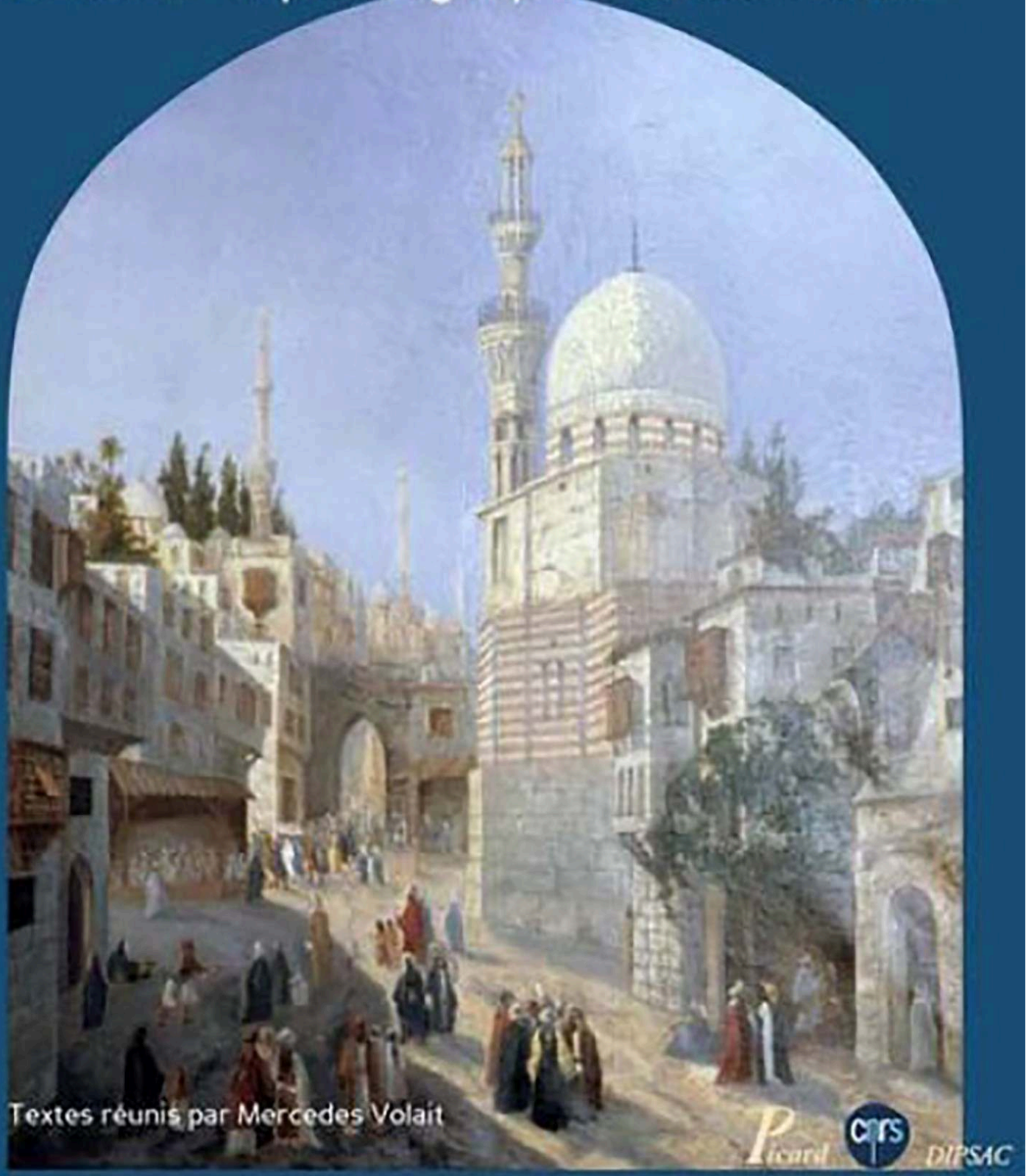




\section{Le Caire dessiné et photographié au XIX ${ }^{\mathrm{e}}$ siècle}

\section{Mercedes Volait (dir.)}

DOI : 10.4000/books.inha.4853

Éditeur : Publications de l'Institut national d'histoire de l'art, Picard

Lieu d'édition : Paris

Année d'édition : 2013

Date de mise en ligne : 5 décembre 2017

Collection : InVisu

ISBN électronique : 9782917902806

\section{Sbooks}

http://books.openedition.org

\section{Édition imprimée}

Date de publication : 1 janvier 2013

ISBN : 9782708409415

\section{Référence électronique}

VOLAIT, Mercedes (dir.). Le Caire dessiné et photographié au XIX ${ }^{X}$ siècle. Nouvelle édition [en ligne] Paris : Publications de l'Institut national d'histoire de l'art, 2013 (généré le 18 décembre 2020). Disponible sur Internet : <http://books.openedition.org/inha/4853>. ISBN : 9782917902806 . DOI : https://doi.org/10.4000/books.inha.4853.

Ce document a été généré automatiquement le 18 décembre 2020.

(C) Publications de l'Institut national d'histoire de l'art, 2013

Conditions d'utilisation :

http://www.openedition.org/6540 
Depuis la grande expédition d'Égypte qui marqua les esprits, seuls des voyageurs aussi célèbres que Maxime Du Camp et Gustave Flaubert sont restés dans les mémoires, alors que d'autres sont complètement oubliés ou connus des seuls spécialistes.

Pourtant, leurs travaux restent des sources irremplaçables sur une ville en grande partie disparue. En effet, tout au long du XIX ${ }^{\mathrm{e}}$ siècle, beaucoup de monuments périrent faute d'entretien et à partir des années 1870, le khédive Ismaïl entreprit des travaux d'embellissement pour donner à la capitale de l'Égypte un aspect européen, aux prix d'importantes démolitions. Tous ces voyageurs, architectes, peintres, « antiquaires » furent subjugués par l'architecture médiévale du Caire et par le décor géométrique de ses bâtiments civils et religieux. Ils tentèrent à travers leurs dessins, photographies et relevés de faire connaître ces richesses artistiques que certains prévoyaient de publier dans des recueils, dont quelques-uns virent le jour.

Ce livre a pour vocation de sortir de l'ombre ces passionnés qui offrent encore aujourd'hui des témoignages uniques assortis souvent de descriptions de dessins, de photographies ou d'écrits théoriques en règle générale peu accessibles. Un ensemble de spécialistes met ici en valeur ces documents tombés dans l'oubli et présente des synthèses de leurs œuvres et de leurs apports à la connaissance du Caire médiéval.

La présente version numérique est revue et corrigée par rapport à la version publiée en 2013 aux éditions Picard. 
Un art architectural et ornemental découvert dans les monuments du Caire Mercedes Volait

La mise en images des monuments du Caire

Absences et omissions

La théorie critique à l'épreuve des sources

La représentation architecturale de l'Égypte dans les Expositions universelles

Présence du Caire dans la culture artistique du XIX ${ }^{e}$ siècle

\section{Les monuments par le dessin}

„Mein Fritz geht nach Aegypten !” Friedrich Maximilian Hessemer sur les traces de l'arc brisé au Caire

Maryse Bideault

Vers l'Égypte

Au Caire

Du morcellement à la totalité, de la division à l'unité. En quête d'une résolution conciliatrice

James Wild, Cairo and the South Kensington Museum

Abraham Thomas

"Ceci aura néanmoins probablement son utilité. " Willem de Famars Testas au Caire, $1858-1860$

Jan de Hond

Willem de Famars et l'expédition d'Émile Prisse d'Avennes en Égypte

Le fonds Prisse d'Avennes à la Bibliothèque nationale de France

La contribution de Testas à L'Art arabe

Photographies

Travail personnel

D'une exactitude scrupuleuse et artistiquement accomplie : Le Caire dans l'œuvre graphique de Jules Bourgoin

Maryse Bideault

En Égypte dans les années 1863-1866 : pour une généalogie graphique des arts arabes

Les années 1880-1884 et le Précis de l'art arabe

František Schmoranz le Jeune (1845-1892)

Milan Němeček

\section{De l'estampage à la photographie}

Victorien Pierre Lottin de Laval et la Lottinoplastie Nicole Zapata-Aubé

Première mission en Orient : 1843-1846

Le procédé de moulage breveté sous le nom de Lottinoplastie ou Lottinoplastique

La découverte de Ninive

Seconde mission officielle 1850-1851 : Voyage dans la péninsule arabique du Sinaï et l'Égypte Moyenne

L'époque des amateurs : 1839-1860

Hélène Bocard 
La redécouverte d'un précurseur : Joseph-Philibert Girault de Prangey (1804-1892)

Sylvie Aubenas

L'œuvre méconnu d'un voyageur érudit

Girault de Prangey et la pratique du daguerréotype

Histoire de la collection

Topographical Photography in Cairo: The Lens of Beniamino Facchinelli Ola Seif

"Rue du Caire" : Beyond the World Fairs's representation

Facchinelli's contribution to Cairene domestic architecture

À travers Le Caire, l'œuvre de Gervais-Courtellemont en Égypte de 1894 à 1911

Emmanuelle Devos

Jules Gervais-Courtellemont (1863-1931)

Le Caire reproduit en noir et blanc

Le Caire projeté en couleurs

Photographes du Caire dans le dernier tiers du XIX siècle : les ateliers commerciaux Thomas Cazentre

Abdullah Frères (1858-1899)

Antonio Beato (ca. 1825-1906)

Émile et Hippolyte Béchard (actifs entre 1870 et ca. 1880)

Maison Bonfils (1867-1932)

G. Lekegian (actif entre 1887 et 1925 environ)

Pascal Sebah; Sebah et Joaillier ; Jean Pascal Sebah

Georges et Constantin Zangaki (ca. 1880-1915)

Autres photographes

\section{Théories et histoires de l'art islamique}

Astrées polygonales, galérites pyramidales, sycomores " arrondis comme des dômes ", palmiers " élancés comme des minarets »: Le Caire d'Adalbert de Beaumont Chantal Bouchon

Au Caire

Retour d'Égypte

Visiter Le Caire en compagnie d'Émile Isambert, auteur de l'Itinéraire descriptif de

l'Orient

Hélène Morlier

Les « modèles » et les guides précurseurs de l'Itinéraire descriptif de l'Orient (1861)

Le Guide en Orient de Richard et Quétin (1851)

Julius Franz-Pasha's Die Baukunst des Islam (Islamic architecture) of 1887 as part of the Manual of Architecture

Elke Pflugradt-Abdel Aziz

Background to Die Baukunst des Islam (The Islamic architecture)

The origin of Die Baukunst des Islam

The critical reception of Die Baukunst des Islam

Max Herz Pasha on Arab-Islamic Art in Egypt

István Ormos

«Mudéjar » et identité nationale en Espagne au XIXe siècle

Antonio Urquízar Herrera

Amador de los Ríos et El estilo mudéjar en arquitectura

Mudéjar et identité nationale 
Ugo Monneret de Villard et la découverte de l'Oriente entre Croce et Strzygowski Silvia Armando

L'influence de Benedetto Croce

Josef Strzygowski et la quête des origines de l'architecture médiévale

L'archéologue Monneret de Villard 


\title{
Un art architectural et ornemental découvert dans les monuments du Caire
}

\author{
Mercedes Volait
}

1 À l'heure où les collections d'art islamique sont mises à l'honneur et redéployées dans tous les grands musées du monde, du Metropolitan Museum of Art de New York, qui a inauguré en 2012 ses nouvelles salles consacrées «à l'art des territoires arabes, de la Turquie, de l'Iran, de l'Asie centrale et du sous-continent indien tardif » (en bref, à ce qu'il dénommait auparavant "art islamique»), au Museum für Islamische Kunst (installé dans une aile du Pergamonmuseum, Staatliche Museen zu Berlin) qui entend tripler l'espace dévolu à l'art islamique d'ici 2019, en passant par le nouveau département des Arts de l'Islam créé au musée du Louvre, il est à propos de rappeler le rôle joué par l'architecture et l'ornement dans la réception en Occident des univers artistiques propres au monde musulman. C'est en effet par les monuments et les entrelacs découverts en Andalousie et au Moyen-Orient que l'Europe des arts et du goût a commencé à apprécier comme forme artistique à part entière ce qu'elle a longtemps nommé « l'art arabe » - conquête de l'Algérie oblige - avant de percevoir les similitudes entre art andalou, copte ou persan et dès lors forger l'idée d'art "sarrasin", «mahométan», et désormais «islamique», en référence non pas à la religion musulmane, mais à la civilisation qui prospéra en terre d'islam.

\section{La mise en images des monuments du Caire}

2 Les monuments du Caire - ville sacrée « capitale par excellence de l'art arabe » en 1881 - ont été, aux côtés de l'Alhambra ${ }^{1}$ et des édifices de la Perse, les protagonistes majeurs de cette appréciation. Impressionnants par leur quantité - plus de 800 identifiés dès 1880 , dont environ 500 ont survécu jusqu'à nos jours ${ }^{2}-$, par leur diversité (l'architecture religieuse comme l'architecture militaire, commerciale ou résidentielle), par la richesse de leurs décors (travail du bois, du marbre, du stuc...), ils ont attiré tout 
au long du XIX $\mathrm{X}^{\mathrm{e}}$ siècle des cohortes de peintres, dessinateurs, photographes, dont la plupart ont été bien oubliés depuis.

3 Ainsi les mêmes jalons de la découverte de l'architecture du Caire sont-ils inlassablement repris: les planches gravées, approximatives, des artistes de la Commission des sciences et des arts qui accompagnèrent Bonaparte en Égypte en 1798, le recueil produit par l'architecte marseillais Pascal-Xavier Coste à l'issue de relevés exécutés entre 1817 et $1822^{3}$, les publications de l'artiste et antiquaire Émile Prisse d'Avennes $^{4}$ ou encore celles du théoricien de l'ornement Jules Bourgoin ${ }^{5}$; les illustrations de surcroît sont citées sans être passées au crible d'une véritable critique de sources. L'étude en cours des papiers de Jules Bourgoin montre bien pourtant ce que l'on gagne à tenter de percer les logiques qui animent pareils relevés 6 . Si ces grandes enquêtes eurent un impact et une notoriété décisifs, elles ne constituent d'autre part que la partie émergée de l'iceberg d'un phénomène de bien plus grande amplitude, ainsi qu'on le découvre chaque jour davantage à la seule exploration des collections patrimoniales françaises 7 . À partir de la fin des années 1870, Le Caire se trouvait à 7 jours de Marseille ; la commodité du voyage, la sûreté de la ville, la douceur du climat hivernal, la facilité des contacts, firent le reste : d'innombrables artistes, dessinateurs, calotypistes visitèrent la capitale égyptienne et représentèrent ses monuments, avec les projets artistiques ou documentaires les plus divers, tout au long du XIX ${ }^{e}$ siècle. On a tenté d'offrir ici un panorama renouvelé de cette curiosité, en mettant d'une part l'accent sur des figures méconnues voire inconnues, et en tentant d'autre part de dépasser le biais national qui conduit à ne regarder depuis la France que les artistes français, ou depuis l'Angleterre les seuls voyageurs anglo-saxons, au risque d'isoler artificiellement des entreprises qui purent être liées sur place, en résonance ou en concurrence. Le cas du photographe italien Benjamin Facchinelli (?-1899) ${ }^{8}$, qui travaillait sur commande pour les amateurs français Arthur Rhoné et Ambroise Baudry, membres d'un groupe international de défenseurs du patrimoine cairote, en offre un exemple éclairant pour la fin du XIX $x^{e}$ siècle. L'ambition de l'ouvrage est ainsi de proposer quelques jalons pour une histoire globale et connectée de l'antiquariat consacré aux monuments du Caire au XIX ${ }^{\mathrm{e}}$ siècle.

\section{Absences et omissions}

Nombre d'artistes hexagonaux ne figurent pas dans le présent recueil, faute de travaux en cours sur leur œuvre ou leur périple. Au XIX ${ }^{e}$ siècle, la visite des monuments du Caire tenait lieu de Grand Tour à de nombreux d'architectes ${ }^{9}$. Ce n'est plus à Rome ou à Athènes que l'on se faisait l'œil et la main, mais dans les nécropoles du Caire, ou les cours de ses mosquées historiques. Achille Joyau (1831-1873) s'échappait régulièrement de la Villa Médicis pour donner libre cours à son pinceau dans les ruelles de la capitale égyptienne. Bien avant lui, Gabriel Toudouze (1811-1854), élève de Labrouste et talentueux aquafortiste, avait entrepris d'envoyer au Salon les éléments d'un travail commencé en 1843 sur l'architecture religieuse et sépulcrale du Caire (fig.1), interrompu par sa disparition prématurée ${ }^{10}$. L'étude devait aboutir à la publication de "Souvenirs de voyage " dont seule la première livraison parut ${ }^{11}$. Parmi les architectes de l'École des beaux-arts dont les travaux furent récompensés, à partir de 1881, par une bourse de voyage généreusement dotée, plusieurs choisirent de sillonner la Méditerranée orientale. Fils du Grand Prix de Rome Alfred Normand, Paul Normand 
(1861-1945) rapporta, d'un séjour de plusieurs mois au Caire en 1894, un reportage photographique détaillé des grandes mosquées funéraires de la Cité des morts ${ }^{12}$. Malheureusement, aucun de ces voyages n'a été jusqu'à présent étudié.

5 On peut en dire autant de bien des excursions de peintres. Amable Crapelet (1822-1867) se rendit régulièrement en Égypte à partir de 1852, et en rapporta des centaines de dessins (fig. 2), en partie conservés au département des Arts graphiques du Louvre et dans des collections particulières comme l'atteste le nombre de ses aquarelles égyptiennes passées en vente publique ces dernières années ${ }^{13}$. Si l'art de Crapelet passe pour avoir sacrifié la vérité locale à la recherche de l'effet, certains dessins aquarellés ont, en plus de leurs chatoyantes colorations, une précision toute archéologique ${ }^{14}$. Prosper Barbot (1798-1878), illustrateur du voyage d'Alexandre Bida, effectua le voyage d'Égypte en 1844-1846, et rapporta lui aussi de nombreuses vues du Caire. Il faudrait encore pouvoir rouvrir le dossier de l'éclatante peinture topographique de Prosper Marilhat - encore trop peu étudiée - ou des dessins archéologiques d'Adrien Dauzats, pour n'évoquer que les artistes français.

Un autre grand absent est Léon de Laborde (1807-1869). L'archiviste, diplomate et historien d'art est surtout connu pour son rapport De l'Union des arts et de l'industrie, rédigé pour l'Exposition universelle de Londres de 1851 en vue de défendre l'art français à l'âge de la révolution industrielle et les possibilités de son renouveau en s'appuyant sur l'architecture. Ses années de formation furent nourries de voyages au Moyen-Orient, qui passaient inévitablement par Le Caire, où il séjourna en 1826 et 1827. L'expérience était limitée dans le temps, mais aurait été fondatrice - plus de 30 ans plus tard, ses écrits continuaient à y faire référence ${ }^{15}$. Sa curiosité va bien au-delà de l'architecture, puisqu'on lui doit, entre autres, un surprenant texte sur la magie ${ }^{16}$ qui offre l'indice d'un intérêt plus large pour la culture et la société locales, qu'il partagea avec d'autres contemporains comme son ami le vicomte Aldabert de Beaumont.

1. Gabriel toudouze, Route du Caire à Suez, Tombeaux des [illisible].

Gravure destinée à l'illustration de l'ouvrage : Alfred maury, Album des souvenirs de voyages. Orient. Vues des monuments les plus célèbres de Jérusalem et du Caire, dessinées sur nature et gravées à l'eau forte par Gabriel Toudouze, texte par Alfred Maury. 


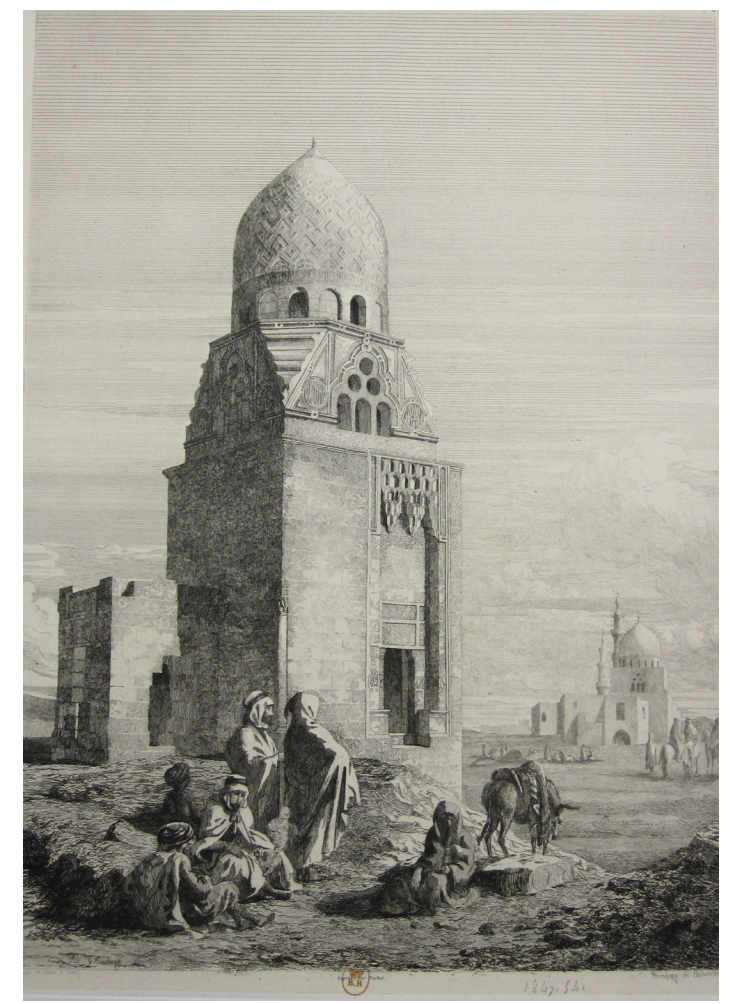

Source : Paris (France), Bibliothèque nationale de France, département des Estampes et de la Photographie.

2. Amable CRAPELET, Entrée d'une mosquée au Caire. [mosquée al-Shawazliyya, 1754], aquarelle, vers 1853.

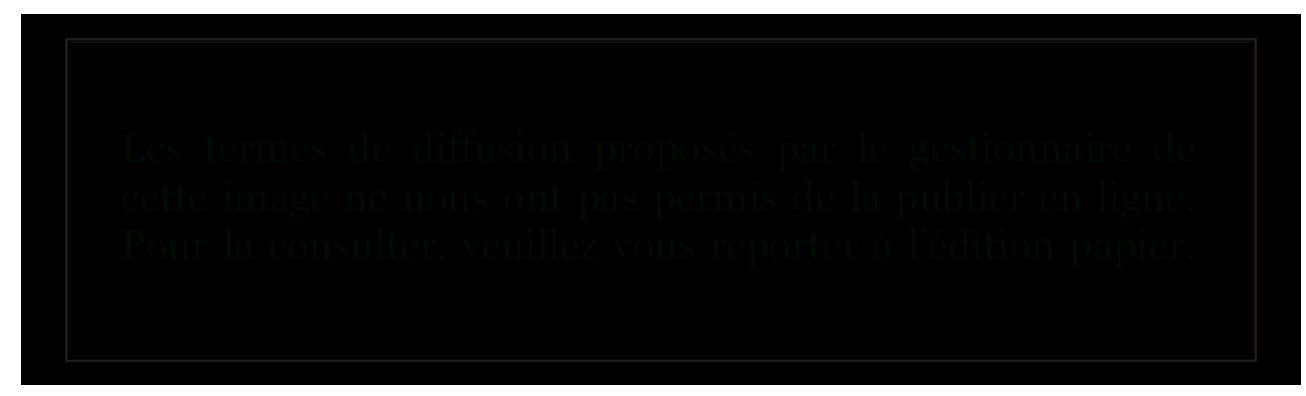

Source : Paris (France), musée du Louvre.

\section{La théorie critique à l'épreuve des sources}

La bibliographie anglo-saxonne, et en particulier celle se reconnaissant sous la bannière de la "théorie critique", souligne l'artificialité produite par ces représentations européennes d'architecture islamique, et plus encore leur caractère normatif en matière de figuration spatiale et urbaine ${ }^{17}$. Les stratégies et les charges idéologiques du regard à l'œuvre dans bien des images produites par les artistes ou les commentaires des historiens d'art étrangers à l'Égypte ont été abondamment commentées et dénoncées ${ }^{18}$. Antonio Urquizar et Silvia Armando montrent ici dans quelles perspectives intellectuelles, et avec quels attendus, des savoirs sur l'architecture vernaculaire se sont développés en Espagne ou en Italie ${ }^{19}$. La découverte 
de l'architecture de style mudejar avait un but politique à peine dissimulé. Quant à l'archéologue Monneret de Villard, il a hésité longuement entre diverses influences intellectuelles, tiraillé par les turbulences des époques pendant lesquelles il a exercé.

Il est peu douteux que d'une image à l'autre, quelque chose de l'ordre de «lieux communs visuels" s'est constitué dans l'imaginaire européen relatif au Caire. La remarquable monographie consacrée par l'historien Douglas Nickel à l'un des premiers « artistes topographiques » venu en Égypte, le photographe Francis Frith (1822-1898) ${ }^{20}$, pointe cependant, en s'appuyant sur une solide documentation, combien la seule critique idéologique, externaliste, d'un œuvre figuré peut être impuissante à en capter les déterminants et les enjeux, quand elle ne s'égare pas dans les contresens et les contre-vérités ${ }^{21}$. Ainsi l'auteur montre-t-il par exemple que doté d'une fortune personnelle, Frith n'avait pas les visées purement commerciales qui lui ont été prêtées. Grâce aux archives privées auxquelles il a eu accès, et en particulier au journal intime du photographe, il peut établir que son aventure orientale fut d'abord d'ordre spirituel. Invalidée par la confrontation au matériau empirique, l'analyse purement critique des images rencontre en l'occurrence une limite forte.

Plutôt qu'à celle d'idées abstraites et désincarnées, conduisant à des interprétations peu étayées, c'est à une histoire des pratiques qu'il convient plutôt de s'atteler, dans une perspective qui prend en compte non seulement la biographie de l'artiste et la matérialité de sa production graphique, mais s'intéresse également à la fabrication technique des images, à leurs commanditaires, à leur circulation, à leur éventuelle publication, à leur réception, à leurs connexions avec d'autres représentations visuelles ou textuelles, à leurs obsessions ou omissions, etc. C'est dans cette perspective que les conditions de l'enquête comme les opérations qu'elle engage (techniques d'estampage ou procédés photographiques ${ }^{22}$, par exemple) ont été détaillées dans ces pages chaque fois que l'information existait. L'iconographie des artistes et amateurs en voyage n'a pas été négligée et peut s'avérer très éclairante (fig. 3). Ainsi cette rare représentation d'un intérieur de dahabiyya occupé par des Européens en habits égyptiens, due à Aldabert de Beaumont, suggère que le dépaysement oriental était aussi affaire de style de vie et d'incorporation de postures et de vêtures étrangères à sa propre culture. 
3. [Artiste européen sur le motif] in Commission de l'Égypte (Paris), [Recueill. Dessins réalisés lors de l'expédition d'Égypte pour la Commision d'Égypte], tome II bis, s. I. n. d.

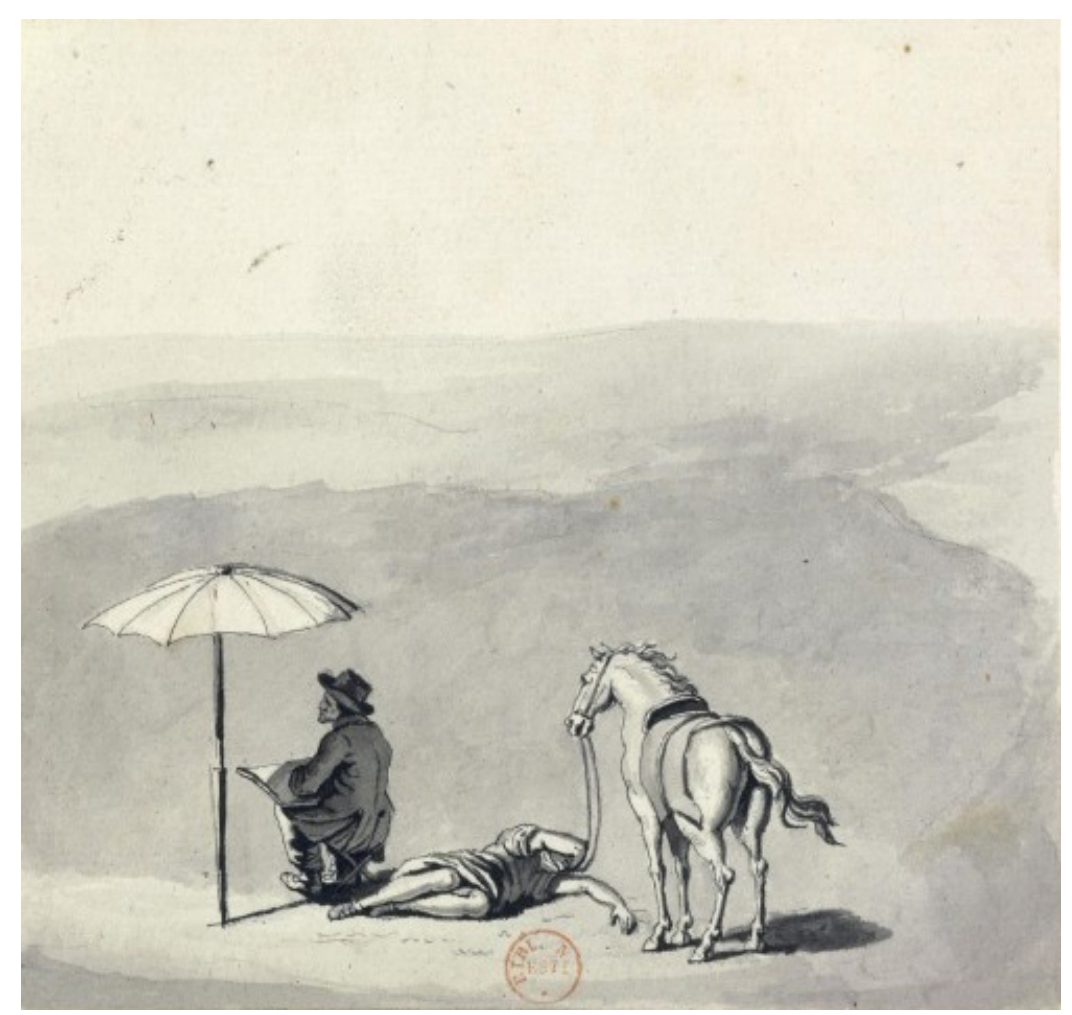

Source: Paris (France), Bibliothèque nationale de France, département des Estampes et de la Photographie.

\section{La représentation architecturale de l'Égypte dans les Expositions universelles}

L'incomparable effort documentaire appliqué au Caire au XIX siècle a peu d'équivalent. Rares sont les villes historiques - hormis Rome ou Paris - à avoir bénéficié de pareil investissement. Les projets picturaux et éditoriaux qui l'animent sont très divers, et parfois bien surprenants à l'image de la curieuse théorie développée par Adalbert de Beaumont sur l'origine marine, et plus précisément "madréporique ", du décor rayonnant de l'ornement islamique ${ }^{23}$.

11 La représentation architecturale de l'Égypte dans les expositions internationales est un autre moteur décisif. Pour concevoir l'imposant ensemble de pavillons édifiés à Vienne en 1873 au temps de la plus grande splendeur du règne khédivial, l'architecte tchèque František Schmoranz le Jeune ${ }^{24}$ entreprit le relevé détaillé de plusieurs mosquées du Caire, ainsi que de la fameuse maison du Mufti, visitée par tant de voyageurs européens à partir de 1865. Ses dessins rehaussés d'aquarelles sont aujourd'hui la seule trace existante de la mosquée Azbak, disparue depuis bien longtemps. De cette immersion prolongée dans le patrimoine monumental du Caire, Schmoranz tira un ensemble de constructions savamment pensées et d'habiles proportions, dont un mausolée et un minaret à la mamelouke, qui font nettement illusion. On peut en dire à peu près autant des rues du Caire reconstituées à Paris en 1889 ou à Chicago en 1893 : si la critique en a surtout le caractère folklorique en raison des animations qui y avaient cours (transport 
à dos d'âne, travail artisanal ou danse du ventre), ce sont d'abord des tours de force architecturaux animés par un parti de véracité - au point que la copie est souvent prise pour l'original : il n'est que de considérer les nombreuses toiles intitulées « Rue du Caire » qui passent pour représenter une rue cairote, alors qu'elles n'en illustrent en fait que l'avatar parisien ou américain. La rue présentée à Paris en 1889 était d'ailleurs due à un connaisseur, le collectionneur d'art islamique Alphonse Delort de Gléon, dont les collections, patiemment assemblées en Égypte, et assorties d'un legs, sont à l'origine de la section musulmane du musée du Louvre ${ }^{25}$; la reconstitution de l'Exposition de 1893 est l'œuvre d'un architecte qui dirigea pendant 25 ans avec dévouement, talent et compétence la restauration des monuments du Caire, Max $\mathrm{HerZ}^{26}$, dont l'œuvre au sein du Comité de conservation des monuments de l'art arabe est ici retracée.

\section{Présence du Caire dans la culture artistique du XIX siècle}

12 L'expérience fut déterminante pour tous les voyageurs évoqués. Certains en tirèrent profit pour la suite de leur carrière comme Willem de Famars Testas qui devint « le » peinte orientaliste néerlandais. D'autres comme James Wild ${ }^{27}$, Julius Franz pacha ${ }^{28}$ et Max Herz bey se dévouèrent à la cause des arts islamiques en fondant des musées ou en protégeant coûte que coûte le patrimoine architectural menacé du Caire. Réfugié en Normandie après avoir échoué à faire reconnaître ses travaux, Lottin de Laval continua de peindre l'Orient qui l'avait subjugué et créa son propre musée pour abriter les estampages et moulages rapportés d'Égypte.

13 C'est une somme de connaissances non négligeable qui a été ainsi constituée, exposée et transmise au XIX ${ }^{e}$ siècle sur une ville extra-européenne. Produite par des amateurs érudits, partis en solitaire ou membres de missions savantes, cette connaissance a parfois bien vieilli, mais elle témoigne d'une proximité effective avec des architectures, des formes ornementales, une culture et une société, qui sont redevenues, à mesure que le $\mathrm{xx}^{\mathrm{e}}$ siècle réifiait les avant-gardes et le primitivisme, périphériques à l'histoire de l'art, et désormais très étrangères à l'honnête homme d'aujourd'hui.

\section{NOTES}

1. Mariam ROSSER-OWEN, Islamic Arts from Spain, Londres : V\&A Publishing, 2010.

2. Nicholas WARNER, The Monuments of Historic Cairo: A Map and Descriptive Catalogue, Le Caire : The American University in Cairo Press, 2005 (American Research Center in Egypt Conservation series, 1).

3. Xavier Pascal coste, Architecture arabe, ou Monuments du Kaire, mesurés et dessinés, de 1818 à 1826, Paris: Firmin-Didot 1837 ; Dominique JACOBI (dir.), Pascal Coste, Toutes les Égypte, Marseille: Parenthèses, 1998.

4. Visions d'Égypte: Émile Prisse d'Avennes (1807-1879), catalogue d'exposition (Paris, Bibliothèque nationale de France, $1^{\mathrm{er}}$ mars-5 juin 2011), Paris : BnF ; Musée du Louvre, 2011. 
5. Jules BOURGOIN, Les Arts arabes, architecture, menuiserie, bronzes, plafonds, revêtements, marbres, pavements, vitraux, avec un texte descriptif et explicatif et le trait général de l'art arabe, Paris: $\mathrm{V}^{\mathrm{ve}} \mathrm{A}$. Morel et $\mathrm{C}^{\mathrm{ie}}, 1873$.

6. Voir Maryse BIDEAULT, « D'une exactitude scrupuleuse et artistiquement accomplie : Le Caire dans l'œuvre graphique de Jules Bourgoin », in Mercedes volait (dir.), Le Caire dessiné et photographié au XIXe siècle, Paris: Picard, 2013, p. 95-116. URL: http://inha.revues.org/4875. Consulté le 15 mai 2016.

7. Maryse BIDEAULT, L'iconographie du Caire dans les collections patrimoniales françaises, Rapport pour le ministère de la Culture et de la Communication, 2010 (inédit). URL : http://inha.revues.org/ 4617. Consulté le 2 mai 2016.

8. Voir Ola SEIF, «The Lens of Beniamino Facchinelli », in Mercedes VOLAIT (dir.), op. cit. (note 6), p. 195-214. URL : http://inha.revues.org/4884.

9. Mercedes volait, Fous du Caire: Architectes, excentriques et amateurs d'art islamique en Égypte (1867-1914), Forcalquier : L'Archange minotaure, 2009.

10. Je remercie Marc Le Cœur pour m'avoir montré le bel ensemble qui en subsiste dans les collections du département des Estampes et de la Photographie de la BnF.

11. Vues des monuments les plus célèbres de Jérusalem et du Caire, dessinées sur nature par Gabriel Toudouze, texte par Alfred Maury, Paris : chez l'auteur, 1853.

12. Albums conservés à la bibliothèque municipale de Nantes; Maryse BIDEAULT, op.cit. (note 7). URL : http://inha.revues.org/4723. Consulté le 2 mai 2016.

13. Plus d'une centaine d'œuvres référencées sur la seule base Art Price, par exemple, depuis 1997.

14. Maryse BIDEAULT, op. cit. (note 7), p. 63-74. URL: http://inha.revues.org/4752. Consulté le 2 mai 2016.

15. Pascale LINANT DE BELLEFONDS, «Léon de Laborde », in François POUILLON (dir.), Dictionnaire des orientalistes de langue française, Nouvelle édition revue et augmentée, Paris: Karthala, 2012, p. 602-603; voir également Geneviève BRESC-BAUTIER, «Laborde, Léon-Emmanuel-Simon-Joseph (vicomte, comte, puis marquis de)» inDictionnaire critique des historiens de l'art. URL : http:// www.inha.fr/fr/ressources/publications/publications-numeriques/dictionnaire-critique-deshistoriens-de-l-art/laborde-leon-emmanuel-simon-joseph.html. Consulté le 23 novembre 2015.

16. Léon DE LABORDE, Recherches de ce qu'il s'est conservé dans l'Égypte moderne de la science des anciens magiciens. Paris : J. Renouard, 1841.

17. Derek GREGORY, «Emperors of the Gaze : Photographic Practices and Productions of Space in Egypt, 1839-1914 ", in Joan SCHWARTZ and James RYAN (dirs.), Picturing place: photography and the geographical imagination, Londres; New York, NY : I. B. Tauris, 2003 (International Library of Human Geography), p. 195-225.

18. Sans revenir à la critique classique de l'orientalisme par Edward Said, voir par exemple, pour la photographie, Carol ARMSTRONG, Scenes in a library : reading the photograph in the book, 1843-1875, Cambridge, MA : The MIT Press, 1998.

19. Voir ici respectivement Antonio URQUízAR HERRERA, " "Mudéjar" et identité nationale en Espagne au XIX siècle », in Mercedes volait (dir.), op. cit. (note 6), p. 343-360. URL : http:// inha.revues.org/4884; et Silvia ARMANDO, «Ugo Monneret de Villard et la découverte de l'Oriente entre Croce et Strzygowski » in Mercedes volait (dir.), op. cit. (note 6), p. 361-390. URL : http:// inha.revues.org/4901. Consultés le 2 mai 2016.

20. Voir Hélène BOCARD, «L'époque des amateurs : 1839-1860", in Mercedes VOLAIT (dir.), op. cit. (note 6), p. 174-175. URL : https://inha.revues.org/4880.

21. Douglas R. NICKEL, Francis Frith in Egypt and Palestine: A Victorian photographer abroad, Princeton, NJ : Princeton University Press, 2003, p. 9-19. 
22. Voir Jan DE HOND, « “Ceci aura néanmoins probablement son utilité.” Willem de Famars Testas au Caire, 1858-1860», in Mercedes volait (dir.), op.cit. (note 6), p. 69-94. URL: http:// inha.revues.org/4873; et Nicole ZAPATA-AUBÉ, «Victorien Pierre Lottin de Laval et la Lottinoplastie ", in Mercedes VolaIT (dir.), op.cit. (note 6), p.139-156. URL: http:// inha.revues.org/4878. Consultés le 2 mai 2016.

23. Voir Chantal BOUCHON, "Astrées polygonales, galérites pyramidales, sycomores "arrondis comme des dômes", palmiers "élancés comme des minarets" : Le Caire d'Adalbert de Beaumont ", in Mercedes volait (dir.), op. cit. (note 6), p. 245-274. URL : http://inha.revues.org/4893. Consulté le 2 mai 2016.

24. Voir Milan NĚMEČEK, « František Schmoranz le Jeune (1845-1892)», in Mercedes volAIT (dir.), op. cit (note 6), p. 117-138. URL : https://inha.revues.org/4876. Consulté le 2 mai 2016.

25. Mercedes volait, Fous du Caire, op. cit. (note 9).

26. István ORMOS, Max Herz Pasha (1856-1919) - His Life and Career, Cairo : IFAO, 2009. Voir aussi István ORMOS, « Max Herz Pasha on Arab-Islamic Art in Egypt », in Mercedes volAIT (dir.), op. cit. (note 6), p. 311-342. URL : http://inha.revues.org/4898. Consulté le 2 mai 2016.

27. Voir Abraham thомаs, "James Wild, Cairo and the South Kensington Museum ", in Mercedes volAit (dir.), op. cit. (note 6), p. 41-68. URL: http://inha.revues.org/4871. Consulté le 2 mai 2016.

28. Voir Elke PfLUGRADT-ABDEL AZIZ, «Julius Franz-Pasha's Die Baukunst des Islam (Islamic architecture) of 1887 as part of the Manual of Architecture », in Mercedes volAIT (dir.), op. cit. (note 6), p. 297-310. URL : https://inha.revues.org/4897. Consulté le 2 mai 2016.

\section{AUTEUR}

\section{MERCEDES VOLAIT}

Directeur de recherche, InVisu, USR 3103 du CNRS, Paris ; spécialiste de l'architecture en Égypte aux XIX ${ }^{\mathrm{e}}$ et $\mathrm{XX}^{\mathrm{e}}$ siècles. 
Les monuments par le dessin 


\title{
„Mein Fritz geht nach Aegypten!" Friedrich Maximilian Hessemer sur les traces de l'arc brisé au Caire
}

\author{
Maryse Bideault
}

\section{NOTE DE L'ÉDITEUR}

Sauf mention contraire, toutes les œuvres reproduites sont de F. M. Hessemer.

La première impression que l'architecte allemand Friedrich Maximilian Hessemer (fig. 1) eut du Caire, le 15 octobre 1829, était celle d'une ville qui lui apparut comme un contrepoint à Rome où il avait résidé plus d'un an. Il lui était pourtant impossible de dire en faveur duquel des deux endroits penchait la balance de ses sentiments. Il reconnaissait toutefois que Rome n'avait pas produit sur lui, aussi brusquement, une telle émotion. Dans la lumière matinale, le voyageur faisait face à "une mer de maisons, de coupoles, de tours ${ }^{1}{ }^{\prime}$ et se trouvait rapidement immergé dans une cité dont il admettait qu'il fallait en avoir toutes les clés pour en pénétrer le sens, au risque sinon d'en percevoir le chaos très rapidement. Il savait gré à son interprète et serviteur, Hadgieh Soleiman [Haggi Sulayman], de lui être particulièrement attentionné, de tout lui montrer et de lui expliquer ce qu'il devait savoir. 


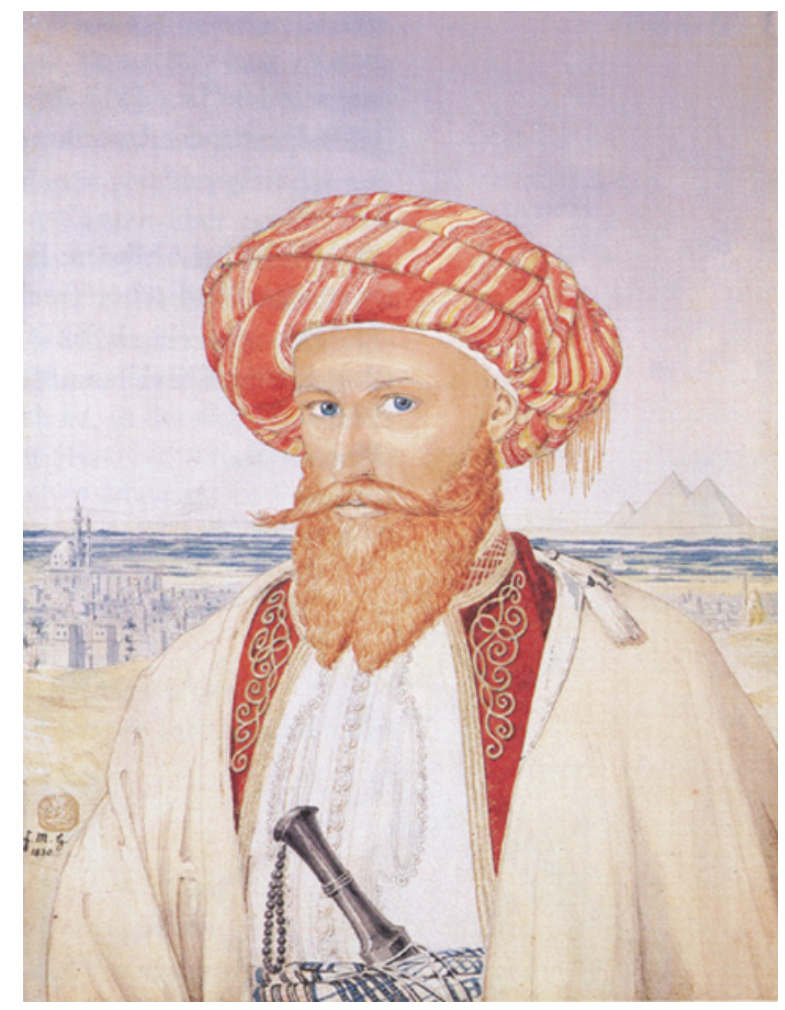

Source: Ein Frankfurter Baumeister in Ägypten, Francfort-sur-le-Main, 2001, p. 243.

2 Ce séjour en Égypte, et plus particulièrement au Caire, en 1829-1830, prit place sous de bons auspices, même si le prétexte de son organisation semblait, à Hessemer déjà, et plus encore à nous, assez étrange : le jeune architecte allemand fut envoyé en Égypte, en tous cas il accepta l'invitation qui lui fut faite avec une grande curiosité, par un Britannique rencontré à Rome, Henry Gally Knight (1786-1846), pour documenter au travers de dessins les preuves de l'origine orientale de l'arc brisé, théorie que l'instigateur du voyage défendait.

De son séjour dont il écrivit qu'il fut marqué à jamais, Hessemer revint avec un grand nombre de dessins et d'aquarelles ${ }^{2}$ qui informent, à des degrés divers, de l'accomplissement de la tâche qui lui avait été confiée. Ce corpus graphique doit être mis en perspective, non seulement en regard de l'histoire figurée du Caire depuis le début du XIX ${ }^{e}$ siècle, mais aussi par rapport à l'œuvre et à la carrière de l'architecte qui fut un des derniers à représenter les monuments du Caire avant l'invention de la photographie.

4 En outre, Hessemer laissa de ce voyage un récit très circonstancié sous la forme d'un journal de voyage et d'une correspondance assidue adressée à son père ${ }^{3}$. Il est intéressant de noter qu'au journal destiné à son père, mais que celui-ci ne pourrait lire qu'une fois le voyageur revenu au pays, s'est substituée une correspondance qui venait, avec davantage de régularité malgré les difficultés d'acheminement du courrier, renseigner et divertir le parent, déjà âgé et malade, demeuré en Hesse. Tous ces documents livrent quantité d'impressions libres, parfois mitigées, riches d'enseignement qui permettent de mieux comprendre le personnage, mais aussi de saisir son appréhension du monde nouveau qui s'ouvrait alors à lui. 
Des nombreux artistes, archéologues ou antiquaires qui voyagèrent en Égypte au cours de la première moitié $\mathrm{du} \mathrm{XIX}^{\mathrm{e}}$ siècle, et plus encore de ceux qui demeurèrent au Caire quelque temps, subsiste un certain nombre de récits, de journaux ou de correspondances qui viennent, par l'écriture de soi, par les émotions exprimées, par les faits rapportés, non seulement enrichir la connaissance que l'on peut avoir des auteurs et des réseaux sociaux dans lesquels ils s'inscrivent, mais aussi les rattacher à leur histoire nationale et éclairer leur manière d'être au monde.

6 Tous ces écrits partagent les évocations du climat difficile à supporter pour un Occidental, climat dont les changements rendent les traversées par mer et voyages sur le Nil aventureux, mais aussi le travail de dessinateur compliqué par les températures excessives, les mentions des épidémies et maladies endémiques de l'Égypte, ou encore les difficultés de relations avec les autochtones comme avec les autorités en place, mais aussi, pour les plus sensibles des diaristes et épistoliers, la surprise, l'admiration ou le dégoût.

7 Hessemer s'est fait un scripteur des plus prolixes et des plus intéressants pour peu que l'on ausculte avec attention ces sources. Car s'il n'a pas assez d'yeux pour noter tout ce qui l'entoure, il n'hésite pas, à plusieurs reprises, à se servir de ses observations pour établir des parallèles ou des comparaisons aboutissant à des réflexions plutôt profondes sur l'histoire de son pays dans son temps.

Ce n'est pas seulement parce qu'ils se trouvaient au Caire au même moment, ou parce qu'ils avaient à peu près le même âge, qu'Hessemer et Nestor L'Hôte (1804-1842) ${ }^{4}$, dans leurs journaux et lettres, partageaient beaucoup de choses. Certes, Nestor L'Hôte, peintre de formation, un des dessinateurs attachés à la mission franco-toscane de 1828-1830, se trouve être là, au sein d'un groupe chargé d'une tâche scientifique, assuré des introductions et des protections que pouvait assurer le prestige de Champollion. Le travail sur les monuments de l'Égypte ancienne était prioritaire, mais quand L'Hôte se trouvait au Caire, il consacrait son temps à parcourir la ville et à dessiner monuments et scènes de rue. Hessemer, architecte de formation, n'était, à son arrivée, agrégé à aucun groupe ; la communauté germanophone était infiniment moins bien représentée que les communautés française ou britannique. Il n'était pas sur place pour dessiner les édifices de l'Égypte ancienne - il le fit toutefois de sa propre initiative - mais ceux du Caire islamique. Il n'en demeure pas moins que les deux jeunes gens éprouvent quantité d'impressions communes.

9 La figure et l'œuvre d'Hessemer ont été remises en pleine lumière par une exposition consacrée au Frankfurter Baumeister in Ägypten ${ }^{5}$, montée en 2001 à Francfort-sur-le-Main et qui offrait au public quelque 104 œuvres et objets exposés, dont un certain nombre encore en mains privées, mais aussi par l'édition critique de son journal de voyage et de sa correspondance ${ }^{6}$.

10 Né le 24 février 1800 à Darmstadt, dans le grand-duché de Hesse, August Wilhelm Friedrich Maximilian Hessemer était le fils du Baurat ${ }^{7}$ Johann Friedrich Bernhard Hessemer (1769-1831). Les liens familiaux avec le milieu architectural local furent renforcés par le mariage, en secondes noces, du père de Friedrich Maximilian avec une des sept sœurs de l'architecte Georg Moller (1784-1852). Arrivé à la conclusion que la carrière militaire choisie pour lui par sa famille ne convenait pas à sa nature, il entreprit des études de sciences et de philosophie à l'université de Giessen. Les années passées à Giessen lui ouvrirent un horizon spirituel et politique. En effet, il s'y lia, entre autres, avec les frères Karl (1796-1840) et August Follen (1794-1855), qui étaient des 
cousins, et avec leur groupe d'étudiants radicaux, les Giessener Schwarzen (ou Germanenbund), une sorte de fraternité étudiante nationale-radicale et républicaine ${ }^{8}$, fondée en 1815, dont les buts étaient de réaliser l'unité allemande, si nécessaire par la force, sur des bases nationalistes, chrétiennes et républicaines. L'appartenance d'Hessemer à cette cellule et son adhésion aux idées d'unité alors prônées se lisent en palimpseste dans la partie théorique développée dans son ouvrage Arabische und AltItalienische Bau-Verzierungen publié en plusieurs livraisons entre 1836 et $1842^{9}$, et conditionnent définitivement son approche des arts de l'Islam mais aussi de l'esthétique de l'ornement.

11 Il effectua son service militaire en 1820, tout en travaillant dans le bureau de son parent, Georg Moller, architecte à Darmstadt ${ }^{10}$, qui joua un rôle important non seulement dans la formation du jeune Hessemer, mais aussi dans le développement d'un attrait pour l'Italie, pour le Moyen Âge et pour l'ornement. La carrière d'architecte entreprise par Hessemer l'amena, en 1824, à la fonction d'Oberbaukondukteur des différentes constructions (églises, écoles, bâtiments officiels etc.) du grand-duché de Hesse, activité qui, si elle ne le passionnait peut-être pas, lui permettait de dessiner au crayon tous les édifices visités, constituant ainsi un ensemble documentaire d'un intérêt inappréciable aujourd'hui ${ }^{11}$. La mise en parallèle des trois grands ensembles de documents graphiques réalisés par Hessemer en quelques années - 1824 pour les localités et édifices de Hesse, 1828-1830 pour l'Italie, et 1829-1830 pour l'Égypte - oblige à admettre que la confrontation avec des paysages et des types de construction totalement différents ou nouveaux n'influa pas sur le style du dessinateur. On reconnaît une permanence dans la mise en place de l'édifice dans le paysage, ainsi qu'un trait de crayon qui n'est nullement bousculé par la rencontre avec soit une lumière différente, soit des matériaux de construction inhabituels ou des polychromies rares.

12 Dans la tradition romantique allemande du Wanderer, Hessemer entreprit en 1827 un voyage vers le sud qu'il débuta, comme Johann Gottfried Seume (1763-1810) ${ }^{12}$ en 1802, seul et à pied, choisissant de partir le même jour de l'année que Johann Wolfgang von Goethe vingt-et-un ans plus tôt, un 3 septembre. Si le pérégrin éprouvait un désir d'Italie, c'est également à son oncle Georg Moller qu'il en était redevable. Ce dernier avait voyagé dans la Péninsule et séjourné à Rome de 1807 à 1810 et conseilla au jeune Hessemer de regarder les édifices médiévaux et lui recommanda aussi de faire, parallèlement aux dessins de paysages et lieux, des carnets où il relèverait des détails d'architecture, d'ornements. Mais il semble ne pas avoir eu de véritable plan. Il pensait être absent d'Allemagne deux ans; en réalité, le voyage dura plus de trois ans. Le but devait être Rome, éventuellement Naples; ce fut finalement l'île de Philae au cœur de l'Égypte.

13 Tout dans le récit qu'Hessemer fit de ce séjour en Italie évoque les liens établis entre ces « ernste Künstler, fröhliche Menschen » [des artistes graves, des hommes joyeux] ${ }^{13}$ qui se retrouvaient et se croisaient à Rome au travers de réseaux artistiques et littéraires, qui s'agitaient dans une savante, mais néanmoins allègre, ambiance et nouaient des amitiés solides dont témoignent les textes laissés dans l'Album Amicorum ou Gedenkbuch ${ }^{14}$, signés des noms les plus célèbres des Allemands de Rome : Georg August Christian Kestner, Joseph Anton Koch, Wilhelm Ahlborn, Jacob Felsing etc. 


\section{Vers l'Égypte}

14 Le voyage fut décidé à Rome au début de l'année 1829. C'est à une rencontre avec l'antiquaire, politicien, écrivain voyageur, théoricien de l'architecture, ami de Walter Scott et de William Wiberforce, mécène de Joseph Mallord William Turner, Lord Henry Gally Knight ${ }^{15}$, qui avait antérieurement commis quelques poèmes (entre autres Ilderim : A Syrian tale (1816) ; Alashtar: An Arabian tale (1817)) ${ }^{16}$ après avoir voyagé en Orient, ce que peu d'écrivains romantiques avaient vraiment fait, qu'Hessemer dut le financement de ce voyage.

15 Cette rencontre, déjà conseillée par Georg Moller dans une lettre adressée à son neveu ${ }^{17}$, fut organisée par l'intermédiaire du diplomate et collectionneur Georg Christian August Kestner ${ }^{18}$, un des fondateurs de l'Institut archéologique allemand de Rome et frère d'un des administrateurs du Städelsches Kunstinstitut de Francfort-surle-Main, et du peintre Theodor Rehbenitz, alors secrétaire du ministre résident de Prusse auprès du Saint-Siège, Christian Carl Josias Freiherr von Bunsen. Henry Gally Knight, qui ne publia qu'à partir de 1836 son premier ouvrage sur l'architecture en Normandie $^{19}$, puis en 1838 et 1840 ses ouvrages sur les Normands de Sicile ${ }^{20}$, se trouvait alors à Rome et avait déjà le projet de rechercher l'origine de l'arc brisé, ou en tierspoint, en Orient. Impressionné par les qualités de dessinateur de Friedrich Maximilian Hessemer qui pouvait lui présenter les dessins d'architecture et d'ornement qu'il avait réalisés en Italie, l'antiquaire distingué proposa au jeune architecte allemand de partir chercher en Égypte les traces des architectures « byzantine et sarrasine » et d'en porter témoignage dans des dessins et relevés ${ }^{21}$. Il y a là, sous-jacents, tous les arguments du débat théorique sur les origines orientales de l'art gothique qui se fit jour, à partir du XVII siècle ${ }^{22}$, sous des expressions les plus variées. Quand il se trouvait à Rome, Henry Gally Knight n'avait pas encore effectué son "voyage archéologique » en Normandie (1831) ni son "excursion monumentale» en Sicile et en Calabre (automne 1836). Toutefois les prémices de son étude étaient déjà là et Hessemer devait assurer la collecte des informations nécessaires. Le jeune architecte hessois adhérait-il à cet argument? Dans une lettre adressée le 26 janvier 1829 à Georg Moller ${ }^{23}$, Friedrich Maximilian Hessemer retraçait la pensée de Gally Knight; mais la missive trahissait également les efforts d'Hessemer pour se persuader du bien-fondé de cette théorie, n'hésitant pas à mettre en parallèle cette démarche avec celle d'une recherche, au travers des langues, de l'origine de l'article. Mais en conclusion, il n'hésitait pas à écrire : „und wenn aber auch diese nicht wäre, so acht ich doch diese Reise für mich von beteutendem Vortheil" [quand bien même ceci ne serait pas, je considère que ce voyage me sera du plus grand bénéfice].

16 Un certain nombre des lettres d'Italie sont pleines des détails de l'organisation du séjour en Égypte, dont Hessemer dit, en s'adressant à son père «si tu savais ce qu'[il] coûte, tu serais effaré ", et qui semble particulièrement bien préparé.

17 Le jeune architecte était muni de documents officiels, de lettres de recommandation et de lettres de crédit, les clauses du contrat signé avec Gally Knight étaient clairement établies. Si le nombre de dessins à fournir n'était pas exactement précisé, le commanditaire laissant à Hessemer le soin de juger de ce qui était à faire, la tâche était définie par un paiement à la pièce : pour une feuille esquissée nécessitant quelque 2 ou 3 jours, 4 écus (Scudi), pour une feuille plus aboutie, qui demandait 5 à 6 jours, 2 louis d'or (Luigi) ${ }^{24}$. Avant de partir pour l'Égypte, Hessemer visita la Sicile, destination qui 
n'était pas envisagée au départ de Darmstadt. Arrivé à Messine le 3 juin 1829, il séjourna sur l'île jusqu'au 8 août, date à laquelle il embarqua pour Malte. Hessemer continua de dessiner, tout d'abord les phares et fortifications des côtes siciliennes, avant de débarquer à La Vallette le 11 du même mois et où l'attente d'un passage pour Alexandrie fut longue. Mais Malte était déjà un premier contact avec l'Orient puisque la fonction d'escale maritime de l'île faisait que s'y croisaient des voyageurs très divers, dont ceux qui commerçaient avec l'Égypte. Dès cette escale, Hessemer fit part dans ces lettres de ce qui n'étaient encore que des petites remarques nostalgiques, qu'il s'agisse du chœur des chasseurs du Freischutz qu'il entendait jouer d'un bateau en partance pour Livourne ou du plaisir qu'il avait à échanger quelques mots d'allemand avec les deux fils d'un marchand d'Augsbourg qui s'en retournaient vers Naples. Le voyageur n'était plus, comme en Italie, entouré d'amis fidèles; il se trouvait désormais seul, en terre étrangère, et commençait déjà à ressentir un certain vague à l'âme, l'appel de l'Heimat.

C'est à bord du Corriere d'Egitto qu'il embarqua enfin le 21 août 1829. Un de ses compagnons de voyage était Robert Hay ${ }^{25}$, l'égyptologue qui avait déjà longuement séjourné en Égypte. Ce premier contact avec Hay fut suivi de nombreux autres au Caire. Mais le départ ne se fit finalement que le 2 septembre. La véritable rencontre avec l'Orient eut lieu à La Canée, en Crète: des Turcs y circulaient, la mosquée des Janissaires dominait le port vénitien et Hessemer la dessina, tout en expérimentant pour la première fois les difficultés rencontrées à entrer dans ces édifices interdits aux infidèles. Enfin, le 21 septembre, "ecco, la colonna di Pompeo!". Hessemer demeura à Alexandrie jusqu'au 9 octobre au matin, ce qui lui permit non seulement de prendre les premiers contacts officiels et personnels - il y rencontra Haggi Sulayman, antérieurement accompagnateur de Français de la mission Champollion, qui le seconda fidèlement durant tout son séjour en Égypte et dont Hessemer loua les services -, mais aussi de dessiner quelques vues et monuments d'Alexandrie, dont plusieurs mosquées, davantage que la plupart des artistes voyageurs pressés d'atteindre Le Caire.

\section{Au Caire}

Arrivé au port de Boulaq le 15 octobre, et une fois les formalités accomplies, Hessemer s'installa dans le quartier franc, le Muski, où il loua une chambre chez un certain sieur Novelli, à proximité du consulat de Prusse. Après avoir eu un premier aperçu de la ville à dos d'âne, il se fixa pour but de pénétrer dans une mosquée pour la première fois le lendemain matin. La première d'entre elles fut celle du sultan Hasan, et le 17 octobre, il visita trois autres mosquées, vandalisées par les Français qui en avaient arraché les parements de marbre pour les emporter à Paris, et laissées depuis à l'abandon; il monta également au sommet d'un minaret pour jouir du panorama de la ville. Mais déjà une autre aventure l'appelait puisqu'il ne résista pas à la proposition faite par un ancien capitaine de frégate anglais, rencontré peu de jours auparavant, William Henvey, qui l'invita à se joindre à lui pour une remontée du Nil. Hessemer se lance dans un voyage, qui lui fut reproché par la suite par son commanditaire, dont il rapporta quantité de dessins et d'aquarelles de monuments de l'Égypte ancienne (il resta seul sur l'île de Philae du 10 novembre au $1^{\text {er }}$ décembre 1829) mais aussi de mosquées vues le long du Nil (Beni Souef, Minia, Assiout, Girga, Louxor) avant de rejoindre Le Caire le 25 décembre. Pour lui, le dessin qu'il fit ce jour-là des carrières de Tura et d'al-Ma'sara au 
sud du Caire, dont furent extraites les pierres des pyramides, était le dernier de la série qui documentait son voyage en Haute-Égypte.

Dès lors, Hessemer s'installa au Caire et y résida jusqu'au 31 mars 1830. Il notait que si dans une ouverture de Gaspare Spontini on ne savait plus où donner de l'oreille, au Caire on ne savait plus où donner des yeux. Il exerça son regard tout d'abord sur la foule, soulignant la mosaïque des populations qui s'y croisaient, la variété de couleurs des vêtements aux séduisants mouvements, comme dans le turban, par exemple, qu'Hessemer opposait au pathétique chapeau feutre occidental (fig. 1-2). Il ne pouvait s'empêcher de relever le paradoxe de l'absence d'harmonie qui naissait de l'uniformité des vêtements occidentaux.

2. Wilhelm Ahlborn, F. M. Hessemer en costume local et fumant la pipe, mine de plomb et aquarelle.

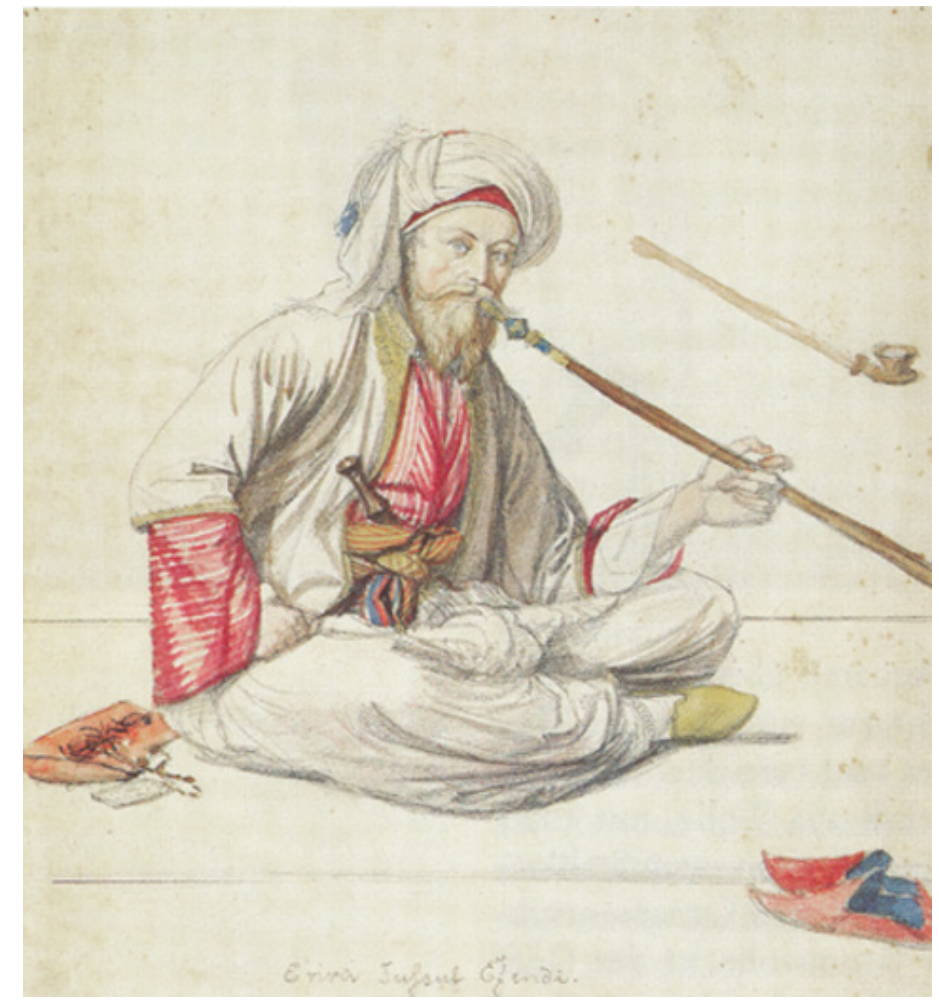

Source: Ein Frankfurter Baumeister in Ägypten, Francfort-sur-le-Main, 2001, p. 244.

21 Muni de lettres de recommandation, Hessemer s'acquitta de diverses visites officielles : lui, le protestant, il rencontra, pour lui remettre une lettre d'un cardinal romain, le directeur du monastère de la Congrégation pour la propagation de la foi ; il alla voir Giuseppe Acerbi, alors consul général d'Autriche en Égypte, ou encore Giovanni Anastasi, un Grec d'origine, consul de Suède à Alexandrie mais aussi collectionneur, pour qui le jeune architecte dessina un projet de demeure et reçut de lui, non seulement quelques pièces antiques, mais surtout un anneau sigillaire en héliotrope ou hyacinte qu'Hessemer fit graver de son nom arabe (Yussuf, « parce que suis ton Joseph en Égypte » écrivait-il à son père ;effendi, parce qu'il est lettré) et de la date de 1830. Il s'en servit pour apposer son timbre sur la plupart de ses dessins (fig. 3). 
3. Timbre arabe de Friedrich Maximilian Hessemer.

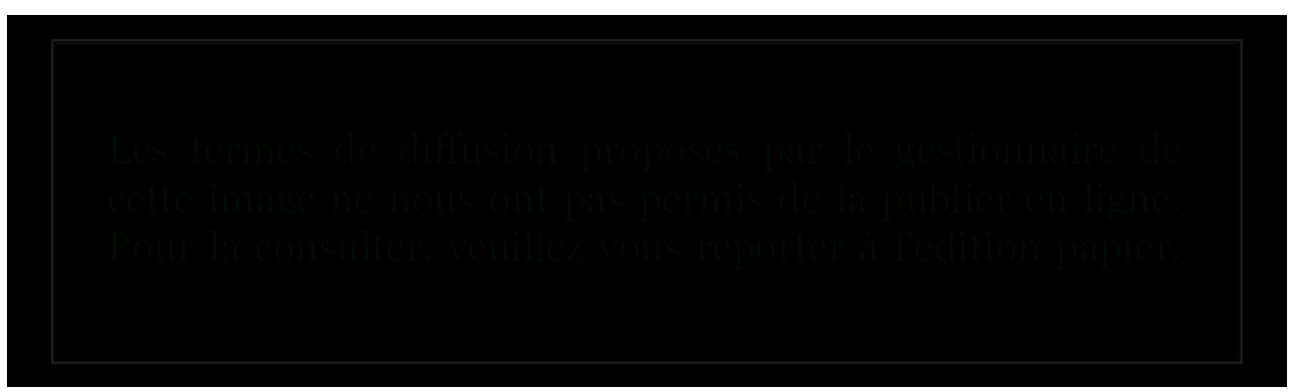

Source: Francfort-sur-le-Main (Allemagne), Städelsches Kunstinstitut, Graphische Sammlung.

C'est surtout le milieu des Anglo-Saxons d'Égypte qu'il fut amené à fréquenter, et plus particulièrement l'égyptologue Robert Hay autour duquel gravitaient John Gardner Wilkinson, James Burton (il est à noter que sur le dessin Inv. Nr. 5196, Hessemer s'était amusé à accoler aux noms des trois Britanniques des prénoms de prophètes : Ismaël pour Wilkinson, Aioub [sic] pour Burton, Itriss [sic] pour Hay). Il eut l'occasion de se rendre à plusieurs reprises, à l'invitation de Robert Hay, dans la maison remarquablement aménagée et décorée que celui-ci occupait, dans un faubourg du Caire, avec son épouse Kalitza Psaraki, fille d'un magistrat crétois sauvée du marché aux esclaves à Alexandrie. Hessemer donne une description de cette demeure et il se peut que le dessin d'un intérieur de maison au Caire (Francfort-sur-le-Main, Städelsches Kunstinstitut, Graphische Sammlung, Inv. Nr. 5205) fasse voir le salon de la résidence de Robert Hay.

Hessemer eut l'occasion de réaliser des portraits de quelques-uns de ces Britanniques dont la plupart montrèrent un intérêt évident pour ses dessins. Il céda certaines de ses feuilles au capitaine William Henvey; Robert Hay, qui avait quelque temps auparavant acquis des dessins de Pascal-Xavier Coste figurant Le Caire, l'approvisionna en très beau papier à dessin anglais. Il mentionnait dans ses lettres d'autres personnages rencontrés au Caire, dont des dessinateurs français, l'un, au service de Burton, qui cherchait à acquérir auprès d'Hessemer talent et méthode, qualités que le jeune Allemand lui déniait, et deux autres, liés à la mission Champollion, occupés le 16 janvier 1830 à dessiner des édifices "sarrazins" de la Citadelle à l'art desquels, selon Hessemer, ils semblaient ne rien comprendre et qu'ils rendaient avec une superficialité étonnante. Un croisement des sources ${ }^{26}$ permet d'identifier ces artistes français avec deux des trois dessinateurs de la mission franco-toscane de1828-1830 (Nestor L'Hôte, François-Édouard Bertin et Pierre-François Lehoux) qui, entre début novembre 1829 et début février 1830, dans l'attente d'un navire à destination de Toulon, poursuivaient avec ardeur le relevé des paysages et édifices du Caire, plus particulièrement vus de la citadelle, multipliant les études à l'huile et les pochades qui devaient servir à la réalisation d'un panorama à Paris ${ }^{27}$.

Le séjour avait été préparé avec application à Rome. Hessemer s'était non seulement bien documenté en allant très assidûment consulter les volumes de la Description de l'Égypte à l'Académie de France, mais il devait aussi se faire envoyer, par l'intermédiaire de Georg Moller, des planches gravées destinées à l'ouvrage de Pascal-Xavier Coste, Architecture arabe ou monuments du Kaire, mesurés et dessinés de 1818à $1826^{28}$. Muni de cartes qu'il dit être en français (les seules dont il pouvait disposer à cette date étaient celles publiées dans la Description de l'Égypte et d'ailleurs, même si Hessemer prend la 
précaution de souligner que les noms des édifices qui légendent ses dessins sont tels qu'il a pu les saisir à l'oreille, un certain nombre de ces toponymes sont directement pris de l'explication du plan de la Description abrégée de la ville et de la citadelle du Kaire d'Edme Jomard), Hessemer arpenta la ville, usant plusieurs paires de chaussures, entrant dans tant de mosquées qu'il avouait, dans une lettre du 3 janvier 1830, aspirer au repos tel un cerf forcé. Avec l'aide de son fidèle serviteur qui lui enseignait les rites qui s'y déroulaient et les comportements à adopter à l'intérieur des édifices religieux, vêtu comme un musulman (barbu, blond roux aux yeux bleu très clair, il s'avouait à luimême ne pas pouvoir être pris pour un Arabe, mais pensait passer pour un $\operatorname{Turc}^{29}$ ), il put pénétrer dans un certain nombre de mosquées.

Sur le nombre de dessins et d'aquarelles connus qu'Hessemer fit des édifices du Caire, il semble qu'il y ait moins de vues intérieures que de vues extérieures ou de perspectives. En outre, ces dessins d'intérieur sont réalisés sur des feuilles généralement plus petites. Mais Hessemer a aussi couvert des feuilles de dessins d'ornements ou d'inscriptions qu'il n'avait pu observer qu'une fois à l'intérieur des édifices de culte.

Paradoxe : comme le jeune architecte le soulignait dans une lettre du 22 janvier 1830, si les maisons privées du Caire étaient plutôt uniformes dans leur absence de signes extérieurs, les mosquées, qui bénéficiaient davantage d'attention dans leur décor et ornementation, demeuraient toutefois si cernées de constructions et souvent situées dans des rues si étroites qu'il était très difficile d'en obtenir un point de vue. Hessemer, habitué aux dégagements accordés aux édifices prestigieux en Italie, éprouvait donc des difficultés à dessiner des façades ou des élévations extérieures. Il n'en produisit pas moins des panoramas de la ville, des vues perspectives de mosquées, comme celle de Salar et Sangar al-Gawli à Qal'at al-Kabsh (fig. 4) qu'il visita le 3 janvier 1830 et dont le dessin qui en est donné, parce que l'édifice se trouve sur une éminence, n'est pas si éloigné des vues faites de certains édifices à Pérouse ou à Gubbio en Italie.

4. [Mosquée Salar et Sangar al-Gawli, Le Caire], graphite sur papier.

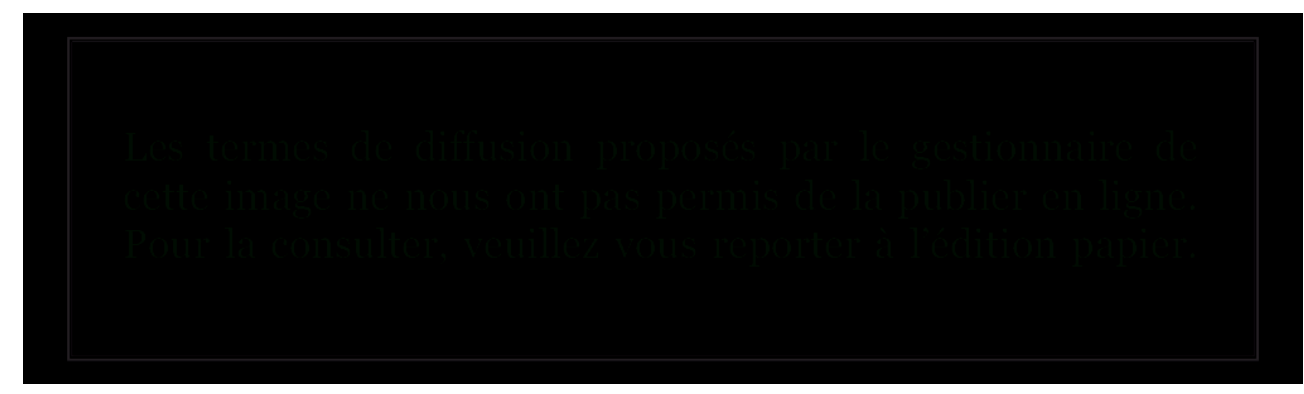

Source: Francfort-sur-le-Main (Allemagne), Städelsches Kunstinstitut, Graphische Sammlung.

Son album de dessins fut inauguré, le 26 décembre 1829, par une vue de la madrasa du sultan Hasan, le plus impressionnant des édifices religieux du Caire. Le 5 janvier 1830, il fit deux dessins, sous des angles différents, de la mosquée Abu al-'Ila de Boulaq. Une aquarelle, aujourd'hui au British Museum (fig. 5) ${ }^{30}$, par ailleurs acquise auprès d'un descendant de Robert Hay, fut faite d'après un de ces dessins, mais l'artiste y plaça quelques personnages colorés qui animent la scène et nota non seulement la bichromie des assises mais aussi la riche polychromie originelle du portail. 
5. [Mosquée Abu al-'Ila à Boulaq], Le Caire, aquarelle sur papier.

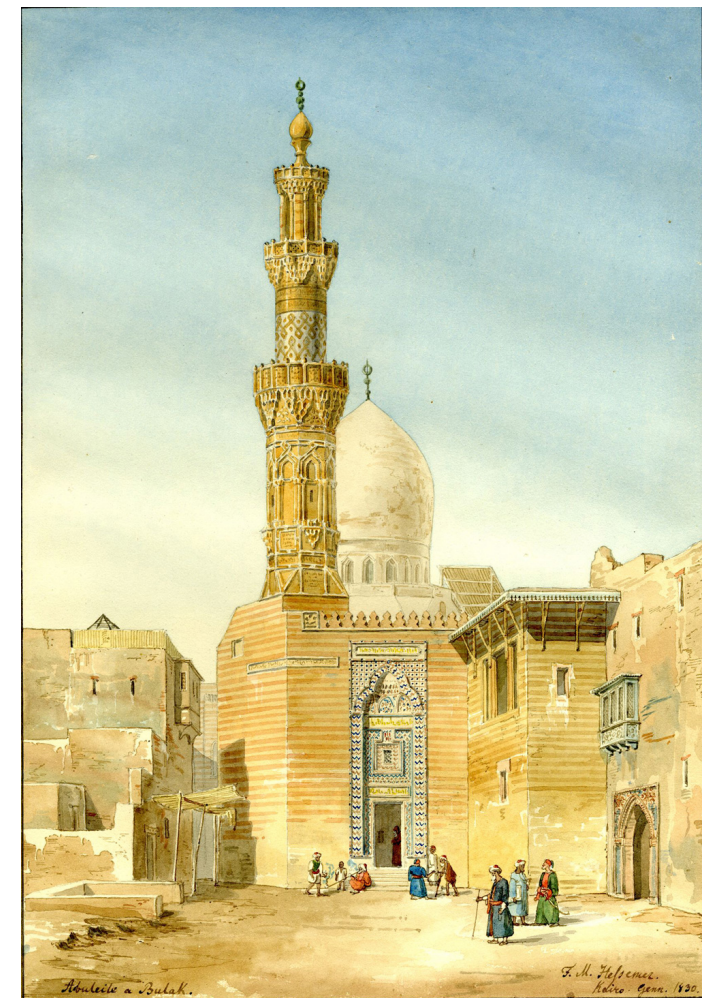

Source: Londres (Royaume Uni), British Museum, Department of Prints and Drawings (Inv. 1879).

28 À la date du 14 janvier, Hessemer disait être entré dans 22 mosquées ; le 29 du mois, il réalisait quatre dessins dans l'enceinte de la Citadelle. Il venait, par cette frénésie, pallier le retard pris dans son travail à cause de la peste qui s'était déclarée au Caire au cours du mois de décembre 1829 et qui l'avait empêché de travailler à l'extérieur. Ainsi dessina-t-il la plupart des mosquées cairotes, grandes et plus petites, comme celle d'almalika Safiyya située dans le quartier de Dawdiyya (fig. 6), vue de l'extérieur avec son étagement de coupoles, ou l'intérieur du couloir conduisant au mausolée de la mosquée Salar et Sangar al-Gawli (fig. 7).

6. [Mosquée al-malika Safiyya, Le Caire], graphite sur papier.

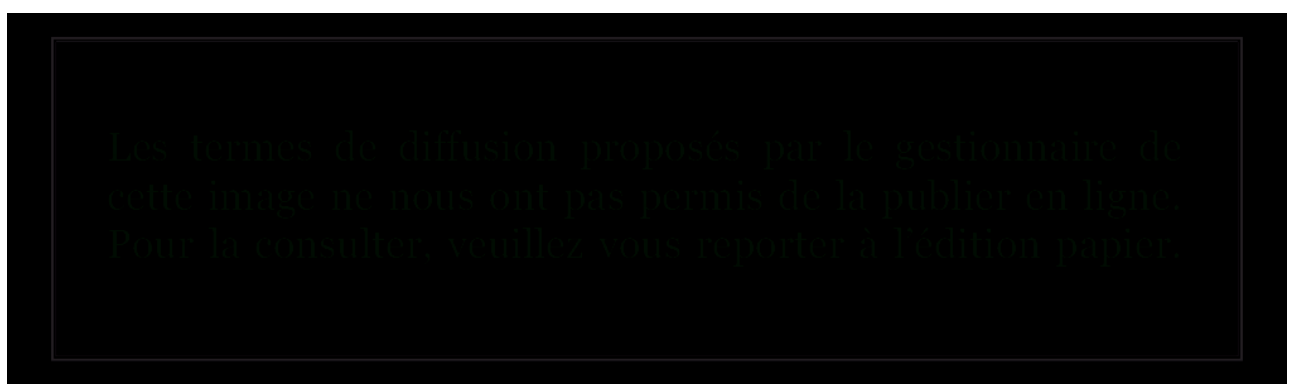

Source: Francfort-sur-le-Main (Allemagne), Städelsches Kunstinstitut, Graphische Sammlung. 
7. [Mosquée Salar et Sangar al-Gawli: couloir conduisant au mausolée, Le Caire], aquarelle sur papier.

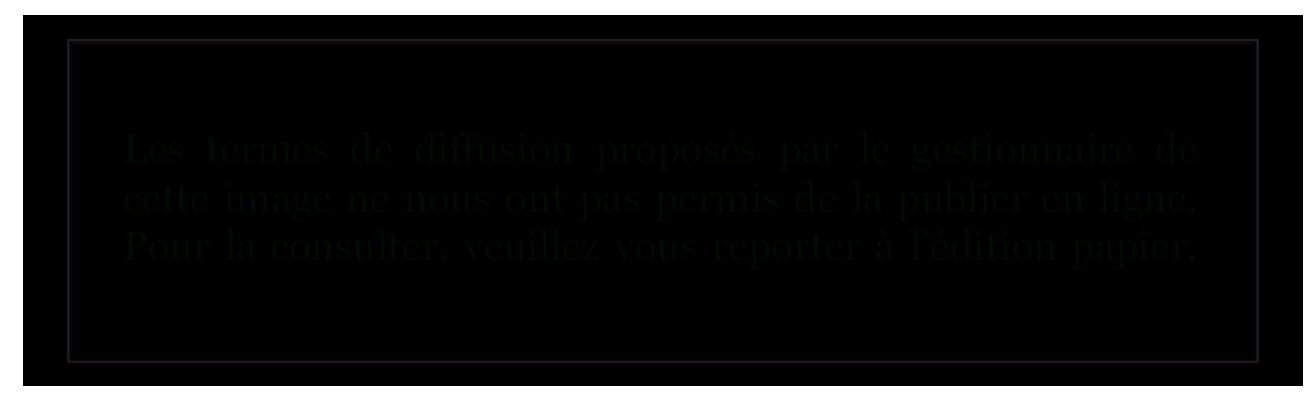

Source: Francfort-sur-le-Main (Allemagne), Städelsches Kunstinstitut, Graphische Sammlung.

Hessemer ne pouvait oublier qu'il avait été envoyé en Égypte sur les traces de l'arc brisé. Qu'en est-il dans son corpus graphique connu? Peu de dessins témoignent de cette recherche. On sait que Henry Gally Knight fit savoir son mécontentement lorsqu'Hessemer lui eut soumis le résultat de son travail ${ }^{31}$. Bien sûr ne lui échappa pas le portail gothique en marbre remployé à la façade de la madrasa du sultan mamelouk al-Nasir Muhammad que deux épigraphes placées sur le monument et, surtout, deux passages de l'historien et chroniqueur al-Maqrizi, permettaient d'identifier comme provenant de la cathédrale de la Sainte-Croix de Saint-Jean-d'Acre ${ }^{32}$. Il en fit d'ailleurs deux dessins, dont un des petits chapiteaux avec le départ des voussures et du réseau aveugle. Il n'est pas impossible non plus que le dessin Inv. Nr. 5213 de la Graphische Sammlung du Städelsches Kunstinstitut, figurant, ouvert sur une ruelle du Caire, un portail (fig. 8) dont Hessemer s'était efforcé à relever les profils de la modénature toute gothique, ne constitue un autre témoignage de cette recherche; enfin, l'attention du dessinateur fut retenue par les deux portails aux arcs trilobés inscrits sous les archivoltes dans la partie basse du portail ottoman occidental de la mosquée al-Azhar.

8. [Portail près de la mosquée Salar et Sangar al-Gawli (?), Le Caire], graphite sur papier.

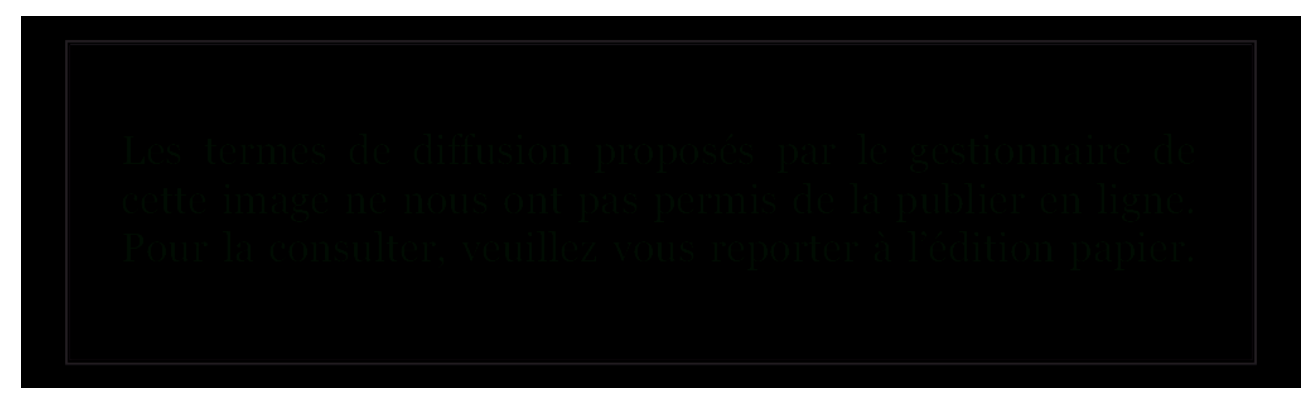

Source: Francfort-sur-le-Main (Allemagne), Städelsches Kunstinstitut, Graphische Sammlung.

Même si l'on ajoute à ces exemples de remplois d'autres relevés d'arcs brisés qui se voient dans les divers monuments visités, il faut reconnaitre que l'ensemble est bien maigre pour venir illustrer de manière satisfaisante la théorie que Gally Knight voulait soutenir dans une publication à venir et qui ne vit pas le jour.

31 Le corpus graphique d'Hessemer, tel qu'il nous est parvenu, est surtout constitué de dessins de mosquées et de tombeaux ou mosquées funéraires, ainsi que de portes monumentales. Contrairement aux dessinateurs de la Description de l'Égypte ou à PascalXavier Coste avant lui, ou encore à Adalbert de Beaumont ou Prisse d'Avennes après lui, F. M. Hessemer ne semble pas avoir regardé les sabil, sabil-kuttab, les okels, les cafés, les 
jardins. De même, il ne montre aucun intérêt pour les moucharabiehs en bois tourné, pour les vantaux richement ornés des portes de mosquées, non plus pour les sujets ou scènes "ethnographiques" qu'il décrivait avec talent dans son journal ou sa correspondance. Il n'est que peu de feuilles figurant des personnages; encore sont-ils là pour animer les scènes. Hessemer est un dessinateur d'architecture, ou un architectedessinateur. Dans Arabische und Alt-Italienische Bau-Verzierungen il n'est que trois planches, sur les 60 consacrées à l'art arabe, pour illustrer l'ornementation et la décoration d'édifices privés, essentiellement des maisons.

L'attrait qu'Hessemer montrait pour l'ornementation architecturale se voit dans quantité d'esquisses, de relevés : ornements qui s'accumulent sur les piédroits et dans la voussure de portails comme celui qu'il dessine dans la ruelle des Carriers [Siket il Magjar i.e. Sikkat al-Mahgar] (fig. 9), ornements géométriques dont il retraça le schéma de composition, rinceaux des claustras de baies ou d'arcades comme à la mosquée Salar et Sangar al-Gawli (fig. 10) dont la beauté et la finesse du travail attirèrent également, plus tard, l'œil d'Adalbert de Beaumont et de Prisse d'Avennes, inscriptions et versets du Coran courant le long des murs à l'intérieur des édifices religieux, qui l'impressionnèrent au point qu'il les introduisit dans son roman en vers Jussuf und Nafisse (1847) et qu'il discourra sur leur emploi, enfin tout ce qui lui servit pour les planches en couleurs de son ouvrage Arabische und Alt-ItalienischeBau-Verzierungen.

9. Porte dans le Sikkat al-Mahjar, Le Caire, graphite sur papier.

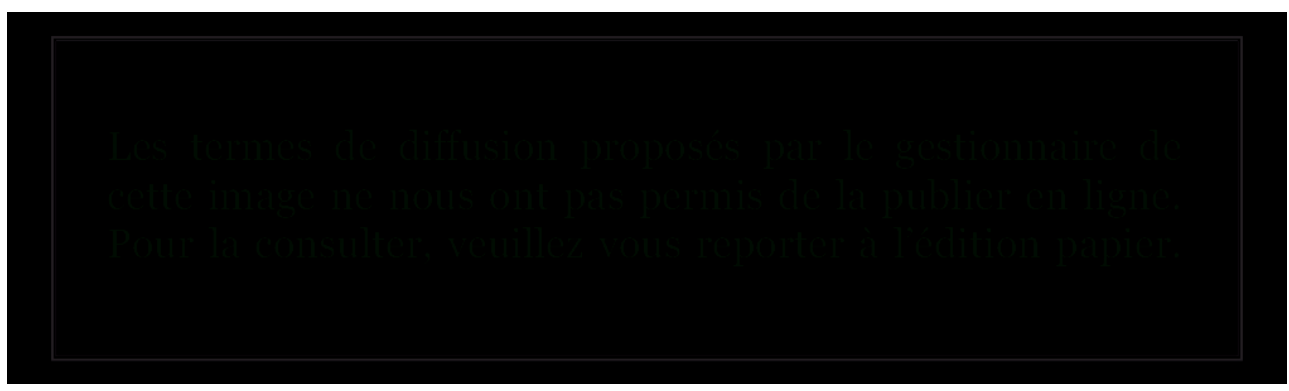

Source: Francfort-sur-le-Main (Allemagne), Städelsches Kunstinstitut, Graphische Sammlung.

10. Étude de rinceaux d'une baie de la mosquée Salar et Sangar al-Gawli, Le Caire, graphite sur papier.

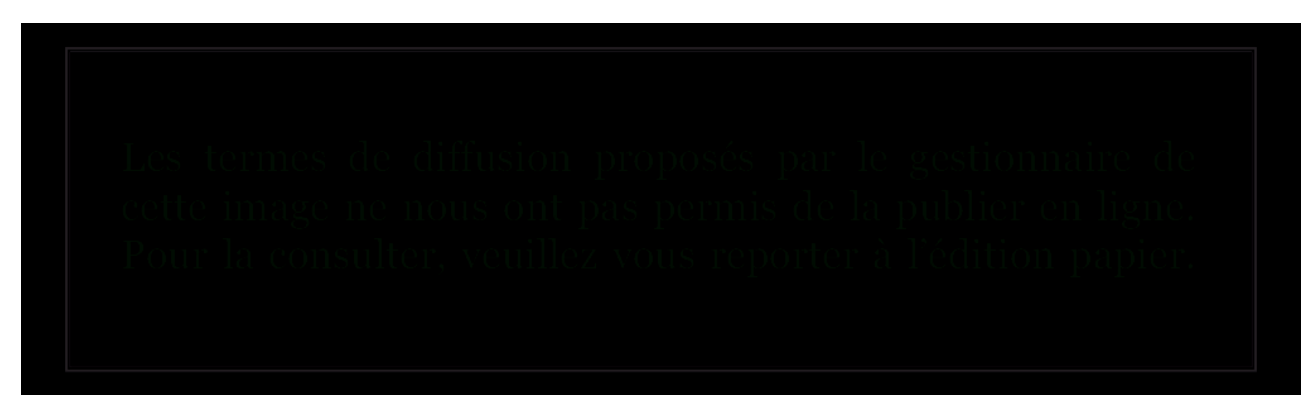

Source: Francfort-sur-le-Main (Allemagne), Städelsches Kunstinstitut, Graphische Sammlung.

Le séjour au Caire s'acheva le $1^{\mathrm{er}}$ avril 1830 . Une certaine lassitude commençait à apparaître dans les écrits d'Hessemer, l'absence de nouvelles de son père lui était source d'inquiétude. Hessemer demeura de nouveau un certain temps à Alexandrie puisque le bateau pour l'Italie ne partit finalement que le 5 mai pour enfin atteindre, le 
28 mai 1830, le port de Trieste où commença une longue quarantaine. C'est là qu'Hessemer se dépouilla de son costume turc (non sans s'être portraituré pour en conserver un souvenir) et revêtit de vieux vêtements délavés acquis en Sicile. Ce n'est que le 27 septembre de la même année qu'il rejoignit Karlsruhe, après avoir passé de nouveau plusieurs mois en Italie.

Ainsi s'achève le long voyage de formation de Friedrich Maximilian Hessemer qui entreprit une carrière académique au sein du Städelsches Kunstinstitut dans laquelle la confrontation avec l'art de l'Égypte musulmane eut une certaine résonance.

\section{Du morcellement à la totalité, de la division à l'unité. En quête d'une résolution conciliatrice}

Dès le mois de juillet 1830 à Rome, Hessemer l'Égyptien eut l'occasion de montrer ses dessins, en particulier au sculpteur danois Bertel Thorvaldsen qui y prit de l'intérêt, et de tenir quelques conférences sur ce voyage devant une assemblée de connaissances allemandes et danoises. Une fois rentré à Francfort-sur-le-Main en août 1830, Hessemer prit possession de la chaire d'enseignement d'architecture, de mathématiques, de perspective et de dessin au Städelsches Kunstinstitut, position qui lui avait été assurée avant son départ pour l'Égypte et qu'il occupa jusqu'à sa mort en 1860. Au cours de sa carrière d'enseignant, il eut l'occasion de donner des conférences sur l'Égypte tant ancienne que moderne. Mais son œuvre d'architecte demeura rare, aucunement influencée par sa connaissance de l'art islamique mais bien davantage par sa formation auprès de son oncle, l'architecte Georg Moller. Un néo-médiévalisme prévalut, qu'il soit néo-gothique ou influencé par le Rundbogenstil ${ }^{33}$.

À Francfort, Hessemer avait une vie privée et sociale active : dès 1831, il entra dans une célèbre loge maçonnique, dont le nom, Zur Einigkeit im Orient, est à mettre en relation avec l'aspiration à l'unité qui sous-tend sa réflexion, depuis ses années d'études à Giessen jusqu'à l'introduction rédigée pour Arabische und Alt-Italienische BauVerzierungen; il poursuivit, en la développant, son activité d'écrivain dont la production, toujours largement inédite, ne connut pas le succès escompté ; il continua d'entretenir des relations avec la plupart des artistes rencontrés à Rome mais aussi avec des intellectuels comme l'historien, universitaire et homme politique libéral Georg Gottfried Gervinus (1805-1871) ou le médecin aliéniste Heinrich Hoffmann (1809-1894), célèbre auteur du livre pour enfants Struwwelpeter [Pierre l'Ébouriffé], mais aussi humoriste, et qui fut le fondateur de plusieurs sociétés, autant d'ateliers de création réunissant peintres, poètes et musiciens, telles que Die Tutti Frutti und ihre Bäder im Ganges au sein de laquelle Hessemer avait comme surnom « la datte » en raison de son séjour en Égypte, ou bien encore Die Gesellschaft in den Katakomben fondée en 1849 avec Hessemer. 
11. [Sans titre], aquarelle sur papier.

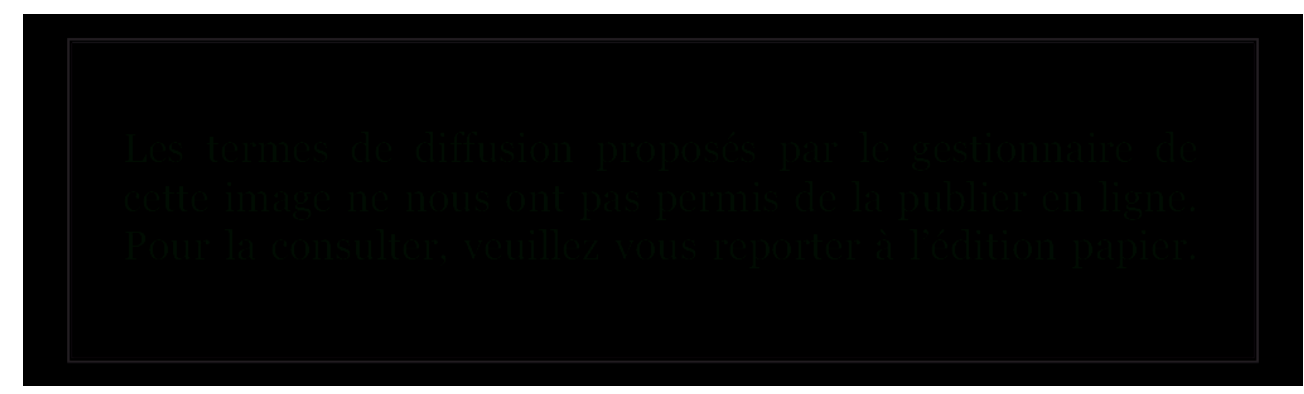

Source: Francfort-sur-le-Main (Allemagne), Städelsches Kunstinstitut, Graphische Sammlung.

Qu'en est-il donc de l'influence de ce voyage qui aurait changé sa vie ? C'est assurément dans l'introduction programmatique de son ouvrage Arabische und Alt-Italienische BauVerzierungen qu'il faut la chercher. L'ouvrage, qui fut publié à partir de 1836, en 10 livraisons trimestrielles offrant chacune 10 planches chromolithographiées, connut sa première édition complète en 1842 chez l'éditeur berlinois Reimer, avec 120 planches en couleurs, 60 pour l'art arabe et 60 pour l'art médiéval italien, une préface, une introduction de 34 pages, des notices explicatives des planches et une dédicace pleine de gratitude à Henry Gally Knight, le commanditaire du voyage en Égypte, alors même que celui-ci avait déjà reproché à Hessemer la mission non remplie. Si la maison Reimer s'était fait une spécialité des publications prestigieuses, dont certaines furent particulièrement réussies du point de vue technique, comme Ornamente aller klassischen Kunstepochen nach den Originalen in ihren eigenthümlichen Farben de Wilhelm Zahn (1843-1848), il faut reconnaître que la gravure et l'impression des planches de l'ouvrage d'Hessemer sont décevantes en regard de la luminosité des aquarelles préparatoires conservées à la Graphische Sammlung du Städelsches Kunstinstitut (Inv.- Nr. 1592). Toutefois, il faut souligner que ces mêmes œuvres préparatoires ne cherchent pas à rendre les différents plans et effets de profondeur sur lesquels l'auteur discourt tant dans son texte introductif. Hessemer avait dessiné, pour la partie relative à l'art arabe, six autres planches qui n'ont pas été retenues et qui, sauf exception, ne portent aucune légende (fig. 10). Sur les 60 planches de l'art arabe, 58 concernent des monuments du Caire, essentiellement des édifices religieux ou funéraires, trois planches illustrent des édifices privés (fig. 11), enfin deux planches seulement viennent témoigner du type d'ornement différent, tant par la technique que par les couleurs, rencontré à Alexandrie. Divers types, formes et techniques représentent les ornements les plus variés : décors muraux ou de sols, mosaïques, marbres, stucs, pierres, panneaux de bois, peintures murales, bois travaillé mais aussi tenture de laine (fig. 12-15). 
12. Ornements géométriques dans divers édifices privés, Le Caire, étude préparatoire pour la pl. I. 58 d'Arabische und Alt-Italienische Bau-Verzierungen, aquarelle sur papier.

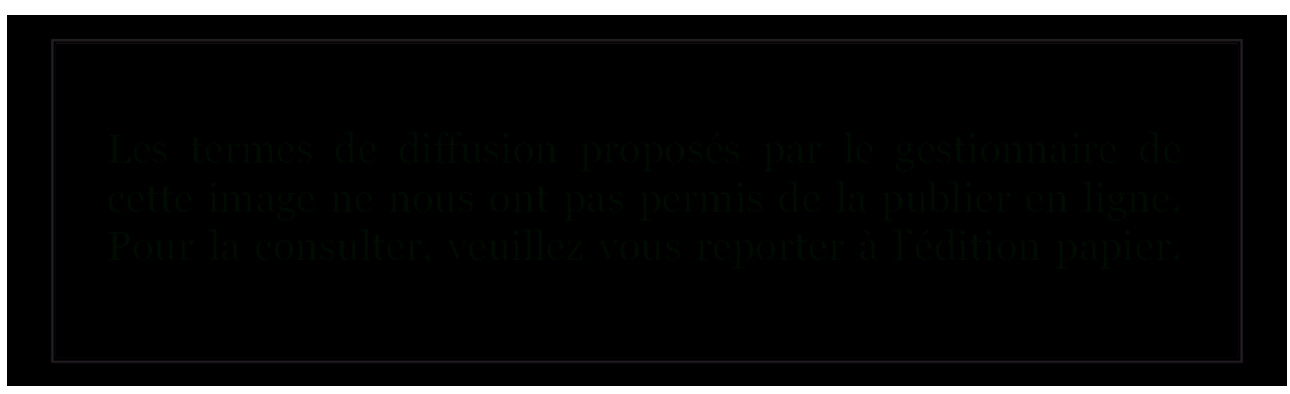

Source: Francfort-sur-le-Main (Allemagne), Städelsches Kunstinstitut, Graphische Sammlung.

L'introduction d'Arabische und Alt-Italienische Bau-Verzierungen attend encore une étude approfondie tant y est complexe la pensée de l'auteur qui se ressent non seulement de sa formation philosophique mais aussi de son engagement politique. Il ne manqua pas de placer, sans conviction aucune, des réflexions sur l'origine de l'arc brisé, et se rendit ainsi quitte de la tâche qui lui avait été assignée par Henry Gally Knight. Mais c'est surtout là qu'Hessemer exposait sa perception de l'ornement, illustrée par des exemples tirés de l'Égypte islamique et de l'Italie médiévale, tout en la rapportant toujours à la question contemporaine de l'architecture et des arts qui en dépendent, celle du „In welchem Style sollen wir bauen?" [En quel style devons-nous construire ?] posée en 1828 par Heinrich Hübsch. Chez Hessemer, l'ornement arabe est défini dans une constante analogie avec la vie, dans la relation entre l'extérieur (ce qui se voit) et l'intérieur (ce qui se vit) : ainsi les types d'ornementation sont mis en parallèle, dans la prédilection montrée pour le mouvement, avec la complexité des turbans ou de certains vêtements, le jeu des misbaha, celui des échecs ; dans l'emploi des inscriptions qui courent en haut des murs intérieurs des mosquées, ainsi que des "arcs-en-ciel mouvants " (Jussuf und Nafisse, 1847) ou sur les tambours des dômes ou coupoles, et donc de la calligraphie, avec l'omniprésence de l'écrit dans les amulettes, les anneaux sigillaires, les tatouages corporels mais aussi avec la psalmodie du Coran; dans leur aspect labyrinthique et la fascination pour les nœuds, avec l'importance de la magie et de la sorcellerie (Hessemer fit appel au verset 4 de la sourate 113 qui invoque les « souffleuses de nœuds»).

13. Décor pariétal en mosaïque dans le tombeau du sultan Qalawun, Le Caire, étude préparatoire pour la pl. I.36 d'Arabische und Alt-Italienische Bau-Verzierungen, aquarelle sur papier.

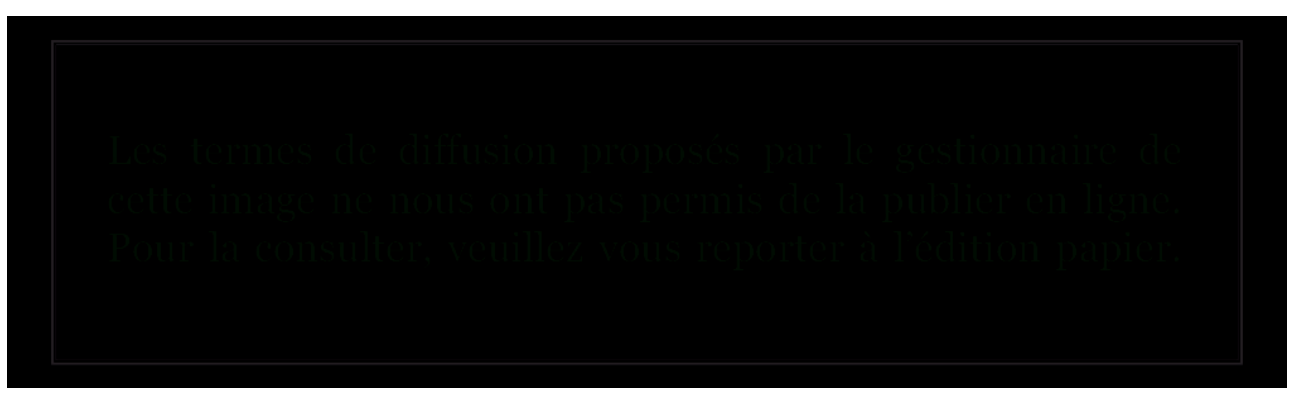

Source: Francfort-sur-le-Main (Allemagne), Städelsches Kunstinstitut, Graphische Sammlung.

Il soulignait aussi la mise en abyme de l'ornement dont l'arrière-plan ou fond est travaillé et orné, tel « du miel pas assez doux auquel il aurait fallu rajouter du sucre » 
ou encore quand l'écriture est ornée et que cet élément confère à l'ornementation un aspect calligraphique.

14. Ornement sculpté au portail occidental de la madrasa du sultan Hasan, Le Caire, étude préparatoire pour la partie supérieure de la pl. I.56 d'Arabische und Alt-Italienische Bau-Verzierungen, aquarelle sur papier.

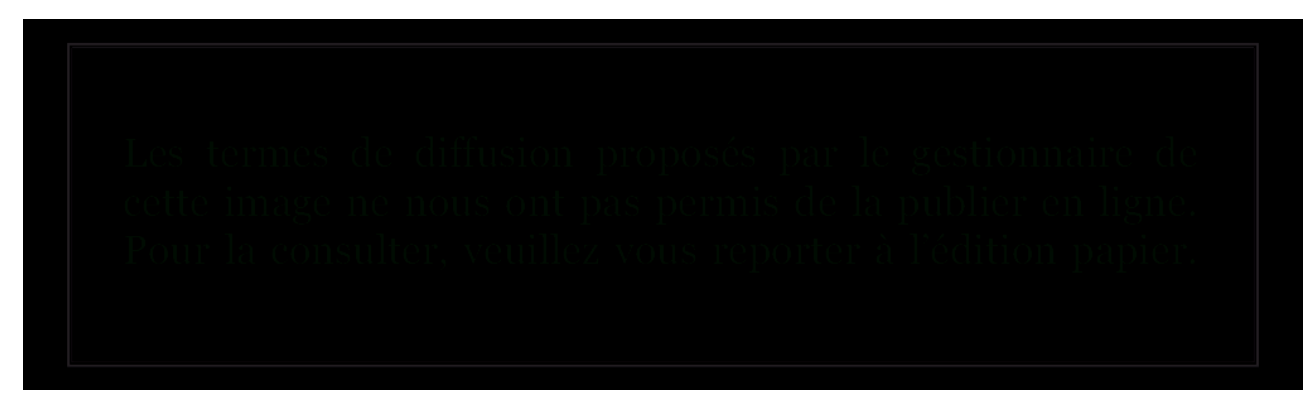

Source: Francfort-sur-le-Main (Allemagne), Städelsches Kunstinstitut, Graphische Sammlung.

Mais ce qui prédomine dans la réflexion d'Hessemer, c'est le rôle d'unité identificatrice joué par l'ornement qui, selon lui, offre une résolution conciliatrice en abolissant les divergences sociales et culturelles, et développe une harmonie qui vient résoudre les problèmes de morcellement politique, social et religieux. Alors qu'on ne trouve, dans l'introduction d'Arabische und Alt-Italienische Bau-Verzierungen, le terme d'« arabesques » employé qu'une seule fois, et encore sur le même plan que "grotesques, mauresques ", c'est toute l'esthétique de l'ornementation développée par Hessemer qui est " arabesque »: il montre que plus les formes ornementales sont inventives, hardies, complexes, plus elles entraînent dans les méandres de leurs formes, plus elles illustrent la puissance de la force combinatoire. Du fait même qu'elles réalisent l'union, la fusion d'éléments hétérogènes, elles tendent à harmoniser les contrastes ${ }^{34}$.

15. Couronnements ajourés des murs de la mosquée al-Azhar, Le Caire, étude préparatoire pour la pl. I.22 d'Arabische und Alt-Italienische Bau-Verzierungen, aquarelle sur papier.

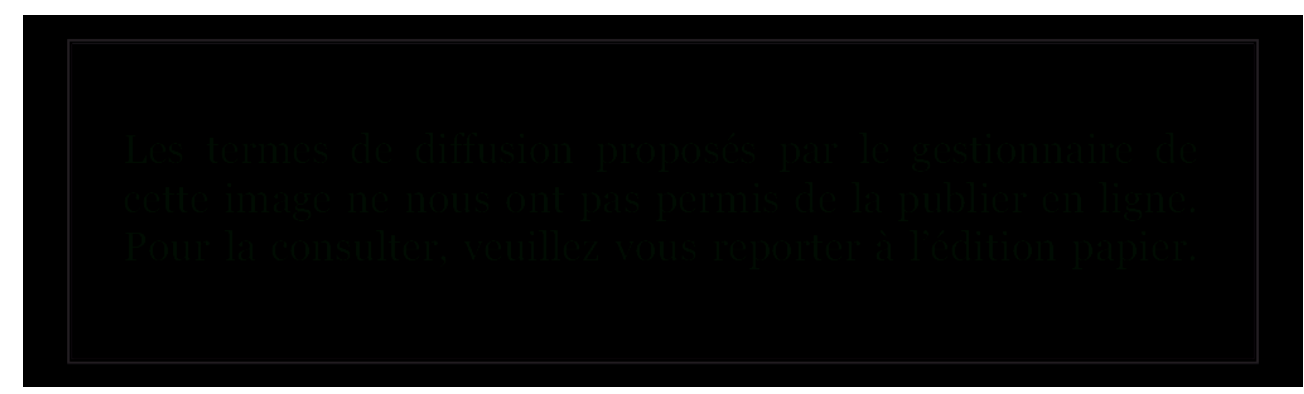

Source: Francfort-sur-le-Main (Allemagne), Städelsches Kunstinstitut, Graphische Sammlung.

Se retrouvent là les préoccupations d'Hessemer, les idées d'unité politique et sociale défendues au sein des Giessener Schwarzen dans sa jeunesse, au sein de la loge maçonnique Zur Einigkeit im Orient plus tard, au sein du Städelsches Kunstinstitut où il professait. C'est dans ce sens que l'on doit comprendre la réflexion de Friedrich Maximilian Hessemer sur l'empreinte définitive que ce voyage en Égypte eut sur lui. 


\section{NOTES}

1. Lettre du 15 octobre 1829.

2. F. M. Hessemer revint de son périple de trois ans avec quelque 500 dessins et aquarelles conservés aujourd'hui à la Graphische Sammlung du Städelsches Kunstinstitut, Francfort-sur-leMain (Allemagne). Quelques autres œuvres graphiques se trouvent dans les collections de la Graphische Sammlung du Hessisches Landesmuseum, Darmstadt ; d'autres, moins nombreuses, sont dispersées.

3. Francfort-sur-le-Main (Allemagne), Städelsches Kunstinstitut, Graphische Sammlung, Inv.- Nr. 927. Au moment de l'exposition, ce journal et cette correspondance, réunis en trois volumes, n'avaient pas encore fait l'objet d'une édition critique. C'est la germaniste italienne Maria Teresa MORREALE, avec la collaboration de Christa STAUB, qui édita ces textes: Friedrich Maximilian Hessemer. Briefe seiner Reise nach Italien, Malta und Ägypten 1827-1830, Hambourg: MaximilianGesellschaft, 2002-2003, 2 vol. (Bd. I : Italien und Malta ; Bd. II : Ägypten und Italien).

4. Voir Diane haRLÉ et Jean LefEBVRE (dirs.), Sur le Nil avec Champollion. Lettres, journaux et dessins inédits de Nestor L'Hôte. Premier voyage en Égypte - 1828-1830, Orléans ; Caen : Éditions Paradigme, 1993.

5. Jürgen eICHENAUER et Clemens GREVE (dirs.), Friedrich Maximilian Hessemer (1800-1860). Ein Frankfurter Baumeister in Ägypten, Francfort-sur-le-Main: Waldemar Kramer, 2001 (Mäzene, Stitfer, Stadtkultur, Bd.3). À cette date, l'édition critique du journal de voyage et de la correspondance d'Hessemer (voir note 2) n'était pas encore parue.

6. Voir la note 3.

7. Charge officielle correspondant, en France sous l'Ancien Régime, à la fonction d'intendant des bâtiments.

8. Sur ce mouvement, voir Hermann HAUPT, Karl Follen und die Gießener Schwarzen. Beiträge zur Geschichte der politischen Geheimbünde und der Verfassungs-Entwicklung deralten Burschenschaft in den Jahren 1815-1819, Giessen : Töpelmann, 1907. Plus largement sur les milieux religieux, politiques et intellectuels à Giessen entre 1770 et 1830, voir Rolf HAASER, Spätaufklärung und Gegenaufklärung. Bedingungen und Auswirkungen der religiösen, politischen und ästhetischen Streitkultur in Giessen zwischen 1770 und 1830, Darmstadt: Hessische Historische Kommission Darmstadt; Marbourg: Historische Kommission für Hessen, 1997 (Quellen und Forschungen zur hessischen Geschichte, 114).

9. Arabische und Alt-Italienische Bau-Verzierungen. Gesammelt, gezeichnet und mit erläuterndem Texte begleitet von F. M. Hessemer, Professor der Baukunst am Städelschen Kunst-Institute zu Frankfurt am Main. Mit 120 in Farbengedruckten Tafeln, Berlin : bei G. Reimer, 1842.

10. Paola BARBERA, Giuseppe ROTOLO, «Friedrich Maximilian Hessemer: il viaggio e l'architettura », in Maria GIUfFrè, Paola BARBERA, Gabriella CIANCIOLO COSENTINo (dirs.), The time of Schinkel and the age of Neoclassicism between Palermo and Berlin, Cannitello: Biblioteca del Cenide, 2006 (Learning from), p. 231-237. Sur Georg Moller, voir Marie FRÖLICH et Hans-Günther SPERLICH, Georg Moller. Baumeister der Romantik, Darmstadt : Roether, 1959. Sur les relations établies entre F. M. Hessemer et G. Moller, voir Gerhard вотT, « Gotische Denkmalpflege im Vormärz - Friedrich Maximilian Hessemer und sein Lehrer Georg Moller ", in Jürgen EICHENAUER et Clemens GREVE (dirs.), Friedrich Maximilian Hessemer (1800-1860)..., op. cit. (note 5), p. 120-139.

11. Carl HESSEMER (dir.), Wanderungen durch Hessen vor hundert Jahren. Skizzen von Friedrich Maximilian Hessemer, Marbourg: Elwert, 1927. Ces œuvres graphiques sont, pour la plupart, conservées à la Graphische Sammlung du Städelsches Kunstinstitut, Francfort-sur-le-Main (Allemagne). Un autre ensemble a partiellement disparu dans l'incendie des Denkmalarchiv de 
Darmstadt le11 septembre 1944. D'autres dessins conservés d'édifices médiévaux de Hesse sont publiés en ligne URL: http://cgi-host.uni-marburg.de/ hlgl/ortsansichten. Consulté le 3 mai 2011.

12. Johann Gottfried Seume a rapporté son voyage en Italie dans Spaziergang nach Syrakus, Braunschweig, [s. n.], 1803, 3 vol. Une édition critique en français vient d'être publiée sous la direction de Marcel MOUSELER, Johann Gottfried Seume. Voyage à Syracuse, Rennes: Presses universitaires de Rennes, 2011 (Mémoire commune).

13. Voir l'ouvrage de Hans GELLER, "Ernste Künstler, fröhliche Menschen»: Zeichnungen und Aufzeichnungen deutscher Künstler in Rom zu Beginn des 19. Jahrhunderts. Joseph Führich und seine Freunde, Munich : Münchner Verlag und Graphische Kunstanstalten, 1947.

14. Cet Album Amicorum, ou Gedenkbuch, a été transcrit et édité par Christa STAUB, Friedrich Maximilian Hessemer. Gedenkbuch seiner Reise nach Italien und Ägypten 1827-1830, Darmstadt: Gesellschaft Hessischer Literaturfreunde, 2007.

15. La première mention d'Henry Gally Knight dans la correspondance de F. M. Hessemer se trouve dans une lettre en date du 14 janvier 1829, adressée à Georg Moller (publiée dans Friedrich Maximilian Hessemer. Briefe seiner Reise... op. cit. (note 3), t. I, p. 474-480.

16. Eastern sketches, in verse... Londres : John Murray, 1819 ( $2^{\mathrm{e}}$ édition) qui contient: Ilderim, a Syrian tale (1816) ; Phrosyne, a Grecian tale ; Alashtar, an Arabian tale (1817), publiés avec une préface qui indique bien que Gally Knight a visité les pays concernés.

17. Voir la note 15.

18. August Kestner und seine Zeit, 1777-1853. Das glückliche Leben des Diplomaten, Kunstsammlers und Mäzens in Hannover und Rom / aus Briefen und Tagebüchern zusammengestellt von Marie Jorns, Hanovre : Madsack, 1965.

19. Henry GALLY KNIGHT, An architectural tour in Normandy with some remarks on Norman architecture, Londres : John Murray, 1836.

20. Henry GALLY KNIGHT, The Normans in Sicily: being a sequel to "An architectural tour in Normandy", Londres :John Murray, 1838; IDEM, Saracenic and Norman Remains to illustrate the "Normans in Sicily ", Londres : John Murray, 1840.

21. Martin Bommas cite en note 9, p. 57, de sa contribution intitulée «"Wer Ägypten nicht sah, der kennt den Menschen nicht" - Hessemers Reise in den Orient ", in Jürgen EICHENAUER et Clemens GREVE (dirs.), Friedrich Maximilian Hessemer (1800-1860)..., op. cit. (note 5), que le contrat rédigé en allemand entre Gally Knight et Hessemer le 18 janvier 1829 est toujours conservé, avec d'autres documents personnels, dans une collection privée.

22. Pour une approche de la question de l'origine orientale de l'arc brisé, et partant du gothique, voir Paul FRANKL, The Gothic. Literary sources and interpretations through eight centuries, Princeton, NJ : Princeton University Press, 1960, plus spécialement p. 356-377 (Saracen theory of Wren, Evelyn and Fénelon) et les entrées Arabic; arch-pointed (origin of); Saracen theory; saracens de l'index des matières. Il est à noter qu'Henry Gally Knight, en qualité d'historien de l'architecture médiévale, est totalement absent de l'étude de Frankl. Voir également Louis BATISSIER, «De l'origine de l'architecture ogivale ", in Histoire de l'art monumental dans l'antiquité et au Moyen Âge suivie d'un traité de la peinture sur verre, Paris: Furne et Cie, 1860 ( 1 ère édition en 1845), p. 512-515. Sur les théories britanniques et leur influence en Allemagne autour de 1800, voir Sigrid BERTULEIT, Gotischorientalische Stilgenese. Englische Theorien zum Ursprung der Gotik und ihr Einfluß in Deutschland um 1800, Francfort-sur-le-Main : Lang, 1989, (Europäische Hochschulschriften : 28 ; 103).

23. Voir Maria Teresa MORREALE (dir.), Friedrich Maximilian Hessemer. Briefe seine Reise...., op. cit. (note 3), vol. 1, p. 481-487.

24. Ces informations sont données dans une lettre adressée par Hessemer à son père de Rome le 4 mars 1829 (publiée dans Maria Teresa MORREALE, ibid. (note 3), vol. 1, p. 515). 
25. À propos de l'égyptologue Robert Hay, voir Selwyn TILLETT, Egypt itself. The career of Robert Hay, Esquire of Linplum and Nunraw, 1799-1863, Londres : SD Books, 1984 ; Jane Waldron GRUTZ, The lost portfolios of Robert Hay. URL: http://archive.aramcoworld.com/issue/200302/ the.lost.portfolios.of.robert.hay.htm. Consulté le 10 mai 2011. Robert Hay a laissé de ses séjours des journaux (Londres, British Library, Ms Add 31054) et de très nombreuses œuvres graphiques réunies en 49 volumes (Londres, British Library, Mss Add 29812-29860) renfermant aussi des dessins de monuments islamiques du Caire qui ne furent que partiellement réutilisés dans les planches lithographiées accompagnant sa publication, Illustrations of Cairo, parue en 1840, le reste des illustrations étant empruntées à Owen Browne Carter et Charles Laver.

26. Nous remercions Mercedes Volait d'avoir suggéré cette identification qui est venue se vérifier.

27. Concernant ce projet ambitieux qui ne vit toutefois pas le jour, voir les lettres de Nestor L'Hôte publiées par Diane HARLÉ et Jean LEFEBVRE, op. cit. (note 4), part. p. 294-315.

28. Sur Pascal-Xavier Coste en Égypte, voir Pascal cosTE, Notes et souvenirs de voyage 1817-1877... : Mémoires d'un artiste, Marseille : Cayer, 1878, 2 vol. ; Dominique JACOBI (dir.), Pascal Coste, toutes les Égypte, Marseille: Parenthèses/Bibliothèque municipale de Marseille, 1998, catalogue de l'exposition (Marseille, Bibliothèque municipale, 17 juin-30 septembre 1998). Il est à noter que Robert Hay, qu'Hessemer fréquenta durant son séjour, avait eu l'occasion d'acquérir au Caire, vraisemblablement en 1827 auprès de Coste, un ensemble de dessins et aquarelles qu'il avait l'intention de publier, ce qui ne se fit pas. Coste publia ses propres œuvres graphiques dans son ouvrage Architecture arabe ou monuments du Kaire, mesurés et dessinés de 1818 à 1826, Paris : FirminDidot, 1837. Robert Hay qui avait conservé ces dessins jusqu'à sa mort en 1863 (ils se trouvent aujourd'hui au Victoria and Albert Museum, Londres, SD. 272) ne les avait plus au Caire en 1830 et Hessemer n'avait donc pas pu les voir.

29. À ce sujet, il est intéressant de mettre en parallèle la "prise d'habit » d'Hessemer qui se laissa pousser une imposante barbe et une longue chevelure avec le récit de la même opération, que fit, à l'automne 1828, Nestor L'Hôte : «Enfin, bien étrillés, bien rançonnés, pour perdre tout ce que nous avons de français fors le cœur, nous nous sommes affublés du costume turc. Le sacrifice de nos chevelures est fait et nos têtes, rases jusqu'à l'épiderme, sont couvertes de larges turbans. ... tels nous sommes tous, tel est aussi votre fils, dont une figure maigre et roussie et des moustaches microscopiques peuvent compléter le signalement. Le sérieux de nos physionomies en impose sans doute aux musulmans, ou plutôt leur habitude de voir des Européens avec les habits orientaux » (voir Diane HARLÉ et Jean LEFEBVRE (dirs.), op. cit. (note 4), p. 75).

30. Londres (Royaume Uni), British Museum, Department of Prints and Drawings, 1879, 1011.1410. Voir : http://www.britishmuseum.org/research.aspx. Consulté le 23 novembre 2015.

31. Sur les critiques adressées par Gally Knight à Hessemer, voir Martin BommAs, «"Wer Ägypten nicht sah, der kennt den Menschen nicht" - Hessemers Reise in den Orient », in Jürgen EICHENAUER et Clemens GREVE (dirs.), Friedrich Maximilian Hessemer (1800-1860)..., op. cit. (note 5), p. 63-64.

32. Philippe PlaGNiEUX, «Le portail d'Acre transporté au Caire. Sources et diffusion des modèles rayonnants en Terre sainte au milieu du XIII ${ }^{\mathrm{e}}$ siècle ", Bulletin monumental, vol. 164, n 1, 2006, «L'architecture en Terre sainte au temps de Saint Louis », p. 61-66.

33. En ce qui concerne l'activité de F. M. Hessemer comme architecte, voir les contributions de Jürgen EICHENAUER, «Romantische Architektur und Freimaurertum - Friedrich Maximilian Hessemer als Lehrer ", in Jürgen EICHENAUER, Clemens GREVE (dirs.), Friedrich Maximilian Hessemer (1800-1860)..., op. cit. (note 5), p.68-104; Gerhard вотт, " "Meine Composition der Walhalla" Hessemers Entwurf eines Nationaldenkmals », ibid., p. 105-119 ; IDEM, « Gotische Denkmalplege im Vormärz - Friedrich Maximilian Hessemer und sein Lehrer Georg Moller », ibid., p. 120-139. 
34. Sur l'esthétique de l'arabesque dans la théorie romantique, et plus spécialement chez Schlegel, voir Alain MUZELLE, L'Arabesque. La théorie romantique de Friedrich Schlegel à l'époque de l'«Athenaüm », Paris : Presses de l'Université Paris-Sorbonne, 2006 (Monde germanique).

\section{AUTEUR}

\section{MARYSE BIDEAULT}

Responsable de recherches documentaires, InVisu, USR 3103 du CNRS, Paris. 


\title{
James Wild, Cairo and the South Kensington Museum
}

\author{
Abraham Thomas
}

\section{AUTHOR'S NOTE}

For their invaluable assistance at various archives, I would like to thank staff at The Griffith Institute, Oxford; Sir John Soane's Museum, London and staff at The National Archives, Kew. I am also grateful to Briony Llewellyn for sharing her notes on Wild with me, and for her helpful suggestions and encouragement.

1 In his recollections of the great Prussian expedition to Egypt and Nubia in the 1840s, Carl Richard Lepsius described James Wild as "a young architect, full of genius, [who] seeks with enthusiasm in the East a new field for the exercise of the rich and various gifts with which he is endowed" .These words were praise indeed. However, other accounts reveal some of the early frustrations felt by this precocious, ambitious architect:

"Although considered successful by his contemporaries, [Wild] was profoundly discontented with his work. He chafed at the various restrictions which in those days prevented the Gothic designer from following the leading characteristics of the style... Another cause for his discontent was the parsimonious expenditure on sculptured and coloured ornamentation, both of which he considered essential to the proper rendering of the Gothic style'."

Having built six Gothic churches by the age of twenty six, it is significant that for his next building project - Christ Church in Streatham, south London - Wild collaborated with Owen Jones and Joseph Bonomi, two men with extensive experience of travel in the Near East. Bonomi had spent ten years in Egypt as a salaried artist, and came home in 1834, the same year that Owen Jones returned from his ground-breaking studies of Islamic decoration at the Alhambra Palace. Wild was one of the subscribers to Jones's seminal Alhambra publication, produced in parts between 1836 and 1845, thus coinciding with the period of the Christ Church project ${ }^{3}$. 
1. Johann Jakob FREY, L'expédition prussienne en Égypte, menée par Lepsius, au sommet de la pyramide de Khéops à Gizeh, le 15 octobre 1842, watercolour, coloured lithography.

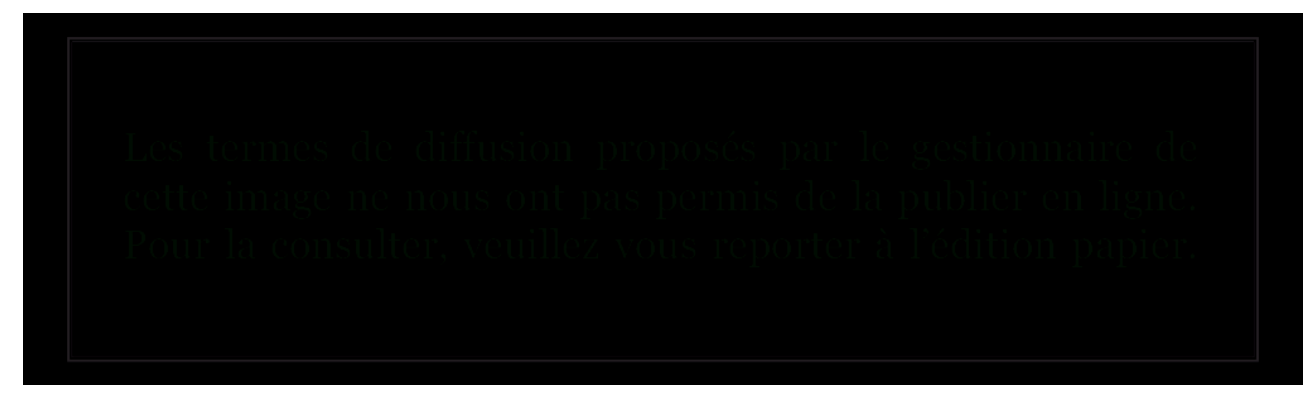

James Wild, wearing a turban, is standing behind the man waving his hat under the Prussian flag.

Source: Berlin (Deutschland), Ägyptisches Museum und Papyrussammlung (SMPK).

Jones became Wild's brother-in-law when in 1842 Jones married Wild's sister Isabella. The two men became great friends, and it seems that they also shared many of the same opinions on design reform. Jones published his theories in the celebrated design sourcebook, The Grammar of Ornament $t^{4}$. It is interesting to note the following statement in Jones's preface: "The principles discoverable in the works of the past belong to us; not so the results. It is taking the end for the means ${ }^{5}$."

4 This elegant passage, summarising Jones's disapproval of the "unfortunate tendency" towards copying and historicism, echoes the sentiments of a letter which Wild wrote one month after the consecration of Christ Church:

"I object in the first place to the adopting [of] any style. This word style... seems to be the chief source of all our architectural failures. Those who can really appreciate what is beautiful in ancient architecture... know why it is in vain to imitate the more prominent features as a sort of decoration to new buildings without all the circumstances which created the architecture it is wished to imitate. We must study from all sources and adapt and apply our knowledge with invention, as our forefathers did, or we can but produce caricatures of their works ${ }^{6} . "$

Christ Church has been described as Early Christian in plan, Italian Romanesque in composition, Ottoman in its bay elevations, and Alhambresque, Mamluk, Sevillean, and Ancient Egyptian in its ornament ${ }^{7}$. This hybrid approach seems in keeping with Wild's earlier statements, and hints at a restless mind exploring the thresholds between conventional style categories. Jones was responsible for the decorative scheme of the column capitals and apse which were executed with a liberal mix of Byzantine/Turkish and Alhambresque ornament. In 1840, Wild wrote to Bonomi asking for advice on the design for the church "which gets more Egyptian every day".

Bonomi was invited to join Lepsius's Prussian expedition to Egypt after a chance encounter in the British Museum with the Prussian crown prince and Lepsius himself 9 Wild was soon recruited as an architectural draughtsman for the expedition, doubtless encouraged by Jones, the supportive brother-in-law who had returned from his own Near Eastern travels only eight years previously. The group departed in 1842, with the objective of completing extensive surveys of Ancient Egyptian monuments (ill. 1). The surviving drawings by Wild from this period illustrate a clear aptitude for rigorous and sustained investigation ${ }^{10}$. Meticulously observed sketches of ceiling decoration, elaborate wall friezes and tomb details offer a tantalising promise of Wild's later studies of Arab ornament in Cairo (ill. 2). Tellingly, Bonomi described Wild at this time as 
"dull" but "determined"11. An early indication of Wild's interest in Islamic design presents itself in a sketchbook marked 'Nile vol. II' where, nestled amongst the usual Egyptological drawings, we find ten pages dedicated to sketches of ornament from mosques and private houses in "Girgeh" [Girga]. It is possible that this burgeoning curiosity was encouraged by the Egyptologist and Orientalist, Edward Lane. Wild, Bonomi and Lepsius were frequent visitors to Lane's Cairo house. When Lane had first arrived in Egypt in the 1820s he lived exclusively in the Muslim areas of Cairo, learnt to speak Arabic fluently and adopted the "native" dress ${ }^{12}$. This desire to blend in with the local population pre-empts the strategy applied by Wild a number of years later in 1847 when he became the first Westerner to gain access to the Ummayyad Mosque in Damascus. Wild had obtained a decree from the Ottoman Porte granting an "inspection of the Great Mosque"13. The British Consul official in Damascus was "horrified" by the prospect of a "desecration of the sacred building by an infidel", declaring that Wild's tenacity would lead to "death at the hands of the Mohammedan custodians if discovered". Not to be deterred, Wild forged ahead with his "Arabic language, native dress" and a "certain ascetic appearance" providing an "ample disguise" to enable the "gratification of seeing the Holy Place without exciting the slightest suspicion". Wild took his leave of Lepsius in April 1844 and resolved to settle in Cairo, where for the next three years he dedicated himself to the study of Arabian architecture and decorative design. A letter written by Lane later that year, noting that Wild now seemed to be "more industrious", attests to the renewed vigour with which Wild applied himself in this new branch of his Near Eastern studies ${ }^{14}$. Wild had also grown frustrated with the expedition, complaining to Bonomi that "[Lepsius] cares to talk about nothing that does not directly tend to be useful for himself" 15 . An account describing Wild's residence in Cairo notes that "drawing in the East involves no inconsiderable amount of inconvenience, not to say danger, from the great suspicion of the natives of the use which may be made of their treasures". It appears that Wild took many precautions when recording the Arab architectural details of Cairo:

"What could not be done in the daytime had to be accomplished at night. From time to time in his wanderings he "marked in" the objects he desired to copy, prepared his damped paper for squeezes, and in the darkness set forth and obtained impressions with such perfect exactness of details as could not be obtained by drawing under an umbrella without intrusion ${ }^{16}$."

7 While acknowledging Wild's night-time heroics, we should not lose sight of the fact that his focus on domestic, secular architecture was a relatively rare and refreshing approach. As one of his protégés, Caspar Purdon Clarke, stated:

[Wild]"cared more for dwellings of burgher people than for temples or palaces, and as these houses were selected for careful study on their merits rather than for their history, in his sketch-books an invaluable record has been preserved of domestic interiors, especially of Cairo and Damascus, which have long since been swept away before modern improvements ${ }^{17}$." 
2. Detail of a papyrus floral column from a shrine in Egyptian tomb; sketchbook drawing by James Wild, 1842-44.

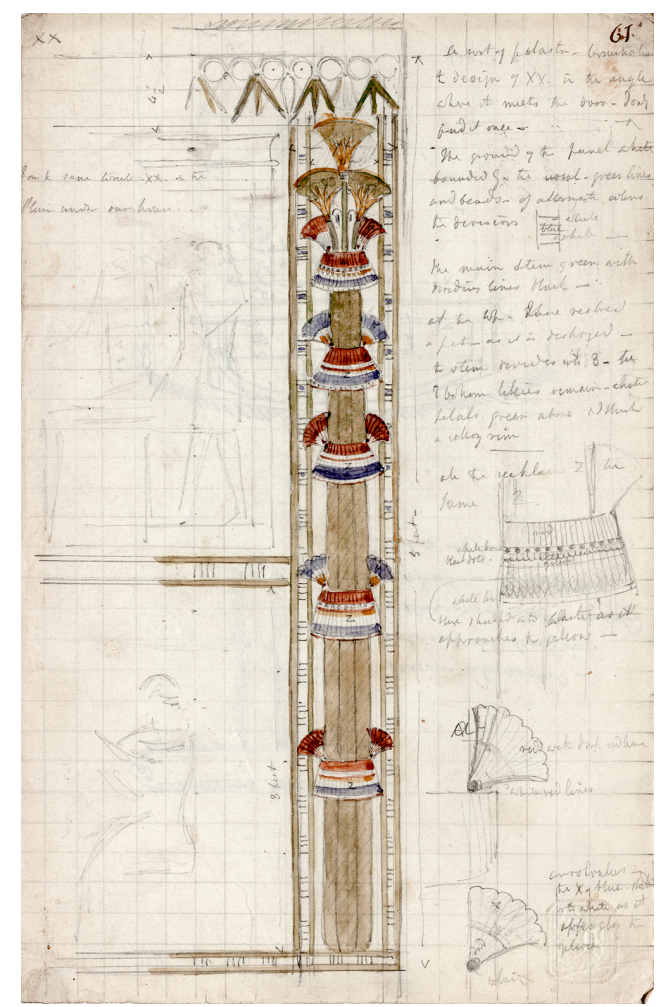

Source: Oxford (United Kingdom), Griffith Institute, University of Oxford (Wild MSS, II, Volume A, p.61)

8 Years later, the architectural historian John Summerson pondered upon the legacy of Wild's Cairo and Damascus sketches, stating that "it would be interesting to know whether any of Wild's work here has been preserved, for his drawings would form a valuable record of much Arab work which has since been swept away ${ }^{18}$."

9 Thankfully, nine of Wild's Cairo sketchbooks survive in the collections of the Victoria and Albert Museum. They were donated as a group to the Museum by his daughter Elizabeth Wild in 1938, nine years after Summerson wrote his article ${ }^{19}$. Miss Wild wrote to the Museum authorities stating that she should like to offer a "collection of his drawings and notebooks on art in Cairo and Damascus - of great value now as so much has been swept away since then ${ }^{20}$."The Museum considered the drawings to be "extremely competent...neat, well-glossed with technical information and measurements...excellent records of every kind of Moslem architecture...A great part of the drawings is concerned with interior decoration (stained glass, woodwork and ceramic etc.) and many of the examples from which they were taken will have disappeared ${ }^{21}$." 
3. Drawing of wooden door panel, with construction details, from James Wild Cairo sketchbook, 1844-48.

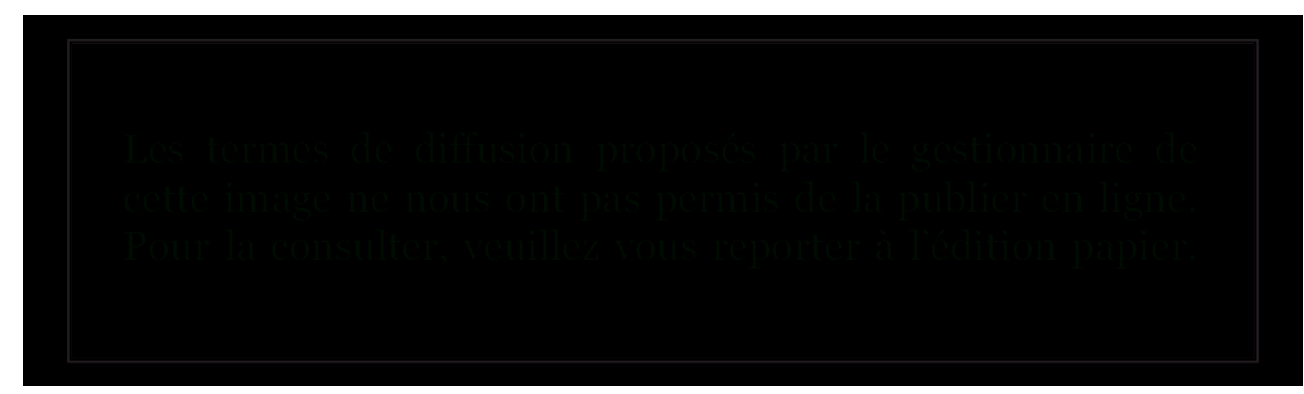

Source: London (United Kingdom), V\&A Images (E.3843:125-1938).

4. Plan of ceiling, including projecting windows, from James Wild Cairo sketchbook, 1844-48.

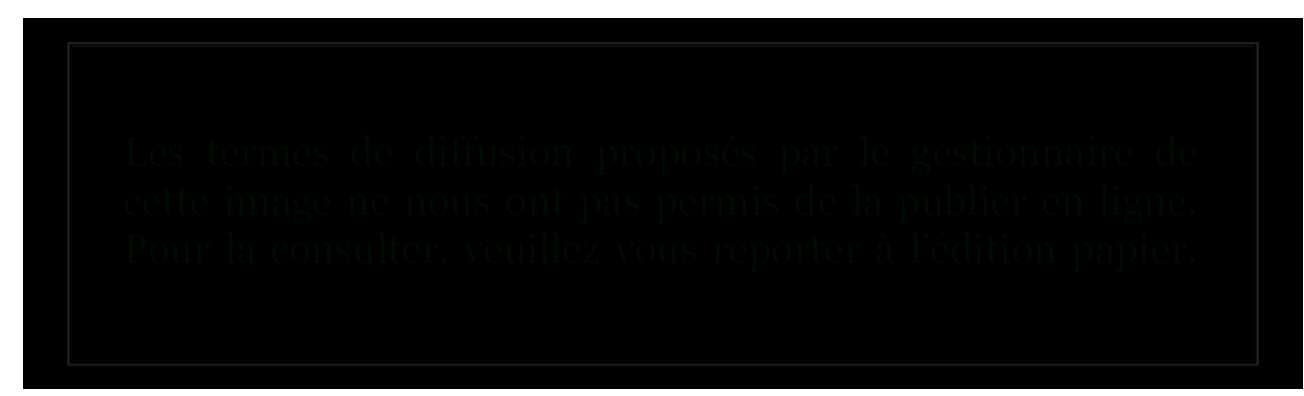

Source: London (United Kingdom), V\&A Images (E.3768-1938).

The Cairo sketchbooks are a wonderfully detailed and faithful record of Arab architecture and design (ill. 3-4). The pages are populated with carefully observed drawings of stained glass windows, marble mosaics, muqarnas vaulting, stone carving, and numerous architectural plans, sections and elevations which record key examples of both religious buildings and, most notably, domestic dwellings. Purdon Clarke noted that Wild "possessed, [to] a remarkable degree, the necessary analytical power" to collect in his sketchbooks "a mass of delicately drawn details which more properly reflect the ideas he sought than any of his subsequent works exemplified ${ }^{22}$." Foreshadowing an obituary for Owen Jones in which he was recognized for the "examples and writings [which] have done more to implant a knowledge of true Art than if he had left us a magnitude of buildings ${ }^{23}$ ", Purdon Clarke seems to be identifying much of the common ground between these brothers-in-law. In his preparation for the Grammar, Jones consulted Wild on the Egyptian chapter, and based the entire Arabian section on Wild's Cairo drawings. Jones considered Wild's sketches to be "very faithful transcripts of Cairean ornament ${ }^{24}$ ". In the preface, Jones expressed the hope that this modest collaboration might lead to a more comprehensive publication of Wild's drawings:

"In the formation of the Egyptian Collection I received much valuable assistance from Mr. J. Bonomi, and from Mr. James Wild, who has also contributed the materials for the Arabian collection, his long residence in Cairo having afforded him the opportunity of forming a very large collection of Cairean Ornament, of which the portion contained in this work can give but an imperfect idea, and which I trust he may some day be encouraged to publish in a complete form ${ }^{25}$." 
5. Drawing of marble mosaic details, from James Wild Cairo sketchbook, 1844-48.

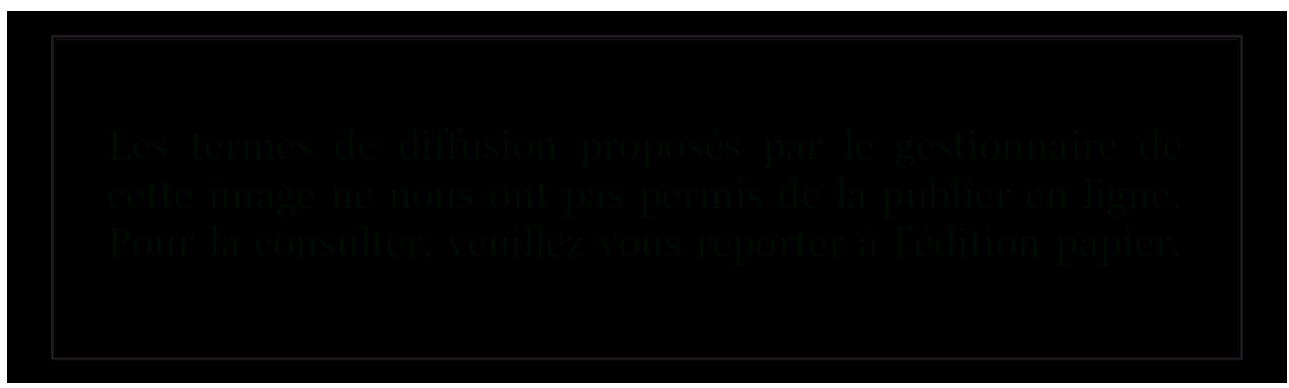

Source: London (United Kingdom), V\&A Images (E.3843:78-1938).

6. Plate "Arabian No. 5" from The Grammar of Ornament by Owen Jones, 1856.

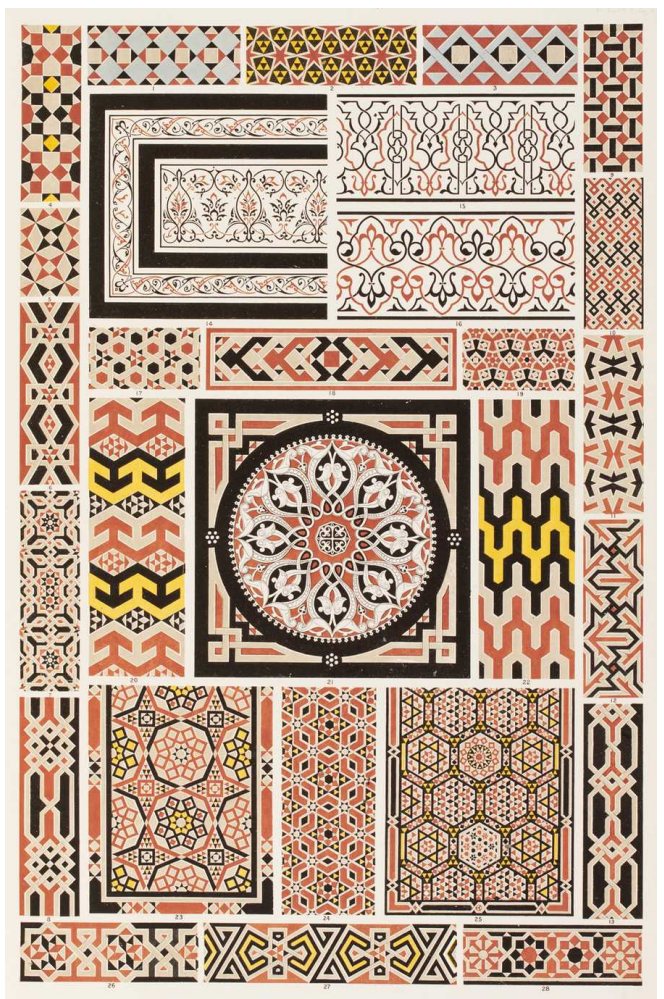

11 Reflecting the value of Wild's studies as a lasting, reliable source for writers, the fifth edition of Lane's Modern Egyptians, which included an appendix on "Arabian Architecture", came supplied with references to Wild's sketches. In a footnote relating to the mosques of Cairo, Lane's nephew Edward Stanley Poole, stated that "careful drawings of this ornament have been published in the 'Grammar of Ornament', from the collection of Mr James Wild." Singling out a particularly impressive group of architectural details, he encouraged the reader to "see especially the series from the mosque of Ibn Tulun, plate XXXI ${ }^{26}$." The majority of Grammar's Arabian chapter consists of architectural features, including examples of woodwork, plaster and stone mosaic (ill.5-6). Many of these samples of ornament can be traced back to the Wild sketchbooks in the V\&A. However, there is one plate consisting of designs "traced from a splendid copy of the Koran in the Mosque Barquqiyya (ill. 7-9) ${ }^{27}$. Up until now it had been unclear which Wild drawings Jones had based this page on. Recent research has confirmed that some of the source material for this plate resides in a volume of 
"Islamic drawings' by Wild held in the collections of Sir John Soane's Museum ${ }^{28}$. The volume also includes drawings of Persian ornament (possibly taken from manuscripts) and examples of Chinese decoration.

Soon after settling in Cairo in 1844, Wild received a commission to design a British cemetery for the local expatriate community. The British consul in Cairo, Alfred Walne, wrote to the Consul-General, Charles John Barnett, to explain that "the want of a British Protestant burial ground has long been seriously [felt] by the residents, but has become quite indispensable in consequence of the overland communication between Europe and India ${ }^{29 "}$. A subsequent letter from Barnett to the British Foreign Secretary, Lord Aberdeen, reveals that the Pasha had been "well disposed to assist" but that "no piece of ground, the property of the Government, could be found suitable to the purpose ${ }^{30}$. Thanks to negotiations initiated by Barnett, a portion of land, set aside for a French Roman Catholic cemetery, was ceded by the French Consulate to the British residents ${ }^{31}$. The local residents raised a substantial sum of money through voluntary donations and deposited this with the British Consulate. Walne wrote to the Consulate in June 1844, enclosing "plans of the Cairo burial ground, and of the gateway and lodges for the pastor, as prepared by Mr Wild the architect with the connaissance of the resident subscribers" ${ }^{32}$. In response to a request for matched funds, the Foreign office granted $£ 150$ towards construction costs the following month ${ }^{33}$. It appears, however, that the project was never executed. The designs, which survive in The National Archives, indicate a simple gateway which on the internal side incorporates a cavetto cornice flanked by twin pylon-like lodges, and on the street-side boasts double doors inset with wooden mashrabiyyah grills (undoubtedly sourced from the numerous domestic dwellings that Wild was studying at this time). As Mark Crinson has previously noted, the gate represented, on one side, the association of ancient Egyptian architecture with death, and on the other side, Wild's new-found interest in the Arab architecture of the medieval streets of Cairo. ${ }^{34}$

7. Drawing by James Wild, taken from a 14th-century Cairo Mamluk manuscript; contained in an album of drawings of Islamic ornament.

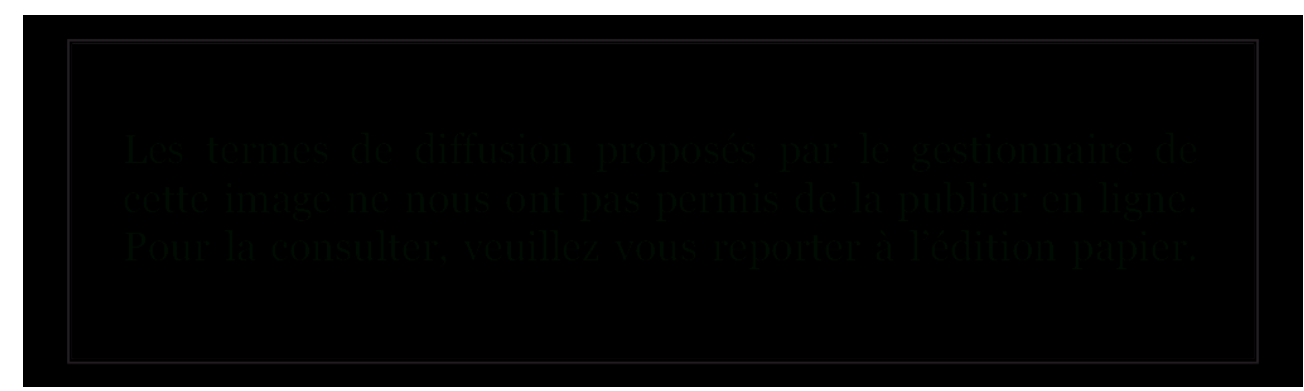


8. Drawing by James Wild, taken from a 14th century Cairo Mamluk manuscript; contained in an album of drawings of Islamic ornament.

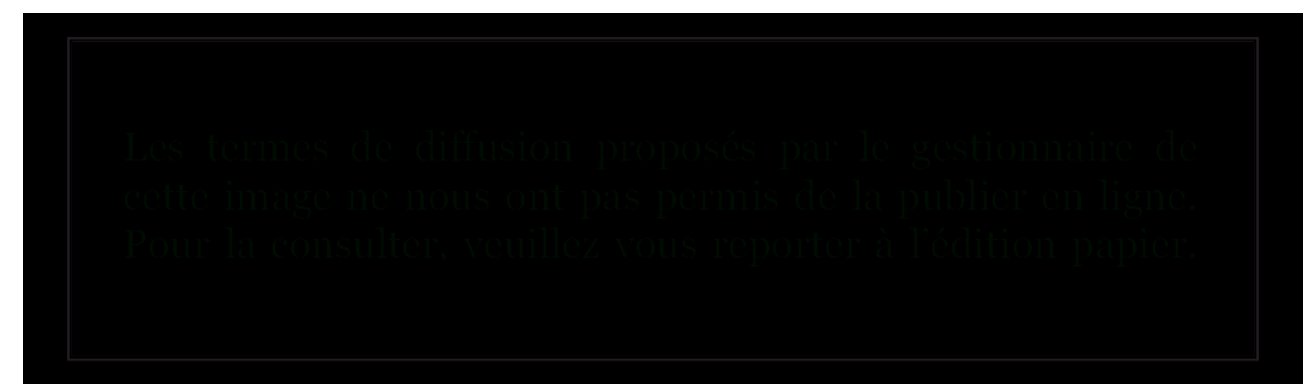

Source: London (United Kingdom), Courtesy of the Trustees of Sir John Soane's Museum (Vol 108/18).

9. Plate "Arabian No. 4" from The Grammar of Ornament by Owen Jones, 1856.

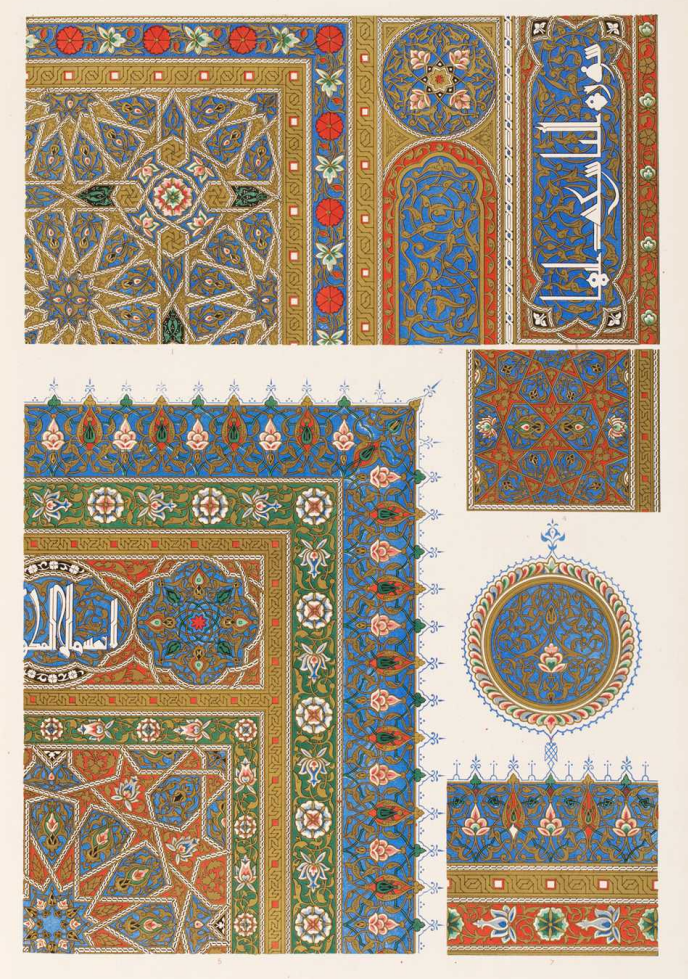

13 The same year, 1844, saw the recommencement of discussions regarding a proposed Anglican church in Alexandria. In a personal letter to John Bidwell, the Superintendent of the Consular Office, Barnett outlined the case for urgent action:

"I am frequently asked a question which embarrasses me very much, it is this "When is your church to be built?" Above four years ago the Pasha gave [us] a piece of ground for the purpose, and all that we have yet to show towards a Church is one stone upon which the Arabs copulate, and a trench in which they perform a dirtier process. A plan for a Gothic church was some time ago sent to us by the [Cambridge] Camden Society, approved...by the Residents, and...submitted to Government. I individually entirely disapprove of a Gothic building, as unsuited to the climate, and likely to be little in harmony with the other buildings which will surround it...It is little to the credit of us as Christians that we have not taken advantage of the tolerance shown us by the Pasha. ${ }^{35}$ " 
Wild won the commission for the church of St. Mark in Alexandria in 1845, although the project was not completed until ten years later, in 1855, after many delays and long periods of inactivity. Barnett had indicated in his letter to Bidwell that he would have liked "a simple Greek building" - however Wild, in an echo of his scheme at Christ Church, decided to employ a hybrid approach. John Summerson described the result as "a church of considerable originality in a strongly Europeanized version of the Saracenic style ${ }^{36 "}$. According to a contemporary report in The Builder, the Pasha, Muhammad Ali, had "expressed a wish that the structure should harmonize with the neighbouring buildings, and be worthy of the English people ${ }^{37 "}$. Wild published a statement declaring that the design of this church was intended "to conciliate the opinion of the Arab inhabitants, and to meet the comprehension of native artificers" while also representing a scheme which "carries out a general sentiment of Arabian detail 38 ". Wild's ambition to channel the Arabian ornament of Cairo is perhaps best illustrated by his unrealised proposal for a campanile adjoining St. Mark's. There were two successive designs for the tower. The first resembled a minaret to some extent, with levels half-screened with mashrabiyyah, a balcony complete with mabkhara pavilion and muqarnas cornice, and a "summit in the form of a cupola, in the Arab style ${ }^{39 "}$. Crinson has previously remarked that the second proposal, with its Venetian campanile and pyramidal spire, represents a transfer of the scheme's Islamic details from the tower to the external ornament of the church ${ }^{40}$. Alluding to the growing collection of architectural details filling up Wild's sketchbooks, Crinson has also pointed out that the church's carved crenellation and cusped archivolts might all be based on the ornament that Wild had been studying in Islamic Cairo at that time. He noted also that the muqarnas-decorated beams of St. Mark's wooden roof were close to those that Wild had drawn in several Cairene houses ${ }^{41}$.

10. Drawing of windows in coloured glass set in plaster, from domestic houses, from James Wild Cairo sketchbook, 1844-48.

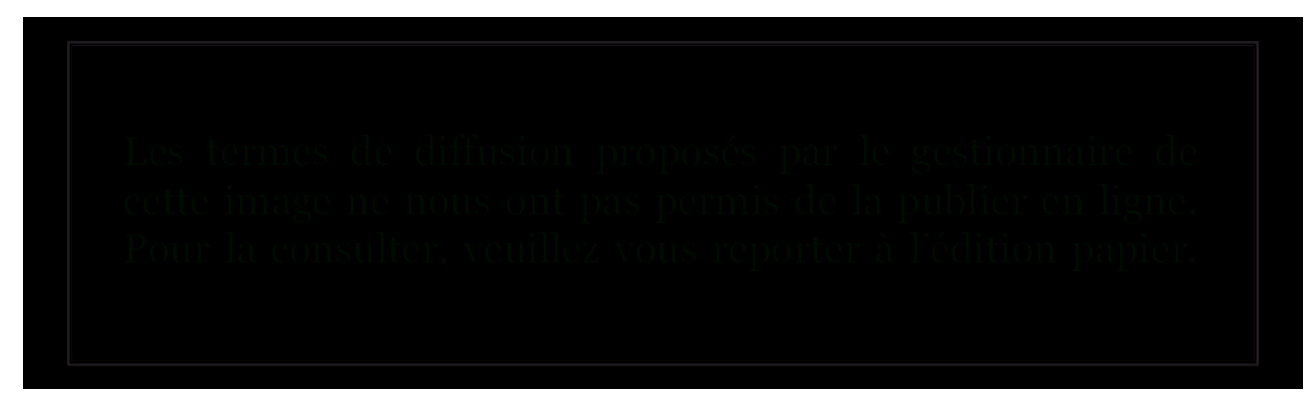

Source: London (United Kingdom), V\&A Images (E.3711-1938).

Despite the unrealised ambitions for his 'Islamic' campanile, Wild may have found comfort in the successful completion of his Water Tower at Great Grimsby docks. Built in 1852, soon after Wild's return to England (via Constantinople, Italy and Spain) the tower's mix of western and eastern influences was not lost on the architectural historian Nikolaus Pevsner who observed that Wild had been "gathering in his sketchbooks ideas of which he put some to use here in Grimsby" and stated that "the tower...is straight from Italy, but the crowning minaret is Oriental ${ }^{42 "}$.

16 It is likely that Wild received the tower commission through Henry Cole, a leading figure in the design reform movement, who in 1847 had been asked to manage the public relations for the Grimsby docks project ${ }^{43}$. Cole had employed Wild as decorative 
architect at the 1851 Great Exhibition, and in 1863 he invited Wild to become an expert adviser for the South Kensington Museum (later renamed the Victoria and Albert Museum), where Cole was Director. Wild's knowledge was particularly valued in matters relating to Arabian art. His knowledge of Arab architecture proved useful when in 1871 the Museum's Assistant Director, Philip Cunliffe-Owen, recommended that "Mr J. W. Wild, Architect, who has been for some time a resident at Cairo, be employed to draw up a report upon the Buildings and Architectural Ornament in the City" and "receive [the] usual fee for professional assistance ${ }^{44}$ ". Wild's services even extended to designing built projects for the Museum. In 1865, Wild wrote a letter offering to execute a "pierced Arab window" for the sum of $£ 10^{45}$. In October of the following year, Henry Cole approved the order for Wild's Arabian stained glass window to be "placed in the upper compartments in the Oriental Courts" ${ }^{\prime 6}$. These galleries had been completed recently by Wild's brother-in-law, Owen Jones, and included Indian and Chinese \& Japanese Courts. Wild's first-hand knowledge of the traditional craft techniques employed in the creation of Arab windows was revealed during a meeting at the Royal Institute of British Architects (ill.10). In response to the architect George Aitchison's description of the windows of Cairene houses as "more enchanting and fairy-like than the stained glass of the Duomo of Florence or of Chartres cathedral", Wild recalled an episode from his own time in Cairo:

"I caused to be executed when I was living at Cairo a window similar to those described. An old man came to my house and brought with him a frame, something like a frame to hold a slate for pencils. The frame was laid on the ground, filled with plaster, and then left for the plaster to dry. Next day a diagram was made upon it, and the plaster was cut like cheese. The whole thing was soon finished, and on the afternoon of the same day the workman inserted the glass by sticking it in at the back $^{47}$."

11. Design by James Wild for a window in Arab style for the South Kensington Museum's Oriental Courts; ca. 1866.

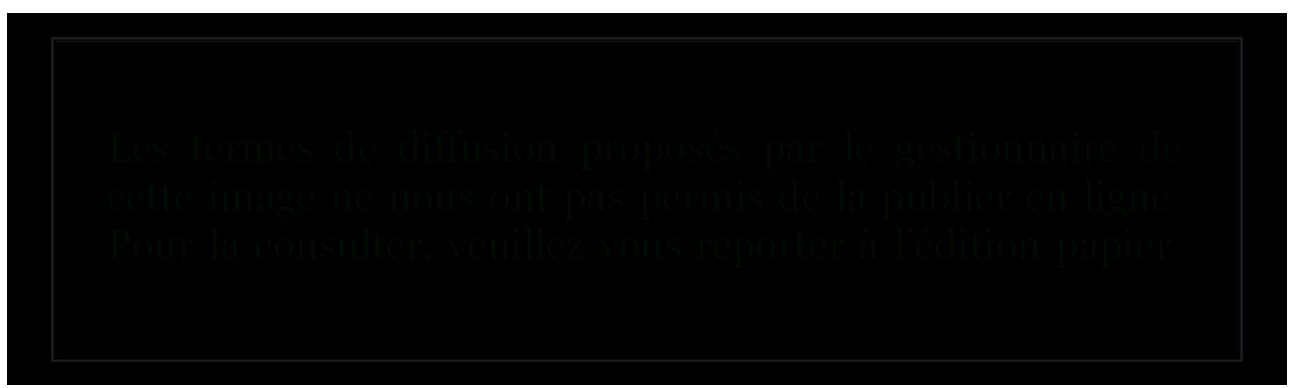

Source: London (United Kingdom), V\&A Images (E.3705-1938).

Records indicate that Wild was not paid for his Oriental Court Arab window until eleven years after the original commission ${ }^{48}$. It appears that other options may have been considered during the intervening period. Wild wrote to Cole in 1867 to inform him that a "Mr. J. Spencer Bell has offered to lend to the Museum a perforated plaster window from Cairo, filled with stained glass" ${ }^{49}$. The window was duly received and registered as a loan object, but existing correspondence suggests that it was never exhibited due to its dilapidated state ${ }^{50}$. Wild's window was eventually installed (ill. 11), and was fabricated by the stained glass manufacturers Powell \& Sons who also provided the stained glass windows for Wild's church in Alexandria ${ }^{51}$. Years later a commentator in The Times would describe the "miscellaneous windows at the opposite side of the 
South Court, with Mr. Wild's admirable imitations" 52 . Wild continued his role as the Museum's resident Arabian expert, albeit on an occasional basis, even during his later years when serving as curator of Sir John Soane's Museum. In an Art Referee report from 1881, Wild advised on the potential acquisition of a perforated brass lamp which had been offered to the Museum by a Mr Mohammed Joseph for the sum of $£ 30^{53}$. Describing this "large domed lantern" as being "probably about A.D. 1700, and of Cairo or Damascus work...probably taken from some mosque or tomb", Wild went on to recommend that the offer be declined, explaining that "the general design is very good but the perforated brass work is not particularly fine in execution".

In addition to acting as an occasional Art Referee, Wild had an impact at South Kensington by selling objects directly from his own collection. As an example, in October 1866 Wild sold to the Museum a group of eight "Indian illuminated drawings" for $£ 30^{54}$. However, the Museum's most significant acquisition from Wild came in 1860 with the purchase of a "Saracenic glass lamp" 55 for the considerable sum of $£ 200^{56}$. This was the first mosque lamp to enter the Museum's collections (ill. 12). Amongst the Wild drawings held at the Soane are two sketches of this lamp, including a detailed study of the underside body decoration (ill. 13, 15) ${ }^{57}$. It is possible that staff had seen this lamp a few years previously when it had been on loan to the 1857 Art Treasures Exhibition in Manchester (ill. 14) ${ }^{58}$. Writing on 'Vitreous Art' for the exhibition catalogue, the British Museum's expert on Oriental glass, Augustus Wollaston Franks, had singled out Wild's mosque lamp for particular praise:

"Among the specimens which have come to us from the East, there are few more elegant than the lamp represented [here]. It was obtained by its present possessor, Mr. Wild, in Cairo, and has been supposed to have been taken from the mosque of Sultan Hassan [Sultan Hasan], in which still hang several lamps of the same kind, shedding a dim light over its magnificent vaults ${ }^{59}$."

Franks also noted that "another lamp, very similar in form, has been recently brought from Egypt, and is destined to be placed in the Louvre". Interestingly, Matthew Digby Wyatt's chapter on 'Metallic Art' included a woodcut illustration of a "full-size specimen of Medieval Arabic damascening, from a bowl" which also came from Wild's collection, and was presumably also acquired during his time in Cairo ${ }^{60}$. Later accounts testify to the continuing prestige attached to Wild's mosque lamp. Describing a group of lamps that were soon to be acquired by the Museum as part of the Meymar Collection of Arab Art, Reginald Stuart Poole in 1867 stated that "these lamps do not equal in beauty or in preservation the lamp purchased of Mr. James Wild" ${ }^{1}$. Almost twenty years later his nephew and fellow Orientalist, Stanley Lane-Poole, concurred with this assessment, expressing the opinion that Wild's mosque lamp was the "gem of the collection"62. To get a sense of how the lamp related to other objects on display in the Museum, we only have to turn to Moncure Conway's 1875 account of a stroll through the Ceramics Gallery ${ }^{63}$. Contemplating the decoration of a neighbouring Urbino plate, Conway notes that "It is curious to compare such arabesques with the ornament on a piece of real Arabic work, such as the accompanying ancient lamp." An illustration of Wild's lamp is included, together with the caption: Glass Lamp from an Arab Mosque - Fourteenth Century. Two years after this purchase from Wild, a further four mosque lamps appeared in the galleries (albeit temporarily) as part of the South Kensington Museum's major Loan Exhibition of $1862^{64}$. The lamps came from the distinguished collections of Hollingworth Magniac, Francis Baring and Felix Slade. Magniac contributed a particularly fine 14th-century Mamluk lamp from the Mosque of 
Sultan Hasan in Cairo, and was therefore of similar date and from the same supposed source as Wild's mosque lamp.

12. 14th century enamelled glass mosque lamp from Cairo, sold by James Wild to the V\&A Museum in 1860 .

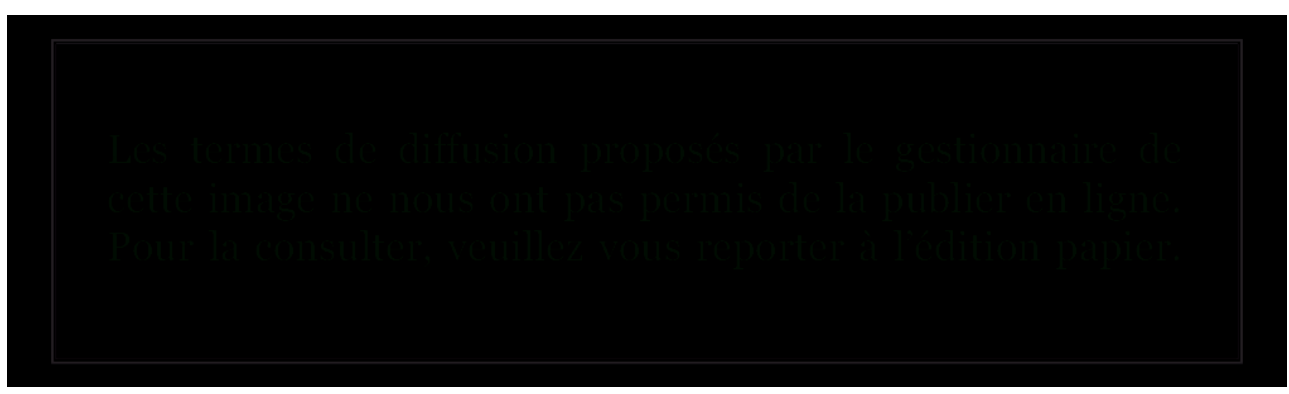

Source: London (United Kingdom), V\&A Images (E.6820-1860).

13. Drawing by James Wild of his Cairo mosque lamp, contained in an album of drawings of Islamic ornament.

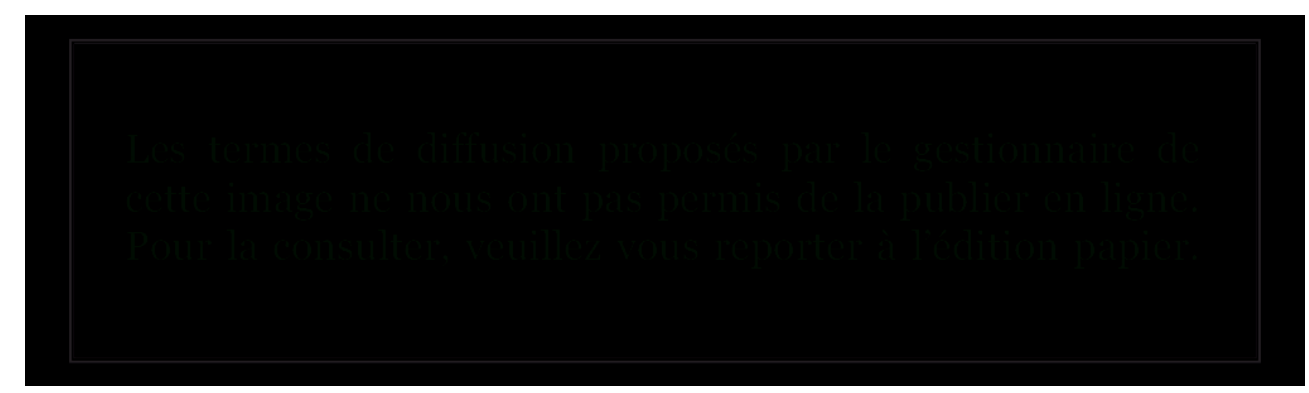

Source: London (United Kingdom), Courtesy of the Trustees of Sir John Soane's Museum. 
14. Plate "Vitreous Art" from J. B. Waring, Art Treasures of the United Kingdom from the Art Treasures Exhibition, Manchester, 1858, depicting James Wild's Cairo mosque lamp.

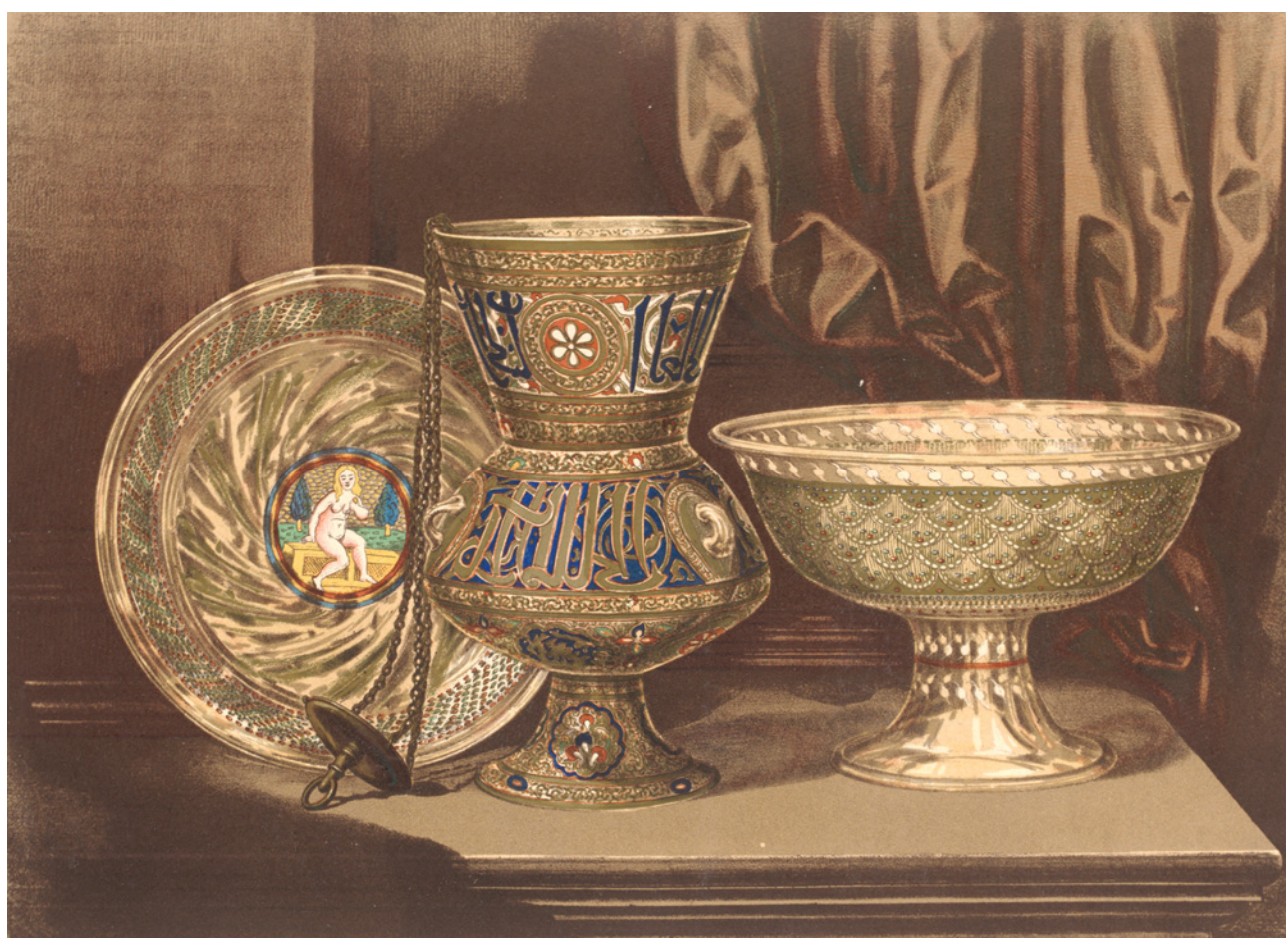

15. Drawing by James Wild of his Cairo mosque lamp, contained in an album of drawings of Islamic ornament.

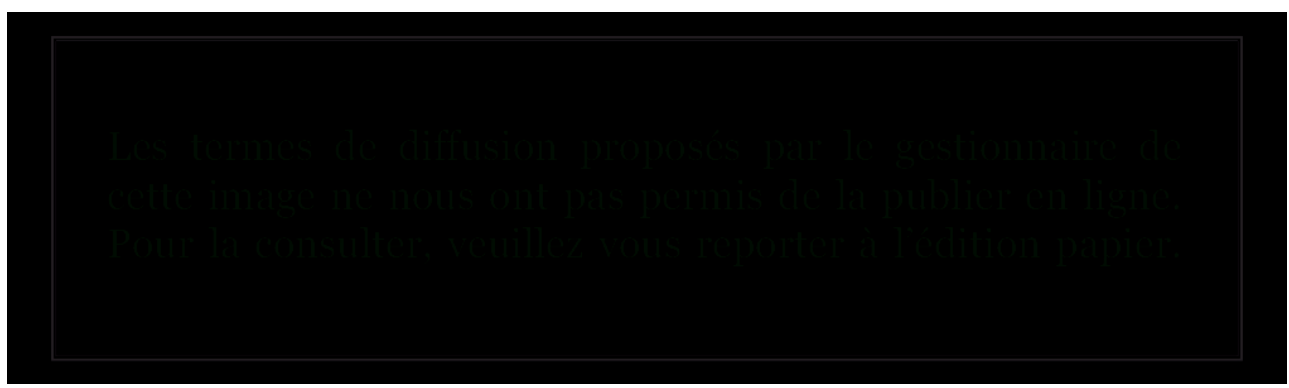

Source: London (United Kingdom), Courtesy of the Trustees of Sir John Soane's Museum (Vol 108/69).

20 Like Wild, Frank Dillon was another artist-traveller whose Arabian objects found a home in the South Kensington Museum. In 1865 he donated some examples of "Cairene" ceramics, described as "wall tiles, with foliage pattern on white ground" ${ }^{6}$. Dillon visited Egypt a number of times, from the 1850s through to the 1870s. Living in Cairo for extended periods of time he was keen to study modest domestic dwellings, rather than focus exclusively on the more obvious religious buildings and public spaces. Like Wild, Dillon sought to create faithful records of Arabian architecture. His paintings conveyed the intricacies of Islamic design, avoiding the inventive embellishment and fanciful romanticism exemplified by other Orientalist painters who had visited Cairo before him, such as David Roberts and John Frederick Lewis ${ }^{66}$. Dillon built an Arab studio at his house in Kensington to aid the completion of paintings which were worked up from original drawings and sketched watercolours made in Cairo. As evidence of Dillon's commitment to accurate Islamic decorative details, the 
studio was furnished with a number of Arabian objects, some of which were likely to have been sourced from Wild's own collection. In a letter dating from the 1940s, Wild's daughter Elizabeth wrote to the South Kensington Museum offering to donate a number of "Near Eastern works of art" that had been in her father's possession; namely a "beautiful rosewater bottle, 16th-century inlaid pearl table, Koran stand, brass ewer and basin ${ }^{67}$." Miss Wild revealed that these "were lent at one time to a Mr Dillon, and were meant to be left to your Museum, but unfortunately were sent to me here when the roads were so bad." Objects fitting the description of these that belonged to Wild do crop up in a number of Dillon's paintings. Sadly, the South Kensington authorities declined Miss Wild's offer. The Museum's Director stated, rather dismissively, that "we have a good deal of that inlaid mother-of-pearl stuff; and beautiful as it is I doubt if we should be justified in accepting more ${ }^{68}$." Dillon's Arab studio was illustrated in Georg Ebers's Ägypten in Bild und Wort (ill. 16), and it is tempting to wonder if the inlaid pearl table, Koran stand and brass basin depicted therein are in fact the very same objects that were lent from Wild ${ }^{69}$. In 1878, not long after Dillon had built his Arab studio, Wild was appointed curator of Sir John Soane's Museum, where he busied himself with many alterations to the house. One of his final projects was the construction of a new 'Egyptian' anteroom which was started in 1889, just three years before Wild's death ${ }^{70}$. Decorated with "ornamental pitch pine work" faithfully reproduced many examples of Arabian woodwork with which Wild was familiar from his time in Cairo over forty years before (ill. 17). Wild's obituary in The Times noted that Wild "did much for the Soane Museum, particularly in the construction of a...new room, in the building of which he showed his learned acquaintance with the principles of that leading Arab feature"72. As Michael Darby has previously observed, Wild's choice of a Cairene style for the Egyptian Room may have been "the action of an old man re-living the days of his youth when he spent several years in Cairo producing hundreds of drawings of similar woodwork"73. However it is also possible that Wild had wanted to create a room similar in atmosphere to Dillon's Arab Studio in Kensington, but one that here at Lincoln's Inn Fields would be intended for a public audience. 
16. “Mr. Frank Dillon's Studio".

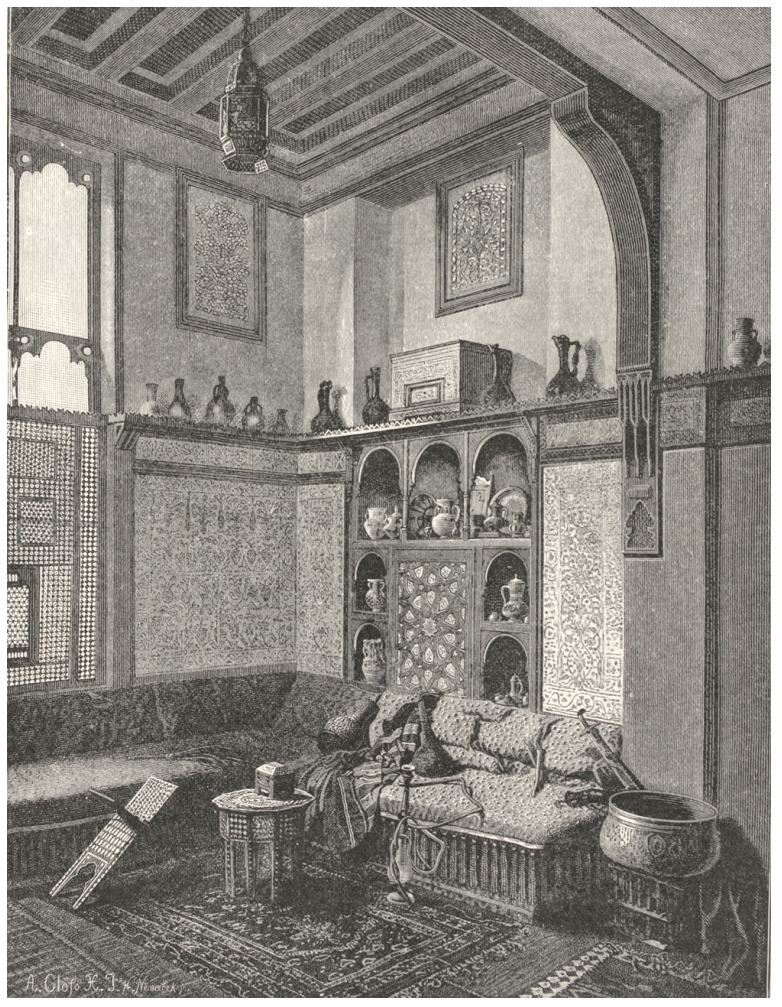

Source: G. EBERs, ̈̈gypten in Bild und Wort, 1880.

21 A number of Dillon's paintings were placed on display at the Royal Institute of British Architects during a lecture entitled 'The Arab House of Egypt' ${ }^{74}$. The paper dealt with the architecture of Cairo and reflected a burgeoning interest in Arab construction techniques. It is the ensuing discussion that is particularly interesting, shedding light as it does on the wider debate regarding preservation and collecting that had been ongoing during the $1880 \mathrm{~s}^{75}$. The architect Richard Phené Spiers, who as a young man had spent over a year travelling through the Near East, stated:

"I can only join...in bewailing the destruction of these beautiful works of art, many of those in Mr. Frank Dillon's drawings having already been pulled down, and their decorative features broken up or stolen. In this respect I am afraid Europeans are to blame, and even Count St. Maurice...is responsible for the destruction of a great deal, having been given a free hand (so I am informed) to appropriate for his own house any little accessories he might come across which attracted his fancy ${ }^{76}$."

17. Detail of wood panelling in the "Egyptian" ante-room, designed by James Wild for Sir John Soane's Museum.

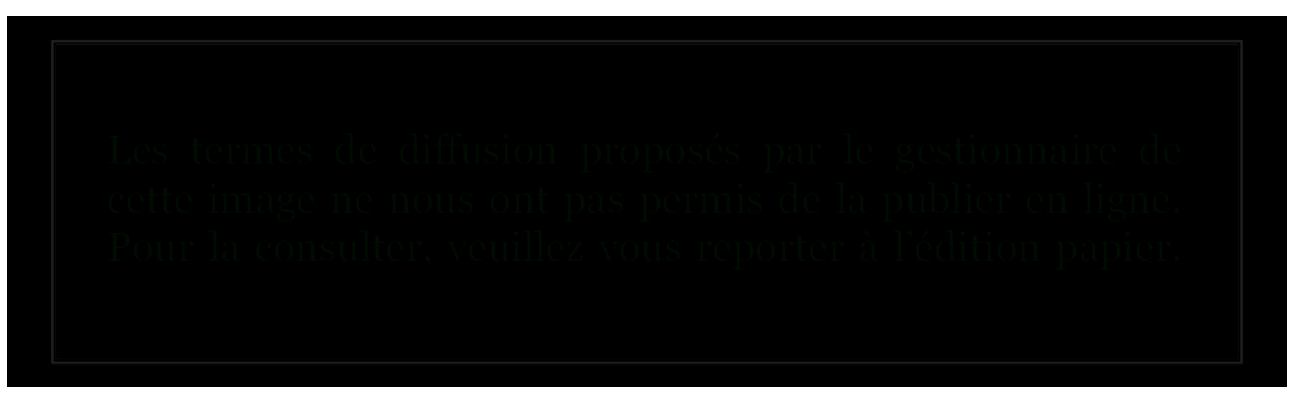

Source: London (United Kingdom), Courtesy of the Trustees of Sir John Soane's Museum. 
In response to the question of whether "the exportation of the woodwork of Cairo is still going on at the rate which it did some ten or twelve years ago", the architect Richard Herbert Carpenter replied that this was now "by no means easy", but declared that in 1876, while in Cairo, he had "a whole house-front offered...at a wonderfully cheap rate", adding that the only difficulty was that of it "being taken down for sale to Christians" 77 . Despite having earlier mourned the looting of Arabian architectural features, Spiers confessed that "two years ago I got a rather interesting shop-front" and bemoaned the fact that "it has now become very difficult to get fine examples"78. He also recounted a tale of Dillon visiting Cairo's 'House of the Mufti' in 1869 where he painted "two large panels of Persian tiles" which "some years afterwards" were gone. It appears that Dillon "found [the tiles] afterwards in the shop of a bric-a-brac dealer in the 1878 Exhibition at Paris"79. It is interesting that, despite the criticism earlier directed towards Count St. Maurice, Spiers failed to mention the role of the South Kensington Museum in these matters. According to contemporary accounts, Gaston de St. Maurice held an "official position in the household of the ex-Khedive Ismail" which gave him "unusual facilities for acquiring objects of art in Cairo" and he "employed his opportunities well" ${ }^{80}$. St. Maurice had been commissioned by the Khedive to form a collection of Islamic art for the Arab section of the 1878 Paris Exhibition. He wrote to the South Kensington Museum in 1882 with an invitation to examine the collection in detail at Paris's musée des Arts décoratifs, where the objects were on display at that time $^{81}$. He also mentioned a house that he had built in Cairo "in antique style with materials brought from the finest palaces of the 14th, 15th and 16th Centuries....ceilings - carved, painted and gilt, mosaics of marble and mother-ofpearl..." He stated that "it might be feasible for [the Museum] to purchase and collect either in whole or in part the ancient materials in question" before concluding that "they would certainly form a unique collection, such as it would be impossible to form again at any price". James Wild was consulted, and subsequently advised that this "very fine collection" would be "most valuable to the students of Eastern Art" Purdon Clarke, in reference to the Meymar Collection of Arab Art (procured at the previous Paris Exhibition) declared that “...to add this [St. Maurice] collection to that purchased in 1867 would form a Museum of Arabian Art of a character so complete that little would be left possible to improve it, and one which would in the future increase in value when in the not too far distant future the Arab Quarter with its merchant palaces and inimitable monuments has been improved off the map of Cairo" ${ }^{83}$. This last line resonates with the sentiments expressed in an article published earlier that year, in which the author had wistfully recalled the "good old days" in Cairo when the "forest of these minarets seemed to vie with the forest of palms around and about them":

"Hardly a tile now glistens on the domes of the tombs of the Caliphs... the other tombs seem, with few exceptions, to have been swept away, and the streets of Cairo are being widened with a ruthless hand to admit the streams of hackney carriages which have, with the wealthier classes, superseded the donkeys of their fathers. Straight boulevards have taken the place of the endless turns, the infinite variety of house...Flat, illmade Venetians have driven away the Musharabia lattices; the pickaxe and the crowbar seem at work from morning to night in every quarter of Cairo, and its former inhabitants are flying from their demolished houses... ${ }^{84 "}$

Stanley Lane-Poole concurred with this assessment. In his St. Maurice report he stated that "the collection is of the greatest value and rarity and it is extremely unlikely that the Museum will ever again have such an opportunity of acquiring so many rare and highly interesting examples of an art that is yearly becoming more difficult to study, of 
which specimens are fast disappearing" ${ }^{85}$. The collection, duly purchased, was described in The Times as comprising "some of the rarest and most exquisite specimens [from Cairo] that have ever been seen in Europe" ${ }^{16}$. The negotiation of this major acquisition came in the immediate aftermath of the 1882 Anglo-Egyptian War, which saw Wild's church of St. Mark narrowly escape destruction during the British fleet's three-day bombardment of Alexandria. In early 1883 Lane-Poole was sent on a "special mission" to Cairo by the South Kensington Museum "with the view of discovering whether the disturbances had brought many objects of Saracenic art into the market" 87 . A substantial collection was acquired, including examples of metalwork, ceramics and woodwork. The highlight was a "room from Cairo", purchased for $£ 39$ from the Cairo dealer Gasparo Giuliana ("Négociant de Mucharabie \& d'Antiquitiés") ${ }^{88}$, complete with carved wooden ceiling, mashrabiyyah and "a row of stucco lights filled in with pieces of coloured glass" 89 . The room was displayed just inside the Museum's side entrance, but unfortunately was "squeezed behind the turnstile, decapitated as to its cupola, and contracted to three-fourths of its natural width in order to leave space for the footway" ${ }^{\prime 0}$.

The enduring value of Wild's Cairo sketchbooks, even forty years after their creation, was demonstrated by Lane-Poole in the introduction to his 1886 book, Art of the Saracens:

"I have to acknowledge much private assistance from friends who have made Saracenic art their study. Mr. J. W. Wild, the curator of Sir John Soane's Museum, than whom there lives no better authority on the architecture of Cairo, has kindly read and approved the...chapters on architecture, stone and plaster, and mosaic, and has generously placed his interesting Egyptian notes and sketch-books at my disposal ${ }^{91}$."

The swift and sudden changes witnessed in the Arab quarter of Cairo assigned a new significance and importance to the architectural records preserved in Wild's drawings from the 1840s. Wild's sketches proved particularly useful when they enabled the Museum to reunite two groups of carved wooden panels belonging to the same minbar from the mosque of Ibn Tulun:

"The removal [of the minbar] must have been effected in comparatively recent times, for when Mr James Wild...was in Cairo, about 1845, the older pulpit was still standing; and he made a drawing of the geometrical arrangement of the panels, which is still preserved in his sketch-books, and which was turned to some advantage some years ago, when the fragments of the pulpit-sides were acquired by the South Kensington Museum from M. Meymar...The pulpit did not arrive in England in its original shape, but consisted merely of a collection of loose panels, which Mr Wild, with the help of his sketch, arranged in a square, which now hangs on the walls of the Museum....When the Museum acquired the magnificent collection of M. de St Maurice, in 1884, I was able to identify the fine panels which the late owner had fitted into the framework of a modern and ill-proportioned door as portions of the same pulpit ${ }^{92}$.

Wild died on the 7th of November 1892 at Sir John Soane's Museum. It was noted at the time of his death that "visitors, especially students, will miss his kindly courtesy and great readiness to help them ${ }^{93}$." Wild's impact may not necessarily be measured by an extensive list of built works, or by an abundance of publications. However, through a steadfast dedication to the study of Arabian design, his specialist knowledge which earned the respect of esteemed colleagues, and the legacy that resides within his meticulous sketches of buildings long since altered or demolished, James Wild remains 
a figure who deserves admiration and, most importantly, further study. Reflecting his originality and dogged determination, one of his obituaries summarized:

"The great characteristics of Wild as an architect are knowledge without servility. He was never a copyist or imitator, but always employed his learning in the spirit of the masters whom he understood. His conscientiousness was extreme, almost to a fault, if a virtue can so be characterised ${ }^{94}$."

\section{NOTES}

1. Richard LEPSIUS, Letters from Egypt, Ethiopia, and the Peninsula of Sinai, London: Bohn, 1853, p. 35

2. Caspar PURDON CLARKE, "James W. Wild [obituary]," The R.I.B.A. Journal, $30^{\text {th }}$ March 1893.

3. Owen JONES, Plans, Elevations, Sections and Details of the Alhambra (issued in parts, 1836-1845). This was a landmark publication not only for the meticulous, detailed records of Islamic architectural details, but also for the fact that Jones laboured and experimented over a number of years, producing the first ever book to boast a sustained use of chromolithography.

4. Owen JONES, The Grammar of Ornament, London: Day \& Son, 1856.

5. Ibid., Proposition 36.

6. Borthwick Institute of Historical Research (Hickleton papers), York. A2.42.5, Wild-Wood, $14^{\text {th }}$ December 1841, as cited in Mark CRINSON, "Leading Into Captivity: James Wild and his work in Egypt," Georgian Group Journal, 1995, p. 53.

7. David VAN ZANTEN, The Architectural Polychromy of the 1830s, New York, NY: Garland Publishing, 1977, p. 347 (Outstanding dissertations in the fine arts).

8. Cambridge (United Kingdom), Cambridge University Library, Joseph Bonomi papers, Add. 9389/2/W/49-64 James William Wild.

9. Peter MEADows, "Joseph Bonomi," in Oxford Dictionary of National Biography, Oxford: Oxford University Press, 2004.

10. The Griffith Institute (University of Oxford) holds a collection of drawings by Wild from his time on the Lepsius expedition, consisting of two portfolios of drawings and plans, and three notebooks with sketches.

11. Letter from Joseph Bonomi to F.O. Ward, $6^{\text {th }}$ September 1842, private collection of Yvonne Neville-Rolfe, as cited in Jason тномPSON, Edward William Lane, 1870-1876: the life of the pioneering Egyptologist and Orientalist, London: Haus, 2010, p. 513.

12. See Jason тномPSon, "Edward William Lane," in Oxford Dictionary of National Biography, Oxford: Oxford University Press, 2004.

13. "T.P.", "The Late Curator of Sir John Soane's Museum," The Art Journal, vol. 13, 1893, p. $120-121$.

14. Letter from Edward Lane to Joseph Bonomi, $17^{\text {th }}$ December 1844, private collection of Yvonne Neville-Rolfe, as cited in Jason THOMPSON, op. cit. (note 11), p. 534.

15. Idem, letter from James Wild to Joseph Bonomi, $25^{\text {th }}$ April 1844, as cited in Jason THOMPson, op. cit. (note 11), p. 539.

16. “Т.P.," op. cit. (note 13), p. 121.

17. Caspar PURDON CLARKE, op. cit. (note 2), p. 276.

18. John SUMMERSON, “An Early Modernist: James Wild and His Work," The Architects' Journal, $9^{\text {th }}$ January 1929, p. 59. 
19. The drawings presented by Elizabeth Wild also include sketches from Italy, Spain and Damascus (V\&A: E.3644 to 4084-1938).

20. London (United Kingdom), V\&A Archives, Elizabeth Henrietta Mary Wild nominal file, MA/1/ W1860.

21. Ibid.

22. Caspar PURDON CLARKE, op. cit. (note 2), p. 276.

23. Obituary for Owen Jones, Building News, $8^{\text {th }}$ May 1874.

24. Owen JONES, op. cit. (note 4), The Grammar of Ornament, introduction to Chapter VIII, "Arabian Ornament".

25. Ibid. (preface), $15^{\text {th }}$ December 1856.

26. Edward William LANE, An Account of the Manners and Customs of the Modern Egyptians, Edward Stanley POolE (ed.), London: John Murray, 1860, Appendix F, “II - Arabian Architecture”, 342.

27. Owen JONES, op. cit. (note 4), The Grammar of Ornament, description of Plate XXXIV, Chapter VIII, "Arabian Ornament".

28. See James WiLD, Volume 108, Sir John Soane's Museum collections, catalogued as "Volume containing designs for tiles...designs for wallpaper...studies of Islamic ornament from manuscripts, silks ceramics etc. (95 items)". I am grateful to my colleagues Mariam Rosser-Owen and Moya Carey in the Middle East section of the Asia Department at the V\&A, for their assistance in identifying these drawings as copies of $14^{\text {th }}$ century Mamluk Quran manuscripts.

29. Richmond, Surrey (United Kingdom), The National Archives, Letter from Alfred Walne to Charles John Barnett, $18^{\text {th }}$ March 1844, Foreign Office records, FO 78/583.

30. IDEM, letter from Colonel Charles John Barnett to George Hamilton-Gordon, $4^{\text {th }}$ Earl of Aberdeen, $23^{\text {rd }}$ March 1844.

31. Ibid.

32. IDEM, letter from Alfred Walne to Stoddart, $18^{\text {th }}$ June 1844.

33. IDEM, letter from John Bidwell (Superintendent of the Consular Service, Foreign Office) to Colonel Charles John Barnett, $26^{\text {th }}$ July 1844.

34. Mark CRINSON, op. cit. (note 6), 56.

35. Richmond, Surrey (United Kingdom), The National Archives, Personal letter from Colonel Charles John Barnett to John Bidwell, 22 ${ }^{\text {nd }}$ March 1844, Foreign Office records, FO 78/583.

36. John SUMMERSON, op. cit. (note 18), p. 59.

37. The Builder, $5^{\text {th }}$ September 1846, p. 421.

38. Ibid., as cited in Mark CRINSON, op. cit. (note 6).

39. Reginald Stuart POoLE, "James William Wild" [obituary], The Academy, no.1073 (26 ${ }^{\text {th }}$ November 1892), 489.

40. Mark CRINSON, op. cit. (note 6), p. 60 .

41. Ibid.

42. Nikolaus PEVSNER and John HARRIS, The Buildings of England: Lincolnshire, London: Penguin Books, 1989, p. 343.

43. See Elizabeth BONYTHON and Anthony BURTON, The Great Exhibitor: The Life and Work of Henry Cole, London: V\&A Publications, 2003, p. 74-75.

44. Board Minutes of the Department of Science \& Art, The National Archives, ED 28/27, 22 ${ }^{\text {nd }}$ December 1871.

45. Precis Minutes of the Department of Science \& Art, V\&A Archive, $23^{\text {rd }}$ March 1865.

46. Ibid.

47. RI.BA. Transactions $1880-1881$, Persian Architecture and Construction, discussion of paper (31 $1^{\text {st }}$ January 1881$)$, p. 174.

48. Precis Minutes of the Department of Science \& Art, V\&A Archive, $10^{\text {th }}$ April 1877. 
49. Letter from James Wild to Henry Cole, $11^{\text {th }}$ February 1867 , RP/1867/3299, on J. Spencer Bell nominal file, MA/1/B1022, V\&A Archive.

50. London (United Kingdom), V\&A Archives, Request to repair window, Departmental minutes, $18^{\text {th }}$ October 1869 , J. Spencer Bell nominal file, MA/1/B1022.

51. Reginald Stuart POOLE, op. cit. (note 39).

52. "Saracenic Art at The South Kensington Museum", The Times, $23^{\text {rd }}$ October 1884.

53. South Kensington Museum Art Referee Report, $11^{\text {th }}$ November $1881, R P / 1881 / 5885$.

54. London (United Kingdom), V\&A, Word \& Image Department, 1866 Accession Registers; these Mughal paintings currently reside in the collections of the Asia Department: AL.4935 to 4942.

55. Precis Minutes of the Department of Science \& Art, London (United Kingdom), V\&A Archive, $26^{\text {th }}$ January 1860.

56. Inventory of Art Objects Acquired in the Year 1860 (South Kensington Museum: 1868). The lamp is currently on display in the V\&A's Jameel Gallery of the Islamic Middle East (V\&A museum number 6820-1860).

57. James WILD, Volume 108, Sir John Soane's Museum collections, op. cit. (note 28).

58. See J. B. WARING, Art Treasures of the United Kingdom from the Art Treasures Exhibition, Manchester; London: Day \& Son, 1858.

59. Ibid., "Vitreous Art", p. 6.

60. Ibid., "Metallic Art", p. 32.

61. Reginald Stuart POOLE, "Meymar Collection of Arab Art" (report), in Fifteenth Report of the Science and Art Department, London: Eyre and Spottiswoode, 1868, p. 234.

62. Stanley LANE-POOLE, The Art of the Saracens in Egypt, London: Chapman and Hall, 1886.

63. Moncure Conway, “The South Kensington Museum”, Harper's New Monthly Magazine, 1875.

64. John Charles ROBINSON (ed.), Catalogue of the Special Exhibition of Works of Art on Loan at the South Kensington Museum, June 1862, London: 1863, p. 387.

65. Thirteenth Report of the Science and Art Department, London: Eyre and Spottiswoode, 1866, p. 174.

66. See Briony LLEWELLYN, "Frank Dillon and Victorian Pictures of Old Cairo Houses," Ur: The International Magazine of Arab Culture, no.3, 1984, p. 3-10, for a detailed study of Dillon's time in Cairo, including his association with Wild.

67. Elizabeth Wild nominal file, op. cit. (note 20), letter from Miss Wild to the Museum, $18^{\text {th }}$ February 1941.

68. Ibid., correspondence from Sir Eric Maclagan to colleagues, March 1941.

69. Georg EBERS, Ägypten in Bild und Wort, dargestellt von unseren ersten Künstlern, vol. 2, Stuttgart, Leipzig, 1878-1880, p. 85.

70. Helen DoREY, Ground Floor Ante-Room, report for Sir John Soane's Museum, 2007.

71. Michael DARBY, The Design and Construction of the New Picture Room and the Ante Room with Special Reference to their Decoration, report for Sir John Soane's Museum, 1993.

72. Obituary for James Wild, The Times, $11^{\text {th }}$ November 1892.

73. Ibid.

74. Count Riamo d'HULST, “The Arab House of Egypt," R.I.B.A Transactions, $2^{\text {nd }}$ series, vol. 6 (1889/1890), p. 221-242.

75. See "Monuments of Arab Art in Cairo," The Times, $3^{\text {rd }}$ January 1882.

76. Riamo d'HULST, op. cit. (note 74), p. 237.

77. For a verbatim account of the discussion, see the R.I.B.A. Journal (Proceedings), vol.6, p. 355-358.

78. Ibid., p. 357.

79. Ibid.

80. "Saracenic Art at The South Kensington Museum", The Times, op. cit. (note 52). 
81. London (United Kingdom), V\&A Archives, Letter from Saint-Maurice to Philip Cunliffe-Owen, $24^{\text {th }}$ October 1882, in Gaston de Saint-Maurice nominal file, MA/1/S180.

82. IDEM, letter from Wild, $21^{\text {st }}$ November 1883.

83. IDEM, letter from Purdon Clarke, $28^{\text {th }}$ October 1882.

84. "Monuments of Arab Art in Cairo," The Times, op. cit. (note 75).

85. Report by Lane-Poole, $8^{\text {th }}$ November 1883 , in Gaston de Saint-Maurice nominal file, op. cit. (note 81).

86. "Saracenic Art at The South Kensington Museum," The Times, op. cit. (note 52).

87. Ibid.

88. London (United Kingdom), V\&A Archives, Invoice from Gasparo Giuliana, in Stanley LanePoole nominal file, MA/1/2257.

89. List of Objects in the Art Division, South Kensington Museum, Acquired during the Year 1883, London: Eyre and Spottiswoode, 1884, 126 (V\&A museum number 1193-1883, subsequently disposed).

90. "Saracenic Art at The South Kensington Museum," The Times, op. cit. (note 52).

91. Stanley LANE-POOLE, The Art of the Saracens in Egypt, op. cit. (note 62).

92. Ibid., p. 111-117.

93. Reginald Stuart POoLE, "James William Wild" [obituary], op. cit. (note 39).

94. Ibid.

\section{AUTHOR}

\section{ABRAHAM THOMAS}

Curator of Designs, Victoria and Albert Museum, London. 
«Ceci aura néanmoins probablement son utilité. » Willem de Famars Testas au Caire, 1858-1860

\author{
Jan de Hond
}

Traduction : Catherine Warnand

\title{
NOTE DE L'ÉDITEUR
}

Sauf mention contraire, toutes les œuvres reproduites sont de Willem de Famars Testas.

1 En France, le peintre néerlandais Willem de Famars Testas (1834-1896) est surtout connu pour sa participation à une caravane de peintres qui voyagea en Orient sous la conduite de Jean-Léon Gérôme en 1868. Une exposition itinérante a été consacrée à ce voyage d'artistes en $1993^{1}$. Toutefois, nous étudierons ici un voyage en Égypte que Testas effectua en 1858-1860 en tant que membre d'une expédition dirigée par l'égyptologue français Émile Prisse d'Avennes, qui procéda au relevé de monuments tant pharaoniques qu'islamiques. L'expédition devait fournir matière à la publication de deux ouvrages illustrés, l'un sur l'art pharaonique (Histoire de l'art égyptien), l'autre sur l'art arabe (L'Art arabe). Cette étude se concentre sur le séjour de Testas au Caire et la façon dont il a documenté les monuments arabes de cette ville. Quelle fut la contribution de Testas à l'expédition de Prisse et au recueil illustré L'Art arabe? Et enfin, dans quelle mesure ce voyage a-t-il influencé la suite de la carrière menée par Testas en qualité d'artiste indépendant? 


\section{Willem de Famars et l'expédition d'Émile Prisse d'Avennes en Égypte}

2 En janvier 1868, le peintre néerlandais Willem de Famars Testas (fig. 1) arriva au Caire. Il avait visité l'Égypte pour la première fois dix ans plus tôt, et les retrouvailles avec cette ville qui l'avait si profondément marqué à l'époque ranimèrent immédiatement son enthousiasme :

«Je ne veux pas commencer à décrire mes sensations quand je me retrouvai dans ces rues populeuses, dont le souvenir était resté si intact dans ma mémoire. Mes compagnons ont dû éprouver comme moi, quand j'y arrivai pour la première fois, cet ébahissement et cet enthousiasme que tout artiste doit éprouver à l'aspect de cette ville si originale et ce peuple si pittoresque ${ }^{2}$.»

3 Testas se trouvait en illustre compagnie. Le chef de l'expédition n'était autre que JeanLéon Gérôme, peintre à succès devenu le chef de file et le principal représentant de l'orientalisme en France. Il était accompagné de cinq autres peintres et de son beaufrère, le marchand d'art et photographe Albert Goupil ${ }^{3}$. Les membres de ce groupe d'artistes entamèrent leur aventure orientale par une visite du Caire et de ses environs, pour traverser ensuite le Sinaï en caravane et se rendre à Jérusalem en passant par le monastère Sainte-Catherine et la cité en ruines de Pétra. De là, ils firent un périple jusqu'à Damas, où ils prirent la diligence pour Beyrouth, terminus de l'expédition pour la plupart d'entre eux. Le voyage du Caire à Beyrouth avait duré environ quatre mois.

Ces messieurs conservèrent un certain train de vie pendant leur voyage. Ils avaient à leur disposition un guide, deux domestiques et un cuisinier assisté d'un esclave. Il fallait encore ajouter à ce personnel les nombreux accompagnateurs chargés de s'occuper des ânes, des chevaux et des dromadaires. La méharée, surtout, devait avoir fière allure. Dans le Sinaï, elle se composait de neuf dromadaires pour les voyageurs et de trente-huit bêtes de somme: dix-huit chargées de la nourriture, quatre de l'eau, deux du vin, sept du fourrage pour les bêtes, trois des tentes, trois du matériel de cuisine et des bagages et une du matériel photographique de Goupil. Dans les villes, la compagnie logeait dans des hôtels de luxe et, régulièrement, elle était invitée à dîner par des diplomates occidentaux ou des responsables locaux. Pour le reste, nos artistes passaient leur temps à visiter les principales curiosités et à faire des croquis et des études à l'huile. Ce voyage fut incontestablement un point culminant de la carrière artistique de Testas. Voyager en Orient avec Gérôme scellait sa reconnaissance internationale en tant qu'artiste orientaliste.

5 Il est difficile d'imaginer un contraste plus grand entre le Grand Tour oriental que Testas entreprit en 1868 et son premier voyage en Égypte dix ans plus tôt. En 1858, le peintre, alors âgé de 24 ans, venait juste de terminer sa formation à l'Académie de dessin de La Haye et se trouvait au début de sa carrière artistique lorsque le hasard lui donna l'occasion de visiter l'Orient. Il apprit par un cousin habitant à Paris, Florent Prisse, qu'un parent éloigné, Émile Prisse d'Avennes (1807-1879), était sur le point de monter une expédition scientifique en Égypte. Prisse avait déjà visité le Moyen-Orient auparavant. Il avait travaillé pendant quelques années comme ingénieur au service du vice-roi d'Égypte Mohammed Ali et avait ensuite fait par ses propres moyens plusieurs grandes expéditions à travers la région. Il y réalisa des fouilles et rassembla une importante collection d'art de l'Égypte ancienne. De retour en France, il publia quelques importants ouvrages sur l'Égypte des pharaons et l'Égypte contemporaine, 
notamment Les Monuments égyptiens en 1847. Prisse était donc un éminent égyptologue et orientaliste, même si ses méthodes controversées et son caractère buté n'étaient pas toujours appréciés par ses collègues. En 1858, Prisse avait déjà des projets très avancés de publication de son monumental ouvrage L'Histoire de l'art égyptien, et peut-être avaitil déjà à l'esprit un ouvrage sur L'Art arabe, un livre tout aussi ambitieux avec un album d'images en plusieurs tomes sur l'art islamique du Caire ${ }^{4}$. Prisse avait besoin de données supplémentaires - surtout de la documentation visuelle - pour les deux séries. C'était principalement pour cette raison qu'il préparait une nouvelle expédition en Égypte.

6 Un voyage en Égypte était très tentant pour Testas. Un tel périple lui offrait une formidable occasion de se spécialiser dans l'orientalisme, un genre très populaire en Europe au milieu du XIXe siècle et encore très peu pratiqué aux Pays-Bas ${ }^{5}$. Lorsque le jeune Néerlandais contacta son docte parent pour lui demander s'il pouvait participer au voyage en Égypte, celui-ci y consentit à condition qu'il payât lui-même la traversée jusqu'à Alexandrie; il pourrait ensuite participer au reste du voyage aux frais de l'expédition. Prisse avait déjà engagé un dessinateur et un photographe pour documenter et inventorier les principaux monuments et œuvres d'art, de sorte que Testas allait en principe pouvoir travailler pour lui-même. Dans la pratique, les choses allaient être bien différentes. Juste avant le départ, le dessinateur recruté fit défection, si bien que Testas dut en réalité assumer presque tout son travail. Il ne se doutait toutefois pas encore de cela lorsque, le 9 mai 1858, il prit congé de ses parents à Utrecht et partit pour Paris, première étape d'une expédition qui, d'après les estimations, devait durer quelque six mois. Grâce à son journal qui a été conservé, à ses lettres de voyage à sa mère et à quelques documents d'archives épars, nous disposons d'informations relativement précises sur le voyage de Testas en Égypte et son déroulement dramatique ${ }^{6}$.

7 Après la défection du dessinateur, l'expédition ne se composait donc plus que de trois personnes: son chef Émile Prisse d'Avennes, l'artiste Willem de Famars Testas et le photographe Édouard Jarrot ${ }^{7}$. Après une traversée en bateau sans problème depuis Marseille, nos compagnons de voyage arrivèrent à Alexandrie le 6 juin 1858. Au premier contact, la ville déçut quelque peu Testas : «Alexandrie est beaucoup trop européenne pour faire forte impression », écrivit-il à ses parents ${ }^{8}$. Prisse y rendit visite à quelques vieilles connaissances, parmi lesquelles l'égyptologue français Auguste Mariette, et essaya d'obtenir des firmans (décrets) l'autorisant à visiter et étudier les monuments égyptiens. Le 23 juin, ils prirent le train pour Le Caire et furent beaucoup plus impressionnés par cette ville. Testas n'en revenait pas de l'animation qui régnait dans les ruelles et il tomba immédiatement sous le charme du bazar :

« une rue étroite couverte de déversoirs et de planches, bordée de boutiques ou de réduits rectangulaires où les marchands sont tranquillement assis à fumer et ne montrent absolument aucun empressement à vous fourguer quelque chose [...] Ici et là se trouvent de superbes fontaines [...] et des cours intérieures avec des portes, des colonnades, etc., de l'allure la plus belle - mieux encore : la plus pittoresque ${ }^{9}{ }^{\prime}$. Il visita aussitôt quelques «superbes mosquées, avec leurs minarets et leurs très pittoresques fontaines $[. . .]^{10} »$.

8 Les boutiques, rues animées, mosquées, cours intérieures, fontaines et portes qui séduisirent tant Testas au cours de ses premières journées au Caire continuèrent de le fasciner toute sa vie durant. Par la suite, ces sujets resurgirent sans cesse dans ses dessins et ses tableaux. 
9 Au début, les trois membres de l'expédition logeaient à l'hôtel, mais Prisse loua assez rapidement une maison. Il trouva une simple demeure avec une terrasse sur le toit qui, selon Testas, était très agréable pendant les chauds mois d'été. Aux dires du Néerlandais, ils vivaient désormais «tout à fait à l'orientale ${ }^{11}$ ». Ils dormaient sur des nattes à même le sol sous le ciel étoilé et mangeaient avec les doigts, accroupis autour d'une petite table. Leur régime alimentaire occidental avait fait place à des plats de la cuisine orientale. Après un certain temps, Testas renonça aussi à son accoutrement occidental pour adopter la tenue vestimentaire locale, qu'il ne trouvait au demeurant pas très commode: le pantalon large qui avait toujours tendance à descendre, les tozluks ou jambières avec leur infinité de petites agrafes, le gilet avec sa trentaine de petits boutons très peu pratiques et les babouches « qui donnent l'impression que l'on marche sur des chaussettes ${ }^{12}$ ». Ce costume présentait néanmoins aussi des avantages indéniables: Testas n'était pas immédiatement repéré en tant qu'occidental et il pouvait ainsi travailler à l'aise, non seulement dans les rues mais aussi et surtout dans les mosquées.

10 Même si Testas finit par dessiner pour lui-même en Égypte, il dut assez rapidement reprendre le rôle du dessinateur démissionnaire de Prisse. Sur l'ordre de Prisse, il passait désormais des journées entières à fixer sur papier toutes sortes d'œuvres d'art et de monuments pour L'Art arabe à paraître. Testas dessinait des plans, des intérieurs, des détails d'architecture et des scènes de rue, mais participait aussi à la fabrication de calques (reproduction sur du papier transparent du dessin de dallages et de marqueteries par exemple) et d'estampages (impression en relief, avec du papier humide non collé, de portes ou reliefs muraux par exemple). Il voulait bien croire que ce travail lui serait utile plus tard, mais il était loin de le trouver agréable. Tous les jours, sauf le vendredi, il travaillait depuis tôt le matin jusque tard le soir dans les mosquées du Caire. Il trouvait pénible et ennuyeux de réaliser les dessins architectoniques qu'il était censé faire. Parfois, il devait marcher une bonne heure pour atteindre sa destination, parce que Prisse était trop près de ses sous pour lui louer un âne. Testas souffrait de surcroît de dysenterie et devait se contenter dans la journée d'un régime de « riz-riz-riz ${ }^{13}$ ». Mais le pire était encore le caractère très désagréable de son patron. Prisse était un personnage tyrannique, sans cesse prêt à décocher ses flèches. Lorsque Testas rentrait à la maison après une longue journée de labeur dans une mosquée, il se faisait aussitôt rabrouer :

« Ensuite j'ai droit à mon commentaire sur mon travail et mon peu d'empressement à l'ornement et au dessin rectiligne (que j'ai toujours fui), avec les inévitables noms sarcastiques de grand enfant, cornichon, comme un bœuf au travail, et cætera. Et après cela, il faudrait que je fasse gentiment la conversation à ce tyran, qui chicane sur tout, réprimande tout le monde, est très ambitieux et suffisant, et qui pense être le premier et le plus parfait de l'humanité, me traite toujours comme quelqu'un de très inférieur à lui, nullement comme un compagnon de voyage mais comme un ouvrier à sa solde. Je passe la soirée à achever mon travail de la journée ou une autre tâche imposée par M. Prisse, parfois jusqu'à onze heures et demie du soir. Charmant voyage ${ }^{14}$ !»

11 Prisse, exigeant, pria même son dessinateur d'avaler quelques pilules de haschisch. Un collègue égyptologue, l'Américain Edwin Smith, avait déjà consommé du haschisch, mais n'arrivait pas à se rappeler exactement ce qu'il avait ressenti ensuite. Voilà pourquoi Testas devait prendre un peu de stupéfiant en même temps que Smith, dans l'espoir que le Néerlandais serait, lui, capable de raconter ses expériences après coup. $\mathrm{Au}$ début, Testas et Smith n'observèrent pas grand-chose, si ce n'est que la drogue les 
rendait somnolents. Après que l'Américain fut allé au lit, Testas décida d'avaler ce qui restait de pilules. Elles eurent cette fois de l'effet, et il réveilla sur-le-champ Jarrot, qui dut noter tout ce qu'éprouvait Testas, pour qu'il puisse le rapporter à Prisse le lendemain. Dans une lettre à sa mère, Testas écrivit que la tête lui avait d'abord tourné un peu, puis qu'il avait été brusquement pris d'une « irrésistible envie de rire »: «mes joues furent comme spontanément tirées vers le haut, à tel point que cela me faisait mal, comme si elles voulaient se détacher de la pommette, et je dus rire $»^{15}$. Il avait des difficultés à mettre de l'ordre dans ses pensées. Les idées se bousculaient, s'enchaînaient et se fondaient imperceptiblement " comme dans un kaléidoscope » :

« Je comparai alors en pensée mon état à ces belles portes incrustées et arabesques arabes, qui, composées de toutes sortes de petites pièces de forme différente, constituaient un tout agréable. Très souvent, une même idée surnageait, revenant comme en boucle, surtout que mon état était très étrange et burlesque, etc., et c'était alors à nouveau le point de départ d'autres idées ${ }^{16}$. "

Entre deux fous rires, il continuait à abreuver le pauvre Jarrot de phrases. Testas luimême croyait être très éloquent, mais il parlait souvent de manière totalement incohérente et de surcroît partiellement en néerlandais. Testas finit quand même par se mettre au lit, bien que le «carrousel des idées en tous genres » se poursuivît. Il ne s'endormit qu'à deux heures du matin. Quoiqu'un peu nauséeux le lendemain, il conclut néanmoins qu'il avait trouvé l'essai plaisant : « En somme, tout ceci est une expérience agréable, bien que l'on sente que l'on ne pourrait pas rester longtemps dans un tel état de tension sans devenir fou ${ }^{17}$ ».

Son expérience du haschisch fut un de ses rares moments de distraction dans une existence plutôt ennuyeuse et monotone. À plusieurs reprises, il fit savoir à ses parents qu'il aspirait à leur agréable et aimable compagnie et à la vie paisible du foyer. Il supportait difficilement de vivre avec « deux personnes d'une autre nation, parlant une autre langue, dans un pays étranger sans connaissances ni amis, jour après jour en tête à tête ${ }^{18}$. Pour comble d'infortune, le séjour dura de surcroît bien plus que les six mois prévus initialement. Jarrot eut des problèmes pour photographier et tomba assez vite malade, ce qui expliquait une partie du retard, alors que Prisse ne cessait d'ordonner de nouveaux travaux. Lorsqu'ils embarquèrent finalement le 6 juin 1859 sur le bateau qui devait leur faire remonter le Nil en direction du sud, ils avaient passé presque une année au Caire. Testas en avait vraiment assez: «Malgré son côté pittoresque, je ne peux plus sentir ni voir Le Caire ${ }^{19}$ ». Il était content de quitter la ville, mais redoutait en même temps ce qui l'attendait encore. Il avait même songé à rentrer seul chez lui s'il devait continuer à ne faire que copier des hiéroglyphes et des chapiteaux.

Le voyage en bateau conduisit l'expédition jusqu'à Abou Simbel en Nubie. En cours de route, ils visitèrent et firent le relevé de nombreux monuments pharaoniques et classiques comme les ruines d'Assyut, Dendérah, Karnak, Louxor et Philae. Une nouvelle fois, ils prirent beaucoup de retard. Testas devait toujours travailler très dur, mais il avait apparemment un peu plus de temps pour lui. Il attendait néanmoins avec impatience "le jour de notre affranchissement de l'esclavage égyptien ${ }^{20}$ ». Ce moment arriva seulement le 12 juin 1860, lorsqu'il monta à bord du paquebot L'Euphrate à Alexandrie. Quand Testas put enfin serrer ses parents dans ses bras quelques semaines plus tard, son absence avait duré 2 ans et 2 mois. Malgré toutes les privations, il dut reconnaître que tout cela n'avait pas été inutile : «Je suis, tout bien considéré, presque fier d'avoir contribué à un ouvrage qui est certainement le meilleur qui ait paru à propos de l'Égypte, tant pour ce qui est de son exécution que de son exactitude ${ }^{21} »$. 
Pour son compagnon de voyage le photographe Jarrot, l'aventure égyptienne s'acheva sur une note beaucoup moins positive. Nous savons par les notes du journal de Testas qu'il fut gravement malade pendant une bonne partie du voyage et qu'au Caire déjà, il avait voulu plier bagage pour rentrer à Paris. Testas réussit seulement à le faire changer d'avis en insistant sur le fait qu'il allait devoir payer des dommages et intérêts colossaux à Prisse s'il résiliait son contrat. Dans les dernières semaines de leur séjour égyptien, les choses empirèrent pour Jarrot. Lors d'une visite chez l'égyptologue Auguste Mariette, il perdit la tête. Il était « complètement dément » d'après Testas et, avec l'aide du consulat français, il fut rapatrié directement en France. Mais lorsque Prisse et Testas arrivèrent à Paris quelques semaines plus tard, personne ne savait ce qu'était devenu le malheureux photographe. Renseignements pris à Marseille, il s'avéra que Jarrot y avait été interné dans une institution. Après quelques jours, son état sembla s'améliorer légèrement, et il put rejoindre sa famille à Paris. Nous ignorons cependant tout de la suite de la carrière de Jarrot: les privations en Égypte avaientelles définitivement eu raison de lui ${ }^{22}$ ?

1. Portrait de Willem de Famars Testas, carte de visite, W.C. Van Dijk photographe, Utrecht.

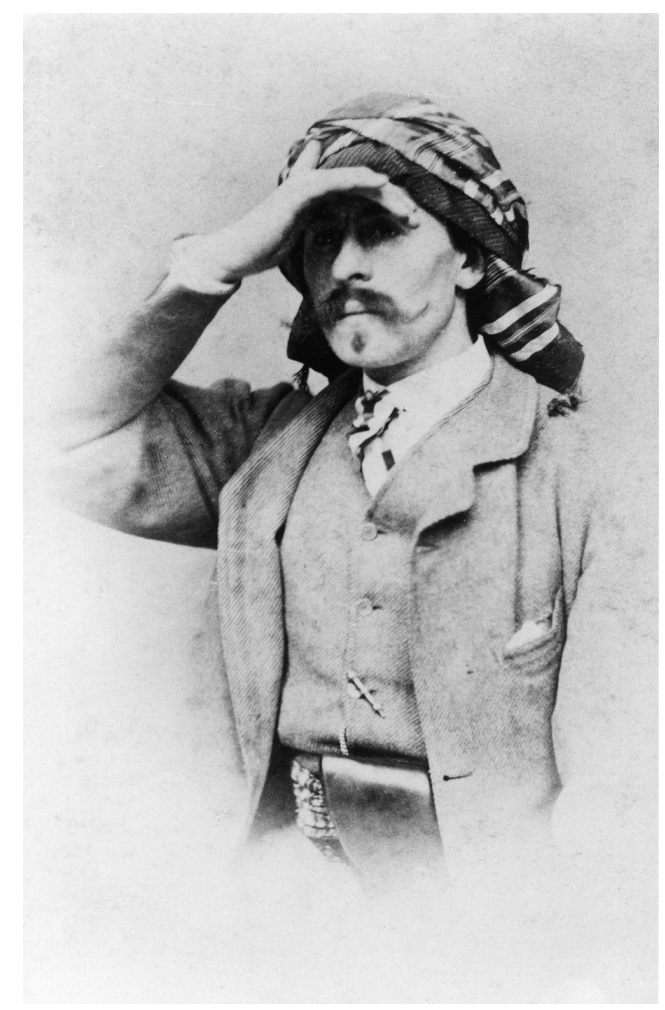

Source : Leyde (Pays-Bas), Rijksmuseum van Oudheden.

\section{Le fonds Prisse d'Avennes à la Bibliothèque nationale de France}

Prisse lui-même n'était certainement pas mécontent des résultats de son expédition. D'Égypte, il écrivit à son ami l'archéologue Félicien de Saulcy qu'il avait comparé sur place les principaux ouvrages illustrés avec la réalité et qu'il avait pu constater que la plupart des illustrations étaient très imprécises. Heureusement, il avait désormais 
rassemblé suffisamment de documentation pour publier un nouvel ouvrage de référence sur l'Égypte, qui allait surpasser largement les ouvrages plus anciens :

« Je rapporte 300 dessins parmi lesquels il y a des calques coloriés de 7 à 8 mètres de longueur, plus de 400 mètres d'estampages, 150 photographies sans compter pareil nombre de stéréoscopes, puis mes croquis et mes notes ${ }^{23}$.

17 Une grande partie de cette collection, complétée par des documents des précédentes expéditions de Prisse et des photographies et illustrations d'autres artistes, se trouve encore aujourd'hui dans les papiers de Prisse à la Bibliothèque nationale de France à Paris, département des Manuscrits, fonds Prisse d'Avennes (cité ensuite "le fonds Prisse »).

Ce très volumineux ensemble de documents d'archives est en fait la documentation visuelle et textuelle que Prisse a rassemblée au cours de sa carrière et qu'il a en partie utilisée comme base pour ses publications ultérieures, en particulier son Histoire de l'art égyptien et L'Art arabe. Le fonds Prisse étonne non seulement par son ampleur, mais aussi par la diversité des techniques : gravures, lithographies, photographies, dessins, aquarelles, estampages et calques.

Quelle est la part de Testas dans cette documentation? Elle est difficile, voire impossible, à établir à partir des seules données du fonds Prisse. Aucune des œuvres n'a en effet été signée et beaucoup d'entre elles, les feuilles plus techniques en tout cas, comme les plans, les dessins architectoniques au trait, les calques et les estampages, ne trahissent aucun style personnel. Heureusement, on trouve dans des collections néerlandaises quelques documents d'archives qui peuvent être utiles pour l'attribution des œuvres du fonds Prisse. Testas mentionne une seule fois ses activités dans son journal ou ses lettres de voyage, mais un élément beaucoup plus important dans ce cadre est la "Liste de mes occupations pour M. Prisse lors de mon voyage en Égypte » (ci-après la Liste) qui est conservée au Rijksmuseum van Oudheden de Leyde ${ }^{24}$. Cette liste recense la bagatelle de 188 commandes exécutées pour Prisse, dont un certain nombre se composent de plusieurs éléments. Par exemple, la commande 30 comporte ainsi 6 calques coloriés de tableaux en faïence de la mosquée d'Ibrahim Agha. Il s'agit donc en réalité d'un nombre encore beaucoup plus important d'œuvres. De plus, Testas semble n'avoir répertorié que les produits finis destinés à Prisse. De nombreux croquis à main levée et d'autres études de détails, que nous connaissons par le fonds Prisse ou d'autres collections néerlandaises, ne sont pas mentionnés dans la Liste mais sont néanmoins de Testas. La Liste est donc loin d'être exhaustive et doit être utilisée avec une certaine prudence, mais elle demeure bien sûr une indication très importante et très utile sur les activités de Testas. Quelque 78 articles de la Liste ont trait à des œuvres d'art, des monuments et des scènes de rue du Caire islamique, tandis que le reste concerne l'Égypte pharaonique. Il ressort en outre de la Liste que Testas ne s'était pas limité au dessin et à l'aquarelle, mais qu'il avait aussi réalisé des dizaines de calques et d'estampages, effectué des relevés, dressé des plans et même rédigé des contrats et des questionnaires pour Prisse. La description dans la Liste est parfois assez vague, comme "Porte maison Arabe », mais elle est le plus souvent tellement précise que les sujets peuvent être retrouvés sans problème dans le fonds Prisse.

Outre la Liste, nous pouvons aussi nous servir, pour identifier l'artiste, des œuvres de Testas qui sont conservées dans quatre collections néerlandaises: le Rijksmuseum à Amsterdam, le Teylers Museum à Haarlem, le Rijksmuseum van Oudheden à Leyde et une collection privée. On y trouve parfois des croquis, des études préliminaires, voire 
des calques de motifs qui figurent également dans le fonds Prisse. C'est ainsi que l'on trouve à Paris une aquarelle d'une cheminée qui ne figure pas dans la Liste (fig. 2). Cette cheminée apparaît toutefois aussi sur une page d'un carnet de croquis de voyage de Testas qui est conservé au Rijksmuseum (fig. 3). Nous pouvons dès lors attribuer le dessin parisien à l'artiste néerlandais.

21 Une attribution à Testas est rarement étayée par plusieurs sources. C'est par exemple le cas de la série de charmants croquis de boutiques du Caire qui fait partie du fonds Prisse ${ }^{25}$. Tout d'abord, nous les retrouvons dans la Liste sous les numéros 86 (« deux dessins de boutiques: vendeur de pipes et marchand de semsémieh [gourdes]») et 88 (" deux dessins de boutiques de fruitiers »). Le fait que ces dessins aient effectivement été réalisés par Testas est aussi confirmé par des analogies de style avec des dessins et des aquarelles de Testas se trouvant dans des collections néerlandaises et traitant en partie le même sujet ${ }^{26}$. Les personnages au visage schématique un peu plat, l'attention portée au réalisme des détails de l'architecture et du travail des artisans et la présence étonnamment fréquente d'enfants, de chiens, d'ânes et de chevaux sont typiques du style du Néerlandais. Pour lever définitivement tous les doutes, il existe aussi un calque d'une des boutiques du fonds Prisse (fig. 4) dans une collection privée comprenant des œuvres du fonds d'atelier de Testas (fig. 5). À partir de critères stylistiques, nous pouvons affirmer sans hésitation qu'une grande partie des autres dessins de scènes de rue et de figures isolées du fonds Prisse a également été réalisée par Testas, mais pas tous cependant. Prisse était aussi un habile dessinateur, et une partie des aquarelles du fonds Prisse, par exemple, s'avère être de sa main. C'est incontestablement le cas de la série d'études à l'aquarelle de "types» égyptiens. Certains de ces personnages reviennent dans les lithographies de l'Oriental Album. Characters, Costumes, and Modes of Life in the Valley of the Nile de James Augustus St. John de 1851. Sur la page de titre de cet ouvrage, il est clairement indiqué que ces lithographies ont été réalisées d'après des croquis originaux de Prisse : « illustrated from designs taken on the spot by E. Prisse $»^{27}$. Ces originaux se trouvent pour une part dans le fonds Prisse. 
2. Croquis de voyage avec cheminées au Caire, mine de plomb, pinceau et encre, rehaussé de blanc sur papier bleu gris.

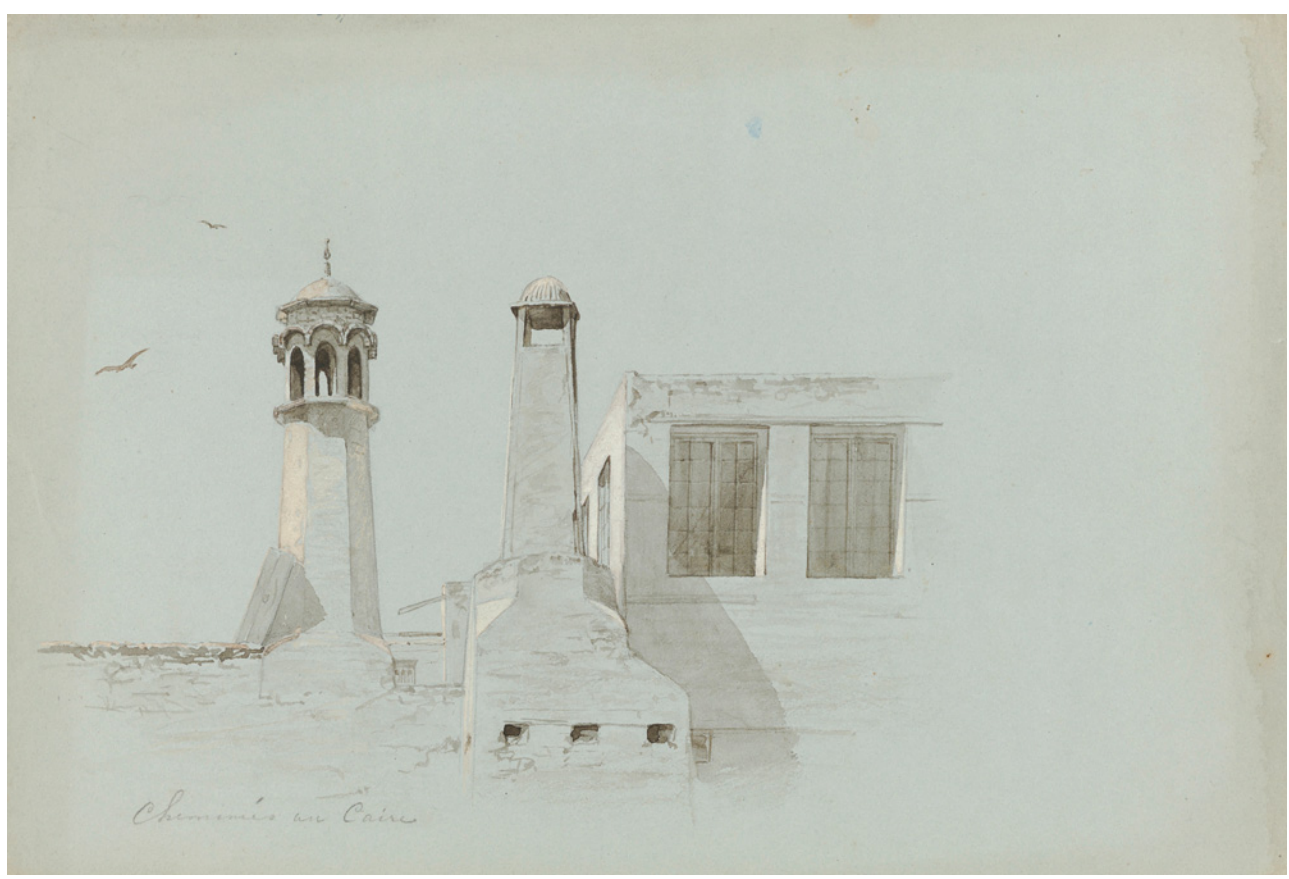

Source : Paris (France), BnF, département des Manuscrits, fonds Prisse d'Avesnes, 27-VII-1 / f. 76.

3. Cheminée au Caire, aquarelle.

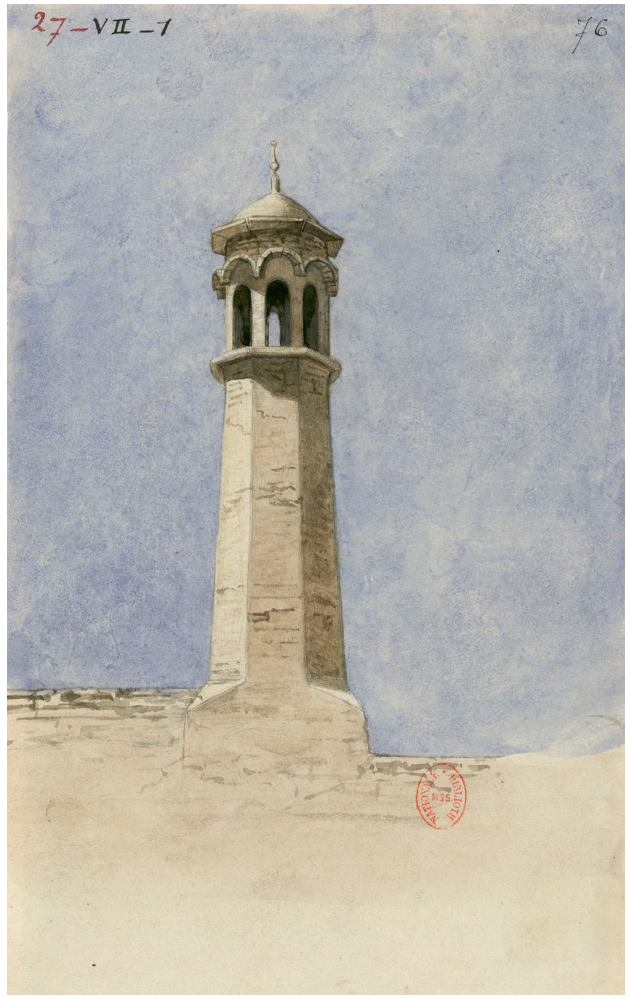

Source : Amsterdam (Pays-Bas), Rijksmuseum : RP-T-1981 : 1-a. 
4. Une boutique au Caire, mine de plomb et encre.

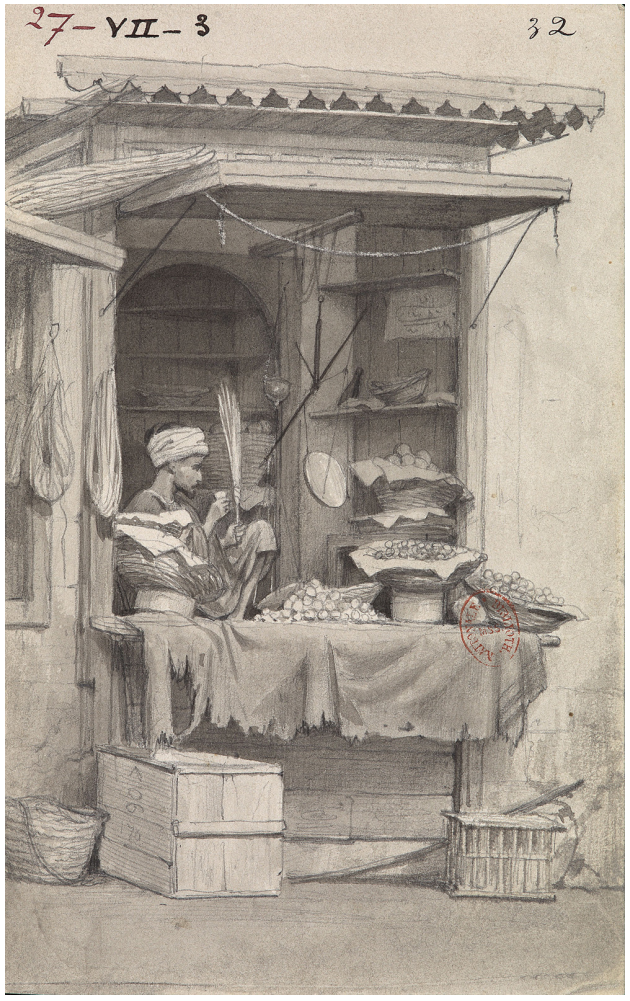

Source : Paris (France), BnF, département des Manuscrits, fonds Prisse d'Avesnes, 27-VII-3 / f. 32.

5. Croquis de voyage représentant une boutique au Caire, mine de plomb sur calque.

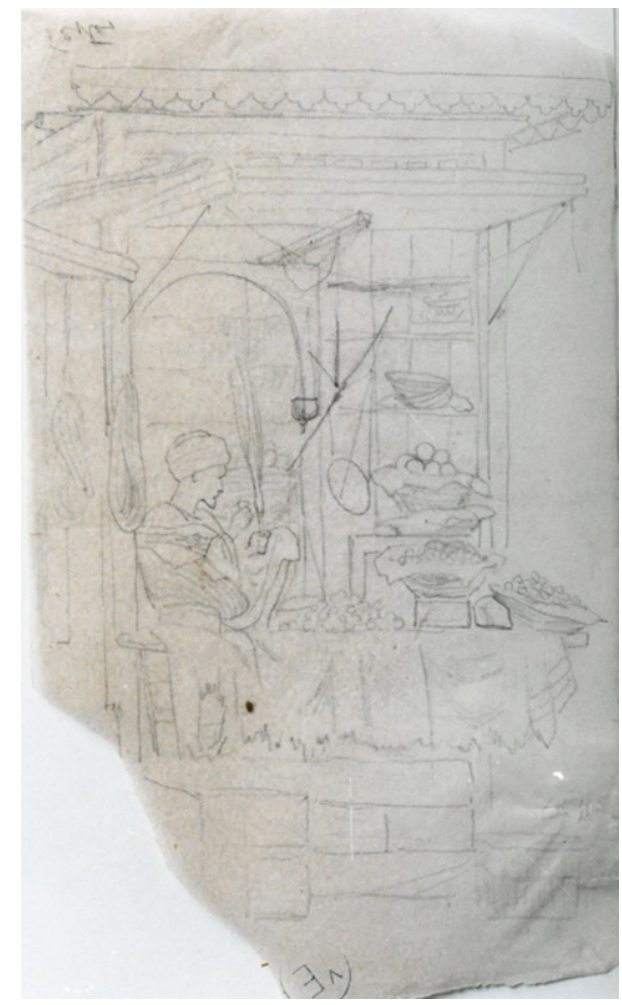

Source : Pays-Bas, collection privée, TTS 040. 


\section{La contribution de Testas à L'Art arabe} attribuée à Testas, il est étonnant que son nom ne soit cité qu'une seule fois comme auteur sur les lithographies - 200 au total - de L'Art arabe : à la planche 134 Beyt El-Emyr [Bayt al-Amir]. Moucharabyeh intérieur (XVIII ${ }^{e}$ siècle) ${ }^{28}$. Ceci est d'autant plus étrange que sur la Liste sont également cités beaucoup plus d'œuvres d'art et de monuments qui ont aussi été représentés dans L'Art arabe. Luitgard Mols a récemment comparé les planches de L'Art arabe avec les articles de la Liste de Testas et est arrivée à non moins de 26 «analogies " ${ }^{29}$. Prisse n'aurait-il pas utilisé le travail de Testas ou n'a-t-il simplement pas mentionné le nom de celui-ci?

Sur la base des recherches qu'elle a menées sur les œuvres de Testas dans les collections néerlandaises, Luitgard Mols a déjà conclu qu'un nombre beaucoup plus important d'illustrations de L'Art arabe sont à mettre directement en rapport avec des croquis ou des études de Testas. Elle a trouvé, pour 8 planches de L'Art arabe, des dessins correspondants dans les collections néerlandaises ${ }^{30}$. Elle conclut que la contribution de Testas à L'Art arabe a dépassé de loin cette seule planche signée ; cette affirmation est étayée par divers exemples tirés du fonds Prisse (non étudié par L. Mols). Nous nous proposons de le montrer à l'aide d'études de cas: les planches de la mosquée al-Burdayni et celles du mausolée de Qaytbay dans L'Art arabe. Ces exemples illustrent clairement à quel point il est parfois compliqué de retrouver la trace des originaux des lithographies de L'Art arabe. Les planches s'avèrent en effet être composées de plusieurs études de détails dans différentes techniques.

l'année 1859. Cette petite mosquée avait un décor intérieur très riche, avec de superbes mosaïques murales aux dessins géométriques complexes et des plafonds vivement colorés. Bien les dessiner n'était pas une sinécure :

" Actuellement, je travaille comme dessinateur rémunéré, je suis assis ou debout à travailler chaque jour dans les mosquées, du petit matin jusqu'au coucher du soleil, à l'exception du seul vendredi [...] J'ai ainsi passé tout le mois de janvier dans la petite mosquée Bordu, en compagnie du Janissaire avec qui je ne peux pas parler et qui se met toujours à dormir. Je me casse la tête sur des dessins architectoniques, avec des ornements qui sont à peine visibles et font trembler ${ }^{31}$.»

Le résultat d'un mois de souffrance et de renoncement se retrouve dans la Liste (n.51-56) : un dessin colorié d'un mur complet avec mosaïques murales et fenêtres ; des dessins coloriés des plafonds ; des calques coloriés de mosaïques murales, et des dessins de détails tels que des inscriptions et des bordures décorées. Presque tous ces dessins reviennent aussi sous la forme de lithographies dans L'Art arabe: la planche 59 montre un vue générale d'un mur richement décoré, suivie de trois planches avec des détails des mosaïques murales (pl. 60-62). Un peu plus loin, se trouvent deux planches de plafonds de la même mosquée (pl. 68-69), à nouveau suivies d'une série de détails de plafonds (pl. 70-71). Dans le fonds Prisse sont conservés quelques-uns des dessins originaux de Testas à la base des lithographies.

Commençons par la planche 59, Mosquée d'El-Bordeyny [al-Burdayni], intérieur de la salle principale (fig. 6). Nous n'avons pas retrouvé dans le fonds Prisse le grand dessin du mur avec les mosaïques pariétales et les fenêtres que Testas citait dans la Liste ( $\left.{ }^{\circ}{ }^{\circ 4}\right)$. Mais y 
figure en revanche une étude - intéressante pour nous - sur papier quadrillé de quelques décorations murales avec des textes arabes (fig. 7). La troisième décoration sur cette étude revient aussi sur la lithographie (sur la colonne en bas à gauche). Un petit dessin d'une des fenêtres réalisé par Testas est également conservé dans une collection privée néerlandaise ${ }^{32}$.

Si, pour cette lithographie, nous ne connaissons que des études de deux petits détails, pour la lithographie du grand plafond de la mosquée al-Burdayni (fig. 8), il existe en revanche une étude préliminaire beaucoup plus détaillée dans le fonds Prisse (fig. 9). Sur ce dessin (Liste 51), Testas avait représenté très précisément les décorations, puis mis les principales parties en couleur. Sur la base de ce dessin, le lithographe a pu aisément tracer un projet détaillé sur la pierre ${ }^{33}$.

Le deuxième exemple, le mausolée du sultan Qaytbay, ne fut certainement pas non plus tâche aisée pour Testas. D'après la Liste, il avait réalisé deux grands dessins de l'intérieur de la mosquée, puis plusieurs estampages, entre autres du minbar (Liste 64-66). Ces études correspondent exactement aux quatre planches de L'Art arabe qui ont pour sujet l'intérieur de cette mosquée : deux vues générales de l'intérieur, une planche du minbar et une planche avec des détails des portes et des armoires (pl. 20, 21, 89, 101).

Dans ce cas, une des deux grandes ébauches de l'intérieur (Liste 64) a bien été conservée (fig. 10). Il s'agit d'un de ces dessins architectoniques au trait que Testas avait en horreur. Ce dessin a servi de base à la lithographie dans L'Art arabe, si ce n'est que le cadrage de la lithographie est un peu plus serré (fig. 11). Les détails n'ont pas été indiqués sur ce dessin. Le lithographe disposait probablement aussi d'études de détails séparées pour peaufiner sa planche. Nous retrouvons de telles études de détails tant dans le fonds Prisse que dans une collection privée néerlandaise, par exemple un calque des inscriptions au-dessus de l'arc ou une feuille avec une des portes en bois (fig. 12) ${ }^{34}$. Un même procédé a probablement été utilisé pour la planche 89 de L'Art arabe, le minbar de la mosquée de Qaytbay. Le dessin au trait du fonds Prisse, très précis, a incontestablement servi de point de départ. Le personnage sur l'escalier est clairement l'œuvre de Testas (fig. 13). Les reliefs sur le minbar ne sont rendus que schématiquement. Pour ceux-ci, le lithographe a eu une fois de plus recours aux estampages que, d'après la Liste (66), Testas avait effectués sur ce minbar ${ }^{35}$.

Ce ne sont que deux exemples, mais à la lumière des journaux de Testas, de la Liste et d'une comparaison avec les œuvres de Testas conservées dans le fonds Prisse et les collections néerlandaises, un nombre beaucoup plus important de planches de L'Art arabe peut être mis en rapport avec des dessins, des estampages et des calques réalisés par Testas. Sa contribution au célèbre ouvrage illustré est donc beaucoup plus importante que ce qu'on supposait précédemment. 
6. Mosquée d'El Bordeyny [al-Burdayni]. Intérieur de la salle principale (XVIIe siècle).

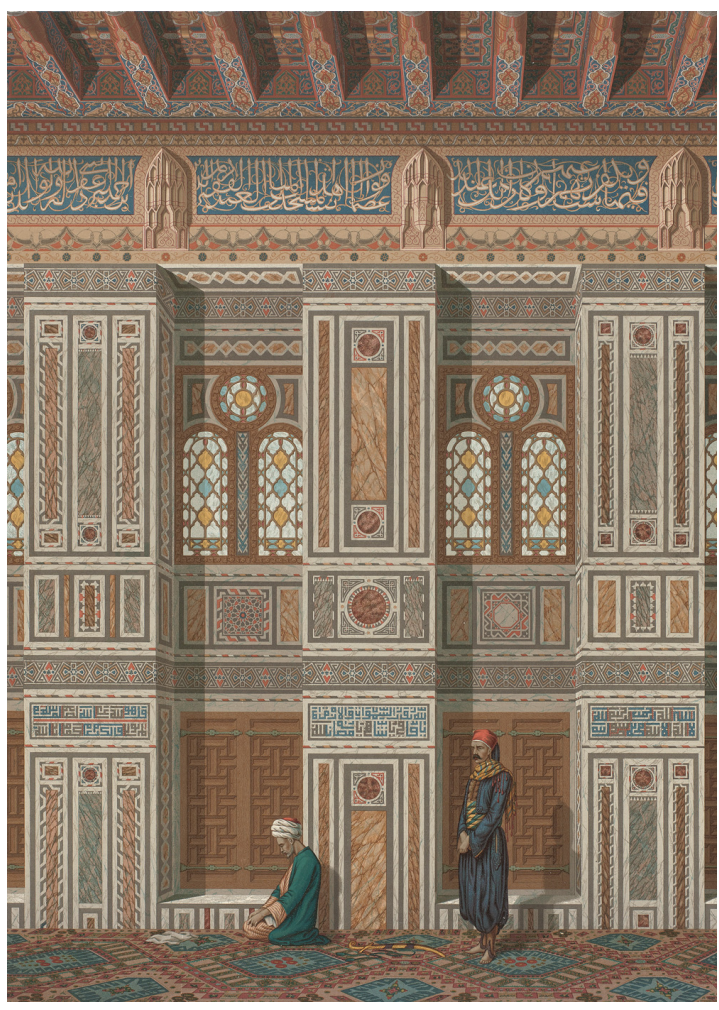

Source : Émile PRISSE d'AVENNES, L'Art arabe, pl. 59.

7. Mosaïques de la mosquée d'El Bourdény [al-Burdayni], aquarelle sur papier quadrillé.

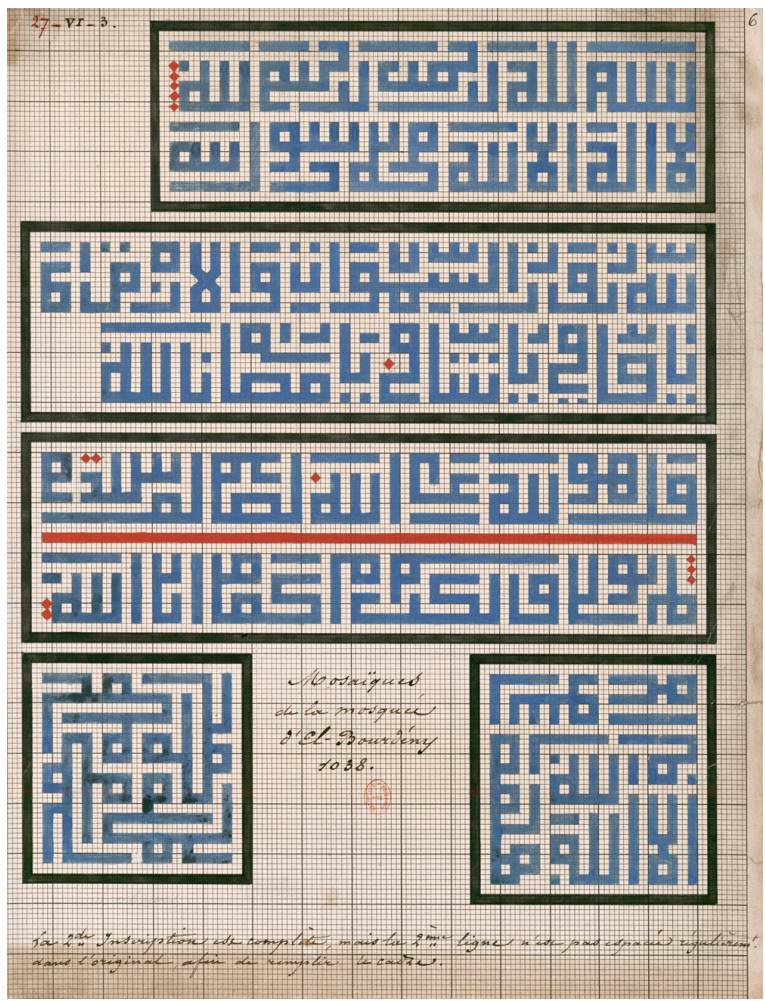

Source: Paris (France), BnF, département des Manuscrits, fonds Prisse d'Avesnes, 27-VI-3 / f. 6. 
8. Mosquée d'El Bordeyny [al-Burdayni]. Détails du grand plafond.

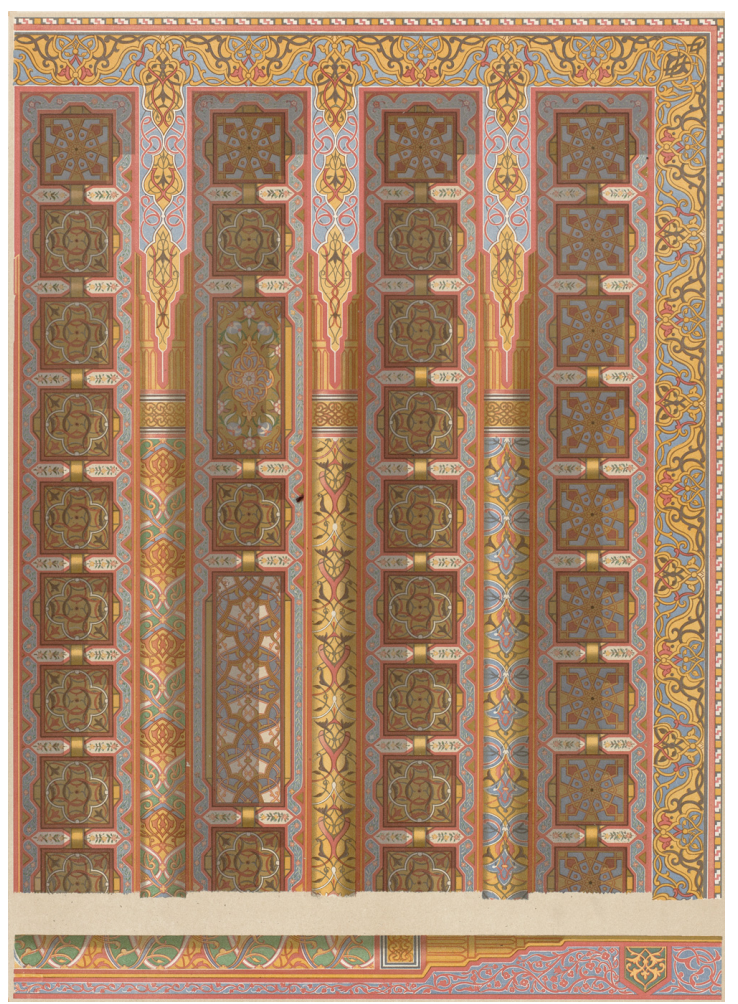

Source : Émile PRISSE d'AVENNES, L'Art arabe, pl. 69.

9. Étude du plafond de la mosquée al-Burdayni, mine de plomb et aquarelle.

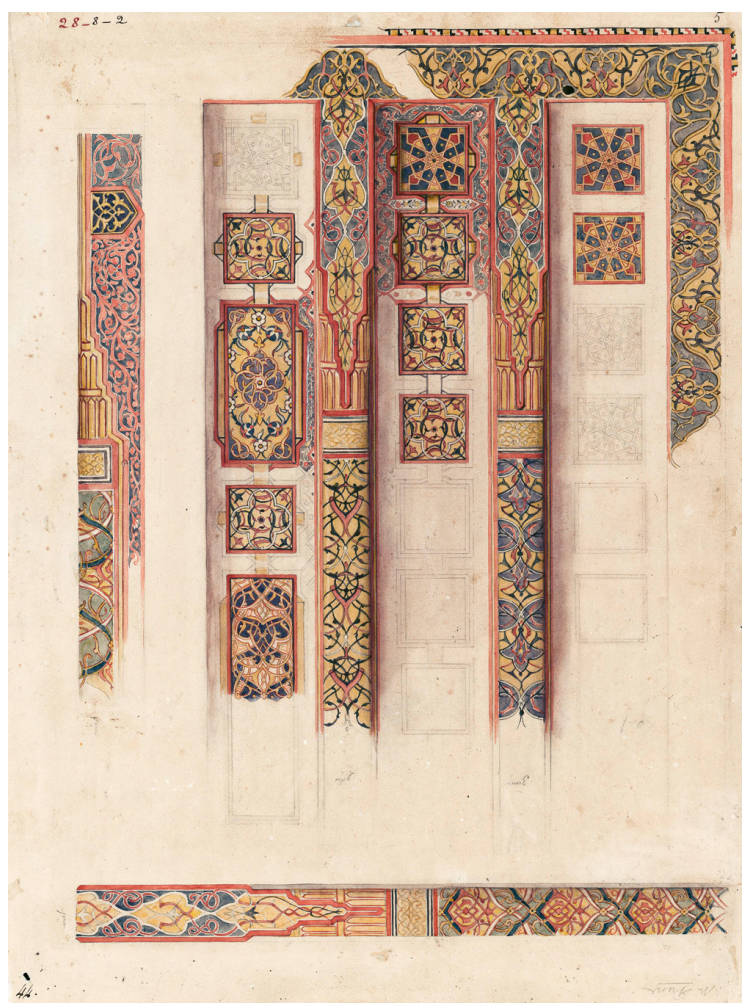

Source : Paris (France), BnF, département des Manuscrits, fonds Prisse d'Avesnes, 28-8-2 / f. 5. 
10. Intérieur de la mosquée de Qaytbay, Le Caire, dessin.

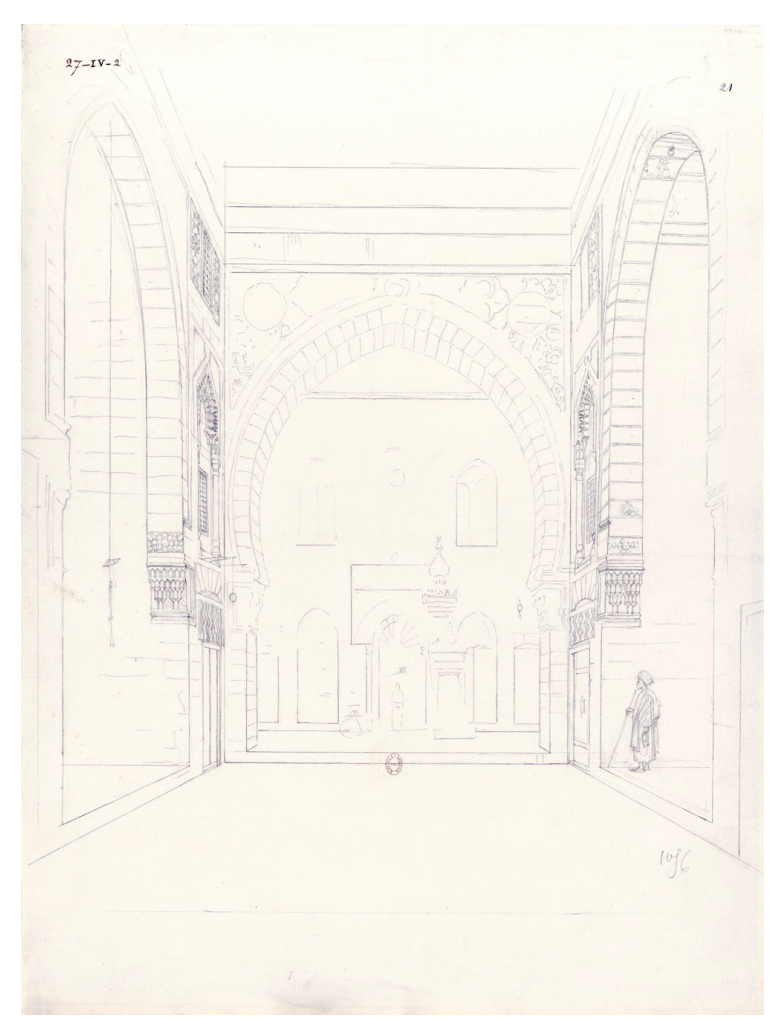

Source: Paris (France), BnF, département des Manuscrits, fonds Prisse d'Avesnes, 27-IV-2 / f. 21.

11. Mosquée de Qaytbay (intra muros). Élévation du côté du mihrab (XVe siècle).

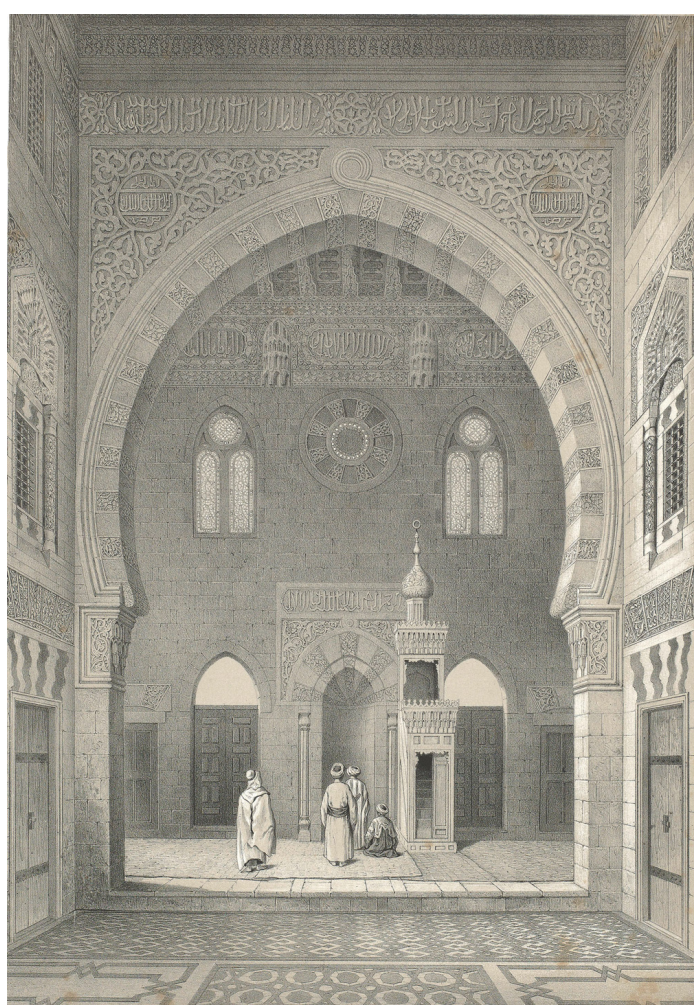

Source : Émile PRISSE d'AVENNES, L'Art arabe, pl. 21. 
12. Études de porte, ornements, architecture dans la mosquée de Qaytbay, Le Caire, dessin à la mine de plomb.

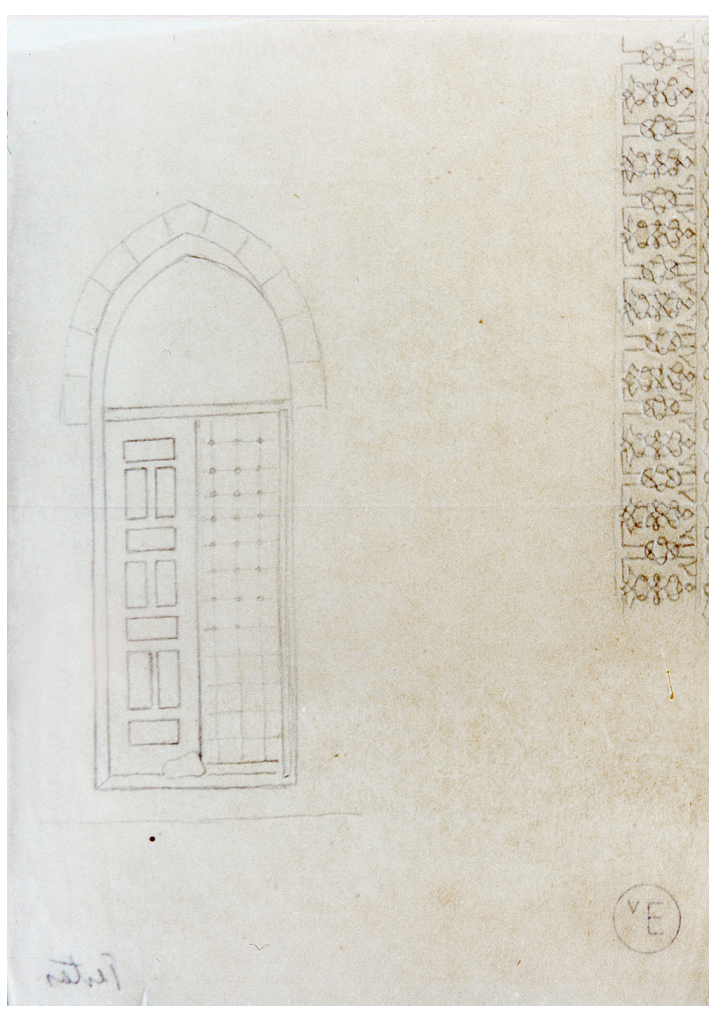

Source : Pays-Bas, collection privée, TTS 093. 
13. Minbar dans la mosquée de Qaytbay, Le Caire, dessin à la mine de plomb.

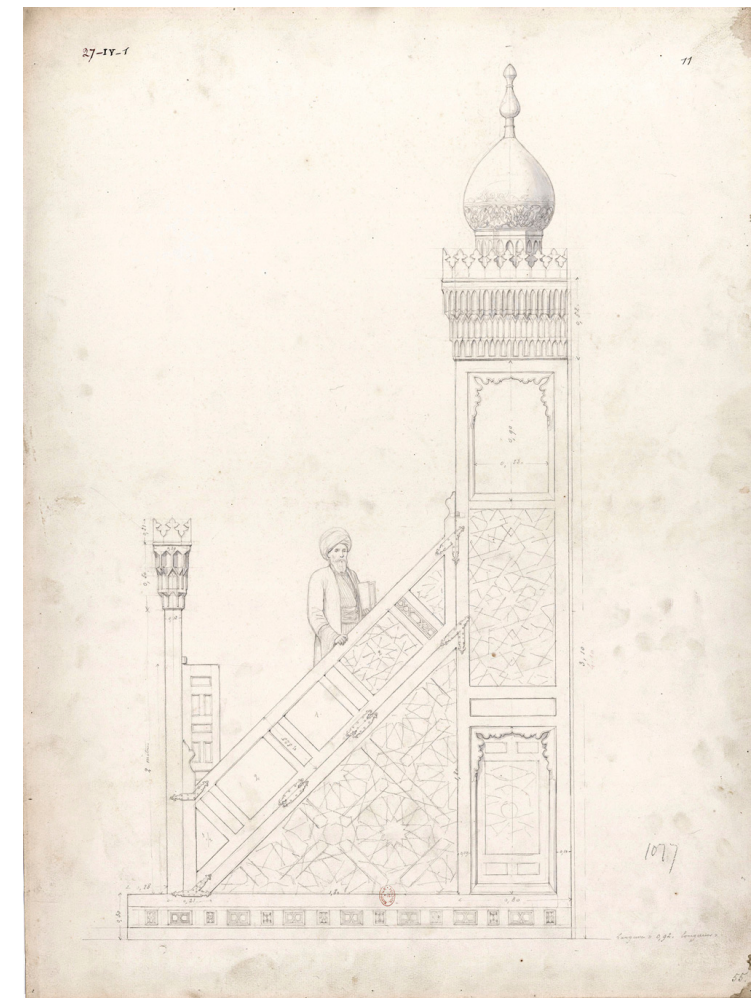

Source : Paris (France), BnF, département des Manuscrits, fonds Prisse d'Avesnes, 27-IV-1 / f. 11.

\section{Photographies}

Un médium qui n'a pas encore été évoqué jusqu'à présent est la photographie. Cela semble logique, puisque le photographe de l'expédition était Édouard Jarrot, et non Testas. Pourtant, Testas est aussi intervenu dans les photographies, certes pas en qualité de photographe, mais comme dessinateur ${ }^{36}$. Au début du voyage, Jarrot fut confronté à de nombreux problèmes techniques : travailler avec des négatifs sur verre au collodion humide s'avéra très malaisé sous le climat égyptien. La situation s'améliora nettement lorsqu'il passa aux négatifs sur verre à l'albumine ${ }^{37}$. Testas s'entendait bien avec Jarrot. Ils avaient tous deux à peu près le même âge et étaient au début de leur carrière. Souvent, ils partaient ensemble immortaliser les mosquées et autres monuments du Caire, Jarrot armé de son équipement photographique, Testas de son carnet de croquis. Pour l'un comme pour l'autre, il n'était pas toujours simple de travailler au milieu de l'agitation de la ville :

«Dommage que l'on ne puisse pas voir de loin la plupart des mosquées, puisque les rues sont trop étroites, et qu'il soit donc impossible de rendre celles-ci par la photographie ; même les dessiner est infaisable. À cela il faut ajouter la cohue : une multitude d'ânes, de dromadaires, de marchands, de soldats à cheval, de voitures et de chariots, tout cela grouille dans la confusion la plus totale ${ }^{38}$. "

En dépit de sa longue maladie et de ses problèmes mentaux, qui allaient finalement conduire à son dramatique effondrement psychologique, Jarrot eut quand même à son actif une production considérable. Il fit quelque 200 épreuves photographiques pendant le voyage, dont environ 50 doubles. Une bonne partie d'entre elles sont aujourd'hui 
conservées dans le fonds Prisse. Ce ne sont au demeurant pas les seules photographies de cette collection, il s'y trouve également des œuvres d'autres photographes, comme Maxime Du Camp, Ernst Benecke, Félix Teynard, Gustave Le Gray, Wilhelm Hammerschmidt et John Beasley Greene ${ }^{39}$.

Prisse a utilisé les photographies non seulement comme matériel documentaire visuel, mais aussi comme modèles destinés au lithographe, qui pouvait ainsi tracer les compositions sur la pierre pratiquement sans adaptation. Dans L'Art arabe, ce sont surtout les lithographies de l'extérieur de mosquées et de détails d'architecture qui dérivent en droite ligne des photographies de Jarrot conservées dans le fonds Prisse : les mêmes détails, représentés exactement sous le même angle.

Mais outre ces photographies ordinaires, il existe aussi une série de tirages sur papier salé qui ont été retouchés ultérieurement. Les contours des bâtiments ont été repassés à la plume ou les tirages ont été mis en couleur à l'aquarelle. Ces tirages sur papier salé coloriés sont parfois appelés des photographies peintes. Cette technique est surtout connue pour avoir été utilisée dans la photographie de portraits mais pas tellement pour la photographie d'architecture. Pourtant, la retouche et la mise en couleur de tirages photographiques au sel comptaient parmi les occupations courantes de Testas, car nous en retrouvons plusieurs exemples dans sa Liste ${ }^{40}$. Il s'agissait souvent de repasser sur des lignes de contour, de manière à ce que les détails ressortent mieux, ce qui facilitait le travail du lithographe. Ce procédé est parfaitement illustré par la photographie d'un détail sculpté de la mosquée d'al-Salih Tala'i'. Dans le fonds Prisse, il en existe une photographie ordinaire et un tirage beaucoup plus pâle, qui a été retouché et légèrement mis en couleur ultérieurement par Testas ${ }^{41}$. Dans L'Art arabe, nous voyons comment le lithographe, enfin, a intégré cette photographie retouchée dans une planche plus grande, avec différents détails de la mosquée (pl. 5).

Mais les interventions de Testas sur les épreuves photographiques ne se limitaient pas à l'accentuation de contours ou à la mise en couleur : parfois, il devait aussi ajouter de nouveaux éléments. Parmi les travaux accomplis pour Prisse, il avait ainsi mentionné sur la Liste $\left(\mathrm{n}^{\circ} 79\right)$ : «retouché et mis des figures dans 5 photographies $»^{42}$. Le fonds Prisse comprend effectivement quelques tirages sur papier salé coloriés, qui ont été agrémentés de figures dessinées (fig. 14). Les personnages, mais aussi et surtout les ânes et les chiens, sont indéniablement de la main de Testas. Le tirage de ces épreuves sur papier salé est en outre volontairement assez pâle, pour que le dessinateur puisse mieux faire son travail.

Pourquoi le photographe et le dessinateur auraient-ils travaillé conjointement pour arriver à ce résultat? Le support photographique présentait incontestablement de grands avantages : la photographie était très fidèle à la réalité et très rapide. Mais elle n'était pas dépourvue de certains inconvénients : aux débuts de la photographie, il était impossible de photographier des personnes en mouvement, et la photographie en couleur n'existait pas. La technique de la photographie peinte s'efforçait de pallier ces manquements. L'artiste devait animer les rues photographiées avec précision, et donner de la couleur aux monuments. Ainsi la force de la photographie et celle de la peinture se combinaient-elles de manière optimale.

37 Le but précis de ces photographies peintes n'est pas toujours clair. Peut-être devaientelles servir d'aide à l'élaboration de compositions pour des aquarelles ou des tableaux. Nous savons qu'au départ, Testas eut des difficultés à dessiner l'architecture et la perspective, et ces photographies retouchées pouvaient certainement lui être utiles 
dans ce cadre ${ }^{43}$. Les photographies peintes auraient aussi pu être destinées au lithographe, afin que celui-ci les transpose directement sur la pierre. Les photographies peintes du fonds Prisse ne sont certes pas reproduites telles dans L'Art arabe, mais nous savons que certaines lithographies de cet ouvrage illustré sont fondées effectivement sur des photographies, auxquelles des figures furent ensuite ajoutées. C'est par exemple le cas de la planche 35, Tombeau d'un émyr dans le cimetière de Karafeh [Qarafa] (fig. 15). Le modèle direct est un tirage sur papier salé qui a été pris du même point de vue (fig. 16). Cette épreuve a du reste aussi été légèrement retouchée : les contours et la décoration du tombeau ont été repassés à l'encre. Sur la lithographie finale, l'environnement a été légèrement modifié : le muret gênant, à gauche, a été supprimé et une partie de la tombe, à droite, a été restituée symétriquement. Un changement plus important est l'ajout d'un petit groupe de personnages qui anime la scène, au premier plan, inspiré d'un dessin (fig. 17) ${ }^{44}$.

Nous présumons que bien d'autres lithographies de L'Art arabe sont fondées sur des photographies auxquelles Testas - ou quelqu'un d'autre - a ajouté des personnages ultérieurement. Les planches 19 Mosquée sépulcrale de Qaytbay, et 26, Mosquée et tombeau d'El-Ghoury [al-Ghawri](fig. 18), ont par exemple une architecture très convaincante, mais les figures sont un peu discordantes par rapport à celle-ci : les proportions ne correspondent pas et le rendu des personnages est d'un style tout différent de celui de l'architecture. Le fonds Prisse comprend plusieurs photographies qui ont peut-être été utilisées comme modèle pour l'architecture des lithographies ${ }^{45}$.

14. Édouard JARROT et Willem de FAMARS TESTAS, Bab el-Charieh [Bab al-Sha'riyya] (porte de la Loi), Le Caire, photographie peinte.

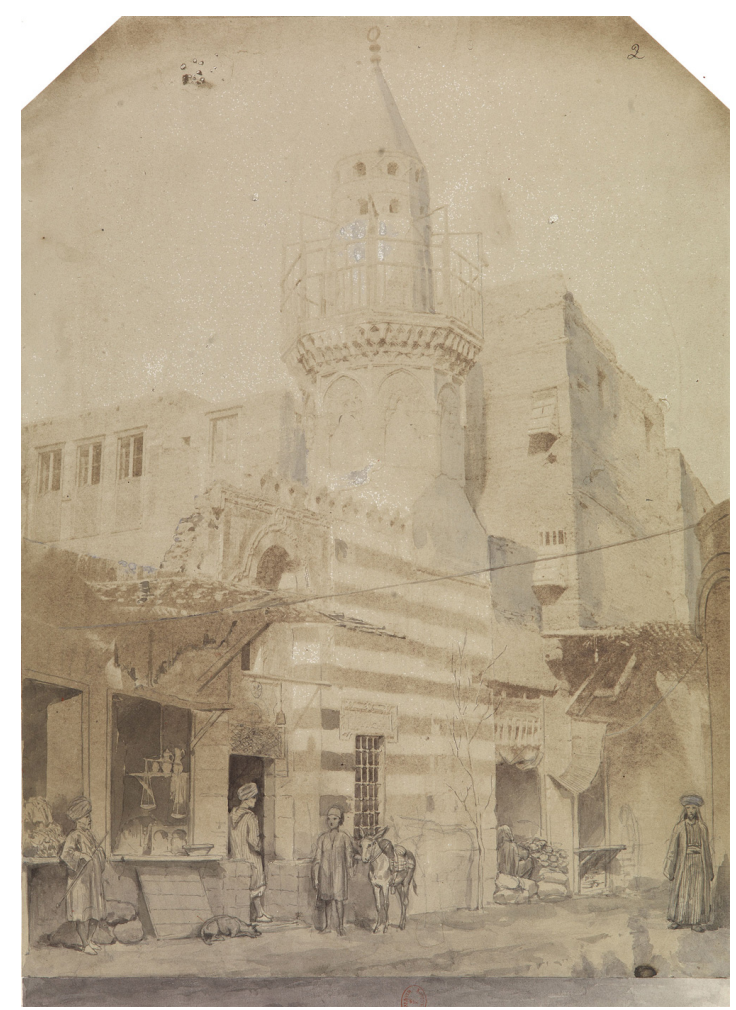


15. Tombeau d'un émyr dans le cimetière de Karafeh [Qarafa] (XVIII ${ }^{\mathrm{e}}$ siècle).

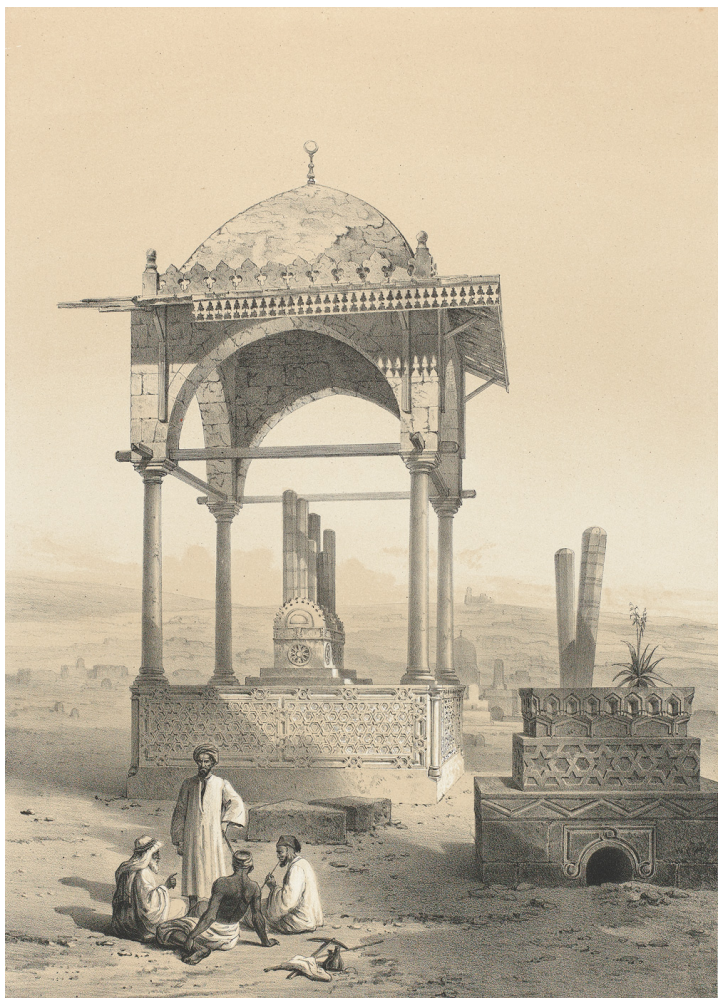

Source : Émile PRISSE d'AVENNES, L'Art arabe, pl. 35.

16. Édouard JARROT, Tombeau à baldaquin près de la tombe de l'imam al-Shafi'i, tirage au sel retouché.

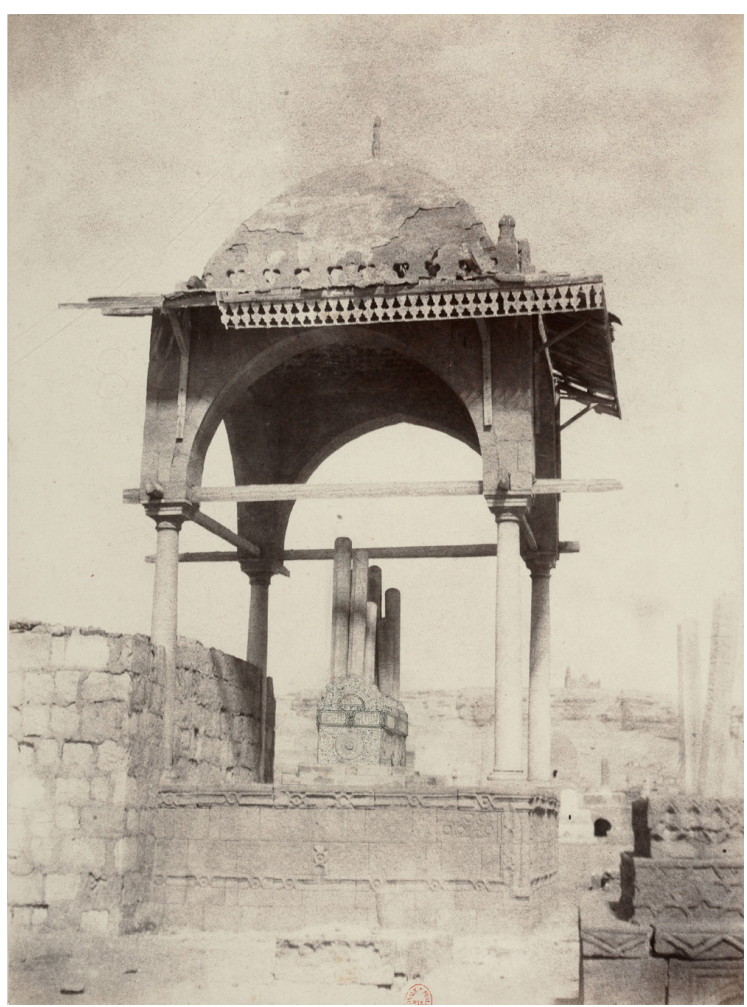

Source : Paris (France), BnF, département des Manuscrits, fonds Prisse d'Avesnes, 24-I-3 / f. 12. 
17. Groupe d'hommes accroupis, crayon et aquarelle.

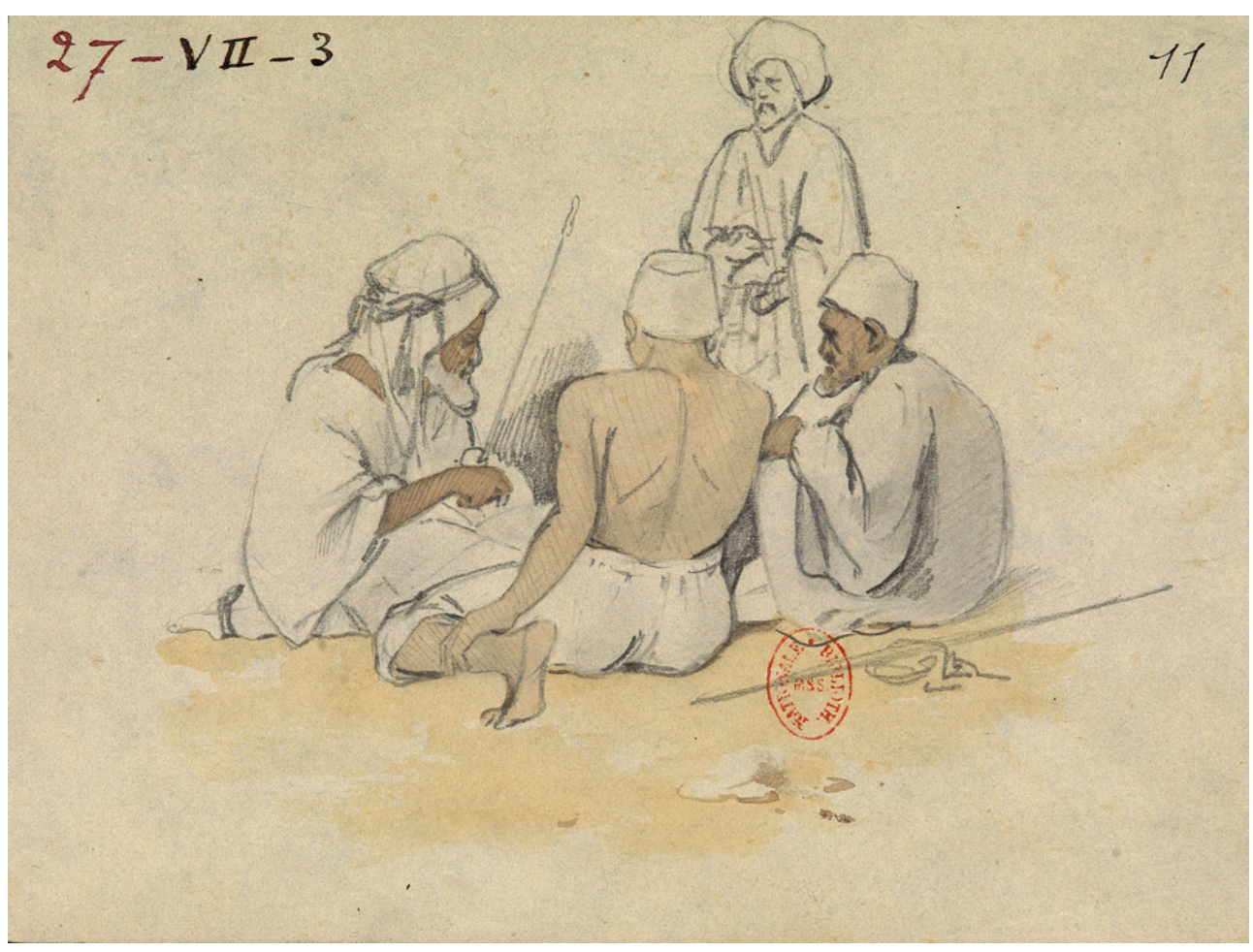

Source : Paris (France), BnF, département des Manuscrits, fonds Prisse d'Avesnes, 27-VII-3 / f. 11.

18. Mosquée et tombeau d'El-Ghoury [al-Ghawri] ( $\mathrm{xvI}$ siècle).

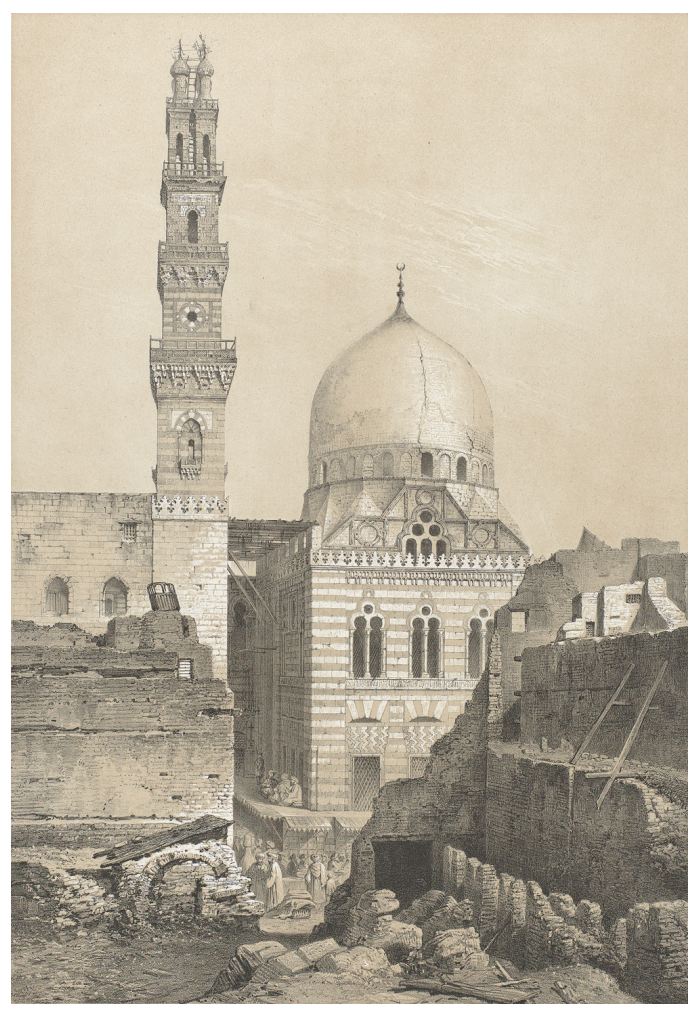

Source : Émile PRISSE D'AVENNES, L'Art arabe, pl. 26. 


\section{Travail personnel} trouva du réconfort en Égypte en pensant qu'il récolterait plus tard les fruits de son voyage : «Ceci aura néanmoins probablement son utilité ; je serai certainement expert en orientalisme, ce qui s'avère déjà utile lorsque l'on veut placer des personnages dans des maisons, des monuments, et cætera ${ }^{46}$ ". L'artiste néerlandais ramena un trésor de croquis et de dessins chez lui. Il se constitua même ses propres archives documentaires, qui sont un peu comparables aux archives de Prisse. Outre ses propres croquis de voyage, il rassembla diverses photographies d'Égypte, de Jarrot et d'autres photographes ${ }^{47}$. Il y avait aussi énormément de calques dans sa documentation : des copies de calques de reliefs pharaoniques et de décorations arabes qu'il avait réalisés en Égypte avec Prisse, mais aussi de fragments d'architecture et de figures isolées. Enfin, il conservait également bon nombre de calques de compositions complètes, des épures quadrillées ou non - qui étaient, semble-t-il, destinées à servir de base à de plus grandes aquarelles ou des peintures à l'huile ${ }^{48}$. Testas prenait manifestement au sérieux son ambition de devenir le premier peintre des Pays-Bas à se spécialiser dans le genre orientaliste.

Tout au long de sa carrière, Testas continua de puiser dans la documentation qu'il avait réunie au cours de son premier voyage. Ses tableaux personnels avaient souvent pour sujet des scènes de rue et des scènes de la vie quotidienne. Ceux-ci ne possédaient certes pas le décor architectural monumental que l'on trouve dans L'Art arabe, mais cela ne veut pas dire que Testas ne se servit pas de ses archives visuelles pour agrémenter ses tableaux de détails authentiques. On a même l'impression qu'il avait copié et réutilisé encore et encore ses détails architecturaux préférés et ses personnages isolés favoris dans de multiples compositions.

41 Le tableau Cour intérieure d'une maison au Caire (1881) est un bon exemple de la méthode de "copier/coller» utilisée par Testas (fig. 19). La toile témoigne de son excellente connaissance de l'architecture arabe, acquise lors de son séjour en Égypte avec Prisse. La superbe porte avec voûte à stalactites (muqarnas) et les moucharabiehs ont été rendus de manière détaillée et convaincante. Pour réaliser cette œuvre, Testas s'est largement inspiré de ses vieux carnets de croquis de 1858-1860. La porte a été copiée d'après une feuille de croquis portant l'inscription " porte de maison avec ornements en bronze au Kaire » (fig. 20). L'ornement mural à gauche (au-dessus de la console) est emprunté à une feuille de croquis avec des études d'architecture qui date de 1859, conservée au Rijksmuseum (fig. 21). Il existe même un croquis et un calque ultérieur de la femme voilée ${ }^{49}$. Ces détails authentiques donnent un charme supplémentaire à ce tableau.

À la fin de sa carrière, en 1890, Testas se servit encore du matériel recueilli lors de son premier séjour au Caire. En 1859, il avait réalisé pour Prisse une Porte de Harem (Liste $\mathrm{n}^{\circ}$ 25) qui fut reproduite à la planche 32 de L'Art arabe (fig. 22). Cette composition continua manifestement à le fasciner, car il en dessina une variante une trentaine d'années plus tard. Le dessin original a disparu, mais nous avons conservé un calque de la composition et une reproduction qui a probablement été publiée autrefois dans une revue et se trouve aujourd'hui au Rijksbureau voor Kunsthistorische Documentatie à La Haye (fig. 23) ${ }^{50}$. Le décor architectural se résume désormais à la moitié inférieure de 
l'ensemble, avec la porte en bois; l'encadrement ornemental complexe a en grande partie été supprimé. Les deux personnages sur la lithographie ont été remplacés par un homme avec son âne et un chat.

43 En résumé, nous pouvons dire qu'une part très considérable des dessins, calques et estampages du fonds Prisse de la Bibliothèque nationale de France a été réalisée par le peintre néerlandais Willem de Famars Testas, un des compagnons de voyage d'Émile Prisse d'Avennes lors de son expédition en Égypte en 1858-1860. Les documents du fonds Prisse ont servi de base aux lithographies du monumental ouvrage illustré L'Art arabe. La contribution de Testas à celui-ci est loin de se limiter à la seule lithographie qui porte son nom. Enfin, nous pouvons conclure que la participation de Testas à l'expédition de Prisse a été déterminante pour le reste de sa carrière. C'est à partir de ce moment-là qu'il décida de se consacrer au genre orientaliste. Non sans succès : il fut le seul peintre néerlandais du $\mathrm{XIX}^{\mathrm{e}}$ siècle qui réussit à acquérir une certaine notoriété même en dehors des Pays-Bas en qualité d'orientaliste. En 1868, il fut même invité par Jean-Léon Gérôme à faire un voyage d'artistes à travers l'Orient en compagnie de quelques autres peintres. Tout au long de sa vie, Testas continua de s'inspirer du travail qu'il avait réalisé en Égypte entre 1858 et 1860.

19. Cour intérieure d'une maison au Caire, 1881, huile sur toile.

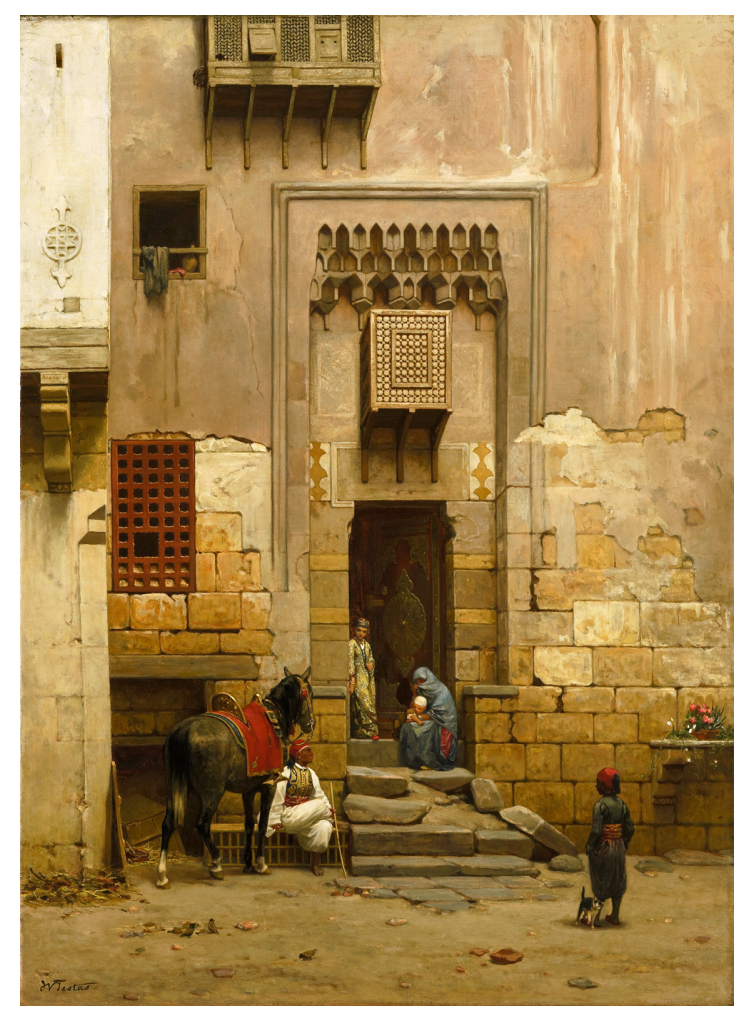

Source : Amsterdam (Pays-Bas), Rijksmuseum, SK-A-1184. 
20. Porte de maison avec ornements en bronze au Kaire, mine de plomb sur papier gris.

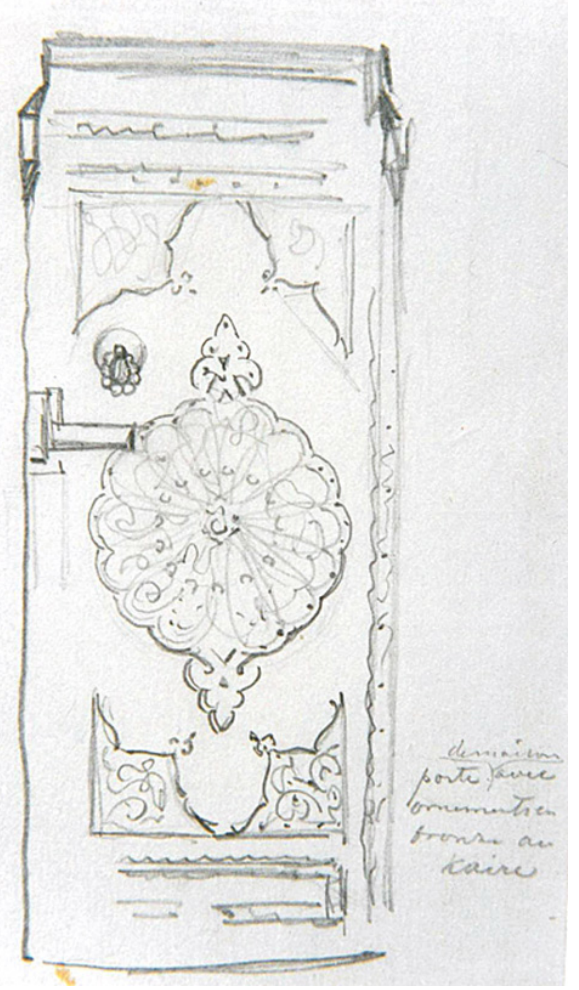

Source : Pays-Bas, collection privée, TTS 010.

21. Croquis de voyage avec études d'architecture, mine de plomb sur papier. Détail de l'ornement mural repris sur le tableau de la fig. 19 .

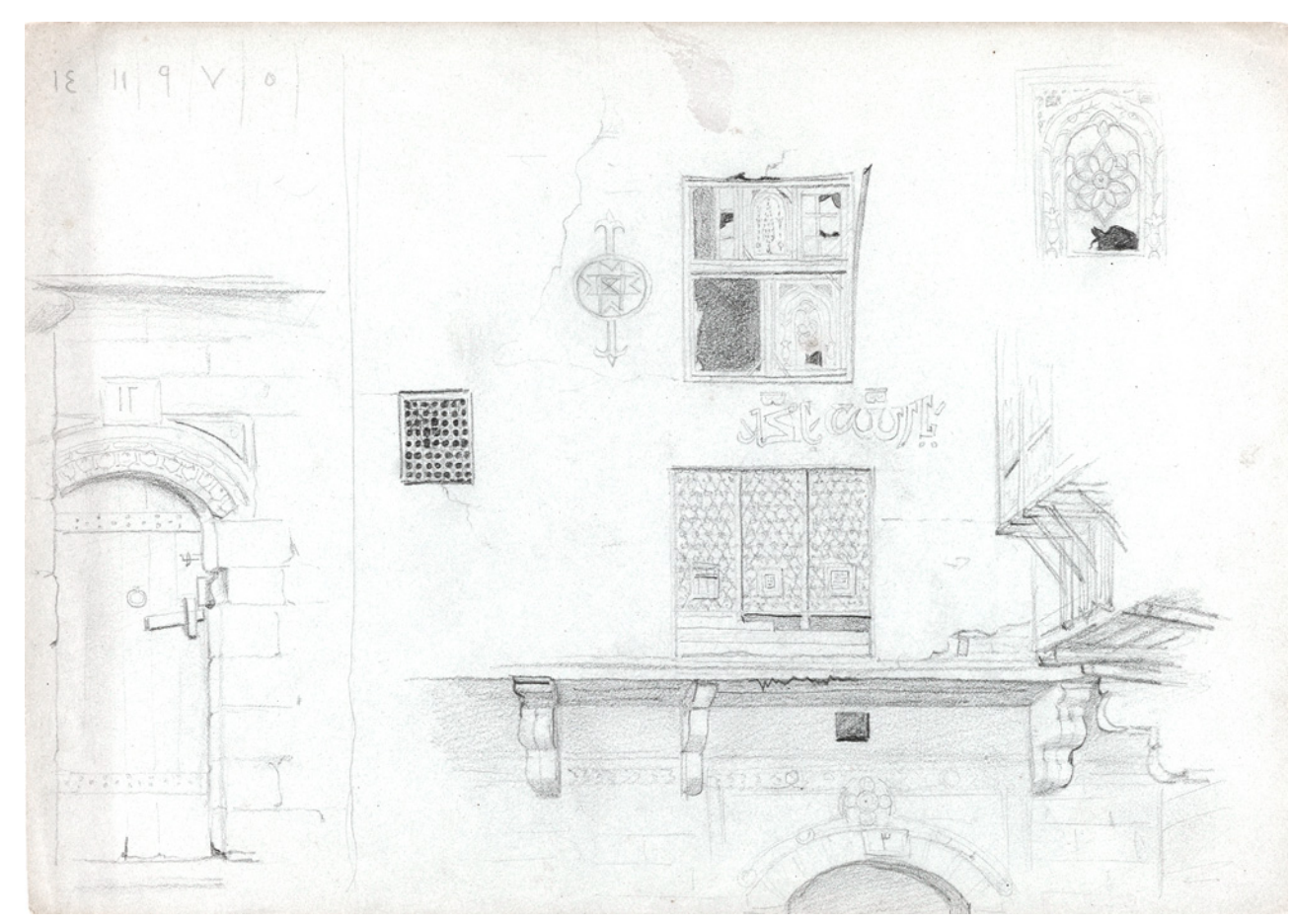

Source : Amsterdam (Pays-Bas), Rijksmuseum, RP-T-1981:91-b. 
22. Beyt el-Emir [bayt al-Amir], porte extérieure du harem (XVIIe siècle).

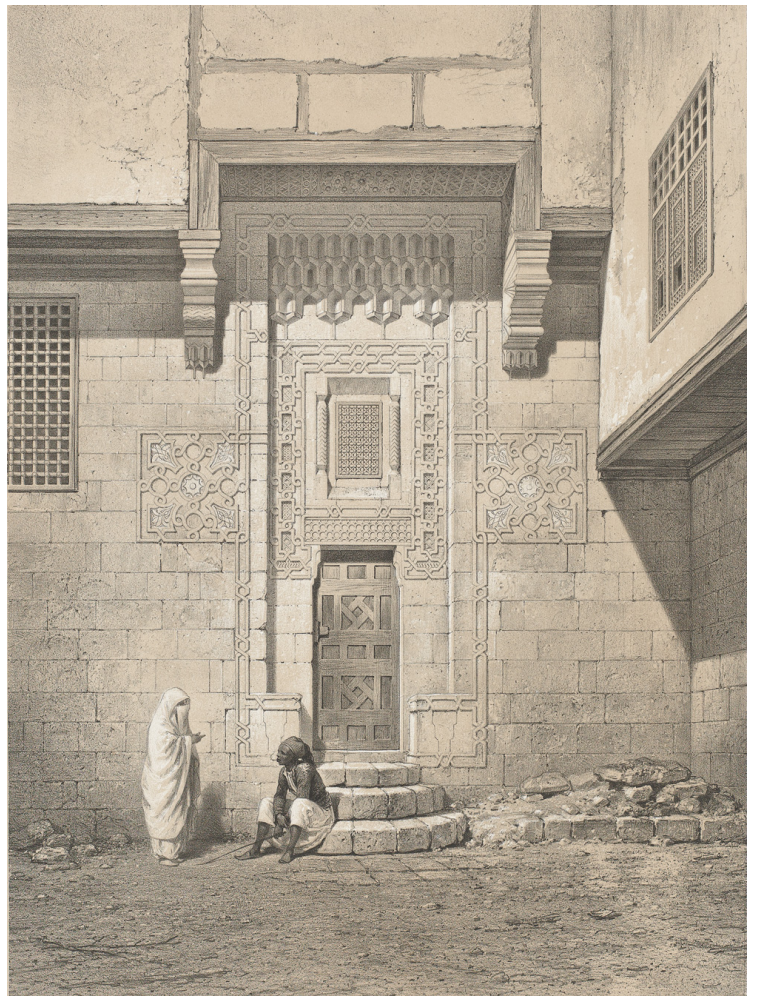

Source : Émile PRISSE d'AVENNES, L'Art arabe, pl. 32.

23. Oriental avec âne près d'une porte, 1890, d'après Willem de Famars Testas, lithographie.

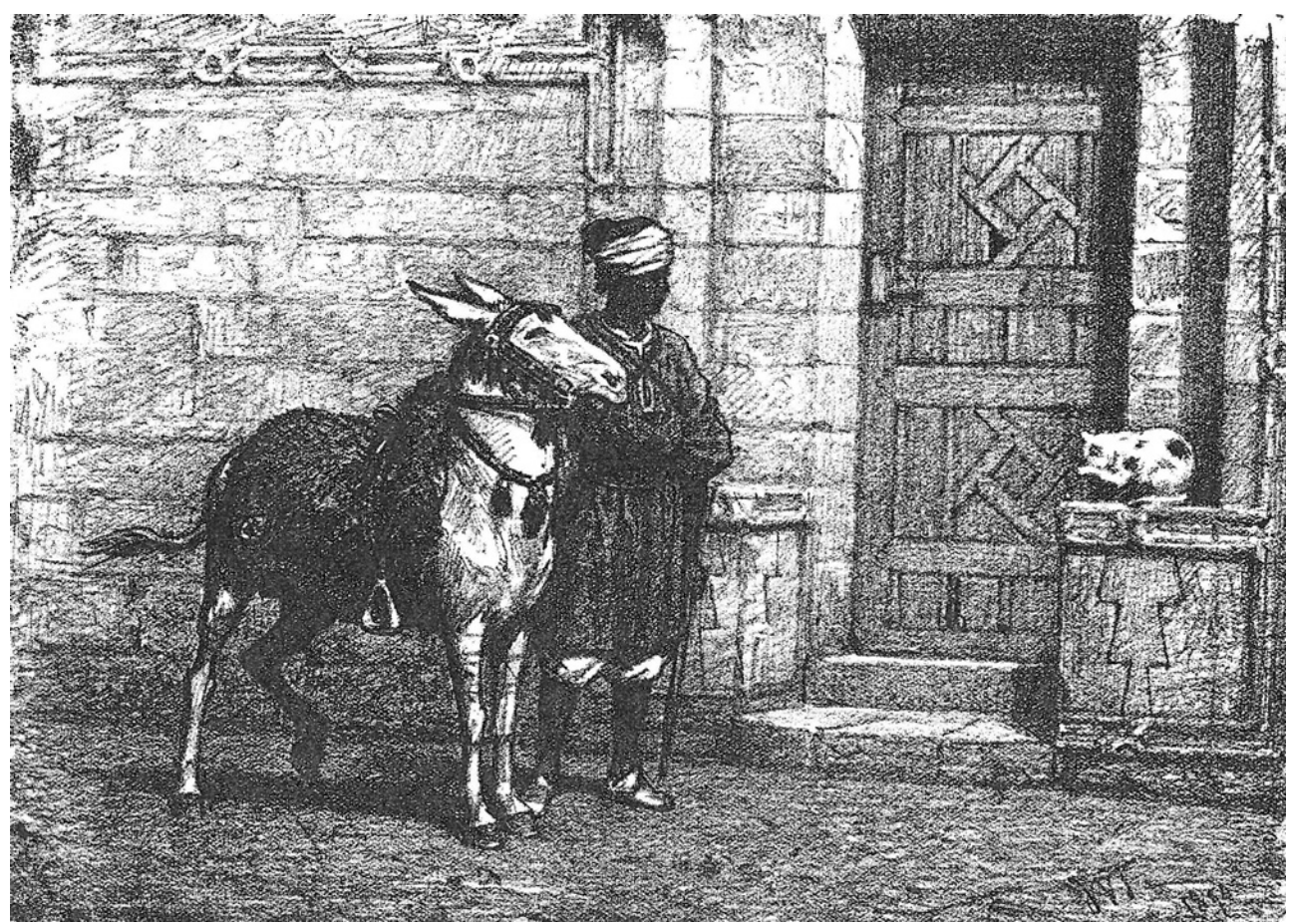

Source : La Haye (Pays-Bas), Rijksbureau voor Kunsthistorische Documentatie. 


\section{NOTES}

1. Cette exposition a été présentée à Tel-Aviv (musée d'Art de Tel-Aviv), Bayonne (musée Léon Bonnat) et Paris (musée Hébert). Elle était accompagnée d'une publication : Album de Voyage. Des artistes en expédition au pays du Levant, Paris : AFAA; RMN, 1993.

2. Le journal tenu par Testas lors de ce deuxième voyage a été reproduit dans son intégralité dans Album de voyage, op. cit. (note 1), p. 89-201, ici p. 98.

3. Outre Jean-Léon Gérôme, Willem de Famars Testas et Albert Goupil, la compagnie se composait des peintres Paul-Marie Lenoir, Jean-Richard Goubie, Léon Bonnat et Ernest Journault. Le voyageur français Wilfrid de Barthélemy, inconnu par ailleurs, fit avec eux le voyage du Caire à Jérusalem, où le journaliste et historien Frédéric Masson (1847-1923) prit sa relève. Voir: Willem de FAMARS TESTAS, De schilderskaravaan 1868, [préfacé et annoté par Maarten J. Raven], Leyde : Ex Oriente Lux ; Louvain : Peeters, 1992, p. 13.

4. Émile PRISSE D’AVENNES, Histoire de l'art égyptien d'après les monuments, depuis les temps les plus reculés jusqu'à la domination romaine, Paris: A. Bertrand, 1878-1879. Émile PRISSE D'AVENNES, L'Art arabe d'après les monuments du Caire depuis le VII siècle jusqu'à la fin du XVII siècle, Paris : A. Morel et Cie, 1877 ; réédition Paris : l'Aventurine, 2002.

5. Pour l'orientalisme aux Pays-Bas, voir : Ronald de LEEUW, « Nederlandse oriëntalisten », Jong Holland, $\mathrm{n}^{\circ} 1$, septembre 1985, p. 10-36; Jan de HOND, Verlangen naar het Oosten. Oriëntalisme in de Nederlandse cultuur ca. 1800-1920, Leiden : Primavera Pers, 2008.

6. Des fragments du journal et extraits de lettres ont été fournis, annotés et préfacés par Maarten Raven : Willem DE FAMARS TESTAS, Reisschetsen uit Egypte, 1858-1860, [adapté et annoté par Maarten J. Raven], Maarssen/'s- Gravenhage,[mq l'éditeur commercial : SDU ; Gary Schwartz], 1988.

7. Des recherches récentes montrent que le prénom le plus souvent attesté de Jarrot serait Édouard: Sylvie AUBENAS, «Un fonds de photographies unique sur l'Égypte », in Visions d'Égypte, Émile Prisse d'Avennes (1807-1879), catalogue d'exposition (Paris, Bibliothèque nationale de France Musée du Louvre, $1^{\mathrm{er}}$ mars-5 juin 2011), Paris : BnF, 2011, p. 119-139, part. p. 122, note 16.

8. Maarten J. RAVEN, op. cit. (note 6), p. 37.

9. Ibid., p. 43-44.

10. Ibid., p. 47.

11. Ibid., p. 53.

12. Ibid., p. 85.

13. Ibid., p. 88.

14. Ibid., p. 88.

15. Ibid., p. 81.

16. Ibid., p. 81.

17. Ibid., p. 82.

18. Ibid., p. 76.

19. Ibid., p. 97.

20. Ibid., p. 161.

21. Ibid., p. 158.

22. Pour Jarrot, voir: Mattie воом, «Tekenen met licht. De fotograaf A. Jarrot en beeldend kunstenaar Willem de Famars Testas in Egypte, 1858-1860 », Bulletin van het Rijksmuseum, vol. 42, $\mathrm{n}^{\circ}$ 3, 1994, p. 185-201 ; Sylvie AUBENAS et Jacques LACARRIÈrE, Voyage en Orient, Paris : BnF ; Hazan, 1999, p. 29-30 ; Sylvie AUBENAS, op. cit. (note 7), p. 119-139, part. 122-123. 
23. Émile Prisse d'Avennes à Louis-Félicien de Saulcy, Gournah 16 janvier 1860. Citation extraite de : Michel DeWACHTER, «Un Avesnois. L’Égyptologue Prisse d'Avennes », Société archéologique \& historique de l'arrondissement d'Avesnes, tome XXX, 1988, p. 174.

24. Cette Liste est aussi reproduite dans Maarten J. RAVEN, op. cit. (note 6), p. 194-200.

25. Illustrations de boutiques : Paris (France), Bibliothèque nationale de France, département des Manuscrits, fonds Prisse d'Avennes, 27-VII-3, f. 32, 33, 69-70, 72.

26. Voir par exemple l'aquarelle signée «Boutique orientale» au Teylers Museum de Haarlem reproduite dans Maarten J. RAVEN, op.cit. (note 6), p. 45 ou un dessin d'une boutique orientale dans un carnet de croquis de voyage de Testas au Rijksmuseum d'Amsterdam (inv. n RPT-1974: 11). Voir les dessins de boutiques reproduits dans Mercedes volart, «Avec le double empressement d'un artiste et d'un antiquaire », in Visions d'Égypte, op. cit. (note 7), p. 93-117, part. p. 116-117.

27. «Illustré à partir de croquis faits sur place par É. Prisse ». Par exemple, le personnage de gauche sur la planche "Arnaout and Osmanli soldiers» et la jeune fille assise sur la planche «Nubian females; Kanoose tribe, Philae» in James Augustus ST. JOHN, Oriental Album. Characters, Costumes, and Modes of Life. The Valley of the Nile. Illustrated with designs taken on the spot by E. Prisse, Londres: Madden, 1851, p. 1 et 49, correspondent en tous points à deux aquarelles du fonds Prisse: "Arnaout» (Paris (France), Bibliothèque nationale de France, département des Manuscrits, fonds Prisse d'Avennes, 26- III-1, f. 12) et « Jeune Nubienne assise » (26-III-1, f. 13).

28. Prisse est mentionné comme auteur pour une grande majorité des planches de L'Art arabe. Pour le reste, quatre autres artistes sont encore cités, outre Testas: Girault de Prangey (11 planches), Ch. De Linas (3 planches), Cournault (9 planches) et Yahia el-Wacetty (4 planches): Luitgard MOLs, «Islamic art and architecture through the eyes of Testas. Documentary drawings and genre scenes ", in Arnoud Jan VRoLIJK et Jan P. HOGENDIJK, O ye Gentlemen. Arabic Studies on Science and Literary Culture in honour of Remke Kruk, Leiden; Boston, MA : Brill, 2007, p. 423-436, p. 424, n. 5. Dans Histoire de l'art égyptien, Testas est mentionné un peu plus souvent - à six reprises - mais ici aussi sa contribution fut certainement beaucoup plus importante (Maarten J. RAVEN, op. cit. (note 6), p. 23).

29. Pour les planches correspondantes dans L'Art arabe et les mentions dans la Liste, voir Luitgard MOLS, op. cit. (note 28), p. 425 avec illustration.

30. Ibid., p. 424-428 et 236.

31. Maarten J. RAVEN, op. cit. (note 6), p. 88.

32. Collection privée, Pays-Bas, TTS 089, illustré dans Luitgard MOLs, op. cit. (note 28), p. 425 avec illustration.

33. Pour la lithographie d'un autre plafond de la même mosquée (pl. 68), une étude de détail se trouve également dans une collection privée néerlandaise (TTS 095) : Luitgard MOLS, op. cit. (note 28), p. 425 avec illustration.

34. Études de détails de l'intérieur de la mosquée de Qaytbay qui reviennent également dans les planches 20 et 21 de L'Art arabe: Paris (France), BnF, département des Manuscrits, fonds Prisse d'Avennes, 27-IV-1, f. 12 (les calques de l'inscription en arabe) et 27-IV-3, f. 2. Également dans une collection privée néerlandaise: TTS 006, TTS 087, TTS 088, TTS 093, TTS 094. Voir aussi Luitgard MOLS, op. cit. (note 28), où TTS 06 et TTS 088 sont reproduits.

35. Liste $\mathrm{n}^{\circ}$ 66, « Estampages du mimber (chaire) etc., mosquée Qaytbay ».

36. Sur le photographe Jarrot et sa collaboration avec Testas en Égypte, voir Mattie воом, op. cit. (note 22), p. 185-201.

37. Maarten J. RAVEN, 1988, p. 53 (note 6).

38. Ibid., p. 47.

39. Mattie воOм, op. cit. (note 22), p. 199 et S. AUBENAS, J. LACARRIÈRE, op. cit. (note 22).

40. Liste, $\mathrm{n}^{\circ} 29,79,112,182$. 
41. Paris (France), BnF, département des Manuscrits, fonds Prisse d'Avennes, respectivement 24I-1, f. 4 et $25-\mathrm{I}-8$, f. 5 .

42. Maarten J. RAVEN, op. cit.(note 6), p. 196.

43. Voir aussi Mattie воом, op. cit. (note 22), qui compare les photographies peintesde ruelles cairotes avec les aquarelles que Testas a faites de ces mêmes ruelles. Elles ne sont certes pas parfaitement identiques, mais présentent quand même de nombreuses similitudes.

44. Voir Marie-Claire SAINT-GERMIER, «Un livre rêvé: l'Égypte monumentale de Prisse d'Avennes ", in Visions d'Égypte, op. cit. (note 7), p. 141-153, part. p. 151.

45. Paris (France), BnF, département des Manuscrits, fonds Prisse d'Avennes, 24-I-2, f. 1 et 3 (photographie du mausolée de Qaytbay).

46. Maarten J. RAVEN, op. cit. (note 6), p. 90.

47. Pour les photos que possédait Testas, voir aussi Mattie воом, op. cit. (note 22).

48. Les reproductions dans Maarten J. RAVEN (op. cit. note 6) donnent une bonne idée de la diversité des archives documentaires de Testas. La majeure partie de celles-ci est conservée au Teylers Museum de Haarlem.

49. Collection privée, Pays-Bas (TTS 047).

50. Des calques de cette composition se trouvent au Teylers Museum de Haarlem: KT 1712, KT 1914, KT 1915.

\section{AUTEURS}

\section{JAN DE HOND}

Curator in the Rijksmuseum's History Department, Amsterdam, Pays-Bas. 


\title{
D'une exactitude scrupuleuse et artistiquement accomplie : Le Caire dans l'œuvre graphique de Jules Bourgoin
}

\author{
Maryse Bideault
}

\section{NOTE DE L'ÉDITEUR}

Sauf mention contraire, toutes les œuvres reproduites sont de Jules Bourgoin.

\author{
«Bientôt il aura dessiné Le Caire tout entier, \\ travail immense, mais qui n'est au-dessus ni de \\ son talent ni de sa patience. Alors les ruines \\ pourront s'accumuler; il nous restera au moins \\ un souvenir exact, une image précise de ce que \\ fut l'art arabe dans une ville où il a traversé \\ toutes les périodes de son développement, depuis \\ ses débuts jusqu'à son apogée, et depuis son \\ apogée jusqu'à sa décadence et à sa fin »
}

1 Cet hommage rendu à Jules Bourgoin $(1838-1908)^{1}$ par le talentueux publiciste Gabriel Charmes (1850-1886), dans son compte rendu de l'ouvrage d'Arthur-Ali Rhoné Coup d'œil sur l'état du Caire ancien et moderne (Paris, 1882)², caractérise, en quelques lignes et avec finesse, l'œuvre de Bourgoin. S'il fustige les piètres qualités de bâtisseurs des Arabes qui, selon lui «élevaient les masses les plus lourdes sur des colonnes inégales mais également fragiles » et dont "l'intérieur [des] murs était formé du plus grossier blocage " mais qui recouvraient le tout de splendides ornements, Charmes ne manque pas de noter que, si en architecture "leur civilisation a manqué de fond », la « surface, qui est exquise, mérite d'être conservée le plus longtemps possible ${ }^{3}$ ». 
2 Or, c'est précisément un des aspects les plus frappants de l'approche de Jules Bourgoin dans son œuvre dessiné des monuments et édifices de la ville du Caire : lui, l'architecte issu de l'École des beaux-arts, n'avait montré que très peu d'intérêt pour les vues perspectives, la monumentalité ou le pittoresque des édifices - il y sacrifia parfois mais peut-être pensait-il que le travail avait déjà été assuré par Pascal-Xavier Coste (1787-1879) dans son Architecture arabe ou monuments du Kaire, mesurés et dessinés de 1818 à $1826^{4}$. Ce qui ressort de l'étude des innombrables dessins, esquisses, croquis rapportés de ses séjours et voyages, c'est un sentiment d'intériorité qui transparaît de l'extrême concentration apportée au fragment, au détail, à l'infiniment petit, un exercice qui n'en aboutira pas moins à l'élaboration, par l'auteur, de synthèses et de théories sur l'art arabe. Certes, dans l'introduction de son premier ouvrage, Les Arts arabes, architecture, menuiserie, bronzes, plafonds, revêtements, marbres, pavements, vitraux, avec un texte descriptif et explicatif et le trait général de l'art arabe, publié en plusieurs livraisons à partir de $1868^{5}$, Bourgoin note que :

"l'objet de notre livre étant de donner une exposition spéciale du système d'ornementation qu'on appelle les entrelacs, nous avons dû, pour le rendre abordable, nous résoudre à sacrifier les ensembles et rapprocher d'une manière artificielle les détails pour en dégager le fond essentiel. Dans la réalité, tous ces détails sont secondaires et, arrivant à leur place, prennent toute leur importance... ${ }^{6} »$.

3 Mais, sauf si l'auteur avait en vue, dès 1863, la rédaction de cet ouvrage, ce qui est improbable, force est de constater que les feuillets de ses carnets ne sont couverts que de relevés de fragments.

4 Cette intériorité, il serait tentant de l'expliquer par la personnalité, difficile de l'avis d'aucuns, de Jules Bourgoin. Peu de traces ou témoignages personnels subsistent; Bourgoin ne semble pas avoir tenu de journal ni entretenu de correspondance assidue dont la consultation serait venue nous éclairer sur tant de points qui restent obscurs. Il s'en est fallu de peu que le personnage demeure sans visage : le seul document connu le montrant est une photographie de groupe, par chance légendée, prise par Émile Brugsch sur la fouille d'Abydos en 1883 (1884), découverte dans la documentation d'Arthur Rhoné (fig. 1)7. Bourgoin, identifié comme "architecte dessinateur et publiciste, attaché à la mission archéologique française ", se trouve en compagnie d'Ambroise Baudry ${ }^{8}$ et de deux autres collaborateurs de Mariette. D'apparence malingre, avec un visage émacié à barbe grise et aux yeux éteints, coiffé d'un tarbouche, Jules Bourgoin paraît davantage que son âge, 45 ans à l'époque. Déjà à cette date il semble s'être rapproché de l'image que donne de lui en 1889 Ambroise Baudry qui le décrit, dans une lettre adressée à son épouse, «plus sec et plus jaune qu'un vieux lézard de la Haute-Égypte »9. 


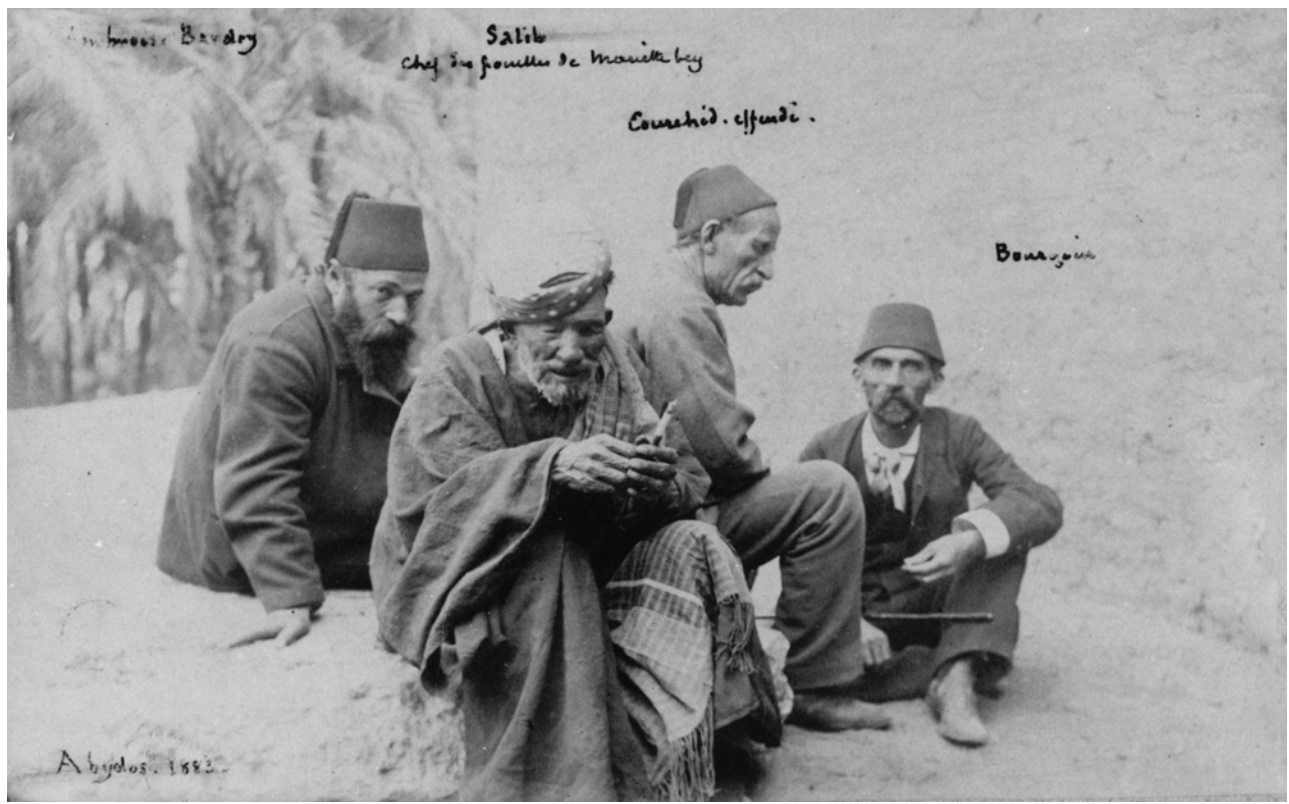

SOURCE : PARIS (FRANCE), COLLÈgE DE FRANCE, INSTITUT D'ÉgYPTOLOgIE.

Parce qu'il mourut en 1908, à Saint-Julien-du-Sault, dans un état de misère déjà entrevu au travers de témoignages émouvants de connaissances qui ne l'avaient pas totalement abandonné, état qu'est venu confirmer un inventaire après décès récemment découvert ${ }^{10}$, on a pu penser que Jules Bourgoin était issu d'un milieu modeste, voire pauvre. En fait, il venait d'une petite bourgeoisie commerçante, ou propriétaire, solidement ancrée dans l'ouest du département de l'Yonne, à Saint-Julien-du-Sault du côté paternel, à Fleury-la-Vallée du côté maternel, les Esclavy, dont la parentèle plus nombreuse semble avoir joui d'un statut social un peu plus élevé. Lui qui, par la suite, eut l'occasion de se présenter comme ayant effectué :

« de longs et studieux séjours tant en Orient que dans les principaux pays d'Europe, où [il] a eu maintes occasions d'étudier les ruines des villes antiques, comme de suivre l'activité journalière des cités vivantes, d'interroger les artisans dans leurs chantiers et leurs ateliers, d'étudier les nombreuses œuvres d'art contenues dans les musées et les collections particulières, de compulser nombreux documents renfermés $\left[\right.$ dans] les bibliothèques et les archives $[. . .]^{11}$ »

se retira, pour des raisons dont on ne sait si elles n'étaient pas dictées par sa seule impécuniosité, dans sa région natale.

7 Jules Bourgoin naquit le 12 décembre 1838 à Joigny, petite ville du département de l'Yonne où son père Louis Étienne Bourgoin (1800-1860), le plus souvent nommé Bourgoin-Esclavy suivant la coutume locale qui fait accoler les patronymes des époux, exerçait comme marchand-épicier, ou plutôt comme épicier-confiseur. Nous ne savons rien du parcours scolaire du jeune Jules Bourgoin, un des quatre enfants vivants de la fratrie : eût-t-il fréquenté le lycée impérial de Sens, ville située à $30 \mathrm{~km}$ au nord de Joigny, qu'il aurait été condisciple d'un autre Icaunais qui lui fut strictement contemporain, devenu égyptologue, que Bourgoin eut l'occasion de côtoyer et avec qui il travailla à partir de 1881 au Caire, à savoir Eugène Lefébure (1838-1908), né à Prunoy, qui prit la suite de Gaston Maspero à la tête de l'École française du Caire. De même que nous n'avons découvert aucune trace d'un quelconque lien entre les deux adolescents 
dans l'Yonne, de même rien ne nous est parvenu sur le type de relations nouées au Caire.

La première mention trouvée de Jules Bourgoin est celle d'élève à l'École impériale des beaux-arts de Paris, dans l'atelier de Simon-Claude Constant-Dufeux entre novembre 1859 et octobre $1860^{12}$. Enregistré sous le numéro 1437, il entra à l'École le même jour que le Britannique Richard Phené Spiers (1838-1916) dans l'atelier de Charles-Auguste Questel, qui eut l'occasion de voyager en Égypte en 1865-1866, au même moment que Jules Bourgoin, et qui se fit un nom parmi les artistes orientalistes britanniques. Si le passage de Bourgoin aux Beaux-Arts peut être qualifié de sans éclat, il n'en sortit pas moins architecte: il est mentionné comme tel à l'adresse du 18 rue Notre-DameMontmartre à Paris dans l'Annuaire des artistes et des amateurs publié en 1861. Rien n'est connu de son activité avant 1863, date à laquelle il obtint une mission du ministère des Affaires étrangères qui le chargeait de la surveillance de travaux effectués à la Maison consulaire d'Alexandrie.

\section{En Égypte dans les années 1863-1866 : pour une généalogie graphique des arts arabes}

9 Il s'agit là du premier séjour de Bourgoin en Égypte, qui aurait duré trois ans, jusqu'en 1866. Bourgoin s'intitule « architecte du gouvernement français en Égypte » et la page de garde d'un de ses nombreux carnets de croquis conservés à la bibliothèque de l'Institut national d'histoire de l'art ${ }^{13}$, porte, très effacée, la mention manuscrite « Appart à Bourgoin architecte à Alexandrie Sa mère habite Joigny ». Si rien n'est su de son intervention au Consulat, ce premier séjour à Alexandrie est documenté par au moins trois carnets de croquis dont certains des feuillets serviront à l'élaboration des 26 planches des Arts arabes consacrées à l'architecture et à la décoration d'édifices d'Alexandrie comme de Basse-Égypte (Rosette, Damanhur, Mansurah, Damiette). Parce qu'il passa dans cette région plus de temps que la plupart des voyageurs-dessinateurs ou photographes du XIX ${ }^{e}$ siècle, pressés, aussitôt débarqués et les formalités accomplies, de rejoindre Le Caire, Jules Bourgoin laissa davantage de témoignages de cette partie de l'Égypte. Par leurs sujets, certains de ses croquis - façades de cafés, portes en bois aux ingénieux systèmes de fermetures, treillis de bois et moucharabiehs, " découpures » de maisons ou encore ornements de proues de dahabiyya, mais aussi structures d'habitations de Rosette, façades de mosquées aux parements de briques émaillées s'inscrivent dans la continuité de ceux déjà rassemblés par les dessinateurs des planches de la Description de l'Égypte ${ }^{14}$, par Pascal-Xavier Coste mais aussi des daguerréotypes de Joseph-Philibert Girault de Prangey (1804-1892) ${ }^{15}$.

10 Attrait de la nouveauté ? Bourgoin sacrifiait au pittoresque en portant son regard sur autre chose que l'architecture et l'ornement: on trouve en effet dans ces carnets quelques croquis de petits métiers (dans la tradition de Pascal-Xavier Coste), de rares portraits de personnages rencontrés ou de scènes de genre, quelques petits paysages ou encore une fleur de datura. Cet intérêt disparaît assez vite: aucun des carnets consacrés à la ville du Caire n'offre plus de notation ou dessin anecdotiques.

11 Parce que de ce premier séjour en Égypte est issu l'ouvrage Les Arts arabes, les carnets qui ont servi de support à la publication ne peuvent qu'être antérieurs à 1866-1867. Certains autres que l'on a pu croire contemporains sont, quant à eux, à rattacher à un 
second voyage effectué dans les années 1870 : ainsi, un des carnets ${ }^{16}$ qui fait voir au folio 46914 un dessin des deux statues de calcaire peint figurant le prince Rahotep et son épouse Nefret, découvertes dans un mastaba de Meidum durant l'hiver 1871 par Auguste Mariette, est forcément plus récent.

Les deux principales difficultés que révèle l'étude de l'œuvre dessiné de Jules Bourgoin est la presque totale absence de mentions chronologiques, et la rareté, voire leur inexactitude quand elles se rencontrent, des notations toponymiques: ainsi, d'une mosquée du XIV siècle, située près de l"Abbasiyya, qu'il qualifiait de chef-d'œuvre et au décor de laquelle il accorda sept des planches couleur des Arts arabes, mais dont il ne jugea pas nécessaire de préciser le nom.

13 Aucune trace de date n'apparaît dans les carnets des années 1863-1866. Si ceux d'Alexandrie et de Basse-Égypte sont les plus anciens, les carnets correspondant au premier séjour cairote ne livrent pas une seule information, ni sur les circonstances du séjour, ni sur le temps passé sur place, ni sur les lieux de résidence de Bourgoin, ou bien encore sur les personnes qu'il fréquentait. Il n'est pas un moment où des Français, architectes, ingénieurs, archéologues, historiens, photographes, ne se trouvaient au Caire. Auguste Mariette (1821-1881) y travaillait à ces dates, de même qu'Emmanuel de Rougé (1811-1872), mais Bourgoin n'était aucunement lié au milieu des égyptologues et à leur sociabilité culturelle, du moins à cette époque. Le long séjour d'Émile Constant Prisse d'Avennes (1807-1879), au cours duquel il rassembla une documentation considérable sur l'art arabe du Caire, s'était achevé au début de l'été $1860^{17}$. Contrairement à la seconde période cairote, en 1880-1884, pendant laquelle Bourgoin fut missionné dans un cadre très défini et dont il résulta la parution du Précis de l'art arabe et Matériaux pour servir à la théorie et à la technique des arts de l'Orient Musulman ${ }^{18}$, il découvrit librement la ville durant ce premier séjour fondateur. 1863 est l'année de l'avènement d'Ismaïl Pacha qui s'attacha à un projet global de développement de la ville, selon un modèle occidental et haussmannien. Dès lors, les journaux et lettres d'Occidentaux résidant au Caire sont remplis d'une nostalgie de la ville ancienne qui disparaît. À cette date, Lucie Duff Gordon rapportait dans ses lettres que :

«les jours de la beauté du Caire sont comptés; les superbes mosquées tombent pièce à pièce ; les fenêtres en treillage pourrissent, et elles sont remplacées par des vitres européennes et par des jalousies » ou encore que :

« le vieux quartier copte est entamé, et d'affreuses maisons françaises, mesquines comme celle que j'habite, se fabriquent instantanément $»^{19}$.

Par son travail, Jules Bourgoin aurait pu combler la Britannique qui aspirait à conserver le souvenir de la ville, écrivant que :

«si j'en avais le moyen, je ferais faire un dessin d'une vieille mosquée que j'aime passionnément et qui tombe en ruine ; [...] À vrai dire je pourrais faire faire un livre entier, car tout est exquis, mais, hélas! Tout s'en va $»^{20}$.

Il arpentait Le Caire, muni de carnets oblongs à la couverture de toile bise, et, comme le Hessois Friedrich Maximilian Hessemer quelque 35 ans auparavant, du plan de la ville accompagnant la Description abrégée de la ville et de la citadelle du Kaire par M. Jomard dans la Description de l'Égypte. État moderne, tome second, II partie, toujours le seul plan complet alors disponible. Quelques feuillets des carnets de Bourgoin, ainsi que certains dessins des années 1880-1884, conservent, dans la graphie adoptée pour les toponymes, la trace du recours aux index accompagnant ce plan; se voit également le report sur la 
feuille des numéros utilisés dans l'index du plan de la ville pour renvoyer à l'indication de la section sur l'emplacement de laquelle les lieux sont situés et les chiffres gravés : par exemple VIII-236 N-6 pour la bayt Khalil pacha. De même, Bourgoin avait connaissance de l'ouvrage d'Hessemer, Arabische und alt-italienische Bau-Verzierungen, publié à Berlin en 1842, dont 60 des 120 planches en couleurs illustraient les ornements de l'Égypte islamique ${ }^{21}$ : non seulement deux planches d'une édition inconnue de cet ouvrage se trouvent dans les papiers du fonds Bourgoin à la bibliothèque de l'INHA, mais encore deux légendes en allemand ont été copiées directement de l'ouvrage d'Hessemer pour être portées sur des feuillets d'un des carnets.

L'examen des carnets de dessins des années 1863-1866 déconcerte : rien ne permet de restituer une logique d'itinéraires dans la ville ou d'expliquer le choix des monuments. En outre, parce que la plupart des pages sont couvertes de détails décontextualisés, il apparaît impossible d'estimer le nombre d'édifices que Bourgoin a pu voir, encore moins ceux dans lesquels il a pu pénétrer ou ceux dont l'accès lui a été impossible. Pour quelques élévations extérieures, le plus souvent des façades (fig. 2), combien de croquis d'éléments architectoniques, de parements mosaïqués, ciselés, incrustés, enduits, de pièces de menuiserie travaillées ou tournées, qui, déjà, inauguraient dans l'œuvre de Bourgoin, cette passion pour la combinaison et l'agencement des formes qu'il cherchait à déconstruire pour mieux les comprendre. Il regardait tous les types d'édifices, tant religieux que profanes : mosquées et madrasas bien sûr, des incontournables aux moins connues, mosquées funéraires ou tombeaux à l'extérieur de la ville, mais aussi les sabil ou fontaines publiques dont il se plaisait à dessiner les grilles structurées ou les salsabil, les écoles coraniques, les demeures et les boutiques aux plafonds richement ornés.

2. [Porche de l'okel de Qaytbay dans le quartier d'al-Azhar], dessin.

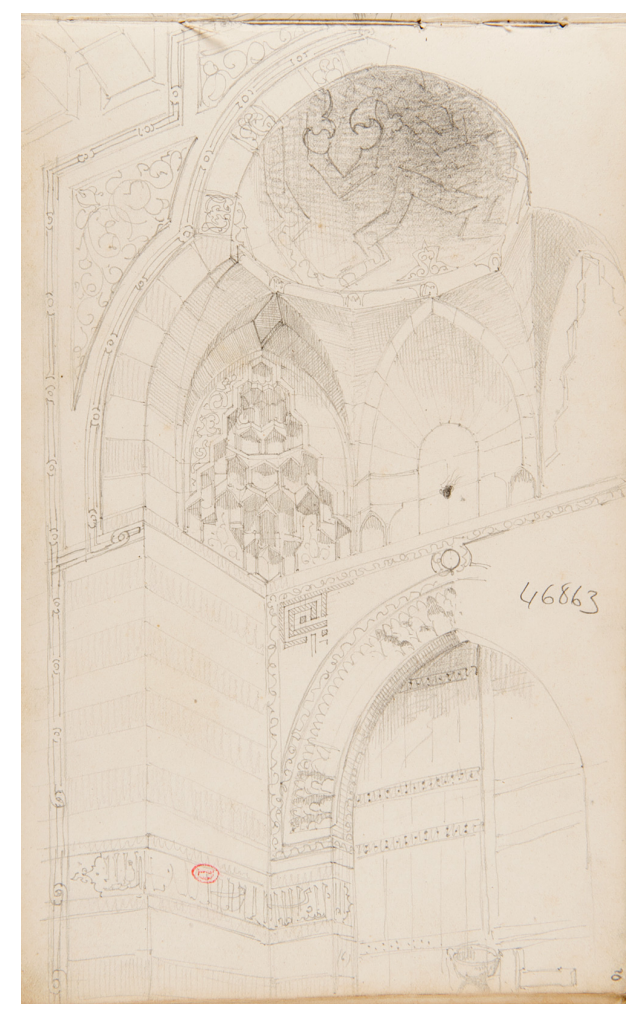

Source: Paris (France), bibliothèque de l'INHA-collections Jacques Doucet, archives 67. 
Une partie du matériel rassemblé au cours de ces trois années servit à la rédaction et à l'illustration des Arts arabes, ouvrage publié en 40 livraisons, à partir de 1867, par l'éditeur parisien A. Morel ${ }^{22}$. Il ne s'agit pas seulement, comme le note Eugène Violletle-Duc dans sa préface :

«... [d']un de ces recueils de gravures agréables à parcourir, qui garnissent les bibliothèques des architectes et des décorateurs, mais que l'on ne consulte guère ; c'est un traité pratique et complet qui découvre tout un ordre nouveau de composition. Si intéressants que soient les exemples recueillis par M. Bourgoin, ils ne sont que la partie la moins importante de l'ouvrage ».

19 Si aux yeux de l'auteur et du préfacier, la partie la plus intéressante, parce que déductive, interprétative et novatrice, est celle intitulée "Le trait de l'art arabe», ce sont, malgré tout, les planches lithographiées qui nous renseignent sur l'appréhension que Bourgoin eût du Caire médiéval et moderne. Ce qui frappe, au premier abord, c'est la représentation des monuments et éléments architectoniques ou décoratifs restitués dans leur état originel, sans aucune trace de ces blessures infligées par le temps et la négligence dont témoignent écrits et photographies. Ainsi, mais les exemples abondent, de la planche X légendée Fontaine de la mosquée Gismah au Caire (fig. 3) dont deux feuillets qui ont servi d'études préparatoires (fig. 4-5) existent dans un des carnets de dessins de la bibliothèque de l'INHA, à Paris ${ }^{23}$. Si la mise en place des différents éléments permet de reconstituer une image d'ensemble de la façade, manquent toutefois les mentions de matériaux, de couleurs qui ont permis à l'artiste cette restitution et l'on peut s'interroger sur la méthode de Bourgoin; avait-il rempli des carnets de notes aujourd'hui perdus, listant les édifices visités avec plus de précisions ? D'autre part, cette planche révèle cette volonté de restitution d'un état idéal; l'authenticité n'est pas la préoccupation de Bourgoin totalement absorbé dans sa démonstration. Ne se protège-t-il pas dans l'avant-propos de sa Désignation et explication des planches des Arts arabes lorsqu'il écrit :

«... [qu'il ne se préoccupe] ni des dates, ni des contestations que pourraient soulever les archéologues. Nous faisons avant tout un livre d'études et nous tenons à lui conserver ce caractère très exclusif ${ }^{24} »$ ? 
3. [Sabil de la madrasa Umm al-sultan Sha'ban], dessin.

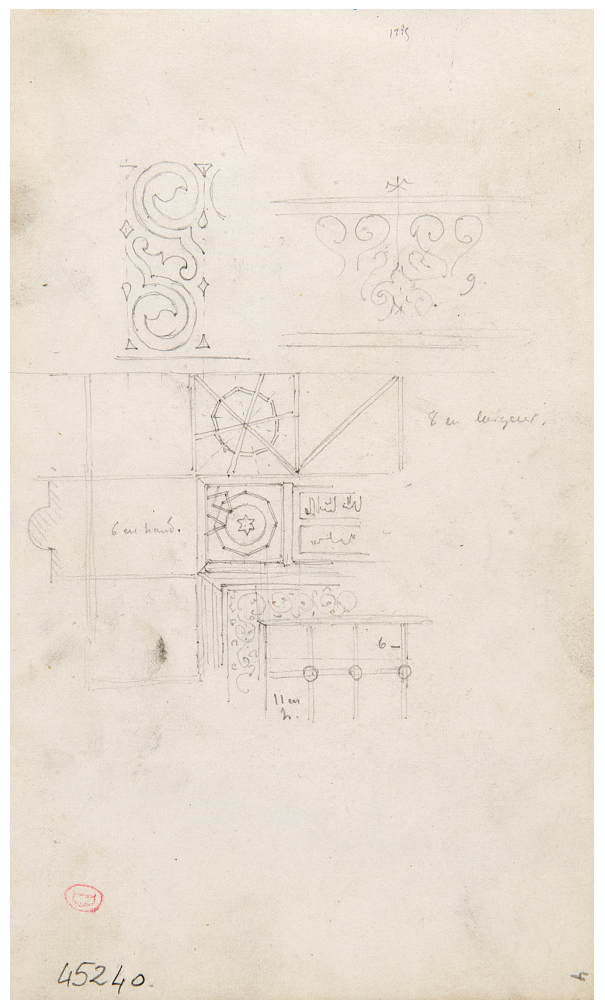

Source : Paris (France), bibliothèque de I'INHA-collections Jacques Doucet, archives 67.

4. [Détail du treillis du sabil de la madrasa Umm al-sultan Sha'ban], dessin.

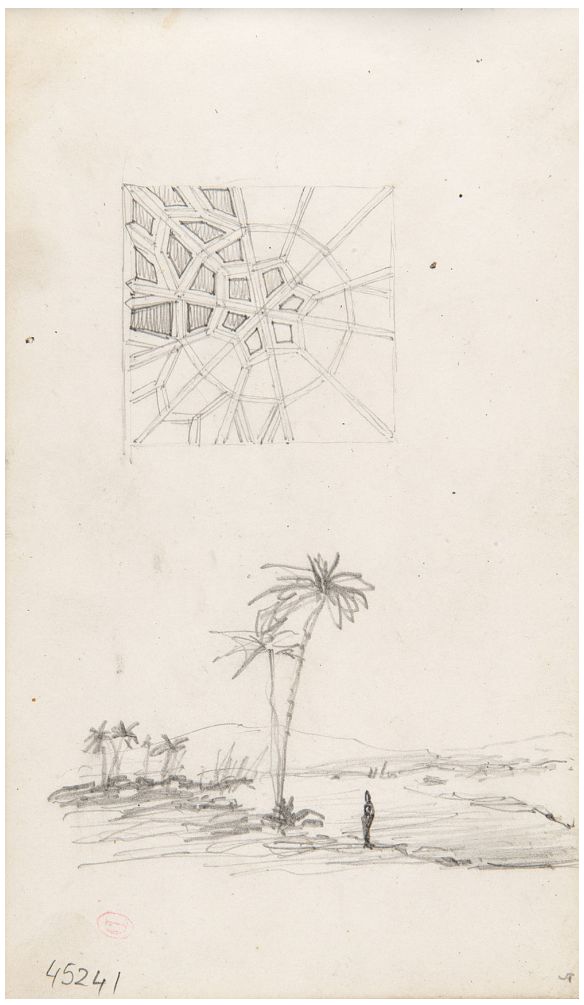

Source: Paris (France), bibliothèque de l'INHA-collections Jacques Doucet, archives 67. 
5. Fontaine de la mosquée Gismah [madrasa Umm al-sultan Sha'ban] au Caire, lithographie.

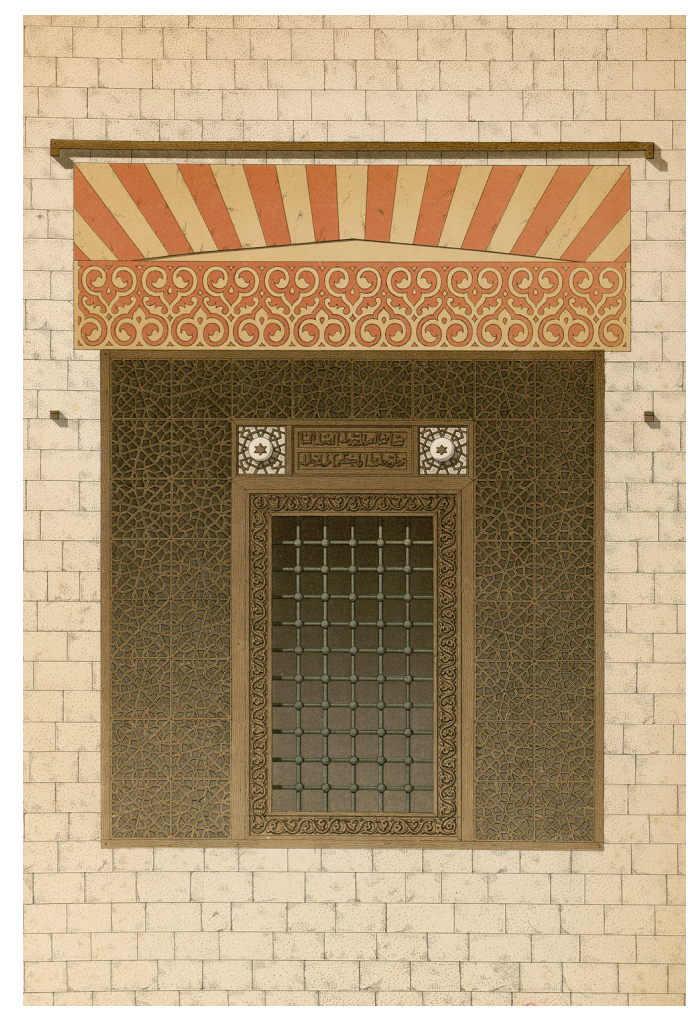

Source : Planche 10 des Arts arabes.

20

Cette fontaine, qui est celle de la madrasa Umm al-sultan Sha'ban, n'était pas, au début des années 1860, dans un état de conservation parfait: en témoigne un cliché pris de cette même façade par le jeune photographe Édouard Athanase Jarrot (1835-1873) ${ }^{25}$ en 1858, au cours de la mission Prisse d'Avennes. Il est tout à fait visible que le treillis de bois a déjà disparu dans sa partie basse et qu'il a été remplacé par des moellons.

21 Avec la parution des Arts arabes s'achève une période de l'activité de Jules Bourgoin. À l'exception de la mission obtenue en 1874 pour Damas, séjour dont il revint aussi avec un grand nombre de dessins et d'aquarelles demeurés quasiment inédits car le projet d'ouvrage qui devait en découler n'avait pu trouver de financement, Bourgoin n'obtint plus de missions importantes. La moisson de dessins faite en Égypte, mais aussi en Palestine, puis en Italie du Sud ${ }^{26}$ et en Grèce en 1868-1869, constitua l'humus de deux autres de ses publications, davantage théoriques et s'inscrivant dans un système de pensée que Bourgoin développa durant ces années, une Théorie de l'ornement (Paris, 1873) et Les éléments de l'art arabe, le trait des entrelacs (Paris, 1879). Il fallut attendre l'année 1880 pour que Jules Bourgoin soit chargé d'une nouvelle mission en Égypte.

\section{Les années 1880-1884 et le Précis de l'art arabe}

Gabriel Charmes soulignait que: «...quand Le Caire n'existera plus, ses cartons pourront le faire revivre ${ }^{27}$. Pendant cet ultime séjour en Égypte, et pas seulement au Caire, séjour émaillé d'allers-retours en France et d'un départ précipité le 21 juin 1882, le dessinateur fut investi de plusieurs missions. C'est l'exactitude scrupuleuse et artistiquement accomplie de son dessin qui le rendait indispensable. D'ailleurs, la 
première tâche qui lui fut confiée en 1880 par le ministère de l'Instruction publique fut d'aller en Égypte avec Georges Bénédite (1857-1926), alors dessinateur sorti de l'École des beaux-arts et futur égyptologue, "étudier les sculptures et peintures des monuments antiques au double point de vue de l'enseignement du dessin et de la formation du musée des moulages au Trocadéro ${ }^{28}$. Son talent fut également mis à profit par l'archéologue Gaston Maspero (1846-1916), avec lequel il travaillait, au sein de l'École française du Caire nouvellement créée - il en fut, un temps, nommé sousdirecteur -, au relevé de plusieurs tombeaux thébains, mais aussi à l'introduction de l'arabisant Hippolyte Dulac aux éléments de l'archéologie arabe et à la formation au dessin et au levé de plans de tous les autres membres et élèves de la Mission, ainsi que par Georges Perrot (1832-1914) et Charles Chipiez (1835-1901) pour l'illustration de leur monumentale Histoire de l'art dans l'Antiquité, et plus particulièrement du tome I consacré à l'Égypte, publié en 1882.

De retour au Caire, Jules Bourgoin entreprit et réalisa un travail d'inventaire dessiné de la ville qui force l'admiration. Lui dont Xavier Charmes, alors chef du secrétariat au ministère de l'Instruction publique, écrivait, en 1881, que si on « le laisse maître de ses actes, juge du travail qu'il peut ou doit faire, il manque de décision et flotte entre plusieurs idées sans savoir choisir $»^{29}$, se trouvait davantage cadré, stimulé par les activités du Comité de conservation des monuments de l'art arabe, créé le 18 décembre $1881^{30}$, dont il fut nommé membre et chargé de la surveillance des dessins et des plans.

On en sait un tout petit peu plus sur la sociabilité culturelle dans laquelle Bourgoin s'inscrivait lors de ce séjour cairote. Il semble qu'il fréquentait un groupe d'amis qui n'avait pas l'heur de plaire à Maspero. En tout cas, les mentions du dessinateur, appelé à des tâches variées - copies, relevés et estampages de monuments de l'Égypte ancienne, dessins du patrimoine monumental de la ville du Caire médiévale et moderne, dessins d'œuvres d'art anciennes conservées dans le musée créé à Boulac ou des pièces d'art musulman déposées dans la mosquée désaffectée d'al-Hakim, dessins d'après les plus beaux manuscrits enluminés de la Bibliothèque khédiviale alors à Darb al-Gamamiz - sont plus nombreuses dans les correspondances tant privées qu'administratives. Si les opinions et jugements sur le personnage sont très divergents, l'unanimité se fait sur ses qualités de dessinateur.

Bourgoin allait, toujours selon Gabriel Charmes «se consacrer à l'étude et à la reproduction minutieuse des trésors antiques du Caire. Il a déjà amassé dans ses cartons de quoi composer plusieurs ouvrages dont l'intérêt sera considérable ${ }^{31}$. Depuis son séjour à Damas en 1874-1875, le dessinateur avait substitué aux carnets des feuilles libres de papier satiné, aujourd'hui fortement jauni, de format $21,9 \times 16,6 \mathrm{~cm}$, mais travaillait toujours à la mine de plomb; au vu de certaines feuilles (fig. 6), on ne peut qu'admirer sa maîtrise de la page, tant le nombre et la variété des dessins y sont grands, tant la souplesse de la main est exceptionnelle. La sûreté du trait s'est considérablement affirmée par rapport aux dessins des années 1863-1866; le dessinateur a atteint une forme de perfection, sachant rendre toutes les finesses $\mathrm{du}$ modelé, mais aussi la vérité de la perspective. Il a aussi développé une sorte de "sténographie » du dessin, expérimentée antérieurement, consistant en un système minutieux de relevé et de notation destiné à désigner tantôt un système de proportions, tantôt un agencement ou jeu des pièces de l'élément dessiné. Ce système est particulièrement efficace dans le relevé de façades très ornées, comme celle de l'okel de Qaytbay au quartier al-Azhar (fig. 7), à la préservation duquel le Comité de 
conservation des monuments de l'art arabe avait énergiquement contribué, ou encore dans celui des moucharabiehs aux assemblages complexes de panneaux de bois aux variantes infinies et à la fragilité extrême, et permet aussi de faire suivre sur une autre feuille les dessins de certains éléments. Le procédé était risqué en cas de bouleversement de l'ordre des feuilles qui ne sont pas numérotées; d'ailleurs, un examen du corpus graphique, qui a connu diverses vicissitudes, oblige à constater que certains relevés demeurent orphelins à jamais ${ }^{32}$.

6. [Portail à la façade ouest de la mosquée de Baybars], dessin.

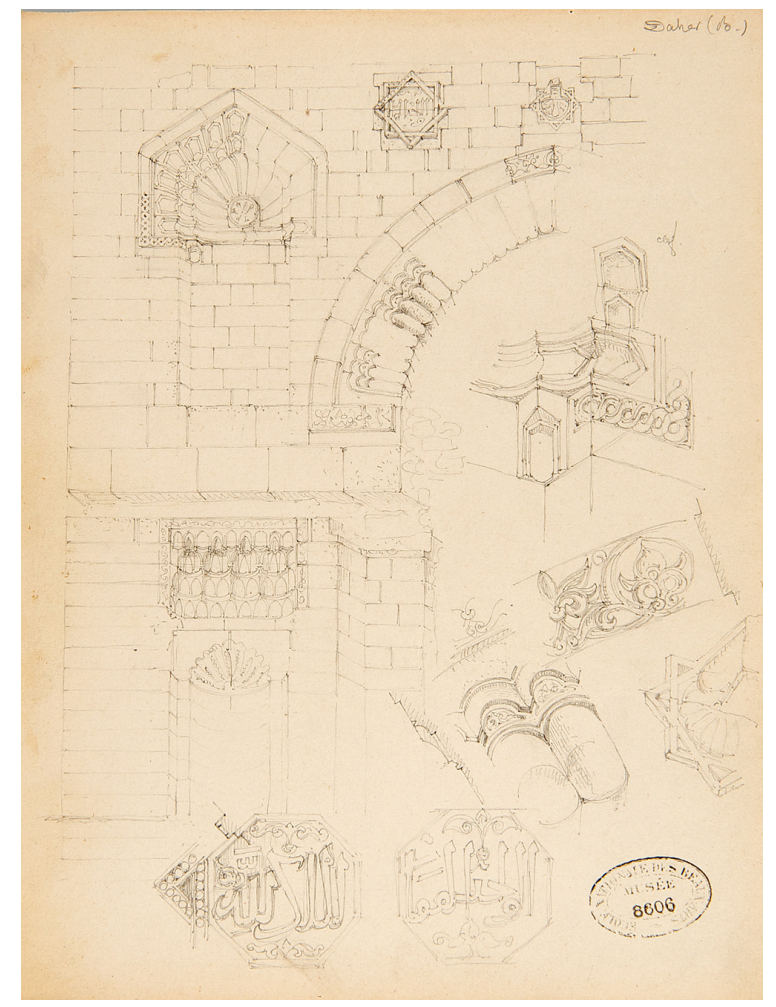

Source: Paris (France), ENSBA, EBA : (7900-0342). 
7. [Ornements de la façade de l'okel de Qaytbay à Bab al-Nasr], dessin.

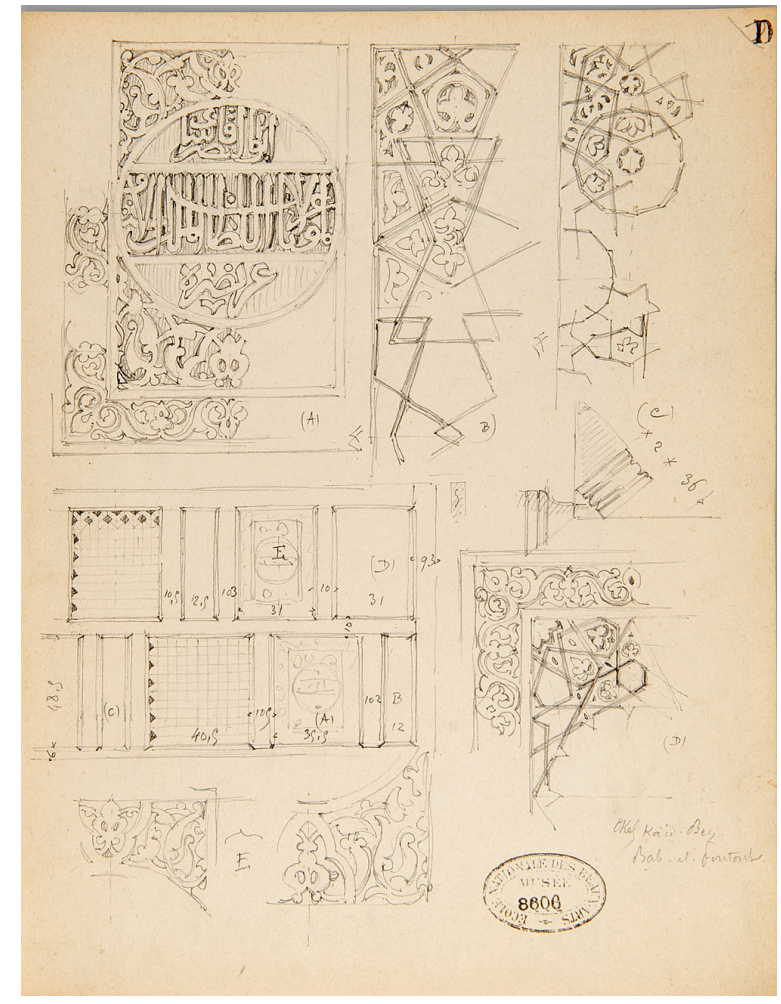

Source: Paris (France), ENSBA, EBA : (7900-0052).

Le récolement virtuel du corpus graphique relatif au Caire n'étant pas encore achevé, il n'est pas encore possible d'évaluer le nombre d'édifices que Bourgoin a dessinés entre 1880 et 1884. Bien davantage qu'en 1863-1866 c'est certain, parfois les mêmes mais rendus de façon bien plus fouillée, d'autres nouveaux, moins connus mais toujours très ornés à l'extérieur ou à l'intérieur, comme la mosquée Hayatim (aujourd'hui mosquée Yusuf Shurbagi) d'époque ottomane, ou la qubba d'al-Fadawiyya à 'Abbasiyya (fig. 8), d'époque mamelouke, qu'il identifiait incorrectement comme Ashraf. Ces inexactitudes lui furent d'ailleurs reprochées par Arthur Rhoné, qui, après lecture des épreuves du Précis de l'art arabe en 1892, lui demanda un certain nombre de précisions ou de modifications. Ainsi, à propos d'une mosquée El-Tirany dont il demandait où elle se situait et s'il ne pouvait s'agir d'une certaine mosquée Â̂-Timoury alors qu'il s'agit en réalité du mausolée d'Azrumuk (ou encore tombeau de Mohamed el-Korâni) : Bourgoin avait apposé le toponyme Kyrani sur des dessins correspondant à des mausolées différents. Il s'agit là d'une des difficultés majeures de l'identification des nombreux dessins du Caire par Bourgoin: sa méconnaissance de la langue arabe jointe à son inconsistance dans le légendage rend la tâche ardue. Ce corpus des années 1880-1884 intègre quelques rares vues d'ensemble comme le dessin de l'intérieur de la khanqah Farag ibn Barquq (fig.9), un certain nombre d'élévations des minarets si caractéristiques du Caire (sans atteindre le nombre des 38 minarets que Girault de Prangey avait photographiés en 1842-1844), de dômes aux décors variés, un grand nombre de relevés de moucharabiehs dont la finesse et l'inventivité du travail du bois ne laissent d'impressionner l'artiste (fig. 10). Il s'intéressa aussi aux palais qui, moins bien protégés parce que demeurés en mains privées, disparaissaient très vite : ainsi 
dessina-t-il les intérieurs de la maison du Cadi ou encore les exceptionnels décors d'une maison du quartier copte (Qasr rumi).

\section{Qubba d'al-Fadawiyya, dessin.}

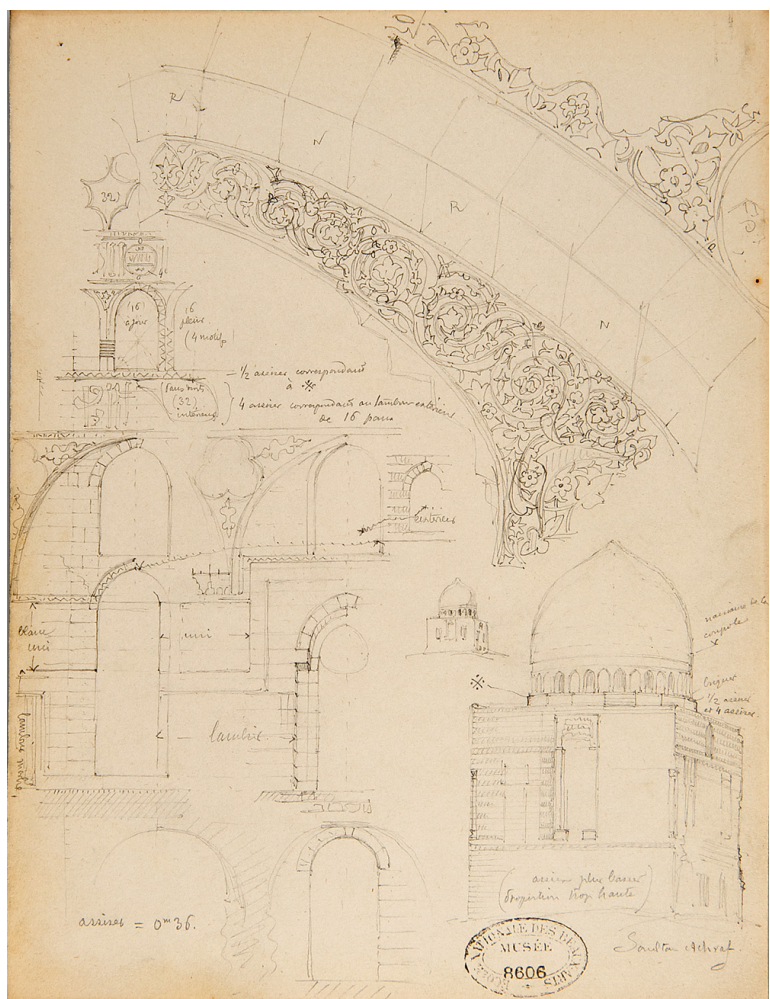

Source : Paris (France), ENSBA, EBA : (7900-0289). 
9. [Intérieur de la khanqah Farag ibn Barquq], dessin.

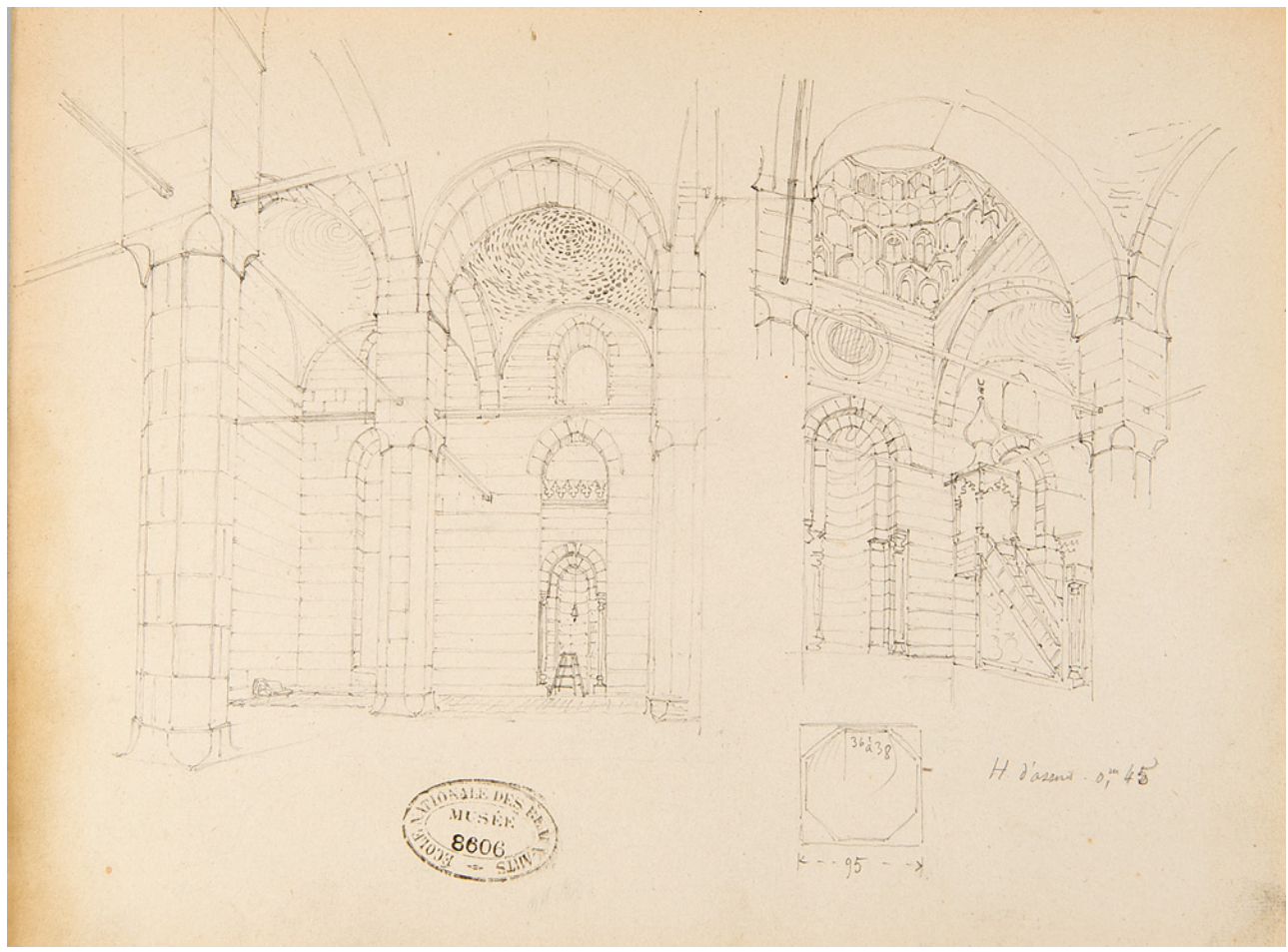

Source: Paris (France), ENSBA, EBA : (7900-0375).

10. [Façade avec moucharabiehs], dessin.

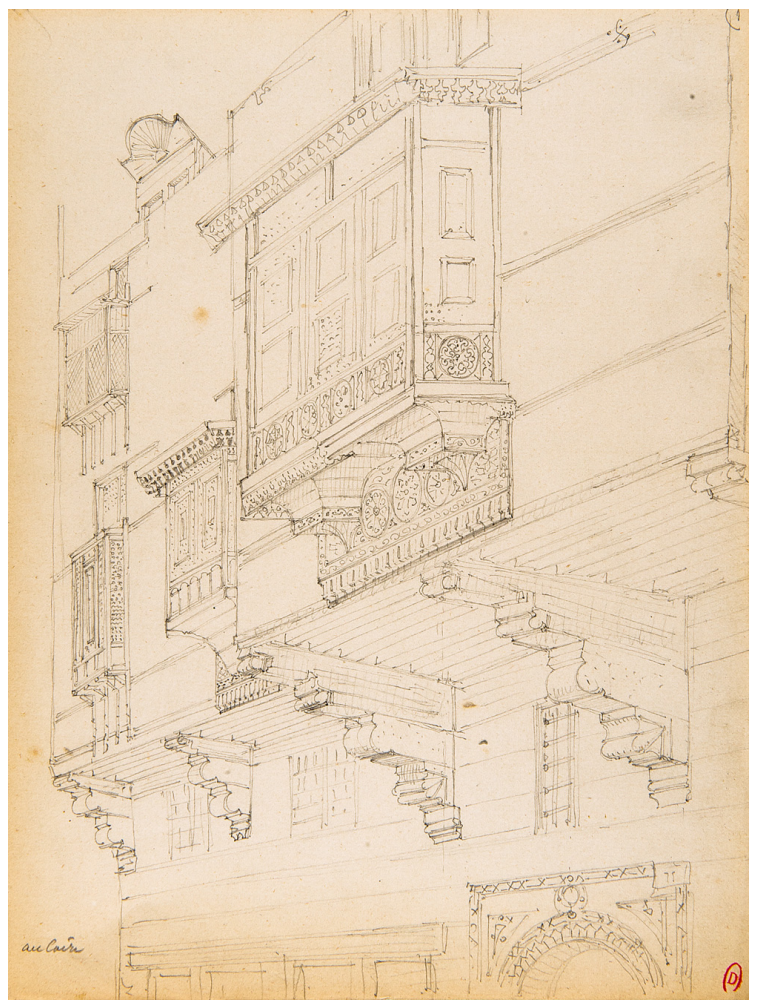

Source : Paris (France), bibliothèque de I'INHA-collections Jacques Doucet, archives 67. 
Les dessins de Bourgoin viennent en écho des remarques de Rhoné dans L'Égypte à petites journées. Études et souvenirs. Le Kaire et ses environs, en 1877, lorsqu'il écrivait à propos d'une porte d'une ancienne maison arabe :

«Les arabesques se mêlent, se quittent, font mille façons autour de rosaces d'un dessin varié ; puis elles se rejoignent pour courir en apparence à l'aventure de nouvelles fantaisies, tandis qu'en réalité elles savent fort bien où elles vont, et ne forment que des combinaisons très positives et très mathématiques... On fixe attentivement un point difficile; mais tout à côté, se trouve un ornement qui sourit: il attire l'œil, trompe la main, tout est à refaire! Et les arabesques de scintiller, de se tordre, de s'échapper de plus belle... ». Mais jamais le crayon de l'artiste ne se lasse.

Si l'entrelacs fut le sujet central des Arts arabes, les muqarnas et stalactites furent le fondement du Précis de l'art arabe : 44 des planches y sont consacrées mais bien d'autres proposent également, pour les minarets, les portails, les coupoles, les crosses, les minbars, les mirhabs, etc. des vues perspectives, des projections et des plans de ces structures complexes caractéristiques (conques, voussures, encorbellements, trompes et écoinçons) (fig. 11). Là se retrouvent non seulement le goût qu'avait Bourgoin des mathématiques, sa volonté de démontrer en offrant des épures et constructions de formes mais aussi sa perfection du rendu graphique.

11. [Porche de la mosquée d'Aslam al-Silahdar], dessin.

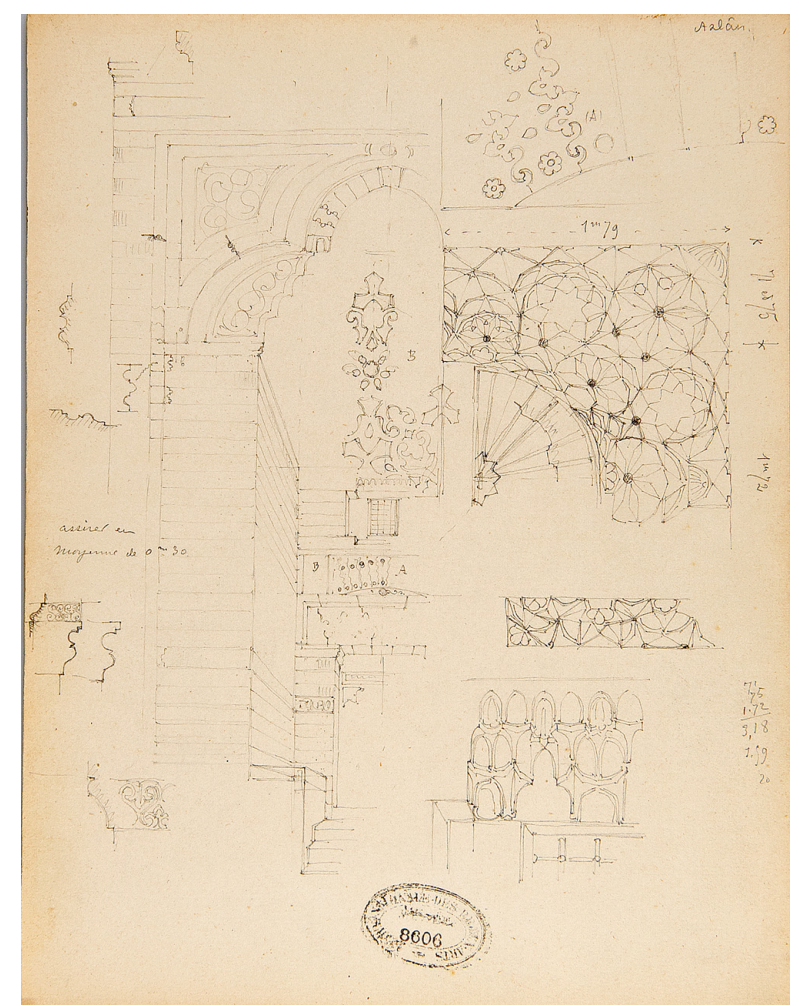

Source : Paris (France), ENSBA, EBA : (7900-0302).

Le Précis de l'art arabe, ce « recueil un peu spécial, un peu technique... » selon les propres mots de Bourgoin, devait être un ouvrage très ambitieux en nombre de planches et en pages de texte. Le coût de réalisation de l'ouvrage contraignit l'auteur à dessiner luimême au trait, sur du papier porcelaine, les planches du Précis, avec, toutefois, l'aide 
d'un jeune dessinateur autrichien qui avait fréquenté l'École des beaux-arts à Paris ${ }^{33}$; finalement il n'y aura que 7 planches couleur alors que l'auteur en avait prévu davantage (fig. 12-13), bien moins que dans les Arts arabes qui en offraient 51. Une partie de texte avec vignettes qui était prévue fut abandonnée. Il n'en demeure pas moins que cet ensemble constitue un recueil inégalé documentant le patrimoine artistique du Caire, d'une manière toute différente de celle de Prisse d'Avennes dans L'Art arabe d'après les monuments du Kaire depuis le VII siècle jusqu'à la fin du XVIII publié entre 1869 et 1877.

12. [Divers ornements dont un pavement en marqueterie de marbre], dessin.

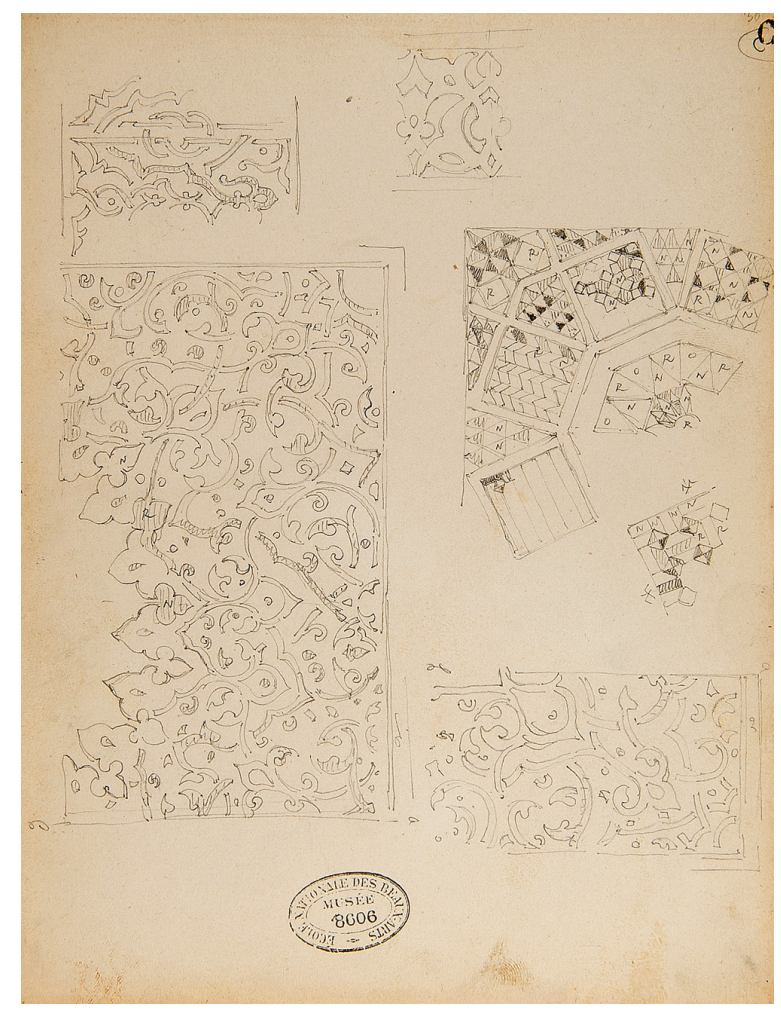

Source : Paris (France), ENSBA, EBA : (7900-0233). 
13. Pavements en marqueterie de marbre, dessin et aquarelle, dessin préparatoire à la pl. 55 des Applications dans le Précis de l'art arabe.

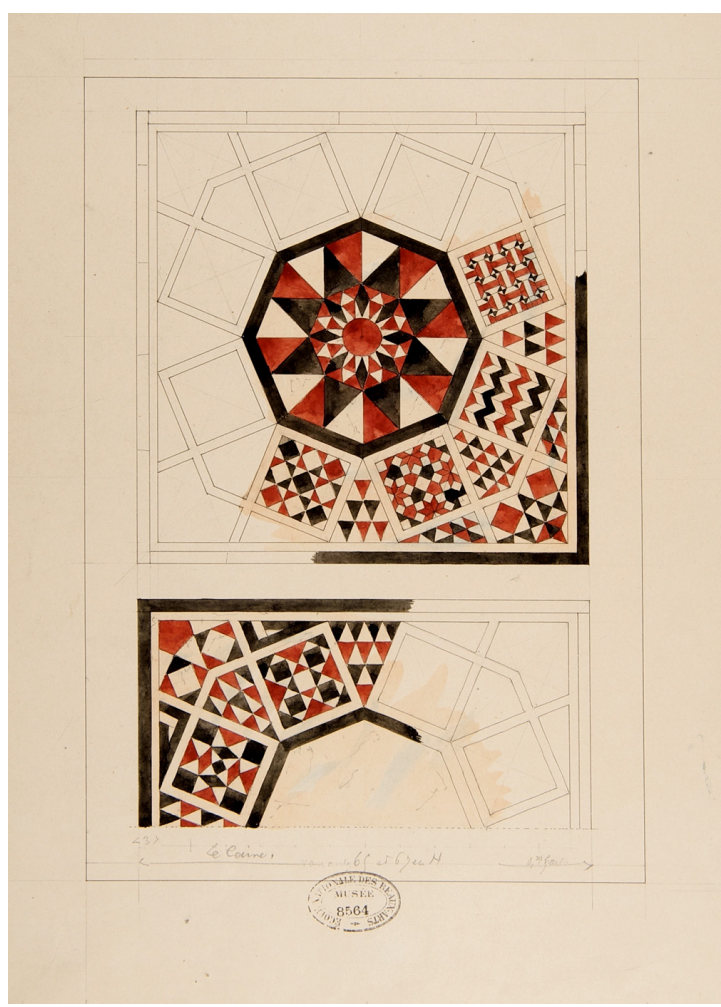

Source: Paris (France), ENSBA, EBA : (7901-0294). matériaux instruits à fond » et la démarche est à mettre en perspective des activités du Comité de conservation des monuments de l'art arabe. La place de Jules Bourgoin était toute désignée au sein de ce comité et son travail ne peut qu'être approché à la lumière des activités d'étude, de préservation ou de restauration du patrimoine monumental cairote. Bourgoin est un de ces serviteurs du patrimoine.

Toutefois, on ne peut manquer de se poser la question de la place de cet œuvre dessiné par rapport à une documentation photographique.

Bourgoin quitta Le Caire en 1884 avec ses dessins (tous ?). Dès lors, le Comité fait appel à la photographie pour garder mémoire des édifices qui disparaissent ou qui appellent à la restauration, en passant commande de campagnes de prises de vues - il est de nombreux ateliers actifs au Caire au cours du troisième quart du XIX ${ }^{e}$ siècle - et en faisant l'acquisition de fonds plus anciens. Si le procédé avait été, dès son invention, vanté par John Ruskin qui y voyait un moyen de susciter, et de satisfaire, un désir de proximité avec l'élément architectural ou sculpté, ce que l'érudit Joseph-Philibert Girault de Prangey, qui avait exercé un regard exceptionnel sur l'architecture, avait compris et réalisé dans ses daguerréotypes du Caire (chapiteaux, claires-voies de baies, détails des dômes des mosquées ou tombeaux, claustras de bois...), la photographie a, le plus souvent, été utilisée pour produire des panoramas, des vues pittoresques du Caire, ce à quoi Bourgoin n'avait pas sacrifié. Peut-on parler d'une complémentarité consciente? Nous l'avons dit plus haut, Bourgoin, dans ses publications, restitue un idéal du monument ou de ses parties; dans ses dessins sur le motif, il ne se préoccupe pas vraiment de noter les manques, les cassures ou épaufrures; la photographie le fait, 
mais trop souvent ne s'intéresse pas suffisamment aux détails, sauf dans le cas de commandes précises.

Même si Gabriel Charmes déplore que :

«ce qui manquera aux dessins de M. Bourgoin, ce sont les nombreuses inscriptions et les innombrables graffiti qui couvrent les murs croulants du Caire. Il y a peutêtre là pour la langue, les arts, les croyances, les mœurs, les légendes et l'histoire arabes les plus précieux documents, qui bientôt ne seront plus ${ }^{34}$."

L'œuvre dessiné de Bourgoin offre non seulement une approche totalement renouvelée des arts arabes mais a pu aussi venir combler, chez Arthur Rhoné, la part de lui-même qui s'en allait constatant la disparition de la ville ancienne du Caire.

\section{NOTES}

1. Mercedes volait, «Dans la fabrique de la connaissance: Jules Bourgoin (1838-1908), un autodidacte au travail ", in Mercedes volAit, Fous du Caire. Excentriques, architectes et amateurs en Égypte 1867-1914, Forcalquier: L'Archange Minotaure, 2009, p. 154-179. Un premier survol de l'œuvre de Bourgoin avait été fait par Mercedes Volait dans la notice «Bourgoin, Jules » de l'Allgemeines Künstlerlexikon, Leipzig, 1996, vol. 13, p. 381 ; ID, «Bourgoin (ou Bourgoin-Esclavy) Jules (Joigny, Yonne, 1838 - Saint-Julien-du-Sault, Yonne, 1908), in François Pouillon (dir.), Dictionnaire des orientalistes de langue française, Paris: Karthala, 2008, p. 141. Une autre notice biographique, plus développée mais avec un grand nombre d'inexactitudes, a été rédigée par Florence сіссотто: Dictionnaire critique des historiens de l'art actifs en France de la Révolution à la Première Guerre mondiale. URL: http://www.inha.fr/fr/ressources/publications/publicationsnumeriques/dictionnaire-critique-des-historiens-de-l-art/bourgoin-jules.html. Consulté le 15 avril 2010.

2. Gabriel CHARMES, «Coup d'œil sur l'état du Caire ancien et moderne », in L'Égypte. Archéologie,

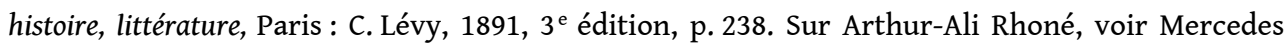
VolAIT, «Arthur-Ali Rhoné (1836-1910). Du Caire ancien au Vieux-Paris ou le patrimoine au prisme de l'érudition dilettante ", Socio-anthropologie, n 19, 2006, p.17-30. URL: https://socioanthropologie.revues.org/543. Consulté le 23 novembre 2015.

3. Gabriel CHARMES, op. cit. (note 2), p. 242.

4. Publié à Paris, chez Firmin-Didot en 1837. Sur Pascal-Xavier Coste, voir Dominique JACoBI (dir.), Pascal Coste, toutes les Égypte, catalogue d'exposition (Marseille, Bibliothèque municipale, 17 juin-30 septembre 1998), Marseille: Parenthèses ; Bibliothèque municipale de Marseille, 1998 : voir plus particulièrement la contribution de Mercedes volAIT, « Les monuments de l'architecture arabe ", p. 97-130. Les dessins et aquarelles préparatoires sont conservés à la Bibliothèque de Marseille à vocation régionale, L'Alcazar, ms 1306-ms 1311.

5. Le Catalogue annuel de la librairie française publié par C. Reinwald en 1868 (onzième année) annonce page 31 la parution, chez A. Morel, des livraisons 1 à 10 de l'ouvrage au prix de $5 \mathrm{fr}$. pour chaque livraison et précise que l'ouvrage sera publié en 40 livraisons, dont 5 paraitront ensemble tous les 2 ou 3 mois. L'édition rencontrée le plus souvent est celle publiée en 1873 chez Vve A. Morel et $\mathrm{C}^{\mathrm{ie}}$. 
6. Jules BOURGoIN, Les Arts arabes, architecture, menuiserie, bronzes, plafonds, revêtements, marbres, pavements, vitraux, avec un texte descriptif et explicatif et le trait général de l'art arabe, Paris: $\mathrm{V}^{\mathrm{ve}} \mathrm{A}$. Morel et $\mathrm{C}^{\mathrm{ie}}, 1873$, p. II.

7. La documentation d'Arthur-Ali Rhoné est conservée au Collège de France. Cette photographie a été publiée par Mercedes volaIT, op. cit. (note 1), p. 174, fig. 126.

8. Mercedes VOLAIT et Marie-Laure CROSNIER LECONTE, L'Égypte d'un architecte: Ambroise Baudry (1838-1906), Paris : Somogy, 1998.

9. Cette lettre, ainsi que les autres signées de Gabriel Charmes, de Gaston Maspero, d'Arthur-Ali Rhoné et d'Ambroise Baudry, citées dans l'article, ont été portées à notre connaissance par Mercedes Volait que nous remercions ici.

10. Cet inventaire après-décès a été dressé les 22,23 et 25 mai 1908 par l'étude de $\mathrm{M}^{\mathrm{e}} \mathrm{A}$. Grégoire, notaire à Saint-Julien-du-Sault, en vue de la vente mobilière organisée le 14 et le 21 juin "au domicile et après le décès de M. Jules Bourgoin, auteur du "Précis de l'Art arabe" ". Nous devons la découverte fortuite de ce document à des amateurs passionnés de Saint-Julien-du-Sault. Qu'ils soient ici remerciés très chaleureusement pour la mise au jour de ce document.

11. Paris (France), Bibliothèque de l'INHA - Collections Jacques Doucet, Fonds Jules Bourgoin, Archives 67, carton 5.

12. Paris (France), Archives nationales, Série AJ 52.

13. De cette période égyptienne, Jules Bourgoin a rapporté une dizaine de carnets, de formats variés, inégalement remplis, qui sont conservés à Paris, bibliothèque de l'INHA - Collections Jacques Doucet, Archives 67. Ces carnets faisaient partie de l'important fonds d'atelier trouvé au domicile de Jules Bourgoin à Saint-Julien-du-Sault en 1908 et qui fut mis en vente publique. Voir supra (note 10).

14. Voir en particulier dans le tome II de L'État moderne: la planche 93 Plans, coupes, élévations et détails de menuiserie d'une maison turque; la planche 96 Vue d'une rue conduisant au Port Vieux.

15. Voir ici Sylvie AUBENAS, «La redécouverte d'un précurseur: Joseph-Philibert Girault de Prangey (1804-1892) », p. 183-194. URL: http://inha.revues.org/4882. Consulté le 4 mai 2016.

16. Paris (France), Bibliothèque de l'INHA, Archives 67, carton 10.

17. Sur cette période de la carrière de Prisse d'Avennes, voir Visions d'Égypte. Émile Prisse d'Avennes (1807-1879), catalogue d'exposition (Paris, Bibliothèque nationale de France - Musée du Louvre, $1^{\mathrm{er}}$ mars-5 juin 2011), Paris : BnF, 2011, et plus particulièrement la contribution de Mercedes VolAIT, « “Avec le double empressement d'un artiste et d'un antiquaire". Les arts de l'Égypte médiévale vus par Émile Prisse d'Avennes ", p. 93-117.

18. Cet ouvrage a d'ailleurs paru comme tome septième des Mémoires publiés par les membres de la Mission archéologique française au Caire, alors publiés sous la direction d'Urbain Bouriant.

19. Lucie DUfF GORDON, Lettres d'Égypte, traduites par Mrs. Rosset $C^{\mathrm{ie}}$, Paris, J. Hetzel et $C^{\mathrm{ie}}, 1879$, p. 49 (lettre du 13 avril 1863), p. 51 (lettre du 21 mai 1863).

20. Ibid., p. 51.

21. Jürgen EICHENAUER et Clemens GREVE, (dirs.), Friedrich Maximilian Hessemer (1800-1860). Ein Frankfurter Baumeister in Ägypten, Frankfurt am Main : Waldemar Kramer, 2001 et ici p. 17-40.

22. Sur l'histoire de la maison d'édition Morel, voir Béatrice BOUvIER, L'édition d'architecture à Paris au XIX ${ }^{e}$ siècle. Les maisons Bance et Morel et la presse architecturale, Genève : Droz, 2004 (Histoire et civilisation du livre, 27), et plus particulièrement le chapitre II, «La librairie centrale d'architecture ou l'œuvre des Morel », p. 43-55.

23. Bibliothèque de l'INHA, Archives 67 , carton 11 , fol. non numérotés.

24. Jules BouRgoIn, Les Arts arabes..., op. cit. (note 6), p. II.

25. Sylvie AUBENAS, «Un fonds unique de photographies sur l'Égypte », in Visions d'Égypte, op. cit. (note 17), p. 118-139. 
26. Sur le voyage en Italie du Sud, voir Maryse BIDEAULT, «L'ordre et la forme : remarques sur les carnets de voyage de Jules Bourgoin dans le sud de l'Italie en 1868-1869", in Bulletin de l'Association des Historiens de l'Art Italien, $\mathrm{n}^{\circ}$ 15-16, 2010, p. 178-188.

27. Gabriel CHARMES, «L'institut d'archéologie orientale du Caire », in L'Égypte. Archéologie, histoire, littérature, Paris, 1891, $3^{\mathrm{e}}$ édition, p. 231.

28. Paris (France), Archives nationales, Série $\mathrm{F}^{21}$ 2284-2, Direction des beaux-arts, ministère de l'Instruction publique à ministère des Travaux publics, lettre en date du 12 janvier 1880.

29. Paris (France), Archives nationales, Série $F^{17}$ 2930, Mission du Caire. $1^{\mathrm{er}}$ dossier Correspondance 1880-82, lettre de X. Charmes à G. Maspero en date du 4 novembre 1881.

30. Mercedes VolAIT, «Amateurs français et dynamique patrimoniale : aux origines du Comité de conservation des monuments de l'art arabe ", in André RAYMOND et Daniel PANZAC (dirs.), La France et l'Égypte à l'époque des vice-rois 1805-1882, Le Caire: IFAO, 2002, p. 311-325 (Cahier des annales islamologiques, 22) ; IDEM, «Du relevé à la conservation des "Monuments de l'art arabe": l'itinéraire égyptien d'Ambroise Baudry (1871-1886)», Revue du monde musulman et de la Méditerranée, vol. 73, $\mathrm{n}^{\circ} 1, \quad 1994$, p.77-97. URL: http://www.persee.fr/doc/ remmm_0997-1327_1994_num_73_1_1668. Consulté le 23 novembre 2015.

31. Gabriel CHARMES, « Coup d'œil sur l'état du Caire ancien et moderne », op. cit. (note 2), p. 237.

32. 638 des dessins d'art islamique réalisés au Caire au cours de ce séjour ont été vendus à l'École des beaux-arts en 1892-1893. Inventoriés, numérisés et catalogués, ils sont désormais accessibles sur le site http://www.ensba.fr/ow2/catzarts/index.xsp. Consulté le 15 septembre 2010. Bourgoin en avait, lui-même, organisé le regroupement et la répartition en 59 cahiers. Certaines chemises de ces cahiers sont aujourd'hui vides et d'autres rassemblent des feuillets erratiques qui nuisent à la cohérence de l'ensemble. D'autres dessins de la même série ont échappé à la sélection faite par Bourgoin et se trouvent aujourd'hui conservés à la bibliothèque de l'INHA - Collections Jacques Doucet, Archives 67.

33. Les planches originales de cette publication ont été vendues en 1890 à la Bibliothèque nationale de France et se trouvent aujourd'hui, reliées en trois volumes, conservées au département des Estampes et de la photographie.

34. Gabriel CHARMES, «L'institut d'archéologie orientale du Caire », op. cit. (note 27), p. 231.

\section{AUTEUR}

\section{MARYSE BIDEAULT}

Responsable de recherches documentaires, InVisu, USR 3103 du CNRS, Paris. 


\section{František Schmoranz le Jeune (1845-1892)}

\section{Milan Němeček}

Traduction : Barbora Faure

L'architecte František Schmoranz le jeune (fig. 1), fondateur, concepteur et directeur de l'École des Arts décoratifs de Prague était à bout de forces lorsqu'il s'éteignit dans son bureau de l'École, le 11 janvier 1892. La célèbre publication Deutsche Bauzeitung écrivit à cette occasion que l'Autriche "perd en lui un de ses artistes les plus sensibles et l'architecture un de ses talents les plus originaux » et que, hormis l'architecte Franz pacha $^{1}$ :

« il n'est probablement guère d'artiste européen qui [...] ait manifesté une connaissance aussi intime de l'art arabe et l'ait à ce point intégré a ses propres formes artistiques $»^{2}$. 


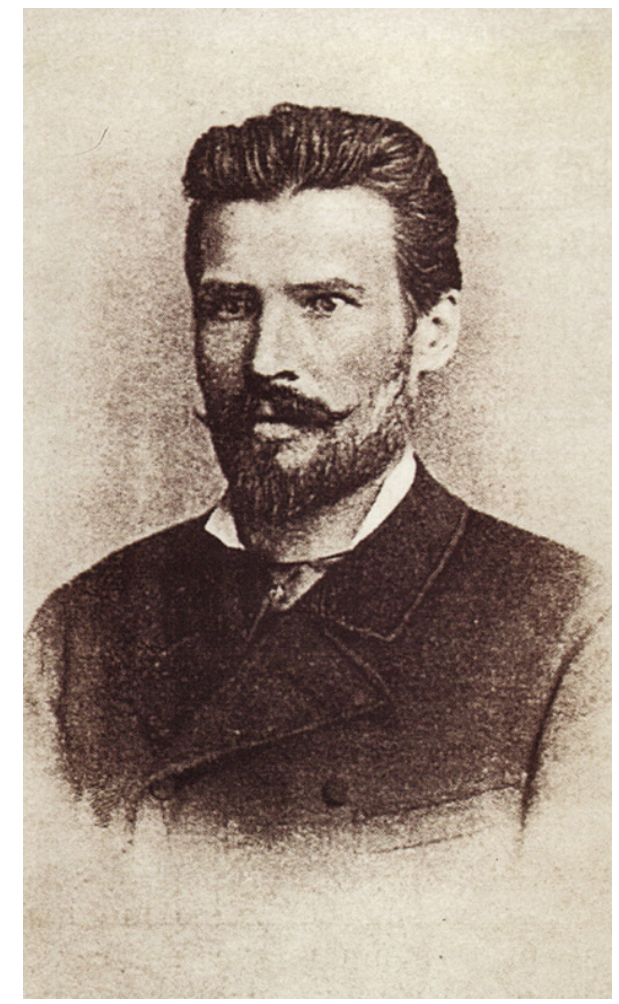

Source : Chrudim (République tchèque), SOkA Státní okresní archiv [Archives nationales du district].

2 Ce commentaire laisse entre autres deviner le peu d'intérêt que le public spécialisé et les architectes d'Europe centrale portaient au Proche-Orient et à l'orientalisme comme expression stylistique architecturale de l'historicisme dont il était issu. Au moment de la mort de Schmoranz, les écrits des historiens de l'art abordaient encore l'orientalisme comme un phénomène marginal dans l'espace centre-européen, en refusant généralement d'admettre qu'il pouvait être un élément significatif de la "guerre des styles » dans laquelle chaque style architectonique devait impérativement être associé à tel ou tel type de construction. Dans ce domaine, l'attitude d'un adepte du style gothique, Karel Schnaase (1798-1875), était particulièrement significative: il considérait l'art oriental islamique ou arabe comme incapable d'une quelconque évolution ${ }^{3}$; Franz Kugler (1808-1858), historien de l'art et représentant de l'école de Berlin, exprimait le même genre d'opinion lorsqu'il reprochait à cet art sa bizarrerie, son manque de discipline et sa raideur ${ }^{4}$. Le Praguois Anton Heinrich Springer (1825-1891) avait vis-à-vis de l'art orientaliste une attitude tout aussi sévère ${ }^{5}$. Un représentant de l'école berlinoise des beaux-arts, l'historien de l'art Wilhelm Lubke (1826-1893) $)^{6}$, montrait un peu moins de raideur en appréciant au moins « sa fantaisie décontractée » et son " originalité ». Il faudra attendre les dernières années du XIX siècle pour que s'amorce, avec l'historien de l'art Alois Riegl (1858-1905) ${ }^{7}$, un revirement dans la manière de percevoir l'art du Proche-Orient.

Cette attitude négative des historiens de l'art vis-à-vis du monde islamique persista dans l'espace centre-européen pendant la plus grande partie du XIXe siècle. Quels facteurs ont métamorphosé l'orientalisme - à l'origine un style romantique secondaire qui concernait essentiellement les fabriques des jardins ou, dans le meilleur des cas les bains et les synagogues - en une source d'inspiration majeure de l'art européen ? 
C'est justement dans la personnalité de František Schmoranz le jeune, un des apôtres de ce style dans les pays germanophones, que l'on peut trouver une des réponses à cette question. Son cheminement vers cette inspiration orientaliste fut tout, sauf direct. En sa qualité de fils d'un célèbre puriste et bâtisseur de maints bâtiments tchèques de style médiéval, František Schmoranz fut très tôt mis en présence de la démarche néogothique. Durant ses années d'études, en 1863-1868, à l'Ecole polytechnique de Prague, dans l'atelier de Josef Zitek, un éminent représentant de la néorenaissance, rien ne laissait supposer que son œuvre s'écarte du droit fil de l'historicisme occidental.

5 František Schmoranz le jeune naquit le 19 novembre 1845 en Bohème orientale, dans la petite ville de Slatiňany. Il était le fils aîné du célèbre architecte et conservateur, František Schmoranz père, auquel on doit la restauration de dizaines d'églises ainsi qu'un certain nombre de châteaux en Bohême orientale édifiés dans l'esprit du romantisme historique ${ }^{8}$. Son frère cadet Josef devint peintre et Gustav, le benjamin de la famille, fut architecte puis directeur du Théâtre national de Prague. Il reçut une éducation primaire chez lui et à Polička où son père dirigeait alors le grand chantier de construction de l'église du doyenné9. Il poursuivit ses études au lycée d'enseignement technique de Kutna Hora puis à l'Ecole polytechnique de Prague, ou il étudia l'architecture sous la direction du professeur Josef Zitek ${ }^{10}$, en compagnie de son collègue et ami de Kutna Hora Jan Machytka, natif de Nova Paka ${ }^{11}$. Dès ces années de formation, Schmoranz s'appliqua à enrichir ses connaissances en effectuant de brefs voyages d'études en France, en Belgique et dans différentes régions allemandes, en réalisant des projets pour le bureau d'études de son père et en faisant des stages pratiques sur les chantiers pendant ses mois de vacances.

6 Une rencontre fortuite fut déterminante pour la carrière de Schmoranz. Le jeune architecte avait tout d'abord décidé ses études à l'École polytechnique de Prague terminées, d'entrer à l'Académie des beaux-arts de Vienne. Sa rencontre avec l'architecte prussien Karl von Diebitsch vint bouleverser ses projets. En effet, Diebitsch, qui travaillait à Hambourg, engagea Schmoranz, dessinateur talentueux, pour l'ouvrage qu'il préparait sur l'architecture arabe. Il le prit aussi comme collaborateur dans son entreprise berlinoise qui réalisait, à ce moment-là, la décoration intérieure du palais cairote de Gazira pour le khédive Isma'il.

7 C'est ainsi qu'à l'automne 1868 Schmoranz s'embarqua pour Le Caire où il se consacra a une étude approfondie de l'architecture islamique ainsi qu'à la décoration du palais de Gazira, construit selon les plans de l'architecte allemand Julius Heinrich Franz, plus connu au Caire sous le nom de Franz Pacha.

8 On aurait pu penser que, pour la décoration du palais, Schmoranz allait puiser son inspiration dans son intérêt pour l'architecture médiévale locale, mais la firme de Karl von Diebitsch se consacrait essentiellement à la fabrication de pièces de fonte dorée préfabriquées, coulées en série dans des ateliers berlinois puis importées au Caire. Au début, les panneaux importés par Diebitsch imitaient la décoration de l'Alhambra, qui représentait dans la vie de Diebitsch une expérience cruciale $^{12}$. František Schmoranz travailla probablement au Caire à la reproduction de nouveaux éléments d'ornementation que l'entreprise Diebitsch réalisa ensuite en masse sous forme d'éléments préfabriqués pour la construction du palais.

9 Par son apparence, le palais du khédive ne s'écarte en rien du courant architectural qui a reçu ensuite le nom de "néorenaissance arabe», en raison de sa conception 
européenne et de ses éléments décoratifs arabes. Pour cette raison, Schmoranz et Diebitsch apparaissent, dans ce cas, tout au plus comme de simples décorateurs (fig. 2).

2. Intérieur du palais de Gazira, photographie.

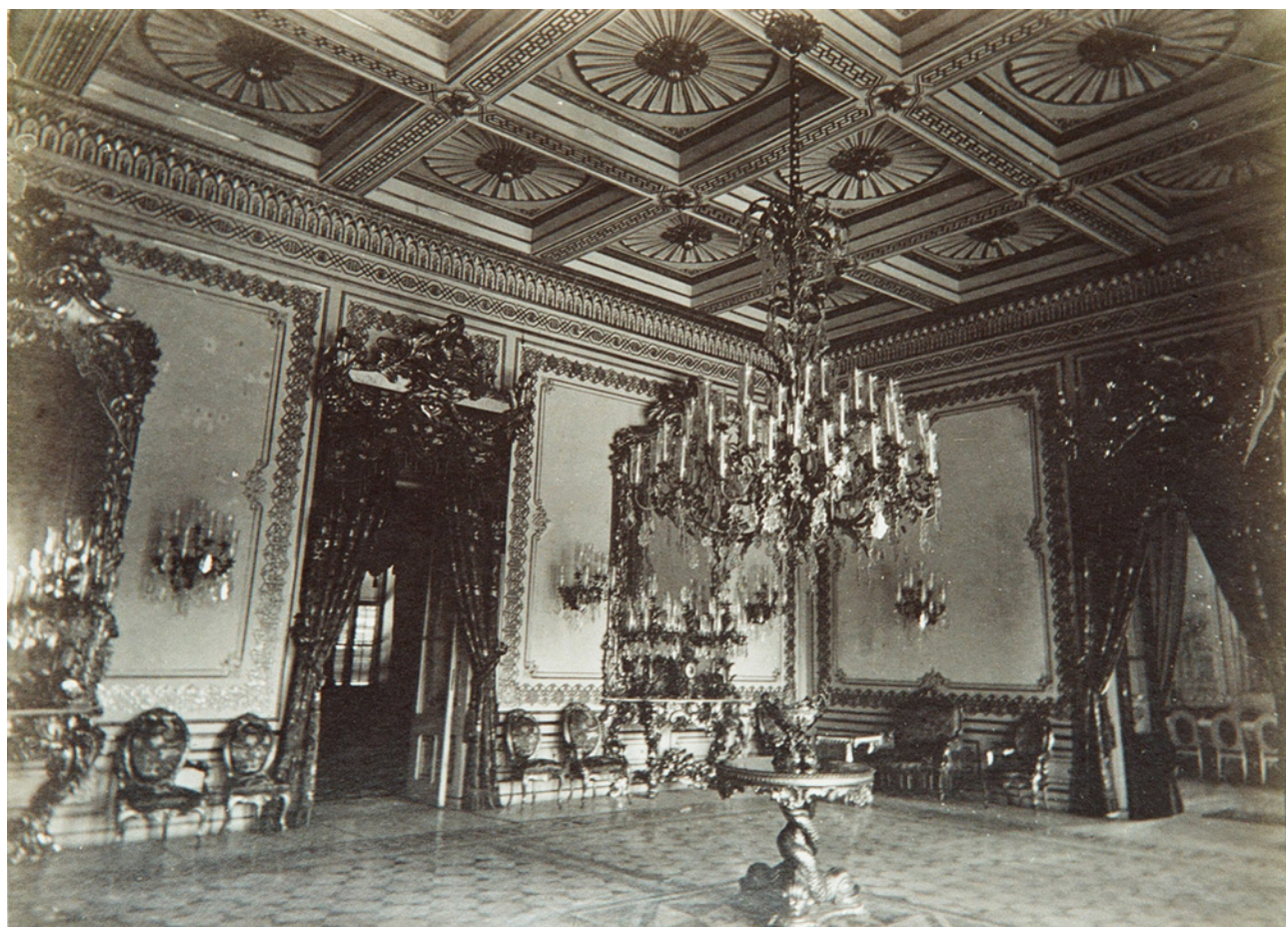

Source : Chrudim (République tchèque), SOkA Státní okresní archiv [Archives nationales du district].

10 Dans la construction du palais de Gazira pour le khédive, la décoration du « kiosque de Muhammad 'Ali » fut pour les deux artistes l'occasion d'une expression beaucoup plus personnelle. Ce pavillon destiné à la réception de visiteurs ${ }^{13}$ associe à un style baroque européen des motifs et des éléments décoratifs traditionnels de l'architecture islamique (fig. 3). Selon l'architecte Tareq Saqr, on y adopte «à côté de hautes fenêtres rectangulaires et de corniches d'époque renaissance, également des arcades islamiques en fer à cheval ». Toutes les arcades en fonte de l'enceinte du palais furent fabriquées en Allemagne à Lauchhammer et Ilsenburg et assemblées au Caire par des ouvriers allemands transportés en Égypte à cette fin ${ }^{14}$ : au Caire apparut ainsi toute une " colonie d'artisans allemands " ${ }^{15}$. Après ce beau succès, Diebitsch fut nommé membre de l'Académie royale artistique de Berlin. Cependant, à peine un mois plus tard, il succomba au Caire à une épidémie de variole. Schmoranz fut alors chargé de la direction et de la liquidation de son entreprise et nommé tuteur de ses enfants. C'est ainsi qu'un grand nombre de réalisations de Diebitsch se retrouvèrent par la suite dans la succession de František Schmoranz le Jeune ${ }^{16}$. 
3. Karl von DIEBITSCH et František SCHMORANZ le Jeune, kiosque de Muhammad 'Ali (salamlik) dans le jardin du palais de Gazira.

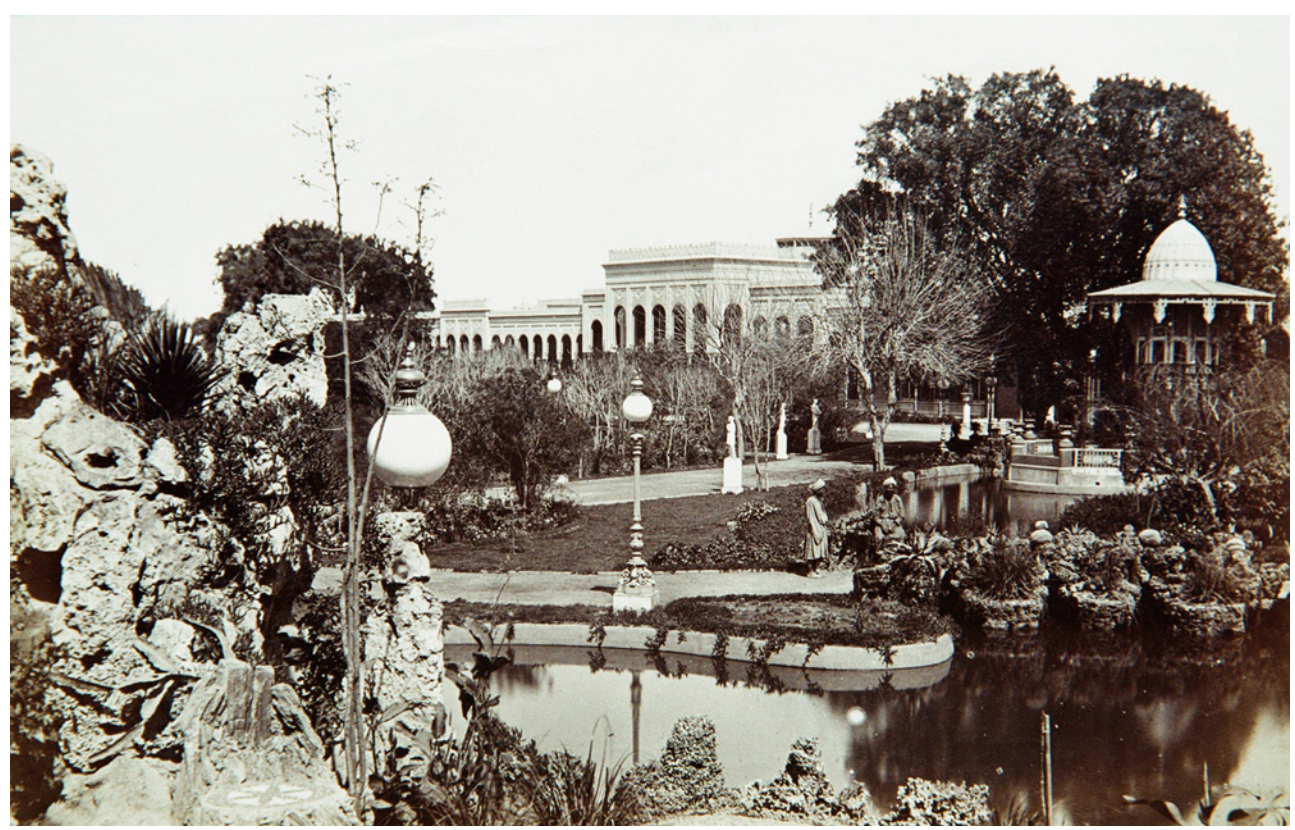

Source : Chrudim (République tchèque), SOkA Státní okresní archiv [Archives nationales du district].

3. Karl von DIEBITSCH et František SCHMORANZ le Jeune, kiosque de Muhammad 'Ali (salamlik) dans le jardin du palais de Gazira.

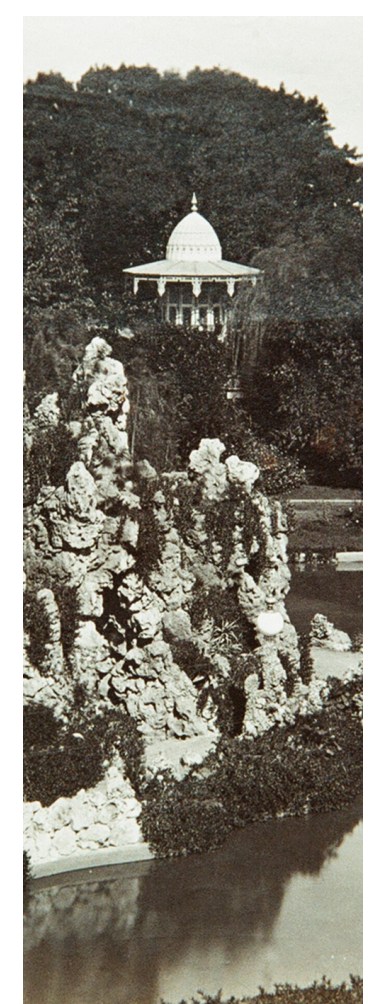

Source : Chrudim (République tchèque), SOkA Státní okresní archiv [Archives nationales du district]

11 La mort de Diebitsch ne marqua pas pour autant la fin des activités de Schmoranz au Proche-Orient car il accepta, à la demande du khédive, une tâche confiée tout d'abord à 
Diebitsch ${ }^{17}$ : la construction d'un palais destiné à la réception des souverains a l'occasion de l'inauguration du canal de Suez, sur la rive même de ce canal. La réussite de Schmoranz au concours international restreint pour la construction de ce palais de la Compagnie universelle du canal de Suez vint confirmer la position qu'il avait acquise auprès du khédive. Schmoranz l'emporta sur deux architectes français et s'engagea à réaliser le projet en moins de six semaines, en association avec « un architecte suisse installé au Caire»! Le jeune architecte parvint à respecter cette promesse téméraire malgré une grève des ouvriers, en convoquant par télégramme plusieurs centaines d'ouvriers remplaçants originaires de Livourne ${ }^{18}$.

Schmoranz donna à son palais éphémère les dimensions respectables de $72 \mathrm{~m}$ sur $25^{19}$. La période de son édification fut marquée par une intense activité de construction due au khédive Isma'il au Caire et dans sa ville nouvelle d'Ismaïlia: le khédive entendait alors imprimer aux bâtiments en projet une expression arabe moderne. Ce nouveau style reçut entre autres l'appellation d' " arabisance » et par la suite un nom un peu plus précis, celui de "renaissance néoarabe ${ }^{20}$. Bien qu'on ignore presque tout de ce palais, la gravure parue dans The Illustrated London News du 18 décembre 1869 et une autre publiée dans L'Illustration du 16 octobre 1869, ainsi qu'une photographie (fig.4) permettent de comprendre que Schmoranz avait dessiné un bâtiment à pavillon central et deux latéraux, avec un étage et une ébauche de cour d'honneur, rappelant le palais de Gazira. L'édifice était placé sur une dalle surélevée et structuré par une large avancée centrale, probablement quadri-axiale, contiguë à une véranda à arcades semblable à celle du palais cairote de Gazira. Les façades latérales étaient aussi dotées de ressauts simples dans les angles des ailes. Des corniches apparentes soulignaient le niveau de l'étage et constituaient une articulation horizontale, tandis que les pilastres des ressauts introduisaient un motif de verticalité. L'illustration ne permet pas de voir les détails de la décoration extérieure, mais on peut penser qu'à cause de la destination éphémère de l'édifice, cette décoration n'était pas très fouillée : il s'agissait en effet d'un palais «improvisé et décoré à l'orientale " $^{21}$. Une véranda à arcades conduisait à un vestibule de "style mauresque " dans lequel débouchait l'escalier principal. Le vestibule était flanqué de deux salons de réception aux vitres polychromes décorés d'une ornementation complexe de sculptures sur bois dans le "style arabe». Au moment de la réception solennelle, l'étage n'était pas terminé. Tous ces éléments permettent de conclure que le premier apport de Schmoranz à l'architecture égyptienne moderne ne se distinguait guère de la production des autres architectes exerçant en Égypte à l'époque. Schmoranz fut également engagé pour l'organisation de la cérémonie d'inauguration du canal de Suez : c'est ce que permet de comprendre son projet pour la décoration solennelle conservé dans les archives de sa succession ${ }^{22}$. 
4. Palais du khédive Isma'il construit pour l'inauguration du canal à Ismaïlia, photographie.

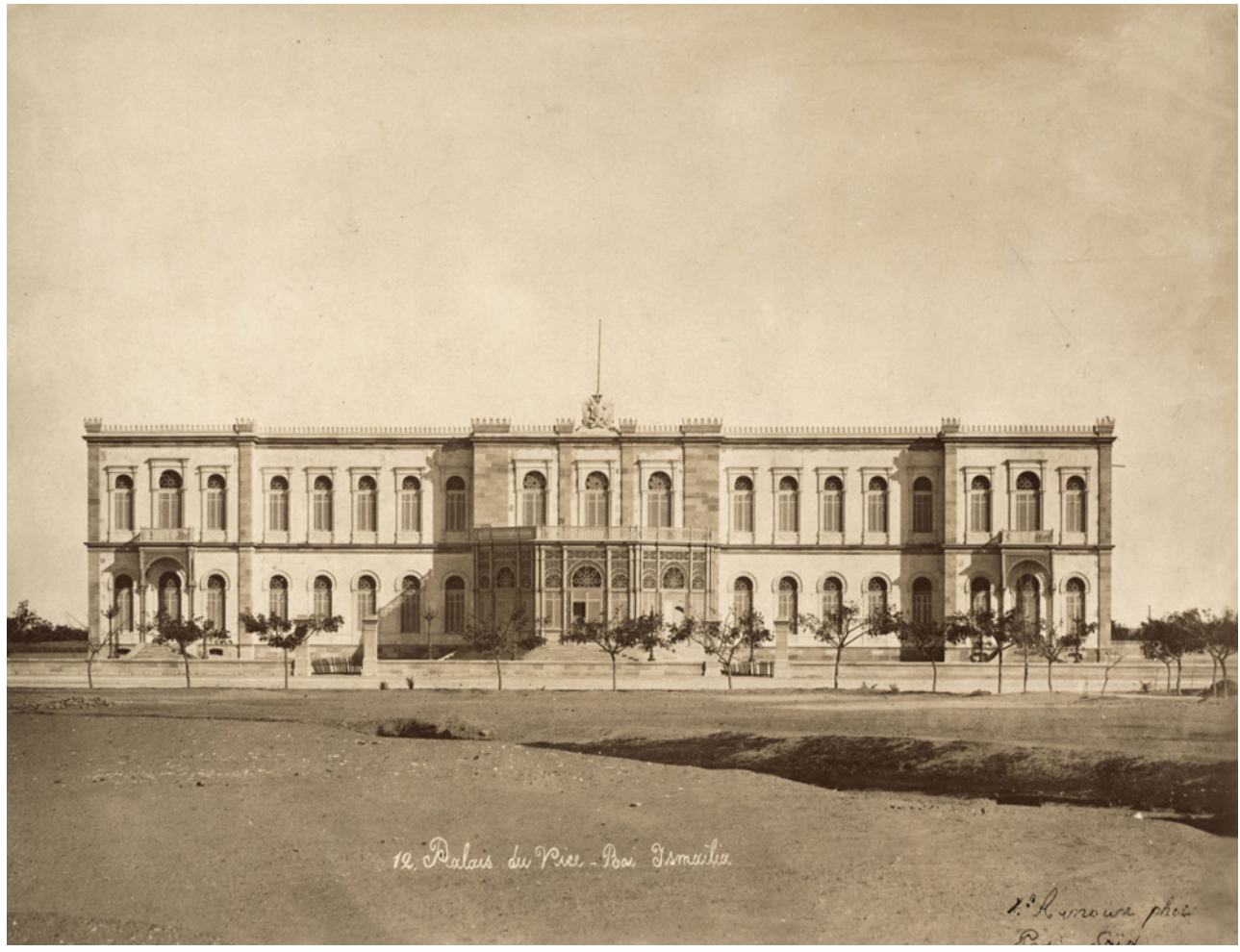

Source : Roubaix (France), Archives nationales du monde du travail (ANMT), Fonds d'archives privées déposées par l'Association du souvenir de Ferdinand de Lesseps et du canal de Suez, fonds photographique Arnoux.

Malgré son succès incontestable, Schmoranz n'avait pas l'intention de s'installer au Caire, bien qu'il ait été captivé par l'architecture de la ville dont il fit de nombreux relevés, comme ceux de la mosquée Azbak, aujourd'hui disparue (fig. 5). Il n'arrivait pas non plus à quitter totalement le Proche-Orient. C'est ainsi qu'il obtint des 1870, une bourse de voyage pour se rendre en Grèce, en Italie, en Haute-Égypte, en Asie Mineure, en Mésopotamie et en Australie, accompagné de son collègue d'études Jan Machytka (fig. 6). Lors de ces voyages, Schmoranz se consacra non seulement aux arts décoratifs et à la classification des styles orientaux ${ }^{23}$, mais aussi à l'étude des plans au sol de maisons arabes. Ses connaissances et ses contacts avec l'élite culturelle et politique égyptienne lui permirent d'obtenir différentes commandes, notamment celle d'illustrations pour des publications de Georg Ebers (fig. 7-8) ${ }^{24}$ ou celle de l'édification du palais du ministre des finances, Isma'il Siddiq al-Mufattish, ainsi que la conception, en collaboration avec Auguste Mariette, d'une «argenterie de table dans le style égyptien ancien $»^{25}$. En 1872, Vienne le récompensa en le nommant membre de sa maison des Artistes (Künstlerhaus). 
5. František schmoRanz le Jeune, intérieur de la mosquée Azbak, Le Caire, 1871.

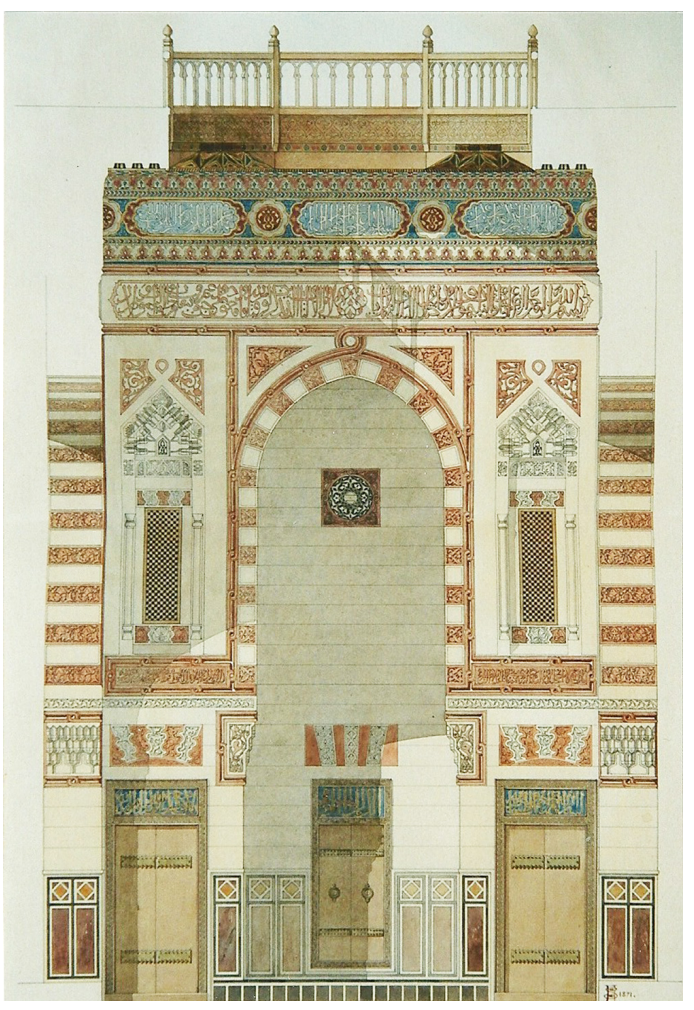

Source : Chrudim (République tchèque), SOkA Státní okresní archiv [Archives nationales du district].

6. František Schmoranz le Jeune et Jan Machykta à Gizeh (Le Caire), 1871.

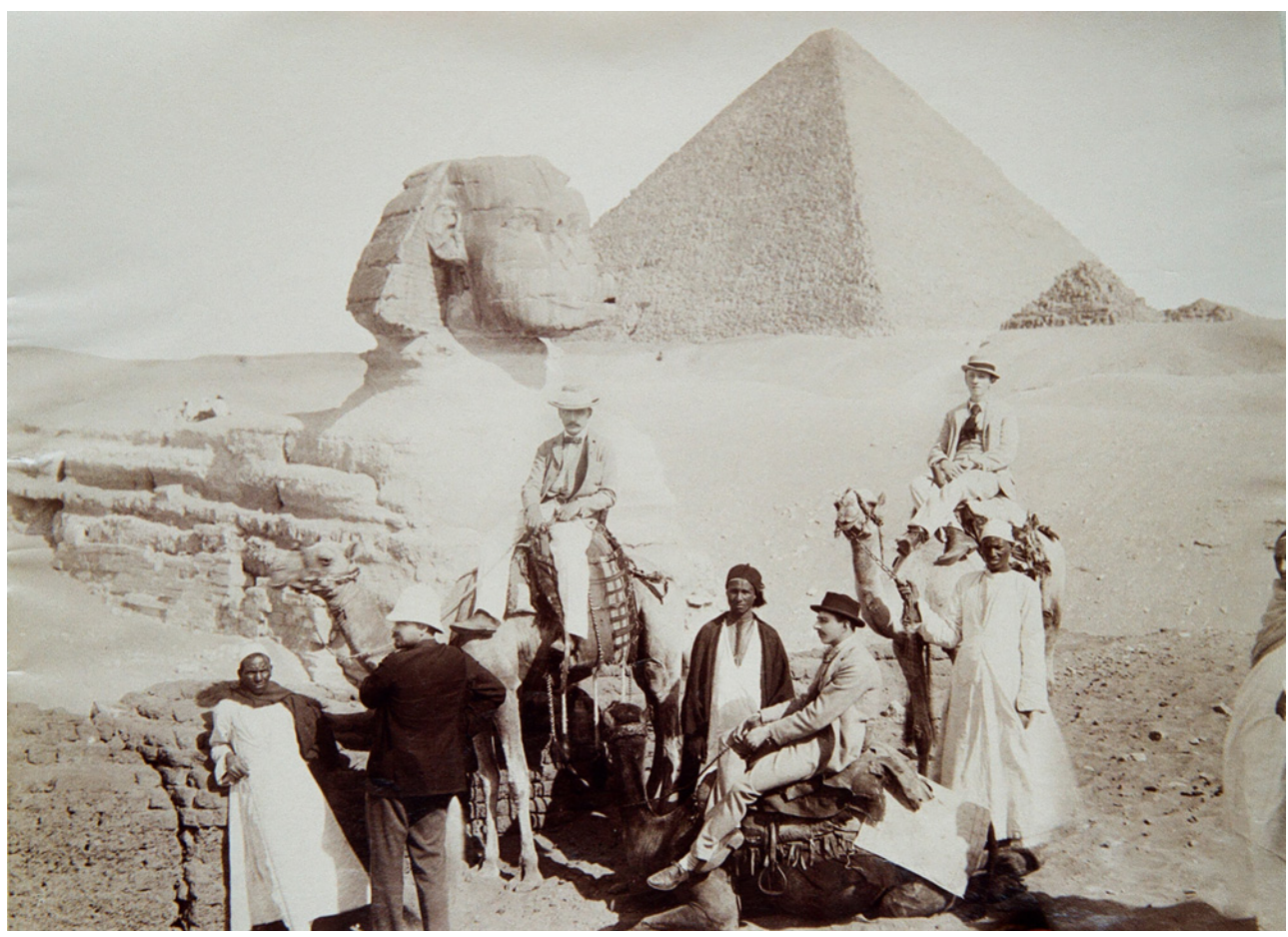

Source : Chrudim (République tchèque), SOkA Státní okresní archiv [Archives nationales du district]. 
7. František SCHMORANZ le Jeune, Dessin préparatoire à la gravure Fernster im Mausoleum des Kalaun [Qalawun], publiée dans Georg EBERS, Ägypten in Bild und Wort, 1880, p. 290.

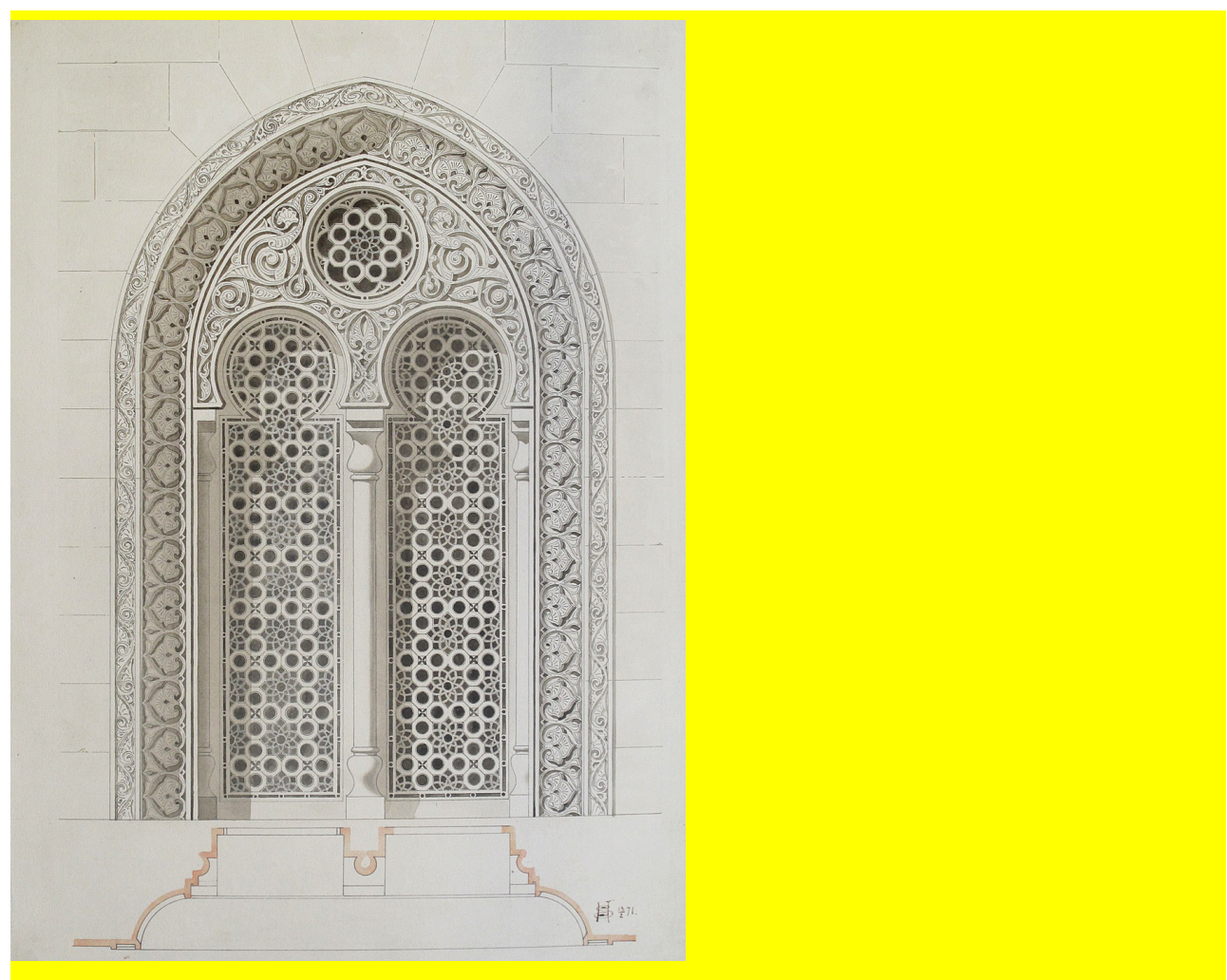

Source : Chrudim (République tchèque), SOkA Státní okresní archiv [Archives nationales du district] (haut). 
7. František SchmoRAnz le Jeune, Fernster im Mausoleum des Kalaun [Qalawun], publiée dans Georg EBERS, Ägypten in Bild und Wort, 1880, p. 290.

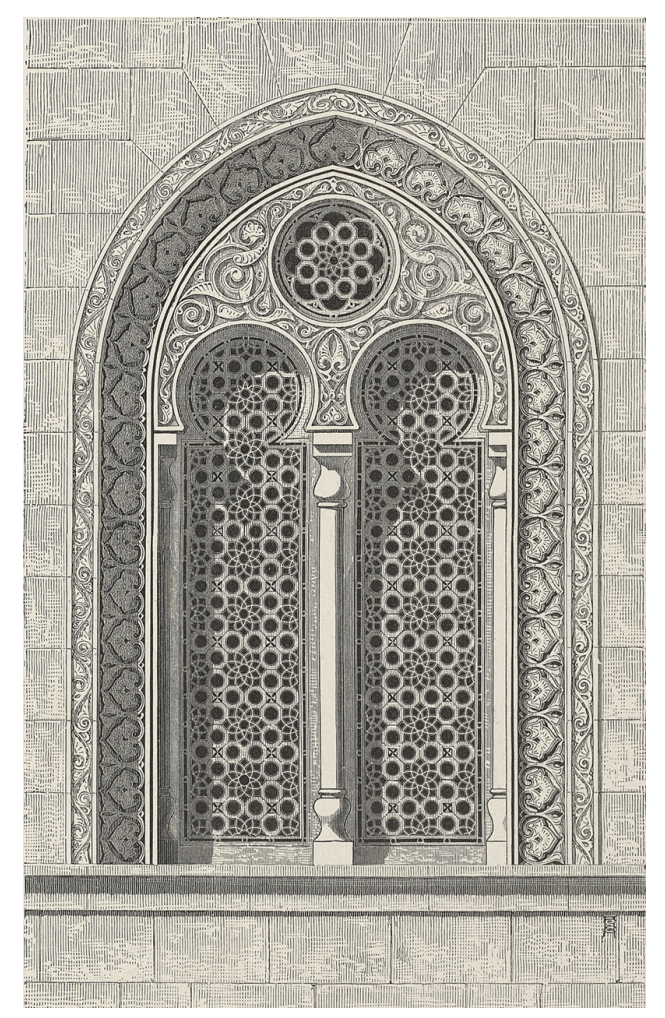

Paris (France), BnF (bas). 
8. Jan Machytka, Inneres der Moschee des Kalaun [Qalawun], gravure reproduite dans Georg EBERS, Ägypten in Bild und Wort, 1880, p. 319.

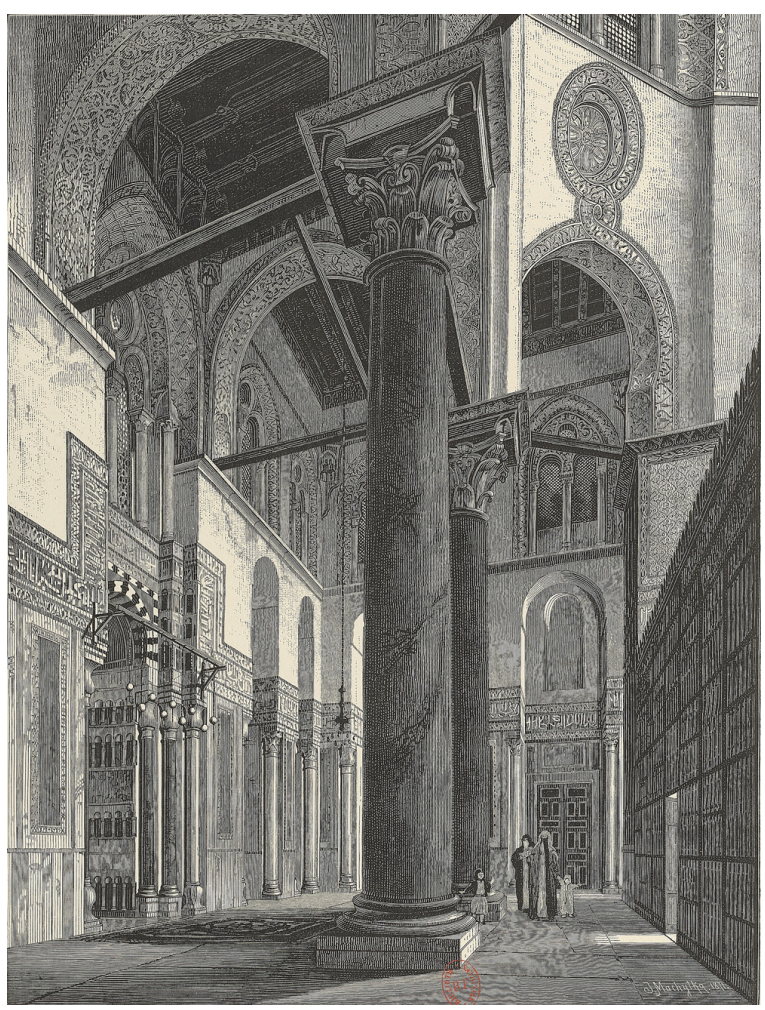

Source : Paris (Paris), BnF (bas).

L'architecte n'avait pas encore trente ans lorsqu'il parvint à la célébrité dans son pays natal, en participant à l'Exposition universelle de Vienne avec son "groupe de constructions égyptiennes ", composé d'une maison arabe, d'une mosquée à minaret et coupole, d'une cour à arcades, d'une cour de ferme et d'une réplique de tombeau rupestre de l'Égypte ancienne : "L'effet d'ensemble de l'édifice, avec ses murs éclatants de couleurs harmonieuses, ses minarets élancés et gracieux et ses grilles fines créait la surprise et dynamisait l'ensemble du groupe. $»^{26}$

Le khédive confia cette tâche à Schmoranz au printemps 1872 en même temps que celle d'installer le secteur égypto-soudanais de l'exposition dans le pavillon de l'Industrie. Schmoranz proposa promptement au vice-roi le projet grandiose d'un vaste complexe symétrique, composé de deux bâtiments, un à deux coupoles et minaret central où il plaçait des bains et l'autre contenant probablement l'exposition principale (fig. 9-10). Un passage couvert reliait les deux constructions. Schmoranz utilisa pour l'édifice principal son motif favori de loggia a arcades sur l'ensemble du pourtour du bâtiment. Ce plan, dont le traitement au sol correspondait à une architecture européenne, fut ensuite réduit à la seule construction des bains, composés d'un bâtiment central avec un étage et de deux petits pavillons de plain-pied. L'architecte enrichit la construction d'un monumental portail en avancée avec des loggias latérales aux fenêtres géminées (fig. 10). La façade était agrémentée d'un attique ornementé, de deux coupoles, de tours d'angles et ornée de bandes blanches et rouges. L'intérieur du bâtiment principal devait être dominé par une salle circulaire qui s'élevait sur les deux niveaux, complétée par une fontaine et une galerie au premier étage. Le rez-de-chaussée comportait, outre quatre vestibules octogonaux et un escalier à sept volées, également des cafés, des 
boutiques de tissus et des locaux techniques. Le plan des bains était judicieusement maîtrisé (fig. 11), tant au rez-de-chaussée que dans la galerie circulaire qui permettait de pénétrer dans sept avancées à extrémités polygonales dont une sur deux débouchait dans des antichambres octogonales, éclairées par des puits de lumière, qui menaient aux cabines de bain. Les salles centrales des pavillons latéraux avaient également un plan octogonal : celui de droite devait servir à la clientèle musulmane, celui de gauche aux visiteurs européens.

9. František SCHMORANZ le Jeune, Projet du quart égyptien à l'Exposition universelle de Vienne, façade principale.

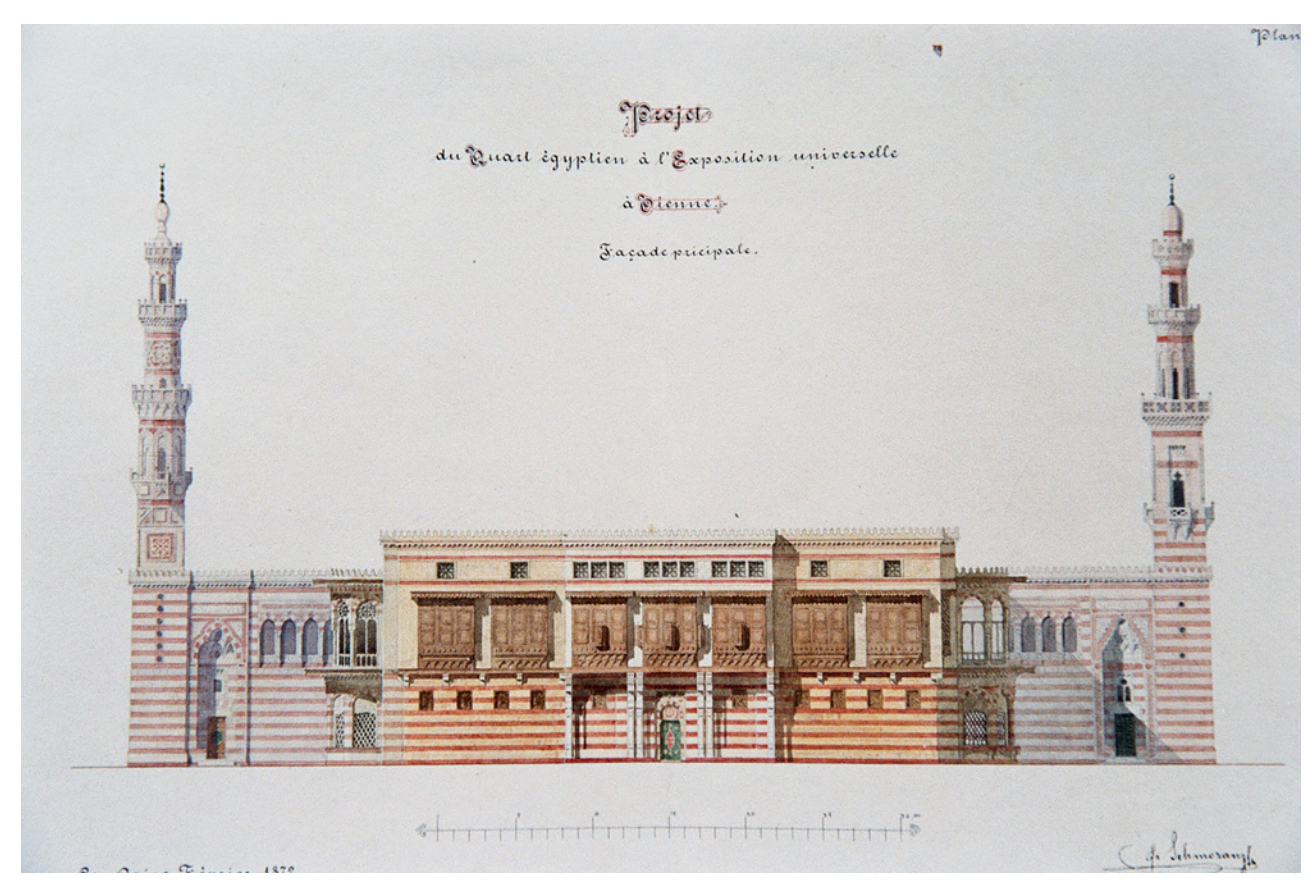

Source : Chrudim (République tchèque), SOkA Státní okresní archiv [Archives nationales du district] 
10. František SCHMORANz le Jeune, Projet d'un bain arabe pour le quart égyptien à l'Exposition universelle de Vienne, façade principale.

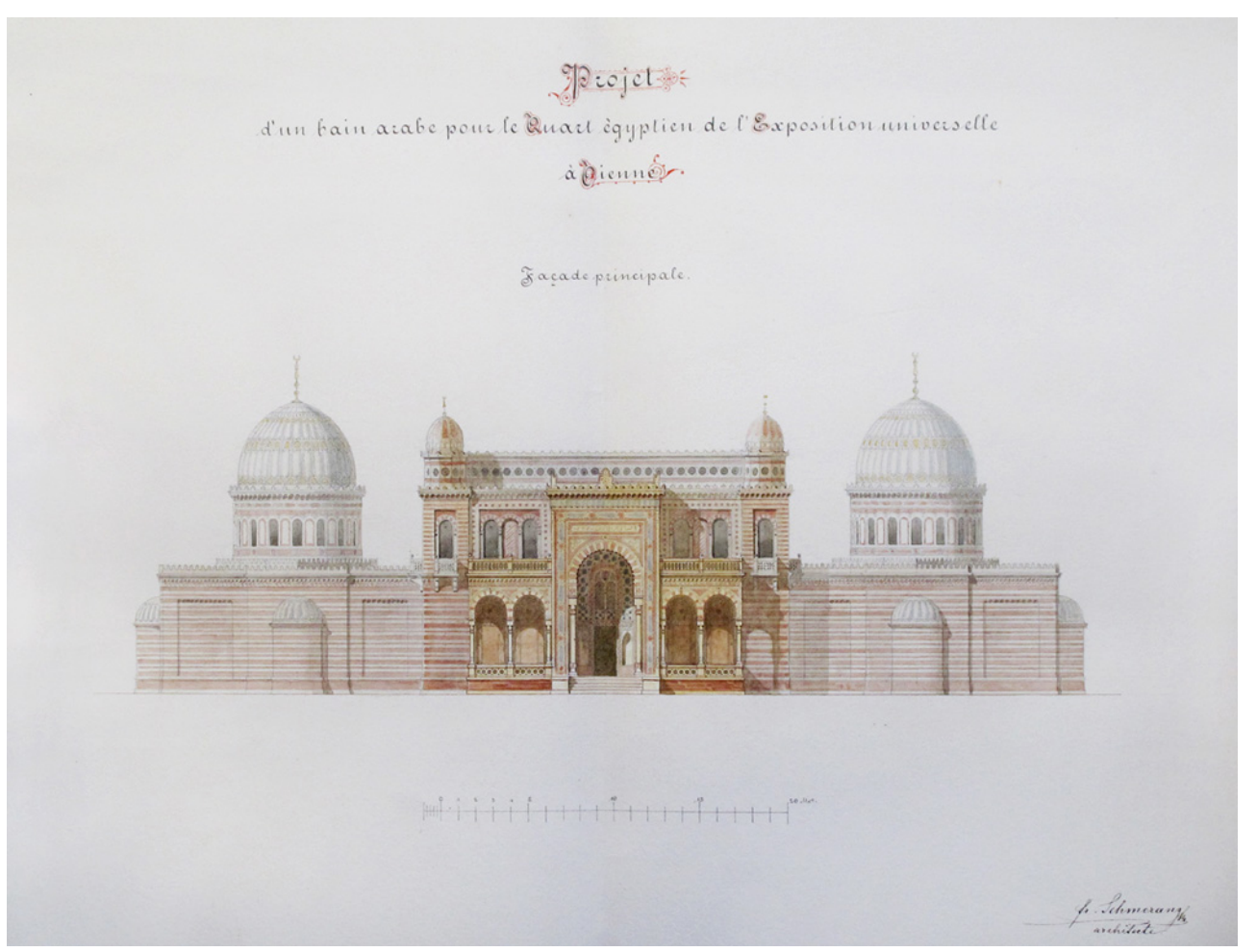

Source : Chrudim (République tchèque), SOkA Státní okresní archiv [Archives nationales du district].

11. František SCHMORANz le Jeune, Projet d'un bain arabe pour le quart égyptien de l'Exposition universelle de Vienne, Rez-de-chaussée.

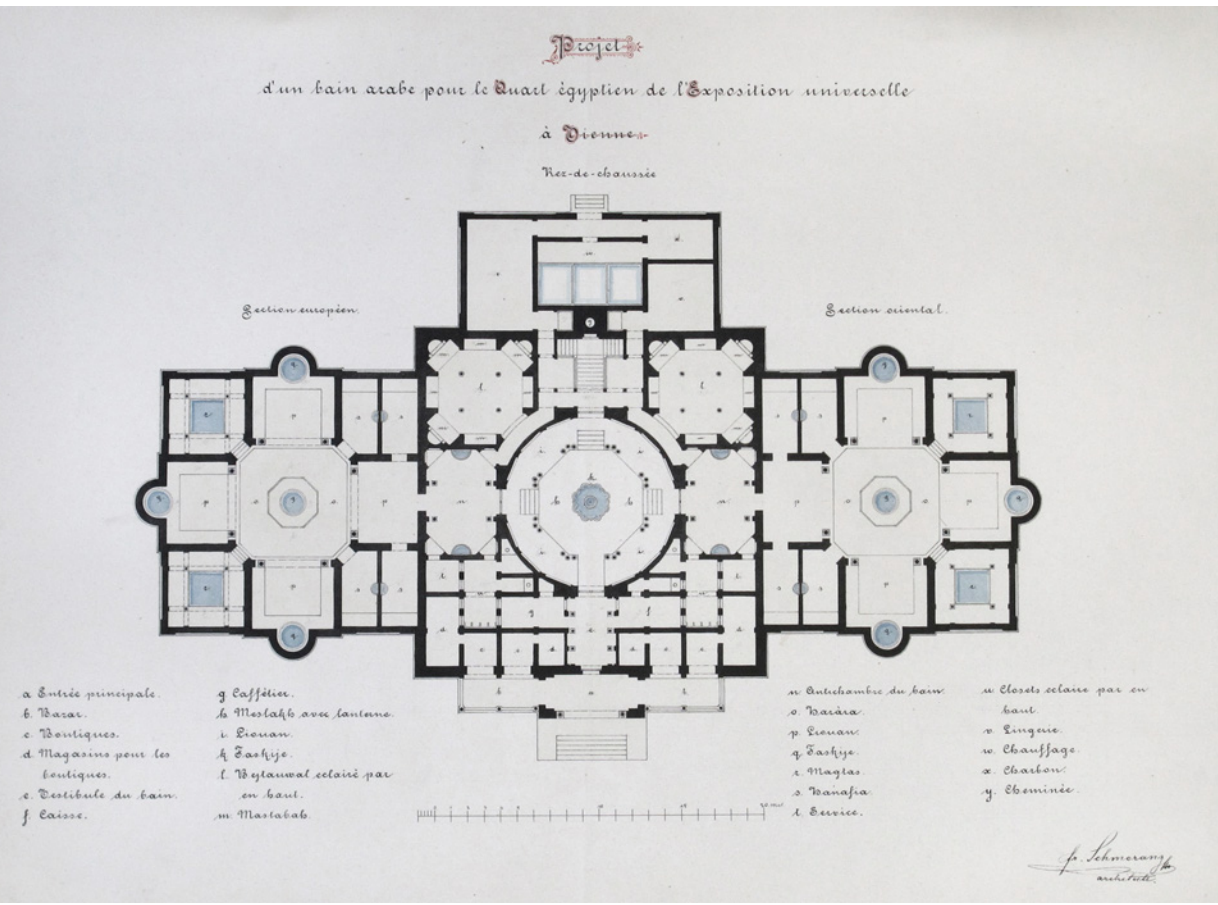

Source : Chrudim (République tchèque), SOkA Státní okresní archiv [Archives nationales du district]. 
11. František SCHMORANZ le Jeune, Projet d'un bain arabe pour le quart égyptien de l'Exposition universelle de Vienne, Premier étage.

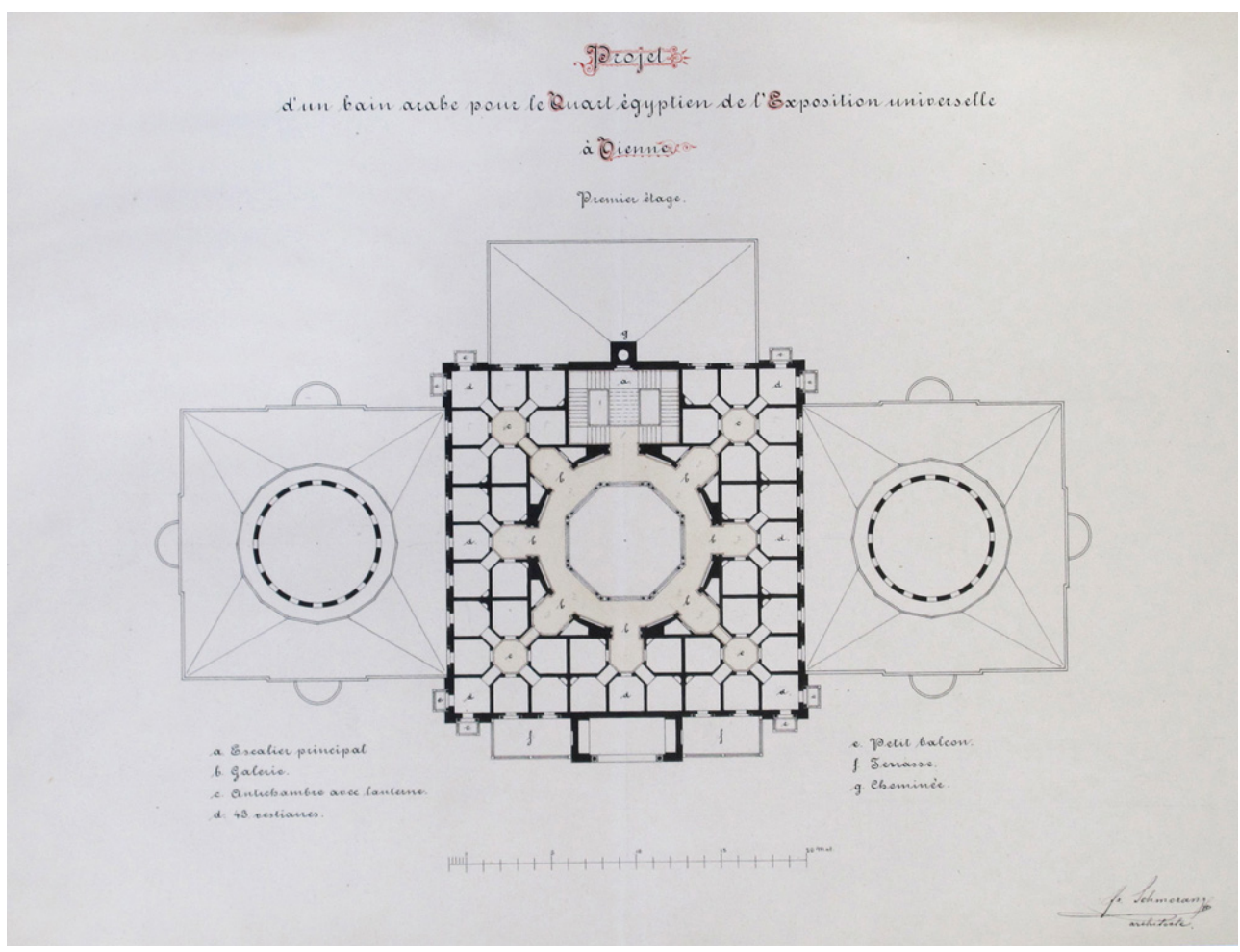

Source : Chrudim (République tchèque), SOkA Státní okresní archiv [Archives nationales du district].

Les deux projets de bains furent finalement abandonnés et le choix se porta sur une «maison arabe » qui devait constituer la dominante du complexe. Elle était constituée d'un bâtiment principal qui comportait, entre autres, une reproduction de maison cairote ancienne, une mosquée à coupole, des minarets et une cour à arcades avec une fontaine (fig. 12-13). À l'intérieur de l'édifice se trouvait également une salle principale - une manzara - avec une fontaine un harem, un café, un bazar et une école. La façade était de nouveau animée par des bandes de briques colorées, sept moucharabiehs donnant sur un jardin (fig. 9). Par son expression et sa morphologie, cet édifice monumental faisait référence à une série de bâtiments cairotes, notamment l'ensemble funéraire de Qaytbay et les minarets du mausolée des émirs Salar et Sangar al-Gawli du Caire ${ }^{27}$. Ce bâtiment principal était complété par une "ferme égyptienne », copie de la résidence de shaykh al-balad, comprenant entre autres une étable, des écuries, un moulin et des pigeonniers, ainsi que par une copie fidèle de la nécropole antique de Beni Hassan ${ }^{28}$, réalisée en pierre avec une imitation d'amas rocheux et contenant, outre les espaces funéraires proprement dits, également une cour à péristyle. Le tombeau renfermait la tombe de Khoum-hotep, un dignitaire de la XII ${ }^{\mathrm{e}}$ dynastie, mais la réalisation de celle-ci fut confiée à Heinrich Brugsch Pacha et Ernst Weidenbach ${ }^{29}$. Des bains arabes, élément inlassablement proposé par Schmoranz, devaient parachever l'ensemble, mais leur construction fut une fois encore abandonnée pour des raisons financières. 
12. Le complexe de la section égyptienne, Exposition universelle de Vienne, 1873, photographie.

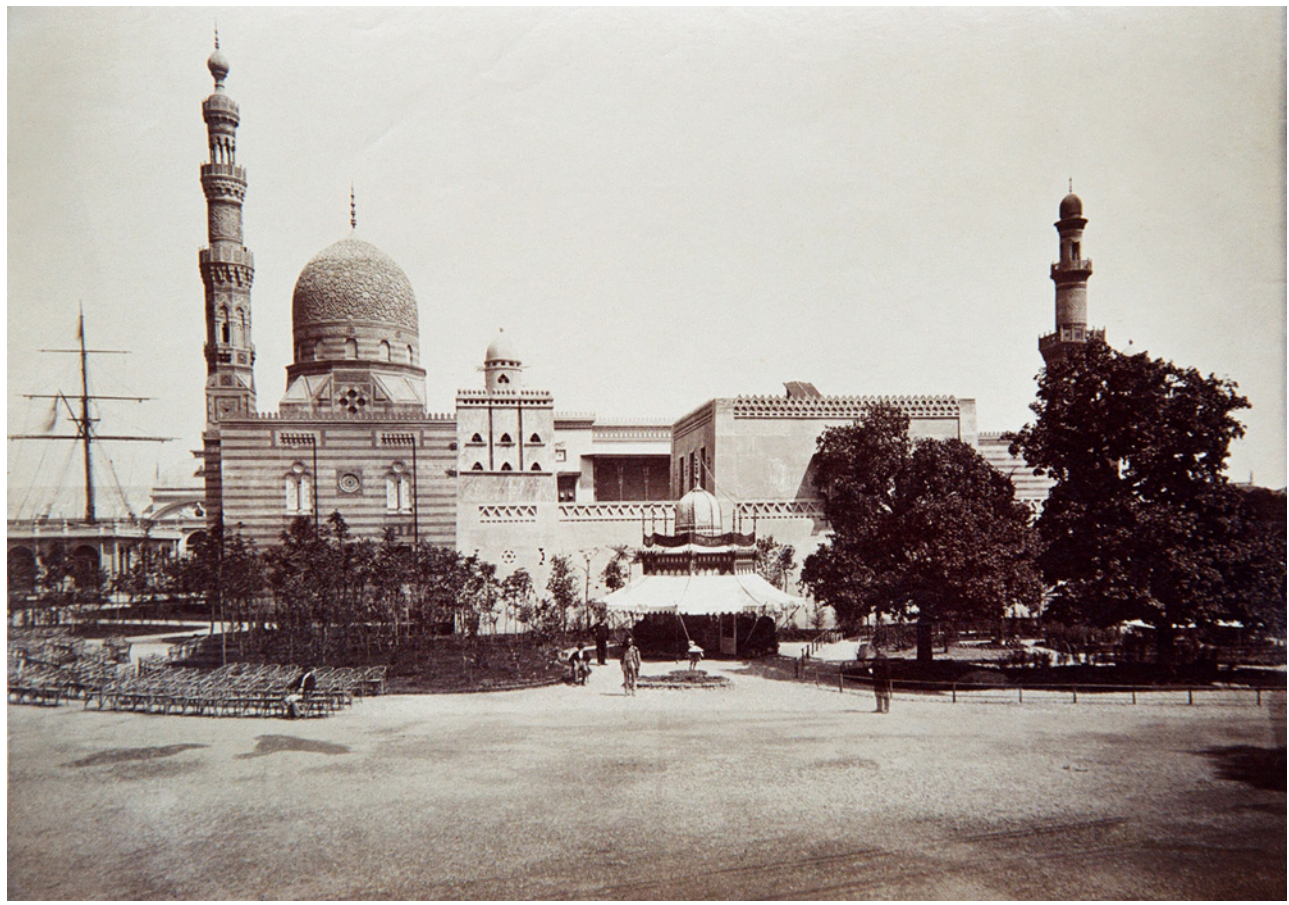

Source : Chrudim (République tchèque), SOkA Státní okresní archiv [Archives nationales du district].

13. Détail du pavillon égyptien, Exposition universelle de Vienne, 1873, photographie.

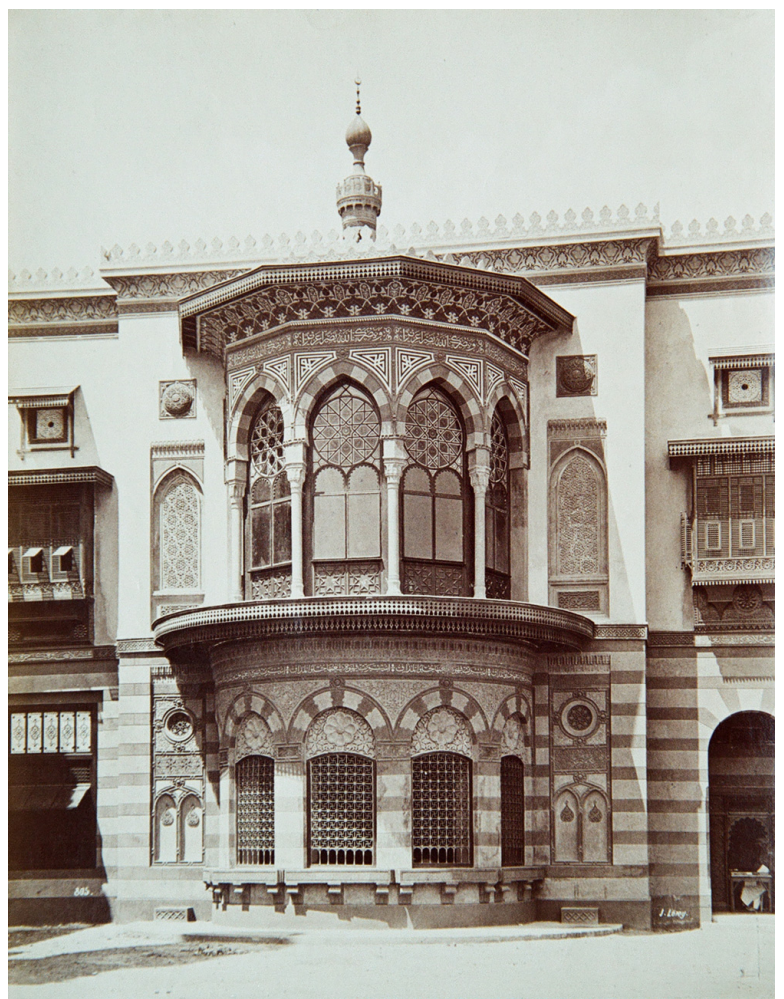

Source : Chrudim (République tchèque), SOkA Státní okresní archiv [Archives nationales du district]

17 Cette réalisation valut à Schmoranz les plus hautes distinctions de l'Exposition : la croix de chevalier de l'ordre de Francois-Joseph Ir, la médaille de l'ordre de l'Osmanie (1874) 
et l'ordre égyptien de Medjidieh $^{30}$. Schmoranz reçut en outre une promesse de commande pour la construction du musée de Boulac et du Musée national égyptien dont il accompagna la création du moins pour ce qui est de son organisation, mais le projet ne vit le jour que bien plus tard ${ }^{31}$. Déçu, Schmoranz retourna en Égypte mais ne tarda pas à repartir pour un voyage d'étude au Proche-Orient. Étant donné les problèmes financiers du khédive, l'architecte revint à Vienne en 1874 et ouvrit un bureau d'étude avec son collègue Machytka, ce qui constituait à l'époque un succès quasiment impensable pour un architecte tchèque. En 1875, le khédive Isma'il lui proposa la direction d'une école "pour la culture de l'art local», mais Schmoranz refusa pour se consacrer entièrement à son bureau d'études et à la vie sociale viennoise $^{32}$. Même au cours des années suivantes, Schmoranz resta encore sur le devant de la scène architecturale et obtint de nombreuses distinctions, par exemple pour ses dessins sur l'Orient islamique à l'Exposition internationale des beaux-arts tenue à Munich en $1879^{33}$. Il reçut une nouvelle occasion d'affirmer sa réputation d'expert en art oriental au cours des années 1881-1883, lorsqu'il fut chargé de la réinstallation d'une partie de l'ancien pavillon d'exposition au musée des Arts appliqués de Vienne, sous forme d'une manzara (fig. 14-15). Machytka et lui complétèrent les éléments du pavillon par la reproduction de décors authentiques de maisons anciennes dont ils avaient fait de fidèles copies (fig. 16-17) ${ }^{34}$.

14. František SCHMORANZ le Jeune, plan et coupes de la manzara installée au musée des Arts appliqués de Vienne, 1881.

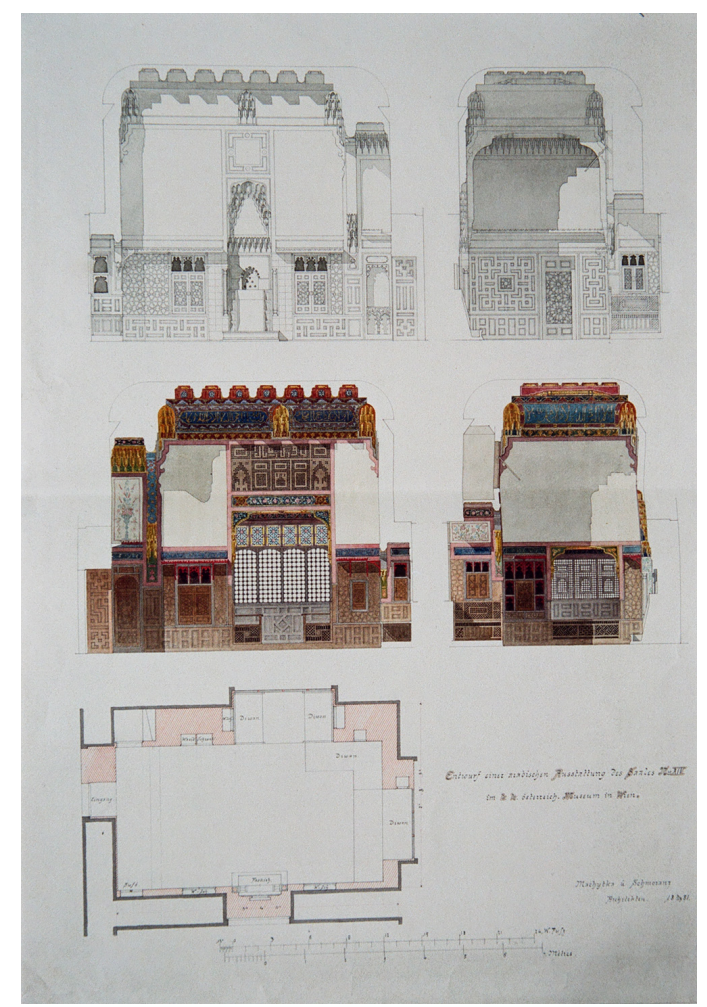

Source : Chrudim (République tchèque), SOkA Státní okresní archiv [Archives nationales du district] 
15. Joseph LöWY, [salle arabe au musée des Arts appliqués de Vienne].

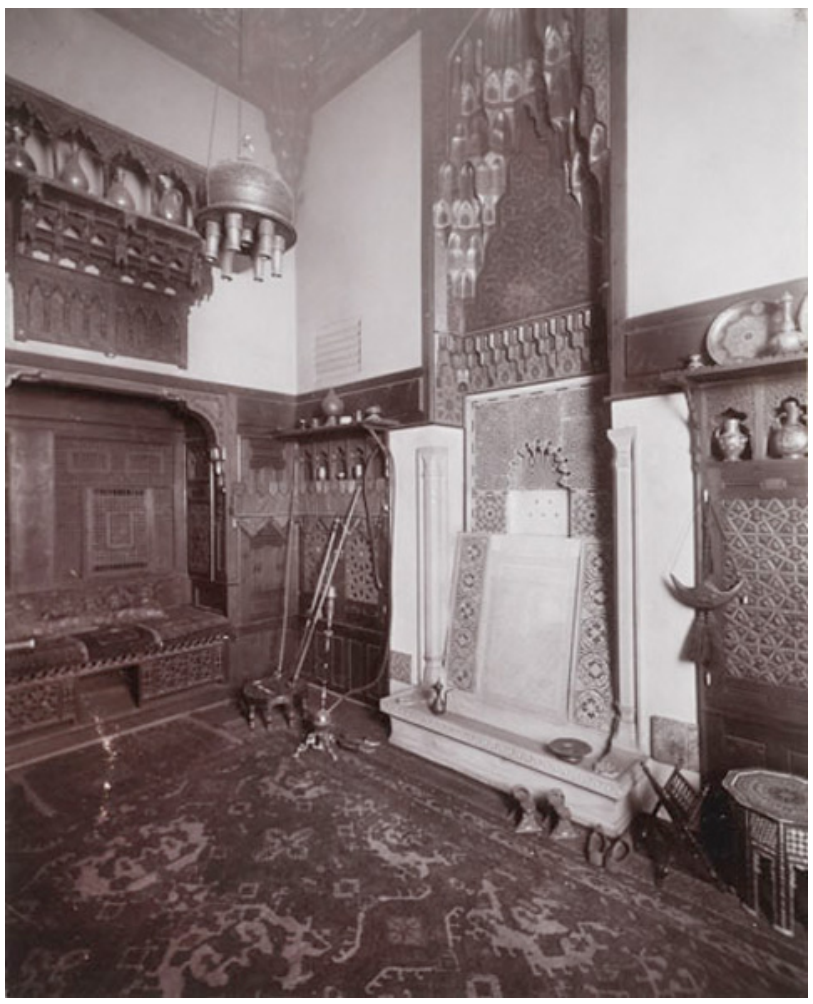

Source: Vienne (Autriche), MAK - Österreichisches Museum für angewandte Kunst (Inv. KI 8557).

16. František SCHMORANZ le Jeune, haremlik d'une maison copte du Caire, reconstitution d'un édifice du XVIII e siècle, 1874.

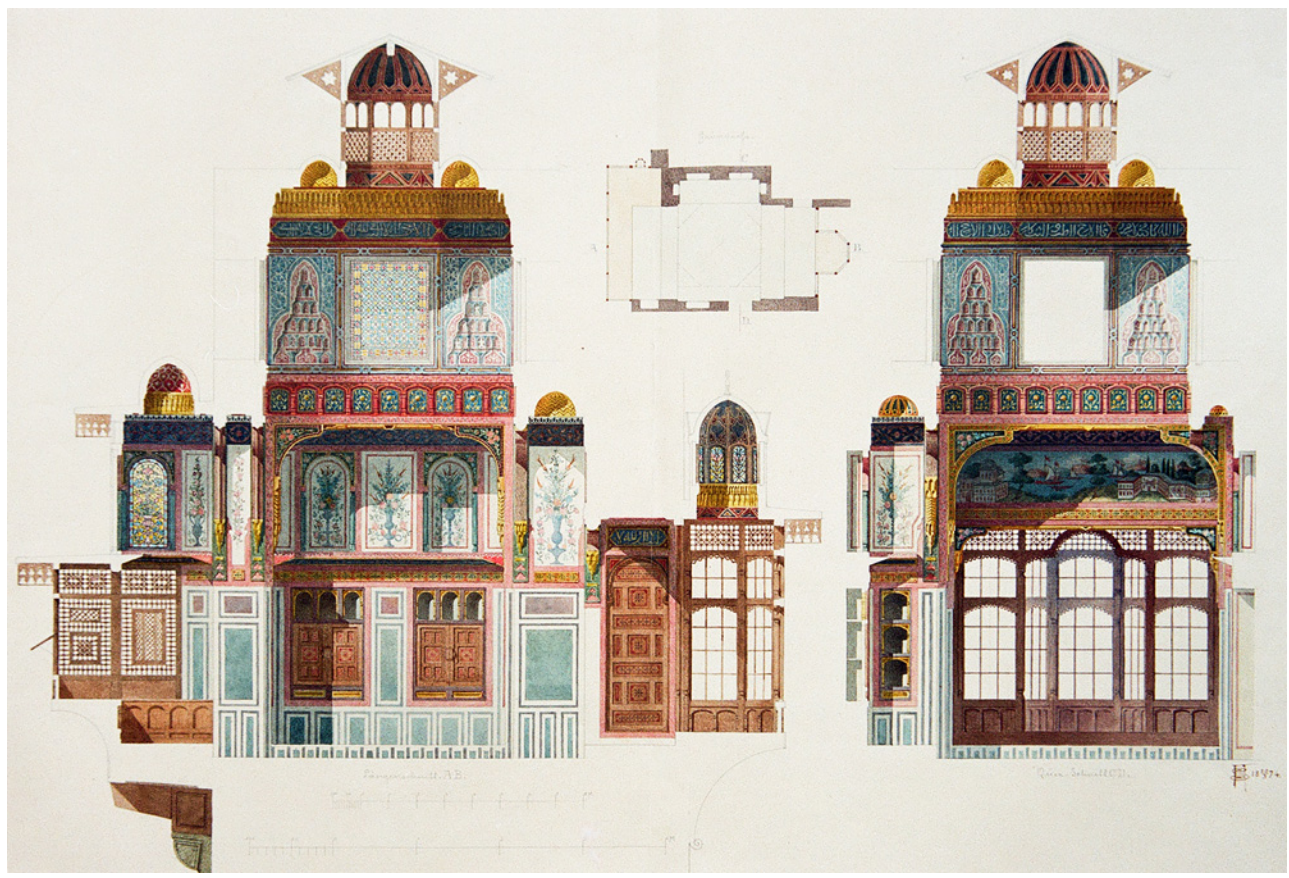

Source : Chrudim (République tchèque), SOkA Státní okresní archiv [Archives nationales du district]. 


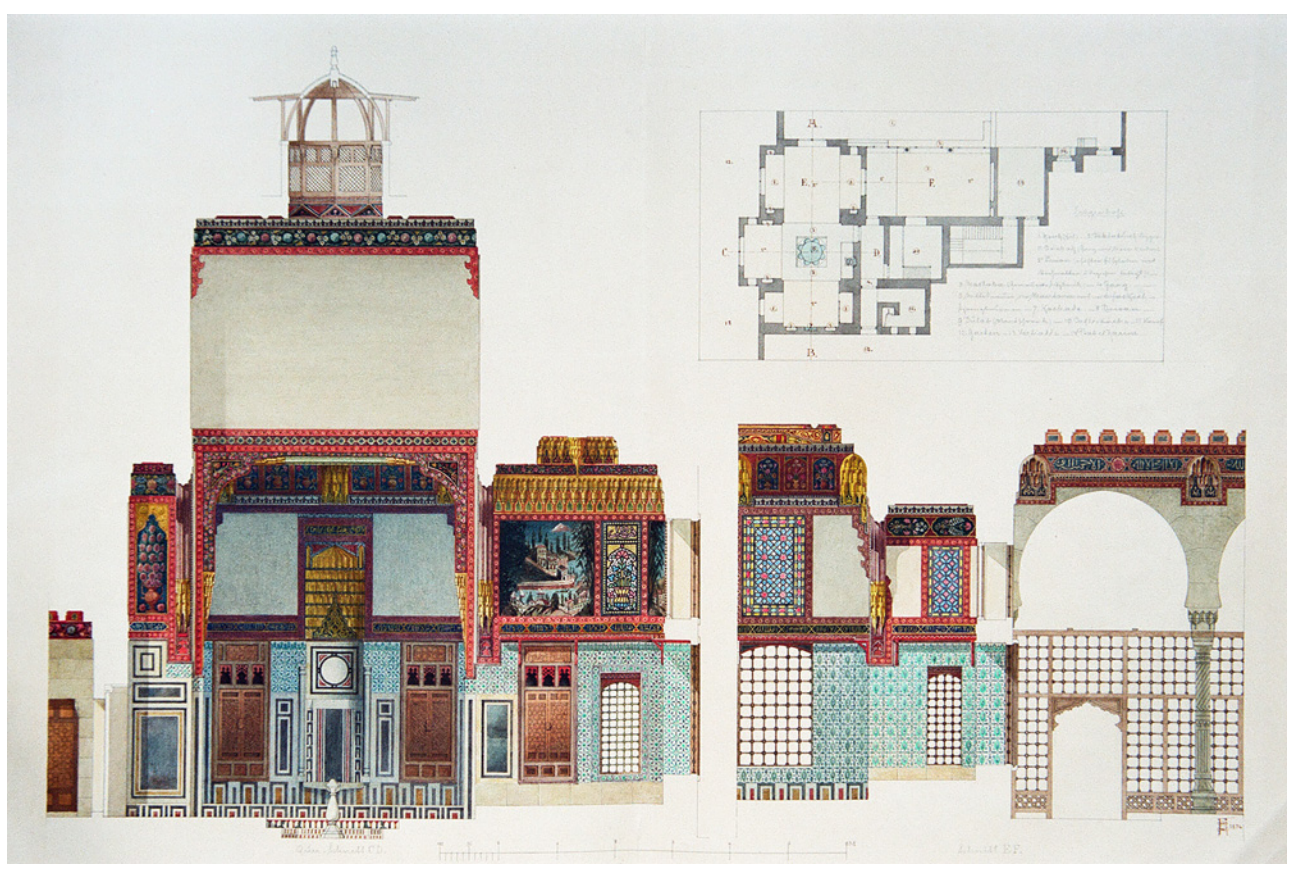

Source : Chrudim (République tchèque), SOkA Státní okresní archiv [Archives nationales du district]

L'agence viennoise de Schmoranz obtenait de nombreuses commandes : une série de maisons de rapport et de villas de banlieue viennoises, la rénovation du palais viennois du comte Harrach, le projet du grand magasin de Lodz, la dernière phase de la construction de l'Institut géologique de Vienne, la résidence de l'évêque orthodoxe, le séminaire théologique de Zadar en Croatie. Le « style byzantin » de ce dernier fut même remarqué par le «Recueil d'architecture $»^{35}$. Son agence collabora également à des projets d'objets d'art décoratif pour les célèbres ateliers viennois de ferronnerie d'art de Valerian Gillar.

En 1878, Schmoranz fut nommé commissaire gouvernemental et chargé de l'installation du département d'art autrichien pour l'Exposition universelle de Paris. Le succès de cette installation lui rapporta une nomination au titre de conseiller de construction impérial et royal et une décoration ${ }^{36}$.

Schmoranz et Machytka furent représentés à l'Exposition par une commande du khédive Isma'il pour un projet de bains turcs ${ }^{37}$ et d'une mosquée; le second de ces projets reçut une médaille d'argent de $\mathrm{II}^{\mathrm{e}}{ }^{\mathrm{C}} \mathrm{lasse}^{38}$. Il s'agit de leur ancien projet de mausolée, dit turba [turbe], pour un martyr turc, le shaykh Gul-Baba, destiné à la ville de Buda en Hongrie. De nouveau, le projet présente une coupole monumentale richement décorée, des minarets élancés et une cour avec un bassin ${ }^{39}$. Bien que ce projet ait suscité l'intérêt, même à l'Exposition internationale de Munich de $1879^{40}$, sa réalisation fut repoussée jusqu'en 1885, date à laquelle intervint la décision définitive de faire appel à une autre solution ${ }^{41}$. La décoration et les différents éléments de construction étaient incontestablement imités de bâtiments cairotes, mais l'ensemble du projet produisait un effet extraordinairement européen, surtout par son plan qui est manifestement une copie conforme d'une église du type « Il Gesù » (fig. 18) dont la nef est remplacée par un atrium ouvert avec une fontaine. Cette apparence est encore renforcée par les deux minarets placés directement au-dessus de l'entrée (fig. 19) ${ }^{42}$. On aurait peine à trouver 
parmi les mosquées anciennes une construction d'ordonnancement aussi sévère. Au Caire, on peut citer la mosquée al-Rifa'i avec ses deux minarets qui s'élancent semblablement vers le ciel, sa coupole de la même forme, ainsi que son portail d'entrée à voûte en stalactite qui présente le même agencement. Il faut cependant noter que cette mosquée fut construite tardivement (1869 et 1912) ${ }^{43}$. Elle comprend le mausolée du khédive Ismail et de son épouse. Bien que la paternité de la mosquée al-Rifa'i soit attribuée à Husayn Fahmy pacha, son plan et sa réalisation formelle sont proches du projet de Schmoranz, proposé un an plus tôt. Le projet de mausolée signé par Schmoranz représente sans conteste la tentative d'une nouvelle acception formelle d'un lieu de piété islamique dans l'imaginaire européen.

18. Rome, plan de l'église del Gesù.

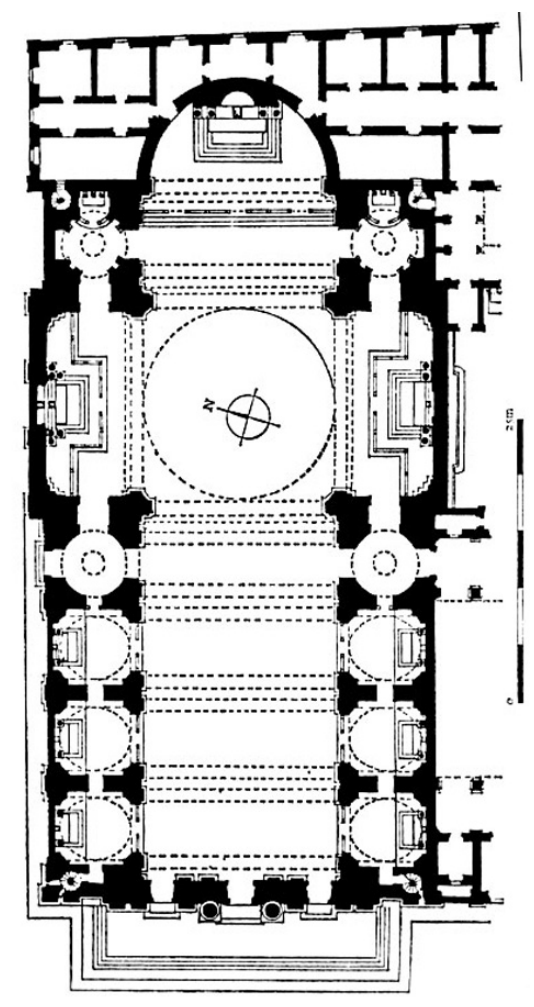

Source : Prague (République tchèque), AA NTM Archiv architektury Národního technického muzea [Archives d'architecture, Musée technique national]. 
19. František schmoranz le Jeune et Jan MACHYTKA, Projet d'une medresseh de S.A. le Khédive Ismaël pacha pour l'Exposition universelle de Paris en 1878.

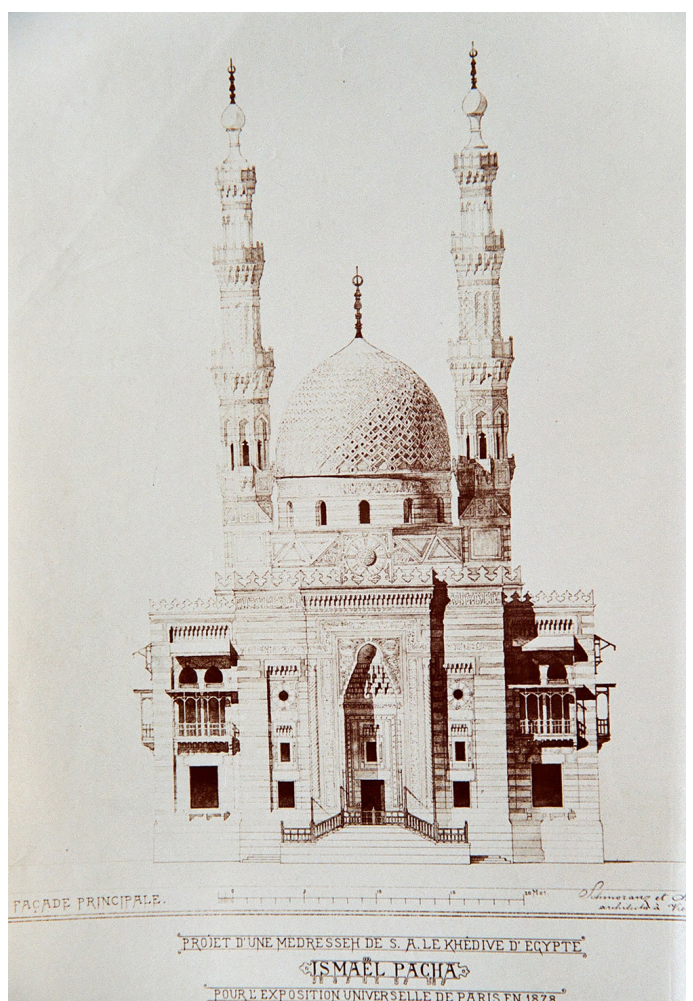

Source : Chrudim (République tchèque), SOkA Státní okresní archiv [Archives nationales du district].

Dans leur Bohême natale, Schmoranz et Machytka construisirent la synagogue dont les plans avaient été projetés par le père de Schmoranz. Les deux associés laissèrent une réalisation de moindre importance dans le style orientalisant : l'Arche d'Alliance " aron ha-kodesh» de la synagogue de Pardubice, datant de 1879 (fig. 20). Il s'agit plus précisément d'une arche-armoire caractéristique, destinée à enclore l'arche, placée devant l'arcade de la nef latérale et dotée d'un ingénieux mécanisme de porte coulissante. 
20.František SCHMORANZ le Jeune et Jan MACHYTKA, arche d'alliance de la synagogue de Pardubice, République tchèque, datée de 1879 , photographie.

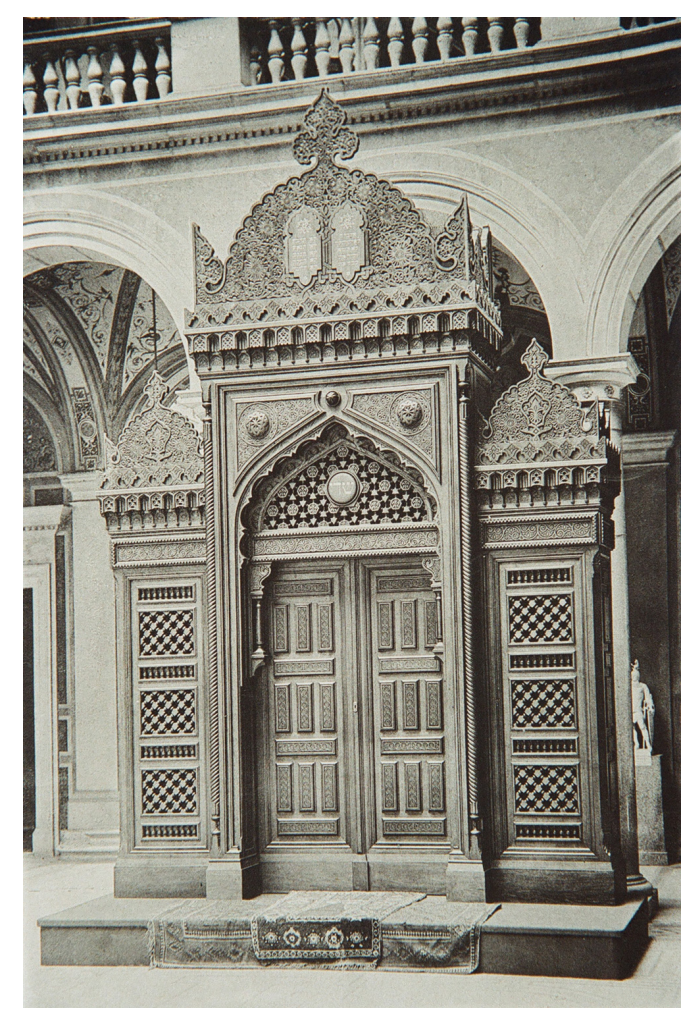

Source : Chrudim (République tchèque), SOkA Státní okresní archiv [Archives nationales du district]

La réalisation mauresque la plus célèbre de Schmoranz reste les bains « Hammam » de Trenčianske Teplice en Slovaquie, conservés jusqu'à nos jours. Il s'agit d'une adjonction aux anciens thermes datant de 1885-1887, commandée par la fille du magnat viennois de la finance, Iphigenia de Sina, duchesse de Castries. Outre les locaux de service, l'annexe de Schmoranz au rez-de-chaussée comprend également des douches, des toilettes, des cabines pour messieurs et des bassins d'eau froide et chaude. L'espace interne est un hall sur deux niveaux: au rez-de-chaussée, des arcades latérales permettent la circulation des baigneurs; à l'étage sont situées les cabines (fig. 21). L'espace central, pavé de mosaïque, est occupé par deux poêles et une fontaine centrale ; il est éclairé par des ouvertures percées dans les coupoles et par une rosace vitrée. 
21. František schmoranz le Jeune, bains de Trenčianské Teplice en Hongrie (actuelle Slovaquie), 1888 , photographie.

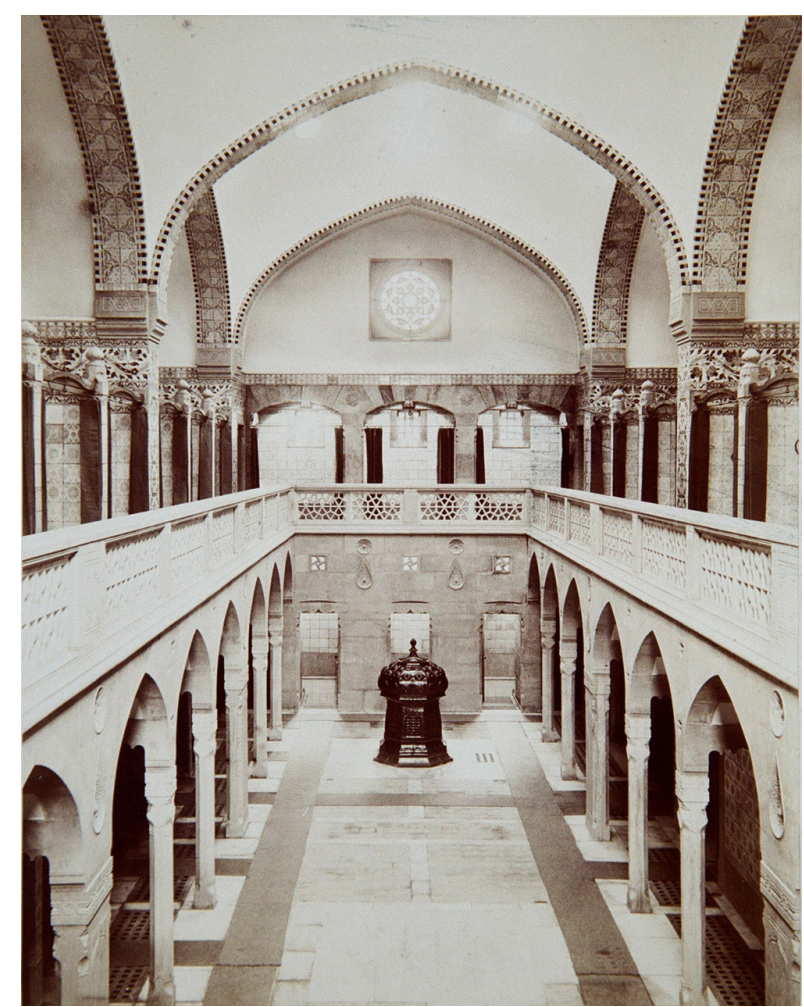

Source : Chrudim (République tchèque), SOkA Státní okresní archiv [Archives nationales du district] claires et rouges. Sur l'avant de la façade principale, il plaça de légers ressauts abritant l'appareillage des bassins couverts de coupoles octogonales basses, donnant à l'ensemble un aspect pittoresque. Cet édifice fut loué par les spécialistes pour ses «menus détails nobles, souples et dépourvus de toute dureté $»^{44}$. L'aspect de ces bains est tellement convaincant qu'on les prit pour un monument ancien, construit par les Turcs encore à l'époque du Pashaluk (province ottomane) de Budin ${ }^{45}$, dès leur inauguration.

Dans leur patrie, la plupart des grands projets de Schmoranz et Machytka prennent les formes stylistiques de la néorenaissance cosmopolite et de ses modes apparentes. Parmi leurs réalisations les plus célèbres, se trouvent les édifices de la faculté de médecine tchèque et surtout le complexe des bâtiments scolaires constitué par l'École des beauxarts, l'École des arts appliqués et l'Institut pédagogique féminin de Prague. C'est surtout le bâtiment de l'ancienne Académie qui traduit une connaissance intime de l'architecture néorenaissance viennoise, celle par exemple des façades de l'université de Vienne, évidemment revue par nos architectes à la lumière de l'historicisme tardif, par exemple en lui imprimant un contraste fondé sur la différenciation entre l'étage inférieur et la mezzanine et les deux niveaux supérieurs élevés, accentués aux angles par des fenêtres à hautes arcatures dépassant la saillie de la corniche. Les architectes firent également appel au style renaissance, qui s'appuie tout à la fois sur l'histoire régionale, mais aussi sur la "renaissance nordique", lors du concours pour la transformation de la Cour italienne (Vlašsky Dvůr) à Kutna Hora. Schmoranz revint à la néorenaissance, cette fois influencée par le classicisme baroque et l'œuvre de Gottfried 
Semper, à l'occasion du concours pour la construction du musée du Royaume de Bohême et sans doute aussi lors du concours pour le Musée nordique de Stockholm. Ce projet qui a obtenu un II prix était pour une partie des spécialistes le plus satisfaisant de tous, par sa conception inhabituelle et progressiste. Schmoranz se souvint des formes du style vieil-allemand de la région de Nuremberg pour le palais de l'industriel František Wiesner à Chrudim. Il opta également pour des formes néogothiques dans son projet de bâtiment du doyenné et le monumental tombeau de Wiesner, réalisé en s'inspirant de monuments italiens : un baldaquin gothique abrite le sarcophage placé sur un socle (fig. 22). Les deux architectes firent encore appel aux styles néoroman et byzantin dans leur projet de l'église Saint-Wenceslas de Prague. On peut aussi considérer que František Schmoranz fut le premier à adopter le style vernaculaire tchèque qu'il appliqua en Bohême orientale au pavillon de chasse du baron Richard Drasche von Wartinberg en 1881, soit une dizaine d'années avant l'apparition de la «fermette tchèque » à l'Exposition du jubilé national de Prague. À la même époque, Schmoranz proposa également pour Budapest un monumental tombeau funéraire, portant une arche d'alliance sur le faîte, pour la famille juive Fischl.

\section{František SCHMORANZ le Jeune, tombeau de la famille Wiesner à Chrudim.}

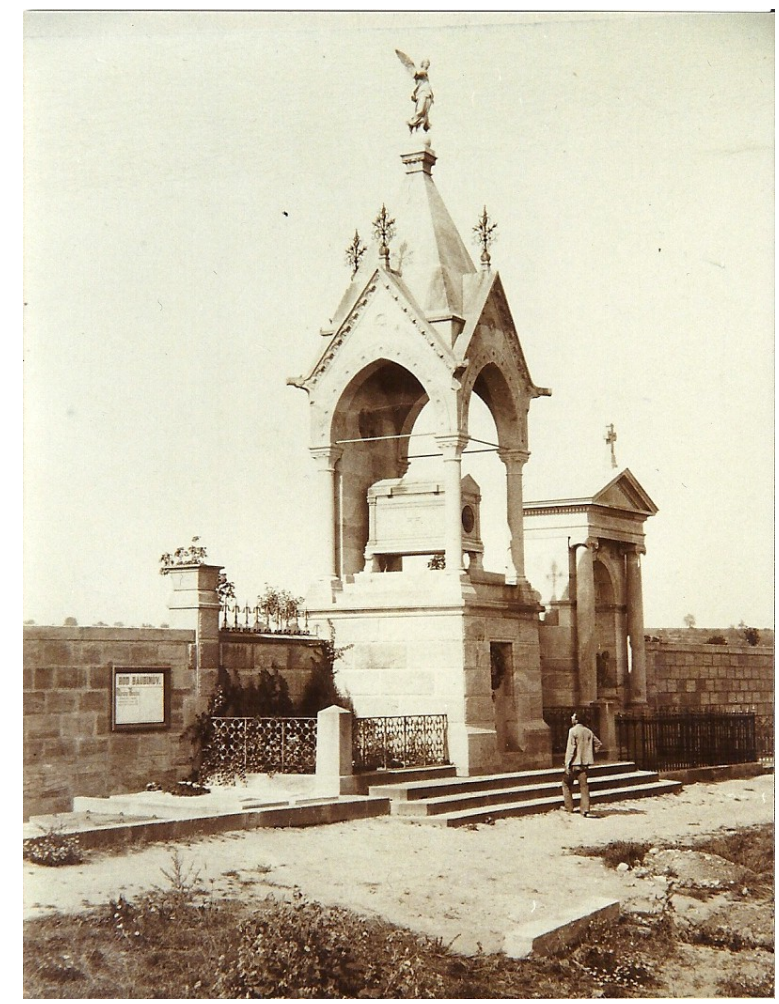

Source : Chrudim (République tchèque), SOkA Státní okresní archiv [Archives nationales du district].

Cette brève esquisse permet de saisir la variété stylistique des deux architectes et de comprendre à quel point ils avaient anticipé le pluralisme stylistique de l'historicisme tardif. Elle montre également que leur architecture islamique n'a pas eu un grand écho en Bohême, à l'exception peut-être des dessins d'objets décoratifs pour les ateliers Gillar et des projets de verrerie de style «mauresque " pour les verriers Lobmeyr \& Meyer et fils. Cet atelier réalisa aussi des projets de Gustav, le frère cadet de Schmoranz, architecte également en relation avec l'Égypte. On peut imaginer que le 
douloureux passé de l'Autriche-Hongrie avec l'Empire ottoman n'est pas étranger à ce rejet. Tandis que l'Égypte ancienne était considérée par les Autrichiens comme un symbole de fidélité, de sagesse, de justice et de durabilité, le style " arabo-mauresque " évoquait soit le souvenir des périls de l'Empire du Croissant, soit le symbole de la victoire sur le « Turc».

Dans la dernière partie de leurs vies, František Schmoranz et son frère Gustav se consacrèrent à la construction de l'École praguoise des arts et métiers, conçue selon le modèle viennois en 1885, et à l'infatigable promotion des arts appliqués en Bohême. Dans cette entreprise aussi, ils mirent à profit leur connaissance de la décoration et des arts appliqués islamiques. František Schmoranz, en qualité d'inspecteur des écoles techniques du textile, était considéré comme un spécialiste de ce domaine, car il avait compilé pour ces écoles un vaste et original catalogue de motifs historiques et modernes. À cette époque, il participa une dernière fois à une commande de galerie d'exposition orientale commandée par le Musée impérial du commerce (Österreichisches Handelsmuseum) pour l'Exposition nationale de Budapest de 1885.

27 L'originalité de la création orientaliste de l'architecte repose dans sa connaissance approfondie de l'architecture islamique, reflétée par son appel à une gamme riche et étendue de motifs ornementaux et par une compréhension exceptionnelle des concepts spatiaux et matériels. Tandis que, dans son projet du palais de Gazira, Franz Pacha procède d'une "manière libre... et non selon une affreuse tradition ancienne $»^{46}$ et que les contemporains virent dans le pavillon égyptien pour l'Exposition de 1867 construits par Jacques Drevet une " anarchie artistique ${ }^{47}$, Schmoranz et Machytka employèrent toujours le décor arabe avec discernement, en harmonie avec le cadre et la destination de l'ouvrage, mais cette démarche ne les empêcha pas de se conformer aux règles de composition architectonique en vigueur dans la culture européenne.

28 Ce qui est spécifique à la création de Schmoranz et Machytka, lorsqu'ils devaient réaliser une architecture orientale dans un cadre européen, c'est que leur entreprise repose en majeure partie sur un historicisme tardif « sévère » qui respecte la pureté du style et reflète l'aspiration a une démarche analytique rationnelle. Dans le cas d'une architecture islamique, cette démarche apporte à la connaissance des Européens une dimension exotique, inspirant un imaginaire subjectif. En revanche, les réalisations cairotes de Schmoranz relèvent d'une démarche différente qui fait appel à un mode contemporain d'architecture historique et constitue une aspiration à doter l'architecture des nouvelles nations islamiques d'une forme d'expression stylistique moderne, par une interpénétration de l'héritage historique et de projets contemporains. Les efforts du khédive Isma'il pour donner au Caire l'aspect d'une ville européenne représentent l'exemple le plus éclatant de ce mouvement. La nouvelle architecture égyptienne puise à dessein dans la tradition locale pour se distinguer ainsi de la gouvernance ottomane. On ne tardera donc pas à voir s'opposer une néorenaissance égyptienne, à laquelle participe en outre František Schmoranz, et un style néo-islamique redevable à l'environnement stambouliote. Le résultat paradoxal de ces efforts sera une oblitération des formes étrangères exotiques à la fois du monde arabe et du monde européen, pour aboutir à une sorte de préfiguration du monde globalisé.

29 Malgré son appartenance incontestable au groupe des architectes les plus illustres de l'historicisme tchèque, bien qu'il les eut surpassés à l'époque de sa plus grande célébrité par ses réalisations et son érudition, même bien au-delà des frontières 
autrichiennes, le nom de František Schmoranz le Jeune et son œuvre sont tombés dans un tel oubli qu'il est resté pratiquement inconnu de l'histoire de l'art tchèque durant tout le $\mathrm{xx}^{\mathrm{e}}$ siècle. Dans le meilleur des cas, on le confond avec son père. La raison principale en est manifestement le caractère distinctement cosmopolite de son œuvre et la perplexité qui en résulte quant à son appartenance stylistique, car sa création diversifiée ne rentre nullement dans le moule fabriqué par les historiens de l'art de l'époque, moule qui se fonde sur les deux notions antithétiques de l'«académisme rigide » et du « réalisme progressiste ».

\section{NOTES}

1. Voir ici Elke PFLUGRADT-ABDEL AZIZ, «Julius Franz-Pashas's Die Baukunst des Islam (Islamic architecture) of 1887 as part of the architectural manual», p. 297-310. URL: https:// inha.revues.org/4897. Consulté le 6 mai 2016.

2. Deutsche Bauzeitung, $\mathrm{n}^{\circ}$ 26, 1982, p. 43-44.

3. Karl [Karel] SCHNAASE, Geschichte des bildenden Künste in Mittelalter I. Altchristliche und mohammedanische Kunst, Düsseldorf : J. Buddeus, 1844, p. 321-332.

4. Franz KUGLER, Handbuch der Kunstgeschichte, Stuttgart: Ebner und Seubert, 1842, p. 393-400.

5. Anton SPRINGER, Kunsthistorische Briefe. Die bildenden Künste in ihrer weltgeschichtlichen Entwicklung, Prague : F. Ehrlich, 1857, p. 416-417.

6. Willhelm LÜBKE, Geschichte des Architectur von den Alten Zeiten bis auf die Gegenwart, Leipzig :

E. Graul, 1855, p. 165.

7. Alois RIEGL, Stilfragen: Grundlegungen zu einer Geschichte der Ornamentik [Questions de style. Fondements d'une histoire de l'ornementation, traduction française, Paris: Hazan, 1992 ; Berlin : E. Siemmens, 1893, p. 307-308.

8. Voir Gustav schmoranz, Hrad Žleby u Časlavě [Le château de Žleby u Časlavě], Édition de la famille Auesperg, 1921, Prague, p. 60-63.

9. Gustav SCHMORANZ, František Schmoranz - životopisny nastin - [Éléments biographiques], in Sbornik Čechů Dolnorakouskych [Répertoire des Tchèques de Basse Autriche], Vienne, 1895, p. 99.

10. Voir surtout les archives du ČVUT - [Institut polytechnique], notamment Franz STARK : Die K.K. Deutsche technische Hochschule, Prague, 1806, p. 467-468. Parmi les «neu ingetreten » [les nouveaux admis] de l'année 1863-1864, on trouve notamment Jan Machytka et František Schmoranz. Les registres de l'institut pour les années 1861-1868 ne nous sont malheureusement pas parvenus, ni ceux des années 1868-1869. On suppose donc que les deux architectes ont dû suivre leur formation entre 1863-1864 et 1867-1868.

11. Voir l'entrée «Machytka, Jan", in Ottův Slovnik naučny [Encyclopédie Otto], vol.16, p. 631-632.

12. Elke Pflugradt-ABdel Aziz, «A Proposal by the architect Carl von Diebitsch (1819-1869): Mudejar Architecture for a Global Civilization », inNabila oULEBSIR et Mercedes VoLAIT dirs.), L'Orientalisme architectural entre imaginaires et savoirs, Paris : Picard ; CNRS, 2009, p. 79 (D'une rive l'autre).URL : https://inha.revues.org/4919. Consulté le 6 mai 2016.

13. Voir l'entrée "Selamlik", in Emeri Johannes VAN DONZEL, Bernard LEWIS et Charles PELLAT (dirs.), The Encyclopedia of Islam (New Edition), vol. 9, Leiden : E. J. Brill, 1997, p. 123. 
14. Tareq M. R. SAQR, Early Twentieth-century Islamic Architecture in Cairo, Le Caire: The American University in Cairo Press, 1993.

15. Isabella FEHLE, Der Maurische Kiosk in Linderhof von Karl von Diebitsch. Ein Beispiel fur die Orientmode im 19. Jahrhundert, Munich : Uni-Druck, 1987, p. 5 sq.

16. Pour la photographie de la villa de Menshausen, voir SOkA [Archives nationales du district], Chrudim, archives F.S. le Jeune, fac-similé $n^{\circ} 20$, voir Isabella FEHLE, op. cit. (note 15), illustration $\mathrm{n}^{\circ}$ 10. Pour la photographie du palais de Nubar pacha, voir SokA, Chrudim, archives F.S. le Jeune, fac-similé, $\mathrm{n}^{\circ} 18$, voir ibid.p. 9 (sans illustration).

17. Isabella FEHLE, op. cit. (note 15), p. 90-91.

18. Gustav schmoRANZ, František Schmoranz, op. cit. (note 9), p. 99.

19. Zeynep ÇЕLIK, Displaying the Orient. Architecture of Islam at nineteenth century World's Fairs, Berkeley, CA : University of California Press, 1992 (Comparative studies on Muslim societies), p. 149.

20. Voir Robert ILBERT et Mercedes VOLAIT, « Neo-Arabic renaissance in Egypt, 1870-1930 », Mimar. Architecture in Development, $\mathrm{n}^{\circ}$ 13, 1984, p. 26-34, ici p. 29 ; Zeynep ÇELIK, op. cit. (note 19), p.159.

21. Isabella FEHLE, op. cit. (note 15), p. 91 ; Charles BLANC, Voyage de la Haute-Égypte, Observations sur les arts égyptien et arabe, Paris : Librairie Renouard, 1876, p. 351.

22. SOkA Chrudim, archives F.S. le Jeune, $n^{\circ}$ d'inventaire 1 , carton $n^{\circ} 56$ - Kresby z Kahiry navrh slavnostni dekorace [Dessins du Caire - Proposition de décoration solennelle].

23. Il faisait par exemple une distinction entre les types arabe, persan et "mauresque " de stalactites. Voir Georg EBERS, Aegypten in Bild und Wort. Dargestellt von unseren ersten Künstlern, vol. I, Stuttgart-Leipzig, 1879, p. 264.

24. Édition tchèque d'Otakar Hostinský voir Georg EBERS, Egypt. Slovem i obrazem ve spolku $s$ vynikajicimi umělci předvadi G. Ebers [L'Égypte en mots et en images, en collaboration avec nos meilleurs artistes proposé par G. Ebers], Praha : F. Simacek, vol. I : 1883 ; vol. II : 1884.

25. Réédition de František Schmoranz, Světozor, 1892, XXVI, p.178; Gustav SCHMORANZ, op.cit. (note 9), p. 99-100.

26. Weltausstellungsalbum. Erinnerung an Wien 1873, p. 5.

27. Zeynep çELIK, op. cit. (note 19), p.63.

28. Karlheintz Roschitz, Wiener Weltausstellung 1873, Vienne; Munich : Jugend und Volk, 1989, p. 98.

29. Johanna HOLAUBEK, "Austrian architects on the Nile (1869-1914) ", in Johanna HOLAUBEK et Hana NAVRATilova (dirs.), Egypt and Austria, I. Proceedings of the Symposium, Prague : Set Out, 2005, p. 52.

30. Ces médailles sont conservées au musée de Trenčin. Voir Ivo schulz (dir.), Rod Schmoranzů ze Slatiňan. Mozaika z dějin rodu[Les Schmoranz de Slatiňany, L'histoire de la famille en mosaïque], Slatiňany, 2002, p. 10.

31. Gustav SChMORANZ, op. cit. (note 9), p. 100.

32. L'expansion politique causa la ruine des finances khédiviales; le khédive tomba sous le contrôle d'une commission des finances européenne. En 1879, il dut abdiquer sous la pression de la France et de l'Angleterre en faveur de son fils Tawfiq. Voir Ottův Slovník naučný [Encyclopédie Otto], XVI, p. 431.

33. Gutav SCHMORANZ, op. cit. (note 9), p. 102.

34. Wilhelm LAUSER, « Die Ka'ah », Allgemeine Kunst-Chronik, $n^{\circ} 236,1883$, p. 317-319.

35. Zprava o vystavě, kterou spolek architektů a inženyrů v kralovstvi českem o velikonocích $r .1882$ uspořádal [Rapport sur l'exposition organisée par la société des architectes et des ingénieurs à Pâques au royaume de Bohême], Zpravy SAI, 1882, XVII, p. 127.

36. Gustav SCHMORANZ, op. cit. (note 9), p. 102 ; décoration mentionnée dans Claude DUCOURTIAL, Ordres et décorations, Paris : PUF, 1957 (Que sais-je, 747). 
37. E. KRASOVÁ, « Hammam », Slovenské kúpele [Les bains en Slovaquie], X/9-10, 1968, p. 105.

38. L'ubomir MRŇA, Architektura a architekti Trenčianskych Teplic [Architecture et architectes de Trenčianské], Teplice : Pamiatky a múzeá, 1997/3, p. 55 ; Gustav ScHMORANZ, op. cit. (note 9), p.100. 39. Op. cit. (note 35), p. 127.

40. «Die Architektur auf der diesjährigen internationalen Kunst-Ausstellung zu München», Deutsche Bauzeitung, vol. 13, 1879, p. 506.

41. E. BALÁZS, « Rose garden revived », The Budapest Sun, 37, 14-20.09.2000, p. 1.

42. AA NTM [Archives d'architecture, Musée technique national], fonds $n^{\circ} 44$, František SCHMORANZ et Jan MACHYTKA, Projet d'une medresseh pour S. A. le khédive d'Égypte ISMAIL PACHA pour l 'Exposition universelle de Paris en 1878 ; SokA Chrudim, archives F.S. le Jeune, Inv. $\mathrm{n}^{\circ} 6$, carton $\mathrm{n}^{\circ} 56$ - plan; Inv. $n^{\circ} 25$, carton $n^{\circ} 63$ - façade principale.

43. Voir ici István ORMOS, "Max Herz Pasha on Arab-Islamic Art in Egypt », p. 311-342. URL : https://inha.revues.org/4898. Consulté le 6 mai 2016.

44. Karel Boromejský MÁDL, Padesát let českého umění výtvarného [Cinquante années de beaux-arts en Bohême] 1848-1898. Zpamátniku České Akademie vydaného na oslavu panovnického jubilea J. V. císaře a krále Františka Josefa I. [Album de l'Académie de Bohême publié pour la célébration du jubilé de Son Altesse l'empereur Francois Joseph ${ }^{\mathrm{er}}$ ], Prague, 1898, p. 73.

45. E. SPIEGL, «Aus der Türkenzeit », Illustriertes Wiener Extrablatt, XVII/326, 24 décembre 1888, p. 1 .

46. Zeynep ÇELIK, op. cit. (note 19), p. 161.

47. Ibid., p. 137.

\section{AUTEURS}

\section{MILAN NĚMEČEK}

Ph.D. History of Architecture, Academy of Arts, Architecture and Design, Prague (République tchèque). 
De l'estampage à la photographie 


\title{
Victorien Pierre Lottin de Laval et la Lottinoplastie
}

\author{
Nicole Zapata-Aubé
}

\section{NOTE DE L'ÉDITEUR}

Sauf mention contraire, tous les documents reproduits sont l'œuvre de Victor Lottin de Laval.

1 Aventurier, voyageur, écrivain, archéologue, peintre, Lottin de Laval (Orbec, 1810Menneval, 1903), de son véritable nom Victorien Pierre Lotin, personnalité oubliée, demeure pourtant une figure emblématique du XIX ${ }^{e}$ siècle.

Issu d'un milieu normand modeste, il s'inventa une famille, un nom et une histoire. Son père, Tranquille Lotin, né à Saint-Germain-d'Aunay dans l'Orne, s'engagea à 21 ans, le 17 septembre 1791, dans le premier bataillon du Calvados. Il reçut son congé le 16 ventôse an X [7 mars 1802] à Maastricht. Il s'installa à Orbec (Calvados), apprit le métier de chapelier et ouvrit un petit commerce. En 1809, à 39 ans, on lui présenta sa future femme, la Rosière de l'année, Marie Victoire Delaval, âgée de 16 ans, choisie par le conseil municipal pour être dotée et mariée le 2 décembre, jour anniversaire du couronnement de sa majesté l'empereur. Un an plus tard, naquît Victorien Pierre. Il avait huit ans, quand sa mère, devenue chapelière, mourut en mettant au monde une petite fille, son second enfant.

C'est grâce à la littérature que Lotin devint Lottin de Laval (fig. 1), plus euphonique dans le Paris monarchique des années 1830. Au nom paternel de Lotin, il associa celui de sa mère «Delaval » qu'il modifia en « de Laval » et s'attacha ainsi aux deux grandes familles les Montmorency-Laval et les Lottin (ou Lotin) de Charny. Le désir de gloire et de reconnaissance ne cessa ensuite de le guider. À la fin de sa vie, dans une lettre adressée à son ami le docteur Célos, Lottin racontait ainsi son enfance :

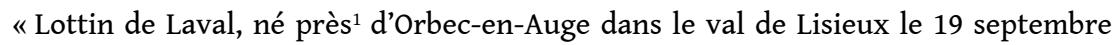
1810 d'une ancienne famille bourguignonne venue s'établir en Beauce au XIV siècle et à Paris vers 14 ... 
Une déchéance vint ruiner l'aîné du nom et son petit-fils, ayant adopté avec ardeur les idées nouvelles, s'enrôla dans les premiers volontaires de la République et fit partie de la célèbre armée de Sambre et Meuse. Il fit onze campagnes et, rentré chez lui, épousa la jeune et belle personne, Anne [sic] Victoire de Laval ${ }^{2}$.

De ce mariage, naquirent notre orientaliste et une sœur (la mère était morte peu de temps après la naissance de sa fille) qui fut élevée chez un grand-oncle paternel, monsieur Jean de Guerpel de Bar, ancien émigré, mort lieutenant-colonel à Argentan vers 1830. Le vieux colonel avait aussi voulu se charger de l'avenir de son petit-neveu mais le vétéran repoussa cette offre généreuse et éleva son fils comme il put. L'enfant était précoce, son intelligence très vive : on songea pour lui à l'état ecclésiastique et on le mit au latin dans une assez pauvre école. Cela dura quelques années, mais la gêne se faisant sentir de plus en plus au foyer paternel, il embrassa son vieux père et partit pour Paris, léger d'argent avec une instruction très imparfaite, afin d'essayer d'améliorer le sort de ceux qu'il laissait. Il n'avait pas quatorze ans. »

1. Thomas COUTURE, Portrait de Lottin de Laval, huile sur toile, 1839.

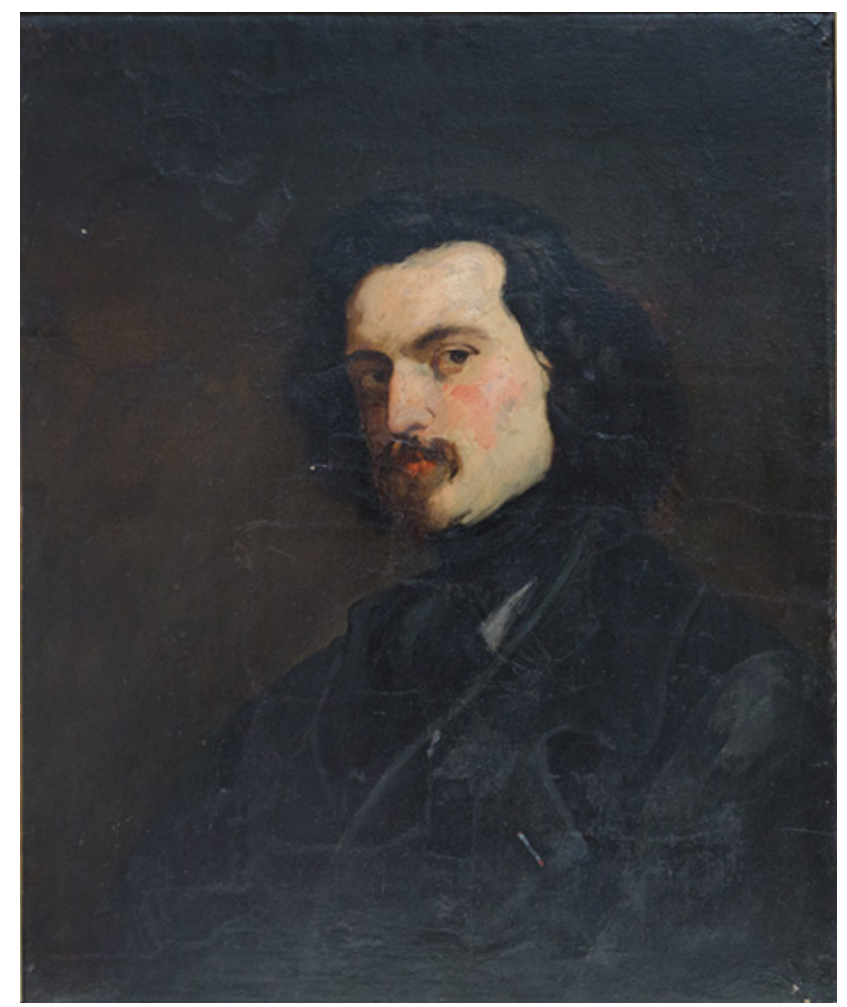

Source : Bernay (France), Musée des beaux-arts, Inv. 991.1.1.

4 Lottin de Laval quitta Orbec entre 1823 et 1824 ; les années qui suivirent, jusqu'en 1830 , restent dans l'ombre. Employé chez un épicier, puis comme « saute-ruisseau » (garçon de courses) à la mairie de Paris, il travaillait le jour et étudiait la nuit. Il semblerait avoir eu quelques appuis politiques en la personne de François Guizot ${ }^{3}$, député du Calvados qui occupa pendant quelques mois en 1830, les fonctions de ministre de l'Intérieur. Il aurait été secrétaire, comme il le rapporte :

«À treize ans et demi, Victor Lotin arrivait à Paris et se logeait chez un de ses oncles occupé tout le jour à d'ingrates besognes manuelles, l'enfant se réfugiait le soir dans la poésie des livres. Dans sa mansarde, à la lueur parcimonieuse, il parfaisait ainsi son instruction, grâce aux volumes empruntés aux cabinets de lecture. La protection de Guizot, alors ministre, le fit entrer en qualité de secrétaire 
chez le comte d'Avesnes. Il touchait cinquante francs par mois pour deux à trois heures de travail par jour. Ce passage chez un homme instruit et qui possédait une superbe bibliothèque fut des plus profitable au jeune Lottin. Peu après, toujours sur la recommandation de Guizot, il fut nommé expéditionnaire à l'Hôtel de ville aux appointements de douze cents francs par an. Assuré de l'existence, il commença à taquiner la muse, il s'essaya au théâtre, Jules Janin lui consacra dans une gazette quelques lignes bienveillantes. Lottin de Laval s'était montré dans ses œuvres et visà-vis même de ses intimes, d'une discrétion rare en ce qui concerne cette période de son existence; période de début, de demi-succès, d'illusions, et d'amertumes. Cependant, petit à petit, le jeune homme faisait son chemin. À 20 ans, il était déjà mêlé au monde littéraire et avait peu après, sa place dans le cénacle romantique. Des artistes comme Eugène Delacroix, Alfred et Tony Johannot, des poètes et écrivains comme Lamartine, Dumas et Georges Sand, des musiciens, Meyerbeer, Rossini, Berlioz, Chopin, Liszt, vivaient avec lui en complète amitié. Il allait parler littérature et art dans l'atelier de Daguerre encore décorateur, mais qui pensait déjà à sa plaque d'argent poli qui devait révolutionner le monde. En 1832, deux sémillants jeunes hommes costumés en abbés de cour se rendaient à un bal masqué chez Alexandre Dumas, c'étaient bras dessus bras dessous, Ernest Legouvé et Lottin de Laval. Ce fut dans ce bouillon de culture de choix, peut-on dire, que se développèrent de la plus heureuse manière, l'âme et l'esprit du gamin d'Orbec. $»^{4}$

5 En 1830, il publia une pièce de théâtre, Benjamin Constant aux Champs Élysées, qui fut représentée pour la première fois, à Paris, au théâtre de l'Ambigu comique, le 8 janvier 1831. Il s'agissait d'un tableau en un acte mêlé de couplets ${ }^{5}$. L'année suivante, le 8 septembre 1832, sur la même scène, fut joué Marguerite de Navarre et Clément Marot ${ }^{6}$, une comédie-vaudeville en un acte. De 1830 à 1842, il écrivit des romans historiques très documentés : Marie de Médicis ${ }^{7}$, Les truands et Enguerrand de Marigny ${ }^{8}$, Robert le Magnifique ${ }^{9}$ ou encore Le Comte de Nety ${ }^{10}$, Les Galanteries du maréchal de Bassompierre ${ }^{11}$, Andalousia, la perle des Andalouses (fig. 2) ${ }^{12}$, Les Comtes de Montgommery ${ }^{13}$ puis, enfin, en 1844, Le Tireur $d^{\prime}{ }^{14}$. L'auteur de ces romans historiques à succès ${ }^{15}$ semblait vivre désormais dans une certaine aisance financière qui lui permit d'acquérir un terrain à Menneval, nommé «Les Trois Vals ", situé près de Bernay, dans l'Eure. Il fit construire une maison de style oriental et rassembla des collections d'œuvres d'art. Doté d'un nom et d'une "fortune", il entreprit de mettre à exécution ses rêves d'aventures et de voyages. Pendant la même période, de 1834 à 1836, Lottin de Laval voyagea en Italie, en Sicile, en Dalmatie et en Illyrie ${ }^{16}$; il publia, en 1837, une relation de ce voyage, sous le titre Un an sur les chemins ${ }^{17}$. Malgré son sous-titre engageant Récits d'excursions dans la Sicile, l'Italie, l'Autriche, l'Illyrie, la Grèce, Constantinople et l'Asie Mineure (fig. 3), il n'est question dans aucun des deux tomes de son voyage en Grèce, ni à Constantinople et encore moins en Asie Mineure.

"Quand il fut las de déchiffrer des chartes poudreuses, de parcourir des collections de mémoires depuis Villehardouin jusqu'à Tallemant de Réaux, quand il eut raconté les prouesses de Tancrède de Sicile, les malheurs d'Enguerrand de Marigny, "les galanteries de Bassompierre", il voulut étudier l'histoire sur les ruines, écrire les faits que nul Hérodote n'eut racontés, demander aux caractères cunéiformes les secrets de Darius et d'Artaxerxés, retrouver l'empreinte des pas de Moïse, de Caleb et de Josué dans le sable des déserts arabiques. Il partit pour l'Asie ${ }^{18}$." 
2. Page de titre de son roman Andalousia, la perle des Andalouses, paru en 1842.

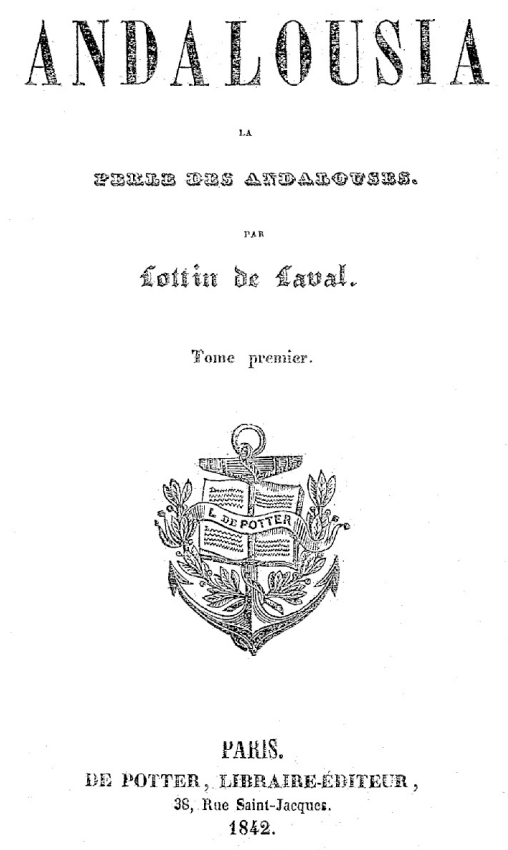

Source : Paris (France), BnF.

3. Page de titre du récit de voyage Un an sur les chemins, paru en 1837.

UN AN

sun

\section{LES CHEMINS}

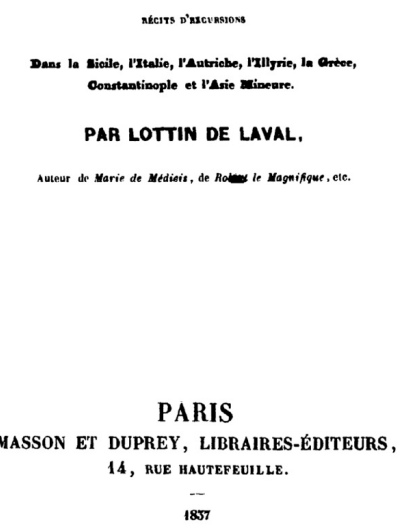

1887 


\section{Première mission en Orient : 1843-1846}

Fort de ses relations et du soutien de personnalités politiques, comme Guizot, il obtint du gouvernement français, en 1843, une mission en Orient qu'il finança en organisant la vente de ses collections personnelles conservées dans la maison des Trois Vals ${ }^{19}$.

Pour ce premier voyage vers l'Orient, il choisit la route terrestre "sur les pas des croisés du $\mathrm{xII}^{\mathrm{e}}$ siècle »: Strasbourg, Karlsruhe, Stuttgart, Augsbourg, Munich, Ratisbonne, où il s'embarqua sur le Danube jusqu'à la mer Noire et atteint Constantinople ${ }^{20}$. Dans un récit haut en couleur, Lottin de Laval évoquait, à la manière des romantiques, les harems comme celui de Kiamil Pacha en Bosnie. L'Orient exerçait son envoûtement : il céda à l'appel; à Constantinople, l'aventure orientale commença (fig. 4-5). Il rapporta de ce voyage de nombreux rapports, carnets de notes et croquis conservés aux Archives départementales de l'Eure. L'étude de ces documents révèle un esprit curieux, mais aussi un manque de formation scientifique.

4. Marine de Laodicea ad Mare (ville de Lattaquié en Syrie), mine de plomb sur papier, rehaussé à la craie blanche.

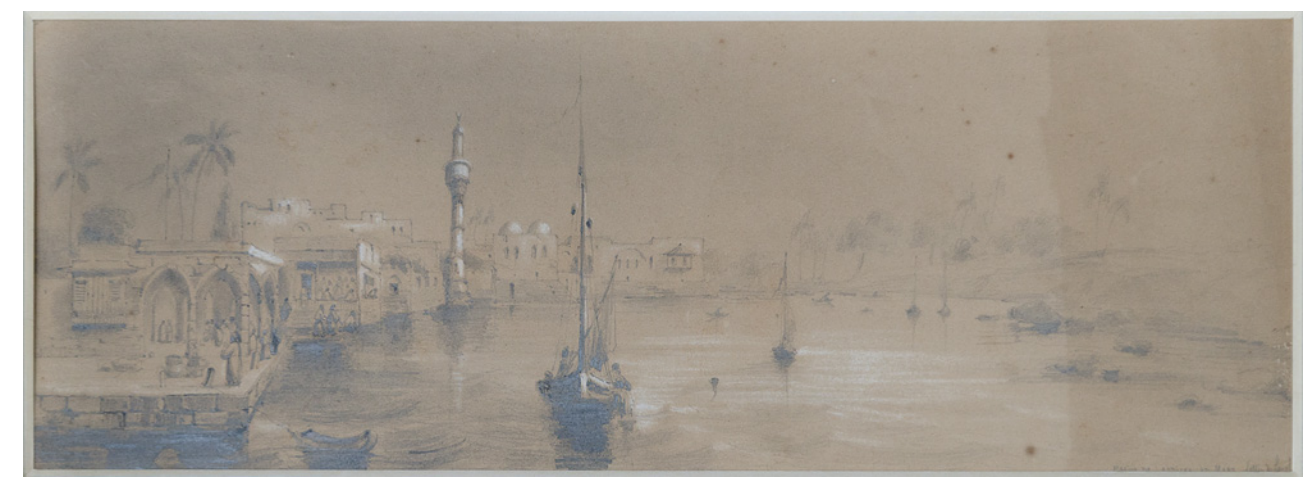

Source : Bernay (France), Musée des beaux-arts, Inv. 895.1.109. 
5. Vue de la Porte de l'Arsenal à Constantinople, mine de plomb sur papier, rehaussé à la craie blanche.

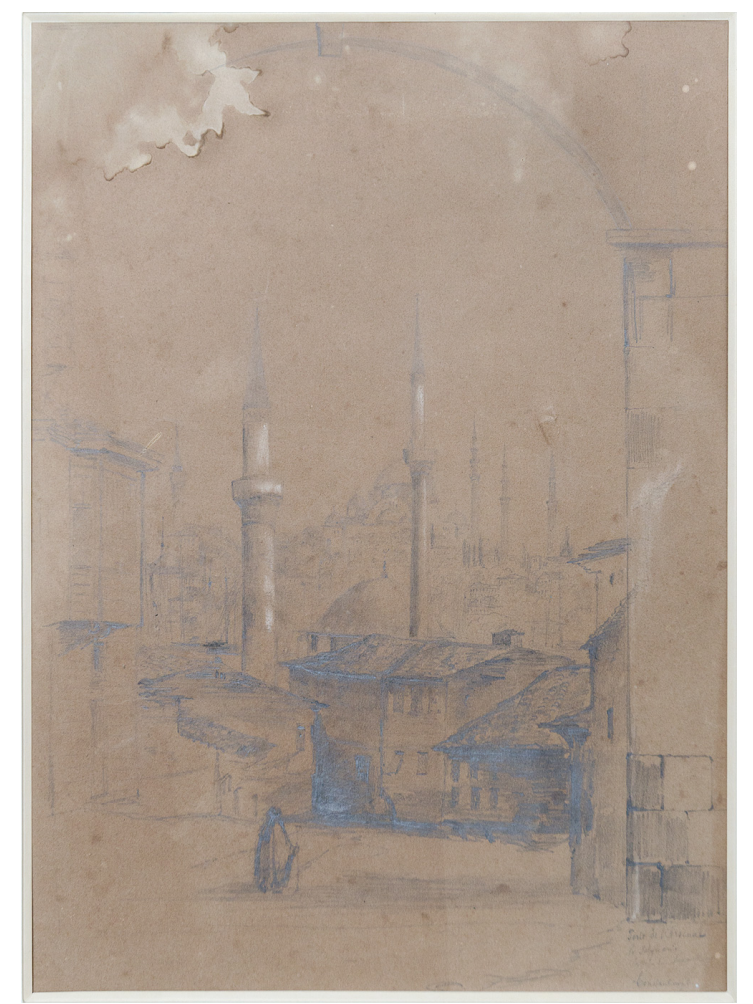

Source : Bernay (France), Musée des beaux-arts, Inv. 895.1.108.

8 La première étape, de 1843 à 1844, le conduisit en Haute-Arménie, dans l'Arabat, le Karsistan et le Suzistan. Il dessinait dans ses carnets les personnages croisés, les villes et les paysages traversés : Erzeroum, Assan Kalé, Kars, Ani... En 1845, il se trouvait en Babylonie quand il y rencontra Paul Émile Botta (1802-1870), alors consul de France à Mossoul. Il adressa au ministère un mémoire intitulé «La Babylonie - La tour de Babel ». Parmi ses compagnons de voyage, Lottin de Laval comptait Charles de Gatines qui publia en 1862 le récit de leur voyage dans le périodique de Prisse d'Avennes, $L a$ Revue de l'Orient, de l'Algérie et des Colonies ${ }^{21}$ sous le titre "Le Journal d'un voyage en Orient de Mossoul à Bagdad (décembre 1844 à janvier 1845) et de Téhéran à Bagdad (1845)» (fig. 6). Deux événements marquèrent cette mission: l'invention de la Lottinoplastie et la découverte de Ninive. 


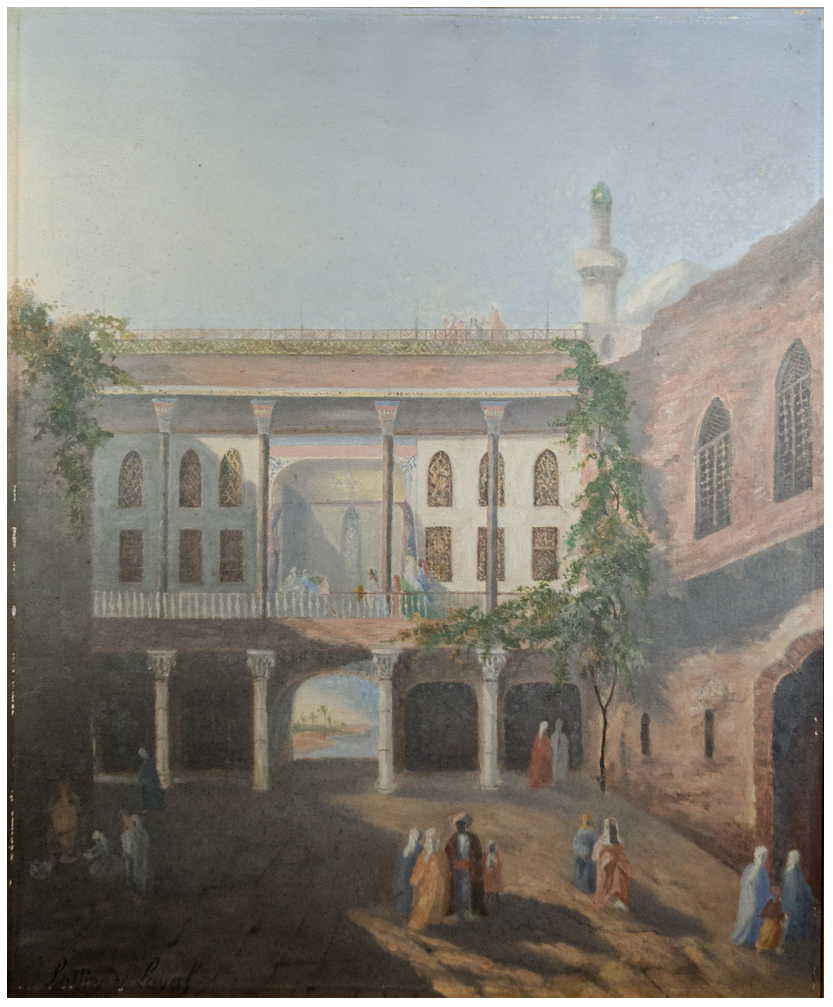

Source : Bernay (France), Musée des beaux-arts, Inv. D 983.1.3.

\section{Le procédé de moulage breveté sous le nom de Lottinoplastie ou Lottinoplastique}

Lottin de Laval s'indignait du "pillage» organisé par les Occidentaux, comme le démontage des temples pour enrichir les musées européens. Il inventa un procédé de reproduction afin d'apporter aux scientifiques des documents grandeur nature, les plus fidèles possible et qui laissaient les originaux intacts et in situ. Dans le Manuel complet de lottinoplastique $e^{22}$, publié en 1857 (fig. 7), il précisait les circonstances de la mise au point de ce procédé, acheté par le gouvernement français dès 1850 :

«Il y a bientôt vingt ans, je me trouvais à Ravenne. Frappé de l'originalité d'une ornementation de l'époque florissante des Amales, j'essayai de la reproduire à l'aide de substances légères et en même temps solides: ma tentative ne réussit que médiocrement ; je la renouvelai à Gênes en 1836, et j'obtins des résultats meilleurs ; je fis quelques moulages en plâtre par mon procédé, des sculptures d'un mince relief et des médailles pisanes. Revenu en France et forcé de me livrer à des travaux de littérature et d'art très actifs, je n'y songeai plus.

Envoyé en mission plus tard, je fis à Vân (Kurdistan) des estampages, en papier non collé, des inscriptions cunéiformes disséminées sur les rochers de l'antique forteresse, ayant remarqué que celles publiées par mon infortuné prédécesseur manquaient d'exactitude : Eugène Burnouf, de tant regrettable mémoire, le grand helléniste Letronne, m'avaient fort recommandé de faire toujours des estampages : malheureusement, je fus assailli par des neiges terribles et des pluies diluviennes dans les montagnes de la Médie Atropatène et les plaines assyriennes, durant l'affreux hiver de 1843-44; et quand j'arrivai à Djezireh-ibn-Omar, ma précieuse récolte était détruite. C'est alors que je me ressouvins des essais tentés en Italie dix 
ans auparavant. Arrivé à Bagdad, je me procurai les substances nécessaires; je moulai immédiatement des sculptures colossales, des bas-reliefs considérables; et dans un bon creux pesant quelques hectogrammes, au lieu de peser des milliers de kilogrammes comme cela a lieu par les procédés ordinaires, je coulai instantanément ces bas-reliefs en plâtre au consulat général, chez mon ami le baron de Vermars, qui, frappé de la grandeur des résultats, me promit de garder religieusement le secret... » (voir en annexe p. 155 la technique de la Lottinoplastie).

MANUEL COMPLET

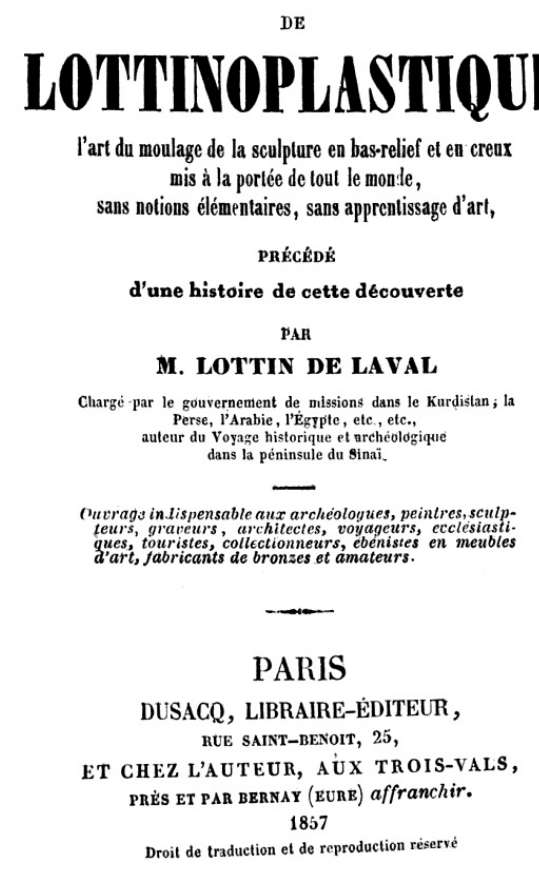

Source: Manuel complet de lottinoplastique, l'art du moulage de la sculpture en bas-relief et en creux mis à la portée de tout le monde... précédé d'une histoire de cette découverte, par M. Lottin de Laval, Paris : Dusacq, 1857.

10 Contrairement aux dessins des voyageurs, les Lottinoplasties présentaient par l'essence de leur procédé toutes les garanties d'exactitude. Dans le cas des inscriptions, les savants devaient confronter les différents dessins et des relevés, publiés ou mis à leur disposition, pour déceler celui qui faisait sens. Avec la Lottinoplastie, l'exactitude de l'empreinte est certaine, elle est généralement très nette et donne lieu à des moulages bien lisibles. C'est une avancée technique qui rend d'immenses services aux linguistes en particulier, comme s'en félicitait le voyageur et antiquaire Isidore Löwenstern (1810-1859 [?]) :

«Le procédé que M. Lottin de Laval a trouvé pour la reproduction identique des monuments, que leur volume, l'éloignement ou d'autres causes ne rendent point susceptibles de transport, est l'une des découvertes modernes les plus importantes. L'obstacle, que le doute sur la fidélité des copies opposait aux progrès des savants et de l'artiste, n'existe plus grâce à cet ingénieux procédé, qui est aussi inappréciable pour la paléographie, que pour d'autres branches des recherches historiques ${ }^{23}$. »

11 Ce procédé connut une application directe dans le domaine de l'imprimerie : il est à l'origine de l'invention du «flan », la mise au point des rotatives qui favorisèrent le 
développement de l'impression de masse et de la presse au XIX ${ }^{e}$ siècle. En effet, le flan est une feuille plastique qui prend l'empreinte d'une forme typographique plane, puis sert de moule pour réaliser une forme typographique cintrée qui s'adapte ensuite à un cylindre de rotative : c'est le principe de la Lottinoplastie.

En 1854, Lottin de Laval révéla le secret de la Lottinoplastie à son ami Léon Eugène Méhédin (1828-1905) chargé d'une mission en Égypte en 1858, effectuée en 1860, puis d'une autre au Mexique en 1864. Fort de cette technique, Méhédin réalisa un moulage de l'obélisque oriental de Louxor en 1440 heures. Ce moulage fut exposé au Salon de 1861. Intéressé par les travaux de Méhédin, Napoléon III émit le désir de voir les ruines de Thèbes reproduites dans le bois de Boulogne ${ }^{24}$, mais ce projet ne vit jamais le jour.

\section{La découverte de Ninive}

Les collections, offertes par Lottin de Laval au musée de Bernay (Eure), rassemblent des moulages de bas-reliefs, des relevés d'inscriptions cunéiformes ou des relevés de décors représentant des personnages. Certains sont datés de 1844 et identifiés comme provenant de "Ninive ${ }^{25}$ ", de "Ninive Khorsabad ${ }^{26}$ ", "de Birs Nemrod ${ }^{27}$ " et « Koïondjuk ${ }^{28}$ ». Ces relevés sont documentés par un article publié en 1899, dans le journal L'Avenir de Bernay, qui reproduit une lettre rédigée par Lottin de Laval, datée du 23 février 1899 et adressée à Gaston Delahaye à Alençon.

Après avoir étudié à Khorsabad, en 1844, les fouilles entreprises précédemment par Botta, Lottin de Laval s'embarqua sur le Tigre à bord d'un kellek (radeau composé d'outres gonflées). Il profita d'une halte pour partir en expédition en compagnie d'un berger qui lui indiqua le nom de la plaine où ils se trouvaient : « Nimroud, c'était Ninive dont je foulais le sol... »; Lottin de Laval venait de découvrir le site antique de Ninive.

Après une première exploration du site de Nimroud, il adressa une demande de crédit au gouvernement français pour le fouiller. Il n'obtint malheureusement pas les moyens espérés. Les archives de Lottin de Laval sont peu précises; toutefois, l'étude des moulages devrait permettre de mieux localiser sa découverte. Selon son récit, Lottin de Laval est alors sur le site de Nimroud-Kallah situé à $30 \mathrm{~km}$ au sud de la véritable Ninive : Quyundjiq ou Koïondjuk. En cette même année 1844, Lottin de Laval procéda à des relevés à Koïondjuk, comme l'atteste une série de bas-reliefs conservés au musée de Bernay ${ }^{29}$.

16 D'après ses écrits, il semble qu'il ait rencontré, à cette même époque, Austen Henry Layard (1817-1894), voyageur et archéologue, alors attaché à l'ambassade anglaise de Constantinople. Des indiscrétions et des renseignements fournis par Lottin de Laval luimême conduisirent Layard sur le site convoité. Officiellement, Layard découvrit Ninive en 1845, mais Botta y avait déjà entrepris les premières fouilles en 1820, et Lottin de Laval relevé des inscriptions en 1844. De retour de son «Expédition scientifique et artistique en Asie et en Afrique », qui avait duré quatre années, Lottin de Laval exposa en 1847 près de cent cinquante moulages de bas-reliefs provenant de Ninive, Babylone et de dix villes de Babylonie, de Châpour, du Khouzistan et de Persépolis (fig. 8), rapportés dans une caisse qui pesait $12 \mathrm{~kg}$. Comme l'indiquait Lottin de Laval :

«Les procédés ordinaires auraient nécessité une mission ruineuse, une dépense de plusieurs centaines de mille francs et l'envoi d'un bâtiment de l'État dans le golfe

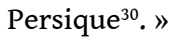


8. Buste de Djmeschid, moulage en plâtre d'un bas-relief de Persépolis, 1845.

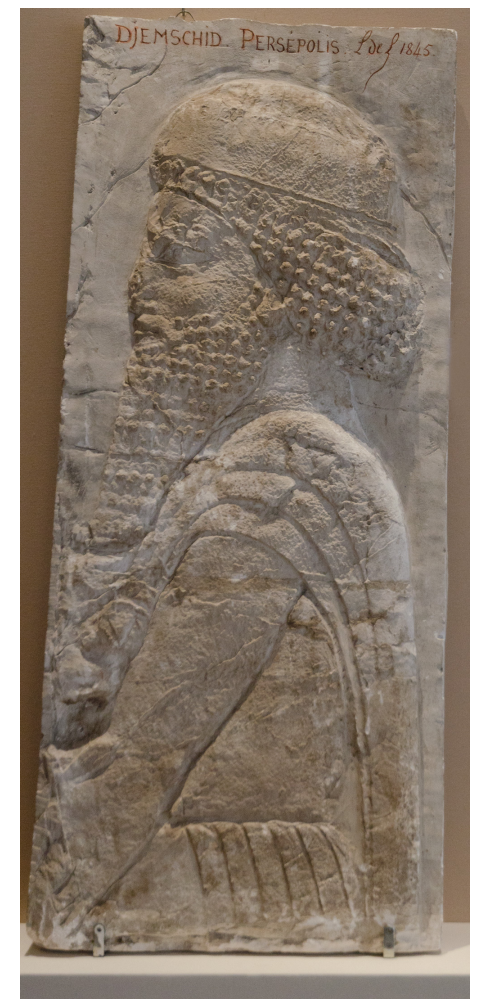

Source : Bernay (France), Musée des beaux-arts, Inv. 895.1.69

\section{Seconde mission officielle 1850-1851 : Voyage dans la péninsule arabique du Sinaï et l'Égypte Moyenne}

Lottin de Laval bénéficia désormais d'une reconnaissance scientifique, et on lui confia une seconde mission en 1850. Les objectifs furent établis dans un courrier daté du 14 décembre 1849 et signé de M. Rouge, conservateur honoraire du musée du Louvre. Ainsi Lottin de Laval était chargé de :

- « mouler en entier les anciens tombeaux de Gizeh [...]

- dans la presqu'île du Sinaï, mouler toutes les inscriptions portant des dates et des cartouches royaux qui se trouvent principalement à Ouadi-Magarah [...]

- le plus intéressant sujet de moulage serait la décoration d'un tombeau à Benihapour et une colonne cannelée d'un péristyle dans la même localité [...]

-à Thèbes, moulage d'un sarcophage [...]

- colosse de Memnon [...]

- deux inscriptions gravées sur les rochers en face de ce colosse [...]

- des chapiteaux dans divers endroits ${ }^{31}$.

Une facture de l'hôtel d'Orient à Alexandrie ${ }^{32}$ date le début de son voyage du 14 janvier 1850. Lottin de Laval remonta ensuite le Nil jusqu'au Caire où il prépara son expédition qui devait le conduire de l'Égypte au Sinaï, sur les traces des Hébreux. Les documents conservés aux archives de l'Eure à Évreux permettent de le suivre pas à pas dans son voyage ${ }^{33}$. Il adressait de nombreux rapports au ministère de l'Instruction publique et des cultes, à monsieur de Saulcy, membre de l'Institut, et des lettres à sa jeune épouse 
Marguerite restée en Normandie. Le 15 février 1850, il se dirigea vers Suez. Il visita ensuite la région de Memphis, les carrières de calcaire de Tura, les pyramides de Dahchour, Saqqarah et d'Abousir. Il continua de mouler des stèles ou des bas-reliefs dans les hypogées avant de retourner au Caire pour relever des inscriptions et des décors arabes de mosquées et de tombeaux, bien que cette tâche n'ait pas été mentionnée dans la liste de ses missions (fig. 9-10). A son retour, Lottin de Laval décora sa maison avec ces moulages. Il en fit aussi des tirages dont la vente lui apportait quelques revenus. Enfin, les moulages furent offerts et conservés au musée de Bernay.

9. Inscriptions kouphiques, moulage en plâtre d'une stèle de la mosquée d'Ibn Tulun au Caire, 1850.

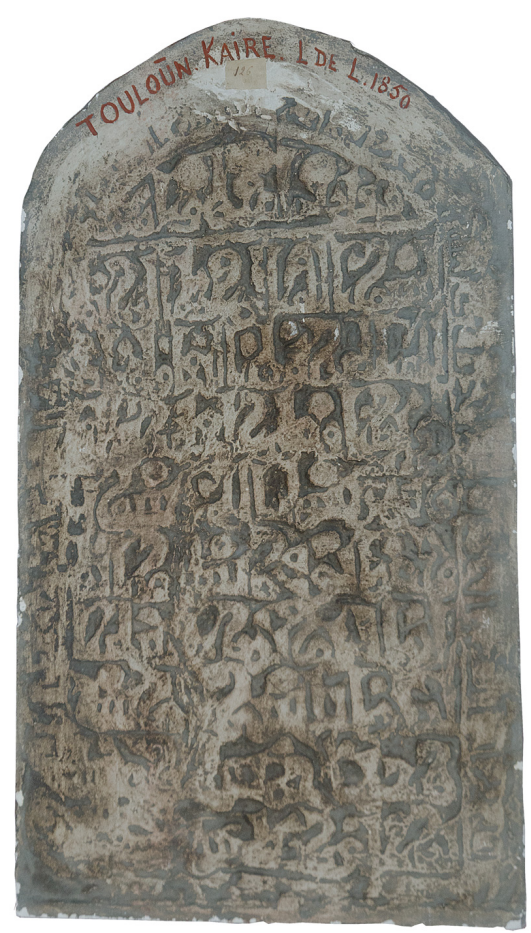

Source : Bernay (France), Musée des beaux-arts, Inv. 895.1.47.

10. Inscriptions arabes, moulage en plâtre d'un bandeau épigraphique portant la mention Member [mimbar] de la mosquée funéraire du Sultan Barkouk [Barquq], Le Caire, 1850.

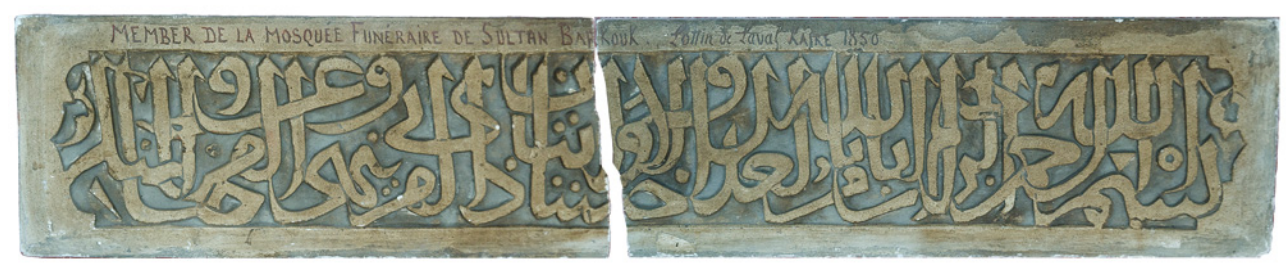

Source : Bernay (France), Musée des beaux-arts, Inv. 895.1.58.

19 du Sinaï et de l'Égypte moyenne ${ }^{34}$. Lottin de Laval rapporta de nombreux relevés d'inscriptions sinaïtiques, publiés ensuite dans son ouvrage et une moisson impressionnante de moulages effectués selon son procédé. Lors de son embarquement à Alexandrie le 23 mai 1850, il fit enregistrer ses bagages avec un excédent de $200 \mathrm{~kg}$ 
correspondant à des centaines de mètres carrés de bas-reliefs estampés. Parmi ces documents, il faut citer le relief de Sahouré relevé à Ouadi-Maghara ${ }^{35}$ dont il décrivit la découverte dans le rapport, adressé au ministère de l'Instruction publique et des cultes, publié en 1851 par l'Imprimerie nationale ${ }^{36}$.

Une commission de l'Académie des inscriptions et belles-lettres se réunit le 25 avril 1851 pour examiner les travaux de Lottin de Laval en Égypte. Les conclusions du rapport sont élogieuses pour leur auteur :

"On pourra étudier et comparer ensemble cette longue série de caractères singuliers dont les analogues ne se rencontrent point ailleurs et dont l'existence dans la péninsule du Sinaï forme un problème historique dont il n'est pas facile de donner la solution ${ }^{37}$."

21 Sa publication intitulée Voyage dans la péninsule arabique du Sinaï et de l'Égypte moyenne (fig. 11) est composée d'un volume de texte et d'un autre de planches selon les modes de reliure. Le récit du voyage ne contient que peu d'informations sur le séjour de l'auteur au Caire, ni aucune indication sur les motivations de Lottin pour mouler des œuvres d'art arabe, et encore moins sur son goût pour celui-ci. Lottin procéda sur place à quelques moulages qui font l'objet de quatre planches consacrées à l'art islamique du Caire (fig. 12-13). Certains des moulages reproduits sont conservés au musée de Bernay (Eure) mais aucun moule fait in situ ne semble faire partie d'une collection publique. Les moulages sont d'une grande exactitude et l'on saisit bien l'enthousiasme d'un linguiste comme Löwenstern : l'empreinte très nette peut être étudiée à loisir par les savants. Dans la plupart des cas, le plâtre a été enduit d'un badigeon qui restitue l'aspect ocré de la pierre. Toutefois, le système a ses limites: en effet, Lottin publia certains moulages (ou la totalité de sa production?) en planches en les présentant en registres avec pour seule légende le nom des édifices où les moulages avaient été effectués : par exemple «Tombeaux d'Imam Schafei [Shafi'i] et des Sultans (Kaire)» ou pire "Monuments arabes du Kaire "... Aucun dessin ou croquis le plus sommaire ne permet de localiser l'emplacement des inscriptions moulées sur les façades ou à l'intérieur de l'édifice; le texte d'accompagnement reste extrêmement flou et ne met en valeur que la témérité de l'auteur. C'est tout à fait dommageable, car la perte d'information est énorme. Lottin avait pourtant pris la peine d'inscrire sur chacun des moules le nom de l'édifice de provenance, parfois une localisation plus significative («member [mimbar] de la mosquée funéraire du sultan Barqouq [Barquq] », supra fig. 10), son nom et la date. Il est difficile de croire qu'aucune note ou croquis n'aient jamais complété ce travail. Malheureusement, ceux-ci s'ils existent, n'ont pas été publiés dans Voyage dans la péninsule arabique du Sinaï et de l'Égypte moyenne. Pourtant, Lottin fit quelques dessins sur place (fig. 14) et peignit des tableaux, peut-être à son retour en France (fig. 15). Dans son ouvrage, Manuel complet de lottinoplastique, Lottin insistait sur l'importance de la notation du lieu directement sur le moule :

«Une précaution que tous les voyageurs doivent prendre, c'est d'écrire sur chaque creux, au-dedans, au moment même où on le détache du monument, la provenance et le caractère de l'œuvre ; j'ai toujours agi ainsi dans mes voyages et m'en suis bien trouvé : sans cela comment aurais-je pu me reconnaître en face de milliers de monuments entassés l'un sur l'autre dans une simple caisse et provenant de tant de coins différents du globe $! »^{38}$ 
VOYAGE

DANS LA

\section{PÉNINSULE ARABIQUE}

DU SINAÏ

ET L'ÉGYPTE MOYENNE

HISTORB, GÉOGRAPHB, EHGGRAPHIS

rout soess usa nusperes

De S. E. M. L. MINISTRR DR LiNSTRUCTION PUBLQUE ET DES CULTES

PAn

M. LOTTIN DE LAVAL

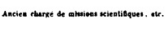

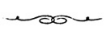

PARIS

GIDE ET C", ÉDiteurs

5, AOB BOMAPAATI

1855-1859

Source : Voyage dans la péninsule arabique du Sinaï et l'Égypte moyenne. Histoire, géographie, épigraphie publié sous les auspices de S. E. M. le Ministre de l'instruction publique et des cultes, Paris : Gide et Cie, éditeurs, 1855-1959.

12. Inscriptions kouphiques, trois moulages en plâtre de bandeaux épigraphiques. Le bandeau inférieur porte la mention Turbé de Sultan Abd er-Rhamann ['Abd al-Rahman], Égypte.

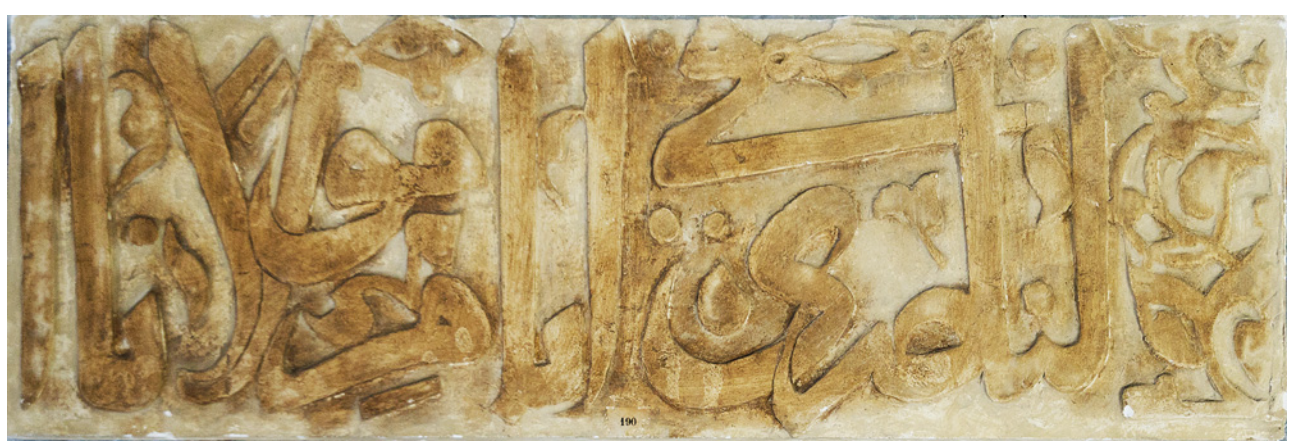

Source : Bernay (France), Musée des beaux-arts, Inv. 895.1.103, 895.1.104 et 895.1.105. 
12. Inscriptions kouphiques, trois moulages en plâtre de bandeaux épigraphiques. Le bandeau inférieur porte la mention Turbé de Sultan Abd er-Rhamann ['Abd al-Rahman], Égypte.

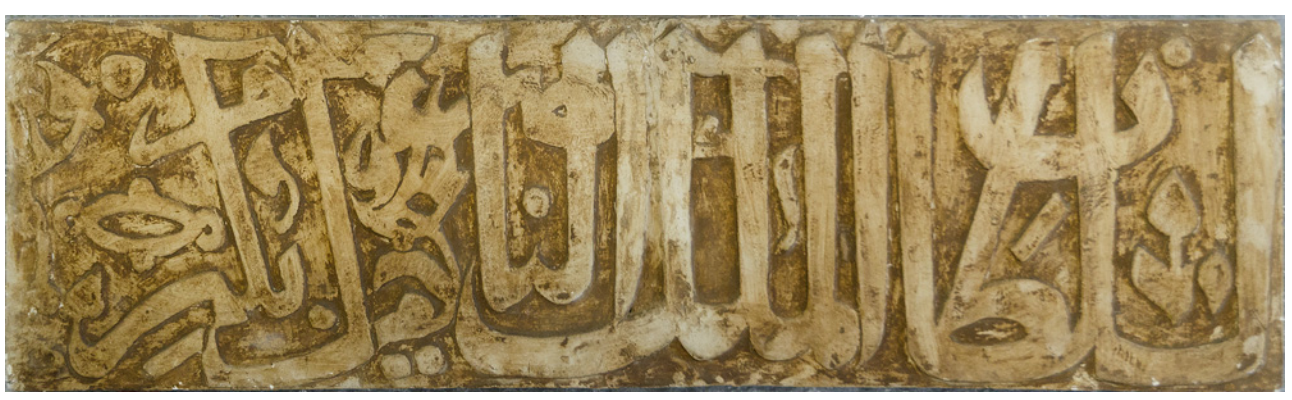

Source : Bernay (France), Musée des beaux-arts, Inv. 895.1.103, 895.1.104 et 895.1.105.

12. Inscriptions kouphiques, trois moulages en plâtre de bandeaux épigraphiques. Le bandeau inférieur porte la mention Turbé de Sultan Abd er-Rhamann ['Abd al-Rahman], Égypte.

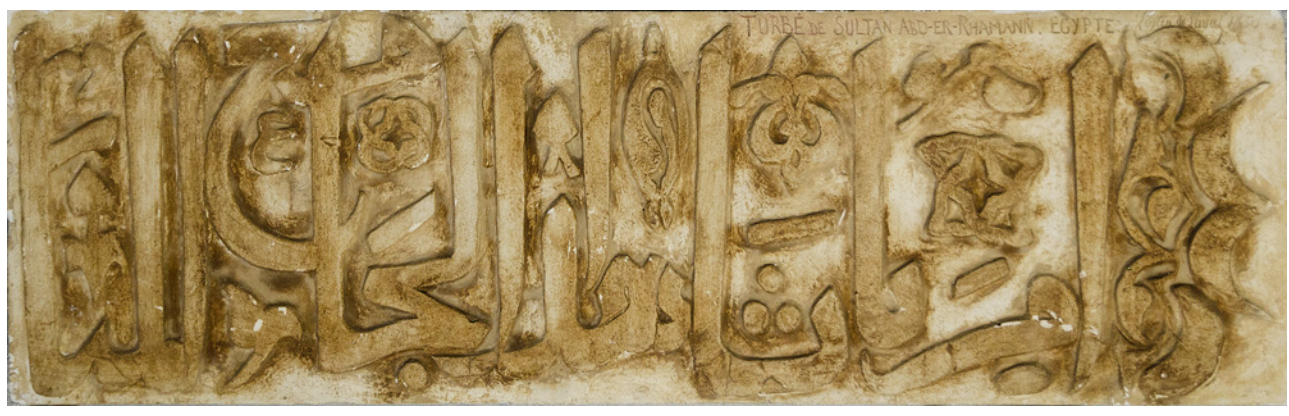

Source : Bernay (France), Musée des beaux-arts, Inv. 895.1.103, 895.1.104 et 895.1.105. 
13. Monuments arabes du Kaire: les trois moulages de la figure 12 sont reproduits sur cette planche extraite de Voyage dans la péninsule arabique du Sinaï et de l'Égypte moyenne, 1855-1859.
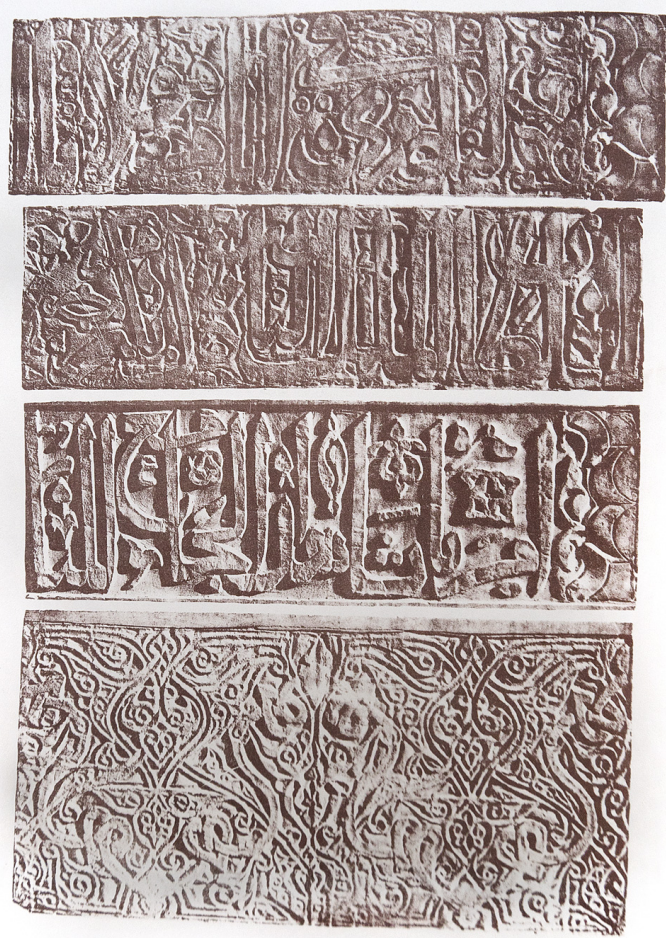

Source : Voyage dans la péninsule arabique du Sinaï et l'Égypte moyenne. Histoire, géographie, épigraphie publié sous les auspices de S. E. M. le Ministre de l'instruction publique et des cultes, Paris : Gide et Cie, éditeurs, 1855-1959. 
14. Kaire, mine de plomb sur papier, rehaussé de couleur.

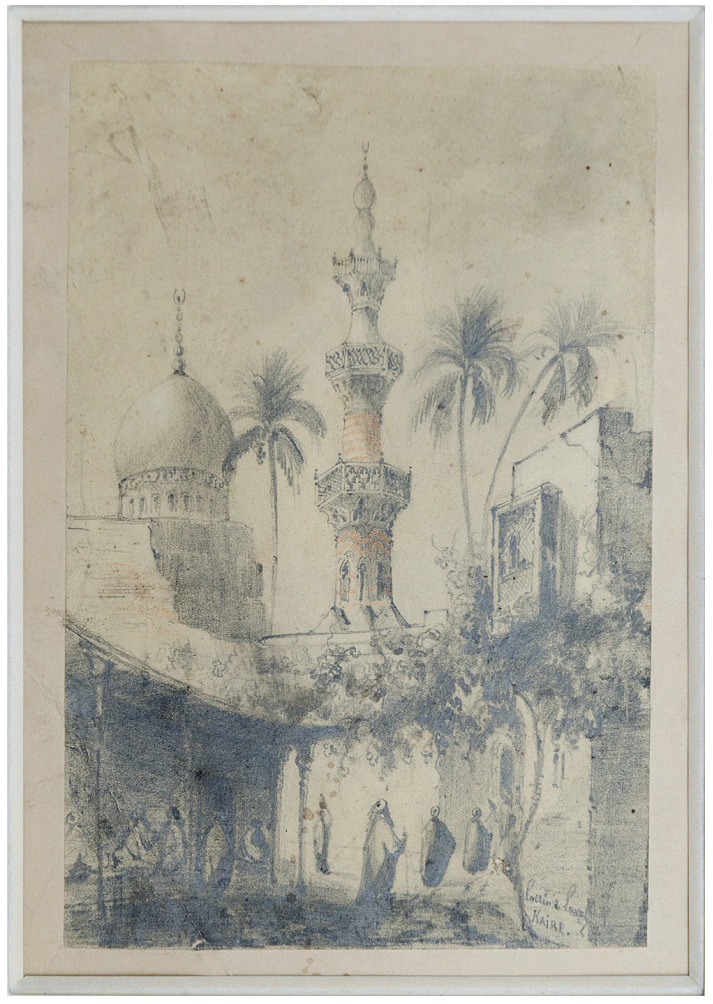

Source : Bernay (France), Musée des beaux-arts, Inv. 895.1.107.

15. Rue du Caire en 1846, huile sur toile, 1895.

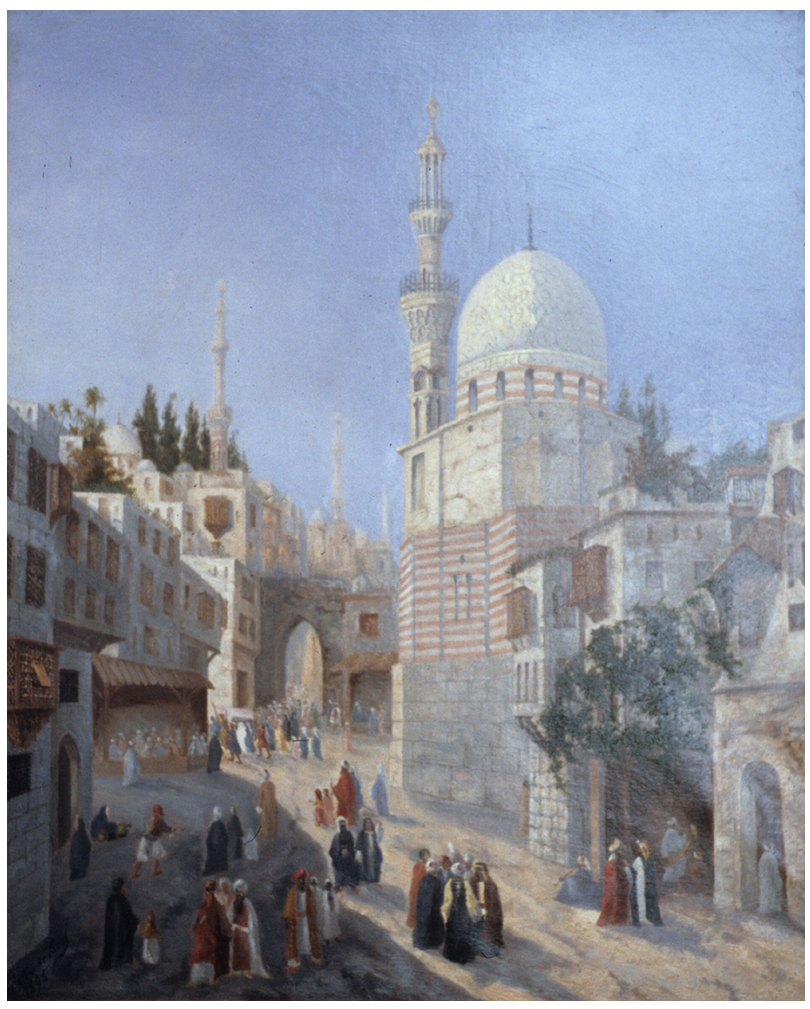

Source : Bernay (France), Musée des beaux-arts, Inv. D 983.1.4. 
Le procédé de la Lottinoplastie était parfait pour reproduire des stèles ou des frises, en revanche une restitution d'ensemble manquait cruellement. Les frises des planches de son livre ne donnent qu'une image très fragmentaire du décor sculpté de quelques édifices islamiques du Caire non identifiés. On peut d'ailleurs se demander si l'inventeur n'était pas victime de son procédé: il ne semblait s'intéresser qu'aux inscriptions ou aux frises, en vérité des éléments faciles à mouler selon sa méthode. Il en est de même pour les inscriptions du Sinaï et les stèles de Ninive dont la taille réduite convenait parfaitement à sa technique. Il est difficile de dire si c'est cette dernière qui guidait ses choix ou s'il sélectionnait des éléments en fonction de ses centres d'intérêt. La liste des tâches définies dans sa mission semblent colossales en regard des moyens techniques qu'il possédait : « mouler en entier les anciens tombeaux de Gizeh" et [un des] "colosse de Memnon ». Cependant, Lottin avait tendance à utiliser le qualificatif « colossal » pour des reliefs qui semblent beaucoup plus réduits, comme par exemple ceux exposés au musée de Bernay, qui mesurent généralement 1 mètre environ de long: "S'il s'agit d'inscriptions d'une dimension considérable ${ }^{39}$, comme les inscriptions arabes du Kaire et des tombeaux des califes et des sultans ${ }^{40}$ ou encore, à propos du transport des moules dans des caisses pour l'expédition en France : "J'ai plié de cette façon en cinq ou six bandes d'une longueur assez considérable, ainsi que les beaux ornements de la mosquée el-Azar [al-Azhar], du tombeau du sultan Barkouk [Barquq] et de cent autres lieux [...] $»^{41}$

Toutefois, en dépit de la propension de l'auteur à l'exagération, les contraintes techniques n'étaient pas seules en cause pour limiter la taille des moulages que lui seul juge gigantesque. La description de sa manière d'opérer explique pourquoi il ne pouvait mouler des reliefs de très grandes dimensions :

«Il y avait de grandes difficultés d'exécution : les cheiks des mosquées, les mollahs, sont très fanatiques pour la plupart, et s'adresser à eux afin d'obtenir une autorisation, c'eût été tout compromettre; je préférais agir d'une façon plus téméraire. [...] Arrivé à el-Azar [al-Azhar] ou ailleurs, j'appliquais immédiatement mon échelle au-dessus du monument convoité par moi ; [...] et en quelques minutes mon travail était terminé ; alors pliant bagage en un clin d'œil, nous remontions sur nos ânes et nous quittions rapidement la place, laissant les spectateurs ébahis. Plusieurs fois je fus inquiété, menacé par les mollahs, mais grâce à l'ophtalmie, qui fait que tout égyptien a la vue basse, on ne s'apercevait même pas que je laissasse mes moules sécher sur l'œuvre; l'après-midi, je revenais à l'heure de la sieste chercher les travaux du matin et je rentrais chez moi harassé, mais bien heureux. $»^{42}$

Le musée du Louvre acheta à leur auteur huit cents moulages qui devaient être présentés selon des conditions bien précises décrites ici :

« convenablement dans l'escalier monumental qui conduit au musée assyrien au premier étage. Ces objets, placés ainsi seraient près de leurs analogues, ne se confondraient cependant pas avec la collection $»^{43}$.

Le Louvre proposa un atelier à Lottin de Laval. En 1851, deux cent quatre-vingt-deux pièces issues de ces moulages furent exposées dans la galerie égyptienne, puis disparurent peu à peu, peut-être victimes de destructions ${ }^{44}$.

Les années 1850 et 1851 marquèrent l'apogée de la carrière de Lottin de Laval: ses collections étaient entrées au Louvre, la publication de son Voyage dans la péninsule arabique du Sinaï et de l'Égypte moyenne était en cours, mais la reconnaissance officielle tardait à venir. Lottin espérait recevoir la Légion d'honneur ou obtenir la direction 
d'une grande mission. En 1851, le ministère lui proposa une mission d'envergure en Mésopotamie et en Médie. Il serait chargé « de relever, de décrire les monuments découverts et exécuter des moulages et des estampages pour les inscriptions en utilisant son procédé ». En août 1851, il apprit qu'il ne pourrait partir comme chef de mission ${ }^{45}$ mais seulement en qualité de conseiller et de technicien avec son procédé de Lottinoplastie. La direction du projet était confiée à l'archéologue et diplomate Victor Place (1818-1875) ${ }^{46}$, à Jules Oppert, futur professeur de philologie et d'archéologie assyrienne au Collège de France (1825-1905) ${ }^{47}$, et à l'orientaliste Fulgence Fresnel (1795-1855). Lottin de Laval refusa un rôle qu'il jugeait subalterne.

Son nom apparut une dernière fois pour un projet en Angleterre. Frédéric Mercey lui proposa une campagne de moulages au British Museum de Londres ${ }^{48}$. Les archives ne révèlent aucune trace de l'aboutissement de ce projet. Lottin de Laval n'en parla jamais. Aigri, las d'attendre une grande mission qui ne vint pas, il se retira dans sa demeure des Trois Vals à Menneval. Attendant en vain l'appel de Paris, il sombra peu à peu dans l'oubli. Il consacra son temps à la peinture, reprenant ses carnets de croquis et ses notes, et combinant des éléments orientaux dans ses tableaux. Il étudia l'histoire normande ${ }^{49}$ et participa à l'aménagement du musée de Bernay. Dans sa maison transformée en palais oriental, il recevait, drapé dans des soies chamarrées, les hôtes de passage au milieu de ses propres œuvres (fig. 16-17).

Malgré ses aspects pratiques indéniables, la Lottinoplastie n'apporta à son inventeur qu'une renommée fugace. De même, ses découvertes archéologiques furent attribuées à d'autres et les chantiers de fouilles conduits par d'autres savants. Ses œuvres littéraires et sa peinture ont subi le même sort : l'oubli.

16. Caravane surprise se réfugiant chez l'imâm Zadé dans le Khôrasan, huile sur toile, vers 1887.

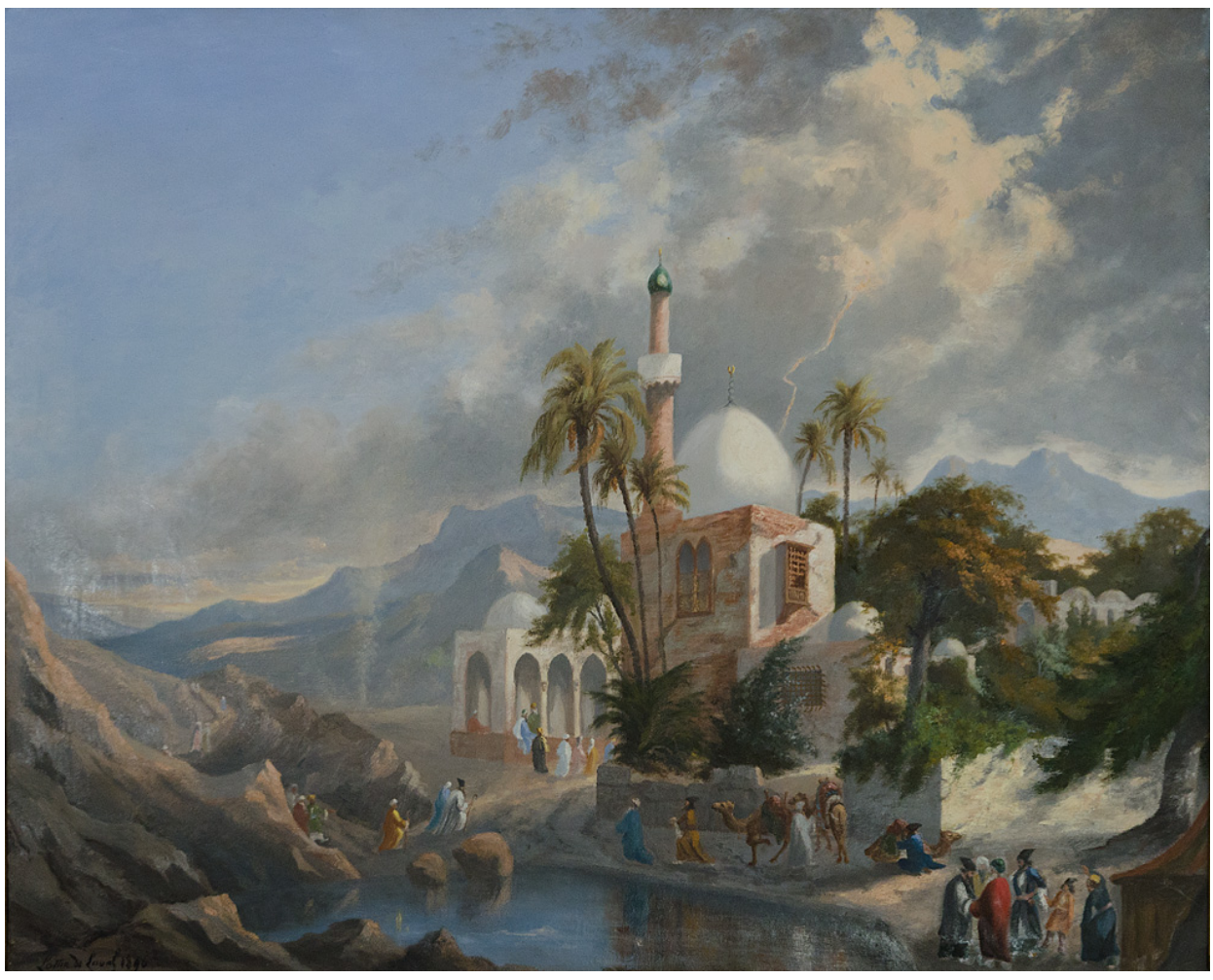

Source : Bernay (France), Musée des beaux-arts, Inv. 866.8.2. 
17. Lottin de Laval dans son atelier de la demeure des Trois Vals à Menneval, photographie, 1898.

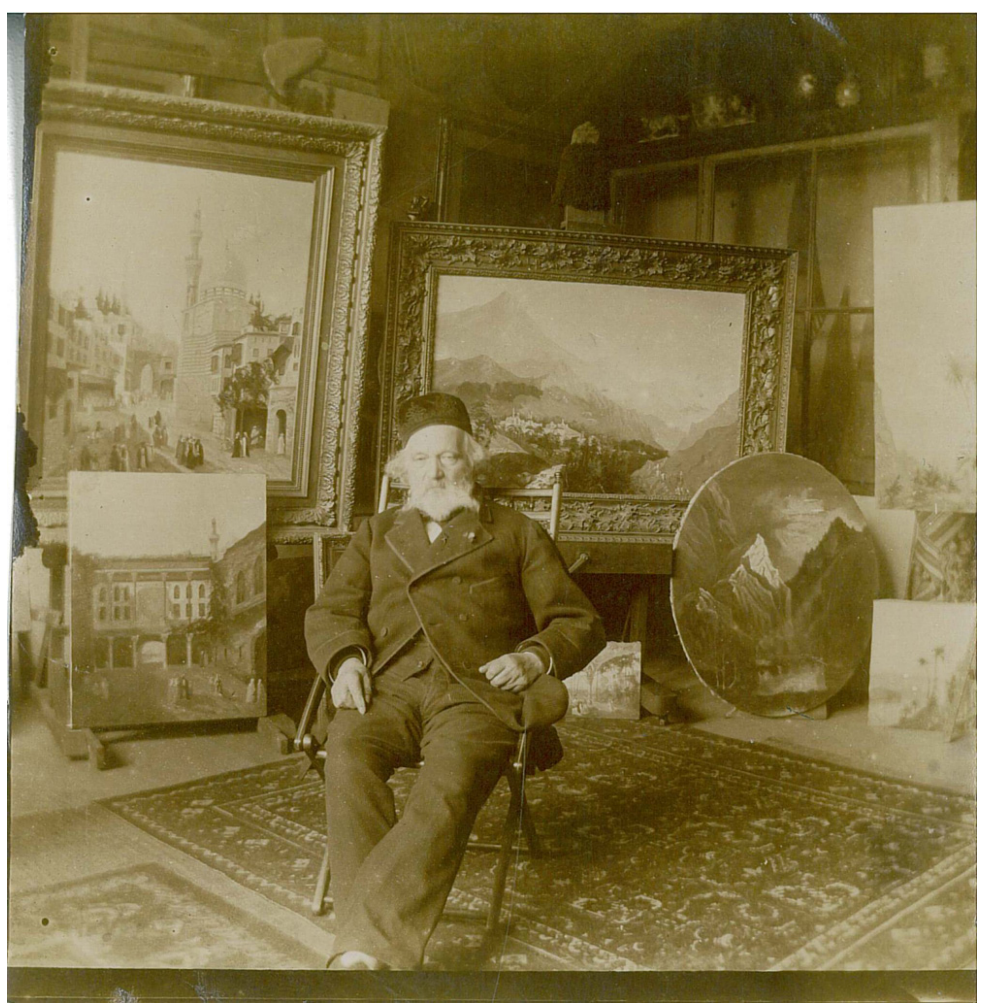

Source : Collection J.-L. Montaggioni.

Inscriptions en arabe, moulage en plâtre d'un bandeau épigraphique provenant du tombeau de l'imam Schafeï [Châfi'i] à Basâtîne, au sud du Caire, 1850.

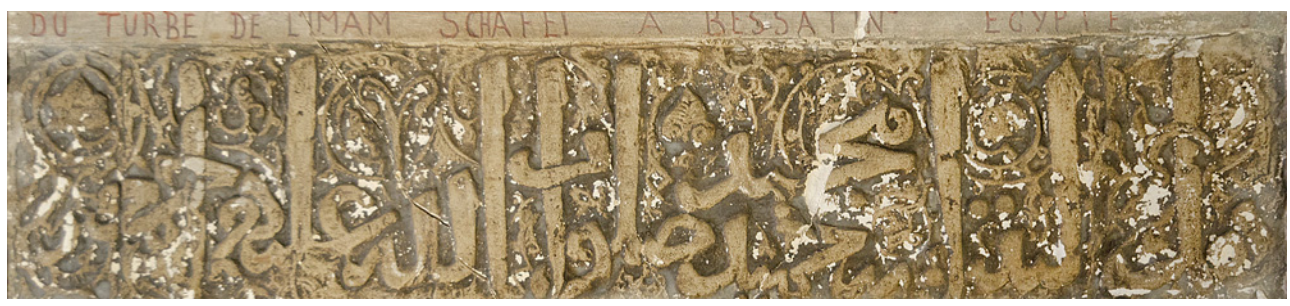

Source : Bernay (France), Musée des beaux-arts, Inv. 895.1.55.

Inscriptions en arabe, moulage en plâtre d'un bandeau épigraphique effectué lors de la mission en Arabie Pétrée de la région de Memphis, 1850.

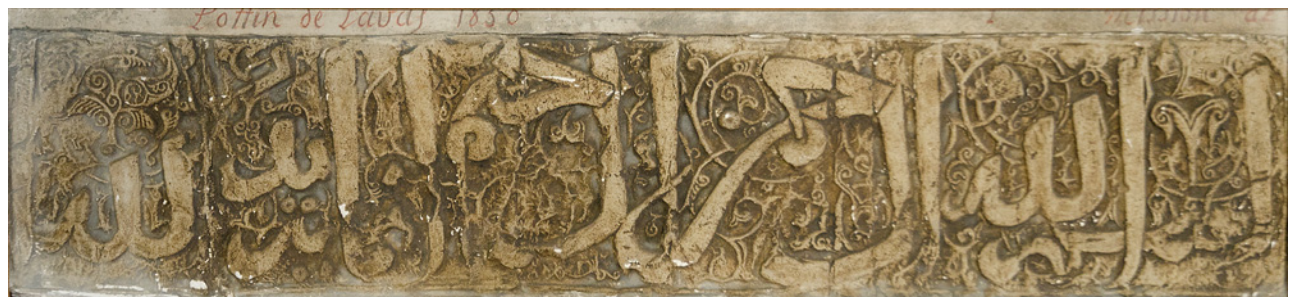

Source : Bernay (France), Musée des beaux-arts, Inv. 895.1.56. 


\section{ANNEXES}

\section{Procédé de moulage de $M$. Lottin de Laval}

Émile Isambert, Itinéraire descriptif, historique et archéologique de l'Orient, I, Grèce et Turquie d'Europe, Paris : Hachette, 1873, p. XXXVI-XXXVII (collection des guides Joanne).

Les objets nécessaires sont :

$1^{\circ}$ plusieurs rames de papier épais, connu dans le commerce sous le nom de gris-bulle, couronne-bulle ou carré-bulle $; 2^{\circ}$ une terrine $; 3^{\circ}$ un gros pinceau de badigeonneur et une large brosse de sanglier ; $4^{\circ}$ de la pâte de papier (qu'on trouve dans tous les bazars d'Afrique ou d'Asie) ; $5^{\circ}$ de la colle de farine (composée de : farine, 1 litre ; alun de roche, 50 grammes) $; 6^{\circ}$ de la gélatine (de pieds de mouton, de gazelle, ou colle de Givet commune ; on peut en fabriquer même dans le désert, avec les restes des animaux qui servent à l'alimentation) ; $7^{\circ}$ de la cire jaune ; $8^{\circ}$ de l'huile grasse ; $9^{\circ}$ de la térébenthine.

Toutes ces substances se trouvent facilement dans les bazars d'Orient. Le plus important à emporter est le bon papier bulle. - Pour faire le moulage d'un grand basrelief, avec saillie considérable, on le mouille à grande eau, puis on fait détremper le papier pendant 30 secondes environ, et on le macule fortement (chose très-essentielle). On en superpose 8 à 10 feuilles dans une large terrine ou un plat en fer blanc, après 30 secondes, on retire la feuille de dessous pour l'appliquer sur le bas-relief, à la partie la plus saillante ; on l'étend dans toute sa longueur, avec le moins de plis possible, et l'on tamponne légèrement avec le gros pinceau. Cette opération doit être continuée sur toute la surface du bas-relief, en ayant soin de superposer les feuilles l'une sur l'autre, de façon que la feuille derrière ne couvre que les deux-tiers de la première. Quand le bas-relief est recouvert dans toute son étendue, on tamponne de nouveau avec le gros pinceau ou une brosse molle. Des déchirures ont lieu, surtout si ce sont des objets de haut relief ; mais ce n'est d'aucune importance ; on doit alors couvrir chaque déchirure avec du même papier collé, plié en double ou en triple, puis on prend de la pâte à papier, qu'on déchire par carrés de 20 centimètres, et qu'on plonge en double dans la terrine. Cette pâte absorbe beaucoup d'eau, et on l'applique rapidement sur toute la superficie du bas-relief, puis avec la large brosse de sanglier, en frappant vigoureusement. Si quelque partie saillante du relief se découvre, on ajoute encore du papier et de la pâte, et l'on tamponne avec précaution. S'il se trouve des creux ou des dessous dans le bas-relief, appliquez-y hardiment de la pâte, et, avec des ébauchoirs à modeler, poussez-là dans tous les creux, puis avec les doigts, pétrissez fortement vos contours. Ce travail préparatoire fini, faites sur toute la surface de votre bas-relief une vigoureuse aspersion d'eau, évitant toutefois d'en introduire par le haut entre le marbre et la pâte, ce qui la ferait se détacher; puis prenez de la colle de farine très cuite, délayée avec de l'eau saturée d'alun, et mêlée au besoin, d'un peu de blanc d'Espagne ; enduisez tout votre bas-relief de ce mastic, et appliquez ensuite une couche générale de papier bulle, en tamponnant fortement. - Cette seconde opération terminée, on le recouvre d'un enduit de gélatine, et on applique une nouvelle couche de papier en tamponnant, et collant bien avec de la colle de pâte les côtés de votre enduit sur la pierre, pour que le vent ne détache pas le moulage si une partie séchait avant l'autre. 
Lorsque le moule est bien sec, on le détache avec précaution ; s'il y a encore de l'humidité dans les épaisseurs, on les met sécher à l'ombre, puis on enduit le tout soit de suif fondu, soit de l'huile additionnée de cire jaune ( 3 onces ou 90 grammes) et d'essence de térébenthine (2 onces ou 60 grammes par litre d'huile). On expose alors le bas-relief à un soleil ardent, qui fait pénétrer les corps gras dans les bons creux, et les met ensuite à l'abri de la pluie, de la neige et de l'humidité. Il faut enduire ensemble le dessous du moule de la même mixtion, et sécher de nouveau. On a alors des bons creux, qui peuvent séjourner 24 heures dans l'eau sans s'altérer. - Pour le transport de ces moules, on les enferme dans une caisse en bois, en les scindant, au besoin, avec de forts ciseaux, en plusieurs pièces bien numérotées qu'il sera facile de rapprocher au retour. Une caisse de 5 pieds de long sur 66 centimètres de large et autant d'épaisseur, a suffi à M. Lottin de Laval pour rapporter toute sa collection des bas-reliefs de Persépolis. - Au retour, mais au retour seulement, on devra faire subir aux moules une dernière cuisson devant un grand feu, puis, quand ils seront tout brûlants, les enduire à l'intérieur d'une mixtion composée d'huile de lin cuite avec de la litharge, de la cire jaune et de l'essence de térébenthine, et chauffer ensuite, dans un four, à $80^{\circ}$ ou $100^{\circ}$, pendant une demiheure. - Les bons creux peuvent alors servir à tirer autant d'épreuves en relief qu'on voudra. - En résumé, substituer de la pâte de papier au plâtre pour le moulage, consolider avec la colle de farine aluminée et la gélatine, puis sécher au soleil avec de la mixture grasse : tel est le procédé de M. Lottin de Laval.

Pour une inscription ou une sculpture de peu de relief, on peut naturellement mettre beaucoup moins de pâte, et prendre moins de précautions.

\section{NOTES}

1. Il s'invente un nom et une famille et cherche à brouiller les pistes : il est né à Orbec.

2. Anne Victoire Delaval était la fille d'un petit propriétaire rural qui n'avait que le nom en commun avec l'illustre maison Laval.

3. François Guizot, 1787-1874, député du Calvados de 1830 à 1848, ami proche du duc de Broglie, député de l'Eure, son voisin.

4. Victor LE FORT, «Lottin de Laval, le père du flan », Revue illustrée du Calvados, avril 1914. URL: http://www.bmlisieux.com/normandie/lottin01.htm. Consulté le 2 novembre 2015.

5. Benjamin ANTIER, Victor LOTTIN et Édouard DAMARIN, Benjamin Constant aux Champs-Élisées; un tableau en acte mêlé de couplets, Paris : Malaisie, 1830.

6. Victorien Pierre LotTIN DE LAVAL, Marguerite de Navarre et Clément Marot, Paris : Dondey-Dupré, père et fils, 1832.

7. IDEM, Marie de Médicis, histoire du règne de Louis XIII, d'après les manuscrits inédits du cardinal de Richelieu et d'un bénédictin, 1610-1642, Paris : A. Dupont, 1834.

8. IDEM., Les Truands et Enguerrand de Marigny, histoire du règne de Philippe le Bel, Paris: H.

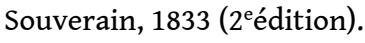

9. IDEM, Robert le Magnifique, histoire de la Normandie au XI siècle, Paris : A. Dupont, 1834.

10. IDEM, Le Comte de Nety (1074-1086), Bruxelles : J. Jamar, 1838.

11. IDEM, Les Galanteries du maréchal de Bassompierre, Paris : Hortet et Ozanne, 1839.

12. IDEM, Andalousia, la perle des Andalouses, Paris : L. de Potter, 1842.

13. IDEM, Les Comtes de Montgommery, roman historique, Paris : L. de Potter, 1842.

14. IDEM, Le Tireur d'or, Nancy : impr. Hinzelin, 1844. 
15. Stendhal parle de Lottin de Laval dans la Lettre à monsieur E. D. Forgues à Paris : "Civita Vecchia le 12 janvier 1840 [...] Ne me répondez pas par politesse, je vous dégage de cet ennui. Le roman est-il mort? Pourquoi ? que font les dames qui s'ennuient à la campagne de huit à dix heures du soir? Est-ce tout simplement qu'on ne lit plus les romans de M. Lottin ? Rome a été bien amusante depuis deux mois. Rien d'héroïque dans l'œil, mais éduqué, voilà tout. ».

16. Ses carnets de ce voyage sont conservés à la bibliothèque municipale de Rouen.

17. Victorien Pierre LotTIN DE LAVAL, Un an sur les chemins. Récits d'excursions dans la Sicile, l'Italie, l'Autriche, l'illyrie, la Grèce, Constantinople et l'Asie Mineure, Paris : Masson et Duprey, 1837, 2 vol.

18. Léon TYSSANDIER, Figures parisiennes, Paris : P. Ollendorff, 1887.

19. Voir Nicole ZAPATA-AUBÉ (dir.), Lottin de Laval, archéologue et peintre orientaliste, 1910-1903, Bernay : Édition de l'Association pour la promotion de la culture, 1997.

20. Cette première partie de son voyage est publiée dans Recueil de la Société d'agriculture, sciences, arts et belles-lettres du département de l'Eure, tome 5, 1917, p. 80.

21. Paris : Éditions B. Duprat, 1862.

22. Victorien Pierre LotTIN DE LAVAL, Manuel complet de Lottinoplastique, l'art du moulage de la sculpture en bas-relief et en creux mis à la portée de tout le monde, sans notions élémentaires, sans apprentissage d'art, précédé d'une histoire de cette découverte, Paris : Dusacq, 1857.

23. Isidore LÖWENSTERN, Exposé des éléments constitutifs du système de la troisième écriture cunéiforme de Persépolis, Paris : A. Franck, 1847, p. 76.

24. D'après Dollfus, dans Bulletin de la Société française d'égyptologie, 80, octobre 1977, p. 19 (document émanant du secrétariat de l'Empereur et signé du chef de cabinet Marquant).

25. Bernay (France), Musée des beaux-arts, Inv. 895.1.59, 895.1.65, 895.1.66, 895.1.70, 895.1.71, 895.1.78, 895.1.86.

26. Bernay (France), Musée des beaux-arts, Inv. 895.1.63, 895.1.64, 895.1.72, 895.1.73, 895.1.74 et 895.1.75.

27. Bernay (France), Musée des beaux-arts, Inv. 895.1.94 et 895.1.97.

28. Bernay (France), Musée des beaux-arts, Inv. 895.1.68 et 895.1.87.

29. Bernay (France), Musée des beaux-arts, Inv. 895.1.68 et 895.1.87.

30. Nicole ZAPATA-AUBÉ, "Lottin de Laval. Premiers voyages", in Nicole ZAPATA-AUBÉ, op.cit. (note 19), p. 52.

31. Paris (France), musée du Louvre, documentation des Antiquités orientales ; B4 1850, Lottin de Laval. Ces archives conservent également une correspondance entre Lottin de Laval et l'administration du Louvre.

32. Évreux (France), Archives départementales de l'Eure, fonds Lottin de Laval, IIF.

33. Évreux (France), Archives départementales de l'Eure, fonds Lottin de Laval, série IIF 3708 à IIF 3722.

34. Victorien Pierre LOTTIN DE LAVAL, Voyage dans la péninsule arabique du Sinaï et l'Égypte moyenne: Histoire, géographie, épigraphie publié sous les auspices de S. E. M. le Ministre de l'instruction publique et des cultes, Paris : Gide et $C^{\text {ie }}, 1855-1859$.

35. Voir l'article d'Anne АмIOT, «Voyages dans la péninsule arabique du Sinaï et de l'Égypte moyenne », in Nicole ZAPATA-AUBÉ, op. cit. (note 19), p. 61-108.

36. Archives des missions scientifiques et littéraires, janvier 1851.

37. Le Moniteur du 7 mai 1851.

38. Victorien Pierre LOTTIN DE LAVAL, Manuel complet de Lottinoplastique, op. cit. (note 22), p. 61-62.

39. C'est nous qui soulignons.

40. Victorien Pierre LOTTIN DE LAVAL, Manuel complet de Lottinoplastique, op. cit. (note 22), p. 60-61.

41. Ibid.

42. Victorien Pierre Lottin de Laval, op. cit. (note 34), p. 308-309. 
43. Lettre du directeur des Musées au ministère de l'Intérieur du 30 mai 1850, Paris, Archives des musées nationaux, musée du Louvre, Antiquités orientales B4.

44. Anne Аміот, «Lottin de Laval au musée du Louvre », in Nicole ZAPATA-AUBÉ, op. cit. (note 19), p. 114-115.

45. Évreux (France), Archives départementales de l'Eure, IIF 3717, série de lettres de François Génin à Lottin de Laval.

46. La mission eut lieu et fut publiée: Victor PLACE, Ninive et l'Assyrie, Paris : Impr. impériale, 1867.

47. Jules OPPERT, EXpédition scientifique en Mésopotamie exécutée par ordre du gouvernement de 1851 à 1854..., Paris : Impr. impériale, 1868-1869. Les notes de Fulgence Fresnel, décédé à Bagdad en 1855, furent incluses dans cette publication.

48. Évreux (France), Archives départementales de l'Eure, IIF 3712, lettre de Mercey à Lottin de Laval.

49. Victorien Pierre LOTTIN DE LAVAL, Bernay et son arrondissement, souvenirs et notices historiques et

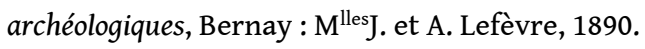

\section{AUTEUR}

\section{NICOLE ZAPATA-AUBÉ}

Conservatrice en chef du patrimoine, directrice du musée Massey, Tarbes, France. 


\title{
L'époque des amateurs : 1839-1860
}

\author{
Hélène Bocard
}

février 2013

1 Dès les premières semaines qui suivirent l'annonce publique, par le député François Arago en août 1839 du procédé Daguerre, des artistes se rendirent en Égypte munis d'une chambre noire. Le 21 octobre de la même année, le peintre Horace Vernet (1789-1863), son élève Frédéric Goupil-Fesquet (1817-1878) et son neveu Charles-Marie Boulton s'embarquaient à Marseille pour rejoindre l'Égypte avec le projet de gagner ensuite la Palestine et le Liban; ils emportaient une chambre noire fournie par l'opticien Lerebours. Au Caire, ils rencontrèrent Pierre-Gaspard-Gustave Joly de Lotbinière (1798-1865), un Suisse devenu Canadien qui s'essayait aussi au nouveau medium et qui se joignit à eux. Grâce au récit illustré qu'en fit Goupil-Fesquet, on connaît les détails de ce voyage ${ }^{1}$. À peine arrivés, les trois hommes furent invités au palais de Muhammad 'Ali ; curieux d'assister à une démonstration du daguerréotype, le vice-roi, à la fois stupéfait et inquiet, s'exclama à l'issue de l'opération : « c'est l'ouvrage du diable!». Goupil-Fesquet évoqua à plusieurs reprises ses déboires avec le daguerréotype, qui nécessitaient de nombreux préparatifs :

«Tout daguerréotypeur passionné connaît l'angoisse d'une opération aussi palpitante d'intérêt, surtout quand l'image désirée est conquise au prix de longues fatigues, après une course de deux lieues, pendant laquelle un âne indomptable vous cahote avec votre chambre obscure sur les genoux, sans que vous puissiez modérer son allure, ni faire comprendre vos désirs à l'ânier. Bref, mon épreuve est manquée ou à peu près. "

Il obtint malgré tout quelques résultats :

« Il me paraissait bien humiliant de rentrer au Caire sans rapporter aucun souvenir des monuments les plus célèbres du monde, en dépit des dénigrements de mes compagnons qui menaçaient de jeter le daguerréotype au Nil, comme un bagage de surcroît ; j'ai la patience, et à moi seul, il est vrai, de préparer encore une dizaine de planches que je polis tant bien que mal et avec toute la rapidité possible ; je m'avise de faire le contraire des prescriptions de M. Daguerre, et, grâce à cet expédient j'obtiens successivement quatre et cinq épreuves tant du sphynx (sic) que des pyramides, en laissant les images exposées pendant 15 minutes au soleil. » 

ensuite gravées et publiées en 1841 par Lerebours dans le premier volume des Excursions daguerriennes.

Dans les années qui suivirent, d'autres voyageurs équipés d'une chambre noire se rendirent en Égypte: Joseph Philibert Girault de Prangey qui étudia l'architecture arabe et mauresque (1842-1844); Gérard de Nerval, dont les essais au daguerréotype furent malheureusement infructueux (1843), ou encore Jules Itier, directeur général des douanes, qui prenait des photographies à l'occasion de ses missions commerciales, et qui parcourut l'Égypte en 1845-1846. À l'exception de Girault de Prangey, les images rapportées par ces voyageurs concernent surtout les vestiges pharaoniques ou les bords $\mathrm{du}$ Nil et très peu la ville arabe. Même si la vogue orientaliste était alors en plein épanouissement, le mouvement initié par l'expédition d'Égypte, à la suite de laquelle se constitua l'égyptologie comme discipline scientifique, focalisait l'attention sur les vestiges de l'Antiquité. Il faut aussi avancer des raisons d'ordre technique : la longueur du temps de pose requis par le daguerréotype rendait difficile à fixer sur la plaque la ville grouillante de monde, d'animaux et de charrettes en mouvement. On citera pour exemple un passage du récit de Pierre Trémaux, Voyage en Éthiopie au Soudan oriental et dans la Nigritie ${ }^{2}$ :

«je serpentai à travers ses ruelles étroites et tortueuses, où, pressé par la foule, tantôt on se heurte aux nombreuses montures de tout genre qui les parcourent, ou bien aux angles saillants des maisons qui anticipent démesurément et sans règle sur ces ruelles, tantôt on se courbe pour laisser passer par-dessus sa tête les charges des gigantesques chameaux qui, avec les ânes, servent, à l'exclusion des voitures, au transport des voyageurs et des marchandises au Caire. »

Une vue prise au daguerréotype vers 1843 montre une place étrangement vide, où seul est visible un homme assis sur un escalier, que l'on a dû faire poser plusieurs minutes ${ }^{3}$. Des lithographies publiées en 1847 d'après des dessins d'Antonio Schranz montrent des rues du Caire peuplées de personnages ; alors que les photographies prises par le même vers 1850 donnent à voir des vues très peu animées. Très vite, cependant, la technique photographique s'améliore et les procédés se diversifient : négatif papier (procédé de Talbot amélioré par Blanquart-Evrard en 1847, procédé sur papier ciré par Le Gray en 1851), négatif sur verre à l'albumine (1847), négatif sur verre au collodion (1851). Les temps de pose raccourcissent de façon significative et les vues commencent à se peupler de personnages (parfois à l'état de trace quand ils ont bougé). Malgré ces améliorations, la réussite d'une image dépendait beaucoup du soin qu'on apportait aux différentes opérations (préparation, développement, fixage) et en Orient les photographes rencontraient des écueils techniques supplémentaires: la chaleur excessive, la poussière ou le sable compliquaient le travail et la couche sensible séchait trop vite alors qu'il était préférable de l'utiliser à l'état humide. Beaucoup de clichés pris dans les premières années d'existence du medium ont disparu, faute d'une maittrise technique suffisante : par exemple, une partie de ceux du révérend George Bridges, qui prit environ 1700 photographies au cours de son Grand Tour méditerranéen entre 1846 et 1851, ou de l'architecte Pierre Trémaux (1818-1895), qui passa sept ans en Afrique du Nord et au Proche- Orient (en Égypte en 1853-1854), qui dut substituer des lithographies à la plupart des photographies de son Voyage au Soudan oriental. Mais si le résultat était encore aléatoire, les améliorations techniques étaient suffisamment importantes pour permettre une diffusion plus large de l'image photographique, notamment au travers de publications. 
Les photographes que nous évoquons ici séjournèrent au Caire entre 1849 et le début des années 1860 , soit juste avant le développement des ateliers commerciaux, dont la production a été diffusée à une échelle beaucoup plus vaste. La plupart pratiquèrent la photographie en amateur, de façon occasionnelle. Ils venaient de toute l'Europe et se rendaient en Égypte, en Terre Sainte, parfois à Constantinople. Certains étaient archéologues (Greene, Teynard), d'autres écrivains (Du Camp), ingénieurs (Robert Murray, Félix Teynard) ou artistes (Bartholdi); ils étaient attirés en Égypte par leur travail, dans le cadre d'une mission ou pour documenter un projet personnel, artistique ou scientifique. Quelques-uns cependant exercèrent en tant que professionnels, dans leur pays d'origine (Frith ou Bedford en Angleterre) ou d'adoption (Robertson à Constantinople); certains enfin s'installèrent au Caire (Schranz, Hammerschmidt, Le Gray). Si quelques travaux récents ont contribué à mettre en lumière quelques personnalités (Frith), d'autres restent encore mal connues (Campigneulles, Jarrot, Schranz). La plupart ont laissé des ensembles, parfois sous forme de recueils ou d'albums publiés, qui comportent le plus souvent un texte (Cammas, Du Camp, Frith, Trémaux). Les recueils sont parfois constitués par d'autres personnes comme le duc de Chartres et le comte de Paris, petits-fils de Louis-Philippe, qui effectuèrent leur Grand Tour méditerranéen en 1859-1860. L'album du comte de Paris concernant l'Égypte ${ }^{4}$ comprend des photographies de James Robertson et de Felice Beato. Celui du duc de Chartres ${ }^{5}$ contient quelques photographies signées Hammerschmidt ou Roberton et Beato (certaines identiques à celles de son frère), mais surtout un nombre important d'images anonymes (certaines sont peut-être de Gustave Le Gray) qui représentent les tombeaux des califes, une rue, des mosquées, la citadelle etc. Les folios de cet album proposent des rapprochements d'images d'un même monument, organisation similaire à celle de l'album du fonds de l'architecte Alfred Armand sur l'Égypte ${ }^{6}$, qui contient des vues attribuées à Campigneulles et aussi beaucoup d'épreuves anonymes (fig. 1). On trouve également une vue du Caire (Rue de la Citadelle et Mosquée d'Ibrahim Ayah [agha], vers 1858-1860) dans l'album constitué par Alphonse de Brébisson, photographe amateur de Falaise ${ }^{7}$.

7 Les premiers photographes évoqués ici sont tous des amateurs, à l'exception d'Antonio Schranz, qui ouvrit ce qui fut sans doute le premier atelier photographique du Caire. 


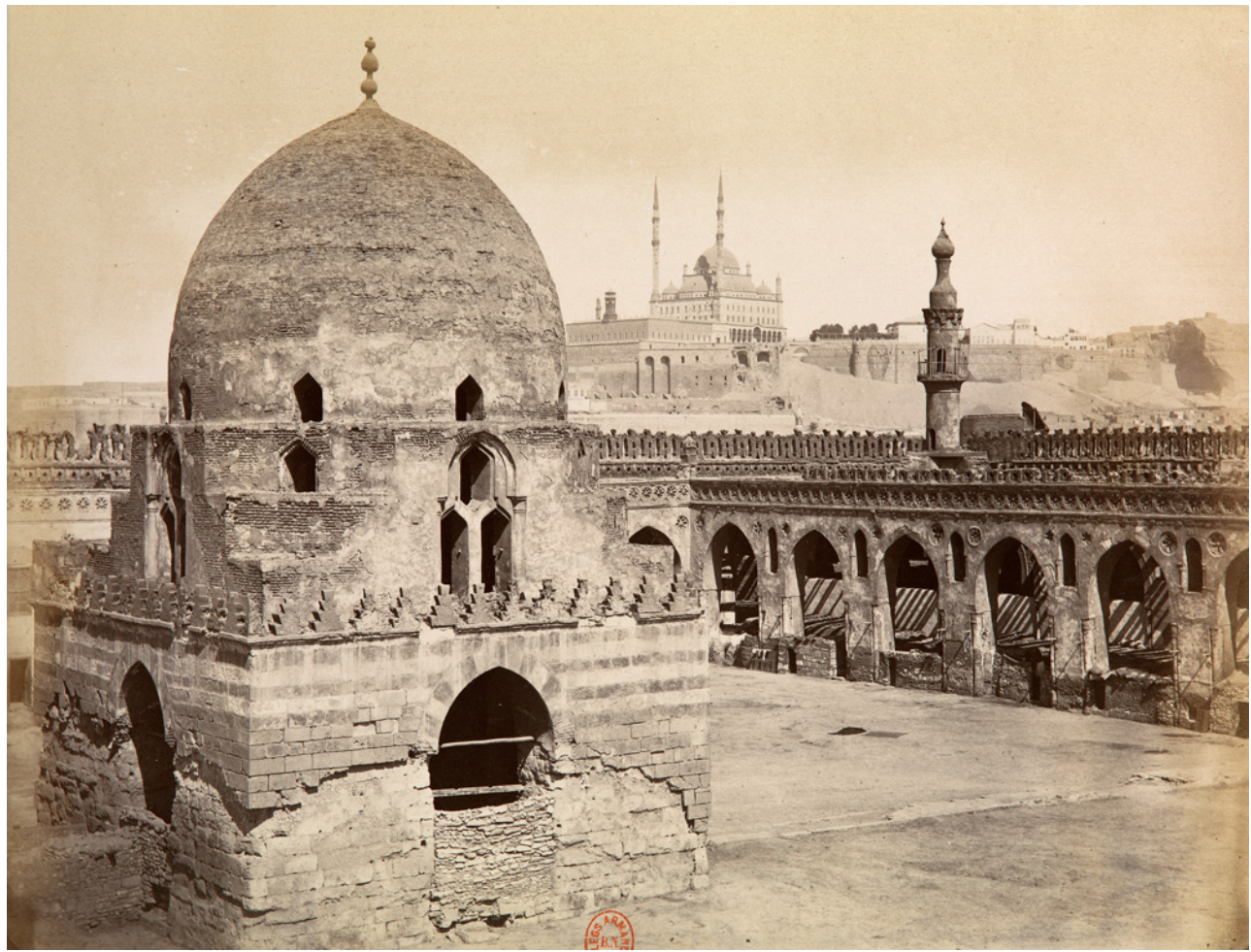

Source : Paris, BnF, collection Armand

\section{Antonio Schranz (1801-après 1865)}

Il était fils d'un peintre d'origine allemande, installé à Malte. Comme son père, il se spécialisa dans la peinture de paysages et de marines. à ce titre, il accompagna des voyageurs anglais autour de la Méditerranée; ainsi, l'ouvrage de Frederik William Robert Stewart, vicomte Castlereagh, A Journey to Damascus, through Egypt, Nubia, Arabia Petraea, Palestine and Syria, publié à Londres en 1847, est illustré de gravures réalisées à partir de dessins signés «A. Schranz 1843 ». Par ailleurs, une série de grandes lithographies datées de $1847^{8}$ réalisées à partir de dessins de Schranz et imprimées chez Lemercier à Paris, montre des rues du Caire, la mosquée du sultan Hasan, la place de l'Azbakiyya vue depuis l'hôtel Shepheards (fig. 2). Fit-il plusieurs séjours au Caire avant de s'y installer comme photographe vers 1849 ? En mai 1850, Florence Nightingale (1820-1910), de passage au Caire, évoque dans une lettre à sa famille sa visite à l'atelier de Schranz. Son activité au Caire comme photographe est attestée jusqu'en 1854, puis il reprit son métier de peintre. Ses vues du Caire sont rigoureusement construites, témoignant d'une attention à l'architecture et aux effets de matière ${ }^{9}$. Certaines compositions sont particulièrement audacieuses, faisant une grande place au vide, au sable, à la pierre ou aux toits des maisons. Plus singulière, l'Entrée des tombes des khalifes montre un site désertique où le regard est attiré par les dais à coupoles et le décor de frise polychrome. Il n'est pas certain que ces images aient été destinées aux touristes, tant elles sont peu conventionnelles. 
La série de photographes que nous évoquerons ensuite sont tous adeptes du négatif papier, plus léger que la plaque de verre et d'une utilisation plus aisée en voyage. Le négatif papier était aussi prisé des amateurs pour son potentiel artistique : la trame du papier produisait un effet de velouté proche d'un dessin ou d'une gravure, par opposition au caractère très léché du daguerréotype.

2. Antonio SCHRANZ, Street in Cairo. Rue du Caire, lithographie par Charles-Claude Bachelier, 1847.

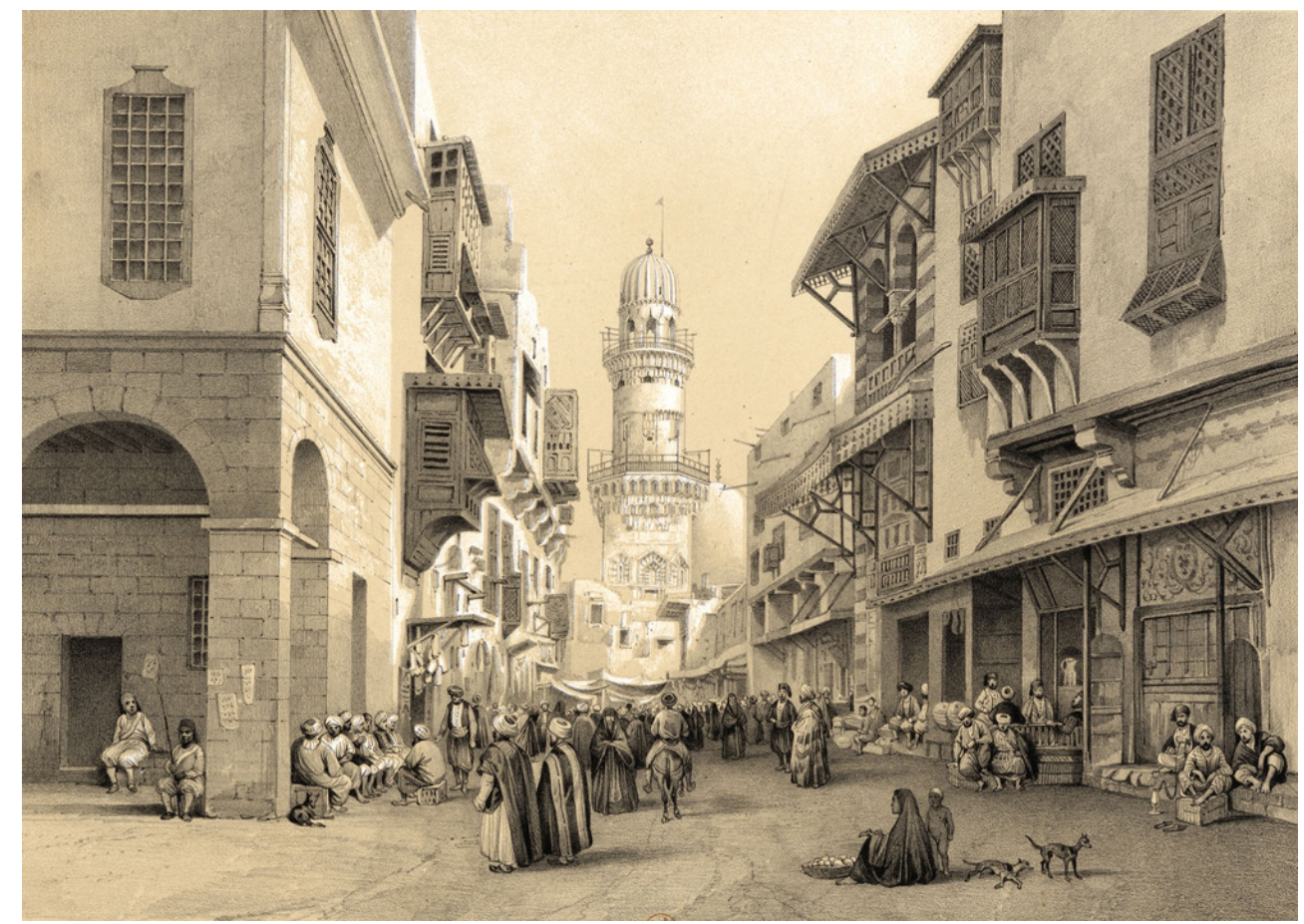

Source : Paris, BnF

\section{Maxime Du Camp (1822-1894)}

En 1849, Maxime Du Camp, écrivain et journaliste, obtint une mission du ministère de l'Instruction publique pour partir en Orient en compagnie de son ami Gustave Flaubert. Ils quittèrent Marseille le 4 novembre 1849 et arrivèrent à Alexandrie le 17 du même mois. Initié à la technique du négatif papier par Gustave Le Gray avant son départ, Du Camp échoua dans ses essais et opta finalement pour le procédé de Blanquart-Evrard que lui avait transmis Alexis de Lagrange, autre photographe amateur. Grâce à sa correspondance et aux Souvenirs littéraires qu'il publia en 1882, on connait bien le détail de ce voyage et les difficultés rencontrées avec la pratique photographique, à savoir la technique mais aussi le conditionnement et le transport du matériel. De ce séjour en Égypte, Du Camp rapporta plus de deux cents clichés réalisés entre novembre 1849 et janvier 1850. Sur ce nombre, 125 furent sélectionnés pour constituer le premier ouvrage illustré de photographies, paru chez Gide et Baudry entre 1852 et 1854 et imprimé par Blanquart-Evrard: Égypte, Nubie, Palestine et Syrie. Dessins photographiques recueillis pendant les années 1849,1850 et 1851 . Cette publication, qu'il qualifia lui-même de « archéologique et daguerrienne » eut un grand succès. Louis de Cormenin, à qui elle était dédiée, en souligna l'importance : 
«la publication de M. Maxime Du Camp complète, sous une forme brève et compréhensible, l'ouvrage des Denon et des Champollion- Figeac, et ouvre une voie nouvelle à l'investigation des orientalistes, comme un horizon particulier aux études des artistes. L'art, à l'égal de la science, y pourra puiser de précieux renseignements. Le mouvement intellectuel dirigé vers l'Orient peut désormais le prendre comme le vadémécum de ses recherches et le manuel le plus certain et le plus intelligent ${ }^{10}$.»

11 La plupart des vues contenues dans l'album concernent l'Égypte pharaonique, où les monuments sont abordés d'une manière très directe, d'un point de vue frontal, sans rien autour qui attire le regard. Bien qu'inexpérimenté, Maxime Du Camp réussit pleinement dans son entreprise, bravant toutes les difficultés :

12 «L'assertion pût-elle passer pour paradoxale, nous pensons que M. Du Camp a réussi dans son entreprise, précisément parce qu'il n'était pas photographe. La préoccupation et les instincts de l'artiste l'ont seuls dirigé, pour le choix du site, du monument, de l'heure, de l'accident et du lieu. Soutenu par ce courage intelligent que rien ne peut ébranler, ni les mécomptes, ni les difficultés, ni les fatigues, ni l'inexpérience, ni l'incommodité d'une insupportable chaleur, ignorant les procédés à sec, qui n'étaient point encore connus, il a dû travailler sous une toile, exposé à une température torride, sans aide et sans direction, laver les épreuves, préparer les plaques, corriger lui-même ses erreurs, recommencer vingt fois, tâtonner, découvrir, et, placé dans des conditions pénibles, isolé de tout renseignement, être à la fois son maître, son élève et son conseil $^{11}$. »

13 Photographe occasionnel, Du Camp témoigne ainsi de l'intérêt précoce que suscita la photographie au sein des milieux aisés et intellectuels. Francis Wey, qui fut un des premiers défenseurs de la photographie, fut séduit par ses images, en particulier par les tombeaux des khalifes :

«Il faudrait les décrire tous, avec leurs vieux murs crénelés, leurs enceintes en ruine, leurs minarets aigus, à quadruple étage, leurs cloîtres d'où s'élancent des palmiers projetant des éventails d'ombre sur les coupoles d'étain, et leurs campaniles à jour, et ces clochetons d'orfèvrerie en forme de cassolettes, tels que le minaret du khalife Haakem [Hakim], où l'on brûlait jadis, en l'honneur de ce héros des légendes arabes, des brassées de bois de santal et d'aloès (...) Mais c'est peu que de décrire tant de choses curieuses et charmantes: le mieux est de les voir, et d'aller en Égypte par la voie héliographique ${ }^{12}$... »

14 Parmi les clichés non retenus pour l'album, plusieurs représentent l'architecture du Caire $^{13}$. Les vues d'ensemble sont privilégiées, qui permettent d'appréhender un monument dans son volume global et dans son environnement: Mosquée et tombeau du sultan Berkouk [khanqah Farag ibn Barquq] (fig.3), Tombeau d'un sultan mamelouk, Tombeau des Ayoubites [Ayyubides]. Il fait ressortir la succession des volumes, le contraste entre la rotondité des coupoles et la verticalité des minarets, entre le cube et la sphère, ainsi que la texture des matériaux (grain de la pierre, sable). Quelques images montrent des détails (Minaret de la mosquée du khalife Haakem [Hakim], Entrée de la mosquée du sultan Berkouk [Barquq], Minaret penché de la mosquée de Bibars [Baybars], mettant en valeur les décors de palmettes ou les assises de peinture rouge et noire (fig. 4). Du Camp s'est également intéressé à l'architecture vernaculaire du Muski (maisons à terrasses et moucharabieh). La plus connue montre un groupe de maisons avec, au premier plan, Gustave Flaubert vêtu à l'orientale. 
3. Maxime DU CAMP, Tombeaux de sultans mamelouks.

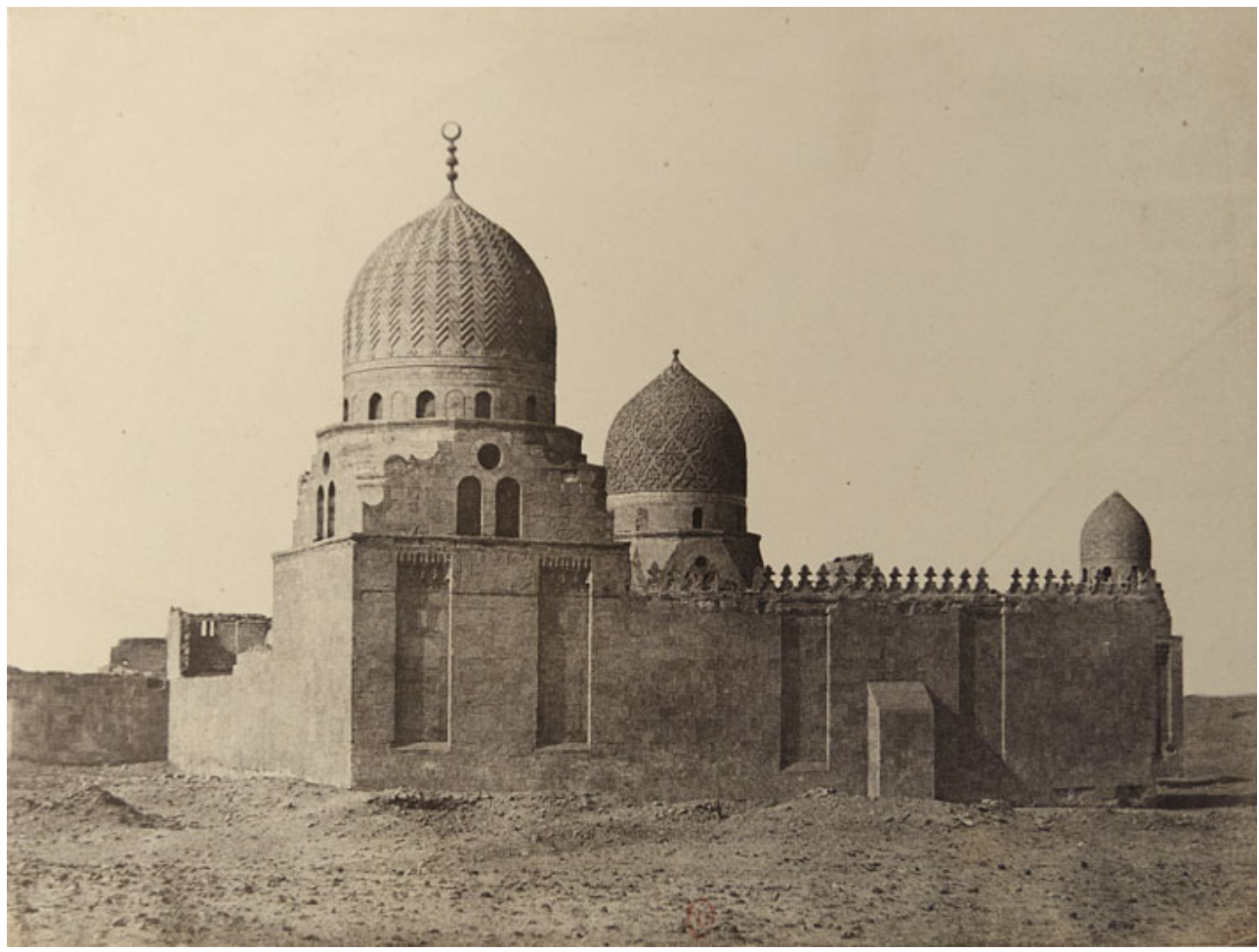

Source: Paris, bibliothèque de l'INHA, collections Jacques Doucet.

\section{Maxime DU CAMP, Le Caire. Vue générale.}

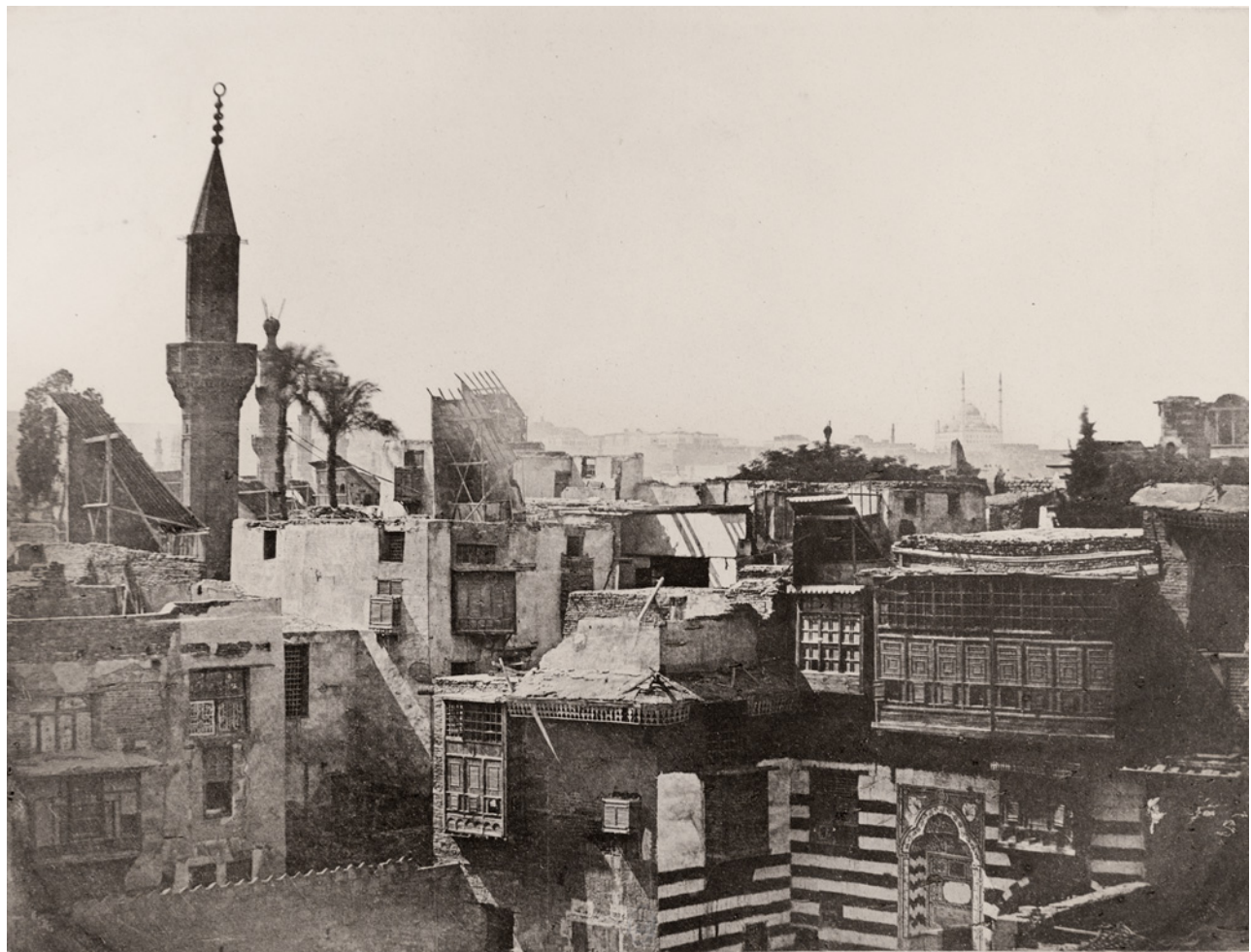

Source : Paris, bibliothèque de l'INHA, collections Jacques Doucet. 


\section{John Shaw Smith (1811-1873)}

15 Ce photographe amateur irlandais était membre de la Dublin Photographic Society (1854-1860). En Orient entre 1850 et 1852, il séjourna en Égypte en novembre 1851. On répertorie actuellement 348 négatifs sur papier ciré dont plus de 300 sur l'Égypte et la Palestine, et 265 positifs sur papier salé, de dimensions variées ${ }^{14}$. Shaw Smith se passionna pour les expériences sur la conservation des tirages, raison pour laquelle sans doute ils présentent des tonalités variées, des surfaces brillantes ou mates selon qu'il cirait ou non ses clichés. Il aimait à retoucher ses négatifs (nuages, architecture) et ses photographies sont souvent légendées et datées à l'encre. Les vues du Caire sont incluses dans une série intitulée Cairo, Pyramids, Palms, Nile Boats qui se retrouvent aussi dans l'album Egypt ${ }^{15}$ : Tombeau et mosquée du Sultan Berkook [khanqah Farag ibn Barquq]; Tombeau et mosquée du Sultan Eshraf [Ashraf]; Porte de Catallet, Rumeyleh [Bab al-'Azab]; La place Uzbekekh [Azbakiyya] (fig. 5); Minaret du tombeau du Sultan Berkook khanqah Farag ibn Barquq]. À plusieurs reprises Shaw Smith photographia la place de l'Ezbekieh [Azbakiyya] et les maisons qui l'entouraient avant qu'elle ne fût transformée en jardin public. Pour certains monuments, il adopte des points de vue très frontaux et des compositions symétriques, parfois proches de ceux de Du Camp, mais d'une qualité technique plus faible.

\section{John SHAW SMITH, Part of the square of the Uzbekekh [Azbakiyya], Cairo.}

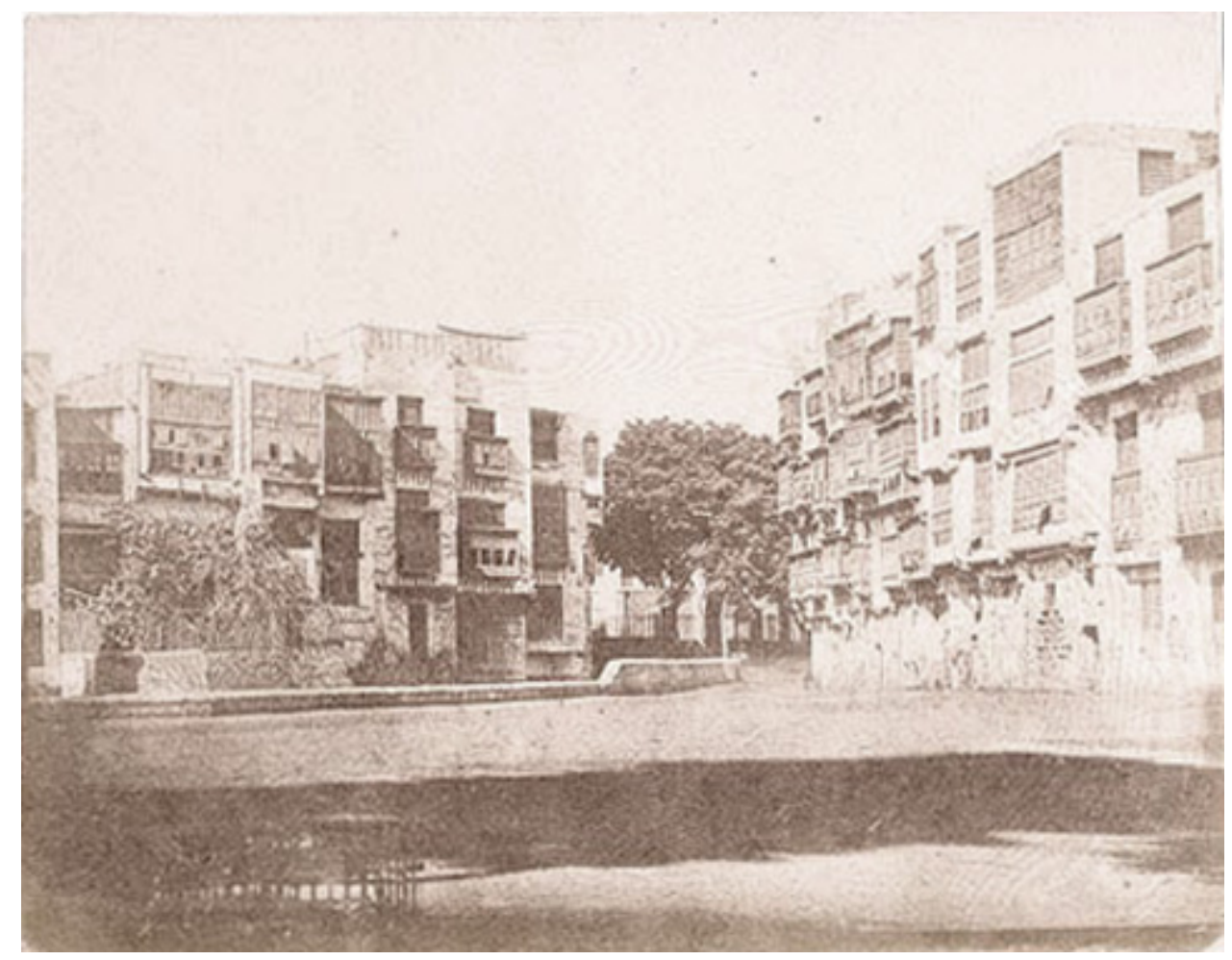

Source : Dublin (Ireland), Courtesy of the National Library of Ireland. 


\section{Félix Teynard (1817-1892)}

Passionné par l'égyptologie dès sa jeunesse, cet ingénieur civil des Mines visita l'Égypte en 1851-1852. De ce premier voyage, Teynard rapporta un ensemble d'épreuves obtenues d'après des négatifs sur papier, qui constituèrent l'album Égypte et Nubie. Sites et monuments les plus intéressants pour l'étude de l'art et de l'histoire. Atlas photographique accompagné de plans et d'une table explicative servant de complément à la grande "description de l'Égypte. Ce somptueux ouvrage en deux volumes, illustré de 160 planches grand format, imprimé par H. de Fonteny, parut entre 1853 et $1858 \mathrm{chez}$ Goupil. Les épreuves sont accompagnées de courts textes descriptifs. Une quinzaine d'exemplaires complets sont aujourd'hui connus. Aussi bien dans le choix des sujets que dans son approche des sites, Teynard s'inscrit dans la continuité de la Description de l'Égypte de Vivant-Denon: par exemple, il photographiait les monuments depuis les mêmes points de vue. Des plans en attestent, sur lesquels il indiquait la position des appareils et les angles de prise de vue. Il constitua une documentation importante sur le site d'Abou Simbel et un reportage exhaustif sur Louxor, Karnak, Philae. En plus des monuments antiques, il photographia les rives du Nil, les indigènes. L'approche du sujet est directe, sensitive. Malgré la démarche scientifique qui y préside, ces images possèdent une dimension poétique incontestable, une note parfois lyrique, créée par de forts contrastes entre les zones de lumière intense et les ombres profondes. Teynard établit ainsi une sorte d'équilibre entre l'enregistrement objectif et l'expérience romantique.

La ville du Caire occupe dans cet ensemble une place réduite, à savoir sept planches contenues dans le premier volume (fig. 6): Boulak [Boulac] : carrefour, mosquée, café; Mosquées d'Iscander-Pacha et du Sultan Haçan [sultan Hasan]; Mosquée du Sultan Haçan sultan Hasan], le tombeau; Mosquée Nâcéryeh [Nasiriyya]; Mosquée d'Amrou ['Amr], intérieur du côté du sanctuaire; Tombeaux de sultans mamelouks; Cimetière des mamelouks. La plupart se caractérisent par des premiers plans dégagés, de beaux effets de matière et des contrastes appuyés entre l'ombre et la lumière. Après son retour en France, l'activité photographique de Teynard se limita à des expérimentations techniques et scientifiques (travaux sur les lentilles). Il retourna en Égypte en 1869, invité officiellement pour l'inauguration du canal de Suez. 
6. Félix TEYNARD, Boûlak [Boulac] - carrefour, mosquée, café, etc., entre 1851 et 1852.

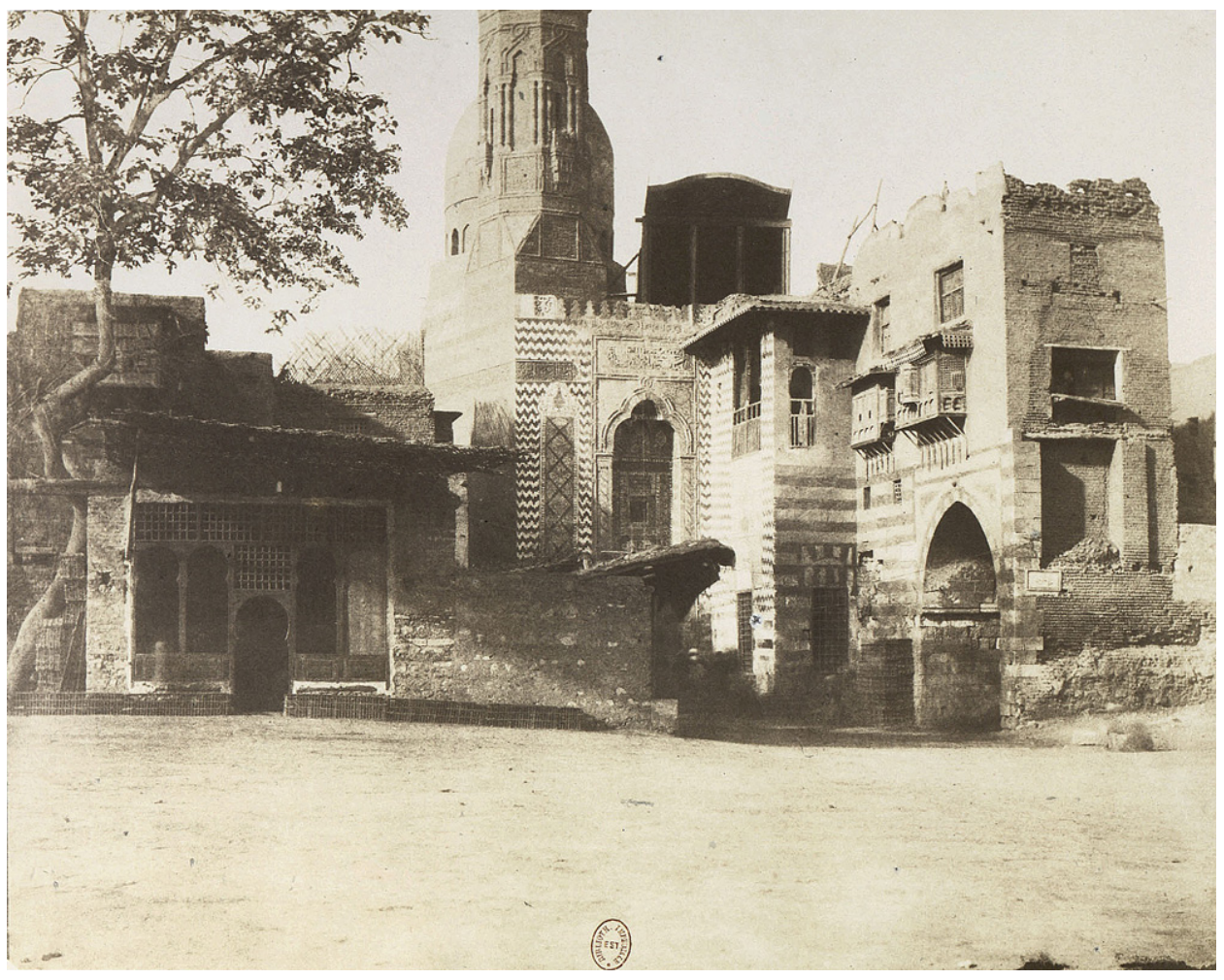

Source : Paris, BnF

6. Félix TEYNARD, Tombeaux des sultans mamelouks, entre 1851 et 1852.

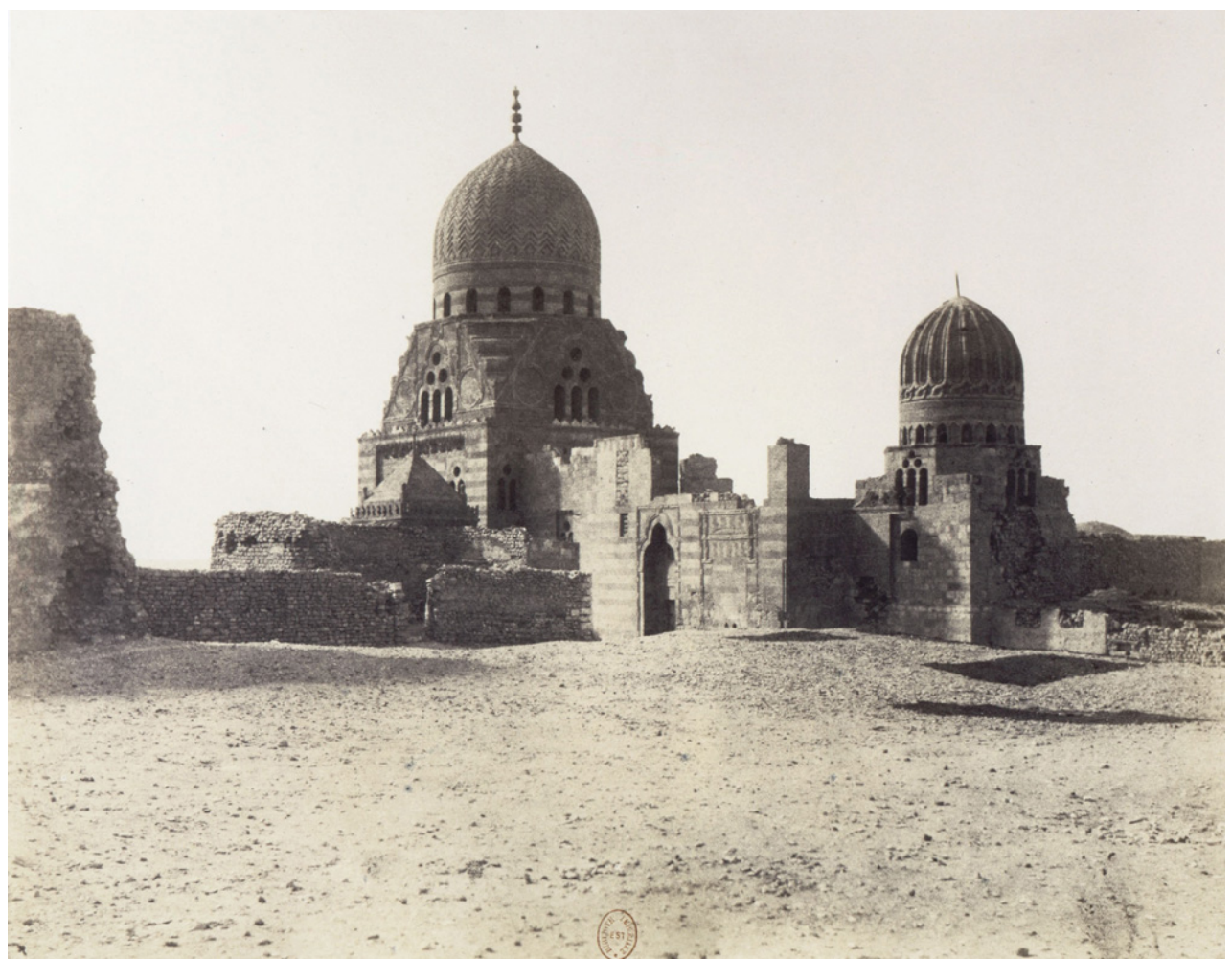

Source : Paris, BnF 


\section{John Beasly Greene (1832-1856)} technique du négatif sur papier ciré auprès de Gustave Le Gray et la lecture des hiéroglyphes auprès d'Emmanuel de Rougé, successeur de Champollion à la tête du département d'égyptologie du Louvre. Il devint membre de différentes sociétés savantes et fut membre fondateur de la Société française de photographie. Il se rendit en Égypte à trois reprises : en 1853-1854 (le long du Nil jusqu'à la seconde cataracte) ; un an plus tard, avec un firman pour engager des fouilles au temple de Ramsès III à Thèbes ; puis, en novembre 1856, séjour interrompu par sa mort soudaine, très peu de temps après son arrivée au Caire. On connaît environ 300 négatifs de Greene, signés et numérotés, organisés en trois séries identifiées par leur initiale: paysages (P), monuments (M), inscriptions (I). Certains tirages furent rassemblés pour constituer un album imprimé par Blanquart-Evrard en 1854 : Le Nil, Monuments, Paysages. Explorations photographiques par John B. Greene. Greene fit don de ses tirages à l'Institut de France, à la Bibliothèque nationale et à la Société française de photographie. Le musée d'Orsay conserve aussi un bel ensemble de négatifs provenant de la collection de Théodule Dévéria, conservateur des antiquités égyptiennes du Louvre. Les vues du Caire montrent la vallée des tombeaux, la cité des morts, des rues, le quartier du Muski, des mosquées et Boulac. Il s'agit le plus souvent de vues d'ensemble aux compositions dominées par un ciel immense et par le vide (sable). Greene était de toute évidence davantage intéressé par l'effet général, par l'inscription graphique des silhouettes des coupoles et des minarets sur le ciel, que par la description de l'architecture proprement dite. Dans certaines vues, les monuments semblent perdus dans l'immensité du désert et du ciel qui tendent à se confondre. Quelques-unes cependant font exception : la cour intérieure de la mosquée Ibn Tulun, où il porte son attention sur les arcades, et la vue d'un ensemble de maisons du Muski, où l'on distingue très nettement la structure des habitations et les fenêtres à moucharabiehs (fig. 7) ${ }^{16}$.

7. John BEASLY GREENE, Quartier du Mûski (?) [Muski], entre 1854 et 1855, négatif papier.

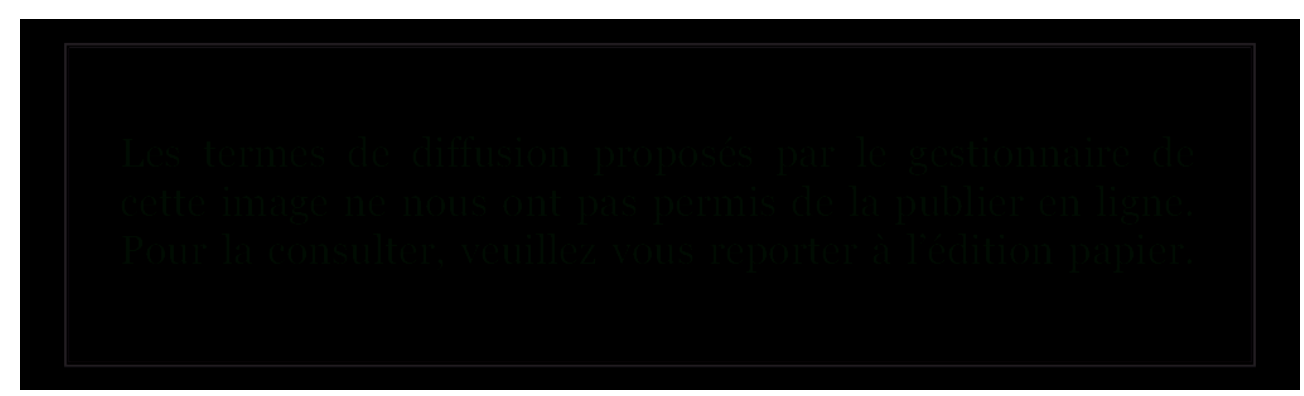

Source : Paris, musée d'Orsay, RMN.

\section{Robert Murray (1822-1893)}

Cet ingénieur civil écossais, originaire d'Édimbourg, travailla à Malte, en Russie et en Égypte. Il arriva au Caire vers 1850 et fut nommé ingénieur en chef du vice-roi 'Abbas $1^{\text {er }}$ Hilmi, pour suivre d'importants travaux en cours (route et voie ferrée entre 
Alexandrie et Le Caire). Autodidacte (il avait appris la technique photographique dans un manuel), il prit, entre 1852 et 1854, des photographies sur négatif papier. En 1856, il exposait 24 photographies d'Égypte et de Malte à l'exposition annuelle de la Société photographique d'Écosse à Édimbourg et, un an plus tard à l'exposition annuelle de la Société photographique de Birmingham.

Dès 1856, l'éditeur londonien Hogarth publiait un imposant album composé de 163 photographies accompagnées d'un texte descriptif par Joseph Bonomi, sculpteur, homme de lettres, égyptologue amateur. Ce fut le plus important album photographique publié alors par Hogarth, avant ceux de Frith et de Bedford. Murray devint ensuite membre de l'Amateur Photographic Association et donna des conférences à la Société photographique d'Édimbourg. Il prit aussi des photographies d'Écosse rassemblées en un album offert à la reine Victoria ${ }^{17}$. Parfait amateur, Murray ne chercha pas à faire la promotion de son travail photographique (nombreux tirages non signés) et son œuvre reste en partie à découvrir ${ }^{18}$. Au Caire, il photographia les maisons de l'Azbakiyya mais aussi des sujets plus inattendus : une école, des jarres, des arbres.

\section{Auguste Bartholdi (1834-1904)}

21 Sculpteur natif de Colmar, élève d'Ary Scheffer et d'Antoine Etex, il partit pour l'Égypte en novembre 1855 avec deux autres artistes, Narcisse Berchère et Édouard Imer ; sur place, ils retrouvèrent Ferdinand de Lesseps, qui dirigeait les travaux du canal de Suez ainsi que les peintres Léon Belly et Jean-Léon Gérôme. De ce séjour de six mois (après l'Égypte, ils allèrent au Yémen), Bartholdi rapporta une centaine de clichés sur négatif papier, technique à laquelle il s'était initié au cours de l'été 1854 (fig. 8). Ces photographies servirent de documentation à Gérôme pour ses tableaux : monuments, paysages (vues du Nil), maisons, bazars, petits commerces. Elles révèlent, malgré une technique hésitante, un sens de la composition, des contrastes de lumière et une puissance esthétique. Bartholdi possédait aussi une collection de photographies sur l'Égypte (Bénécké, Désiré, Hammerschmidt). S'il recourut ensuite à la photographie pour documenter son oeuvre ou en faire la promotion, il en abandonna la pratique. Lors d'un second séjour qu'il fit en Égypte, Bartholdi ne prit d'ailleurs aucune photographie. 
8. Auguste Bartholdi, Le Caire. Corps de garde.

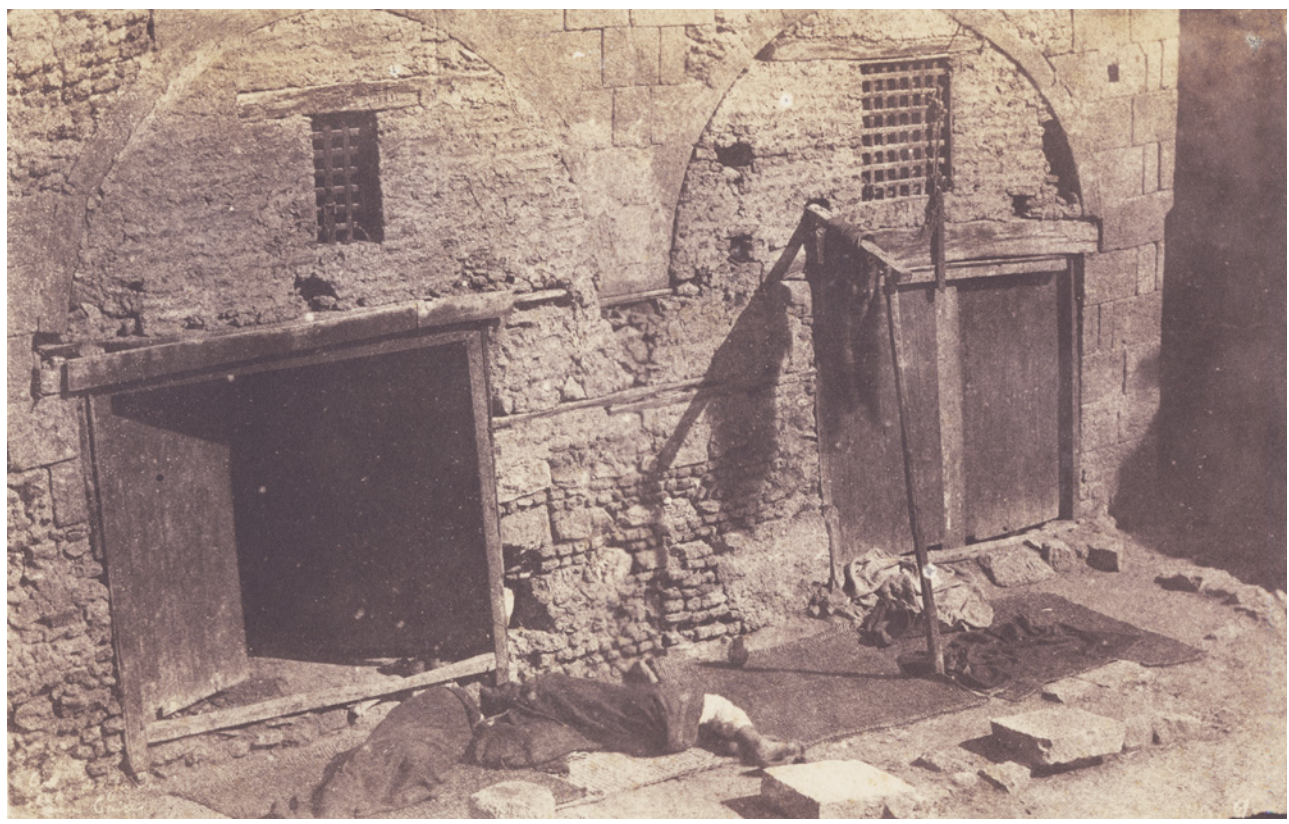

Source : Colmar, musée Bartholdi, reproduction C. Kempf.

\section{Édouard Athanase Jarrot (1835-1873)}

22 Fils d'un photographe professionnel établi à Paris, il partit pour l'Égypte entre 1858 et 1860 avec l'expédition montée par l'archéologue Émile Prisse d'Avennes. Il en rapporta un ensemble de 150 photographies sur papier salé d'après des négatifs papier ainsi que des vues stéréoscopiques. Ces photographies ne portent aucune signature, signe sans doute qu'il considérait cette expérience comme occasionnelle. Les prises de vues ont été réalisées selon les instructions de Prisse d'Avennes lui-même, laissant de toute évidence peu de liberté au photographe. Certaines furent retouchées par l'archéologue, qui s'en servait comme document de travail. Certains tirages de photographies volontairement pâles ont été complétés avec des personnages ou des détails d'architecture par le peintre Wilhem Famars Testas qui travaillait aussi pour le compte de Prisse d'Avennes (voir supra p. 84-87). Beaucoup de ces photographies montrent des détails d'architecture (portes, fenêtres ouvragées) et d'ornementation (fig. 9), dans la lignée des daguerréotypes de Girault de Prangey. 
9. Édouard Athanase JARROT, fenêtre à moucharabieh.

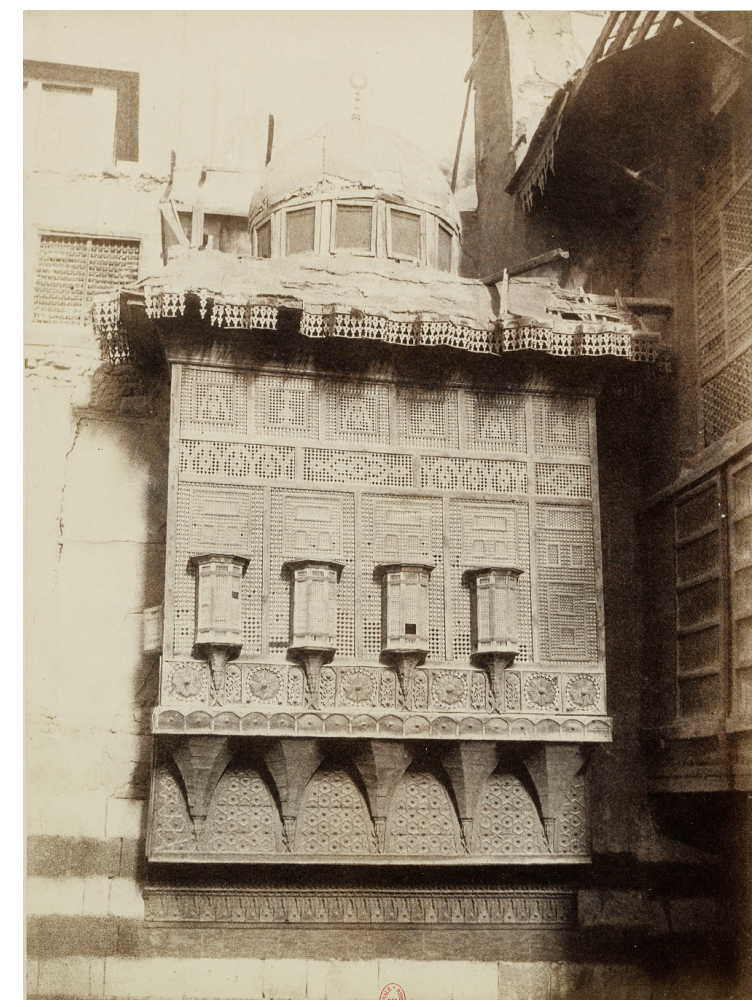

Source : Paris, BnF.

\section{François Joseph Édouard de Fougeroux de Campigneulles (1826-1879)}

On sait encore peu de choses sur ce photographe, issu d'une famille aristocratique du nord de la France, ni dans quel but il se rendit en Orient (Égypte, Nubie, Syrie) entre 1856 et 1858. Il adopta pour ses photographies la technique du papier ciré. En 1859, il exposait à la Société française de photographie une quarantaine d'épreuves de l'Album du voyage au Moyen-Orient (Égypte, Arabie, Syrie) imprimé chez Picart, qui furent remarquées par la critique. L'ensemble comprenait plusieurs vues de la ville du Caire: Rue de la Citadelle et Mosquée d'Ibrahim-Aga [Ibrahim agha], Mosquée de Ketbay [Qaytbay], tombeaux des khalifes; Mosquée près de la place de Roumélich (fig. 10). Mieux connues depuis 2005, date de la vente d'un album de 60 tirages (dont neuf sur Le Caire), les photographies de Campigneulles sont encore relativement rares: en plus d'un ensemble de négatifs conservé au muséum d'histoire naturelle de Lille, certaines épreuves de la collections Armand de la Bibliothèque nationale de France peuvent lui être attribuées. Enfin, la bibliothèque de l'INHA (Paris) conserve un ensemble de dixneuf épreuves (onze sur Le Caire) aux sujets identiques à celles vendues en 2005, mais résultant sans doute de tirages plus tardifs. 
10. François Joseph Édouard de FOUGEROUX DE CAMPIGNEULLES, édifice au Caire.

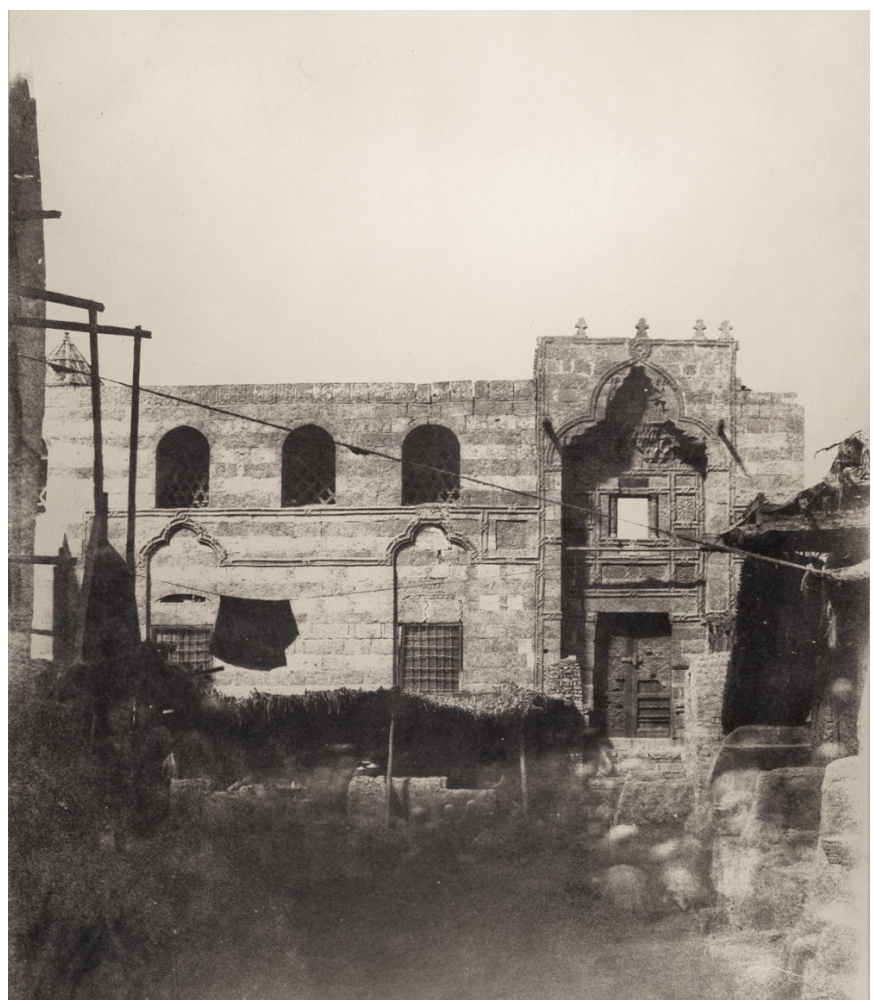

Source : Paris, bibliothèque de I'INHA, collections Jacques Doucet.

10. François Joseph Édouard de FOUGEROUX DE CAMPIGNEULLES, mosquée de Qaytbay.

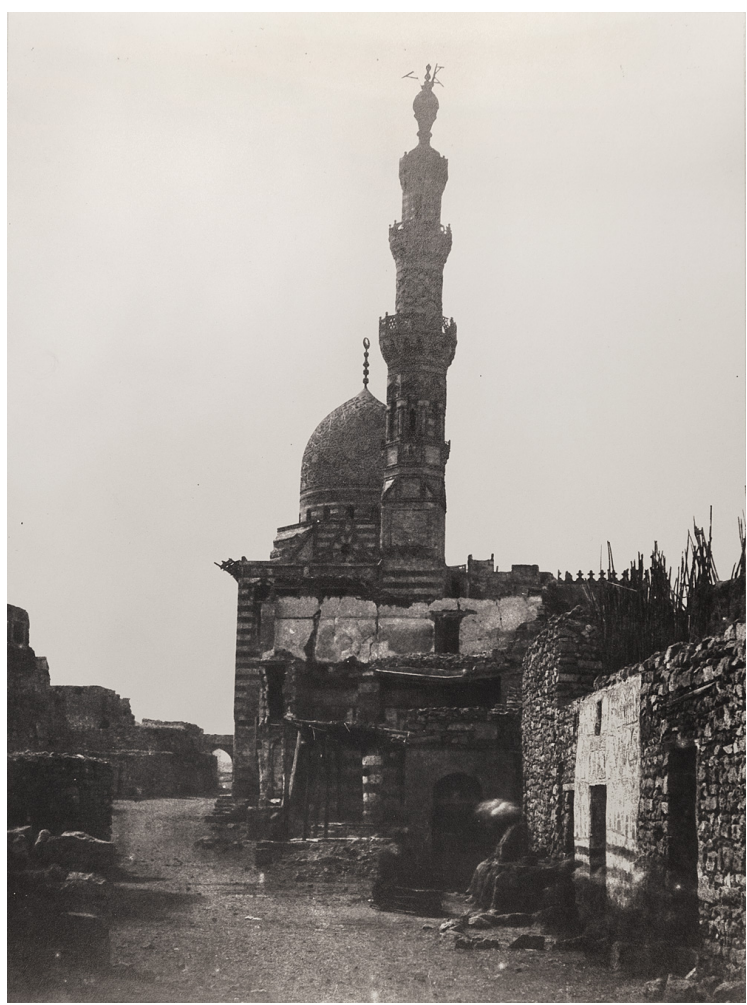

Source : Paris, bibliothèque de l'INHA, collections Jacques Doucet. 


\section{Henri Cammas (1813-1888)} orientaliste Koenig bey et fut nommé correspondant de l'Institut d'Égypte. En mars 1859, il sollicita une mission au ministère des Beaux-Arts pour se rendre en Orient (Égypte, Syrie, Palestine, Perse), accompagné de sa femme et d'André Lefèvre, écrivain et historien. Ils partirent en avril 1859 et voyagèrent jusqu'en septembre 1861. Cammas rapporta de ce périple environ 200 photographies dont 80 de très grands formats (environ 60 sur $30 \mathrm{~cm}$ ). S'il privilégia le négatif papier, Cammas réalisa aussi des photographies d'après le collodion humide ${ }^{19}$.

En 1862, Cammas et Lefèvre publièrent La vallée du Nil, impressions et photographies, ouvrage dédié à Sa'id Pacha, "destiné à colorer, à compléter une série de photographies ». Cet ouvrage est aussi conçu comme un guide, qui livre des conseils pratiques pour les voyageurs photographes:

«Tous les systèmes peuvent être employés; mais les plus prompts sont les meilleurs. L'extrême chaleur évapore les agents chimiques et les formules varient avec la température. La poussière est le fléau de la photographie ; on ne s'en défend que par les soins les plus rigoureux. »

Il y mentionnait les noms de Barbet, pharmacien à Alexandrie et Ammerschmidt (sic), au Caire dans le Muski, chez qui l'amateur photographe pouvait se procurer du matériel. Si l'essentiel de sa production porte sur l'Égypte antique, il s'intéressa aussi à l'architecture arabe du Caire (tombeaux des Khalifes, mosquées), et notamment à l'architecture récente (mosquée de Muhammad 'Ali, le palais de Qasr al-Nil, le palais de Qasr al-Nuzha à Shubra, fig. 11). En 1862, Cammas participait à l'Exposition universelle de Londres (épreuves de $65 \mathrm{~cm}$ de long); en avril de la même année, il exposait à Paris 200 épreuves (les plus grandes mesuraient $1 \mathrm{~m}$ sur $75 \mathrm{~cm}$ ) aux côtés d'aquarelles d'Hector Horeau. En 1863, Cammas adhérait à la Société française de photographie, où il exposa à deux reprises, en 1863 et 1864, des épreuves de grand format qui impressionnèrent les critiques :

" en s'en tenant à cinq ou six mètres, leur effet est prodigieux, et l'on sent très bien qu'il n'y a que le négatif sur papier pour donner ce moelleux harmonieux qui caractérise toutes ses épreuves ${ }^{20} »$.

Il continua d'exploiter son travail pendant quelques années mais on ne lui connaît pas d'autres photographies que celles réalisées en Orient. 


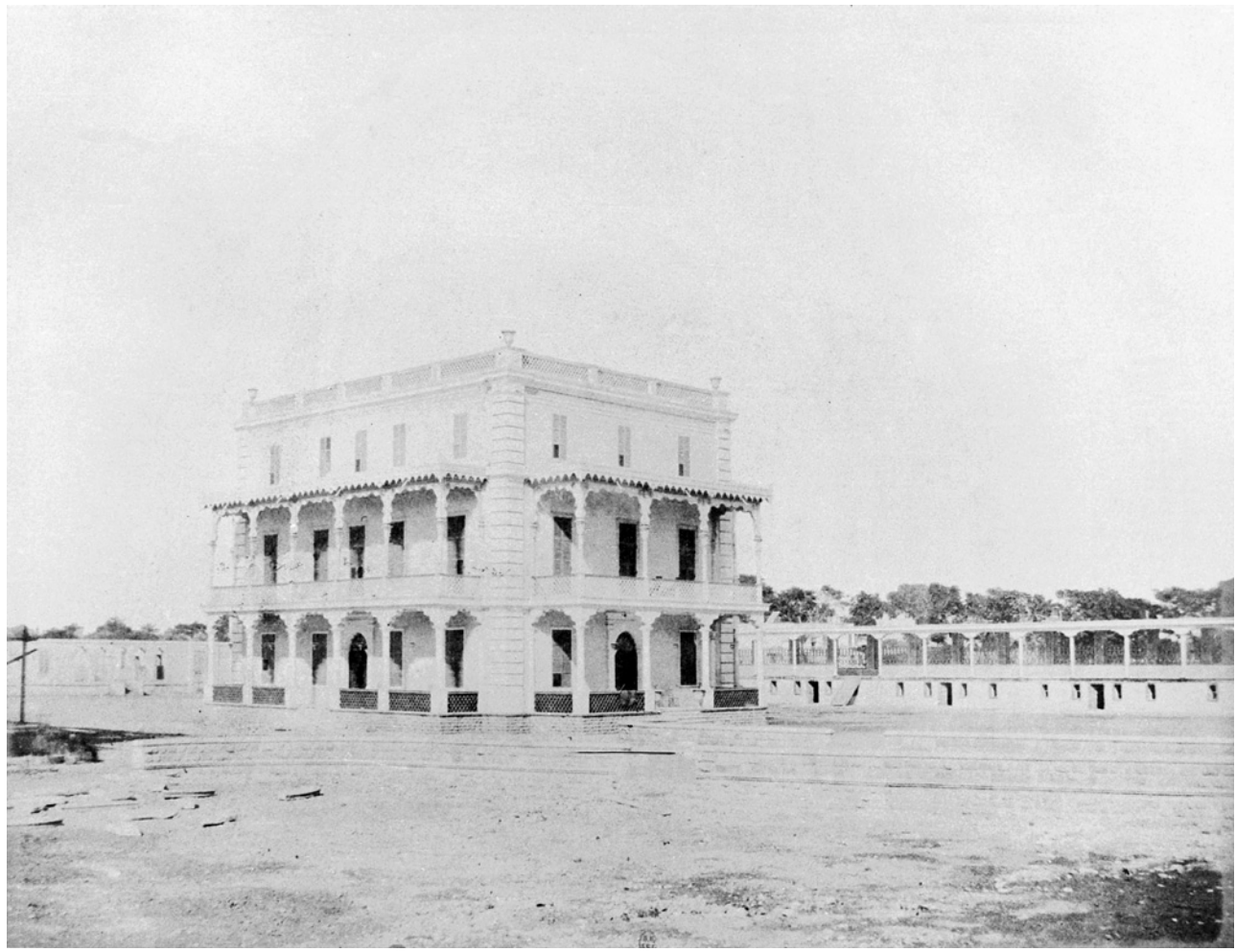

Source : Paris, BnF.

\section{Jakob August Lorent (1813-1884)}

Homme de sciences et inventeur, né à Charleston en Caroline du Sud, il vécut ensuite à Mannheim, où sa mère remariée s'installa en 1818. Après des études scientifiques à l'université de Heidelberg, il voyagea en Égypte et en Asie Mineure en 1837, avec pour objet d'étude le paysage, sur les pas d'Alexandre von Humboldt. Formé à la photographie en 1850 par Talbot à Londres, il utilisa le procédé Talbot qu'il modifia, mais aussi le papier ciré de Le Gray. Après des vues de Venise de très grand format qu'il exposa à Bruxelles en 1856, il prit des photographies de Grenade et d'Algérie en 1858 (étude sur l'art islamique). En 1859, Lorent retourna en Égypte (fig. 12), puis en Nubie, pour constituer une documentation sur l'art égyptien (négatifs de 45 sur $55 \mathrm{~cm}$ ). Ses photographies furent reproduites dans un album dédicacé à Friedrich II, duc de Bade : Ægypten, Alhambra, Tlemsen, Algerien, publié en 1861 à Mannheim. En 1863-1864, il retourna en Égypte, puis se rendit en Turquie et en Syrie. Lorent participa à de nombreuses expositions et fit don de ses photographies à la bibliothèque de Mannheim.

Nous évoquerons maintenant des photographes professionnels qui travaillèrent avec la technique du collodion, entre 1857 et 1862 environ. Plus sensible que le négatif papier, le collodion humide, qui domina la production photographique jusque dans les années 1880 , permettait de mieux capter les sujets en mouvement (même s'il ne s'agit pas encore d'instantanés); aussi voit-on la ville s'animer peu à peu. Le collodion, qui produit une image d'une plus grande finesse, permet aussi de rendre plus précisément des détails. 
12. Jakob August LORENT, Cour de la mosquée Sultan Hassan [Hasan] au Caire.

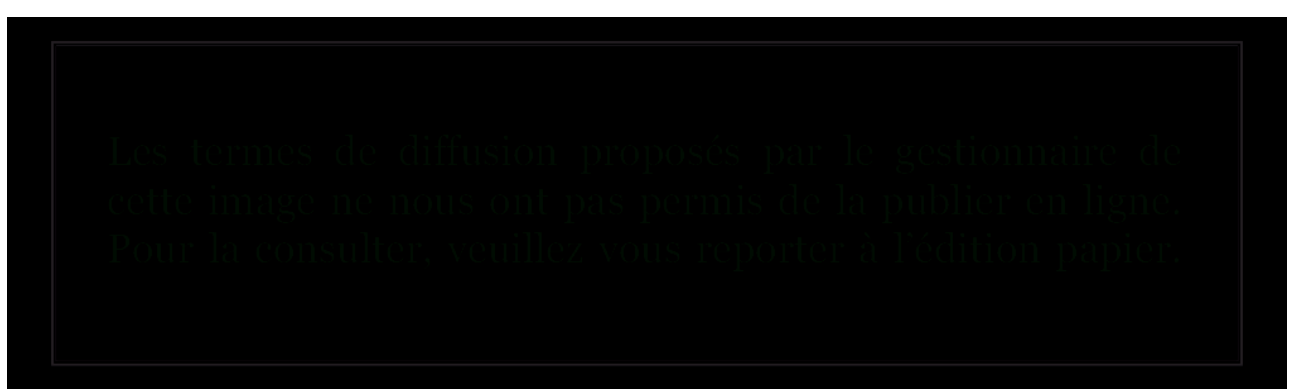

Source : Karlsruhe (Deutschland), Saai-Südwestdeutsches Archiv für Architektur und Ingenieurbau, Bestand August Lorent.

\section{Francis Frith (1822-1898)}

31 Il fut l'un des premiers photographes professionnels après Schranz à enregistrer systématiquement les monuments égyptiens. Il est aussi aujourd'hui un des photographes de cette époque les plus connus grâce aux travaux de D. R. Nickel ${ }^{21}$. Frith était anglais, originaire de Chesterfield dans le Derbyshire, né dans une famille Quaker. Après avoir exercé diverses activités, il se tourna vers la photographie. à trois reprises, entre 1856 et 1859, il se rendit en Égypte, d'où il rapporta de nombreuses vues grands formats (40 sur $50 \mathrm{~cm}$ et 20 sur $25 \mathrm{~cm}$ ) ainsi que des vues stéréoscopiques. Ses photographies furent très largement diffusées, publiées notamment à travers deux albums, Egypt and Palestine photographed and described by Francis Frith (1858-1859), illustrés de photographies originales collées, signées et datées, tirés à 2000 exemplaires (soit un total d'environ 150000 tirages originaux). Les images s'accompagnent de textes qui retracent l'histoire des monuments et en donnent une description ${ }^{22}$. En plus du tour de force qui consistait à préparer des plaques de verre de cette taille sous une tente par une température de $50^{\circ} \mathrm{C}$, les photographies de Frith attestent d'une grande maitrise technique (dégradés, perspectives, transparences). Les vues qu'il prit du Caire montrent des panoramas, des mosquées (fig. 13), des tombeaux, quelques maisons ; très souvent il y introduit des personnages et des animaux (fig. 14). 
13. Francis FRITH, Ruins of the mosque of el-Hakim [al-Hakim].

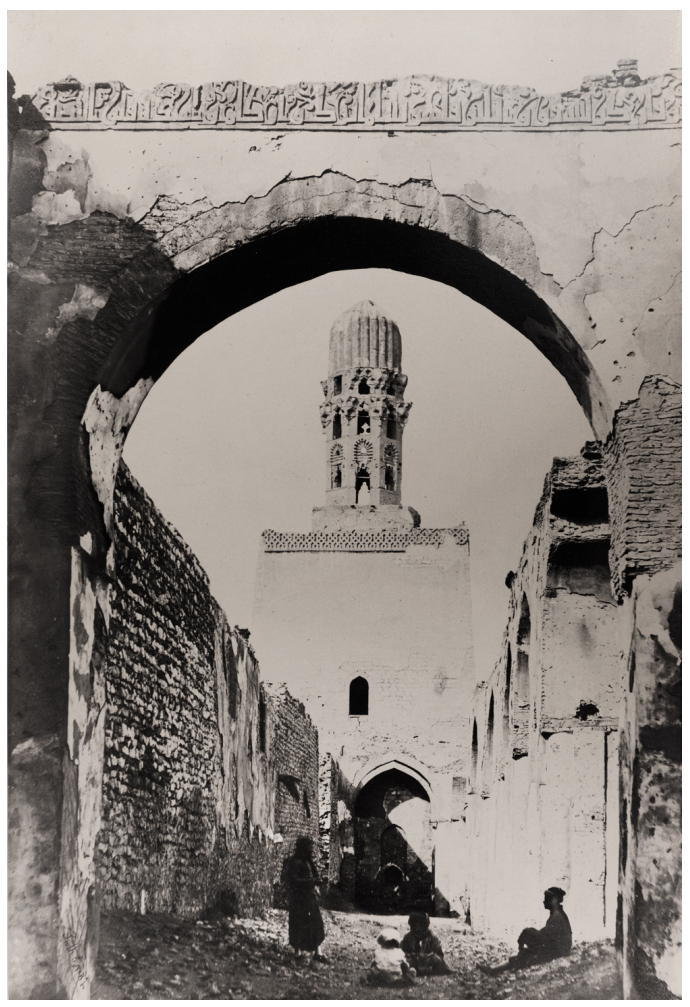

Source : Paris, bibliothèque de I'INHA, collections Jacques Doucet.

14. Francis FRITH, The Bab el-Azab [bab al-'Azab] Citadel Gateway.

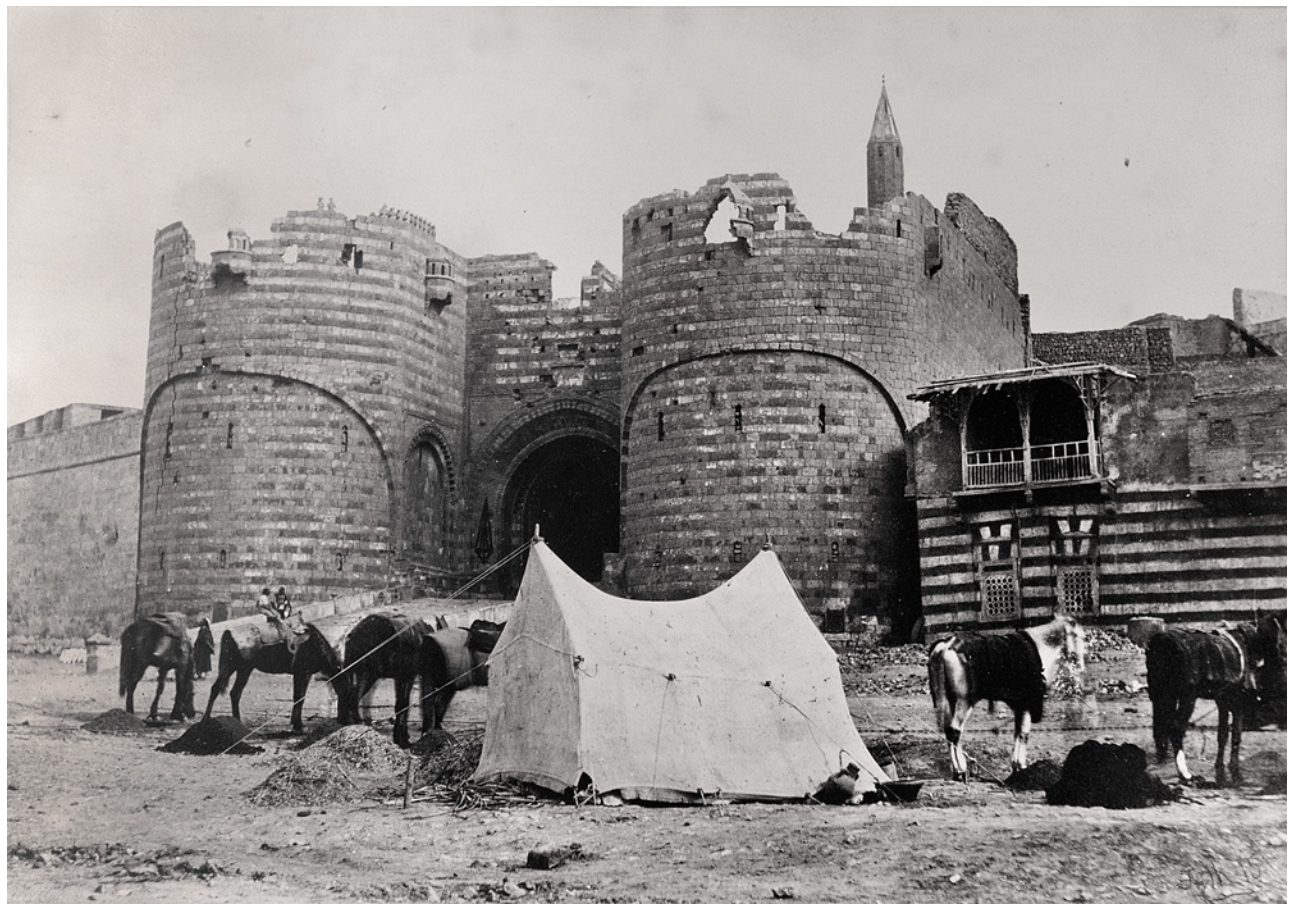

Source : Paris, bibliothèque de I'INHA, collections Jacques Doucet. 


\section{James Robertson (v. 1813-1888)}

Ce graveur écossais fut d'abord en poste à Londres, à la Monnaie, puis à partir de 1841 à Constantinople, où il resta quarante ans. En 1852, peut-être encouragé par Ernest de Caranza, ingénieur à Constantinople et photographe amateur, il se mit à la photographie et la pratiqua pendant une quinzaine d'années. En 1853, il publiait un premier album sur Constantinople et à la fin de l'année 1854, il ouvrait un atelier. Deux ans plus tard, il s'associait avec son beau-frère Felice Beato (Corfou, v. 1834-1906). Au printemps 1857, les deux hommes se trouvaient en Égypte. Les photographies des différents pays du pourtour méditerranéen visités par Robertson (Grèce, Palestine, Égypte) ainsi que des vues qu'il prit sur le champ de bataille de la guerre de Crimée, étaient vendues à Londres et à Paris, et montrées dans des expositions. En 1858, Beato partit pour l'Asie (Calcutta, puis la Chine et le Japon) et en 1881, Robertson le rejoignit au Japon, où il resta jusqu'à sa mort en 1888 .

Les tirages de Robertson et Beato réalisés au Caire en 1857 sont des épreuves de grands formats, le plus souvent sur papier albuminé, d'une extrême finesse ${ }^{23}$; beaucoup montrent des rues, des maisons anciennes et leur décor (fig. 15) ${ }^{24}$.

15. James ROBERTSON, rue du Caire.

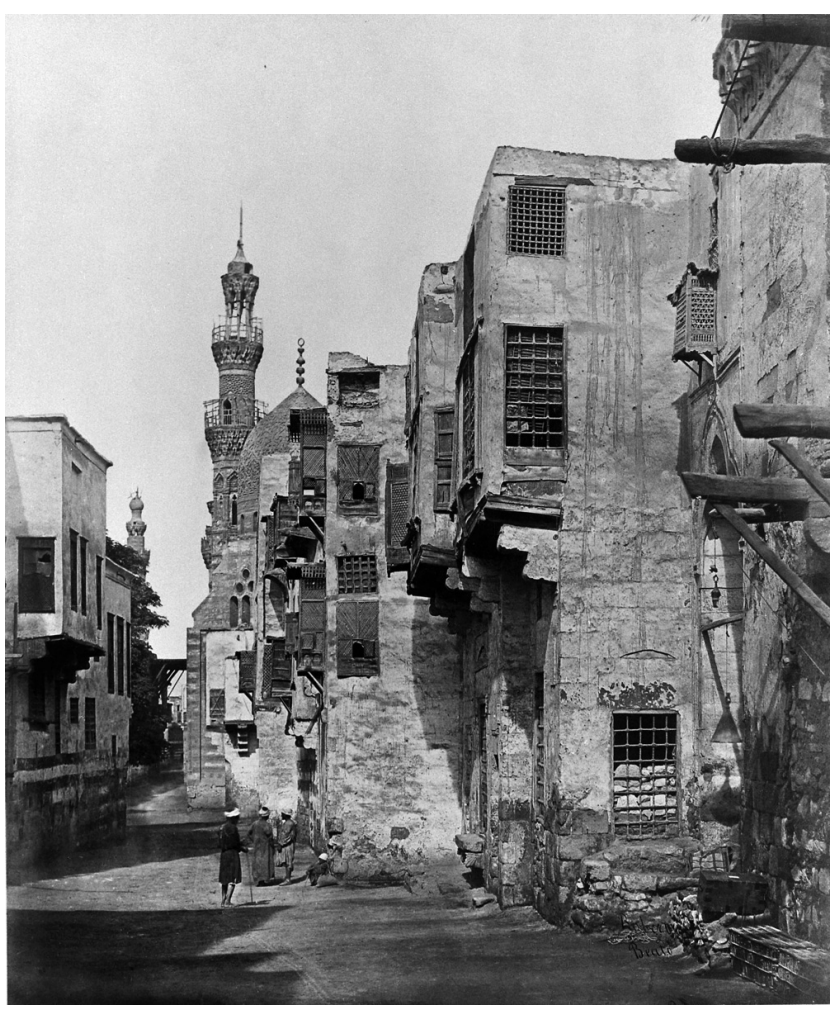

Source : Paris, BnF

\section{Wilhelm Hammerschmidt (v. 1830-après 1869)}

Ce photographe allemand, né à Berlin, arriva au Caire vers 1858 où il ouvrit un atelier dans le quartier du Muski; il y vendait aussi des produits et des équipements 
photographiques. Il utilisa d'abord le procédé Taupenot (mélange de collodion et d'albumine), puis le collodion humide auquel il ajoutait parfois du tanin. En novembre 1860, il envoyait vingt épreuves à la Société française de photographie, dont une dizaine de vues furent exposées en 1861 (trois vues du Caire). Marc-Antoine Gaudin, opticien et critique, fit à cette occasion un commentaire élogieux sur la vue de la mosquée du sultan Hasan :

« cette épreuve, qui est de 0,35 x 0,50, est d'une netteté parfaite dans tous ses plans ; malgré ses grandes dimensions, il s'y trouve plusieurs groupes de personnes purement accidentels, et en preuve de la rapidité avec laquelle le négatif a été obtenu, on voit la trace de gens stationnant à cheval et d'autres en marche; en limitant à deux ou trois secondes le temps employé, on doit se trouver dans le vrai, ce qui donne une haute idée de l'habileté de M. Hammerschmidt ${ }^{25}$. "

Devenu membre de la Société française de photographie en 1862, il y exposa à nouveau en 1863 et en 1864. Il était également membre de la Société photographique de Berlin où il semble avoir conservé un atelier. Enfin, il participa à l'Exposition universelle de 1867 à Paris. Au début, Hammerschmidt prenait des clichés de grands formats, puis il diversifia sa production avec de nombreuses séries de cartes de visite et de vues stéréoscopiques, parfois colorées. Il arpenta le Nil jusqu'au Soudan et au désert lybien, où il prit des vues de l'Égypte antique. Mais il photographia aussi la ville du Caire : ses rues, ses monuments ainsi que des sujets inspirés de la vie quotidienne qui donnèrent lieu à des séries sur les types égyptiens, les artisans, les commerces (cartes de visites et vues stéréoscopiques); sujets qui seront amplement repris par les ateliers commerciaux de la décennie suivante. Vers 1860 , il publia un premier album, Monuments de l'Égypte ancienne et moderne, contenant 83 planches. Un second album, Souvenirs d'Égypte, parut en 1862 (54 planches). L'album Recueil de vues d'Égypte conservé à la bibliothèque de l'INHA comprend 37 planches : vues générales de la ville depuis la citadelle, la mosquée émir Akhur et la mosquée Tulun, vues de rues (fig. 16), maisons coptes à l'Azbakiyya, une vue du tombeau des califes, la chaire de la mosquée sultan Barquq, et aussi, plus rare, une vue du « portale» (sic) du pont de barrage (fig. 17). Ses photographies sont d'une bonne qualité technique, offrant de beaux effets de lumière. Ses vues de l'inauguration du canal de Suez en 1869 furent largement diffusées. Hammerschmidt était alors en mauvaise santé et l'on ignore ce qu'il devint après cette date. 
16. Wilhelm hammERSCHMIDT, Souk El Sillah [Suq al-Silah]. Rue du Caire.

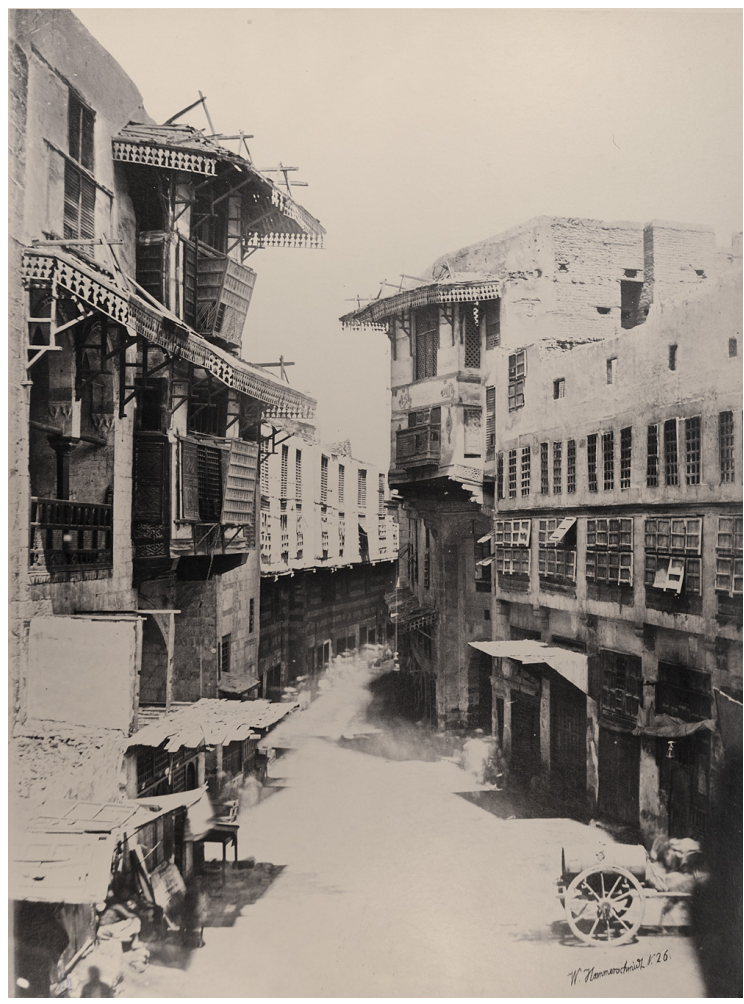

Source : Paris, bibliothèque de I'INHA, collections Jacques Doucet.

17. Wilhelm HAMMERSCHMIDT, «Portale » du pont du barrage.

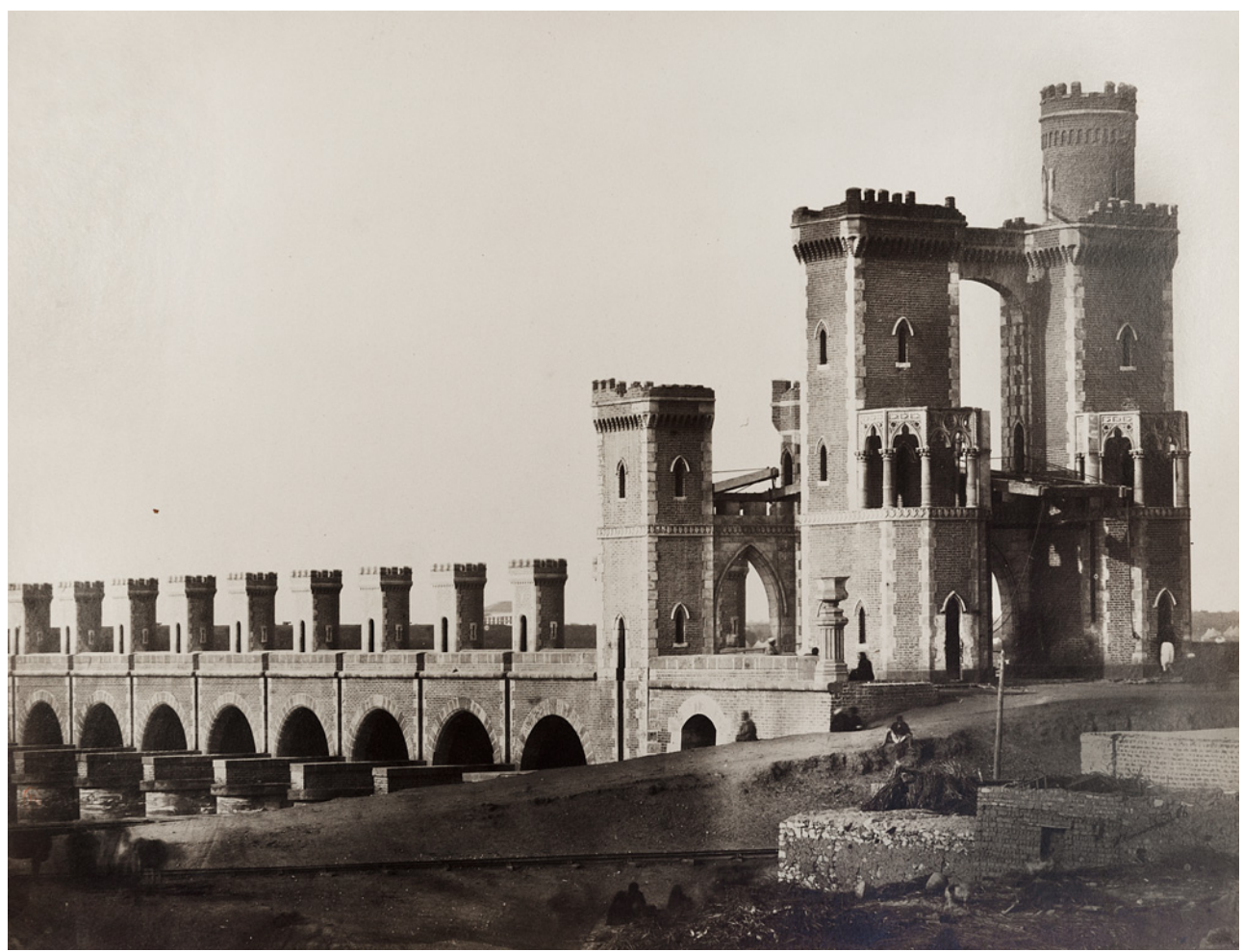

Source : Paris, bibliothèque de I'INHA, collections Jacques Doucet. 


\section{Gustave Le Gray (1820-1884)} l'Orient, à Beyrouth d'abord puis à Alexandrie. Il arriva au Caire vers 1864 et y resta jusqu'à sa mort. Le Gray reçut plusieurs missions de la part du vice-roi Isma'il Pacha dont il accompagna les fils en voyage ; il prit à cette occasion des vues de grand format sur négatif verre et sur négatif papier : paysages le long du Nil, monuments, portraits de groupes; certaines furent montrées à l'exposition universelle de 1867. En plus de ces commandes, Le Gray photographia des types égyptiens et certains sites comme les tombeaux des khalifes ${ }^{26}$. Il se peut qu'il soit l'auteur de certaines vues de l'album du duc de Chartres évoqué plus haut ${ }^{27}$. Le Gray eut plusieurs adresses au Caire, situés dans les quartiers arabes; la maison qu'il occupa dans les années 1870 est connue par plusieurs vues de la cour, dont une image retrouvée récemment.

\section{Henri Bévan (1825-1897)}

Peintre professionnel, il prit des photographies au cours des nombreux voyages qu'il fit à travers le monde. En 1864, il publiait à son compte une série d'albums dont Excursion photographique en Égypte, Grèce, Constantinople et l'île de la Réunion qu'il exposa la même année à la Société française de photographie. Certaines vues portent sur la ville du Caire et montrent notamment des détails de décors de mosquées et de mobilier, images rares dans les corpus des autres photographes ${ }^{28}$.

\section{Francis Bedford (1816-1894)}

Il était aquarelliste, lithographe, dessinateur d'architecture et photographe. Après une carrière de lithographe illustrateur dans les années 1840, il devint photographe professionnel vers 1851, spécialisé dans la reproduction d'objets et la photographie d'architecture, avec un goût prononcé pour les manipulations techniques (retouches, ciels repeints ou re-photographiés). En 1862, Bedford accompagna le prince de Galles en Égypte et en Terre sainte ; les photographies qu'il rapporta furent exposées à Londres en 1862 et éditées en quatre volumes chez Day and Son en 1863. Une douzaine de vues montrent la ville du Caire et ses principaux monuments : les mosquées, la Citadelle, les tombeaux des mamelouks (fig. 18), le palais de Qasr Nasr ${ }^{29}$. 


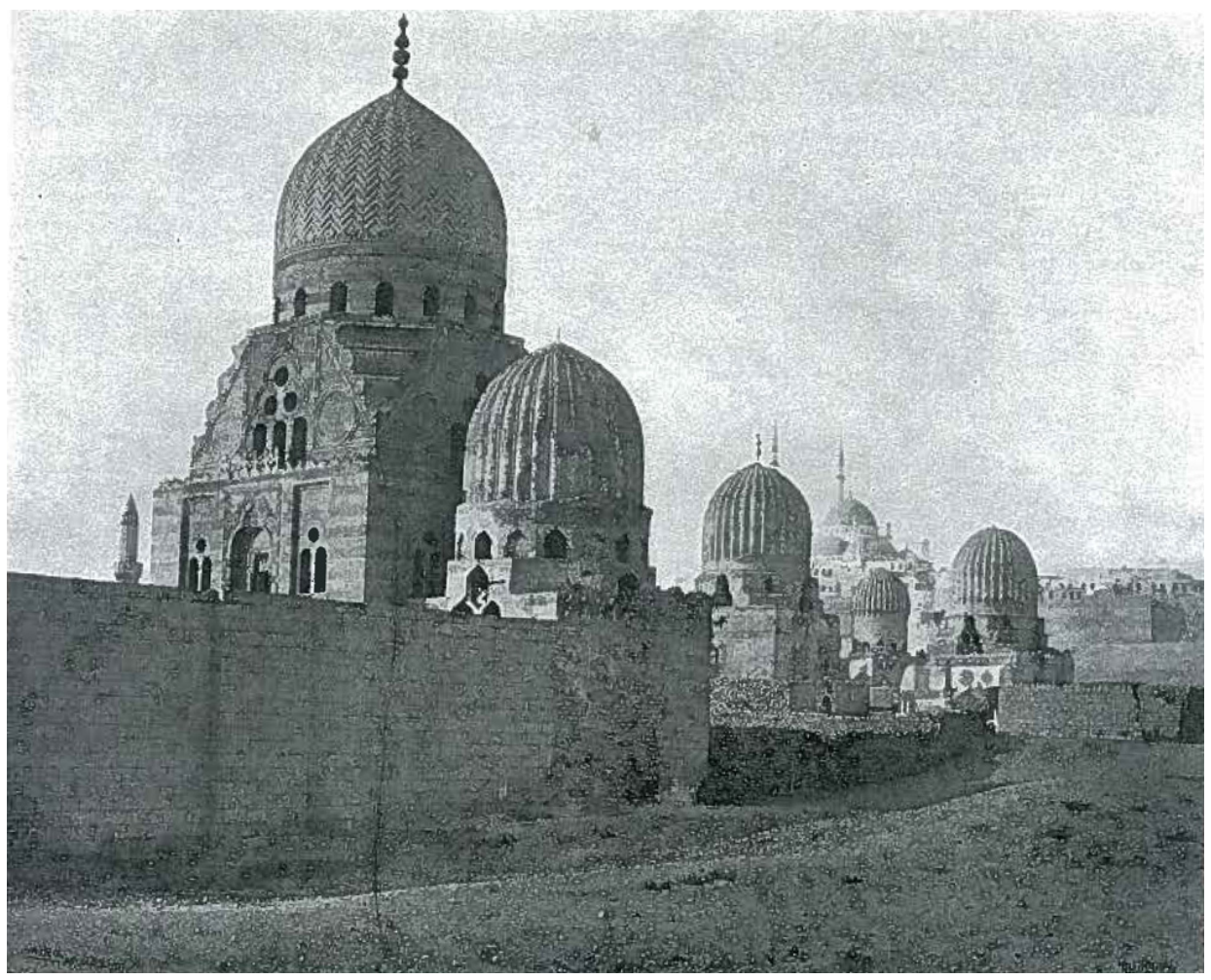

Source : Copenhagen (Danmark), KOB.

En quantité bien moindre que les vues de l'Égypte pharaonique, les photographies de la ville arabe du Caire ne sont pour autant pas absentes des ensembles rapportés par les photographes qui y séjournèrent entre 1849 et 1862. S'ils ont chacun leur propre regard, ils photographient souvent les mêmes sujets, sans doute guidés par quelque cicerone ou drogman: mosquées, tombeaux, Citadelle, la rue de la Citadelle, la place de l'Azbakiyya, quelques maisons anciennes. Les vues générales de la ville prises depuis un point élevé (Du Camp, Schranz), mettent l'accent sur l'immensité, la densité urbaine et le désordre des constructions. Les tombeaux, situés aux limites du désert, durent séduire les photographes pour la beauté du site, mais aussi parce qu'ils offraient une certaine liberté pour opérer, loin du bruit et du mouvement des rues. Même s'ils étaient alors dans un état de semi-abandon, les tombeaux des khalifes étaient appréciés des voyageurs, car leur architecture rappelait celle des mosquées, en plus intime, et davantage mise en valeur du fait de leur isolement. La rue de la Citadelle, avec au premier plan des maisons à moucharabieh et, au fond, la mosquée d'Ibrahim agha, fut souvent photographiée; la perspective marquée accentue l'étroitesse de la rue et conduit le regard jusqu'au minaret s'élevant sur le ciel. En revanche, on l'a vu, les détails d'architecture, de décor ou de mobilier sont plus rares et retinrent surtout l'attention de quelques érudits, comme Girault de Prangey (fig. 19) ou Prisse d'Avesnnes. Pour les professionnels, ce genre d'image était moins facile à vendre que des vues de mosquées, des types égyptiens ou des petits commerces. Période de transition entre la lithographie, où les dessinateurs peuvent arranger la réalité à leur guise, et la photographie des grands ateliers commerciaux, qui renoua avec un certain pittoresque des années 1830-1840, les photographies prises au Caire dans les années 1850 par les amateurs et par les premiers professionnels montrent une ville sans 
artifices, parfois très dégradée (certaines photographies furent prises peu de temps après le tremblement de terre de 1856). Elles reflètent néanmoins une fascination certaine pour l'Orient, son architecture, et son décor, conformes au rêve occidental.

19. Attribué à Joseph-Philibert GIRAULt DE PRANGEY, Vieille place au Caire.

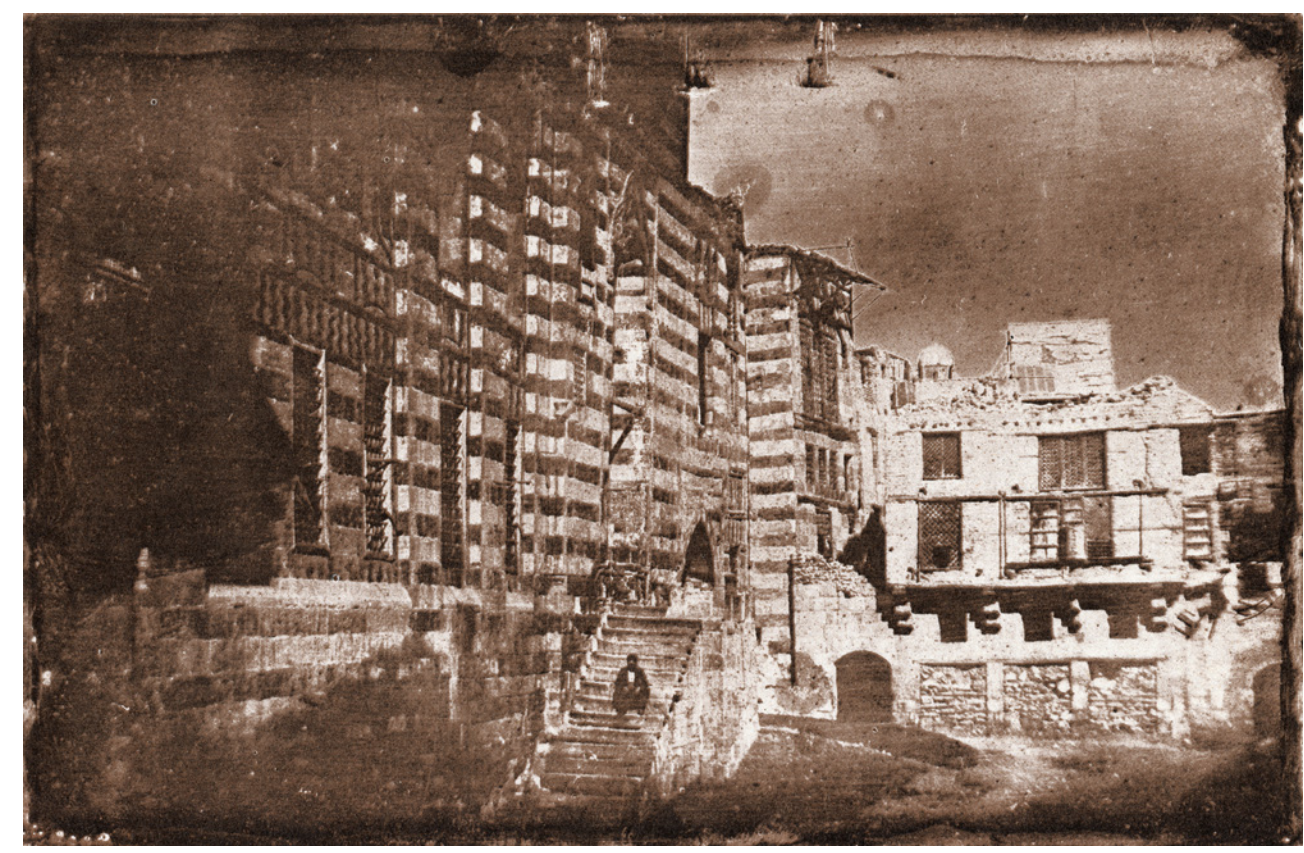

Source : Marie-Thérèse et André JAmmEs, En Égypte au temps de Flaubert 1839-1860. Les premiers photographes, Paris : SFP, 1976, ill. 33.

\section{NOTES}

1. Frédéric GOUPIL-FESQUET, Voyage en Orient fait avec Horace Vernet en 1839 et 1840, Paris : Challamel, 1843.

2. Pierre TRÉMAUX, Voyage en Éthiopie au Soudan oriental et dans la Nigritie, Voyages au Soudan oriental, dans l'Afrique septentrionale et dans l'Asie Mineure exécutés de 1847 à 1854, Paris : Hachette, 1862-1863. 3. Vieille place au Caire, daguerréotype anonyme, reproduit dans le catalogue En Égypte au temps de Flaubert. 1839-1860 : les premiers photographes, Paris : Kodak-Pathé, 1980, nº 33.

4. Henry Cammas, Souvenirs d'Égypte. Offert à son Altesse royale le Comte de Paris, c. 1878.

5. Conservé au musée d'Orsay, Paris, France.

6. Album de la collection de l'architecte Alfred Armand, conservé à la Bibliothèque nationale de France, Paris (France).

7. Album d'Alphonse de Brébisson, conservé au musée d’Orsay, Paris, France.

8. Conservées à la Bibliothèque nationale de France, Paris (France).

9. Getty Research, collection Ken and Jenny Jacobson ; Austin, Harry. Ransom Center, ventes diverses.

10. Louis de CORMENIN, La Lumière, 26 juin 1852. 
11. ID., La Lumière, 12 juin 1852.

12. Francis WEY, La Lumière, 14 septembre 1851.

13. Société de géographie, don Henri Duveyrier.

14. Rochester, George Eastman House ; Dublin (Irlande), National Library of Ireland ; Austin, TX (États-Unis), University of Texas, collection Gernsheim.

15. Photographic Society of Ireland, National Library of Ireland, Dublin (Irlande).

16. Vue positive au Centre canadien d'architecture de Montréal (Canada).

17. Château de Windsor, collection de Sa Majesté Elisabeth II d'Angleterre.

18. Un album de 89 photographies est passé en vente en 1999.

19. Photographies conservées à la Bibliothèque nationale de France, Paris (France).

20. Ernest SAINT-EDME, "Cinquième exposition de la Société française de photographie », Cosmos, 29 mai 1863.

21. Douglas Robert NICKEL, Francis Frith in Egypt and Palestine : A Victorian Photographer Abroad, Princeton, NJ : Princeton University Press, 2004.

22. Un exemplaire est conservé à la bibliothèque de l'INHA, Fonds Jacques-Doucet, Paris (France). 23. Albums du duc de Chartres et du comte de Paris conservés respectivement à la BnF et au musée d'Orsay, Paris (France).

24. Conservée à la Bibliothèque nationale de France, Paris (France).

25. Marc Antoine GAUDIN, "Quatrième exposition de la Société française de photographie », La Lumière, 15 mai 1861.

26. Ancien album Félix Paponot vendu en 2001.

27. Conservé au musée d'Orsay, Paris (France).

28. Quatre vues regroupées sur une même page, Art Institue of Chicago, reproduites dans Nissan PEREZ, Focus East : Early Photography in the Near East (1839-1885), New York, NY : Harry N. Abrams ; Jerusalem : Domino Press ; Israel Museum, 1988, p. 136-137.

29. Copenhague (Danemark), Royal Library.

\section{AUTEUR}

\section{HÉLÈNE BOCARD}

Conservateur en chef du patrimoine, pensionnaire chargée de l'histoire de la photographie à l'INHA, Paris. 


\title{
La redécouverte d'un précurseur : Joseph-Philibert Girault de Prangey (1804-1892)
}

\author{
Sylvie Aubenas
}

\section{NOTE DE L'ÉDITEUR}

Sauf mention contraire, tous les daguerréotypes reproduits sont l'œuvre de JosephPhilibert Girault de Pranguey

Les centaines de daguerréotypes réalisés par Girault de Prangey lors de son voyage en Orient (1842-1845) sont restés longtemps mythiques. Cette œuvre est désormais bien connue des spécialistes de la photographie. De nombreuses ventes aux enchères, publications et expositions ont depuis une dizaine d'années remis au premier plan ce pionnier du daguerréotype qui a laissé une œuvre d'une qualité et d'une ampleur sans équivalent en particulier si l'on considère la période précoce où elle a été réalisée. Les historiographes de l'archéologie moyen-orientale et de l'étude des arts de l'Islam connaissaient ses publications richement illustrées de lithographies. Il est sans doute utile aujourd'hui de faire un bilan des événements récents qui ont permis d'apporter des précisions importantes sur la vie et les travaux de Girault de Prangey, afin de susciter l'étude de référence qui manque encore sur Girault de Prangey archéologue, orientaliste, historien de l'architecture ${ }^{1}$. 
1. [Autoportrait], 1840.

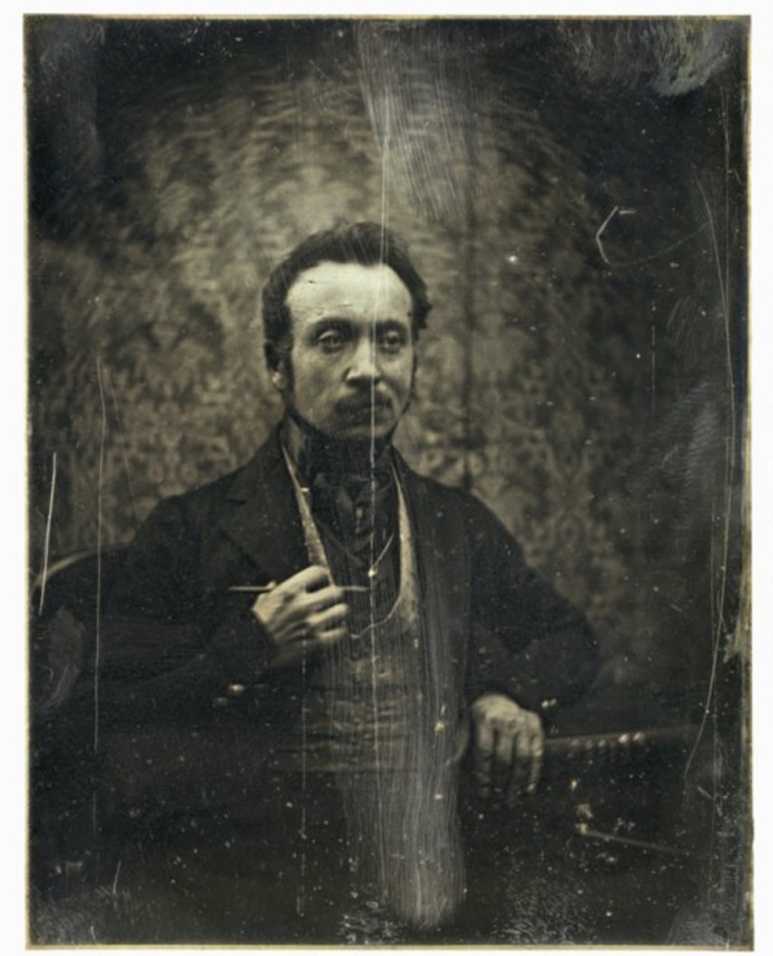

Source : Paris (France), Bibliothèque nationale de France (BnF).

\section{L'œuvre méconnu d'un voyageur érudit}

2 Joseph-Philibert Girault de Prangey naquit à Langres en Haute-Marne, le 20 octobre 1804, dans une famille fortunée de l'aristocratie locale. Il demeura fils unique après la mort en bas âge de ses frères et sœurs. Il s'orienta vers une formation artistique : il étudia le dessin à Langres avec son exact contemporain, le peintre Jules Ziegler. Il poursuivit ensuite ses études à Paris où il reçut des leçons de François Edme Ricois et de Jules Coignet. Son intérêt pour l'archéologie et les monuments antiques se manifestait déjà. En 1831, Girault de Prangey commença le premier de ses nombreux voyages, suivant en cela l'exemple de Coignet. Ce périple l'occupa de 1831 à 1834 : la fortune familiale lui permettait de se consacrer au dessin et à l'archéologie. Il débuta classiquement par l'Italie, visita également l'Algérie, l'Espagne, la Sicile et enfin la Suisse. Il réalisa de très nombreux dessins de monuments et de paysages. Il consacra un séjour particulièrement long à la visite de l'Andalousie et de la Sicile.

3 De retour à Langres, son intérêt pour l'archéologie ne se démentit pas : il fut l'un des membres fondateurs de la Société archéologique de Langres en 1836. 


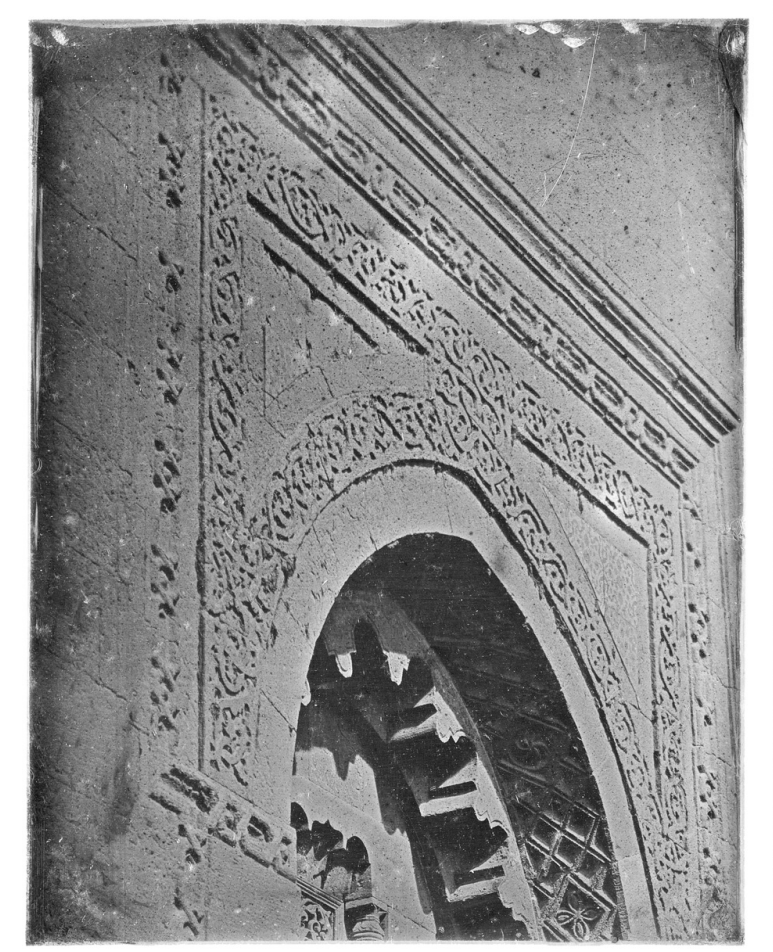

Source : Paris (France), Bibliothèque nationale de France (BnF)

4 Il décida de publier sous forme de recueil de lithographies ses dessins effectués à Cordoue, Séville et Grenade. La première partie des Monuments arabes et moresques de Cordoue, Séville et Grenade dessinés et mesurés en 1832 et $1833^{2}$ parut en 1836. La publication des trois tomes s'étendit jusqu'en 1839 : ce sont Mosquée de Cordoue (tome I), La Giralda et l'Alcazar de Séville (tome II) et les Souvenirs de Grenade et de l'Alhambra (tome 3). Lors de ce voyage, Girault de Prangey avait été particulièrement intéressé par l'architecture arabe d'Espagne et de Sicile. En 1841, il publia un ouvrage, à la fois introduction et complément à ces volumes de planches en couleurs: Essai sur l'architecture des Arabes et des Mores en Espagne, en Sicile et en Barbarie ${ }^{3}$.

5 Il souhaitait continuer ses études sur l'architecture antique et sur l'architecture arabe et les accompagner de nouvelles publications. Il se rendit compte qu'en plus des dessins de son précédent voyage, il fallait désormais s'aider de la photographie. Cette technique était alors très nouvellement apparue. Son intérêt pour les archéologues et historiens avait immédiatement été souligné par les différentes académies : Sciences, Beaux-arts, Inscriptions et belles-lettres. Il comptait ainsi gagner du temps par rapport au dessin et rapporter une plus grande quantité de documents plus exacts. Il s'initia au daguerréotype en 1841, sans doute à Paris. Les premiers daguerréotypes qu'il réalisa et data sur les plaques, cette année-là, sont en effet des vues de monuments parisiens : cathédrale Notre-Dame, Tuileries, tour Saint-Jacques, fontaine du Château d'eau. Nous ignorons malheureusement, faute de documents, auprès de qui il prit des leçons; on peut du moins supposer qu'Hippolyte Bayard, ami de Jules Ziegler, aurait pu être son initiateur. Avant de repartir en voyage, il publia, au début de l'année 1842, un nouveau complément à ses ouvrages précédents sous le titre: Choix d'ornements moresques de l'Alhambra. 


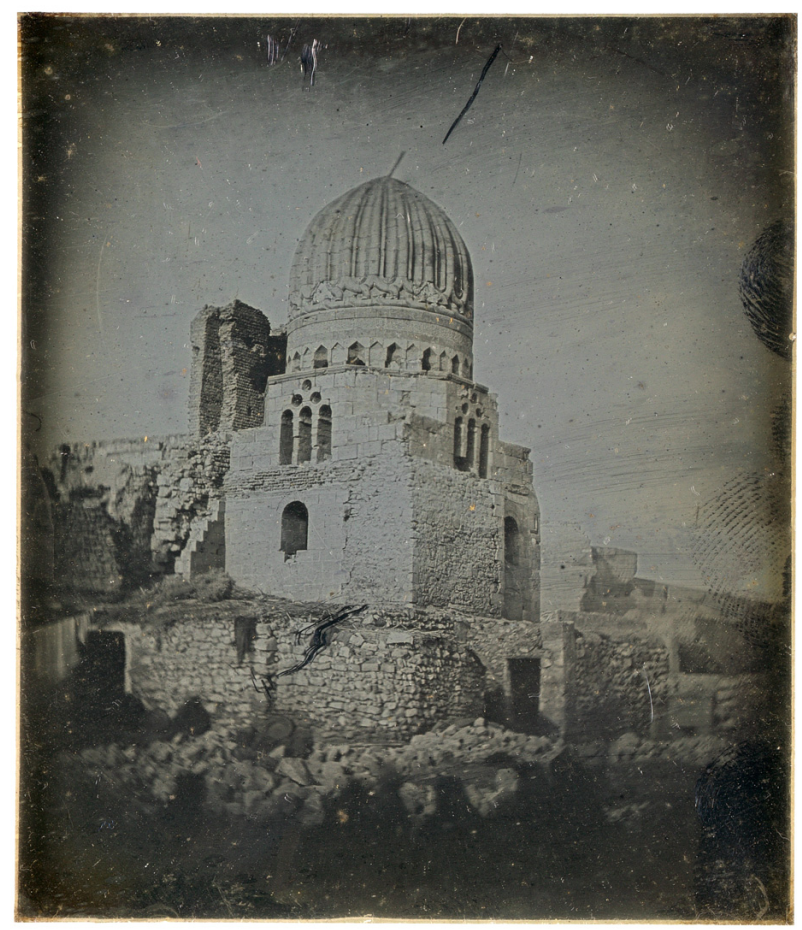

Source : Paris (France), Bibliothèque nationale de France (BnF).

6 Les centaines de photographies rapportées par Girault de Prangey à son retour en 1844 servirent de documentation pour les illustrations des nombreuses publications qu'il prévoyait. En 1846, parurent Les Monuments arabes d'Égypte, de Syrie, d'Asie Mineure dessinés et mesurés de 1842 à $1845^{4}$.

7 De 1847 à 1849, il s'intéressa à Langres et ses environs au travers de cinq articles pour les Mémoires de la Société historique et archéologique de Langres. En 1851, il publia Les Monuments et paysages de l'orient, un recueil de chromolithographies inspirées également des études peintes, dessinées et photographiées réalisées sur place.

8 Ces ouvrages coûteux, publiés à compte d'auteur et restés tous deux inachevés, furent remarqués par ses pairs mais ne rencontrèrent pas le succès public escompté. Le succès auprès du public aurait été le couronnement de tant de peines, de travaux et d'investissements et aussi la condition financière pour l'achèvement de la publication en livraisons. La somme de ses écrits lui valut toutefois d'être élu en 1846 membre honoraire et correspondant du Royal Institute of British Architects. Il décida d'arrêter cette entreprise coûteuse et se tourna vers ses autres centres d'intérêt.

Cruellement déçu et sans doute blessé dans son orgueil, Girault de Prangey, dont les contemporains soulignaient le caractère difficile, se retira dans sa somptueuse villa de style oriental, inspiré des maisons turques de la Corne d'or, le domaine des Tuaires à Courcelles-Val d'Esnoms près de Langres. Il continua de pratiquer le daguerréotype jusqu'au début des années 1850 comme en atteste un ensemble de 61 vues prises en Suisse, conservées au Musée gruérien de Bulle (Suisse), et quelques vues de sa demeure dont les travaux s'achevaient alors. Il se consacra principalement à la culture en serres de fleurs et fruits exotiques. Devenu un original misanthrope, il y passa les quarante 
dernières années de sa vie, recevant peu de visites, alimentant les légendes et les fantasmes de la société langroise. Il mourut dans sa propriété en décembre 1892 sans avoir jamais revu l'Orient depuis son retour, en 1844.

\section{Kaire, Gâma Amr [mosquée 'Amr]. Angle N.O., 1842-1844.}

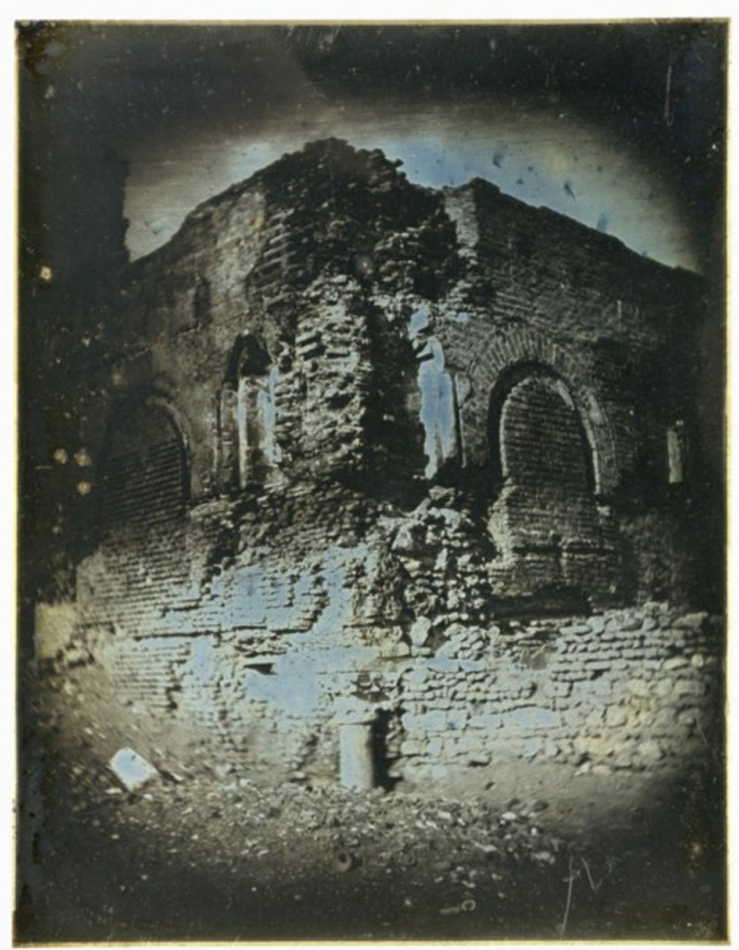

Source : Paris (France), Bibliothèque nationale de France (BnF).

\section{Girault de Prangey et la pratique du daguerréotype}

10 L'utilisation du daguerréotype par Girault de Prangey lors de son voyage de 1842-1845 qui le mena de l'Italie à la Turquie, était bien connue dès cette époque. Il commença son long périple par Rome où il séjourna d'avril à fin juillet 1842. On trouve mention de sa pratique de la photographie dans la correspondance du directeur de la Villa Médicis, Jean-Victor Schnetz. Il écrivait en effet à Raoul-Rochette leur ami commun :

«M. Girault de Prangey daguerréotype tout ce qu'il peut ici, tout y passe, monuments, rues, pifferari, et même cardinaux. Il a même l'ambition de braquer son instrument devant le nez du Saint-Père. Il prétend faire des choses extraordinaires avec son instrument perfectionné ; pour l'œil nu, les améliorations dont il se flatte sont presque nulles: je vois toujours dans ses images les mêmes défauts et les mêmes qualités qu'autrefois ».

11 Une autre lettre au même correspondant, datée du 20 juillet 1842, annonçait le départ $\mathrm{du}$ photographe que, décidemment, il n'appréciait guère :

«J'ai trouvé chez moi hier une carte de Girault de Prangey m'annonçant son départ. Il a fait ici plus de trois cents vues daguerréotypes, je ne le voyais plus que très rarement depuis sa décoration de Saint-Grégoire dont j'avais oublié de lui faire compliments ${ }^{5} »$. 
12 De même, sa moisson photographique est mentionnée à son retour dans les pages du Bulletin monumental :

«Retour de M. Girault de Prangey. M. Girault de Prangey, un des inspecteurs de la Société française [d'archéologie], qui depuis trois ans voyageait en Orient où il avait entrepris de longues et importantes explorations monumentales dont nous avons précédemment entretenu les lecteurs du Bulletin, vient d'arriver à Paris, chargé d'une riche moisson d'observations et de vues prises au Daguerréotype : on porte à 3000 le nombre des vues daguerréotypées par M. de Prangey. Favorisé par une santé qui n'a pas été altérée un seul instant, M. de Prangey a employé, avec le zèle et la sagacité dont il a toujours fait preuve, ses trois années de voyage, et l'on peut apprécier tout ce qu'une pareille exploration a produit de résultats importants pour la science: nous reviendrons sur le voyage de M. de Prangey dont nous voulons seulement aujourd'hui annoncer l'heureux retour $^{6}$ ".

13 Les milliers de dessins, aquarelles et daguerréotypes réalisés durant son voyage étayent la confection des planches lithographiques des deux ouvrages publiés à son retour: Monuments arabes d'Égypte, de Syrie et d'Asie Mineure dessinés et mesurés de 1842 à 1845 paru en 1846 et Monuments et paysages de l'Orient ${ }^{7}$ en 1851.

14 Vingt ans plus tard dans son ouvrage L'Art arabe, Émile Prisse d'Avennes mentionna, à propos d'une mosquée désormais disparue, cette utilisation des daguerréotypes qui constituait désormais la seule source fiable: «Cette vue a été lithographiée par les soins de M. Girault de Prangey d'après ses daguerréotypes ${ }^{8}$ ».

L'ensemble extraordinaire de photographies rapportées d'Orient est encore mentionné dans la notice nécrologique malheureusement très approximative rédigée à sa mort en 1892 par Henri Brocard: «La quantité de plaques daguérriennes qu'il rapporta est considérable, elles remplissent d'immenses caisses et sont classées avec un ordre parfait $^{9} »$. 
5. Vieux Kaire. M. Amr [mosquée ‘Amr]. Nefs. Cour, 1842-1844.

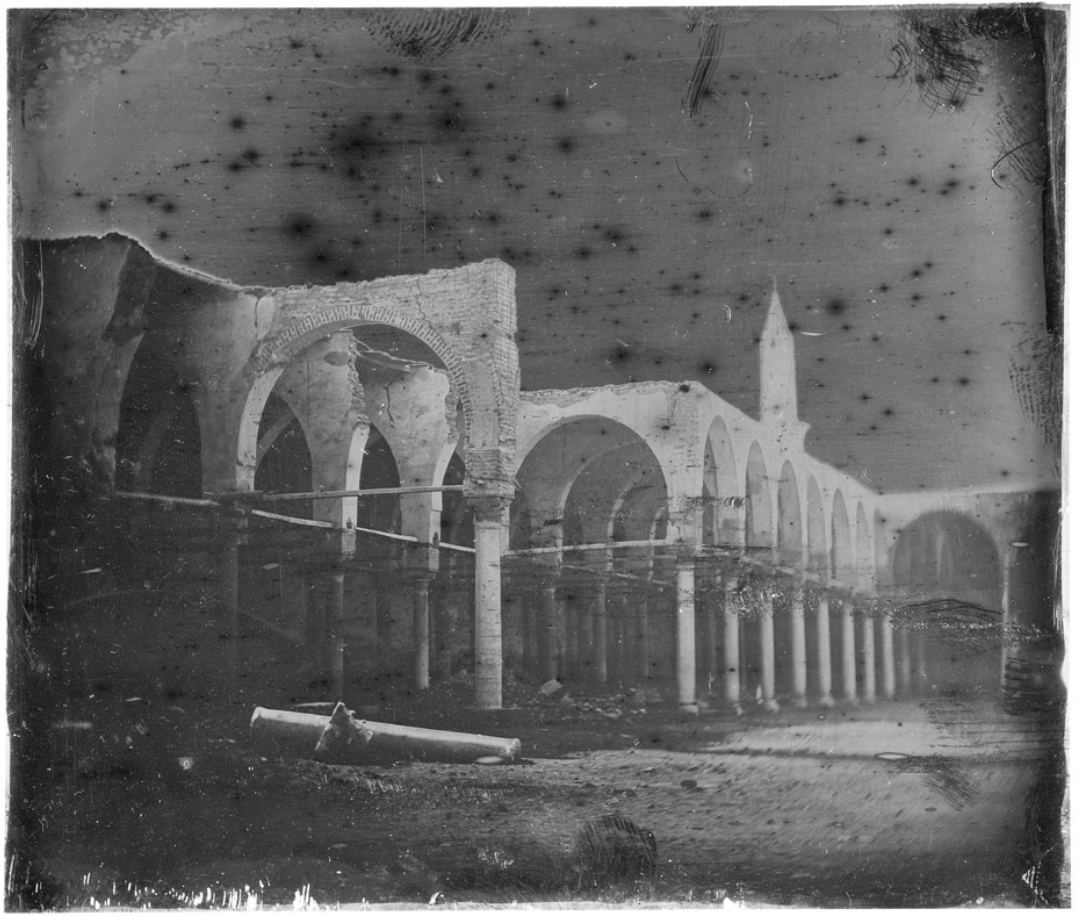

Source : Paris (France), Bibliothèque nationale de France (BnF).

6. Kaire. G. Amr [mosquée 'Amr]. Mihrab à l'extérieur, 1842-1844.

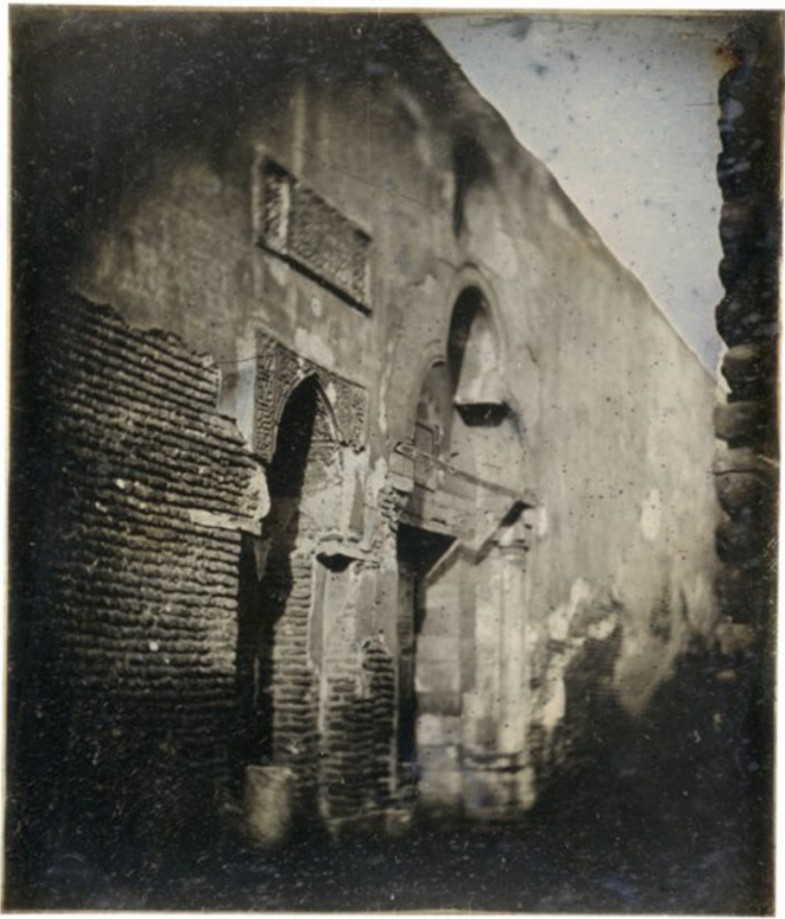

Source : Paris (France), Bibliothèque nationale de France (BnF) 


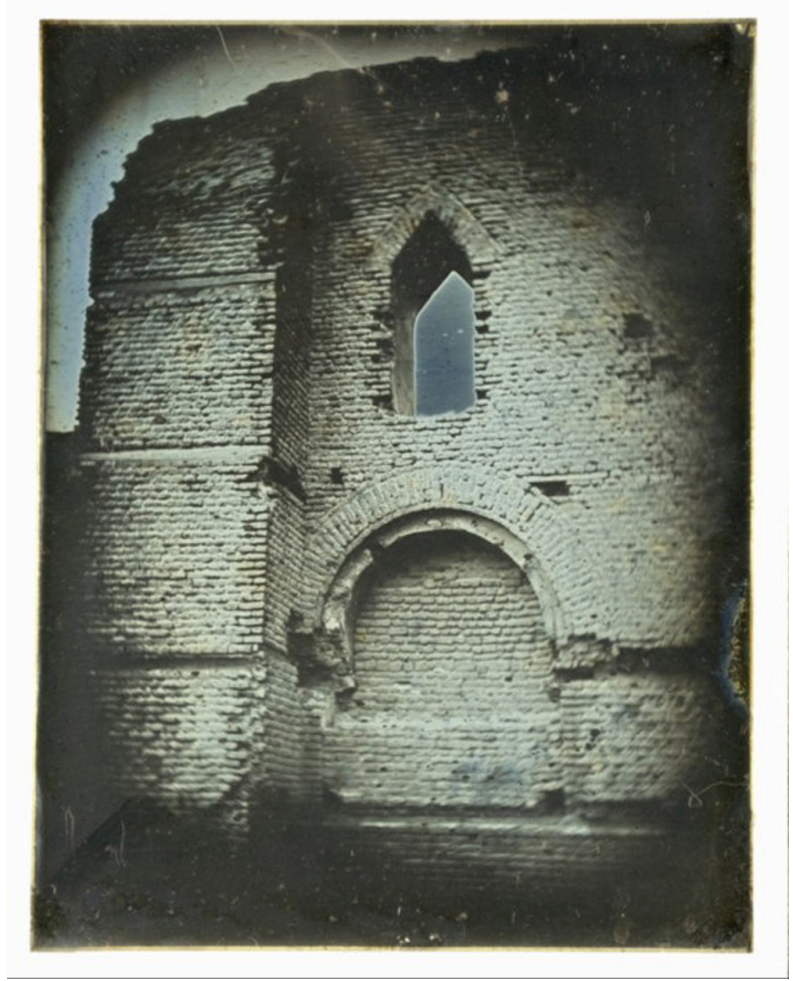

Source : Paris (France), Bibliothèque nationale de France (BnF).

\section{Histoire de la collection}

Après diverses vicissitudes, Girault de Prangey étant mort sans héritiers directs, son domaine en ruines fut racheté en 1920 par son voisin le comte Charles de Simony (1869-1952). Ce dernier retrouva dans les ruines la collection de daguerréotypes :

«Dans une soupente noire, un amas de boîtes rectangulaires gisaient abandonnées ; la collection sans doute complète, des daguerréotypes rapportés du voyage de Girault de Prangey dans l'Orient méditerranéen et en Haute-Égypte, en 1843 et $1844^{10} »$.

Il fit une conférence sur ce sujet à l'Académie de Dijon en 1934. En 1950, conscient de la valeur de ces œuvres et sentant sa fin proche, il fit deux dons importants :

- 20 plaques au département des Estampes de la Bibliothèque nationale (uniquement des vues de Paris réalisées en 1841 avant le voyage en Orient ${ }^{11}$ ) ;

- 61 vues de Suisse au conservateur du Musée gruérien de Bulle en Suisse, Henri Naef, sur les conseils d'un ami commun rencontré à l'Académie de Dijon, le commandant Charrier.

18 À la même époque, les deux historiens de la photographie américains Helmut et Alison Gernsheim entrèrent en contact avec le comte de Simony, et eurent la possibilité de voir l'ensemble de l'œuvre, d'en dresser l'inventaire et d'acquérir dix daguerréotypes du voyage de $1842-1845^{12}$. Ils publièrent les images dès les années 1955-1956 dans leurs ouvrages sur l'invention de la photographie ${ }^{13}$. 
8. Kaire. 1843. G. Kérabat [mosquée Khayrbak]. Min[aret] et coupole, 1843.

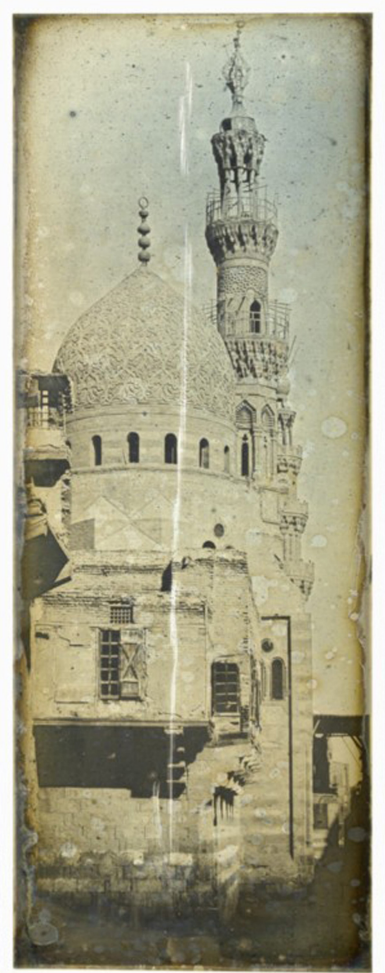

Source : Paris (France), Bibliothèque nationale de France (BnF).

9. Kaire. S. Kérabat [mosquée Khayrbak]. Coupole. 120, 1843.

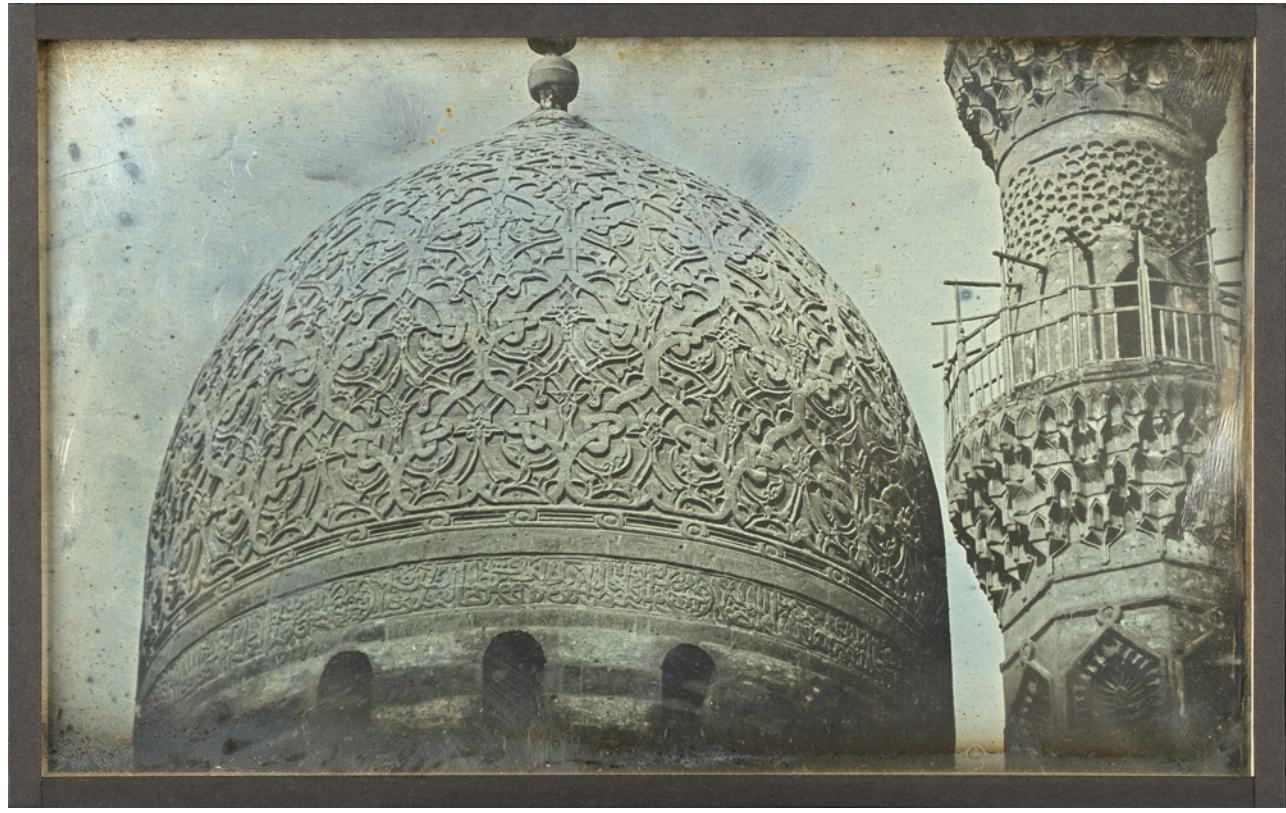

1

Source : Paris (France), Bibliothèque nationale de France (BnF).

19 L'œuvre de Girault de Prangey entra officiellement dans l'histoire de la photographie. En 1970, le grand collectionneur et libraire André Jammes, sollicité par les descendants du comte de Simony, leur donna des conseils pour la conservation des plaques, restées 
nues dans leurs boîtes à rainures depuis 1844 et donc menacées de détériorations diverses ${ }^{14}$. Il conseilla de dépoussiérer et de faire monter sous verre l'ensemble de la collection, contribuant ainsi de manière décisive à sa sauvegarde. Il reçut quelques dizaines de plaques à cette occasion et les conserva dans sa collection personnelle.

10. Kaire. T. [tombeau] du sultan Torabey. Chap., 1842-1844.

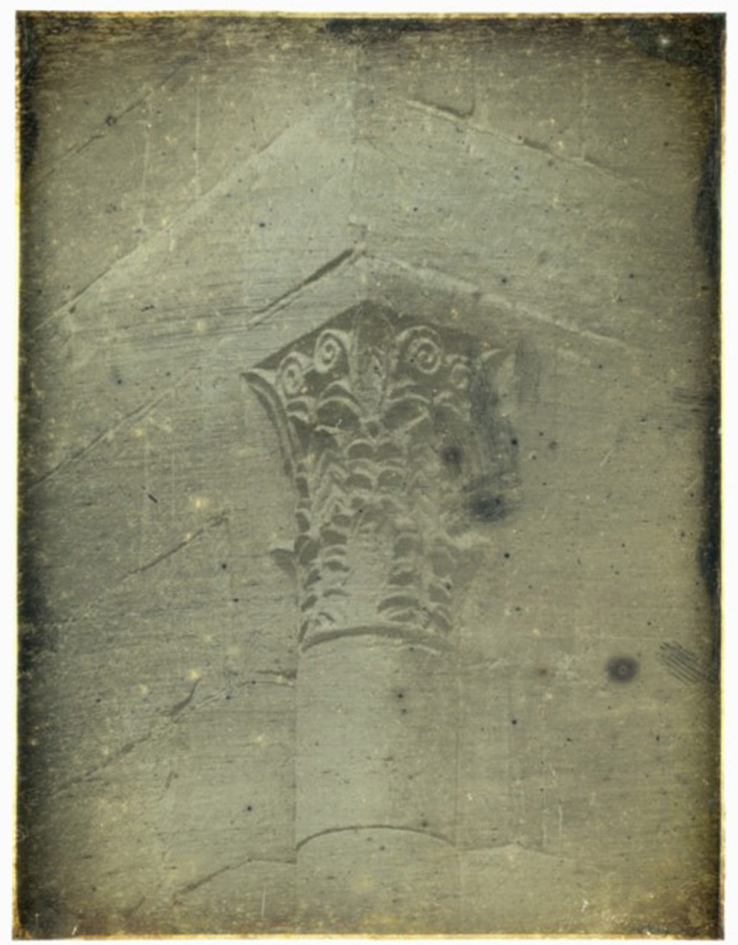

Source : Paris (France), Bibliothèque nationale de France (BnF)

Il faut attendre la fin du XXe siècle pour progresser dans la connaissance de l'œuvre de Girault de Prangey. Jusqu'à ce moment-là, n'avaient été portées à la connaissance du public que les dix plaques des Gernsheim et les vingt de la BnF. En 1998, le musée de Langres organisa une exposition consacrée à Girault de Prangey, premier travail de synthèse sur son œuvre. Pour la première fois de nombreuses aquarelles et des dessins de son voyage étaient reproduits dans le catalogue ${ }^{15}$, mais aucun nouveau daguerréotype n'était publié. Parallèlement à cette exposition, se déroulaient des transactions entre les descendants de Charles de Simony et la Bibliothèque nationale de France. Bernard Marbot ${ }^{16}$ et l'auteur de ces lignes eurent la possibilité de se rendre à Londres chez Christie's pour voir l'ensemble de la collection de daguerréotypes - la maison de ventes britannique servant d'intermédiaire. La BnF, en accord avec la famille, put faire un choix de 158 œuvres, acquises en 2000 pour ses collections. Christie's procéda le 5 mai 2000 à une première vente de 12 daguerréotypes tous reproduits dans le catalogue publié à cette occasion. En 2001, lors de l'exposition Voyage en Orient ${ }^{17}$, quelques-uns des daguerréotypes nouvellement acquis furent présentés au public pour la première fois avec, le cas échéant, les lithographies auxquelles ils avaient servi de modèles. Après cette transaction préalable avec la BnF, destinée à assurer aux collections patrimoniales françaises la possession d'un ensemble représentatif des œuvres de Girault de Prangey, Christie's procéda à une grande vente aux enchères à 
Londres le 20 mai 2003 : 86 photographies furent proposées. Le catalogue de la vente reproduit en couleurs et avec une haute qualité l'ensemble des pièces proposées ${ }^{18}$. Deux textes accompagnent cette publication, l'un de Lyndsey S. Stewart, alors experte chez Christie's pour la photographie qui s'était livrée à des recherches approfondies, l'autre de Roger C. Watson, conservateur du Fox Talbot Museum. De très grandes institutions comme le Metropolitan Museum of Art de New York, le J. Paul Getty Museum et surtout le futur musée de Doha (Qatar) acquirent à des prix sans précédent les plus belles pièces de la vente. Toujours en 2003, se tint au musée d'Orsay une exposition consacrée au daguerréotype français ${ }^{19}$ pour laquelle la BnF prêta onze daguerréotypes, dont sept parmi ceux acquis en $2000^{20}$.

\section{Kaire 1843. Vue géné.[rale] prise de ma terrasse. Ezbékieh [Azbakiyya], 1843.}

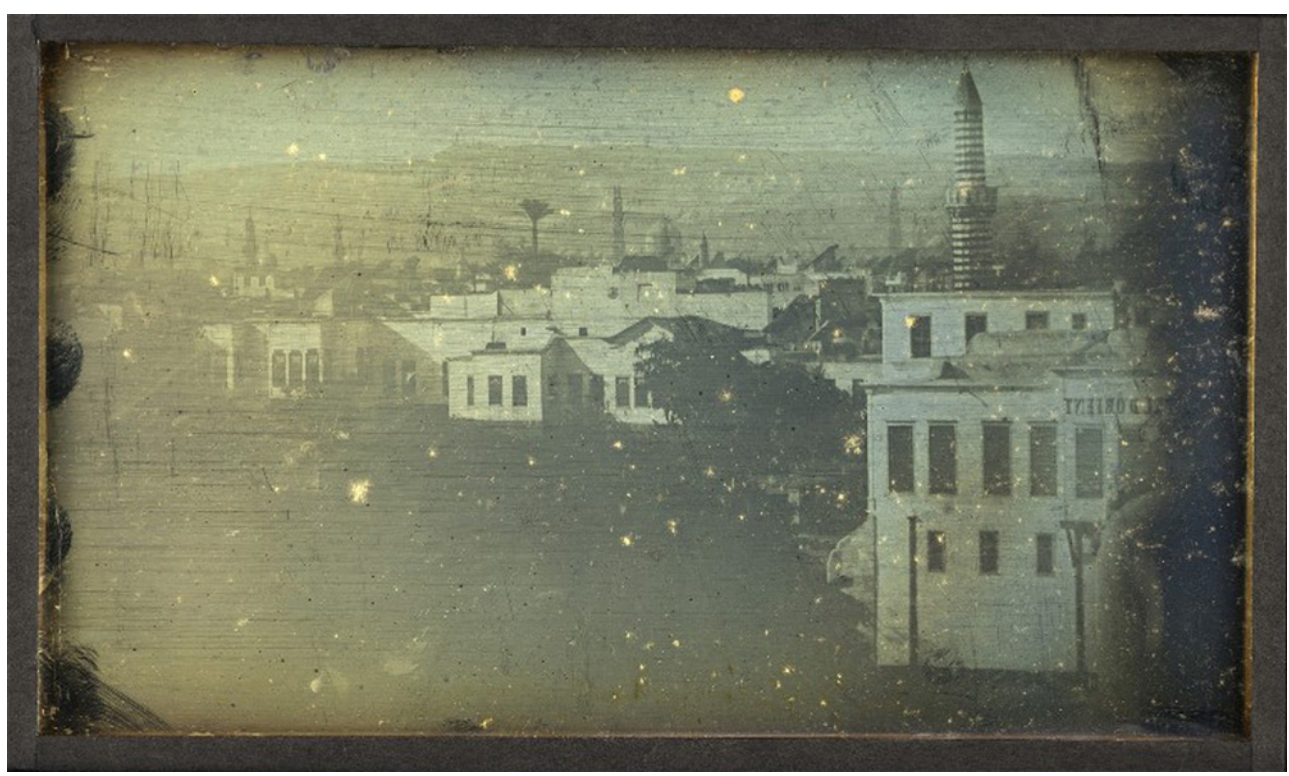

Source : Paris (France), Bibliothèque nationale de France (BnF)

Le 18 mai 2004 Christie's procéda à une seconde vente de 89 daguerréotypes ${ }^{21}$, complétée d'un catalogue illustré. Les textes d'introduction étaient rédigés par Grant Romer ; directeur de la George Eastman House de Rochester (États-Unis), spécialiste des procédés photographiques anciens et par Lindsey S. Stewart. En 2005, pour célébrer la réouverture après rénovation de la villa Getty à Malibu, une exposition sur les photographies anciennes de sites archéologiques fut organisée. Dans le catalogue, un chapitre signé de Lindsey S. Stewart est consacré à Girault de Prangey ${ }^{22}$.

En 2008, le Musée gruérien de Bulle, bénéficiaire des largesses du comte de Simony en 1950, organisa une exposition pour présenter au public les 61 vues de Suisse offertes soixante ans plus tôt, complétée par un catalogue très complet ${ }^{23}$. Le 15 novembre 2008, lors de la quatrième et dernière vente consacrée à la dispersion de leur collection chez Sotheby's ${ }^{24}$, Marie-Thérèse et André Jammes proposèrent 13 daguerréotypes de Girault de Prangey provenant du lot acquis auprès de la famille de Simony en 1970. Ces treize œuvres furent reproduites dans le catalogue de la vente. Parallèlement, la BnF fit l'acquisition auprès d'eux de douze autres plaques ; une treizième étant offerte.

À la demande des descendants du comte de Simony, la maison Christie's procéda à une troisième vente le 7 octobre 2010 et proposait 74 autres daguerréotypes. Le catalogue, 
richement illustré, fut préfacé par Philip Garner, directeur du département de la photographie chez Christie's et historien du médium, et Christophe Dutoit, spécialiste de Girault de Prangey ${ }^{25}$.

\section{Kaire. Matelot. 224, 1843-1844.}

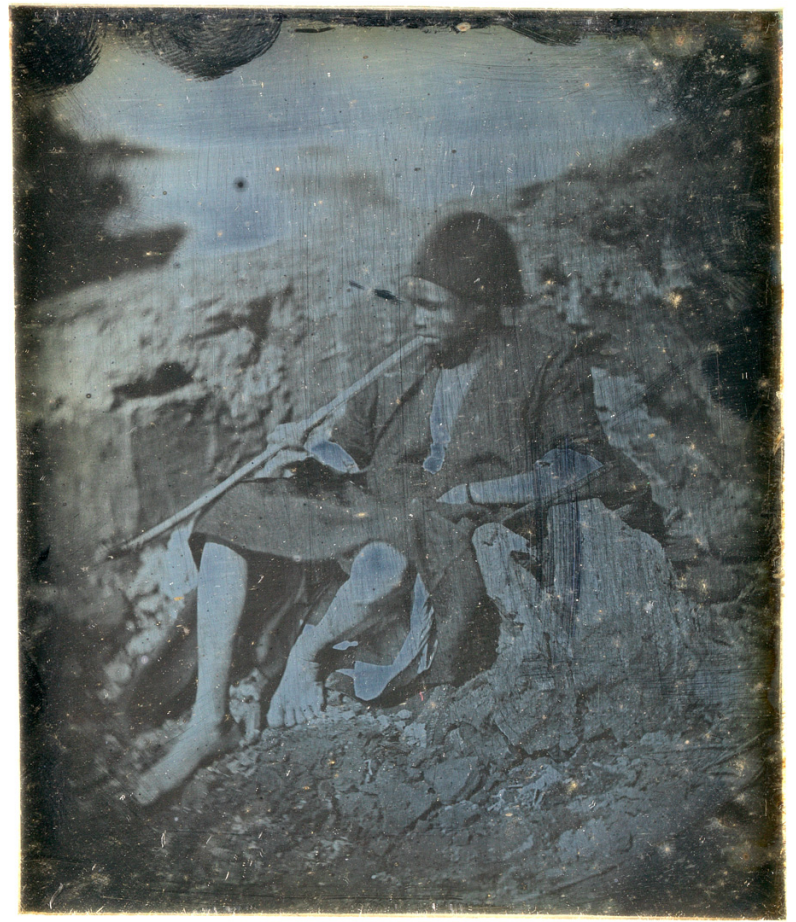

Source : Paris (France), Bibliothèque nationale de France (BnF) quotidienne n'est pas utilisée abusivement dans cette histoire pleine de surprises -, nous ne connaissons pas d'autres publications sur l'œuvre de Girault de Prangey. Ajoutons toutefois que sur les centaines de daguerréotypes restant en possession des descendants du comte de Simony, certains ont pu faire l'objet de transactions dont il ne reste pas de trace bibliographique.

Toutefois, il apparait qu'entre le moment où la villa de Girault de Prangey fut abandonnée après la mort de son intendant et son rachat par Charles de Simony, soit entre 1914 et 1920, des habitants de la région prirent quelques boîtes de daguerréotypes. L'ensemble retrouvé par le comte de Simony en 1920 était donc incomplet. Par la suite, il fut beaucoup mieux conservé et est actuellement en bien meilleur état.

Aujourd'hui entre les catalogues de vente, d'expositions, les sites Internet des différentes institutions ${ }^{26}$, plus de 500 œuvres de Girault de Prangey sont accessibles directement ou en reproductions. Celles qui demeurent inconnues et inédites sont certainement à peu près aussi nombreuses : comme on peut déjà le constater en consultant l'ensemble des images disponibles, Girault de Prangey doublait voire triplait souvent une prise de vue en variant très peu le cadrage. On peut en conclure que dans ce qui demeure inconnu beaucoup d'images sont déjà publiées par ailleurs. 
13. Vieux Caire. Tronc de datier [sic], 1842-1844.

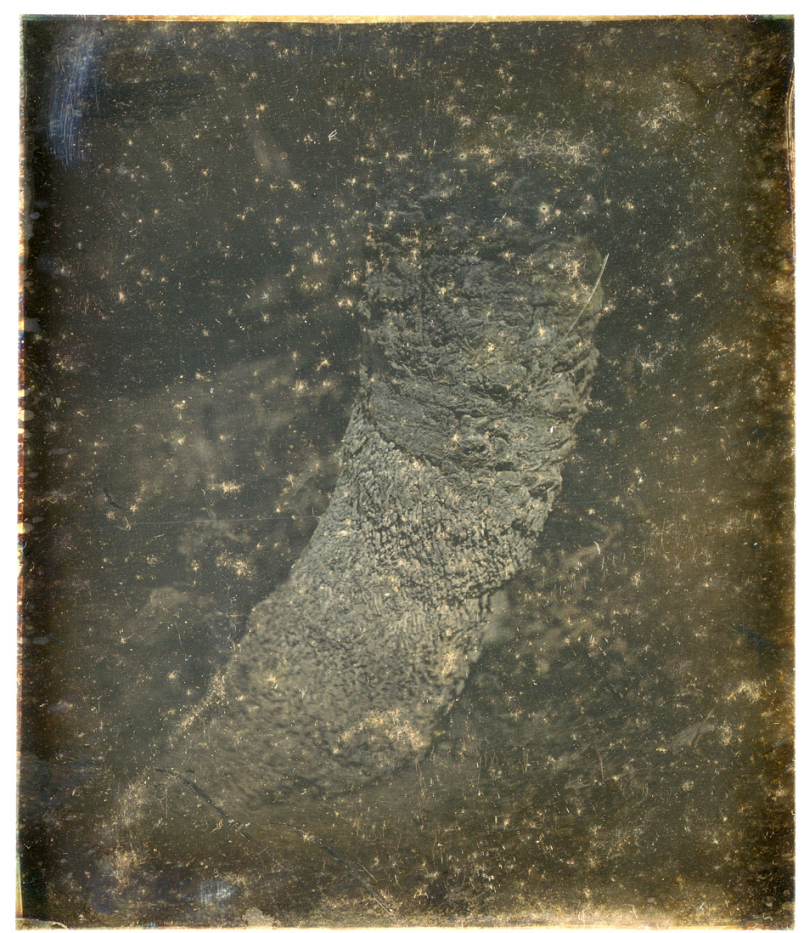

Source : Paris (France), Bibliothèque nationale de France (BnF)

fin du XXe siècle, soit désormais en grande partie dispersé. Cependant, quelles qu'aient été les vicissitudes de son histoire, cet ensemble a finalement beaucoup moins souffert que bien d'autres œuvres de la même époque dont on ne garde trace que par les textes ou le biais de leur interprétation par des gravures.

Tout l'œuvre au daguerréotype de Girault de Prangey ne concerne pas son voyage de 1842-1845, puisqu'il avait réalisé bon nombre de plaques en France avant son départ, en manière d'entraînement, et qu'il en a fait d'autres à son retour. Cependant, ses vues de voyage sont le cœur et la raison d'être de cet ensemble unique. Si l'on soustrait celles qui concernent le tout début de son Grand Tour, Sud de la France et Italie, il reste quelques centaines de vues d'Orient, Égypte et Turquie en particulier. Beaucoup d'entre elles sont les premières représentations photographiques conservées de sites importants, transformés ou détruits depuis les années 1840 .

Girault de Prangey cumulait à lui seul les qualités de peintre, de photographe, d'archéologue, d'orientaliste et de botaniste. Ses photographies ne sont pas celles d'un simple voyageur, même instruit et curieux. Beaucoup d'entre elles représentent des détails d'architecture, des témoignages particulièrement rares d'architecture antique, arabe ou vernaculaire. Au-delà de l'intérêt que cet ensemble a pu susciter parmi les historiens de la photographie, il est nécessaire maintenant que d'autres spécialistes s'emparent de ce corpus unique et étudient son impact sur l'histoire de l'art et de l'archéologie moyen-orientale dans la première moitié du XIX ${ }^{\mathrm{e}}$ siècle. 


\section{NOTES}

1. François Poulloon (dir.), Dictionnaire des orientalistes de langue française, Paris : Karthala, 2008, n'en mentionne en tout cas aucune.

2. Joseph-Philibert GIRAULT DE PRANGEY, Monuments arabes et moresques de Cordoue, Séville et Grenade, dessinés et mesurés en 1832 et 1833, Paris : Veith et Hauser, s.d.

3. IDEM, Essai sur l'architecture des Arabes et des Mores en Espagne, en Sicile et en Barbarie, [suivi d'un appendice contenant les inscriptions de l'Alhambra, publiées et traduites par J. Derembourg], Paris : A. Hauser, 1841.

4. IDEM, Monuments arabes d'Égypte, de Syrie, d'Asie Mineure dessinés et mesurés de 1842 à 1845, Paris : l'auteur, 1846.

5. Émilie ROBBE, Correspondance de Jean-Victor Schnetz, directeur de l'Académie de France à Rome de 1841 à 1846 et de 1853 à 1866 : édition commentée. Thèse pour le diplôme d'archiviste-paléographe, École nationale des Chartes, Paris, 2001, 2 volumes; vol. II, p. 294 et 301. Voir la transcription complète de cette correspondance sur le site de la Bibliothèque de l'Institut de France. La première lettre de Schnetz laisse penser qu'il a pu voir et commenter avec Raoul-Rochette les premiers essais faits par Girault de Prangey à Paris en 1841.

6. Dans Bulletin monumental, vol.11, 1845, p.317. Le chiffre de 3000 paraît très exagéré. L'ensemble rapporté par Girault de Prangey serait en réalité, d'après tous les inventaires étudiés, plus proche de 1000 daguerréotypes ce qui est déjà considérable.

7. Il s'agit en réalité d'un recueil de planches dont il subsiste peu d'exemplaires sous le titre original. Dans la plupart des cas les planches ont été dispersées.

8. Émile PRISSE D'AVENNES, L'art arabe d'après les monuments du Kaire depuis le VII siècle jusqu'à la fin du XVIII , Paris, Ve A. Morel et Cie, [1869]-1877, 1 vol. de texte et 3 vol. de pl., p. 262.

9. "Girault de Prangey », Bulletin de la Société historique et archéologique de Langres, 1893, 4, p. 18.

10. Charles de SIMONY, "Une curieuse figure d'artiste, Girault de Prangey, 1804-1892 ", in Mémoires de l'Académie des Sciences, arts et belles lettres de Dijon, 1934, Dijon : Imprimerie Bernigaud et Privat, 1935.

11. Il s'agit de vues de la cathédrale Notre-Dame, de la tour Saint-Jacques, des Tuileries, de la fontaine du Château d'Eau gelée. Ces images ont été publiées intégralement pour la première fois dans le catalogue de l'exposition du musée Carnavalet, Françoise ReYNAud (dir.), Paris et le daguerréotype, catalogue d'exposition (Paris, musée Carnavalet, 31 octobre 1989-28 février 1990), Paris : Paris Musées, 1989. C'est la connaissance de ces daguerréotypes qui fait écrire à Jean Adhémar et Jacques Lethève à propos de Girault de Prangey dans l'Inventaire du fonds français après 1800, Paris, Bibliothèque nationale, 1955, tome 9, p.164: «Il est l'auteur de quelques lithographies ainsi d'ailleurs que de photographies plus intéressantes ».

12. Ils sont aujourd'hui conservés au Harry Ransom Center de l'université du Texas à Austin (États-Unis).

13. The History of photography from the earliest use of the camera obscura in the eleventh century up to 1914, Londres; New York, NY : Oxford University Press, 1955 et L. J. M. Daguerre, the history of the diorama and the daguerreotype, Londres : Secker and Warburg, 1956.

14. Le fait que ces plaques soient restées sans protection pendant plus de cent ans et manipulées quelquefois sans précaution, explique les dommages que certaines d'entre elles ont subis : traces de doigts, effacement partiel de l'image par frottement, oxydation, etc.

15. Philippe QUETTIER, Jacques-Rémi DAHAN, Pierre-Marc RICHARD, Sur les traces de Girault de Prangey, 1804-1892: dessins, peintures, photographies, études historiques, Langres: Musées de Langres; D. Guéniot, 1998. 
16. Conservateur au département des Estampes et de la photographie à la Bibliothèque nationale de France.

17. Du 16 octobre 2001 au 13 janvier 2002 à la Bibliothèque nationale de France, site Tolbiac, Paris (France). Cette exposition, dont j'ai assuré le commissariat, reprenait un ouvrage du même nom publié en 1999 chez Hazan.

18. Important daguerreotypes by Joseph-Philibert Girault de Prangey from the archive of the artist: auction sale, London, Christie's, 20 May 2003, Londres : Christie's, 2003.

19. Quentin BAJAC, Dominique PLANCHON DE FONT-RÉAULX (dirs.), Le daguerréotype français : un objet photographique, catalogue d'exposition (Paris, musée d'Orsay, 13 mai-17 août 2003 ; New York (États-Unis), Metropolitan Museum of Art, 22 septembre 2003-4 janvier 2004), Paris : RMN, 2003.

20. Sylvie AUBENAS, ibid., p. 344-348 du catalogue, notices 280 à 286.

21. Important Daguerreotypes by Joseph-Philibert Girault de Prangey from the Archive of the Artist, part II, auction sale, London, Christie's, 18 May 2004, Londres : Christie's, 2004.

22. Claire L. LYONS, John K. PAPADOPOULOS, Lindsey S. STEWART, Andrew SZEGEDY-MASZAK, « In perfect order: Antiquity in the daguerreotypes of Joseph-Philibert Girault de Prangey ", in Antiquity \& photography: early views of ancient Mediterranean sites, Londres: Thames and Hudson, 2005, p. 66-91.

23. Christophe MAURON (dir.), Miroirs d'argent: daguerréotypes de Girault de Prangey, catalogue d'exposition (Bulle, Musée gruérien, 30 novembre 2008-29 mars 2009), Genève : Slatkine, 2008.

24. La photographie IV : collection Marie-Thérèse et André Jammes : vente, Paris, [Galerie Charpentier], 15 novembre 2008, Paris : Sotheby' France, 2008, n 11 à 23.

25. A Historic Photographic Grand Tour, Important Daguerreotypes by Joseph-Philibert Girault de Prangey sale auction, New York, Christie's, 7 October 2010, New York, NY : Christie's, 2010.

26. Voir en particulier le catalogue général de la BnF pour les notices et Gallica pour les images ainsi que le site Artprice pour les ventes.

\section{AUTEUR}

\section{SYLVIE AUBENAS}

Directeur du département des Estampes et de la Photographie de la Bibliothèque nationale de France, Paris. 


\title{
Topographical Photography in Cairo: The Lens of Beniamino Facchinelli
}

\author{
Ola Seif
}

\section{EDITOR'S NOTE}

Unless otherwise mentioned, all reproduced photographs are by Beninamino Facchinelli.

1 Nineteenth century photographs of Cairo, especially the last quarter of it, were commonly represented in compiled albums which followed to a fair extent, visually, the section on Egypt in Francis Frith's publications. Typically, they contained an assortment of topics revolving around archaeological monuments from Upper Egypt, the pyramids and panoramic views of Cairo such as the Citadel, in addition to façades and courtyards of Islamic monuments, mainly the mosques of Sultan Hasan and Ibn Tulun. Also available, although they seem as a marginal topic included as a touch of flavour, were the photographs of the "petits métiers", the typical Cairene Street and close ups of the mashrabiyya lattice protruding balconies.

Simultaneously, in the 1880s, the wide spread growing interest in the "Art arabe" but more precisely the creation of the Comité de conservation des monuments de l'art arabe $e^{2}$ in 1881 (hereinafter Comité), eventually redirected the photographic visuality into a new paradigm beyond the touristic repertoire that was already known. Since the Comite's objectives and raison d'être were to survey and salvage Cairene Islamic art and architecture, its assigned photographers were asked to focus on a wider range of monuments than they had done so far in their production for tourists and, thus, systematically produced the "before and after" photographs of monuments in question for restoration by the Comité. As such, over the course of the Comité's seventy-year life span, an extensive photographic archive containing thousands of glass plates, negative films and prints came to exist ${ }^{3}$. To date, the Comité's photographic collection remains, 
for bureaucratic reasons, vastly under researched, which hinders our understanding of the formation of this collection, its methodology, scope, depth and context. The published bulletins of the Comite do reveal the names of some of the earliest commissioned contributing photographers. Those are, in chronological order between the first issue (1882) and that of 1901, Lékégian to whom most of the photographs published in the bulletins are credited, Facchinelli, C.M.A., Banget Bey, M. A. Marchettini, Luzzato, and V. Giuntini ${ }^{4}$. With the exception of the very prolific Gabriel Lékégian, whose name appears in many libraries' holdings, and the lesser famous and moderately profuse Italian photographer Beniamino Facchinelli residing in Cairo between the early 1870s till his death in 1895 and known as the photographer of the album Sites et monuments du Caire in the Alinari collection, the known information about the other contributors to the photographic archives of the Comite is diminutive. This article aims at exploring two atypical and distinctive representations of Cairo distilled from Facchinelli's repertoire which, in contrast with his tourist-oriented contemporary photographers, was largely tailored by the commands of particular orientalists, authors and publishers. Those topics are, firstly, the "Rue du Caire" which gained an iconic popularity during Facchinelli's active years in Cairo due to Egypt's pavilions in the consecutive World Fairs starting from that of Vienna in 1873, Paris in 1878 and again in 1889, and Chicago in 1893, and secondly, the subject of the crumbling domestic "Arabian" architecture, most of which is now non-extant.

1. Facchinelli at home, 1005 rue de l'Hôtel-du-Nil, holding one of his children in his arms.

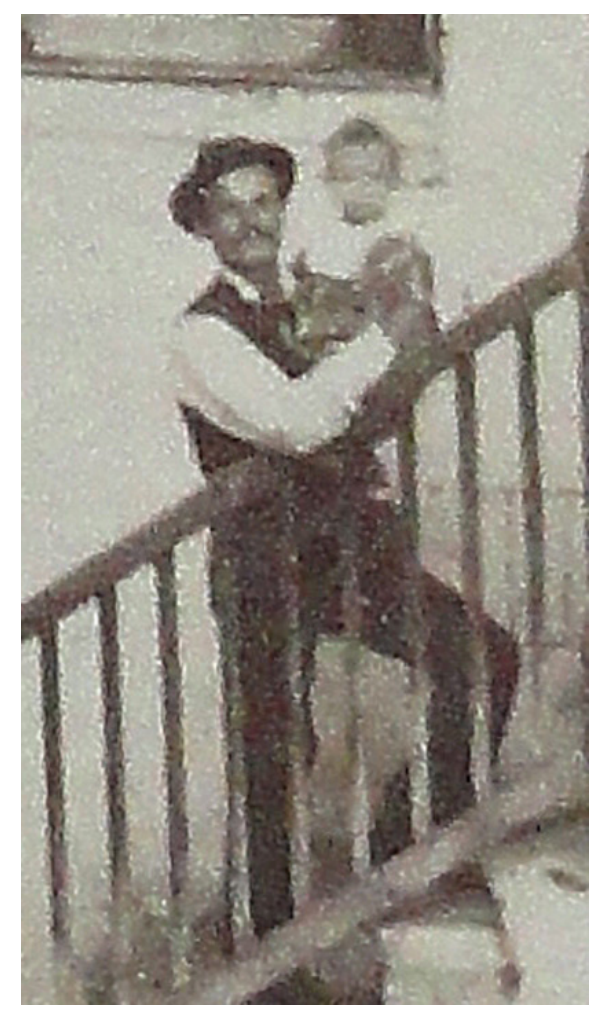

SOURCE : PARIS (FRANCE), BIBLIOTHÈQUE NATIONALE DE FRANCE, DÉPARTEMENT DES ESTAMPES ET DE LA PHOTOgRAPHIE, COLLECTION MAX KARKÉgI. 


\section{"Rue du Caire" : Beyond the World Fairs's representation}

3 The earliest photographs of Cairo as a city were confined to deserted cemeteries and panoramic upper views taken from a higher vantage point such as the citadel hills. Those were followed by the pioneers' photographs of Cairo's main thoroughfares such as Suq al-Silah by Francis Frith, Frank Mason Good, and Hammerschmidt while, on the other hand, Maxime du Camp fancied taking photographs of Cairo's houses from either the roof or the first floor of opposite buildings. On the whole, two factors characterized the earliest photographic depictions of Cairo's streets. The first is the inevitable presence of a minaret and/or a dome in the vanishing point of the perspective and the second is the remarkable stagnancy of the image and the absence of any street life bustling activity. Another unprecedented and rather rare development of the way the street of Cairo was photographed is presented by Émile Béchard who captured a set of domestic architecture façades without including a monument or minaret at the far end of the perspective, as was the norm then (ill. 2) . $^{5}$ In his set of "Rue de Touloun" [Tulun], he captured not only a profusion of mashrabiyya balconies that so strongly characterised Cairene medieval architecture but, more importantly, a demolished building that symbolised the late nineteenth century metamorphosis happening to traditional Cairo, a modernization movement that was tightly paralleled by the rapid emergence of new quarters such as the Ismailiyya quarter and the Gezira Palace to which Béchard dedicated exclusive albums ${ }^{6}$. Being a highly unpopular topic that hardly appealed to the taste of Béchard's touristic clients who rather sought the more popular picturesque themes prevailing then, it is suggested that the capture of this demolished building is not random but meant to document a case whereby the Tanzim institution pulled down a protruding building to apply the prevailing rectification and street straightening regulations ${ }^{7}$. Subsequent images of the same location, by Béchard himself and other photographers, show in this very location a reconstructed building but abiding by the set street alignment specifications. 
2a. H. Béchard, "Rue Touloun" [Tulun], before the intervention works of the Tanzim.

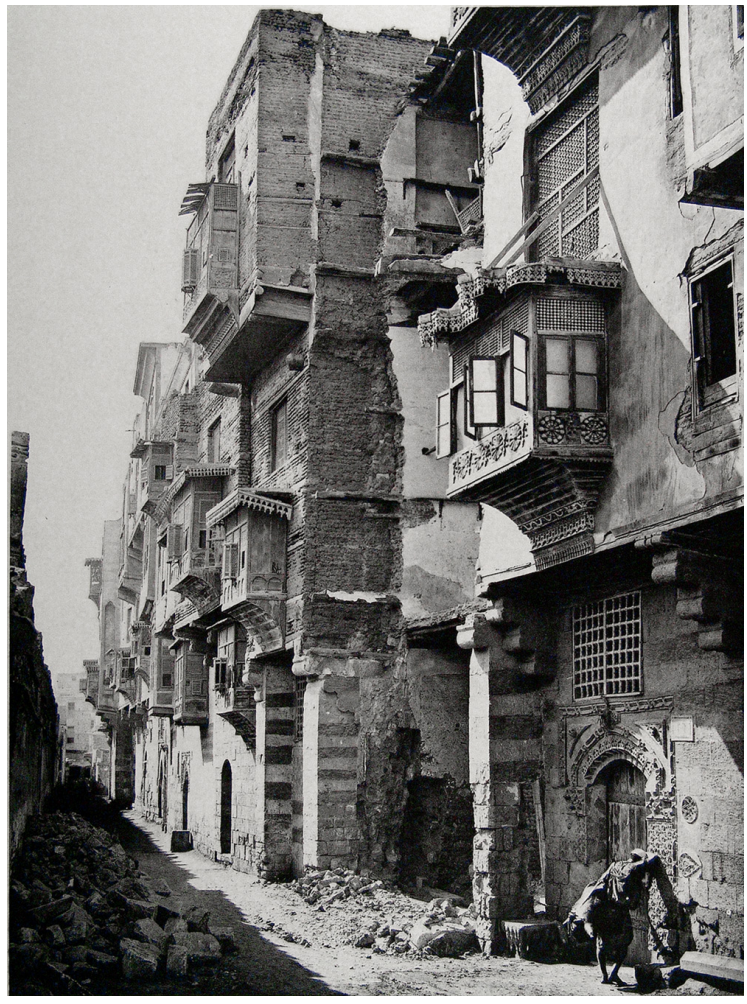

Source : Cairo (Egypt), American University in Cairo, Courtesy Rare Books Special Collections Library.

2b. Unidentified photographer, "Rue Touloun" [Tulun], after the intervention works of the Tanzim.

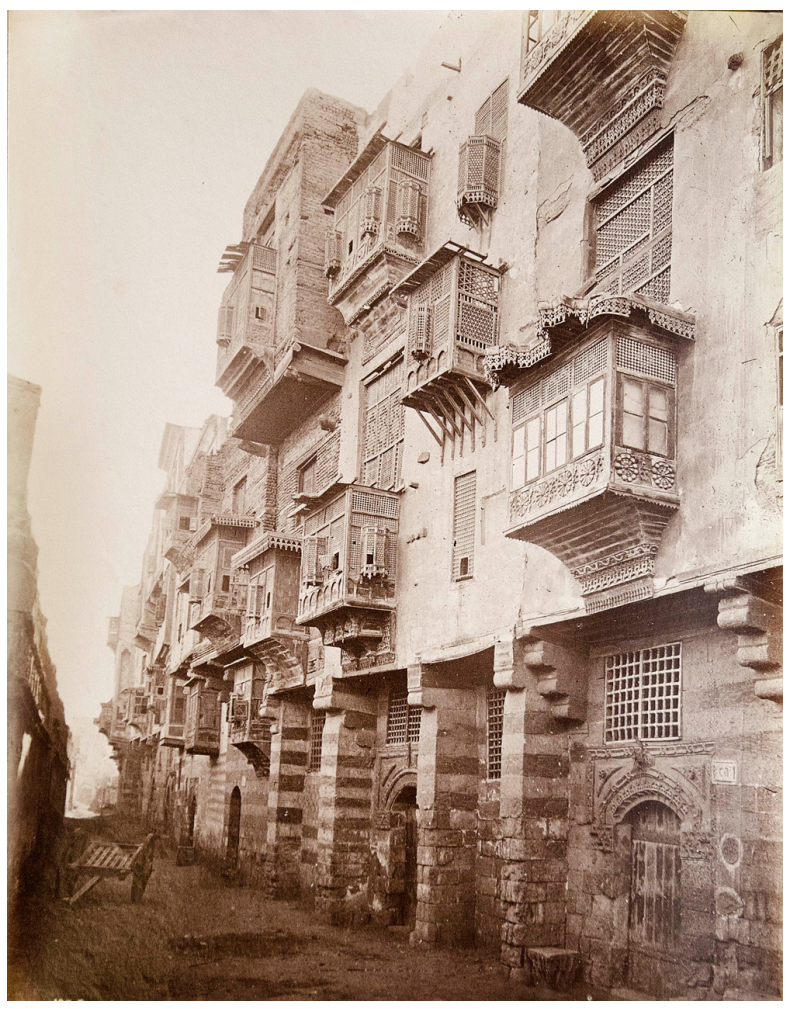

Source : Paris (France), bibliothèque de l'INHA, collection Ballu, Archive 112, carton 11 
Contemporaneously to Émile Béchard, or shortly after his departure from Egypt in 1880, Facchinelli navigated in the streets of Cairo with a purpose beyond photographing the conventional touristic shots. His album Sites et monuments du Caire that was commissioned by Ambroise Baudry and offered to his friend Arthur Rhoné in 1893 distinctively reveals a comprehensive approach to Cairo ${ }^{8}$. The photographs in this album being signed by Facchinelli's embossed hot sealed stamp, enable us by correlation to credit, without a shadow of doubt, to him the long unattributed identical photos in the Jacques Doucet collection housed in the strong room of the Institut national d'histoire de l'art (INHA) in Paris'. Through a selection of four of those, Facchinelli's approach unconventionally sheds light on the Cairene urban life in the last quarter of the nineteenth century. Not only he succeeded in capturing the crowdedness of the Cairo Street but also the introduction of modernism, illustrated graffiti and the less known concept of rukub. ${ }^{10}$

With the "Rue Hamzawi's" photograph Facchinelli merged together the reliability of architectural details that photography provided and the vivacity of the market animation that was henceforth uncultivated by photography and only limited to the compositions of orientalist painters (ill.3) ${ }^{11}$. If the earlier and contemporary photographs placed the minaret at the background of the horizon, Facchinelli respected that compositional perspective but balanced it by revolutionarily introducing in the foreground another core of attention which was the vigorous dynamism happening in the alley as opposed to the standard emptiness that Frith and Hammerschmidt presented in their photographs of both Suq al-Silah and al-Darb alAhmar main thoroughfares. Facchinelli's realistic selection of a side street, and ability to capture its vivacity, its crowdedness and the market animation contrasts with the absence of the human factor or its availability solely for scale reasons in the earlier examples. Photographing the narrowness of the alley with its limited lighting condition, technically, necessitated lower shutter speeds that caused the street crowdedness to appear in the image as blurred movement in the foreground. If by today's standards this blurriness is considered realism and avant-garde photography, it must be realised that in the nineteenth century it was an absolute failure, lack of precision and a rejected poor photograph. This explains why the vibrant al-Mu'izz Street was not photographed by any of the abovementioned pioneers. Finally, although not the main message of the photograph, the minaret of Sultan al-Ashraf Barsbay mosque at the intercession of al-Mu'izz and al-Hamzawi Streets is hereby documented before the intervention of the Comite which replaced the Ottoman pencil shaped top of the minaret appearing in the photograph by the current typical Mamluk-looking onion-shaped finial as it might have originally looked in the fifteenth century. 


\section{Al-Hamzawi street}

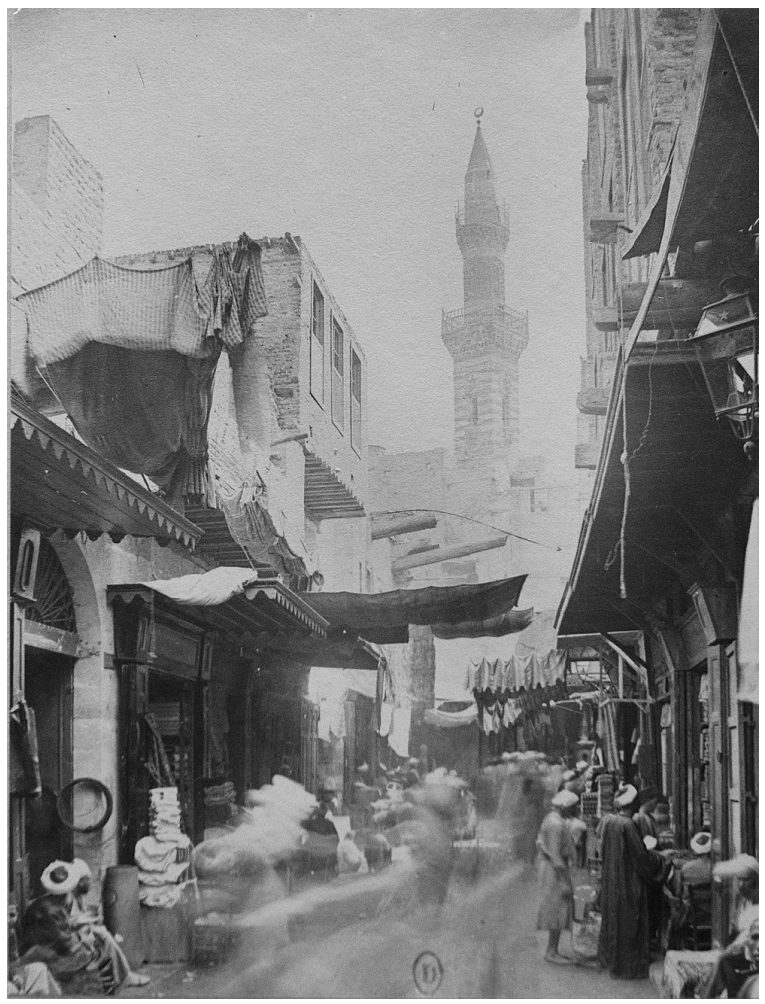

Source : Paris (France), bibliothèque de l'INHA, Photothèque, Archéologie Égypte I, 012, nº 28.

6 While the nineteenth century travellers and the orientalist paintings portrayed the street and alley gates of Cairo as a significant constituent of the Cairene urban fabric, it is worth noting its utter absence from photographic representation except in one of Facchinelli's photographs (ill. 4). The uniqueness of this representation lies in the fact that the gate is unusually surmounted by a balcony protruding from the neighbouring house. This practice, locally referred to as rukub, was quite common in Ottoman and Mamluk times and its regulation fell within the domain of the muhtasib's role of supervision of architectural violations. ${ }^{12}$ The German painter Gustav Bauernfeind has illustrated a similar rukub case in his "A Street Scene in Damascus » (1887) oil painting ${ }^{13}$. A croquis by the French Paul Chardin featured in Arthur Rhoné's article "Coup d'œil sur l'état présent du Caire ancien et moderne" gives indeed an illustration of such doors, but in a truncated view leaving only a glimpse of the corner of the balcony surmounting the gate ${ }^{14}$. While Chardin's illustration provided the known stereotype street gate to the distant western client, Facchinelli's unedited version testifies once more to his observative eye which captured what seemed to him unusual although his understanding of the rukub concept is strongly questionable. Given Rhoné's profound knowledge of Cairo, it is clear that his editorial guidance to Facchinelli and Chardin was highly orchestrated towards the production of publications ultimately enriched with Chardin's illustrations using as a basis Facchinelli's photographs as visual aids. 
4a. Paul CHARDIN, Ancienne porte de quartier, dans la rue conduisant à Bab en-Nasr [Bab al-Nasr].

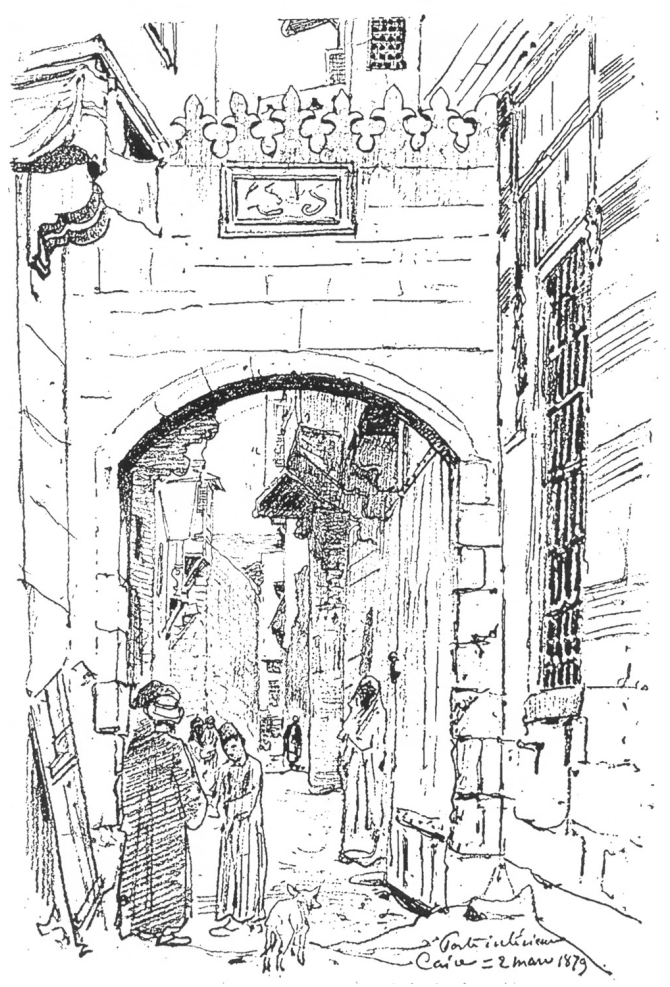

Source : Arthur RHonÉ, "Coup d'œil sur l'état présent du Caire ancien et moderne", Gazette des BeauxArts, 24, 1881-1882, p. 422.

4b. Rukub of an add-on balcony on the gate of an alley.

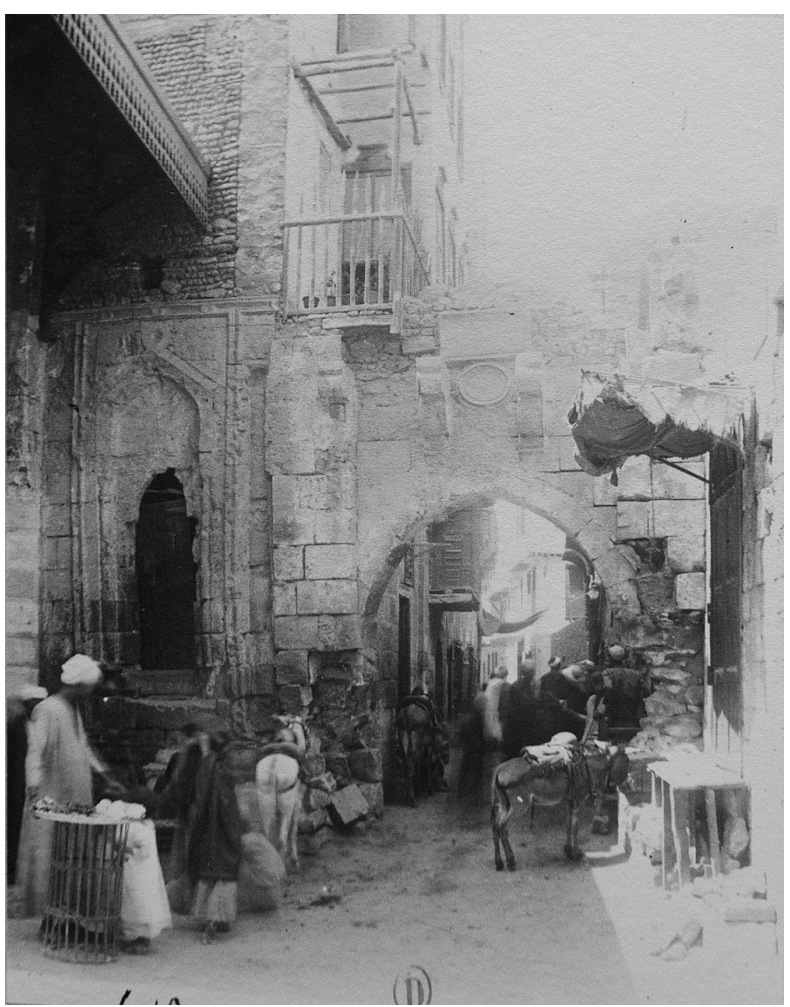

Source : Paris (France), bibliothèque de l'INHA, collections Jacques Doucet. 
If street graffiti is widespread in Historic Cairo streets today, it has roots that cross the nineteenth century even if it was widely unnoticed by the famous photographers of the time. Facchinelli has photographed, at least, two street illustrated graffiti examples. The first is of an unidentified house (ill. 5) and the other is on the side façade of Bayt alRazzaz (ill. 6). Interestingly, both entrance portals are adorned with primitive paintings of popular folk art composed of lions, horses, palm trees and other mythological and zoomorphic creatures whose naivety strongly contrasts with the sophistication of the Ottoman domestic interior murals ${ }^{15}$. What first comes to mind is that they represent heroic scenes of "Abu Zayd al-Hilali" and other epics that are typically told in the coffee shops by the storyteller known as al-hakawati. However, on the grounds of correlation and resemblance with similar still existing drawings found in Upper Egypt a more plausible suggestion is that they represent the welcome and home coming celebration for returning pilgrims. A study on the hagg mural tradition of Upper Egypt reveals that they can be read as eclectic puzzles in which a new image incorporates fragments of both oral and written tradition, Islamic culture and the image of culture of ancient Egypt and the preferences of the family that commissioned the painting ${ }^{16}$. The regrettable absence of successive photographs of the same folk art subject hinders us from figuring out when the nineteenth century patterns of pilgrimage-welcome drawings started to be altered into the contemporary imagery that includes cars, airplanes and ships as they are represented currently. Whether Facchinelli photographed the graffiti out of documentation purposes, astonishment or dislike is unclear but he did instinctively capture a deeply rooted street phenomenon that adds a colourful accent to our knowledge and understanding of a common but overlooked Cairene street practice of the previous century.

5. Graffiti on the entrance gate of an unidentified house.

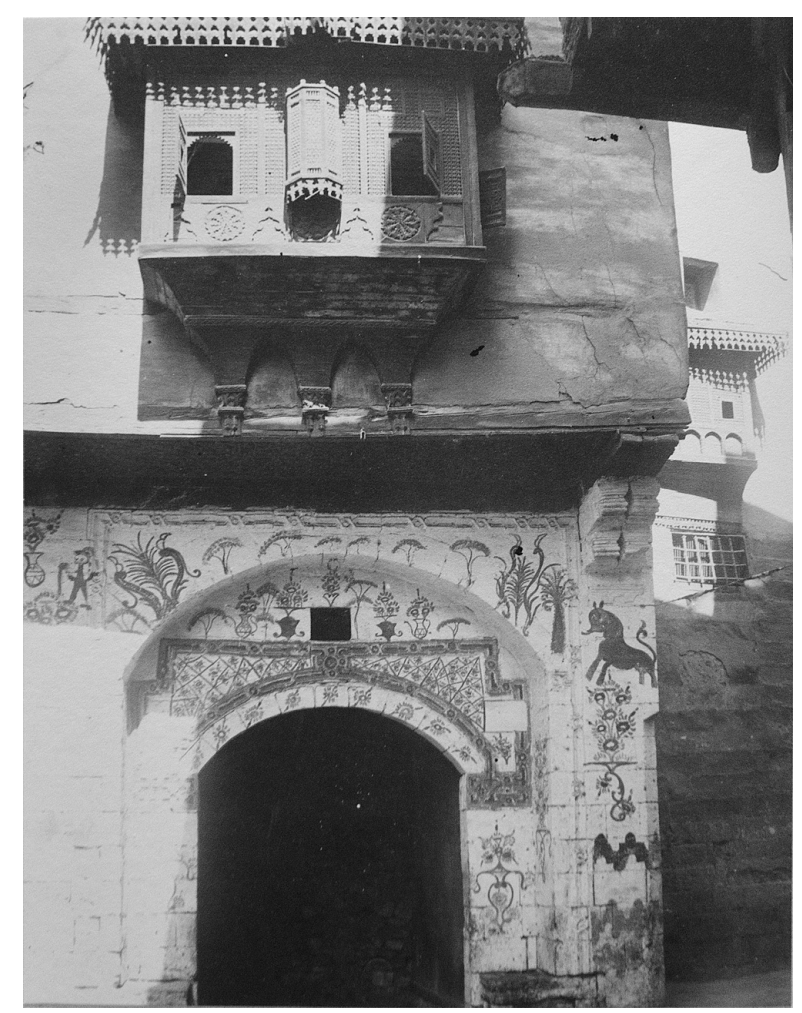

Source : Paris (France), bibliothèque de I'INHA, collections Jacques Doucet. 
6. Graffiti of the entrance gate of Bayt al-Razzaz.

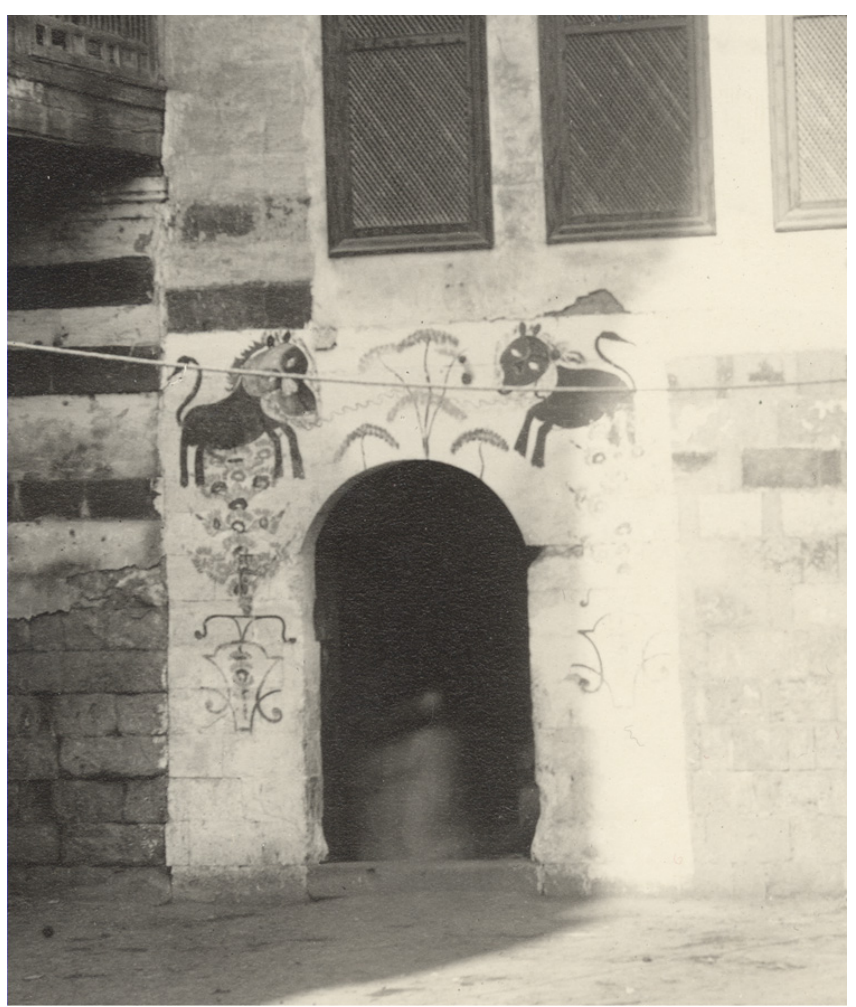

Source : American University in Cairo (Egypt), Courtesy Rare Books Special Collections Library.

Since the mashrabiyya, as an element, was the core of the "Rue du Caire", the icon of its medievalism and at the origin of its picturesqueness, its gradual substitution by a new domestic typology was a trend that puzzled and repelled photographers of the time. Interestingly, Facchinelli wittily adapted to this change of paradigm and photographed the developing style. The house built on Saliba Street is a photograph that raises many issues (ill. 7 $)^{17}$. First, it does not, in any way, fit in the European architectural symphony launched by Khedive Isma'il and the building boom that was taking place in the Isma'iliya quarter nor does it resonate with what came to be known locally as the "rumi" style of architecture that replicated the Balkan domestic model on the Darb alAhmar and Muski Streets. Another interesting occurrence is the evolution of the mashrabiyya proper and its persistence under a variant form although it had become a banned element by law. The discontinued lattice turned wood is replaced by elongated windows with shutters that open in such a way as to allow less privacy than the masharabiyya, which may suggest that the function of the protrusions holding the mashrabiyyas also evolved. On the whole, it is safe to say that the remarkable depth of the newer mashrabiyya version, its poor corbelling and the overall diminished elegance was a transitional architectural phase that appeared on the streets of Cairo at the dawn of its modernity, that a few photographers and travellers understood it and that it remains understudied up till the time of writing these lines. The fact that Facchinelli was himself living in a traditional courtyard house by the Muski district might have helped him realise the strangeness of this façade and new prototype. If travellers, historians, illustrators and chroniclers of Cairo dedicated chapters to the streets of Cairo and its mashrabiyya, their demolition process was mentioned only by passingly 
and the post-demolition transitional architecture was overlooked, regarded regretfully and unrepresented visually. Today, this building and its likes, from the same period, are representative of historicity but equivocally this photograph's value and significance lies in the modernity that Facchinelli wanted to present. This can be understood from the literature of the epoch that are in agreement with Lane's statement in 1896 that "Until about the end of the first quarter of the present century Cairo was wholly an Arabian city" 18 .

7. A house on Saliba Street between the Sabil Kuttab Qaytbay and Qanibay al-Muhammadi Mosque and Shaykhu Complex.

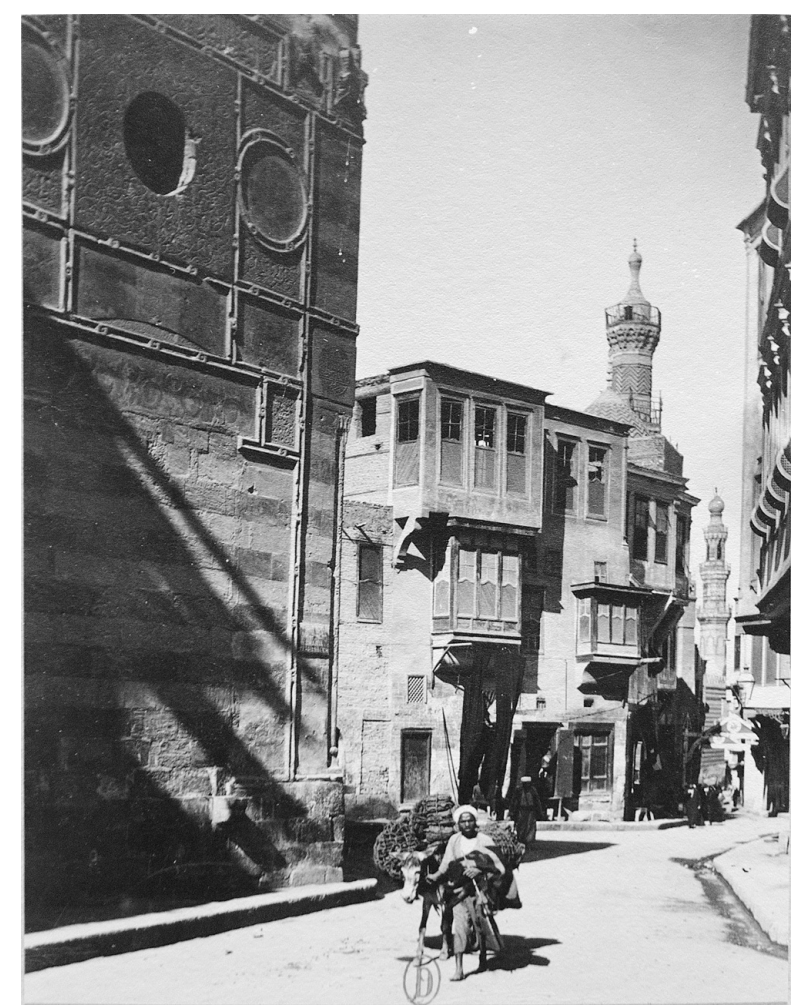

Source : Paris (France), bibliothèque de l'INHA, collections Jacques Doucet.

The topic of "Rue du Caire" has proven that it had more to offer than just the superficial outlook of a few façades backed by a minaret at the vanishing point of the perspective. By capturing some of its aspects Facchinelli earned himself the title of "photographe du cru" because he had carved himself a niche of catering not to the tourist industry but to the travelogues who would have labelled themselves, by today's standards, independent researchers or even anthropologists, historians, architects, urbanists, sociologists or scholars at large. ${ }^{19}$

\section{Facchinelli's contribution to Cairene domestic architecture}

10 Other than the five houses illustrated in the Description de l'Égypte ${ }^{20}$ and orientalists' paintings, Cairene domestic architecture was, photographically speaking, largely overshadowed by the opulence of antiquity. Courtyards of Gustave Le Gray and Shaykh al-Sadat houses were the earliest to be photographed and thus the westerner's 
knowledge of domestic architecture was limited to these two examples until Gamal alDin al-Dhahabi's house was replicated in 1893 at the Chicago World Fair ${ }^{21}$. In the meantime, Facchinelli was inaudibly capturing aspect of lesser known Cairene domestic architecture examples, many of which were subject to the massive demolition movement that swamped Cairo in the 1880 s.

11 The image depicting Sultan Qaytbay's elaborately painted façade (the outer wall of the maq $a d)^{22}$ photographed by Facchinelli represents a colourful revelation to its viewers (ill. 8). While the topic of painting in Cairene domestic architecture is totally understudied, it can at least be mentioned that the two earlier known similar representations are the paintings on the courtyard walls of 'Uthman Bey and Qasim Bey's houses illustrated in the Description de l'Égypte. Thus, this raises the question of whether the paintings on the courtyard of Qaytbay's house are original from the Mamluk period or a later layer from the Ottoman period. On stylistic basis, the absence of vegetal motives and the predominance of geometric pattern and the presence of Qaytbay's typical ranks all suggest that the paintings are original from the Mamluk period. This contrasts with the Ottoman mural found on the side wall of the same maq'ad which features in another photograph by Facchinelli housed in the Creswell photographic collection at the archives of the American University in Cairo ${ }^{23}$. While this mural has long disappeared and the only evidence of it is in Facchinelli's photograph it can be paralleled by other Ottoman natured murals recently restored in the houses of 'Ali Effendi Labib in al-Darb al-Ahmar district and that of Sitt Wasila's house in al-Azhar district. As such, it can be safely said that the value of the photograph of Qaytbay's maq'ad lies not in the fact that it is the only evidence of an extant building that once had a painted façade overlooking the courtyard but it clearly reveals its details and on the other hand, it confirms the credibility of the Description's illustrations, represents an aspects overlooked by orientalist painters and furthers our understanding about the decorative interiors of wealthy and notable Cairene Mamluk houses of the upper echelon of the society in the late fifteenth century. 


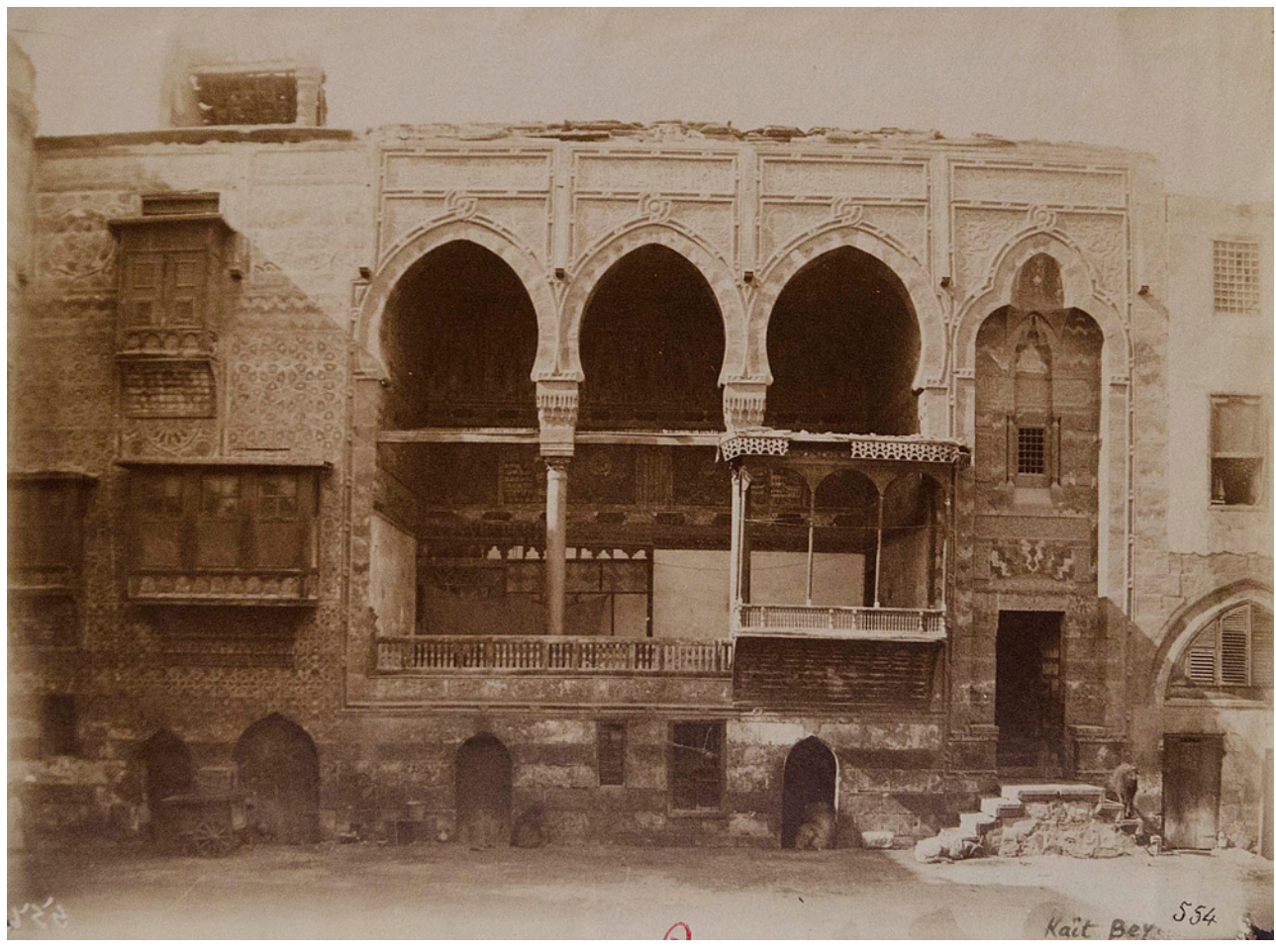

Source : Paris (France), bibliothèque de l'INHA, collection Ballu, Archive 112, carton 11

12 While Georges Pangalo ${ }^{24}$ was salvaging his seventy five mashrabiyya balconies during the massive demolitions of houses in the last quarter of the nineteenth century, he did not document their exact provenance and context. Similarly, the fast demolition of Mamluk and Ottoman houses was an obscure event that was scarcely represented visually. Crumbling stones in a selection of photographs by the lens of Facchinelli were meant to be associated with the eleventh hour of many Mamluk and Ottoman houses rather than to indicate restoration works as is often the case in the Comité's photographs. Another peculiarity is that it sheds light on variable examples of how Cairene medieval houses creatively adapted themselves to the architectural requirements of its owners. In many cases, the spatial expansion adjoining another building to the preexisitng one often required architectural challenges. The most interesting one encountered is that of a niche carved specially to harbor the entrance door of the newly added annex (ill. 9). In other frequently occuring cases, the maq'ad's arches were blocked by wooden panels perhaps because the house fell into disuse or that this was a way of incorporating the maq'ad into the house by converting it to a closed room. Unintentionally, while photographing the base of al-Muayyad's minaret, Facchinelli captured a tiny and hardly noticed mashrabiyya protruding from the side of Bab Zuwaila's right tower (ill. 10). This is, to date, the earliest photographic evidence of the conversion of Bab Zuwaila into residential spaces. Photographed from the front of the tower, it complements David Roberts's famous illustration depicting the rear view of the same tower which once accomodated appartment lodgings that were removed by the Comité in a restoration later than Facchinelli's time. Another surprising example is the rukub of a mashrabiyya balcony onto the back entrance of Imam al-Shafi'i's mausoleum in the Southern Cemetery (ill.11). The inconsistent mashrabiyyas are 
suggestive of variable living standards on each floor of the building, different expansion phases and an unusual encroachment of a residential unit to the mausoleum.

9. Corner of the courtyard of an unidentified house.

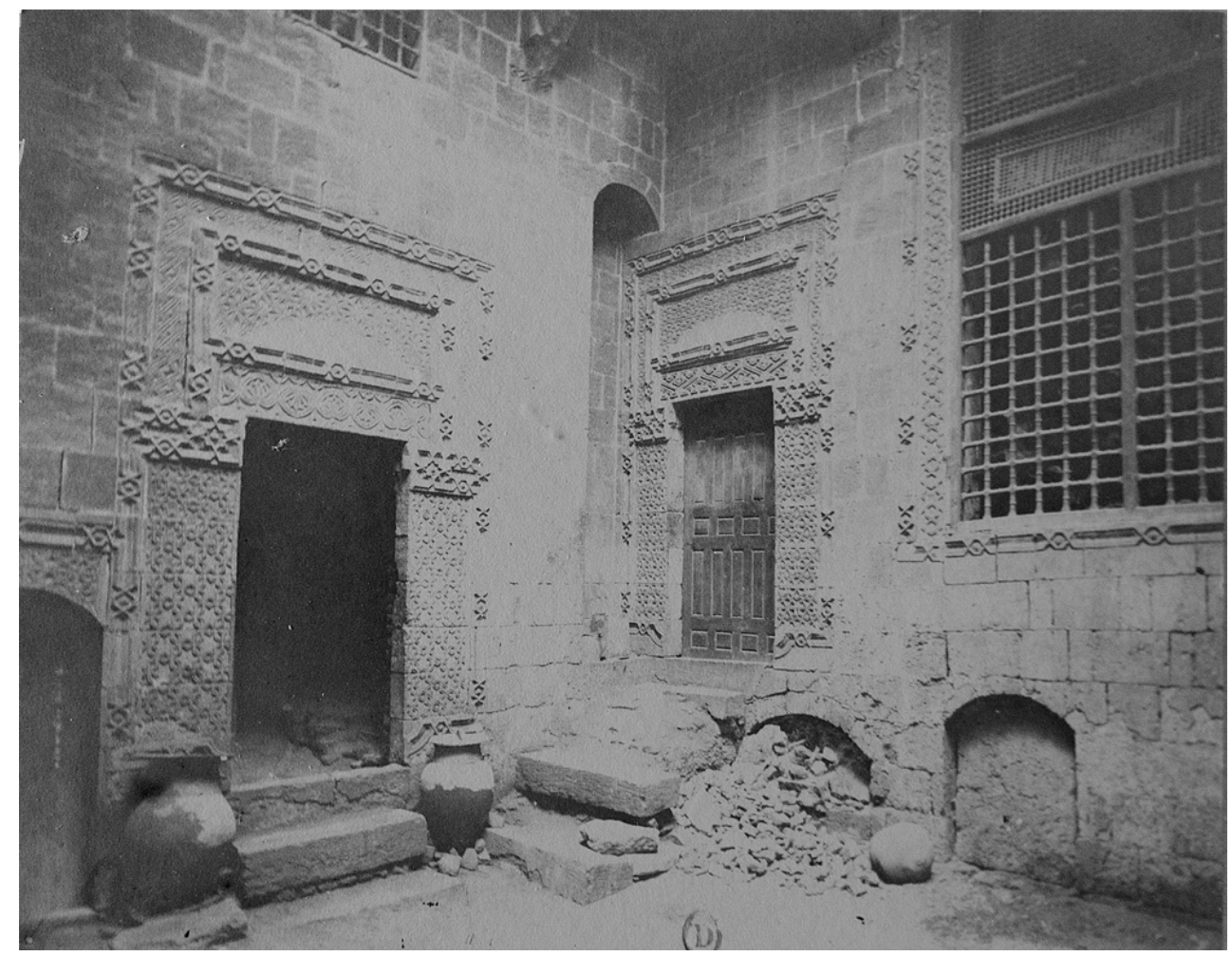

Source : Paris (France), bibliothèque de I'INHA, collections Jacques Doucet. 
10. A mashrabiyya hanging out of the side of Bab Zuwayla's tower at the level of the slits.

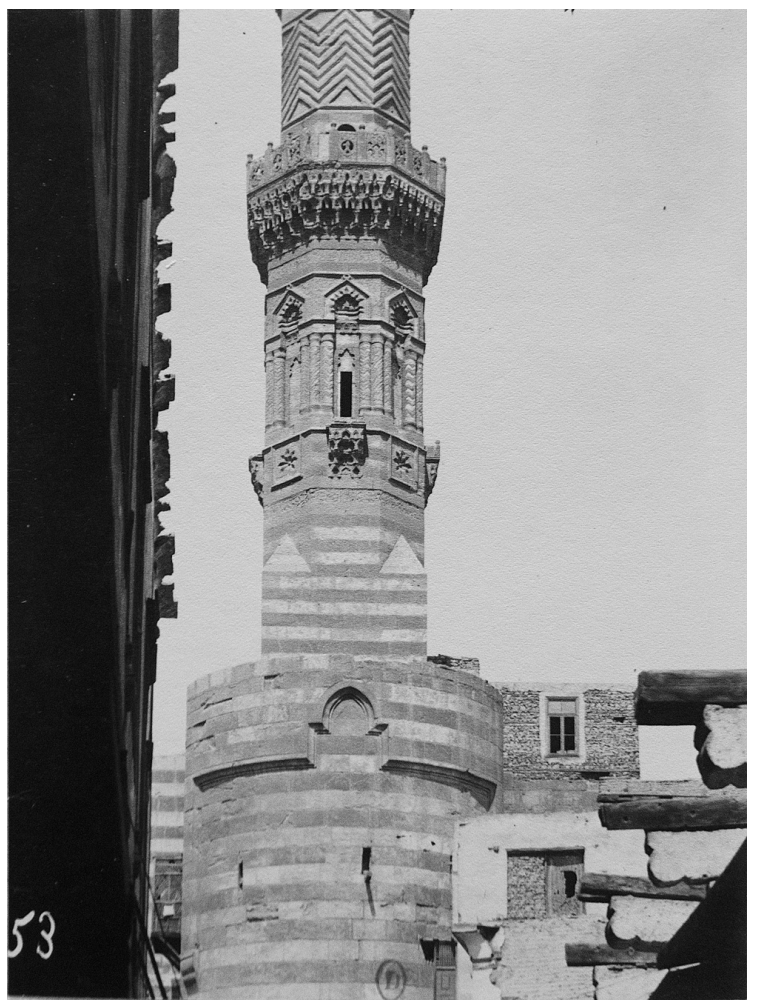

Source : Paris (France), bibliothèque de l'INHA, collections Jacques Doucet.

11. Back entrance of Imam al-Shafi'i's mausoleum in the Southern Cemetery with several examples of unplanned mashrabiyya grills, one of which in a rukub overlap position on the gate.

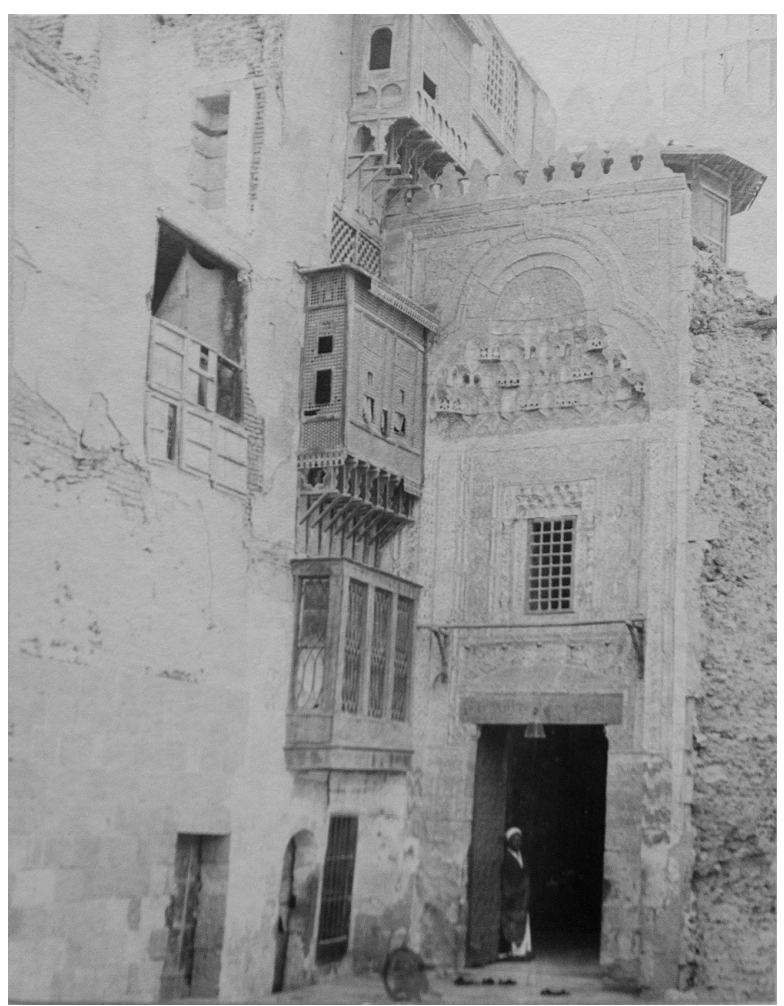

Source: Paris (France), bibliothèque de l'INHA, collections Jacques Doucet. 
topic of representing domestic architecture in nineteenth century photography cannot be closed before considering Facchinelli's Maison Waqf Ahmad Husayn 1757/1798 AD-1171/1213 AH at Bab al-Sha'riyya (ill. 12). Although a few photographs from this house were published in the Comité's 1898 bulletin, this preliminary research did not trigger the Comité's attention to the importance of preserving the remaining examples of domestic architecture by urgently classifying them in the Index to the Muhammedan Monuments of Cairo ${ }^{25}$. In fact, the only reason Ahmad Husayn's house was investigated is that the Awqaf administration requested Herz Pasha's assessment on the level of damage resulting from a theft. Herz's recommendation to acquire from it all remaining items of historic value suitable for the Museum of Arab Art (now Museum of Islamic Art), not to restore the damage and to declassify the house can be translated as an assumption that the Comité was implicitly and short-sightedly signing the decree of knocking down the Maison Waqf of Ahmad Husayn ${ }^{26}$.Today, after its demolition, what the photographs of this house reveal to us is a unique example of two rare architectural features that are absent from all the extant examples of Cairene domestic architecture. Those are the widest mashrabiyya screen extending throughout the width of the courtyard and the rare closed takhtabush through which a glimpse of the capital of its column appears ${ }^{27}$.

12. Mashrabiyya at the house waqf of Ahmad Husayn.

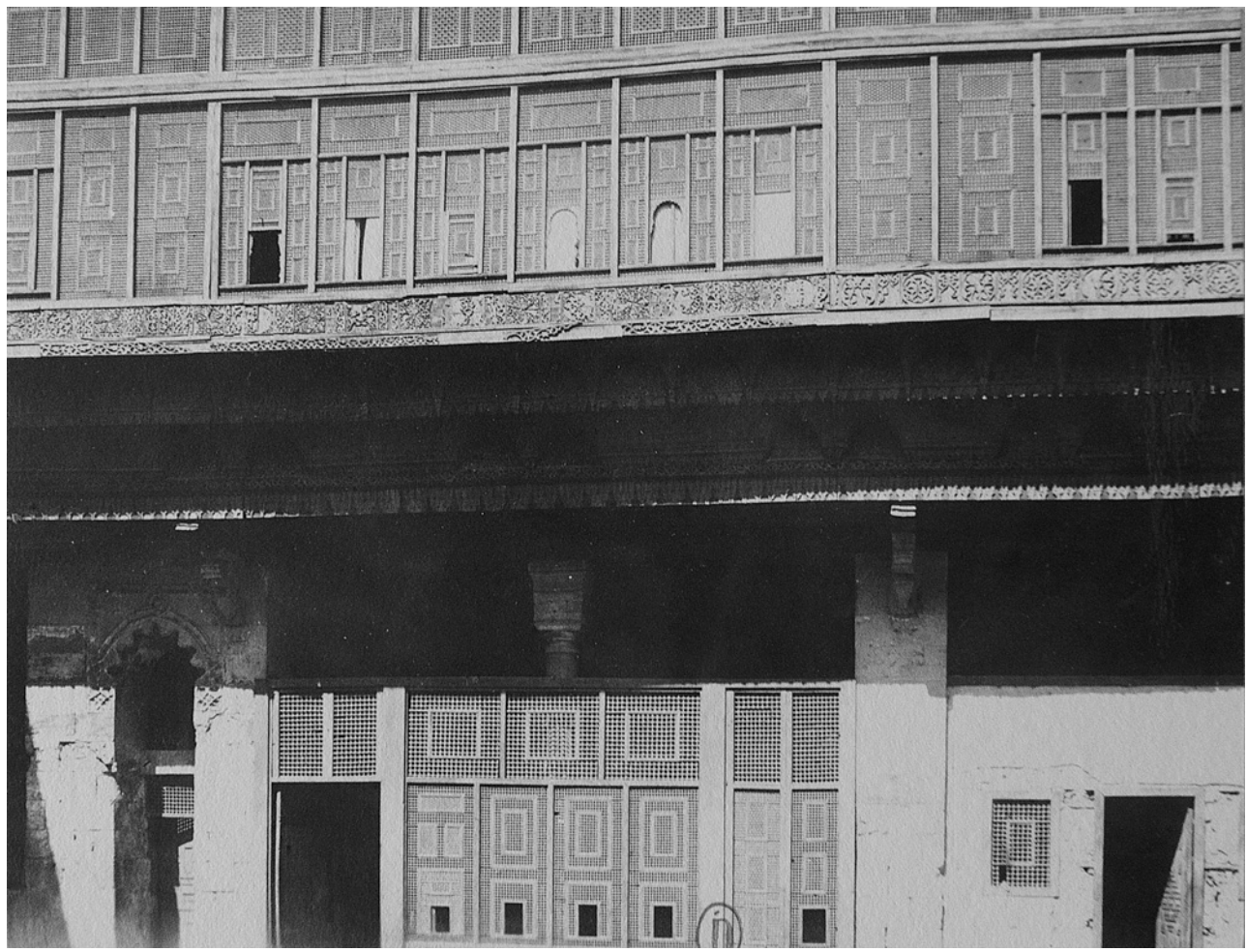

Source : Paris (France), bibliothèque de I'INHA, collections Jacques Doucet.

The privacy of the oriental household, specially its harem, is the major reason that kept European photographers from penetrating it. Facchinelli's infiltration can only be justified by the fact that the houses he entered were abandoned or half demolished. If the orientalists were somewhat imaginative and legendary in their representation, Facchinelli's focus was purely architectural and contrasted with the social approach of 
the Description's depiction of Cairene houses. The variable examples that he presented discredits Stanley Lane Poole's statement mentioning that "But all Cairene houses of the old style are very much alike : they differ only in size and in the richness or poverty of the decoration ; and if our merchant's house is better than most of its neighbors, we have but to substract a few of the statelier rooms, and reduce the scale of the others, to obtain a fair idea of the houses on either hand and round about. ${ }^{28}$ " Further, he implicitly presents the visual hypothesis about the versatility of the masharabiya module and its adaptability to various economic and architectural contexts, to date, an understudied topic.

15 Facchinelli's lens yielded some rarely seen representations of Cairo that stand out from the diverse kaleidoscopic spectrum of topics revolving around the exotic "Orient", or the "en vogue" that his contemporaneous photographers produced. His lens spotted the colourful animation of the "Rue du Caire" and translated them with spontaneity to black and white albumens, it also composed a storyboard of Cairo's modernity "in the making" by documenting the photographs of the rumi buildings in contrast with those of the demolished houses. The visual testimony of the death of Cairo's traditional domestic architecture is a singular historical record that may not have drawn much of the attention of the Comité in the late nineteenth century but certainly does challenge today's social historians, urbanists, architects as much as the collectors of vintage photography.

16 Facchinelli's active years in Cairo (1873-1895) coincided with not only the rise of the Comité in 1881 but with a European collecting fever of "Arab art" objets d'art, the establishment of the Museum of Arab Art in 1881, the compilation of the Index by the Comite and the interventions of the Tanzim institution in the execution of the urban master plan that was to carry Cairo into modernity. But Facchinelli's involvement with the above was indirect and his Comité contributions were marginal as can be deduced from consulting its published bulletins. Not only none of his photographs were published in the Bulletins but he is not mentioned in them until 1895, fourteen years after its foundation when the photographs acquired by the Comite had increased to reach the point of being called a "collection" and accordingly Julius Franz Pasha proposed in 1897 to conserve it by entrusting Max Herz Pasha with the responsibility to commission a cupboard suitable for the conservation and storage of the photographic materials ${ }^{29}$. And since the bulk of this collection was focused on the état des lieux of the monuments that were subject to a Comités decision of either destruction or restoration or the selection of relics for the museum it is, thus, understandable that the Comité was not responsible for Facchinelli's focus on the "Rue du Caire" nor for his interest in the demolition of domestic architecture photographs which surpassed their flat and unilateral scope. However, it may confidently be stated that Facchinelli's collection of "Arab" art, which also included photographs of monuments, developed simultaneously and in parallel to that of the Comité. One such outstanding evidence of overlap is the example of the photograph in the courtyard of the house of Ahmad Husayn (see above) which is credited to Lékégian in the Bulletins of 1898, as well as photographs of the mosques of al-Hayatim and Abu Bakr Mazhar often encountered in Facchinelli's repertoire. Facchinelli was neither a trained urbanist conducting sociophysical structural studies of historic Cairo and its neighbourhoods nor an architect wandering around Cairo but rather a freelance responsive photographer who seized the momentum of the happenings and reflected them faithfully with a visual 
manifestation that surpassed the limitations of the Comités limited photographic approach which could easily be labelled "descriptive".

Alternatively, Facchinelli's fresh optical and insightful depiction of Cairo and its domestic architecture is likely to be closely linked with the French architect Ambroise Baudry in his capacity as a collector of Arab art rather than as a founding board member of the Comité. Baudry who arrived in Cairo in 1871, noted in 1897 at the head of the Sites et monuments du Caire album, that Facchinelli's photographs were produced between 1873 to 1895 . The extent to which Baudry coached Facchinelli during these twenty two progress years of the photographic archive from which Baudry made his selection are yet to be explored from their correspondence together. Whether explicitly assigned by Baudry or not to cover the "Rue du Caire" or the demolition of domestic architecture, Facchinelli approached these early realistic and factual topics with a sharper eye than that of an orientalist fantasist catering to the tourist industry and more perceptive than that of the scholar seeking to leave no stone unturned. While a portion of his production resembled the unsystematic documentation program of Islamic monuments that the Comité engaged in, his representations of the "Rue du Caire" and the demolitions would have fitted reasonably well 'Ali Mubarak's al-Khitat alTawfiqiyya al-Jadida (1886-1889) inclusiveness and comprehensiveness, or ironically contrasted with the photographs taken by Lékégian of Egypt's pavilion in World Exhibitions, especially that of Chicago in 1893.

Upon his death, Facchinelli's archive was regarded as a specialized collection of "Arab" art. In 1899 the Comité decided to buy from his archives the photographs that matched their scope of interest to enrich their own collection. The Comités photographic archive was followed between 1940 s to the 1973 by an equally substantial collection credited to K.A.C. Creswell where some of Facchinelli's topographical views of Cairo found their way but, surprisingly, labeled Giuntini on the back, yet an Italian photographer whose name started to feature in the Bulletins after the death of Facchinelli. By the 1890s, the focus of photographic albums evolved from general selections to specialized topics ${ }^{30}$. But a thorough visual evidence of "Rue du Caire" and domestic architecture remained widely absent and remarkably superficial in both, the albums of the period and the two major collections of Islamic art and architecture. It is hoped that the emergence of hidden specialized albums and/or loose photographs in Diaspora accentuates the study of these two topics, enhances the understanding of their form and function, supports available and ongoing research and triggers newer perspectives about their metamorphoses in the last quarter of the nineteenth century

\section{NOTES}

1. Known today as the Islamic art and architecture. For more on this terminology, see "Arab Art \& Arab Monuments" in Alaa EL-HABASHI's unpublished PhD thesis: From Athar to Monuments: The Interventions of the Comité de Conservation des Monuments de l'Art Arabe, University of Pennsylvania, Philadelphia, 2001. 
2. A body of European archeologists, historians and philanthropists formed in 1881 with the mission of conserving and documenting the "Arab" architecture of Egypt. This Comité has been publishing an annual report, hereinafter Bulletin. See below in this volume: István oRMOs, "Max Herz Pasha on Arab-Islamic Art in Egypt," p. 311-342. URL: https://inha.revues.org/4898.

3. This archive is stored at the Citadel's branch office of the Supreme Council of Antiquities, the restructured body that succeeded the Comite after the 1952 coup d'état in Egypt.

4. While further research in the unpublished documents of the Comité will reveal yet more names of contributors to their photographic archive, it is likely that they may also have purchased some of the commercial photographs readily available on the market.

5. I am thankful to Maryse Bideault and Mercedes Volait for pointing out that the Cairo photographs signed H. Béchard refers to Hippolyte not Henry as is wrongly widespread, and that Hippolyte Béchard never went to Cairo. Accordingly, it can be assumed that all Egypt photos signed "H. Béchard" are really by his brother Émile Béchard, who had a studio in the Azbakiyya gardens, but reprinted later by Hippolyte in France.

6. Album photographique comprenant soixante et une vues exécutées d'après les constructions élevées au nouveau Caire sous le règne de S. A. le Khedive Ismail Pacha, 1874. One copy is in the private collection of the late Max Karkégi and has been bequeathed to the Bibliothèque nationale de France, Paris, France. A copy of the Album des jardins du palais de Guezireh appartenant à S. A. le Khédive Ismail Pacha comprenant 22 vues photographiques exécutées par Émile Béchard, 1874 is kept in the holdings of the Geographical Society in Cairo.

7. The Maglis Tanzim al-Mahrusa, or Cairo Embellishment Commission, was a subsection of the Ministry of Public Works since 1879. Its main function was to regulate streets and buildings. On its history and activity, see Mercedes vOLAIT, Architectes et architectures de l'Égypte moderne (1830-1950): genèse et essor d'une expertise locale, Paris: Maisonneuve et Larose, 2005 (Architectures modernes en Méditerranée), ch. 3.

8. For more on Ambroise Baudry, see Marie-Laure CROSNIER-LECONTE, Mercedes VOLAIT, L'Égypte d'un architecte : Ambroise Baudry (1838-1906), Paris: Somogy Éditions d'art, 1998.

9. The small format series are in boxes Égypte I.12, I.13, I.14, I.15, I.16, and I.17. For further confirmation, the comparison of the identical photographs in the Jacques-Doucet lot with that of in the Alinari album yielded a matching serial number.

10. Rukub is an Arabic word signifying the practice of overlapping an architectural component over another element or structure. Frequent examples are either the floor of a building extending over the roof of the neighboring building or protusion of balconies spreading out over gates.

11. Rue al-Hamzawi, still carrying the same name, is the street perpendicular to Shari' al-Mu'izz at the angle where the complex of Sultan Barsbay is found. It was described in the early Baedecker guidebooks as the street of the foreigners' market.

12. Another example of the rukub is the wakala of Khan al-Khalili that extends over the rab' of Yashbak Min Mahdi al-Dawadar discussed in Ola Seif 's M.A. unpublished thesis at the American University in Cairo, 2005, The Khan al-Khalili district: Development, Topography and Context from the $12^{\text {th }}$ to the $21^{\text {st }}$ Century. Further court examples are presented in Nelly HANNA, Construction Work in Ottoman Cairo 1517-1798, Cairo: IFAO, 1984 (Supplément aux Annales islamologiques, 4).

13. Now in the collection of Shafik Gabr in Cairo, see Masterpieces of Orientalism: The Shafik Gabr Collection, Paris: ACR, 2008, p. 58; 63.

14. Paul CHARDIN, "Ancienne porte de quartier, dans la rue conduisant à Bab-en-Nasr [Bab alNasr]," Gazette des Beaux-Arts. Courrier européen de l'Art et de la Curiosité, vol. 24, 1881, p. 422. Rhoné's visit to Egypt in 1879 was part of the campaign in favour of the creation of the Comité of which he was later a corresponding member.

15. The first house is unidentified. The graffiti on the house of Bayt al-Razzaz disappeared. 
16. Riikka HAAPALAINEN, Goran SCHILDT, Vidar LINDQVIST, On the Pilgrimage: The tradition of Hajj painting in Upper Egypt, Exhibition Catalogue (Cairo, American University in Cairo), Tammisaari : Christine ja Göran Schildtin säätiö, 2004, 14. Similar drawings were found in Luxor photographs of the 1970s.

17. This is a house on Saliba Street located after Qaytbay's Sabil Kuttab, before the Mosque of Qanibay al-Muhammadi ( $\mathrm{n}^{\circ} 151$ on the Index list to Muhammadan Monuments of Cairo).

18. Edward William LANE, Cairo Fifty Years Ago, London: John Murray, 1896, p. 54. The book was published in 1896 and thus the word "present" refers to the late nineteenth century.

19. For one of his main patrons, see Mercedes volait, "Arthur Ali Rhoné (1836-1910): Du Caire ancien au vieux-Paris ou le patrimoine au prisme de l'érudition dilettante," Socio-Anthropologie, no.19, 2006, p. 17-30. URL: https://socio-anthropologie.revues.org/543. Accessed on November 25, 2015.

20. Those are in vol. II (plates 50 to 56): Birkat-al-Fyl [Birkat al-Fil], Azbakiya [Azbakiyya], panoramic views, gates of Cairo. The four houses depicted by the Description de l'Égypte were Osman Bey ['Uthman bey], Soleyman Agha [Sulayman Agha], jardin du Palais d'Ezbekiya [Azbakiyya], et Hassan Kashef [Hasan Kashif] (dôme and shukhshaykha), Ybrahim Kikheyh elSennary [Ibrahim katkhuda al-Sinnari].

21. See István ORMOS, “The Cairo street at the World's Columbian Exposition, Chigaco, 1893”, in L'orientalisme architectural entre imaginaires et savoirs, Paris: Picard; CNRS, 2009 (D'une rive l'autre), 195-214 and about Gamal al-Din al-Dhahabi's house, see in this volume, István Ormos, "Max Herz Pasha...," fig. 10, 14 and 22.

22. The definition of maq'ad is a first storey covered balcony overlooking the courtyard of a house.

23. The Creswell photographic collection at the American University in Cairo holds over thirteen thousand photographs of Islamic architecture almost half of which are dedicated to Cairo. While Creswell's own photographs constitute the majority of the collection, he also assembled work by other earlier photographers. K.A.C. Creswell was a British officer considered the doyen of the first generation of scholars of Islamic art and architecture. He lived in Cairo since the 1920s till his death in the early 1970 during that time he surveyed and photographed the Islamic monuments of Cairo in unprecedented detail and bequeathed his archives, photographic collection and library to the American University in Cairo during his lifetime.

24. Georges Pangalo was the organizer of the Egyptian pavilion at the Chicago World Fair in 1893. Supported by the Hungarian Max Herz Pasha, then head of the technical department of the Comité, he was able not only to reconstruct an entire street but to render it convincing by transplanting seventy five real mashrabiyya grill balconies purchased from the dismantled houses of Cairo.

25. The photograph in the 1898 issue of the Bulletin is taken by Lékégian: pl. II (façade), pl. III-IV ( $q a^{\prime} a$ ). The house was also referred to as École des aveugles located on Shari' Margush in the Bab alSha'riyya district. For more on the compilation of the index see Alaa EL-HABASHI, Nicholas WARNER, "Recording the Monuments of Cairo: an Introduction and Overview", Annales Islamologiques, no. 32, 1998, p. 81-99.

26. "Quatre-vingt-quatrième séance du 7 juin 1898," Bulletin, 1898, p. 78. The Awqaf is the Arabic word for the Endowments foundation. Max Herz was the chief engineer of the Comité. For more on him see István oRMOS, Max Herz Pasha (1856-1919): His Life and Career, Cairo: IFAO, 2009, and in this volume p. 297-310. URL: https://inha.revues.org/4898.

27. The takhtabush is an area overlooking the courtyard, covered by a loggia that is supported by a central column. It's main function was to host certain visitors without letting them in the privacy of the house.

28. Stanley LANE POOLE, Cairo: Sketches of its History, Monuments and Social Life, London: Virtue \& Co, 1895, p. 124. 
29. "Soixante-quatorzième séance du 9 mars 1897", Bulletin, [1898], p. 72.

30. Such as, but not limited to, Lékégian's albums on the Egyptian and British armies or Abdullah Frères' two albums of the visit of Khedive Tawfiq to Upper Egypt, etc.

\section{AUTHOR}

OLA SEIF

Curator of Photography Collections, American University in Cairo. 


\title{
À travers Le Caire, l'œuvre de Gervais-Courtellemont en Égypte de 1894 à 1911
}

\author{
Emmanuelle Devos
}

\section{NOTE DE L'ÉDITEUR}

Sauf mention contraire, toutes les photographies et autochromes sont l'œuvre de Jules Gervais-Courtellemont.

En 1908, pour rendre hommage au peuple égyptien en deuil de son leader politique Mustafa Kamel pacha, Pierre Loti fit paraître dans Le Figaro une lettre de son ami Jules Gervais-Courtellemont ${ }^{1}$. Ce dernier, bien connu des lecteurs de la presse et du public parisien était un explorateur-photographe qui voyagea à travers les pays d'Orient (fig. 1) $)^{2}$. Rendu célèbre en 1894 par sa conversion à la religion musulmane et la publication de son récit Mon voyage à $L a M e c q u e^{3}$, il était considéré comme l'un des spécialistes de l'islam en France. Dans les cercles intellectuels et politiques, il devait cette reconnaissance aussi bien aux nombreux ouvrages édités sous son impulsion qu'à ses talents d'orateur. Il fut accueilli dans les sociétés de géographie et de commerce des régions françaises pour donner des conférences grâce auxquelles il diffusa ses analyses sur l'islam dans le contexte colonial ${ }^{4}$. Sa signature attisait la curiosité des lecteurs de L'Illustration, du Temps et du Journal des Voyages et des Aventures de terre et de mer auxquels le voyageur révélait le pittoresque des pays lointains. À partir d'avril 1908, son nom fit résonner les mystérieuses tonalités de l'Orient qu'il diffusait lors de projections lumineuses proposées sous le titre évocateur de Visions d'Orient. 
1. Jules Gervais-Courtellemont, portrait gravé paru dans L'Illustration, 2703, 15 décembre 1894.

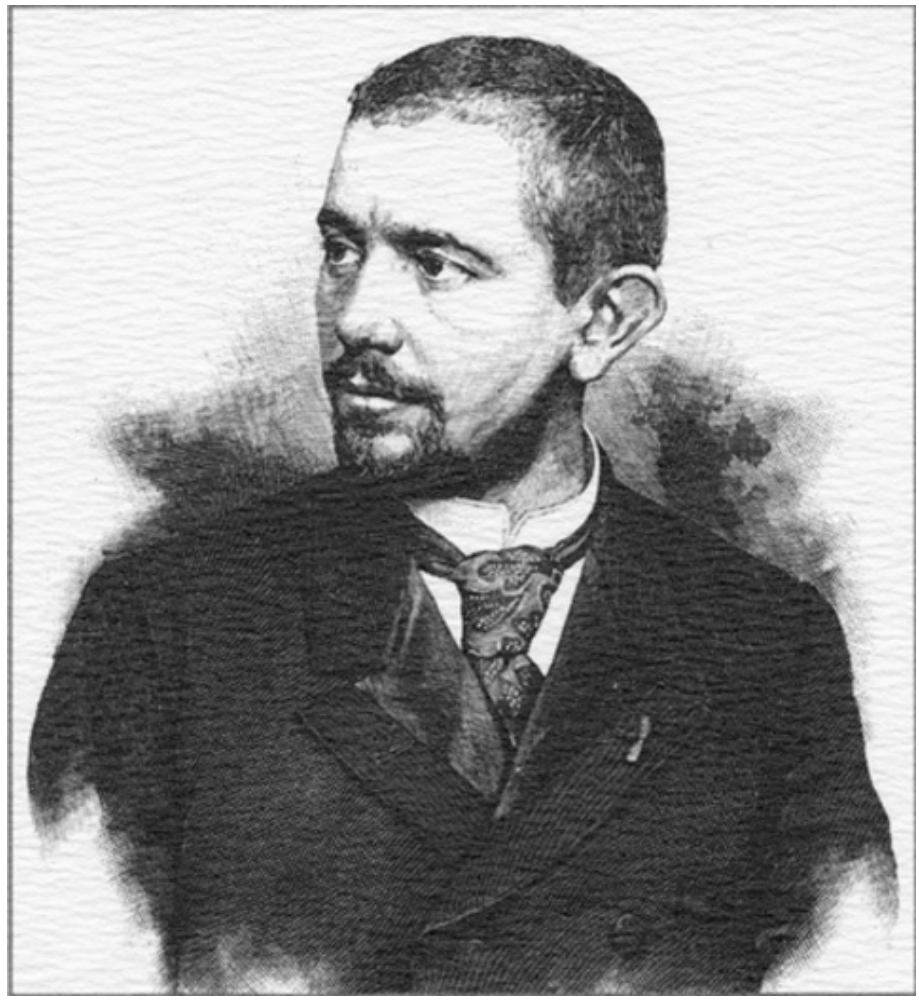

Source : L'Illustration, 2703, 15 décembre 1894

\section{Jules Gervais-Courtellemont (1863-1931)}

2 Jules Gervais-Courtellemont naquit à Avon en Seine-et-Marne en 1863 et partit avec sa famille pour l'Algérie en 1874. À la fin des années 1880, il s'initia à la photographie en compagnie de son ami Léon Gauthier (1862-1949), futur professeur d'histoire de la philosophie musulmane à la faculté des lettres de l'université d'Alger et spécialiste d'Averroès (1126-1198).

3 En 1883, il effectua un premier voyage en Andalousie et en 1885 au Maroc, puis quatre ans plus tard, ouvrit un atelier de photogravure à Alger. Il reproduisit ses photographies pour illustrer plusieurs publications, dont la revue éditée, de 1889 à 1893, avec André Alatissière L'Algérie artistique et pittoresque. En 1894, il épousa en seconde noce Hélène Lallemand, fille de Charles Lallemand, célèbre journaliste et illustrateur, notamment auteur de Jérusalem-Damas et Le Caire (en 1894), ouvrages illustrés de photographies de Jules Gervais-Courtellemont et publiés par sa propre maison d'édition, Gervais-Courtellemont et Cie, à Alger. À l'automne de la même année, converti à l'islam, il se rendit en pèlerinage à La Mecque. Le récit de ce voyage, illustré des premières photographies prises sur place par un Français, fut édité sous le titre Mon voyage à La Mecque, chez Hachette en 1896. À partir de cette expérience, le photographe entreprit de faire connaître ses travaux lors de conférences accompagnées de projections des clichés qu'il rapportait de ses voyages. En 1894, débuta sa collaboration avec L'Illustration, qui cessa en 1923. En 1898, il participa à une croisière dans les Balkans sous l'office de la Revue générale des Sciences, puis partit pour la Chine, le Japon, 
le Tonkin, Madagascar et l'Égypte. En 1901, il se rendit en Perse et en Mésopotamie pour le Comité d'Asie française, puis en Arabie, dans le Caucase et en Turquie.

Entre 1902 et 1903, il fut missionné par le gouverneur général de l'Indochine, Paul Doumer, afin d'entreprendre une importante mission sur la présence musulmane au Yunnan (fig. 2). Prévu pour ne durer que quelques mois et très contesté dans les milieux diplomatiques, ce voyage se prolongea sur une période de 18 mois. Accompagné de sa femme Hélène qui se révéla une collaboratrice avertie, il parcourut ces régions inexplorées de Chine dont ils rapportèrent une analyse politique, géographique, humaine et commerciale.

\section{Jules Gervais-Courtellemont à cheval en Chine.}

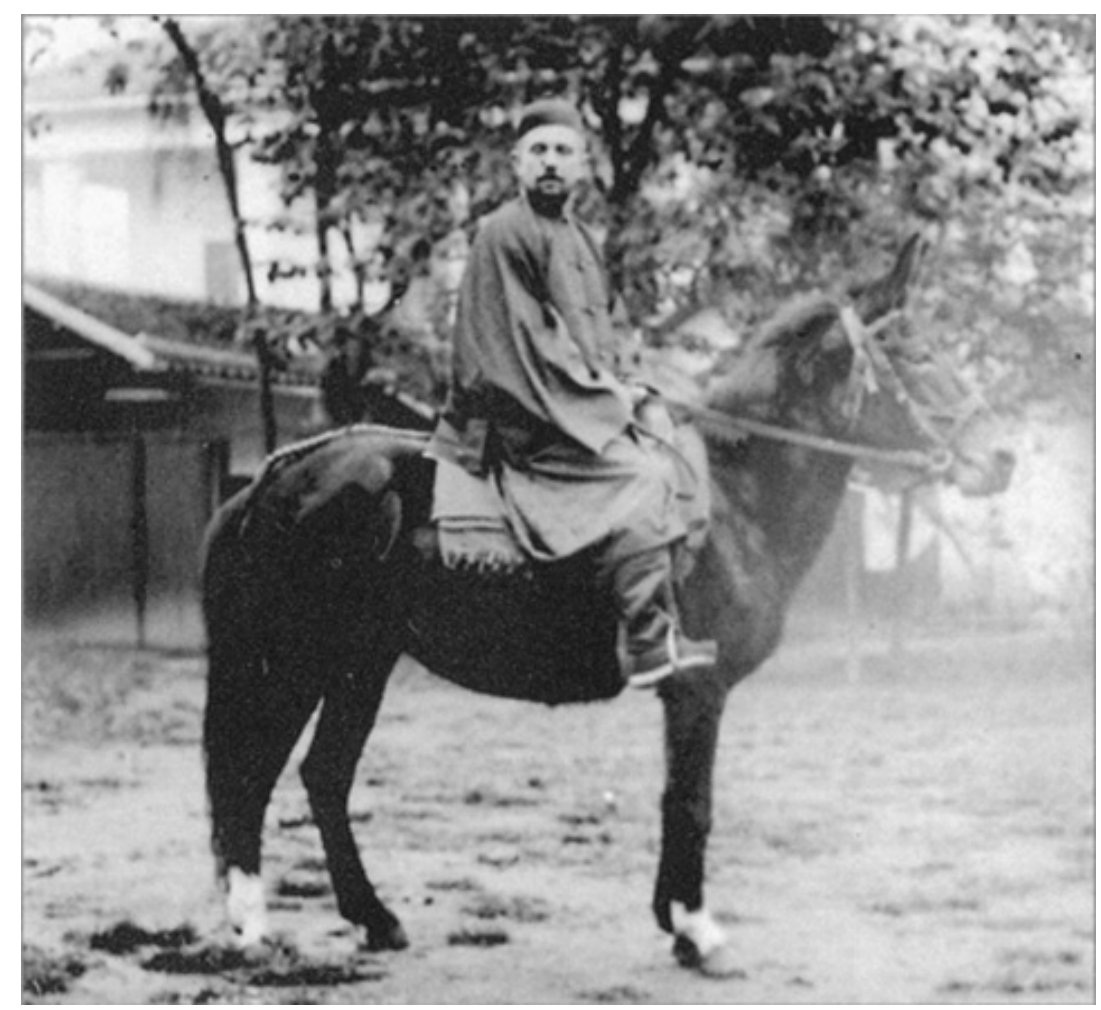

Source : Alain fourauier, Jules Gervais-Courtellemont (1863-1937), l'œuvre d'un photographe, Paris S. Fourquier, 2009 (Au bibliophile parisien, 5).

5 À l'issue de cette aventure, il publia le récit de son périple dans Voyage au Yunnan (1904) et de ses réflexions dans Colonies françaises ${ }^{5}$ (1906), tout en donnant des conférences sur le rôle de la France en Asie à travers le territoire.

En 1907, il s'initia au procédé de photographies en couleurs des frères Lumière et prit ses premiers autochromes. Il voyagea en Turquie, en Palestine, en Syrie et en Égypte d'où il rapporta des clichés en couleurs qu'il destinait à la projection. Annoncées sous le titre de Visions d'Orient, ces présentations débutèrent en février 1908 à Lyon. En 1910 et 1911, il se rendit de nouveau en Égypte, en Algérie, en Tunisie et en Espagne, puis entreprit, en 1912 et 1913, un voyage en Inde avant de retourner au Maroc. Pendant la Première Guerre mondiale, Gervais-Courtellemont effectua de nombreuses prises de vue en couleurs sur le théâtre des opérations militaires, particulièrement autour des champs de batailles de la Marne (1914-1915) puis de Verdun (1917). Il donna des dizaines de conférences sur les hostilités afin d'informer le public des désastres de la 
guerre. Il retourna en Algérie et au Maroc de 1921 à 1923 avant de publier, entre 1923 et 1925, les trois tomes de son imposante œuvre intitulée La Civilisation - Histoire sociale de l'humanité. De 1924 à 1931, il collabora avec le National Geographic Magazine qui publia plusieurs centaines de ses clichés. Il décéda en 1931 dans sa maison de Coutevroult en Seine-et-Marne, en plein projet de publication qu'il voyait être l'aboutissement de ses réflexions sur l'islam. C'est sous le signe de ses influences culturelles européenne et orientale qu'eut lieu son enterrement, inscrivant ce personnage atypique sous le double signe de la tradition chrétienne et musulmane :

«On a célébré ses funérailles lundi dernier, par une belle journée. Dans la « chambre chinoise», il reposait sur un grand lit de parade. Selon un désir souvent exprimé, on l'avait enveloppé de l'irham du pèlerin. Son somptueux manteau d'Arabie recouvrait ses épaules; son turban de La Mecque était plié à son côté ; et, dans sa main à l'anneau d'argent, il tenait le certificat attestant que Hadj-Abdallah était croyant pour de vrai et désireux de rien que du désir du salut. Pourtant, quatre gars de Coutevroult portèrent sa bière à la chapelle. Le curé récita l'office des morts. On chanta le De profundis, puis le psaume de l'éternel repos, et on alla, dans le cimetière ensoleillé, le coucher face à l'Orient ${ }^{6}$. "

\section{Le Caire reproduit en noir et blanc}

7 Si depuis le début des années 1890, Jules Gervais-Courtellemont sillonnait les terres orientales en rapportant, comme l'indique Pierre Loti :

«[...] des chiens, des bateliers, des Syriens, des pyramides, des prêtres grecs, des femmes voilées, des minarets, des ruines, des Juifs misérables, des soldats dépenaillés. Que sais-je, des tombeaux, [ ?], la mosquée d'Omar à Jérusalem et les tombeaux des Califes du Caire, un tas de petites images, qui [...] [apportent], moins les couleurs ${ }^{7}$, une petite bouffée de la vie de là-bas.... "

8 Les clichés monochromes qu'il avait pu en rapporter ne doivent leur postérité qu'aux publications qui en ont été faites. C'est le cas notamment de l'ouvrage de Charles Lallemand, Le Caire, publié en 1894, dont la flatteuse préface de Pierre Loti indique déjà combien le photographe maitrisait son appareil :

«[...] Maintenant vous venez de promener, d'Égypte en Palestine, les verres de vos surprenants appareils et vous avez fixé entre des feuillets de livres les plus fugitifs aspects des choses de là-bas. En des teintes sans nom et infiniment variées, qui donnent l'illusion du soleil ou de la nuit, vous avez rendu et éternisé tout; les horizons fuyants des déserts, avec leurs mirages, avec les vagues silhouettes qui s'y meuvent, les splendeurs mortes des villes; les grandes lignes et l'inexprimable majesté des mosquées saintes, aussi bien que les infimes détails de leurs découpures et de leurs faïences; les attitudes des gestes arabes, avec les regards, les furtives expressions des yeux qui indiquent tout l'insondable lointain des pensées; enfin les lumières des soirs et des matins purs, les éclairages étranges qui ne durent qu'une seconde et la fantasmagorie des ciels lunaires'. »

Durant sa période "noir et blanc", Gervais-Courtellemont s'attacha à photographier les motifs pittoresques de la ville du Caire, les rives animées du Nil, les pyramides de Gizeh et de Saqqarah, puis quelques palmeraies comme celles de Memphis ou les ruines de Thèbes. 
10 Les illustrations du livre de Charles Lallemand, Le Caire, sont insérées dans le texte pour 65 d'entre elles et 23 planches sont reproduites hors-texte ; elles peuvent être réparties en plusieurs groupes :

- l'architecture antique monumentale (pyramides de Gizeh et Saqqarah, le Sphinx) et les antiquités égyptiennes conservées dans le musée qui se trouvait encore à Gizeh à cette époque ;

- les scènes de la vie rurale (labourage, dépiquage, extraction de l'eau des puits);

- les scènes de la vie quotidienne en ville avec des vues générales des rives du Nil et des bateaux accostés, des scènes de rues (vues générales, charrettes transportant des paysans), des représentations des petits métiers (âniers, porteurs d'eau, musiciens), des cérémonies (cortège de mariage) ;

- des vues panoramiques de la ville prises de plusieurs endroits (la Citadelle, le Muqattam);

11 l'architecture islamique (extérieurs et intérieurs de mosquées, fontaines, mausolées).

12 L'intérêt que porte le photographe à la représentation du peuple et ses activités quotidiennes dans les rues de la ville s'inscrit clairement dans cet ouvrage. Il photographie les modes de transport des plus humbles et les vêtements des paysannes. Les réalisations des artisans locaux: dinandiers, musiciens, cardeurs retiennent son attention. Son étude s'arrête de plus sur l'architecture musulmane monumentale. Si ses clichés des célèbres mosquées du Caire comme celles du sultan Hasan et d'Ibn Tulun semblent assez classiques, sa qualité de musulman lui permet de procéder à des prises de vue dans l'intimité de la cour d'al-Ahzar pendant la prière ou les heures d'étude des étudiants et de faire œuvre d'originalité. Il s'intéresse aussi tout particulièrement à la décoration intérieure des édifices cultuels (décors pariétaux de marbre, sculpture des minbars et des portes) dont il prélève de nombreux motifs, tel le décor raffiné la mosquée al-Burdayni ${ }^{10}$ ou bien encore la délicate découpe du minbar de la mosquée de Tulun (fig. 3) ${ }^{11}$. 
3a. Mirhab et mimbar de la mosquée de Bordéini [al-Burdayni], photographie.

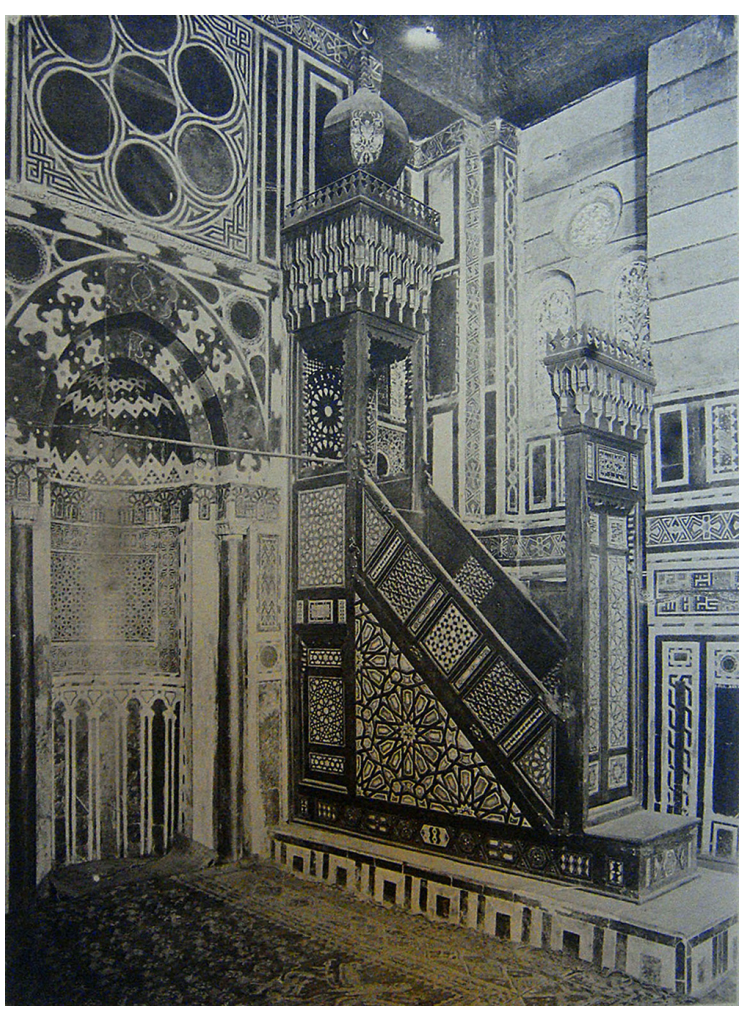

Source : Charles Lallemand, Le Caire, Alger, Gervais-Courtellemont, 1894 (Collections Courtellemont artistique et pittoresque), planche insérée entre les pages 78-79. 
3b. Mimbar de la mosquée de Touloun [Ibn Tulun], photographie.

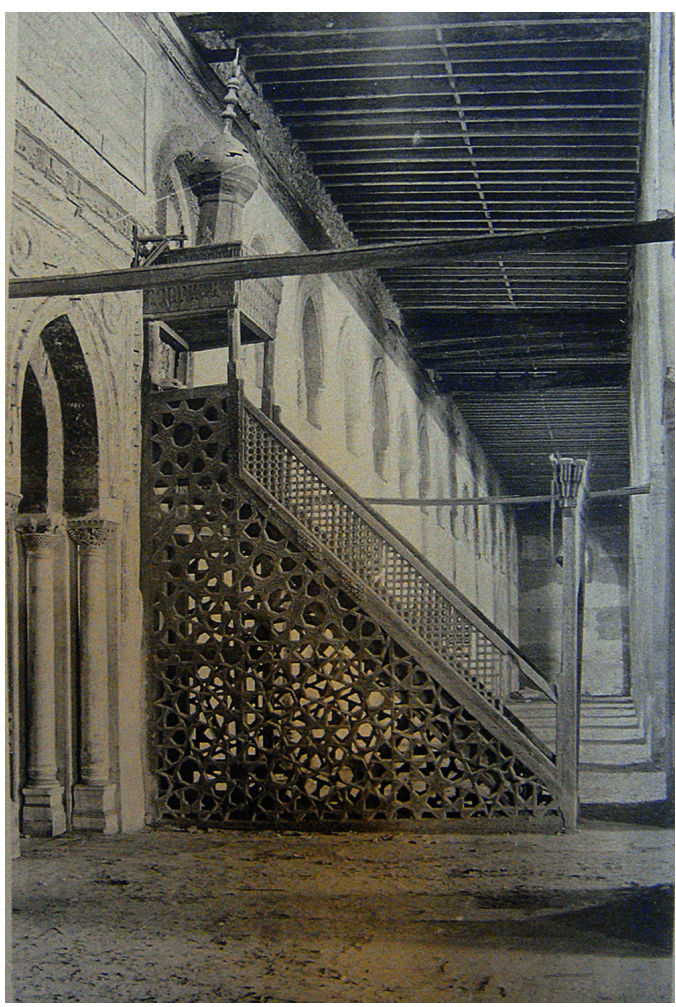

Source : Charles Lallemand, Le Caire, Gervais-Courtellemont, 1894 (Collections Courtellemont artistique et pittoresque), planche insérée entre les pages 84-85.

13 Henri Saladin, lorsqu'il entreprit la publication de son Manuel d'Art musulman en 1907, faisait lui aussi la part belle aux illustrations de Gervais-Courtellemont: «Je dois réserver une place toute spéciale à Gervais-Courtellemont, qui à lui seul, a enrichi cet ouvrage de plus de cent photographies inédites de Palestine, de Syrie, d'Égypte, de Tunisie, de Mésopotamie, de Perse et de Chine ", écrivait-il dans sa préface, incluant neuf de ses clichés sur les vingt-huit illustrations photographiques ayant trait à la représentation d'éléments architecturaux du Caire.

\section{Le Caire projeté en couleurs}

14 Conquis par la couleur, Jules Gervais-Courtellemont se spécialisa dans la pratique de $l^{\prime}$ «Autochrome Lumière $~^{12}$ à la suite de la commercialisation du premier procédé de photographies en couleurs naturelles, découvert et diffusé par les frères Lumière en juin 1907. Cette nouvelle technique, et la maîtrise qu'il en acquit lui permirent, à partir de 1908, de reproduire la lumière et les couleurs des pays d'Orient. En quête de compositions aux teintes subtiles, il s'engagea dans la voie de la photographie en couleurs et exécuta de nombreux autochromes. Réalisée sur un support de verre, l'Autochrome Lumière est destinée à être projetée. C'est donc dans le cadre de projections lumineuses de photographies aux couleurs naturelles que les spectateurs étaient invités à découvrir les Visions d'Orient présentées par Gervais-Courtellemont dès février 1908. Elles retraçaient son récent périple de Constantinople (novembre 1907), Damas, Beyrouth, Jaffa, Jérusalem, et enfin d'Égypte où il séjourna de fin janvier à mifévrier (fig. 4-8). 
4. Autochrome. La vieille mosquée abandonnée du Sultan Tulun [Ibn Tulun] (9 x $12 \mathrm{~cm})$.

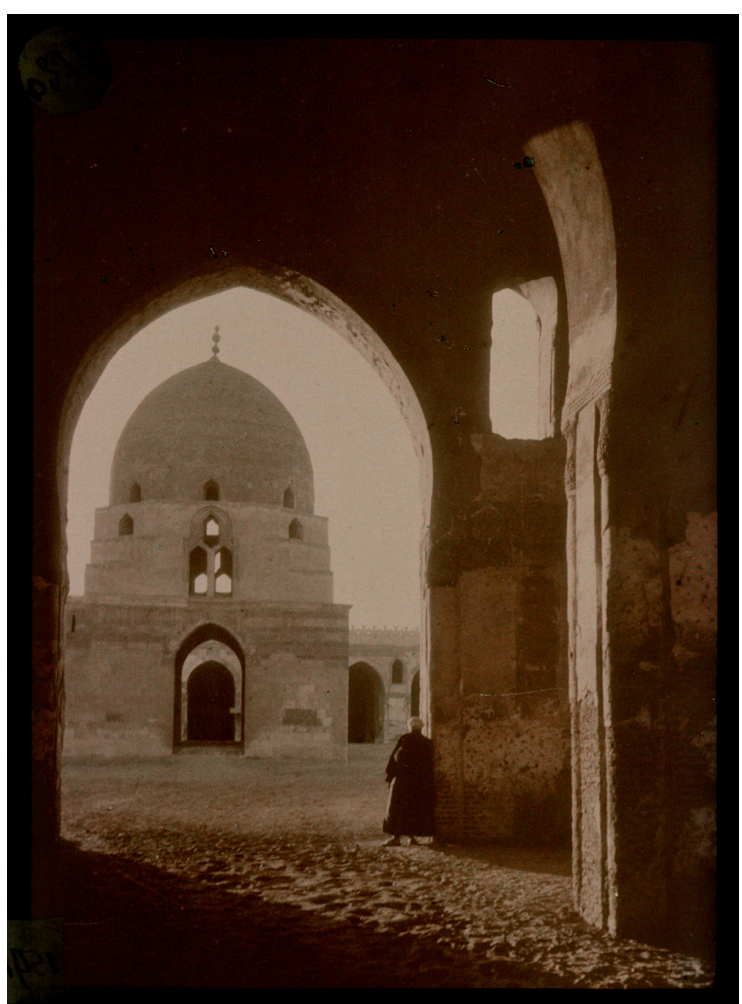

Source : Paris (France), Cinémathèque Robert-Lynen de la Ville de Paris, A1624.

5. Autochrome. Tombeaux des califes - Minaret Backoub [khanqah Farag ibn Barquq] (13 x $18 \mathrm{~cm})$.

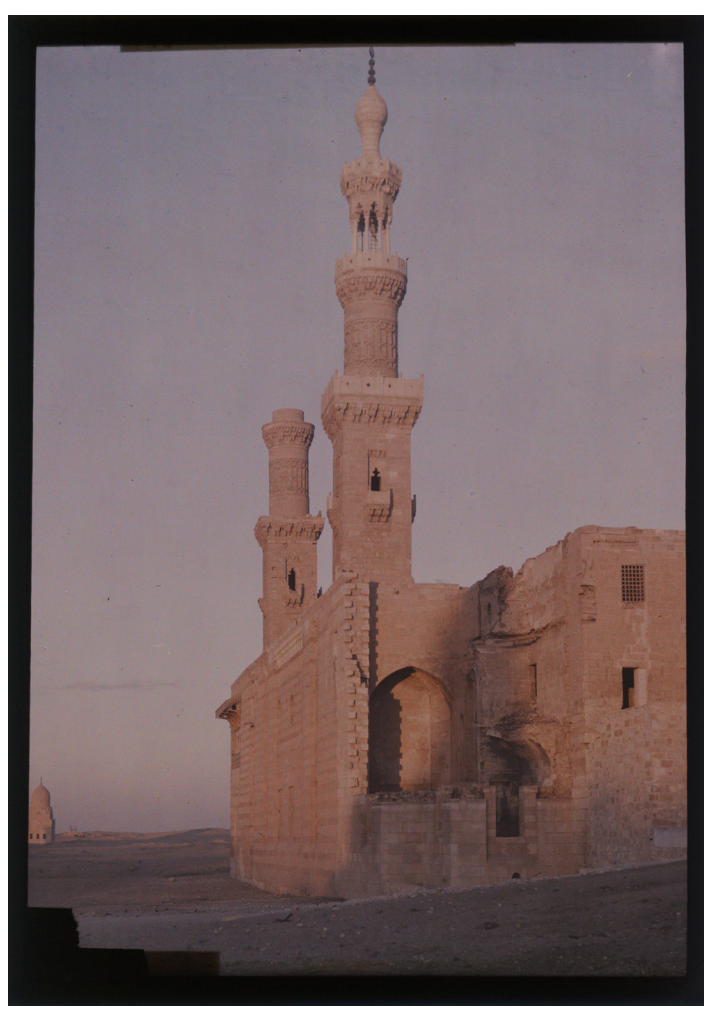

Source : Paris (France), Cinémathèque Robert-Lynen de la Ville de Paris, A1995. 
6. Autochrome. Un artiste peintre $(9 \times 12 \mathrm{~cm})$.

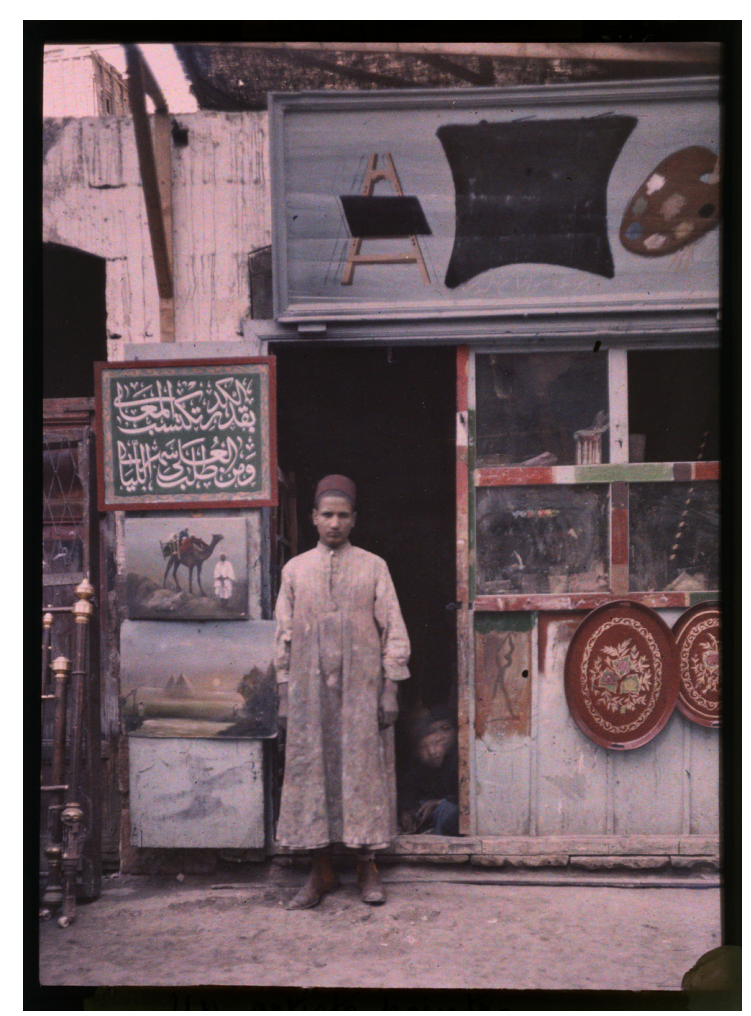

Source: Paris (France), Cinémathèque Robert-Lynen de la Ville de Paris, A1659.

\section{Autochrome. Mosquée Kaït bey [Qaytbay] ( 9 × $12 \mathrm{~cm})$.}

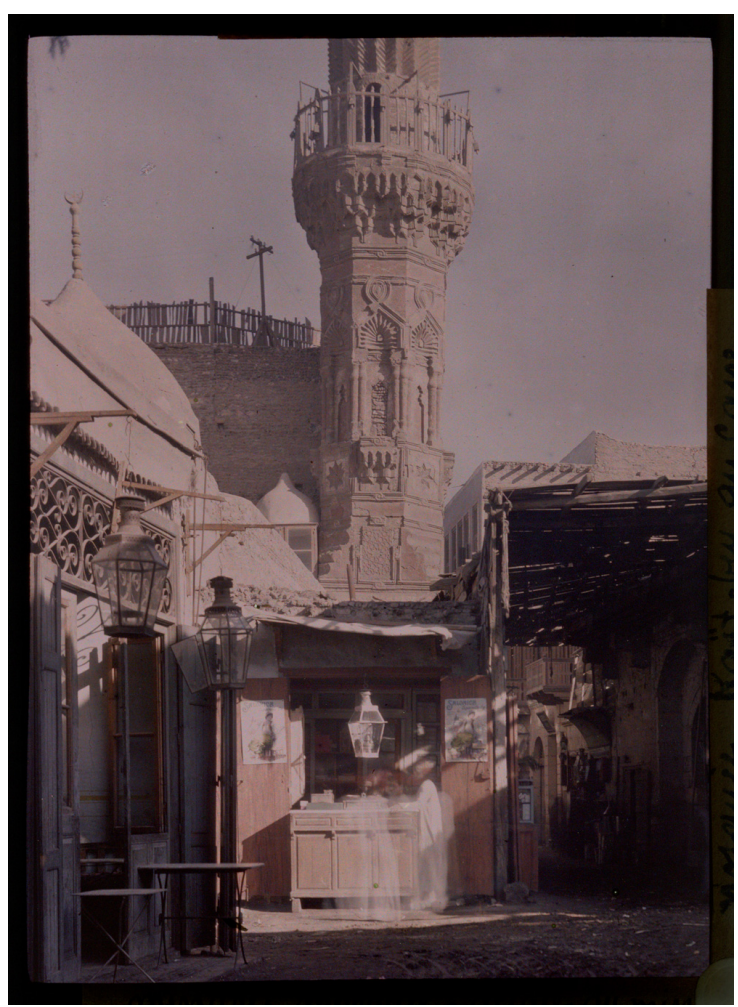

Source: Paris (France), Cinémathèque Robert-Lynen de la Ville de Paris, A1627. 
8. Autochrome. Le Caire $(13 \times 18 \mathrm{~cm})$.

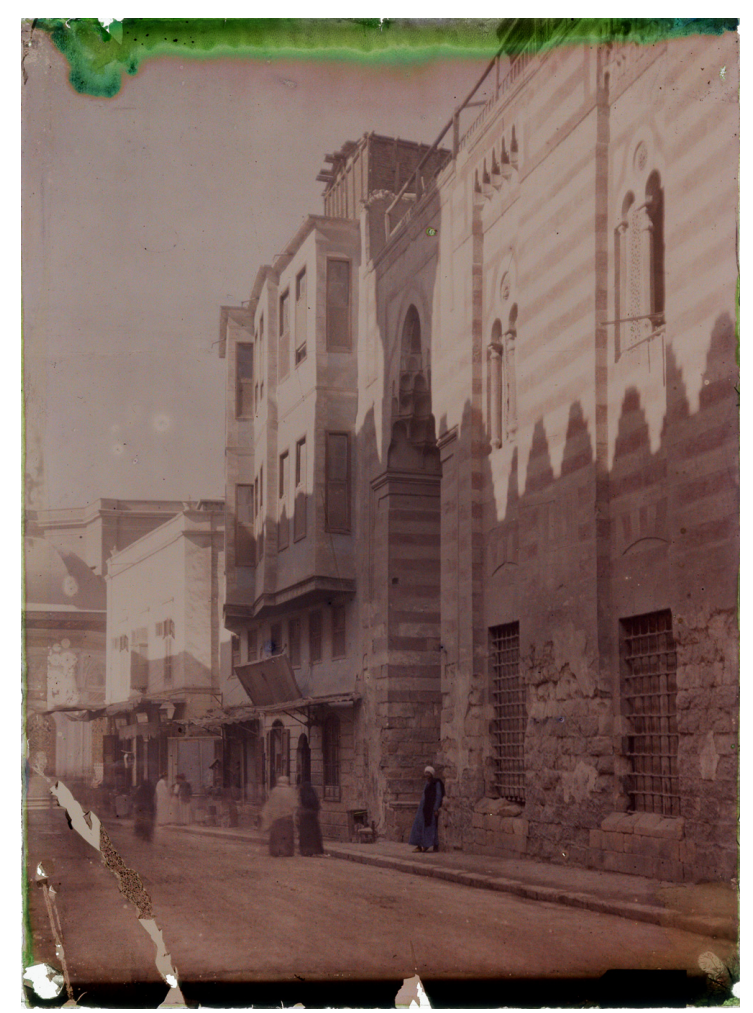

Source: Paris (France), Cinémathèque Robert-Lynen de la Ville de Paris, A2009.

15 Face au succès suscité par ses projections, qu'il organisa régulièrement entre 1908 et 1914 devant des milliers de Parisiens dans le cadre de ses spectacles annoncés sous le titre de Visions d'Art, il est amené à constituer dès 1911 « la plus remarquable et la plus nombreuse collection de photographies en couleurs d'après nature qui existe au monde ${ }^{13} »$.

$16 \mathrm{Au}$ sein de cette collection, l'Égypte tient une place particulière. Aux séries de vues rapportées du Caire et présentées dans le cadre des Visions d'Orient, d'autres conférences dédiées à ce thème étaient régulièrement programmées, telles « Aux pays des pharaons », « Promenades en Égypte », « Dans les temples de la Haute-Égypte » ou encore, «L'Égypte des pharaons jusqu'à nos jours ${ }^{14}$ ».

17 Ses clichés en couleurs regroupent des vues de l'Égypte pharaonique : ruines d'Abydos, de Karnak ou d'Ipsamboul (Abou Simbel), ainsi que quelques autochromes inédits de la sépulture royale d'Aménophis dans la vallée des Rois.

À cette production, marquée par la fascination de l'Antiquité, s'ajoutent de nombreuses photographies faites à l'intérieur de mosquées qui permettent de restituer toutes les finesses colorées des faïences et des découpes architecturales, où l'on retrouve les motifs polychromes de la mosquée al-Burdayni (fig.9), ou encore les détails calligraphiques d'exemplaires du Coran ainsi que des objets conservés dans le récent musée d'Art arabe du Caire (fig. 10). Enfin quelques scènes de la vie quotidienne, les ânes du Caire, et bien sûr de nombreux couchers de soleil (fig. 11), prétexte à fixer les fugitifs et délicats effets des ciels empourprés du Levant, complètent cet ensemble. Toutefois, le pittoresque des vues projetées n'est pas, pour l'auteur, le seul attrait de 
ces projections. L'Égypte est en effet pour Gervais-Courtellemont un pays privilégié dans sa quête de connaissance de l'Orient :

«Toute l'histoire du peuple égyptien est un sujet d'admiration pour qui l'approfondit. En ce qui concerne l'auteur, sept fois en trente années ${ }^{15}$ il est retourné en Égypte pour persévérer dans l'étude qu'il en faisait et de plus en plus attiré, charmé, plus rempli d'admiration pour les progrès sociaux qu'il y voyait réaliser. Des couches les plus humbles, les plus misérables de ce peuple de bronze, jusqu'aux sommets de la hiérarchie sociale, il a voulu tout voir, et de toute son âme il a essayé dans son rayon d'action, chaque fois que l'occasion s'en présentait, de donner confiance à tous en même temps que conscience de leur valeur, de leurs droits, et réchauffer ainsi leur foi dans le succès de leurs revendications légitimes ${ }^{16}$. "

9. Autochrome. Intérieur de la mosquée de Ahmad el Burdayni [al-Burdayni], mirhab et minbar $(13 \times 18 \mathrm{~cm})$.

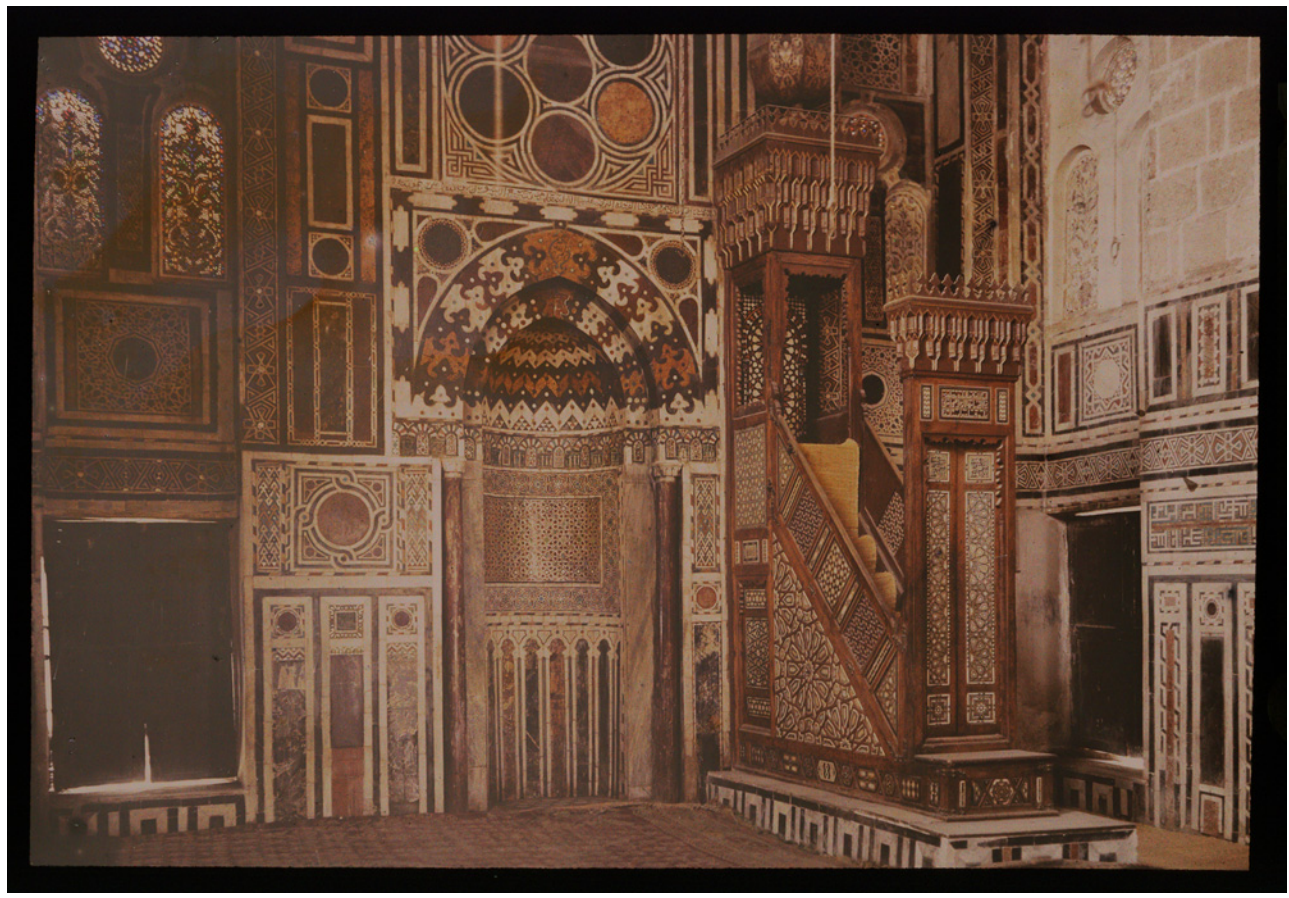

Source: Paris (France), Cinémathèque Robert-Lynen de la Ville de Paris, A2021. 
10. Autochrome. [lampes de mosquée, style mamelouk], (13 x $18 \mathrm{~cm})$.

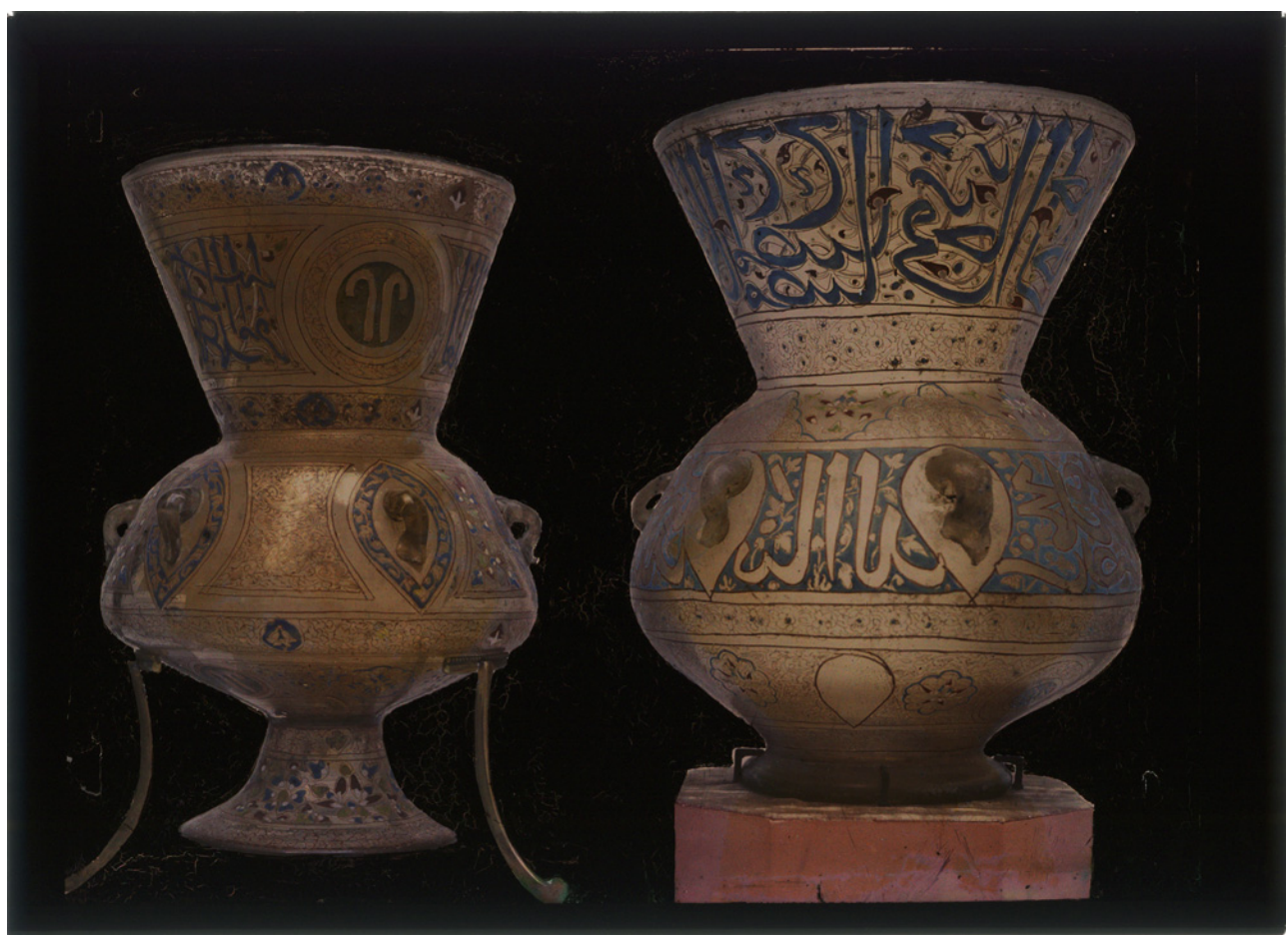

Source : Paris (France), Cinémathèque Robert-Lynen de la Ville de Paris, A2026.

11. Autochrome. [vue de la Citadelle] $(9 \times 12 \mathrm{~cm})$.

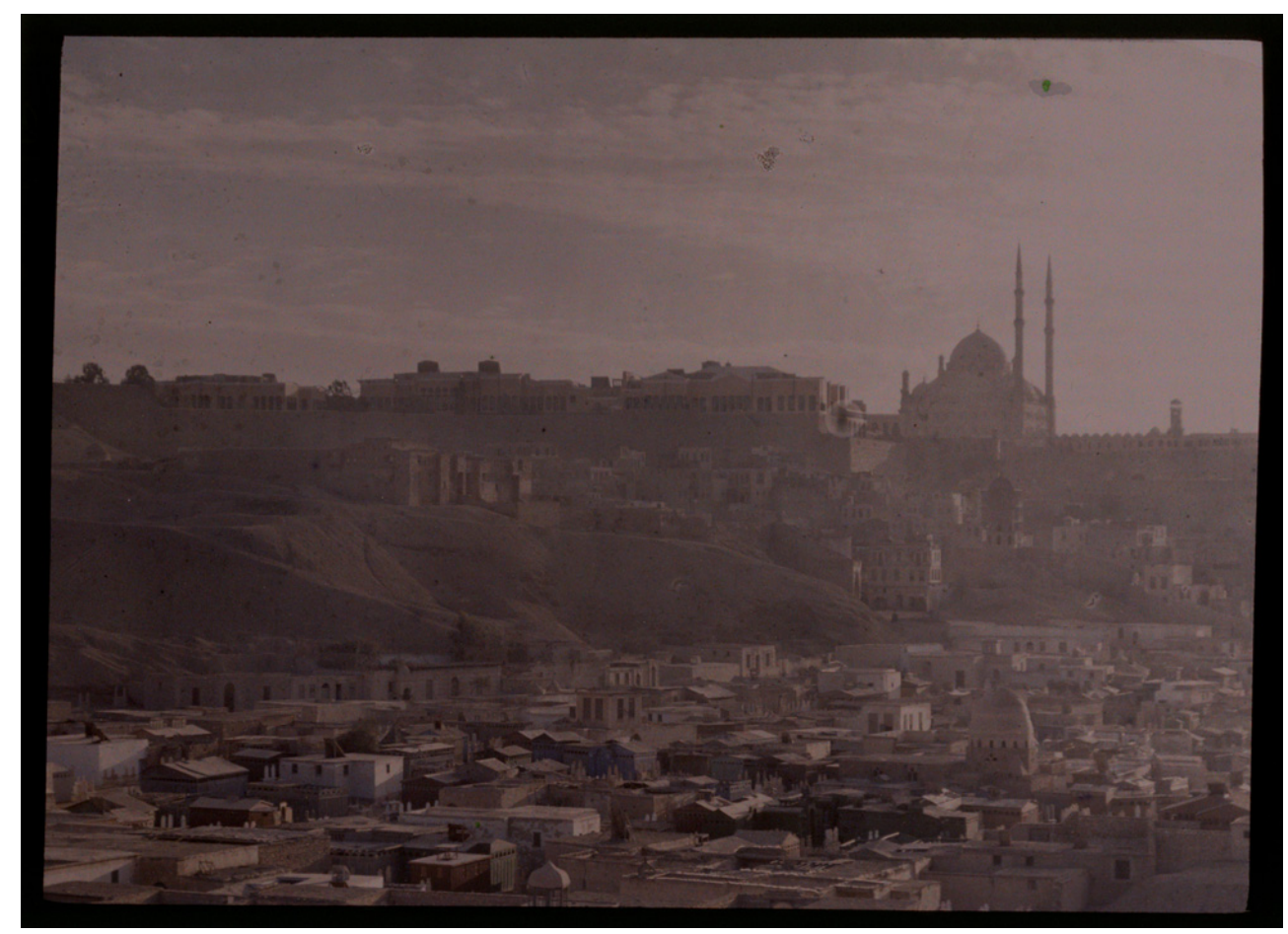

Source: Paris (France), Cinémathèque Robert-Lynen de la Ville de Paris, A1619.

19 C'est pourquoi au-delà de la démarche artistique de son activité, Gervais-Courtellemont aimait inscrire des visées didactiques. Animé de ce double objectif, il invitait à la fois les 
spectateurs à « voyager dans leur fauteuil ${ }^{17}$ ", où grâce à la qualité et au réalisme de ses projections en couleurs, il offrait à son auditoire la possibilité de se plonger dans une profusion d'impressions colorées où se révélait « la vérité vivante et limpide de l'Orient magique vers lequel nos curiosités sont toujours tendues et comme neuves ${ }^{18} »$. Par ses commentaires, décrits comme "aussi colorés que ces images", il apportait des connaissances nouvelles sur les modes de vie des sociétés orientales.

Son introduction aux Visions d'Orient soulignait très nettement cette double perspective :

«Les souvenirs un peu confus des contes qui ont bercé notre enfance ou charmé notre adolescence, vagues réminiscences de romans ou de légendes, ont peuplé nos esprits de "Visions d'Orient" dont les images se précisent en somptueux palais, blanches coupoles et fins minarets, cavaliers fougueux, brandissant le cimeterre, palmiers élancés se découpant sur un ciel très bleu, l'Orient des Mille et une nuits et des croisades. [...] Sur l'Orient aujourd'hui, infiniment plus prosaïque et, de jour en jour, plus modernisé, nous sommes peu ou mal renseignés. Les choses les plus contradictoires nous sont quotidiennement dites sur ces pays et sur ces peuples d'islam dont la civilisation diffère totalement de la nôtre, dont les conceptions philosophiques et sociales, voire économiques, sont aux antipodes de ce que nous considérons comme des vérités. Ils mériteraient d'être mieux connus ${ }^{19}$. »

Profitant de la fascination pour ses images en couleurs, Jules Gervais-Courtellemont se consacra à la diffusion de ses idées auprès d'un large public. Son succès est d'autant plus important que Gervais-Courtellemont était considéré comme un expert de la question de l'Orient en France. Le 3 juin 1908, à l'occasion du Congrès colonial français, il présenta ses autochromes à l'École des hautes études commerciales, lors d'une conférence ayant pour thème "L'islam et les colonies françaises ». Cette présentation lui donna l'occasion de faire plus particulièrement référence à la situation égyptienne. Il se fit le porte-parole des revendications du peuple égyptien en faveur de sa liberté et fit l'éloge des nombreux efforts pour développer l'éducation qui, à ses yeux, représentait la clef de la voie vers l'indépendance. C'est aussi en compagnie de Muhammad Farid (fig. 12) ${ }^{20}$, qu'il présenta le 9 juin 1910 une autre conférence sur ce sujet d'actualité «Le Mouvement national égyptien », au Comité lyonnais de la Mission laïque française.

C'est en artiste engagé qu'il diffusa ses travaux. À son auditoire du Congrès colonial français, il déclara:

«J'ai obtenu avec [les projections d'autochromes] un résultat qui a dépassé mes espérances lorsque, il y a deux mois, j'ai débarqué en France, revenant d'un nouveau voyage en Orient. J'ai escompté et je vois que je ne me suis pas trompé sur les goûts artistiques des Parisiens et des Parisiennes; et grâce à l'attrait des petites «Visions d'Orient », j'ai réuni et retenu des auditoires d'élite, auxquels j'ai pu dire bien des choses qui, sans elles, n'auraient point été écoutées. J'ai la conviction d'avoir créé, en moins de deux mois, un mouvement d'idées qui, je l'espère, ne s'arrêtera plus.... ${ }^{21} . »$

Le fonds de la cinémathèque Robert-Lynen recèle aujourd'hui une partie des autochromes réalisés par Gervais-Courtellemont en Égypte. Cette série représente environ $4 \%$ de son fonds autochromes et comprend cent trente-sept clichés sur verre, dont quatre-vingt-seize sont de format 9 sur $2 \mathrm{~cm}$, destinés principalement à la projection et quarante et un de format 13 sur $18 \mathrm{~cm}$. Elle est composée de sujets collectés lors des séjours qu'il entreprit en 1908 et en 1911. On y retrouve les thèmes précédemment décrits, prélevés au Caire, pour 26 clichés, puis sur les sites situés le 
long des rives sud du Nil (Abydos; Dendérah; Edfou; Kom Ombo; Karnak; Louxor; Médinet Habou et Philae)

Ces images ne nous permettent pas d'emblée d'avoir conscience de l'implication de leur auteur dans la volonté de connaissance de l'Orient auprès de spectateurs européens. C'est pourquoi revenir sur le contexte de leur diffusion nous offre la possibilité de comprendre à la fois la présence de certains clichés tels ceux de la série de portraits d'hommes du monde politique présentant Muhammad Farid (fig. 12), Ali Kemal ${ }^{22}$ ou encore le shaykh Shawush, qu'il intégra dans sa collection, ainsi que de faire un retour sur le parcours tout à fait original de ce photographe.

12. Autochrome. Mohammed bey Farid [Muhammad Farid] $(9 \times 12 \mathrm{~cm})$.

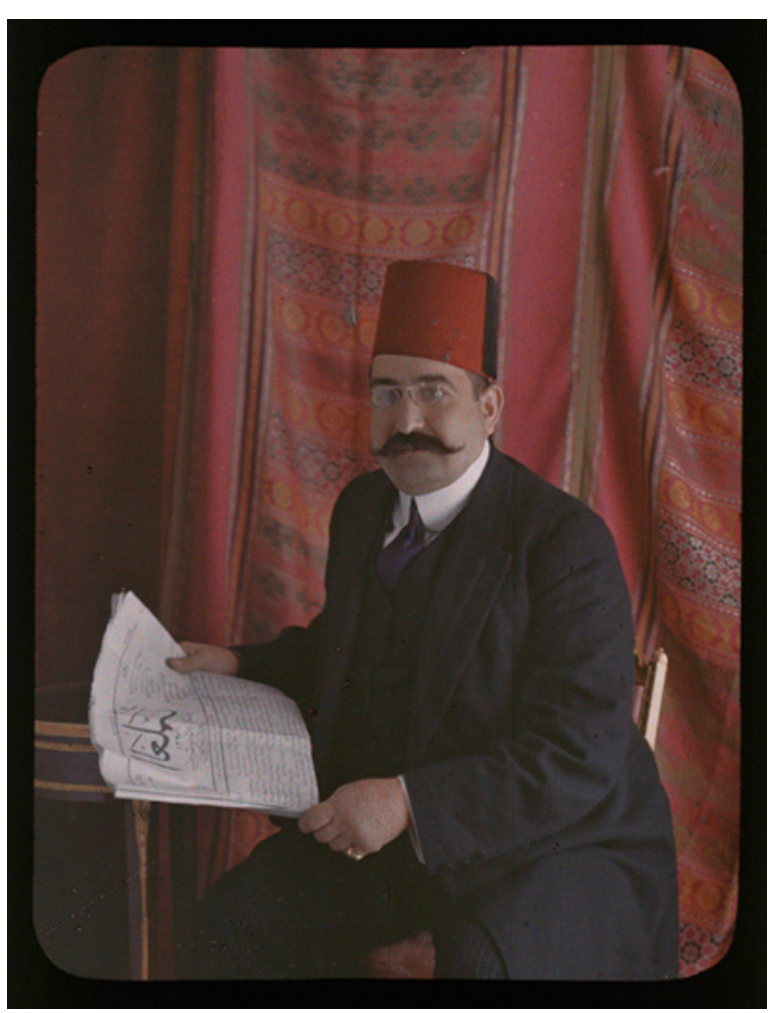

Source : Paris (France), Cinémathèque Robert-Lynen de la Ville de Paris, A1609.

\section{NOTES}

1. Le Figaro, 24 février 1908.

2. Voir Emmanuelle DEvos, "Passeur d'Orient, l'exemple de Jules Gervais-Courtellemont », in Miroirs d'Orients, catalogue d'exposition (Lille, Palais des beaux-arts de Lille, 15 mai-31 août 2009), Paris : Somogy, 2009, p. 85.

3. Jules gervais-courtellemont, Mon voyage à La Mecque, Paris: Hachette, 1895 [réédition Paris : Desclée et Brouwer, 1990, postface de Guy COURTELLEMONT]. 
4. Pour une biographie de cet auteur, se référer à Guy COURTELLEMONT, Le pionnier photographe de Mahomet, Nîmes : éditions Lacours, 1994 ainsi qu'à Emmanuelle DEVos et Béatrice DE PASTRE (dirs.), Les couleurs du voyage, l'œuvre photographique de Jules Gervais-Courtellemont, Paris : Paris-Musée ; Philéas Fogg, 2002.

5. Charles BROSSARD (dir.), Colonies françaises, par un groupe d'écrivains d'explorateurs et de fonctionnaires, Paris : Flammarion, 1906.

6. Myriam HARRY, Le Temps, notice nécrologique, 8 novembre 1931.

7. C'est nous qui soulignons.

8. Alger, lettre de Jules Gervais-Courtellemont à Pierre Loti, 1893, collection particulière.

9. Charles Lallemand, Le Caire, préface de Pierre Loti, Alger : Éditions J. Gervais-Courtellemont \& Cie, 1894.

10. Ibid., planche hors-texte p. 79.

11. Ibid., planche hors-texte p. 83.

12. Nathalie Boulouch, «Les Visions d'Orient de Jules Gervais-Courtellemont, 1895 », in Thierry LEFEBVRE, Philippe-Alain Michaud (dirs.), Exotica, l'attraction des lointains, Paris : AFRHC, 1996, p. 53-61.

13. Anonyme, «Le Palais de l'Autochromie », Photo-Gazette, 25 avril 1911.

14. Projections-conférences présentées à Paris, salle Charras, rue Charras dans le $9 \mathrm{e}$ arrondissement entre 1909 et 1910, puis dans sa propre salle dite salle Montmartre (167, rue Montmartre, $2^{\mathrm{e}}$ arrondissement) entre 1911 et 1914.

15. C'est nous qui soulignons.

16. Jules Gervais-Courtellemont, La Civilisation, Histoire de l'humanité, Paris : Éditions Levasseur, 1923-1925, 3 tomes, voir ici tome 3 p. 360.

17. Selon la brochure publicitaire des Visions d'Orient, sans date, collection Alain Gervais.

18. Georges MONTORGUEIL, « Un photographe », L'Éclair, 3 mai 1911.

19. Jules GERVAIS-COURTELLEMONT, «Visions d'Orient », L'Illustration, 3535, 26 novembre 1910, p. 369 sq.

20. Muhammad Farid (1868-1919), homme politique lié à Mustapha Kamil pacha. Il devint, après le décès de ce dernier en 1908, le deuxième président du Parti national égyptien jusqu'en mars 1912.

21. Congrès colonial français, 1908 : retranscription d'une conférence publique «L'islam et les colonies françaises ", p. 79.

22. Journaliste et éditeur libéral ottoman (1867-1922). (voir http://catalogue.bnf.fr/ark:/12148/ cb135057237/PUBLIC)

\section{AUTEUR}

\section{EMMANUELLE DEVOS}

Responsable de la cinémathèque Robert-Lynen, Paris. 


\title{
Photographes du Caire dans le dernier tiers du XIX ${ }^{\mathrm{e}}$ siècle : les ateliers commerciaux
}

\author{
Thomas Cazentre
}

1 L'histoire de la photographie en Égypte au $\mathrm{XIX}^{\mathrm{e}}$ siècle peut être divisée schématiquement en deux grandes périodes. Jusqu'au milieu des années 1860 , les vues d'Égypte recensées se répartissent entre une production d'amateurs (voyageurs du Grand Tour, artistes venant collecter des images d'Orient pour nourrir leur œuvre de peintre, membres d'expéditions archéologiques...) et une production plus professionnelle, inscrite soit dans un projet éditorial prédéfini (Du Camp, Cammas, Teynard...) soit dans le souci d'enrichir un catalogue (Braun, Frith, Bedford, Hammerschmidt...). Cette distinction amateur/professionnel ne doit évidemment pas être comprise dans le sens qu'elle prendra ultérieurement. Elle ne se fonde que sur le statut social des photographes et la destination première de leur production. Le trait commun de cette première période est bien que, dans l'un comme l'autre cas, il s'agit de photographes qui visitaient l'Égypte, ou y séjournaient, au plus pendant quelques mois, et en rapportaient des images. Dans un marché de la photographie encore embryonnaire, les clients pour ce genre de clichés étaient en Europe. Si des photographes occidentaux avaient ouvert des ateliers dans les grandes villes de la Méditerranée orientale dès l'époque du daguerréotype, c'était principalement comme portraitistes, à l'intention d'une clientèle locale.

2 À partir de la décennie 1860, en revanche, des photographes occidentaux (bientôt suivis par des photographes de Constantinople) s'installèrent progressivement de manière exclusive et permanente dans les villes d'Égypte et du Proche-Orient. Ils y développèrent une production commerciale destinée aux voyageurs occidentaux. L'année 1869, avec l'inauguration du canal de Suez, marqua à cet égard un tournant : la clientèle "touristique » devint un marché significatif. Parallèlement, la fabrication industrielle de supports photographiques standardisés (négatifs sur verre au collodion sec puis au gélatino-bromure d'argent, tirages sur papier albuminé) favorisa cette évolution vers une production commerciale d'images à destination d'une clientèle 
élargie. Si elle était principalement vendue sur place, certains photographes bénéficiaient également de relais de distribution en Europe, voire en Amérique du Nord : partenariat familial pour Béchard, commercial pour Bonfils dont les images de Terre sainte connurent un grand succès dans les milieux évangéliques américains.

3 La plupart de ces photographes commerciaux étaient soit des Européens (Français, Italiens ou Grecs), soit des sujets chrétiens de l'Empire ottoman, principalement arméniens. Les sociétés musulmanes restaient encore très réticentes envers ce nouveau médium, malgré le soutien actif des souverains ottomans et égyptiens, qui n'hésitaient pas à se faire portraiturer, et commandaient des campagnes photographiques destinées à la fois à célébrer le patrimoine historique de leurs états, et à témoigner de leur modernisation en cours. Se constitua ainsi, entre Le Caire, Alexandrie, Port-Saïd, Beyrouth et Damas, un milieu photographique marqué par un réseau complexe de relations et d'interactions mutuelles (concurrence, association, collaboration, succession...) qu'il est parfois difficile de démêler.

4 En dehors des portraits de particuliers, cette production qualifiée plus tard d'orientaliste se répartit presque toujours entre paysages ou vues d'architecture d'une part, et « types » orientaux ou scènes pittoresques, plus ou moins authentiques, d'autre part. Matériellement, elle peut se décliner en cartes de visite ou en vues stéréoscopiques, mais le format de référence reste le tirage de moyen ou grand format, collé sur une planche afin d'être inséré dans un album. C'est principalement dans de tels albums, achetés tout composés ou, plus fréquemment, constitués par chaque voyageur à partir des choix de planches proposés dans les boutiques des photographes, que cette production nous est parvenue. L'usage du français était quasi universel, que ce soit dans la dénomination des ateliers ou dans le légendage des images.

5 La caractérisation thématique et esthétique des œuvres de ces différents ateliers est délicate, et pour tout dire un peu vaine. La connaissance que nous pouvons en avoir est très inégale : certaines productions (Bonfils, Sebah...) sont beaucoup mieux conservées et documentées que d'autres (Délié, Ernié). En outre, ce que l'on sait de la pratique de ces ateliers dément l'idée même d'une singularité : il s'agissait le plus souvent d'une production collective, dont les acteurs (membres de la famille et assistants) changeaient au fil des années. En outre, la vente ou l'échange de clichés entre photographes était une pratique courante, comme le recours aux mêmes figurants dans les types et scènes de genre.

6 Il serait ainsi facile de multiplier les exemples de clichés (à tous les sens du terme) quasi interchangeables bien que d'auteurs distincts. Cela vaut notamment pour l'architecture médiévale du Caire : la cour de la madrasa de sultan Hasan, les nefs à ciel ouvert de la mosquée d'Ibn Tulun, l'enfilade de coupoles et de minarets de la nécropole mamelouke, la rue étroite d'où surgissent les deux minarets de la mosquée de Mu'ayyad Shaykh, se retrouvent sous des signatures différentes avec des variantes insignifiantes. On pourrait au demeurant objecter, non sans raison, que ce conformisme n'est pas propre aux photographes orientaux : à Paris ou à Rome comme au Caire, il n'y a parfois qu'un nombre réduit de solutions visuelles pour rendre compte d'un monument. Néanmoins, au milieu de cette production assez impersonnelle, il arrive souvent qu'une photographie se distingue, soit par une forme de perfection dans le classicisme, soit au contraire par un élément d'originalité, voire d'étrangeté évocatrice.

7 Les historiens considèrent souvent que la première période de production de chaque photographe se distingue, à la fois par l'originalité dont elle peut témoigner, et par le 
soin apporté aux prises de vues et aux tirages ; c'est souvent aussi, malheureusement, celle qui a été le moins bien conservée. Une fois l'atelier établi, sa production tend presque fatalement vers une plus grande négligence technique et une certaine banalité esthétique. Ce processus vaut d'ailleurs pour l'ensemble de cette photographie orientaliste commerciale: plus soignée, plus artistique dans les années 1860 et 1870, elle s'appauvrit qualitativement dans les décennies suivantes. Le tournant du $\mathrm{xx}^{\mathrm{e}}$ siècle, avec l'essor de la carte postale et la démocratisation de la pratique photographique amateur, périma définitivement le modèle économique de ces ateliers, qui disparurent pour la plupart, ou survécurent seulement comme portraitistes.

\section{Abdullah Frères (1858-1899)}

Ce célèbre atelier stambouliote fut créé en 1858 par trois frères arméniens (d'une famille de cinq): Vichen (1820-1902), Kevork (1839-1918) et Hovsep (1830-1908) Abdullah. Avec les ateliers de Pascal Sebah et Basil Kargopoulo, il domina le milieu photographique de Constantinople jusqu'à la fin du XIX siècle. C'est semble-t-il Vichen, peintre miniaturiste de formation, qui s'initia le premier à la photographie auprès d'un certain Rabach, daguerréotypiste allemand installé à Constantinople, dont il finit par racheter l'atelier. En 1863, la maison Abdullah Frères obtint le titre de photographe officiel du sultan Abdulaziz. Ce titre leur conféra un quasi-monopole sur les portraits de membres de la famille impériale et d'officiels de la cour. Ils produisirent également de nombreuses vues de Constantinople, et furent les premiers photographes autorisés à photographier l'intérieur du harem impérial.

9 La révolution de palais qui contraignit Abdulaziz à abdiquer en 1876 entraîna une provisoire disgrâce des frères Abdullah. Leurs difficultés furent aggravées par la défaite turque dans la guerre contre la Russie en 1878. Ces revers de fortune les conduisirent à diversifier leur production, jusque-là concentrée sur la capitale et ses classes dirigeantes, et sans doute aussi à en rabattre sur leurs exigences artistiques. C'est vraisemblablement ce qui explique l'ouverture tardive, par Kevork et Hovsep, d'un atelier au Caire, en 1886, afin de profiter de la clientèle touristique (il est possible qu'un quatrième frère, Kosmi, les ait précédés au Caire dès 1878, sous une autre raison commerciale). Hovsep serait rentré à Constantinople dès 1877 , remplacé par son neveu Abro, fils de Kosmi. Quoi qu'il en soit, la production égyptienne d'Abdullah frères intervint tard, aussi bien dans l'histoire de l'atelier que dans celle de la photographie en Égypte, ce qui explique sa relative banalité; elle connut néanmoins une large diffusion. L'atelier d'Abdullah Frères au Caire ferma en 1895 ; la maison stambouliote fut rachetée en 1899 par son vieux concurrent Sebah.

\section{Antonio Beato (ca. 1825-1906)}

La carrière d'Antonio Beato a été longtemps éclipsée par celle de son frère Felice, pionnier de la photographie en Asie, dont la vie romanesque et l'importance historique excèdent en tout point celles de son cadet. On a ainsi parfois cru qu'Antonio et Felice ne faisaient qu'un. Il arrive encore aujourd'hui que l'on constate une confusion des attributions entre les deux frères, presque toujours au bénéfice de Felice - alors que, contrairement au cas Béchard par exemple, les deux corpus sont clairement distincts, sauf en un ou deux points de tangence. Contrepartie de cette proximité encombrante, 
l'attention toujours renouvelée pour la personne et l'œuvre de Felice et les recherches qu'elle suscite ont permis de mettre au jour certains éléments de la biographie de son frère, encore lacunaire toutefois. La date de naissance d'Antonio Beato reste ainsi inconnue, de même que le lieu. Il est aujourd'hui admis que les frères Beato étaient des sujets britanniques naturalisés d'origine vénitienne, de Vénétie même, ou d'un ancien territoire vénitien, peut-être Corfou. Antonio, cadet supposé, est probablement né vers 1825-1830; quant à sa mort, elle se situe de manière beaucoup mieux avérée en 1905 ou 1906. Il est probable qu'il commença à pratiquer la photographie avec son frère, et le partenaire (et futur beau-frère) de ce dernier, James Robertson. Tous trois étaient présents, de manière attestée, à Jérusalem en 1857. La série sur la Terre sainte produite à ce moment-là par «Robertson \& Beato » comprend quelques vues d'Égypte. Le fait que certaines épreuves soient signées « Robertson, Beato \& Co.» (ou, en français, « et Cie ») laisse supposer qu'Antonio a pu être associé à cette production.

11 Il accompagna ensuite son frère en Asie, en tout cas jusqu'en Inde, puisqu'il possédait un atelier à Calcutta en 1859. Mais, pour des raisons mal connues (mauvaise santé ? échec commercial ? brouille entre les deux frères dont les chemins se séparèrent alors, et semble-t-il définitivement ?), l'expérience indienne tourna court. Dès le tout début des années 1860, il était établi au Caire, « rue de Muski ». S'il garda quelques années une adresse dans la capitale, c'est à Louxor qu'il s'installa définitivement vers 1864. Il y jouissait d'un quasi-monopole sur la vente de photographies aux premiers touristes de la vallée du Nil, et y resta jusqu'à sa mort. Dans sa carrière professionnelle, il utilisa systématiquement la forme francisée de son prénom, "Antoine». Sa production est donc exclusivement égyptienne, constituée pour l'essentiel de paysages, de vues de monuments et de types égyptiens, pour une clientèle touristique : les vues de la vallée du Nil et des monuments pharaoniques de Haute-Égypte sont très nettement majoritaires. Elle compte plusieurs milliers de vues et a été abondamment diffusée. Par sa masse même, elle n'échappe pas à une certaine monotonie; certains critiques distinguent qualitativement les premières œuvres, au début des années 1860, de la production ultérieure, plus stéréotypée. Néanmoins, l'implantation singulière de Beato en Haute-Égypte, la qualité de son regard sur les ruines et l'architecture font de lui le meilleur continuateur, à l'âge de la photographie commerciale, des photographes « archéologues» des décennies précédentes (Greene, Deveria, Teynard...). Il est significatif que le fonds de négatifs, riche de quelque 1500 plaques, ait été acquis par Maspéro en 1907, auprès de la veuve de Beato, pour le musée des Antiquités égyptiennes du Caire. 
1. Antonio Beato, [Le Caire, nécropole nord, complexe funéraire du sultan Barsbay], vers 1860, tirage sur papier albuminé d'après un négatif sur verre au collodion.

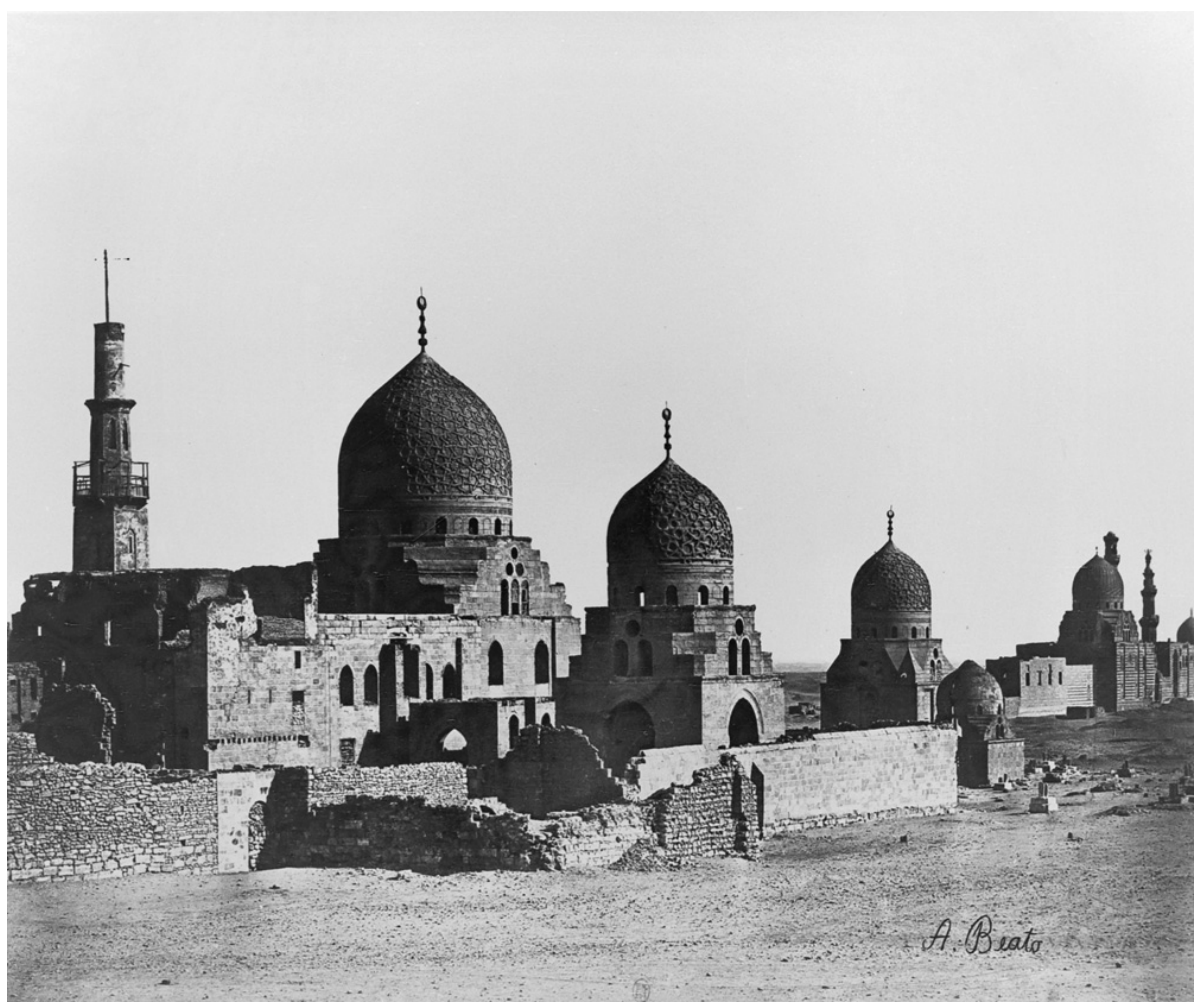

Source : Paris (France), Bibliothèque nationale de France, département des Estampes et de la Photographie.

\section{Émile et Hippolyte Béchard (actifs entre 1870 et ca. 1880)}

Si l'œuvre de la maison Béchard a connu une assez large diffusion, l'absence à peu près totale d'informations biographiques a nourri de nombreuses interrogations sur l'identité même de ces photographes. Le nom d'Émile Béchard, photographe possédant un atelier de portraits dans le quartier de l'Azbakiyya dans les années 1870, est bien attesté : il apparaît au dos de cartes de visite, souvent associé à celui d'Hippolyte Délié, et dans la préface de Palmieri à L'Égypte et la Nubie. Mais l'existence, sur certaines photographies, d'une signature «H. Béchard » (à côté de "Béchard » et «E. Béchard ») a conduit certains historiens à poser l'existence d'un «Henri Béchard». Sa relation familiale avec Émile restait à établir puisqu'aucune trace biographique n'avait été trouvée, laissant d'autres auteurs supposer qu'Émile et « Henri » ne faisaient qu'un. Des documents récemment mis au jour dans les archives du tribunal consulaire du Caire ${ }^{1}$ ont révélé qu'il y avait bien deux frères Béchard: Émile (né le 25 décembre 1844 aux Salles-du-Gardon, dans le Gard), installé en Égypte, et Hippolyte (né dans la même commune le 17 avril 1841).

Hippolyte, demeuré à La Grand-Combe (Gard), s'occupait du tirage et de la diffusion en Europe des photographies de son frère Émile, y compris après le départ d'Égypte de ce dernier, en 1880. Émile s'installa alors à Hyères, puis à Marseille. L'implication étroite d'Hippolyte dans la production de son frère (peut-être conservait-il les négatifs) 
pourrait expliquer qu'il ait fini par signer les photographies de sa propre initiale ; mais rien ne permet de penser qu'il ait lui-même travaillé en Orient.

Trois grands ensembles peuvent être distingués dans l'œuvre de Béchard :

- les 40 planches réalisées avec Délié pour le monumental Album du musée de Boulaq d'Auguste Mariette, publié au Caire en 1872 ;

- une remarquable série de types égyptiens et de scènes de genre, où, dans le décor naturel des vieilles rues du Caire, des Égyptiens prennent la pose de leurs activités quotidiennes, de manière souvent un peu figée mais avec un sens certain de la composition;

- enfin des vues d'Égypte, que l'on retrouve sous forme de phototypies inversées dans L'Égypte et la Nubie, grand album monumental, historique, architectural publié à Paris, par Béchard et Palmieri, en 1887 ; on y compte en particulier 37 vues des monuments du Caire.

Béchard produisit également en 1874 un rare album sur les nouvelles constructions du Caire sous le règne d'Isma'il Pacha. Si l'Égypte de Béchard n'est pas exempte des clichés de la production commerciale qui devait connaître son plein essor dans les décennies suivantes, son œuvre se distingue néanmoins par sa relative cohérence, une remarquable qualité technique et artistique, un sens classique mais indéniable de la composition, aussi bien dans la scène de genre que dans le paysage ou la vue d'architecture.

\section{2. Émile BÉCHARD, Mosquée de Touloum [Ibn Tulun], vue intérieure.}

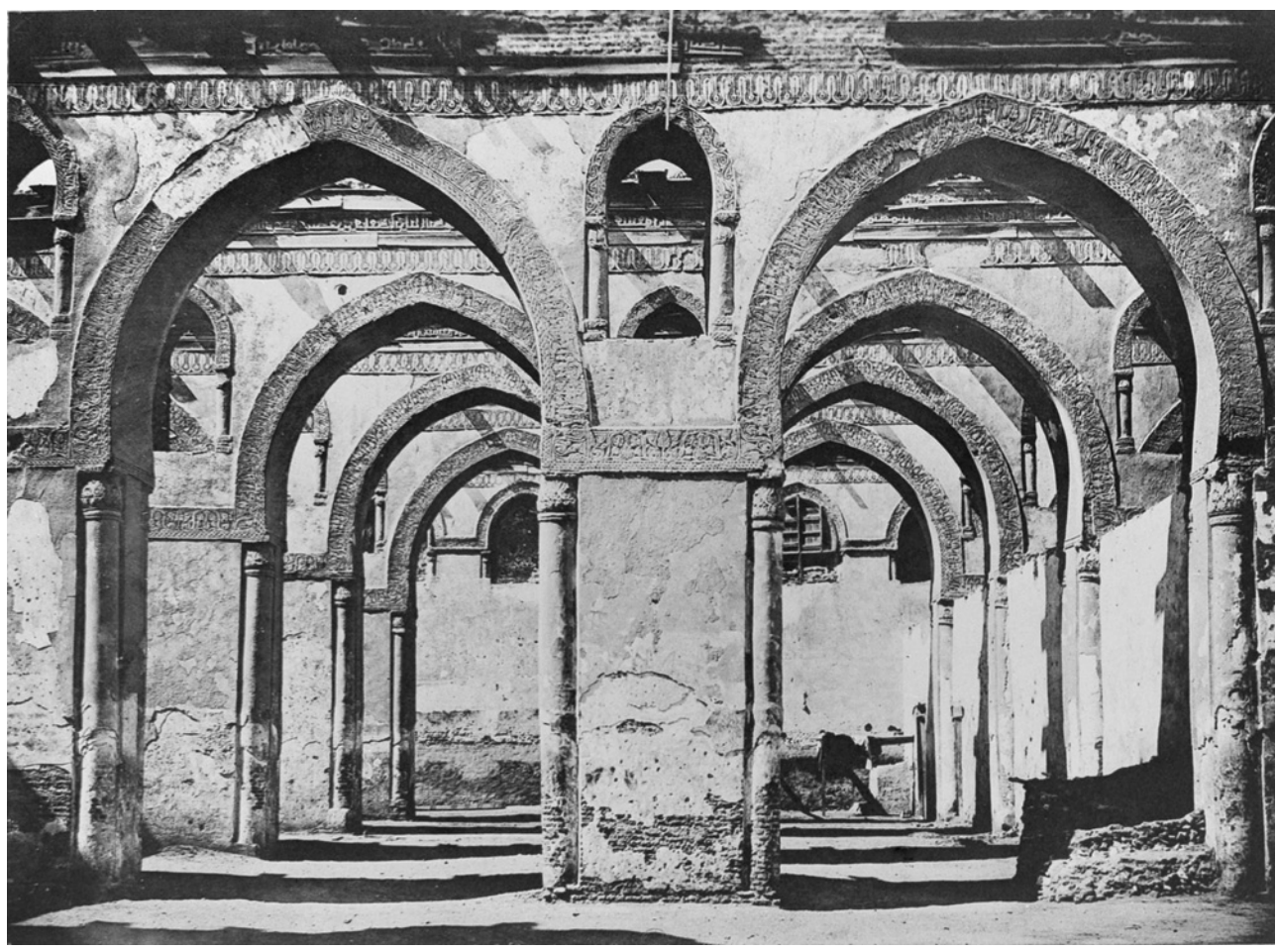

Source: Phototypie extraite de L'Égypte et la Nubie, grand album monumental, historique, architectural. Paris : É. Béchard et A. Palmieri, 1887.

\section{Maison Bonfils (1867-1932)}

16 La maison Bonfils, entreprise familiale installée à Beyrouth, tient une place éminente parmi les photographes commerciaux du Proche-Orient, tant par sa longévité que par 
sa couverture géographique. Les photographies de Bonfils ont connu une abondante diffusion et sont massivement présentes dans les collections publiques et privées ou les ventes. Il est rare qu'un album de "Souvenirs d'Égypte » ou de "Voyage en Terre Sainte » des années 1870 aux années 1910 ne comporte pas de vues signées Bonfils.

Le fondateur est Félix Bonfils (1831-1885), originaire d'Alès, imprimeur et relieur de profession, qui aurait été initié à la photographie par Niepce de Saint-Victor. Son épouse, Marie-Lydie Cabanis (1837-1918) qui avait emmené leur fils Adrien (1861-1929) en voyage de santé au Liban, aurait été séduite par le pays. Elle aurait convaincu son époux de s'y installer comme photographe, activité qu'il pratiquait à Alès depuis 1864 au moins. Telle est du moins la version recueillie dans la mémoire familiale. Selon une autre version, non exclusive de la première, c'est Félix qui aurait découvert le Liban lors de son service militaire. Toujours est-il que la famille Bonfils s'installa en 1867 à Beyrouth, et se mit à produire des photographies dans les domaines habituels de ce genre de maison: portraits de particuliers, vues de paysages et d'architectures, ainsi que des types orientaux à destination des touristes.

La chronologie de leur production, aussi bien que l'identité des photographes qui y ont contribué, sont à peu près impossibles à établir avec précision. Si les rares vues signées «F. Bonfils » semblent dater des premières années d'activité, il est très probable que Félix n'a jamais été l'unique photographe actif: sa femme, puis son fils, ont très certainement pris une part importante dans la production, surtout à partir de 1877, date approximative du retour de Félix en France, dans sa ville d'Alès, d'où il entreprit de diffuser ses vues d'Orient. En témoigne la prestigieuse série de cinq albums intitulés Souvenirs d'Orient: album pittoresque des sites, villes et ruines les plus remarquables [de l'Égypte, de la Nubie, de la Palestine, de la Syrie, d'Athènes et de Constantinople], publiés à Alès en 1877-1878, dans lesquels les tirages albuminés soignés sont accompagnés de notices trilingues (français, anglais, allemand; les vues du Caire sont rassemblées au début du tome 1). Cette publication, au destin éditorial malheureusement avorté, rassemble le meilleur de la production Bonfils «première période ", dont un catalogue du début de 1876 établit la quantité à 99 études de types et 550 vues de sites (dont 39 du Caire; le catalogue de 1901 en compte 301), commercialisées en tirages ou en vues stéréoscopiques.

Outre les trois membres de la famille, plusieurs assistants vinrent rejoindre l'entreprise, dont Henri Rombau, Georges Saboungi et Abraham Guiragossian (1872 ?-1955). Ce dernier racheta en 1909 le fonds à Lydie (Adrien s'était reconverti dans l'hôtellerie dès 1894), mais continua d'utiliser la marque Bonfils jusqu'aux années 1930. Il est donc à peu près impossible d'isoler des "mains » distinctes dans cette production considérable. Ajoutons que certains clichés des premières années furent probablement rachetés à Tancrède Dumas, et que plusieurs images de Bonfils furent diffusées en photochromie par la firme Photoglob de Zurich, sous la signature P. Z., à partir de 1888. Il s'agit donc d'une production inévitablement inégale, et peut-être plus marquante pour les sites syro-libanais (Palmyre, Baalbek), mais centrale dans l'histoire de la photographie orientaliste. 


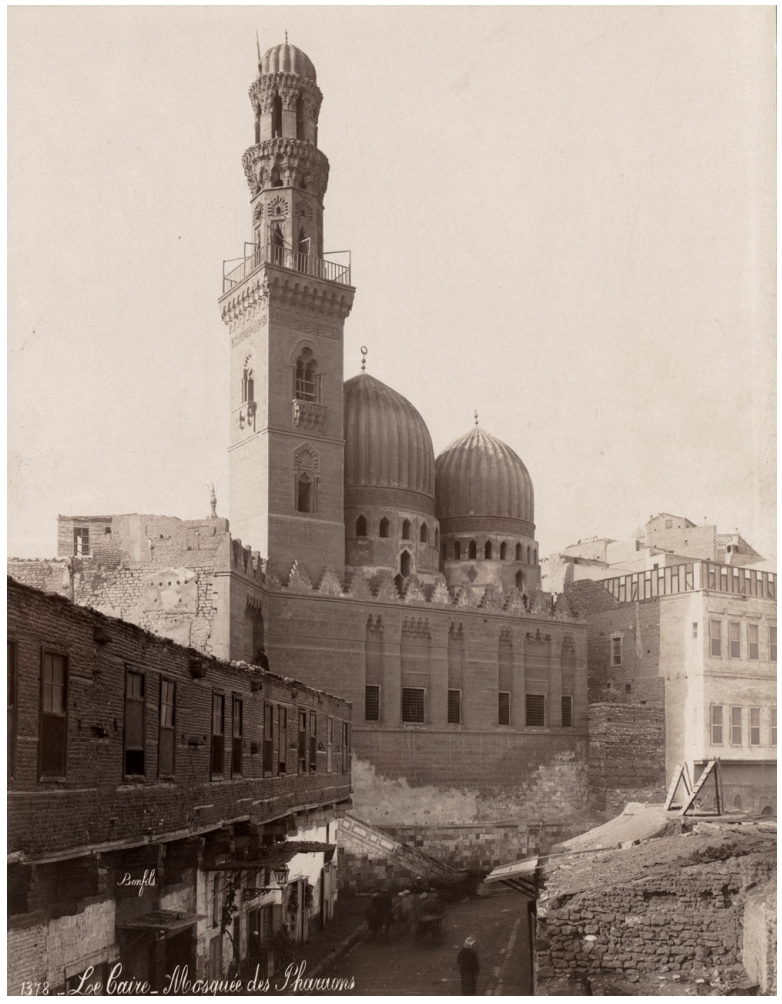

Source : Washington DC (États-Unis), Library of Congress.

\section{G. Lekegian (actif entre 1887 et 1925 environ)}

Comme Zangaki, avec lequel sa production présente de fortes similarités, Lekegian est très représentatif de la seconde génération de photographes commerciaux en Égypte. Ses dates biographiques sont encore inconnues. On a toutefois récemment retrouvé la trace de ses débuts artistiques à Constantinople, où il présenta des aquarelles au salon des jeunes artistes arméniens de Péra en 1882, ce qui laisse supposer une date de naissance aux alentours de $1855-1860^{2}$. Ces œuvres, des types pittoresques campés dans le décor de la rue stambouliote, font preuve d'un réalisme qui pourrait trahir des sources photographiques. Quoi qu'il en soit, entre 1887 et 1892, c'est bien comme photographe que Lekegian s'installa au Caire, dans le quartier de l'Azbakiyya. L'existence de son atelier est attestée jusqu'en 1925, et sa production a connu un large succès auprès des touristes. Lekegian recherchait la reconnaissance officielle et les récompenses : médailles dans des expositions internationales, titres (au contenu flou) de "photographe officiel de l'armée britannique d'occupation », puis du khédive...

21 Pour autant qu'il soit possible de définir un trait distinctif de sa production par rapport à celle de ses confrères et concurrents, comme Zangaki (avec lequel il semble d'ailleurs avoir échangé des négatifs) ou Jean Pascal Sebah, il pourrait être classé dans la catégorie "artistique » héritée de sa formation de peintre. En effet, il se prévalait de cette qualité sur une de ses signatures les plus répandues : «Phot[ographie] Art[istique] G. Lekegian \& Co ». Ses types égyptiens comme ses vues et détails d'architecture égyptienne, antique et médiévale, ont un caractère plus soigné, plus composé, plus 
«pictural » en somme que la moyenne. Elles connurent un succès certain auprès de plusieurs peintres orientalistes qui les transposèrent dans leurs tableaux.

4. G. LEKEGIAN, Rue Bab-el Chahrieh [Bab al-Sha'riyya], vers 1890-1900, tirage sur papier albuminé d'après un négatif sur verre au gélatinobromure d'argent.

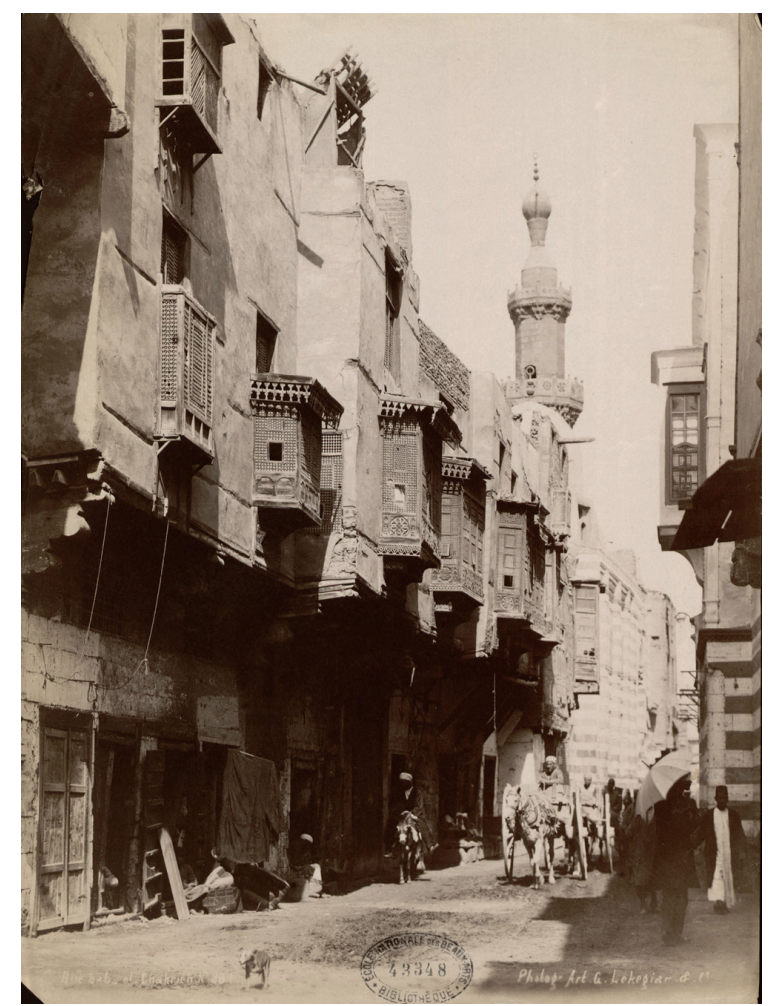

Source : Paris (France), bibliothèque de l'INHA, collections Jacques Doucet.

\section{Pascal Sebah ; Sebah et Joaillier ; Jean Pascal Sebah}

La maison Sebah est l'un des principaux ateliers photographiques stambouliotes. Son activité, à travers les successions, fusions et associations, s'étend sur près d'un siècle, puisque la marque ne disparut qu'en 1952. Le fondateur, Pascal Sebah (1823-1886), chrétien d'origine syrienne par son père et arménienne par sa mère, créa son premier atelier de photographie en 1857 à Constantinople. Dès 1860 il s'installa dans l'artère principale du quartier moderne, la Grande Rue de Péra, et s'associa avec un photographe français, Antoine Laroche. Sa production couvre tous les genres (portraits, types et scènes de genre, paysages et architecture) et se décline en divers formats, $y$ compris la stéréoscopie.

Le titre de photographe officiel de la cour était déjà détenu par la maison Abdullah Frères, avec laquelle Sebah entretint une complexe relation d'association et de rivalité avant d'en racheter le fonds en 1899 ou 1900. Pascal Sebah alla donc chercher la reconnaissance en Europe, et en particulier en France. À partir de 1859, il participa très régulièrement aux expositions parisiennes, recevant plusieurs récompenses de la Société française de photographie. En 1873, il présenta à l'Exposition universelle de Vienne un ouvrage prestigieux réalisé en collaboration avec le peintre Osman Hamdi Bey, Les Costumes populaires de la Turquie. 
24 C'est cette même année que Sebah ouvrit une succursale au Caire, "sur l'Esbekieh » [Azbakiyya], destinée à la fois à la production de portraits pour la clientèle locale et à la photographie pour touristes. La plus grande partie de ses vues d'Égypte datent vraisemblablement des années 1873-1880 ; un catalogue de 1875 en dénombre 117. Les monuments islamiques du Caire y tiennent une place importante : Sebah faisait preuve des mêmes qualités qui distinguent ses meilleures vues de Constantinople ou d'Athènes, que ce soient d'amples panoramas (les nécropoles mameloukes), ou, au contraire, des vues intérieures ou très rapprochées restituant la majesté écrasante d'un édifice (madrasa de sultan Hasan).

Laroche quitta l'entreprise vers 1877 pour s'installer sous son nom au Caire, en association avec Heyman. En 1883, Pascal Sebah fut frappé par une attaque cérébrale, et mourut trois ans plus tard. La succession fut d'abord assurée par son frère Cosmi, qui produisit une série sur Le Caire puis, dès 1888, par son jeune fils Jean, qui signa Jean Pascal (1872-1947). Jean Pascal Sebah, encore très jeune, s'associa au Français Polycarpe Joaillier ; l'abondante production «Sebah \& Joaillier » puis «J. P. Sebah », qui compte une nouvelle série sur l'Égypte, connut un succès considérable jusqu'en 1905, date approximative du départ de Joaillier et de la fermeture de la succursale du Caire ${ }^{3}$.

Comme dans toutes ces entreprises associant les différents membres d'une même famille et des assistants, il est extrêmement délicat de distinguer l'auteur individuel d'une photographie, même si des différences de style et de qualité apparaissent clairement. À cette incertitude s'ajoute le fait que parfois les photographes, bien que concurrents, s'achetaient mutuellement des négatifs pour compléter leurs catalogues. Ainsi la maison Sebah a-t-elle publié sous sa signature des images de Béchard ou d'Abdullah, comme Bonfils l'avait fait avec Tancrède Dumas. 
5. Jean Pascal SEBAH, Tombeau du Sultan Barkouk [khanqah Farag ibn Barquq] (coupole), vers 1890-1900, tirage sur papier albuminé d'après un négatif sur verre au gélatinobromure d'argent.

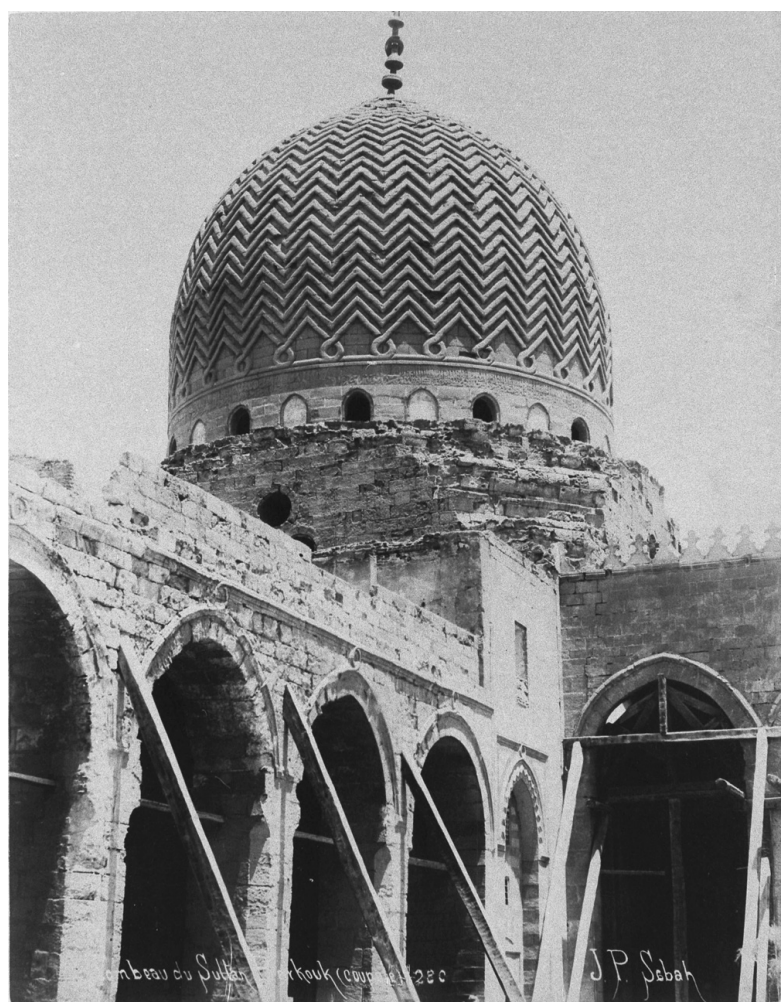

Source : Paris (France), Bibliothèque nationale de France, département des Estampes et de la Photographie.

\section{Georges et Constantin Zangaki (ca. 1880-1915)}

Cet atelier à la production abondante et largement diffusée reste encore faiblement documenté ; toutefois quelques éléments biographiques ont récemment émergé. Les Zangaki étaient deux frères grecs, prénommés Georges et Constantin, originaires de l'île de Milos. Ils s'installèrent à Port-Saïd à une date mal déterminée, mais sans doute assez tardive (vers 1880), peut-être en association ou collaboration avec Hippolyte Arnoux, présent dans la ville depuis les années de construction du canal de Suez. Ils fondèrent rapidement un atelier autonome sous la raison sociale « Zangaki Frères ». Les photographies étaient le plus souvent signées d'une simple mention "Zangaki », très rarement accompagnée des initiales C. ou G., ou du grec « Adelphoi ». Ils ouvrirent dans les années 1890 une succursale au Caire, dont l'existence est encore attestée en 1915. Le rôle respectif de chacun des deux frères dans cette association est impossible à déterminer.

Comme chez la plupart des ateliers concurrents, le catalogue des Zangaki comprend des vues de toute la Méditerranée orientale, ainsi que de l'Algérie, mais l'Égypte domine très largement. La qualité technique et artistique de leur œuvre est très inégale : tirages parfois médiocres, paysages et vues d'architectures souvent banals ou maladroits... Particulièrement abondants, les types orientaux, portraits de groupe et scènes de mœurs illustrent assez bien une certaine décadence de la photographie orientaliste, et son hésitation constante entre exotisme et regard ethnographique. La tendance au 
cliché est certes quasi inhérente au genre, mais là où un Béchard ou un Bonfils savaient racheter l'artificialité du genre par un certain hiératisme, un sens de la composition, du cadre et de la lumière, les prises de vues en atelier des Zangaki relèvent souvent d'une production de masse peu soignée, que les références picturales ne viennent plus inspirer que de très loin: recours à une médiocre toile peinte pour tout décor, éclairages plats, pauses figées et inexpressives trahissant la mise en scène hâtive de figurants peu concernés...

Plus intéressantes et plus caractéristiques, sont les scènes prises en plein air, sur le vif, dans les campagnes égyptiennes et les rues du Caire, qui dans les meilleurs des cas revêtent une spontanéité proche de l'instantané - probablement une conséquence de la technique du négatif au gélatinobromure d'argent, qui s'impose à partir des années 1880.

\section{Autres photographes}

De nombreux autres ateliers ont travaillé en Égypte dans le dernier tiers du XIX siècle et ont ainsi pu occasionnellement produire, ou vendre, des vues du Caire, même si les paysages urbains et vues d'architecture n'occupent qu'une place marginale dans leur production. On peut citer les noms suivants.

\section{Hippolyte Arnoux (dates inconnues)}

31 Ce Français est l'un des premiers photographes installés de manière permanente en Égypte. Il s'établit vers 1865 à Port-Saïd, qui resta son implantation principale jusqu'à la fin des années 1890; une éphémère adresse alexandrine apparut dans les années 1867-1868. Son grand œuvre est la couverture photographique de la construction du canal de Suez, ensemble documentaire de premier ordre et largement diffusé. Le canal, une fois ouvert, continua d'assurer la prospérité d'Arnoux, puisqu'il pouvait profiter de la clientèle des paquebots en route vers l'Asie qui, souvent, ne touchait l'Égypte qu'à l'escale de Port-Saïd. Il possédait, sous l'enseigne "Photographie du Canal», deux ateliers, installés respectivement sur la place principale de la ville et sur un bateau à l'ancre dans le port. Outre les vues du canal, la production qu'il diffusa est surtout constituée de "Types et costume égyptiens", mais on trouve aussi de nombreux paysages et vues de monuments antiques ou médiévaux, dont la paternité reste incertaine : Arnoux avait semble-t-il abondamment pratiqué l'échange de clichés avec d'autres photographes, comme Rombau ou Beato, afin d'étoffer son catalogue. Il fut également associé, dans des conditions mal définies, avec les Grecs Zangaki et Peridis.

\section{Hippolyte Délié}

Ce photographe français installé au Caire dès la fin des années 1860 est surtout connu comme associé d'Émile Béchard, avec lequel il produisit de nombreuses cartes de visite de types égyptiens, et surtout, en 1872, l'Album du Musée de Boulaq. Sa production sous son nom seul ne nous est parvenue que de manière très lacunaire. 


\section{Désiré Ernié}

33 et son prénom en guise de marque commerciale («E. Désiré»), ainsi qu'une lecture erronée («Ermé » pour « Ernié ») ont longtemps nui à son identification correcte. Son installation au Caire fut précoce (1864 ou 1865); il y resta jusqu'aux années 1880 . Il présenta des vues d'Égypte à l'exposition universelle de Paris, en 1867. Son œuvre, encore mal connue, semble se distinguer par un certain naturalisme (série sur les boutiques et les petits métiers dont l'esthétique, en rupture avec la mise en scène orientaliste, tend vers le reportage) et par une place important accordée à la représentation du Caire moderne (peut-être sur commande du khédive).

\section{Fiorillo}

Cette maison familiale, probablement d'origine italienne, fut active à Alexandrie à partir du début des années 1870. Pendant une certaine période, le nom de Fiorillo fut associé à un certain Marquis. Leur production considérable couvre une grande partie du bassin méditerranéen, de l'Algérie au Liban, et jusqu'à des contrées beaucoup plus rarement représentées comme la Nubie ou les villes saintes d'Arabie.

\section{BIBLIOGRAPHIE}

L'Année de l'Arménie à Toulon, catalogue d'exposition (Toulon, Musée des arts asiatiques, 23 mars-10 juin 2007), Toulon : Musée des arts asiatiques, 2007.

POUILLoN François (dir.), Dictionnaire des Orientalistes de langue française, Paris : IISMM ; Karthala, 2008.

L'Orient des photographes arméniens, catalogue d'exposition (Paris, Institut du monde arabe, 20 février-1 ${ }^{\mathrm{er}}$ avril 2007), Paris : Institut du monde arabe ; Cercle d'art, 2007.

Oxford dictionary of national biography, Oxford ; New-York, NY : Oxford University Press, 2004 AUBENAS Sylvie, LACARRIÈRE Jacques, Voyage en Orient, Paris : Bibliothèque nationale de France ; Hazan, 1999.

ÇIZGEN Engin, Photography in the Ottoman Empire, 1839-1919, Beyoğlu-Istanbul : Haşet Kitabevi A. ş., 1987.

DEBBAS Fouad C., Des Photographes à Beyrouth. 1840-1918, Paris : Marval, 2001 (Collection passion).

GAVIN Carney E. S., « Bonfils and the Early Photography of the Near East », Harvard Library Bulletin, vol. $26, \mathrm{n}^{\circ} 4,1978$, p. $442-470$.

GAVIN Carney E. S., The Image of the East. Nineteenth-Century near Eastern Photographs by Bonfils from the Collections of the Harvard Semitic Museum, Chicago, IL ; Londres : The University of Chicago Press, 1982. 
El-HAGE Badr, Des Photographes à Damas, 1840-1918, Paris : Marval, 2000 (Collection Passion).

JACOBSON Ken, Odalisques and Arabesques : Orientalist Photography, 1839-1925, Londres : Bernard Quaritch, 2007, 308 p.

OSMAN Colin, « Antonio Beato, Photographer of the Nile », History of Photography, vol. 14, n², 1990, p. 101-111.

ÖZENDES Engin, Abdullah Frères, Ottoman Court Photographers, Istanbul : Yap1 Kredi, 1998, 247 p.

ÖZENDES Engin, From Sébah \& Joaillier to Foto Sabah. Orientalism in Photography, Istanbul : YKY, 1999, $273 \mathrm{p}$.

ÖZTUNCAY Bahattin, The Photographers of Constantinople : pioneers, studios and artists from $19^{\text {th }}$ century Istanbul. Istanbul : Aygaz, 2003.

PEREZ Nissan N., Focus East : early photography in the Near East, 1839-1885, New York, NY : Harry N. Abram's ; Jerusalem : Domino Press ; Israel Museum, 1988.

THOMAS Ritchie, « Bonfils \& Son, Egypt, Greece and the Levant ; 1867-1894 », History of Photography, vol. 3, n 1, 1979, p. 33-46.

WOODWARD Michelle L., « Between Orientalist Clichés and Images of Modernization. Photographic Practice in the Late Ottoman Era », History of Photography, vol. 27, n 4, 2003, p. 363-374.

ZANNIER Italo (dir.), L'Egitto del Grand Tour nella fotografia degli Zangaki, Milan : Motta/CRAF, 1999.

\section{NOTES}

1. Le mérite de ces découvertes revient à Mercedes Volait, ainsi qu'à Marc Durand, des Archives nationales. Je les remercie vivement, ainsi que Maryse Bideault, pour me les avoir transmises.

2. Je remercie Béatrice Krikorian, de la bibliothèque des Arts décoratifs, pour m’avoir signalé ces informations.

3. B. Öztunçay considère, mais sans étayer son propos, que cette série ne peut être l'œuvre du jeune Sebah, et ne serait constituée que de clichés rachetés à d'autres photographes comme Béchard, Zangaki et Lekegian. Il situe également en 1895 la fermeture du studio cairote.

\section{AUTEUR}

\section{THOMAS CAZENTRE}

Conservateur au département des Estampes et de la Photographie de la Bibliothèque nationale de France, Paris, en charge de la photographe du XIX ${ }^{\mathrm{e}}$ siècle. 
Théories et histoires de l'art islamique 


\title{
Astrées polygonales, galérites pyramidales, sycomores « arrondis comme des dômes ", palmiers "élancés comme des minarets »: Le Caire d'Adalbert de Beaumont
}

\author{
Chantal Bouchon
}

\section{NOTE DE L'ÉDITEUR}

Sauf mention contraire, toutes les œuvres reproduites sont d'Adalbert de Beaumont.

«Bien souvent je suis venu me reposer sur quelque terrasse, au sommet de quelque minaret, pour chercher à comprendre le plan de cette

curieuse ville, qui compte 412 mosquées et tombeaux, 500 minarets, 300 citernes, 60 bains, 34 fontaines, 140 écoles publiques, 11 ou 12 bazars,

1,265 okels ou caravansérais [sic], 71 portes principales, sans parler de celles qui ferment à chaque instant les petites rues, et 1,170 cafés. »

Cette énumération étrange qu'Adolphe Joanne, dans son Voyage en Égypte et en Grèce ${ }^{1}$, cite comme étant d'Adalbert de Beaumont, et qui n'est pas sans rappeler le recensement, toutefois différent, établi par Edme-François Jomard dans la Description abrégée de la ville et de la citadelle du Kaire ${ }^{2}$ (publiée entre 1809 et 1822), ne saurait résumer la perception que le littérateur voyageur avait de la ville du Caire. Car cet " homme qui possédait à merveille les lois de la couleur et du décor pour les avoir étudiées en Orient avec beaucoup de sagacité et de finesse... ${ }^{3}$, séduit par les capitales de l'Empire ottoman, a laissé de ses séjours prolongés dans cette ville des témoignages 
qui ont été autant de jalons utiles à l'élaboration d'une œuvre de pionnier dans l'approche des arts industriels renouvelés par les arts de l'Orient.

2 Né à Paris le 19 mai 1809 d'une famille noble d'ancienne extraction originaire de Touraine, le vicomte Adalbert Marc Bonnin de La Bonninière de Beaumont (fig. 1), fils du général, pair de France, comte de l'Empire, Marc-Antoine de Beaumont (1763-1830), et neveu, du côté maternel, du maréchal Louis Nicolas d'Avout, dit Davout, prince d'Eckmühl (1770-1823), était un homme issu d'un milieu aisé lié à la société du faubourg Saint-Germain ${ }^{4}$, aisance qui, venant s'ajouter à une érudition et à une curiosité certaines, le poussa à entreprendre des voyages. Les appréciations portées sur l'homme Adalbert de Beaumont tout au long de sa vie furent plus que favorables : " un homme d'esprit, qui a vu beaucoup de choses, et avec des yeux d'observateur... » (l'historien chartiste et archéologue Jules Quicherat en $1853^{5}$ ), « fort aimable et convenable en tous points, et bon appréciateur de toutes choses » (Eugène Delacroix en 18556).

3 Après un premier grand périple jusqu'au cap Nord en 1836 dont il rapporta un récit de voyage, des aquarelles figurant paysages et scènes locales, et dont il tira ses premières observations sur les phénomènes de cristallisation, de la neige en l'occurrence, observations dont il se resservit à propos de l'architecture orientale, mais les adaptant à l'environnement en évoquant le sel et certaines concrétions minérales, il se rendit à plusieurs reprises, entre 1834 et 1854, dans le bassin méditerranéen, notamment à Venise, et dans l'Empire ottoman, en Égypte et en Turquie actuelle, d'Istanbul à Brousse et à Trébizonde.

4 C'est en 1843-1844 qu'il séjourna en Égypte, les dates et légendes portées sur les œuvres graphiques rapportées en témoignent ${ }^{7}$. Une fois rentré de ses périples méditerranéens, avec des portefeuilles remplis de dessins, d'aquarelles - n'écrivait-il pas en 1866 - :

« Depuis quelque temps déjà, nous étions occupés du matin au soir à dessiner les minarets, les coupoles des mosquées et des tombeaux, les grilles, les fenêtres sculptées à jour, les broderies d'arabesques, qui donnent aux monuments du Caire un aspect si caractéristique ${ }^{8}$.

5 A. de Beaumont entreprit une carrière nouvelle dont les multiples facettes furent nourries de ces expériences vécues et images rapportées. 


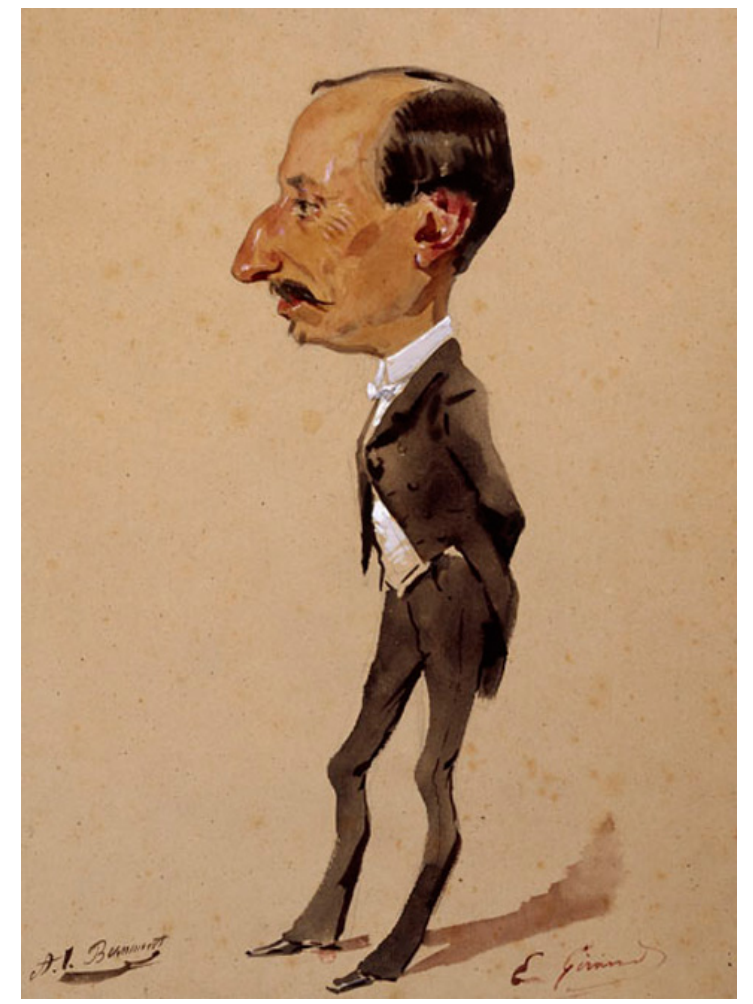

Source : Paris (France), Bibliothèque nationale de France, département des Estampes et de la Photographie.

\section{Au Caire}

\section{Le séjour d'Adalbert de Beaumont}

6 Le voyage qu'entreprend Adalbert de Beaumont en 1843 n'était lié à aucune mission particulière et n'obéissait pas non plus à l'itinéraire traditionnellement défini par le Grand Tour'. Il n'est pas impossible que l'attrait pour l'Égypte ait eu un lien avec la légende auréolant son oncle maternel, le maréchal Davout, qui avait accompagné Bonaparte sur la terre des pharaons. Dans sa découverte de l'Égypte, Adalbert de Beaumont était l'exact contemporain du daguerréotypiste Joseph-Philibert Girault de Prangey qui, entre 1842 et 1844, accomplit un grand voyage photographique autour du bassin méditerranéen, sur les traces de Chateaubriand, aventure artistique et scientifique dont il rapporta près d'un millier de daguerréotypes, des croquis et des aquarelles $^{10}$. Les plaques constituaient une sorte de «bloc-notes photographique » servant d'esquisse pour les lithographies de ses ouvrages sur l'art islamique, entre autres Monuments arabes d'Égypte, de Syrie et d'Asie-Mineure dessinés et mesurés de 1842 à 1845 (Paris, 1846) dans lequel il poursuivait son entreprise de classification des styles et de compréhension des filiations artistiques, et Monuments et Paysages de l'Orient, recueil de chromolithographies (Paris, 1851). Les relations nouées entre Adalbert de Beaumont et Joseph-Philibert Girault de Prangey étaient d'ailleurs établies en France, mais il est tout à fait vraisemblable que des premiers contacts aient été pris au Caire. Beaumont était aussi le contemporain, en Égypte, d'Auguste Gabriel Toudouze (1811-1854), architecte-voyer, dessinateur et graveur, qui fut chargé de missions archéologiques par 
le roi Louis-Philippe de 1831 à 1840 et qui rapporta de ses voyages en Italie et au Moyen-Orient des milliers de dessins où son intérêt pour l'ornement tient une place importante. Il était tout autant le contemporain au Caire de Gérard de Nerval qui y séjourna de début février à début mai 1843 et en laissa un récit où l'histoire personnelle et l'histoire collective s'entremêlent et se fondent ${ }^{11}$.

7 Nous ne savons qu'assez peu de chose du (ou des?) séjour d'Adalbert de Beaumont au Caire. Ils ne sont en effet documentés que par les quelques dessins et aquarelles identifiés et par les publications à l'illustration desquelles ces œuvres graphiques ont parfois servi. Quantitativement, le nombre d'œuvres graphiques connues de la main d'Adalbert de Beaumont, ou supposées telles, relatives à ses séjours en Égypte, est bien inférieur à celui des œuvres liées à la Turquie ottomane. Faut-il tirer de cette constatation qu'Adalbert de Beaumont a séjourné plus longuement en terre ottomane? Que le hasard a fait que davantage d'aquarelles et de dessins illustrant ce séjour nous soient parvenus? Que l'art persan, un style dont le sens chez A. de Beaumont est à considérer avec circonspection, l'a davantage séduit que l'art arabe, cairote en l'occurrence - on ne peut que relever dans ses écrits l'opposition qu'il perçoit entre

«les arabesques qui empruntent aux plantes grimpantes à feuilles et à fleurs régulières et symétriques les enroulements, les rinceaux, entremêlés quelquefois d'animaux aux formes bizarres, mais toujours soumis aux lois des courbes ; ce sont les arabesques fleuries...» et "l'autre genre d'arabesques, que nous nommerons l'arabesque géométrique, [qui] se compose de lignes qui affectent les plus savantes combinaisons, et forment des entrelacs dont la condition première est qu'aucun des traits qui les constituent ne s'interrompe ni ne s'arrête jamais ${ }^{12}$.»

8 Aucun récit de voyage, aucun journal ou correspondance assidue n'ont été retrouvés à ce jour. Certaines observations publiées par Adalbert de Beaumont dans la Revue des Deux Mondes en 1866 aident à comprendre une des interprétations les plus curieuses qui ait été donnée de l'architecture islamique :

«Un jour au Caire, un de ces beaux jours de janvier tout imprégné du parfum des mimosas et des jasmins en fleur, un naturaliste français ${ }^{13}$ dont nous avions fait la connaissance au bazar, nous montra chez lui la collection de coquillages et de madrépores qu'il venait de rapporter des bords de la mer Rouge. Depuis quelque temps déjà, nous étions occupé du matin au soir à dessiner les minarets, les coupoles des mosquées et des tombeaux, les grilles, les fenêtres sculptées à jour, les broderies d'arabesques, qui donnent aux monuments du Caire un aspect si caractéristique. Nous avions l'esprit tout rempli des formes et des motifs du style oriental. Le premier objet qui nous tomba sous les yeux fut une astrée polygonale en forme de colonne, exactement semblable au minaret d'Ibrahim-Agha dont une heure avant nous avions pris le dessin... Nos investigations se firent avec d'autant plus d'intérêt qu'à chaque instant une découverte nouvelle corroborait la première, et que nous trouvions entre les formes ou les dessins des coquillages d'un côté, les ornements [sic] ou les profils des minarets, des arcs et des coupoles de l'autre, des analogies de plus en plus nombreuses. L'astrée qui tomba d'abord sous nos regards et le fût du minaret d'Ibrahim-Agha sont tous deux décorés de polygones rayonnants $[\text { sic }]^{14}$.» (fig. 2). 


\section{2. « Minaret d'Ibrahim-Agha comparé à l'astrée polygonale [madrépore].}

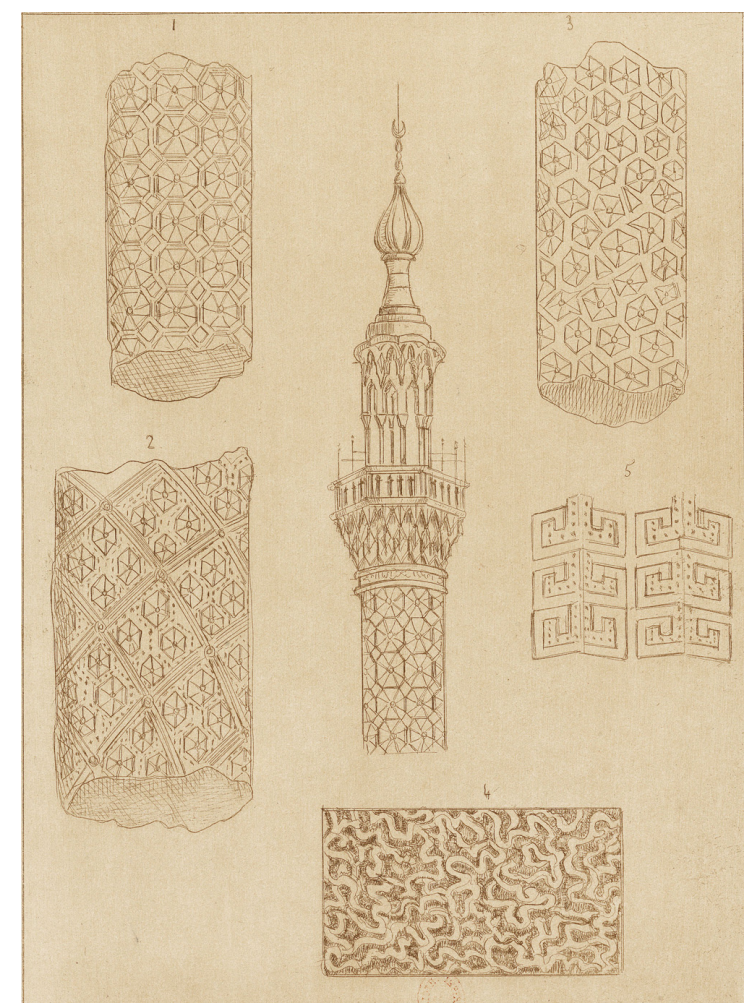

Source : Recueil de dessins pour l'art et l'industrie, 1859, pl. 192. Paris (France), Bibliothèque nationale de France, département des Estampes et de la Photographie.

Le dessinateur aurait pu ajouter à sa démonstration d'autres minarets cairotes, dont les fûts présentent tous une ornementation, à chaque fois différente, qui pourrait elleaussi être assimilée aux structures que les «zoophytes..., oursins échinodermes, ces madrépores, ces astrées ont... appris à l'école de la nature, la grande maîtresse ${ }^{15}$ ». Ou encore, évoquant d'autres structures architectoniques :

«Le dessin d'une galérite pyramidale mis en regard d'une photographie de la coupole des tombeaux des califes présente avec celle-ci de si frappantes similitudes qu'il est au premier aspect impossible de dire lequel des deux dômes est de construction humaine. Sur un autre oursin existe un arc de porte ou de fenêtre qui reproduit l'arc cissoïde des palais arabes ${ }^{16}$.»

Adalbert de Beaumont n'avait pas reçu de formation d'architecte comme Pascal-Xavier Coste $^{17}$ ou Friedrich Maximilian Hessemer ${ }^{18}$, pour ne citer que ces deux noms de voyageurs au Caire qui, antérieurement à Beaumont, laissèrent une abondante oeuvre graphique qui documente la ville du Caire; il est vraisemblable que sa formation de dessinateur ait été liée à son statut social sans qu'il ait pour cela acquis une pratique en atelier; il ne voyageait pas non plus comme Girault de Prangey qui, dès 1831, s'était passionné pour l'architecture arabo-musulmane, en partant à la découverte de l'Andalousie, haut-lieu de la culture arabe entre le VIII et le $\mathrm{XV}^{\mathrm{e}}$ siècle, et pour qui l'art de l'Égypte musulmane était une source; il ne reçut pas non plus l'éblouissement de Prosper Marilhat lors de son séjour en Égypte en 1831-1833, peintre à propos duquel Théophile Gautier écrivit dans la Revue des Deux Mondes du 1erjuillet 1848 :

« Il y avait dans son imagination un perpétuel mirage de dômes d'étain, de minarets d'ivoire, de mosquées aux assises blanches et roses, de caroubiers trapus et de dattiers sveltes...19 » 
11 C'est bien là un des traits caractéristiques de la perception qu'Adalbert de Beaumont avait de certaines formes de l'architecture cairote : y avoir vu des analogies de formes avec la nature et d'en rechercher les parallèles, qu'il s'agisse des galérites pyramidales avec les structures et décors de dômes et coupoles de mosquées ou tombeaux, d'astrées polygonales ou madrépores avec les ornementations des minarets ou encore de cristallisations avec certains éléments architectoniques ; ainsi relève-t-il que :

" la cassérite, ou oxyde d'étain et la marcassite ou fer sulfuré forment des cristaux prismatiques pyramidaux et des stalactites groupées identiques aux frises et aux cordons sculptés des monuments arabes ${ }^{20} »($ fig. 3 ).

\section{3. « Frises, cordons et pendentifs cristalliformes persans et arabes.}

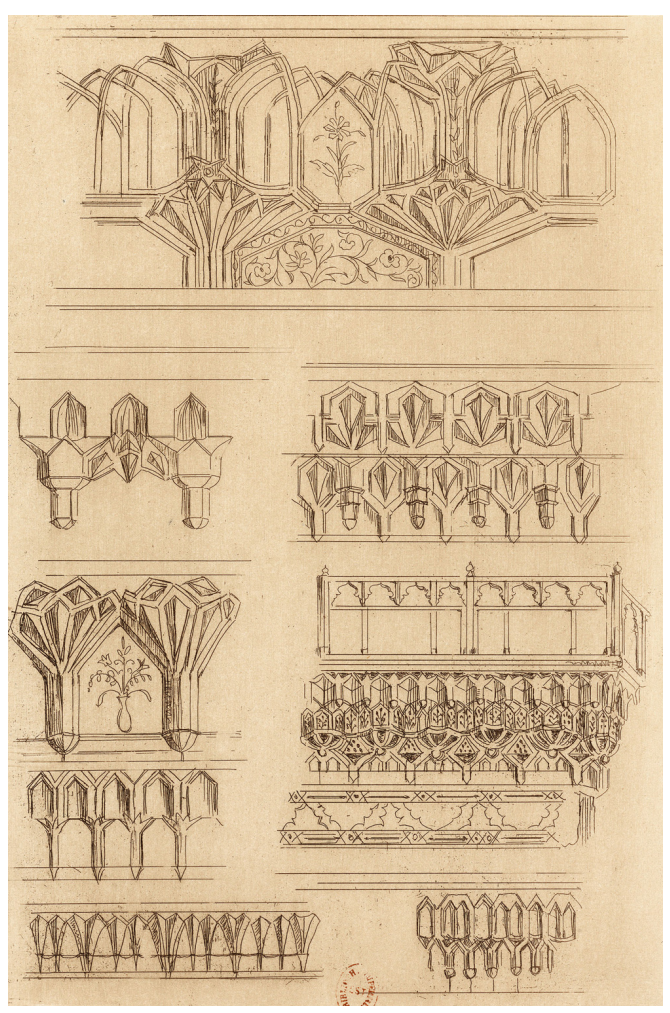

Source : Recueil de dessins pour l'art et l'industrie, 1859, pl. 193. Paris (France), Bibliothèque nationale de France, département des Estampes et de la Photographie.

S'il se décrivait occupé du matin au soir à dessiner tout ce qui donnait aux monuments du Caire un aspect si caractéristique, force est d'admettre que peu de ces dessins et aquarelles nous sont parvenus et que ceux qui nous sont connus illustrent la ville du Caire de manière très disparate.

En ce qui concerne les monuments et édifices, Adalbert de Beaumont s'attachait à représenter aussi bien des vues extérieures ou intérieures - à propos de ces intérieurs, nous ne savons rien des difficultés que Beaumont aurait pu rencontrer, à l'instar de tant d'autres artistes voyageurs, à pénétrer ces édifices religieux interdits aux infidèles -, que des détails de décor et d'ornementation (fig. 4). Il porta son attention aux édifices les plus connus pour leur richesse décorative comme les mosquées al-Mu'ayyad ou Ibn Tulun ou encore le mausolée de Qaytbay, dont il réalisa une aquarelle aboutie ${ }^{21}$ (fig. 5) par laquelle il soulignait la diversité de la décoration architecturale tout en ne négligeant pas la vision pittoresque, animant la scène d'un ânier - comme le note 
Joanne dans son guide « quiconque n'a pas vu l'âne d'Orient ne connaît pas l'un des plus beaux et des meilleurs animaux de la création » - et d'un chamelier. Une vue intérieure du Sanctuaire de la mosquée El Moyed [al-Mu'ayyad] au Caire ${ }^{22}$, réalisée en mars 1843, traduit à la perfection, par la très grande attention portée aux détails, par la délicatesse de l'aquarelle, la richesse ornementale et polychromée de l'édifice. En relation avec cette vue de l'intérieur de la mosquée al-Mu'ayyad, une autre aquarelle d'Adalbert de Beaumont, elle aussi conservée au musée des Arts décoratifs ${ }^{23}$, documente la méthode de travail de l'artiste qui mit en place, en les esquissant, les structures et éléments de l'intérieur, tout ce qui fut précisé et abouti dans l'aquarelle finale. D'autres feuilles, comme celle figurant l'Intérieur de la Mosquée El Ghoury [al-Ghawri] ${ }^{24}$, possèdent un verso couvert d'esquisses de détails ornementaux ${ }^{25}$.

4. Grilles de la mosquée Mahmoud Gaouly [mosquée Salar et Sangar al-Gawli], Caire, mars 1844, graphite, aquarelle sur papier ; repris dans le Recueil, pl. 17 et Ornements arabes, 1882, pl. 7.

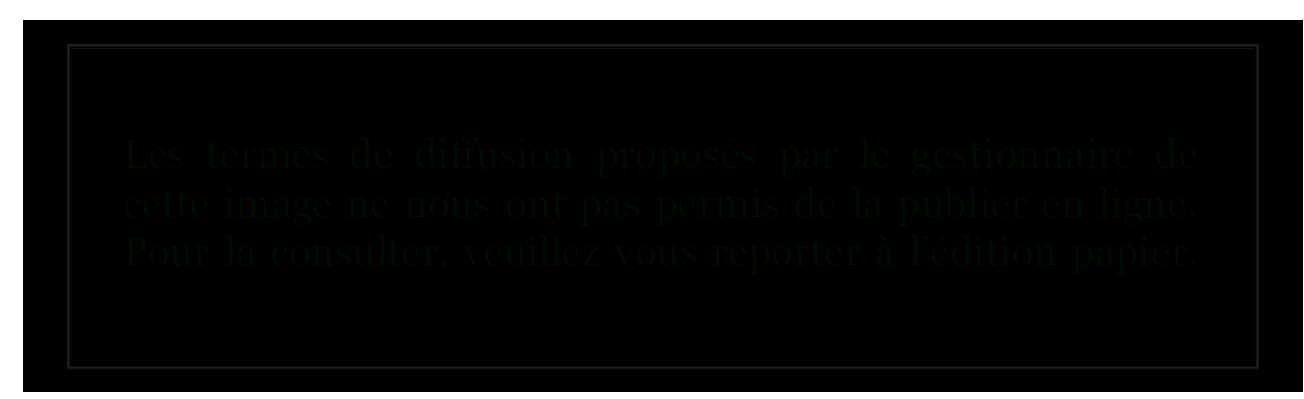

Source : Paris (France), musée des Arts décoratifs (4552).

5. Mosquée Khayd Bey [Qaytbay] (Tombeaux des Califes) Le Caire, graphite; aquarelle sur papier, 1843.

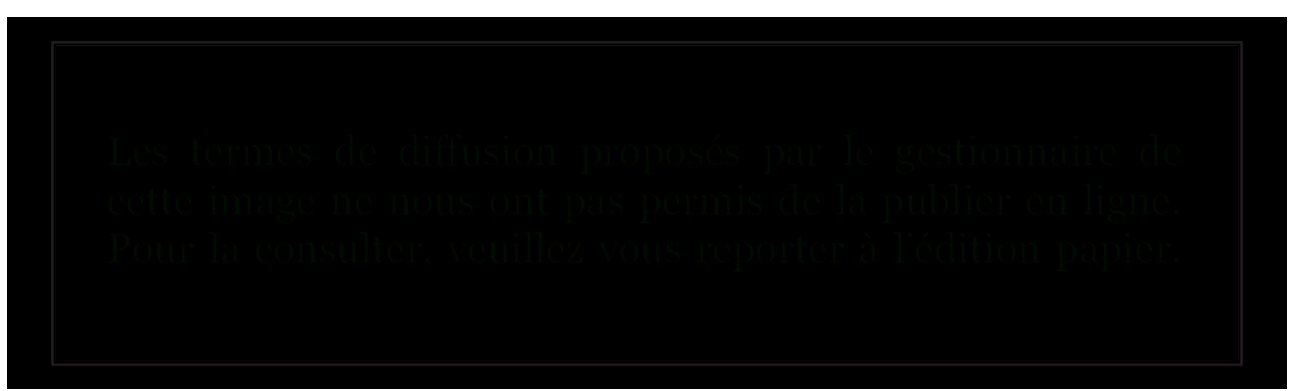

Source : Paris (France), musée des Arts décoratifs (4458).

Il convient de placer dans cette même suite de représentations de monuments islamiques du Caire une estampe de Jean Joseph Sulpis ${ }^{26}$ d'après Adalbert de Beaumont, destinée à une livraison, qui ne vit pas le jour, de la revue fondée par Émile Prisse d'Avennes, Miroir de l'Orient ou tableau historique des croyances, mours, usages, sciences et arts de l'Orient Musulman et Chrétien ${ }^{27}$, estampe légendée Mihrâb et minbar, du Zâwieh d'Ahmed, près de la Mosquée du Sultan El-Mansoûr Kalâoûn [Qalawun], au Kaire (fig. 6) ${ }^{28}$. Audelà du problème introduit par la transposition en lithographie, si talentueux que soit le graveur, nul doute que l'œuvre originale d'Adalbert de Beaumont, dont la localisation actuelle n'est pas connue, devait atteindre un haut niveau de qualité dans le relevé. Là aussi des personnages aux costumes et attitudes variés animent la scène. 
6. Jean-Joseph sULPIS d'après Adalbert de BEAUMONT, Mihrâb et minbar, du Zâwieh d'Ahmed, près de la Mosquée du Sultan El-Mansoûr Kalâoûn [Qalawun], au Kaire.

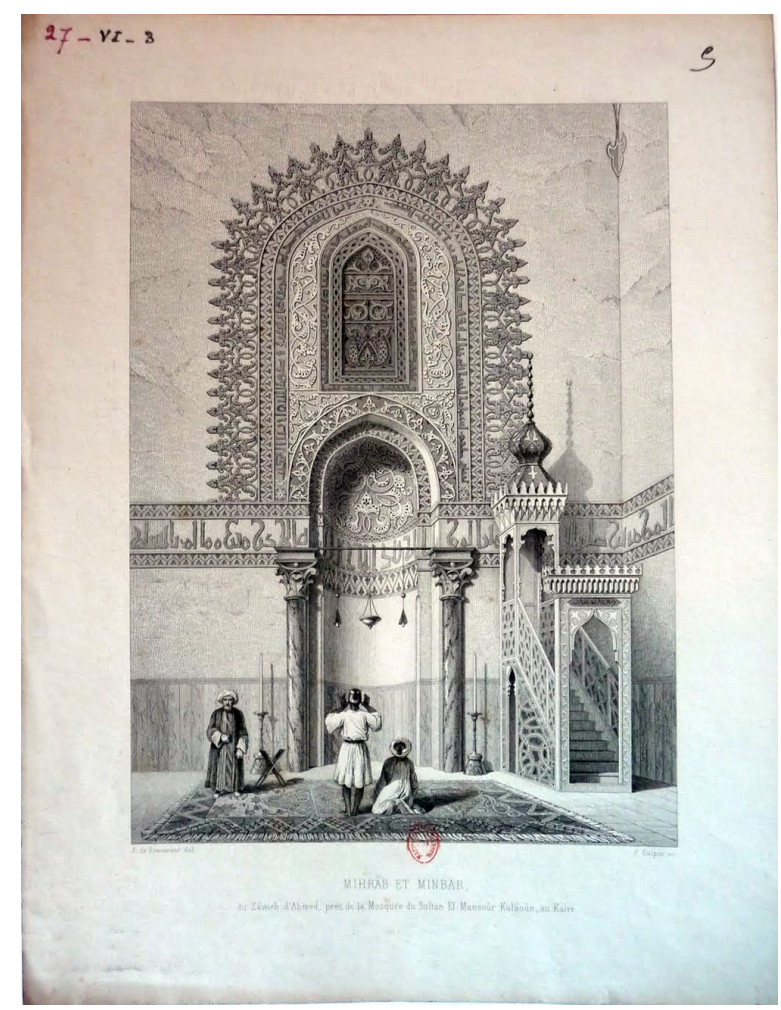

Source : Paris (France), Bibliothèque nationale de France, département des Manuscrits.

15 Quelques autres vues du Caire sont dessinées sur du papier calque, avec toutefois suffisamment de précisions pour pouvoir les réutiliser ultérieurement sur des feuilles de plus grande taille, que l'on n'a toutefois pas retrouvées à l'heure actuelle ${ }^{29}$ (fig. 7).

7. Kaire tombeaux des Kalif... [sic], graphite sur papier calque.

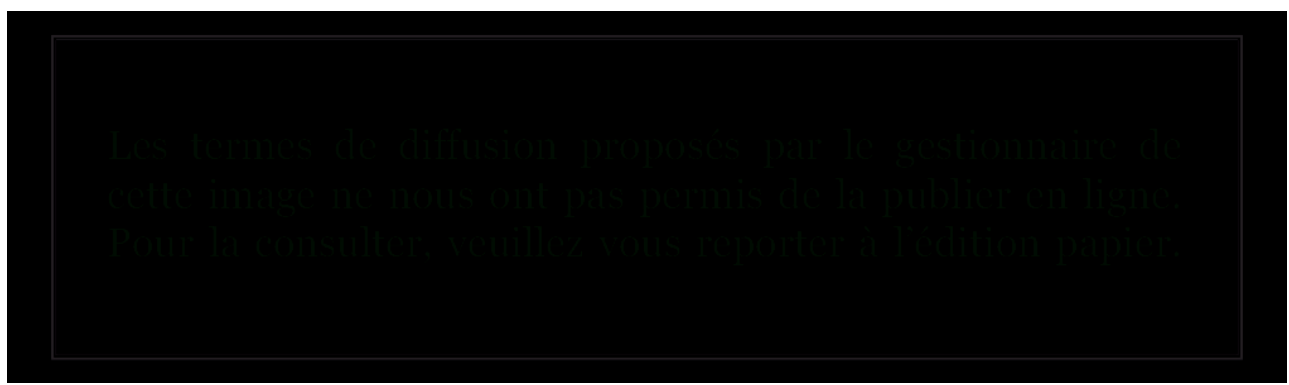

Source : Paris (France), musée des Arts décoratifs (4474).

16 Un tout autre intérêt d'Adalbert de Beaumont est celui montré pour tout ce qui est agrément végétal au sein de la ville, image transposée de l'Éden sur terre. Ce goût de la nature transparaît dans ses descriptions enflammées des jardins, véritables jardins des Hespérides avec leurs pommes d'or et leurs odeurs célestes, qu'il découvre par hasard tant ils sont cachés aux yeux des visiteurs et dont il dit qu'ils eussent pu être une source infinie pour le peintre Prosper Marilhat s'il en avait eu connaissance :

«Une fois entre autres, en me promenant dans un jardin célèbre par ses fleurs, j'aperçus, à travers les grillages des murailles, le lac le plus charmant qu'on puisse 
imaginer : on le nomme Birkeiet-Ginnah, le lac de la Fée ; il est entouré de maisons, de jardins, et de ces jolis kiosques à arcs arabes complètement recouverts par un rideau de dolichos à fleurs violettes, véritable mousse grimpante qui tapisse tout de son épais tissu, et pend en élégants festons jusque dans l'eau, où elle cherche à s'abreuver » [...] « On compte aussi dans la ville vingt-deux jardins principaux qu'on nomme gheyt ou geneyneh, suivant leur grandeur. Dans ces jardins il ne faut chercher ni allées symétriques ni pelouses de gazon dessinées avec art ; ce sont des bosquets touffus croissant comme la nature, comme le hasard le veulent; ce sont des massifs d'orangers, de citronniers, de mimosas parfumés et de tamariscs au feuillage fin comme la mousse, de grenadiers, de myrtes et de cactus, de napecas et de sebbeks, au-dessus desquels le sycomore et le palmier, garnis de plantes grimpantes, s'élèvent majestueusement, les premiers arrondis comme un dôme, avec leurs branches tortueuses et rampantes, les seconds élancés comme des minarets, et contrastant aussi bien par la forme et le feuillage que par la couleur. On y cultive le bananier à la feuille gigantesque, au fruit délicat, les groseilliers du Cap, et cinquante espèces d'oranges, de cédrats et de bergamotes ${ }^{30}$. »

17 Au-delà de sa connaissance des espèces végétales, même les plus locales, qu'il nommait avec exactitude, Adalbert de Beaumont réutilisait ici le principe d'analogie entre la nature et l'architecture qui lui était cher - le sycomore arrondi comme un dôme, le palmier élancé comme un minaret. Ces impressions de luxuriance sont remarquablement rendues dans deux aquarelles du jardin de la tekke des Derviches au Caire $^{31}$ qui avait été antérieurement représenté, mais de manière très différente, par Pascal-Xavier Coste en $1822^{32}$. Elle est aussi ressentie au travers de la vision idéalisée, paradisiaque, qu'il donne d'une partie résidentielle de la ville, autour de l'étang appelé Birkat al-Fil (fig. 8) :

«Le voisinage des mosquées m'indiquait approximativement leur situation [des bassins intérieurs entourés de verdure]; je m'empressai donc de courir à la recherche de cette bonne fortune artistique. À force de questionner, je parvins, à travers des jardins d'orangers, de bananiers et de jasmins, sur le bord d'un de ces lacs enchantés. C'était le Birket-el-Fil, le lac de l'Hippopotame [sic]. On lui donna ce nom après une crue subite du Nil... C'est un aspect enchanteur que ces lacs bordés de jardins et de kiosques où viennent se reposer les riches propriétaires des maisons voisines. Aucune rue, aucun chemin n'y aboutissent, et, pour les voir, il faut y pénétrer par les habitations: aussi sont-ils entièrement ignorés des voyageurs, et même de la plupart des habitants ${ }^{33}$. » 


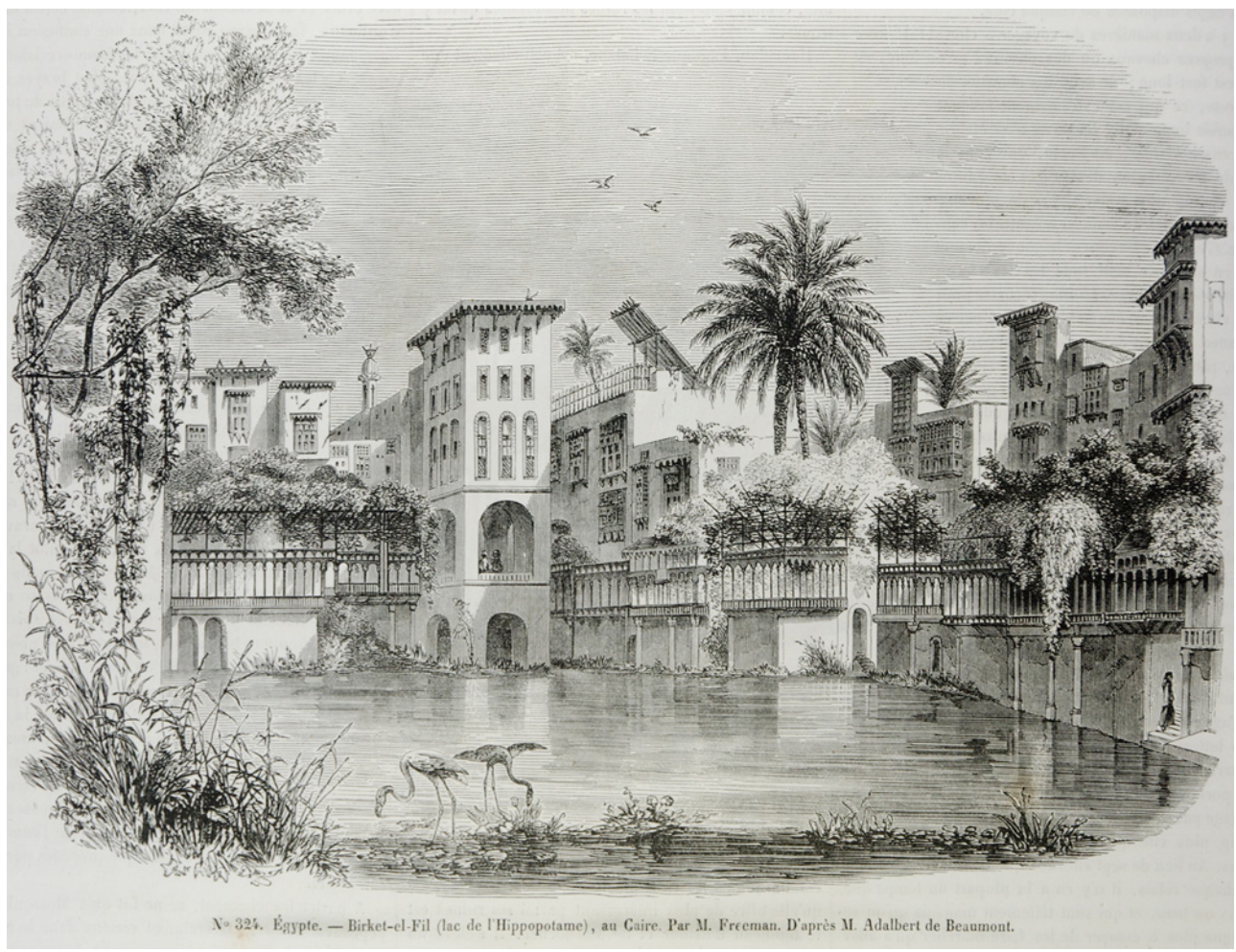

Source : Estampe parue dans Voyage dans les cinq parties du monde, p. 200, gravure n³24.

Doit-on mettre cette passion exprimée pour les plantes et les fleurs avec l'honneur que lui fit un obtenteur français qui donna le nom de Vicomte Adalbert de Beaumont à une variété de phlox herbacé mise dans le commerce en 1858 et que The Florist, fruitist, and garden miscellany décrivait comme étant "bright rose, crimson centre, large flower, very free. $2 \frac{11}{2}$ feet $^{34}$ ? Cette passion pour la nature ne le quitta pas, puisqu'une fois rentré à Paris, il se rendit régulièrement au Jardin des plantes pour ses travaux et pour aider le professeur de physiologie végétale, Georges Ville ${ }^{35}$.

autre ensemble non négligeable de dessins présente une vue davantage ethnographique du Caire. Esthète dans sa sensibilité à la beauté des corps masculins, Adalbert de Beaumont notait :

« Je me souviens qu'en arrivant au Caire où affluent toutes les races de l'Afrique et de l'Asie, je ne discernais aucune nuance, aucune différence d'aspect entre ces figures jaunes, noires, couleur de feu, bleuâtres, café au lait, entre ces têtes larges ou étroites, bombées ou aplaties, aux yeux fendus en amande, relevés, tendres comme ceux de la gazelle ou du phoque, ou bien ronds et farouches comme les yeux d'un tigre en colère. Ce fut seulement après six mois de séjour que je commençai à discerner ces nuances : alors toutes les beautés de la forme et de la couleur de ces créatures de Dieu me révélèrent une harmonie plus fine et plus complète que celle de nos races. Il y a là des types nubiens et abyssiniens bien autrement purs que les plus purs parmi les Grecs ${ }^{36}$. »

Une vingtaine d'aquarelles conservées au musée des Arts décoratifs témoignent de cet intérêt montré pour la variété des types humains rencontrés dans cette ville au carrefour des civilisations et des peuples. L'une de celles-ci, qui confirme une fois de plus les qualités de dessinateur et d'aquarelliste d'Adalbert de Beaumont, fait voir deux 
personnages dont les costumes s'illuminent des couleurs chatoyantes de leur ceinture. D'autres sujets encore davantage " ethnographiques » aux yeux d'un Occidental sont les charmeurs de serpents ou psylles ou encore gaeied ${ }^{37}$, les maïnoungi qui font « danser les singes ", les santons abyssiniens, les magiciens, ou même les "puncht", ces travestis dansants, ce qu'Adolphe Joanne mentionnait comme des curiosités du Caire, mais aussi les scènes de rue ou les cérémonies croquées sur le vif, comme "La fête du Prophète, place de l'Esbekieh, cérémonie du Dojed $\aleph^{38}$, ou encore les cafés et leurs clients (fig. 9), ces cafés du Caire qui avaient tant frappé les voyageurs depuis le début du XIX siècle, les échoppes de petit commerce telles que la Boutique de Sérif ou changeur ${ }^{39}$, toutes ces images qui furent réutilisées pour séduire les lecteurs toujours plus nombreux du Voyage illustré dans les cinq parties du monde en 1846, 1847, 1848, 1849 publié par Adolphe Joanne.

9. Intérieur d'un café au Caire, les Berbères, graphite, aquarelle sur papier.

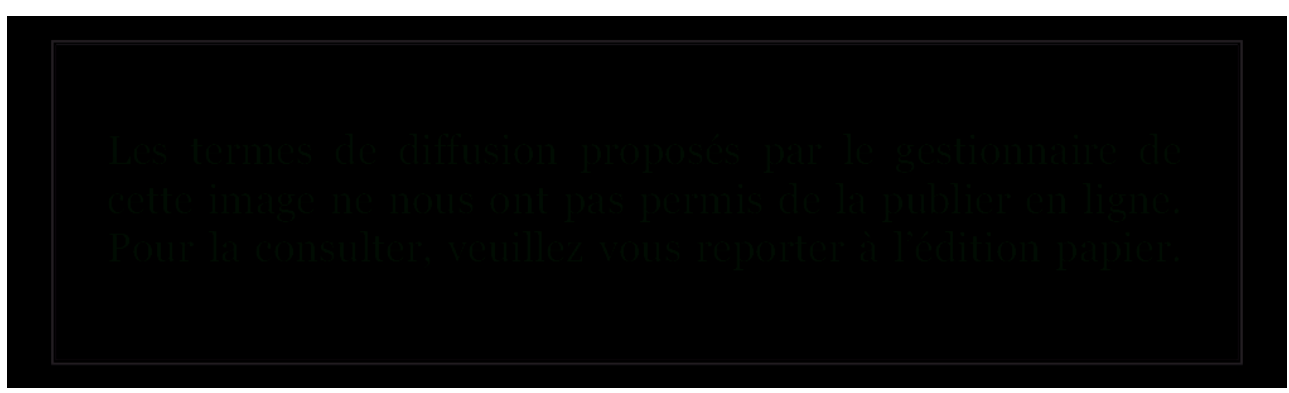

Source : Paris (France), musée des Arts décoratifs (6565i)

21 Que ce soit dans ses œuvres graphiques ou dans ses écrits, la vision qu'Adalbert de Beaumont transmit du Caire porte la marque de son insatiable curiosité liée à un statut social privilégié, qui l'entraînait dans l'élaboration de théories surprenantes sur la vie des formes, théories qu'aurait désavoué tout architecte ou historien de l'architecture.

\section{Le milieu islamophile, sur place et en France}

Adalbert de Beaumont n'était pas seulement un de ces Occidentaux aisés et cultivés qui, comme il y en a tant, voyageaient en Égypte au même moment. Il vint s'agréger à tout un groupe « d'orientalistes, de voyageurs, d'artistes, d'hommes spéciaux, en un mot... » selon une formule d'Émile Prisse d'Avennes ${ }^{40}$.

Il est possible de supposer une rencontre, au Caire, d'Adalbert de Beaumont avec l'égyptologue, archéologue, ethnologue et publiciste Émile Achille Constant Prisse d'Avennes (1807-1879) ${ }^{41}$, lors du premier séjour de celui-ci en Égypte, c'est-à-dire avant 1844, date de son retour en France. Celui-ci, tout d'abord reconnu comme un spécialiste de l'art pharaonique, s'intéressa, également très tôt, aux arts de l'islam et partagea un intérêt commun étendu au phénomène de l'ornement, comme en témoignent les emprunts mutuels que l'on note dans leurs ouvrages respectifs.

Ainsi les emprunts d'Adalbert de Beaumont à Prisse d'Avennes, dessinateur de talent, pour ses recherches relatives au blason qui aboutirent à une publication en $1853^{42}$, touchent à l'Égypte ancienne avec la représentation du papyrus et du lotus ${ }^{43}$; quant aux emprunts, plus tardifs, faits par Prisse aux dessins gravés par Adalbert de Beaumont, ils 
ne sont pas faits sans quelques réticences, car comme l'écrit l'égyptologue dans une lettre adressée à Charles Cournault le 22 juin 1868 :

«Les dessins gravés par Beaumont sont bien mal rendus, et réflexions faites, ces belles pièces valent la peine d'être mieux connues et appréciées, aussi je les reproduirai quand même, heureux de rendre au dessinateur toute la part qui lui revient, ce que notre illustre ami a trop souvent oublié pour ne penser qu'à lui. ${ }^{44}$ ».

Mais Prisse d'Avennes et Adalbert de Beaumont eurent l'occasion de se rencontrer en 1843-1844 autour d'un autre personnage, figure du monde cosmopolite du Caire, le docteur Henry Abbott (1812-1859). Ce médecin était de ces Anglais qu'un intérêt puissant pour les études archéologiques avaient fixés en Égypte. Il avait réuni au Caire une collection d'antiquités égyptiennes dont il accordait aisément l'accès, et sa demeure, qu'Adalbert de Beaumont avait visitée, peut-être même habitée, était devenue le point de ralliement des érudits étrangers séjournant au Caire; en témoignent une belle aquarelle qu'il a faite de l'intérieur de la maison ${ }^{45}$. En outre, Henry Abbott avait créé en 1842, avec la collaboration de Prisse d'Avennes, L'Association littéraire d'Égypte ${ }^{46}$, dont le but était la publication des documents relatifs à l'Égypte et à l'Orient, mais qui avait également constitué une importante bibliothèque dont l'accès était une bonne fortune pour le voyageur qui pouvait y être introduit car il en obtenait le prêt de livres utiles dans ses excursions ${ }^{47}$.

26 On peut se demander si quelques-uns de ces érudits ne sont pas à reconnaître dans les personnages assis, vêtus à l'orientale et, pour deux d'entre eux, fumant le narguilé, à l'intérieur d'une cange sur le Nil dessiné par A. de Beaumont ${ }^{48}$ (fig. 10).

10. Intérieur de barque sur le Nil, 1843, graphite, aquarelle sur papier.

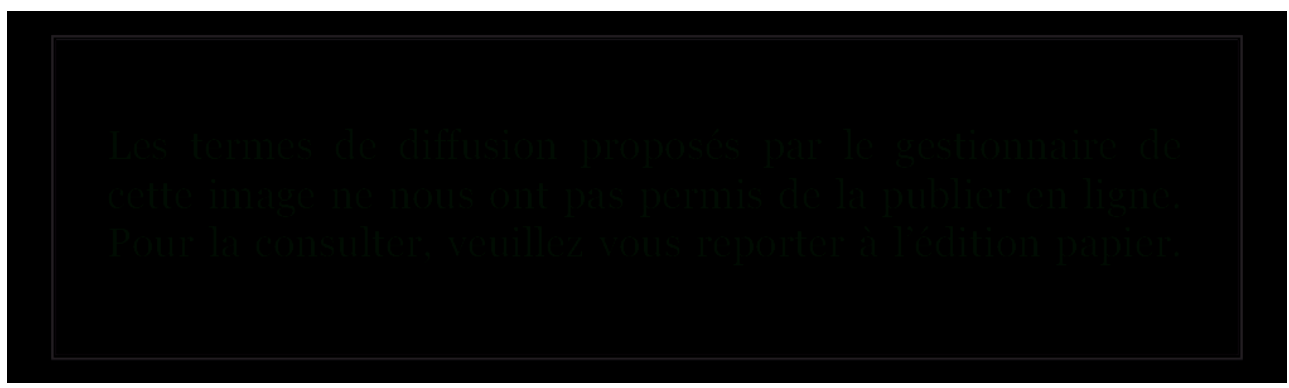

Source : Paris (France), musée des Arts décoratifs (6565p).

27 Les liens d'Adalbert de Beaumont avec Prisse d'Avennes se poursuivirent en France au travers de deux publications lancées par le publiciste au début des années 1850: Miroir de l'Orient ou tableau historique des croyances, mœurs, usages, sciences et arts de l'orient musulman et chrétien, qui ne connut qu'une seule et unique livraison en 1852, mais pour laquelle une planche gravée d'après Adalbert de Beaumont avait été retenue ${ }^{49}$; la Revue orientale et algérienne, dont il ne parut que cinq tomes qui accueillirent toutefois trois contributions d'Adalbert de Beaumont ${ }^{50}$.

Une autre figure de l'orientalisme en France avec laquelle Adalbert de Beaumont, ainsi qu'Émile Prisse d'Avennes, entretinrent des échanges épistolaires, est celle du peintre et voyageur d'origine lorraine Charles Cournault (1815-1904) ${ }^{51}$, qui, s'il ne se rendit pas en Égypte mais privilégia l'Algérie, ne s'intéressa pas moins aux arts décoratifs orientaux, au point d'avoir puisé dans ses portefeuilles de dessins pour la construction et la décoration de la villa mauresque la Douëra qu'il se fit aménager vers 1856 à Malzéville près de $\mathrm{Nancy}^{52}$, décoration pour laquelle Beaumont fournit conseils et 
modèles (ainsi proposa-t-il, entre autres, à Cournault ses moulages de pendentifs arabes d'après un appartement du Caire ${ }^{53}$ ) comme Adalbert de Beaumont puisa dans ses propres œuvres pour le décor du Palazzo Persico qu'il fit bâtir en bordure du bois de Boulogne, maison construite sur le modèle d'un palais de Téhéran ${ }^{54}$. Enfin Prisse d'Avennes édita sept planches d'après Charles Cournault dans son ouvrage L'Art arabe d'après les monuments du Kaire depuis le VII siècle jusqu'à la fin du XVIII ${ }^{e 55}$.

D'autres figures sont également à convoquer si l'on veut compléter ce panorama du milieu orientaliste que fréquenta ou côtoya Adalbert de Beaumont: le prince Alexis Soltykoff (1806-1859), dessinateur amateur, qui avait voyagé en Perse et en Inde et fut un collectionneur fastueux ${ }^{56}$ qui fit cadeau à Adalbert de Beaumont de pièces qu'il avait amassées ; l'orientaliste et ancien directeur de l'Imprimerie nationale du Caire JeanJoseph Marcel (1776-1854) dont Beaumont se procura l'Égypte depuis la conquête des Arabes jusqu'à la domination française dès sa parution et dans les collections duquel il s'attacha, en compagnie de Charles Cournault, à trouver de nouveaux manuscrits enluminés et des objets d'art ${ }^{57}$. Enfin, familier des célèbres "vendredis du Louvre " organisés par le directeur général des Musées nationaux, le comte Émilien de Nieuwerkerke, lui-même collectionneur d'art islamique, Adalbert de Beaumont put demander faveurs et soutien ${ }^{58}$.

Son entregent naturel et son caractère agréable préservèrent Adalbert de Beaumont des inimitiés tenaces fréquentes dans ces milieux d'érudits.

\section{Retour d'Égypte}

\section{Exploitation des sources}

Rentré en France, Adalbert de Beaumont entreprit l'exploitation de ses sources qui se fera essentiellement de trois façons.

«L'artiste littérateur » prit une part active à la nouvelle publication l'Illustration en y donnant des textes relatifs à ses séjours dans des contrées diverses, accompagnés de dessins gravés sur bois. Pour tenir en haleine les quelque 18000 abonnés du journal ${ }^{59}$, les textes abusaient de l'anecdotique et Beaumont puisa dans ses sujets " ethnographiques ", pittoresques, ces "types » croqués au Caire comme dans le cas de la gravure du Gaëdi (psylle égyptien), charmeur de serpents au Kaire, réalisée par Henri Valentin d'après un dessin de Beaumont ${ }^{60}$ (fig. 11), accompagnée d'une longue explication relative à ces hommes dont le métier est de détruire les animaux venimeux dans les maisons. De cet homme "qui portait sur son dos un sac rempli de serpents qu'il déposa à terre », Beaumont fit un croquis chez lui. 
11. Gaëdi (psylle égyptien), charmeur de serpents, au Kaire, estampe signée H. Valentin.

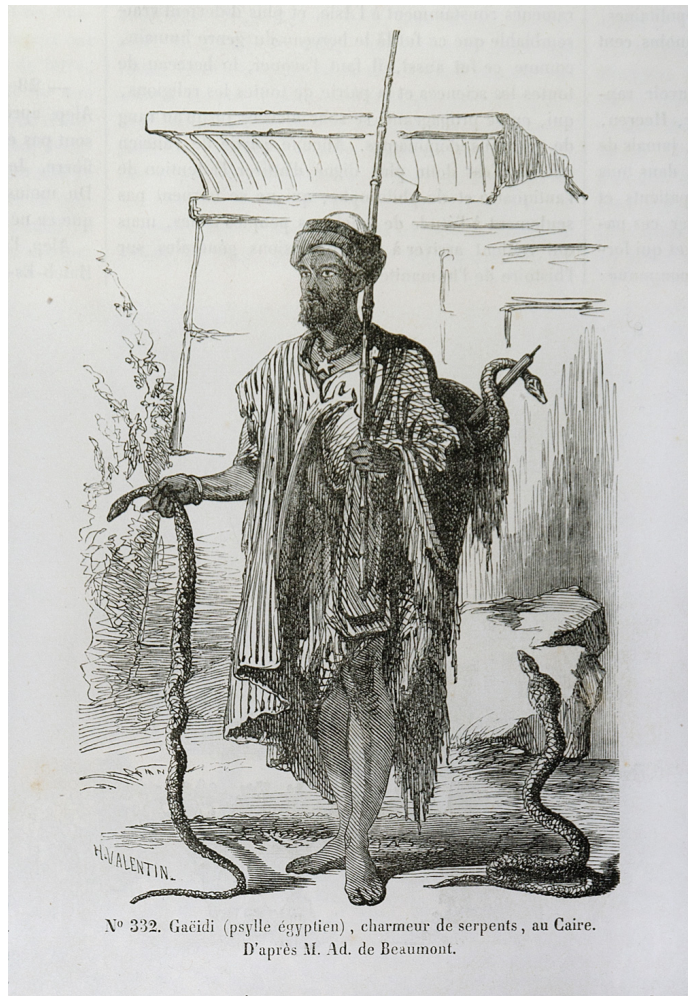

Source : d'après A. de Beaumont, parue dans Voyage dans les cinq parties du monde, p. 205, gravure $n^{\circ} 332$.

Un autre article paru dans L'Illustration en 1852, accompagné du dessin d'ensemble et des détails d'un parfumoir en métal ajouré, exécuté au Caire, qui invitait le lecteur à y voir ou « le dôme élégant du tombeau de Kalaoun [Qalawun] ou la coupole d'IbrahimAga..." ou, une fois renversé, "une lampe merveilleuse dont les légendes et les arabesques en noir se détachent sur la lumière qu'elle renferme ${ }^{61}$, annonçait les préoccupations ultérieures d'Adalbert de Beaumont. Il se servit du dessin de cet objet pour démontrer le degré où l'art était arrivé ainsi que la qualité de l'ornementation. Tout en définissant "le beau pittoresque ", il soulignait l'intérêt de cet objet en le confrontant à la coupole dans l'architecture ou à une lampe sur lesquelles les arabesques permettaient de faire jouer la lumière, sans oublier de mentionner la fonction ornementale de la calligraphie courant tout autour de l'objet et dont le développement était fourni sur la page. Deux autres objets, un « casque persan » et un « chandelier » acheté au Caire, étaient convoqués pour suggérer les possibilités variées de leur usage tout en ne manquant pas de développer une théorie qui lui fut chère, celle du modèle à chercher chez les Orientaux, défendant l'idée que les deux principes, celui de la forme et celui de la couleur, venus de l'Orient, étaient à même de sauver les arts industriels français dont il constatait la décadence lors de sa visite de la Great Exhibition de 1851 au Crystal Palace à Londres.

Un deuxième temps dans l'exploitation de la documentation accumulée au cours de son séjour cairote, et plus largement en Orient, est la réflexion, consacrée à partir de 1849 , à l'étude de la fleur de lis dans un ouvrage intitulé Recherches sur l'origine du blason et en particulier sur la fleur de lis. Fondant sa théorie sur "L'Orient berceau du genre humain », il exposait alors sa méthode issue de celle des sciences naturelles dont les 
maîtres mots étaient «expérimentation et observation directe, avec reproduction par le dessin d'une exactitude poussée jusqu'au scrupule ${ }^{62}$.

«En dessinant les mosquées et les tombeaux, les portes et les murs de Constantinople, du Caire, de Brousse et autres cités de l'Orient ; en rencontrant sans cesse ce fleuron comme le type, disons mieux, comme le générateur de l'arabesque, nous avons dû rechercher d'où venait cet ornement arabe, quelle en était l'origine première. Il nous a été facile d'en retrouver la trace dans l'art de l'antique Égypte, dont l'art arabe n'est que la conséquence et l'entier développement ${ }^{63}$.»

Il était convaincu de l'inspiration trouvée par les Égyptiens dans le règne végétal et que «les Arabes feront de même en cherchant leurs modèles dans les produits de la nature ». Il s'appuyait sur le dessin, plutôt que sur les textes : «mettre en regard, les formes les plus diverses, c'est expliquer à l'aide des yeux, ce que l'esprit ne se représente pas tout d'abord $»^{64}$. Ainsi, l'ouvrage fut complété par vingt-deux planches gravées, fruit de ses comparaisons, pour démontrer l'origine orientale en particulier égyptienne de la fleur de lis. Les planches I et II offrent, preuves à l'appui, le détail de cette forme florale identifiée dans des monuments du Caire, en particulier aux mosquées Ibn Tulun, 'Amr et al-Maridani et aux tombeaux de la ville, dont celui de Qaytbay. Adalbert de Beaumont s'était lancé là dans une entreprise intellectuelle hasardeuse, qui fut aisément mise à mal, en particulier par les archivistes paléographes au nombre desquels Jules Quicherat qui, dans un compte rendu de la publication ${ }^{65}$, démonta point par point la démonstration, insistant sur «la marche vagabonde de l'auteur ".

Le troisième filon d'exploitation des sources accumulées fut le Recueil de dessins pour l'art et l'industrie. Cet ouvrage est le fruit des portefeuilles rassemblés au cours de quinze années de pérégrinations auxquels viennent s'ajouter des planches alimentées par des dessins d'amis ou connaissances tels que Charles Cournault, Jules Laurens ${ }^{66}$ ou Émile Prisse d'Avennes, ou encore d'après des objets vus et sélectionnés dans des collections privées comme celles d'Alphonse de Rothschild ou de Charles Schefer pour ce qui est relatif à l'Égypte. La date de 1859 portée sur la page de titre est celle du début d'une aventure éditoriale qui va se poursuivre, selon les termes du prospectus, " indéfiniment " $^{67}$. Les planches gravées au format folio sont destinées aux industriels et aux écoles faisant œuvre d'enseignement par l'étude de l'ornement « afin de mettre l'art industriel dans la bonne voie $»^{68}$. Par leur composition, les planches qui sont d'une qualité très inégale tant dans le dessin que la gravure - la plupart portent la mention A. de Beaumont inc., quelques autres E. Collinot inc. -, illustrent le propos d'Adalbert de Beaumont qui est de fournir des modèles d'ornements. Si treize des planches légendées Le Caire offrent le relevé d'un élément architectonique ou décoratif ou calligraphique identifiable, les autres sont des planches d'analogies - par exemple les séries de lambrequins (fig. 12), de couronnements de dômes, de minarets, de grilles ou les arcs de balustrade, balcon, niche, armoire, fontaine - ou de modèles dont la fonction est explicitée par la légende, comme la planche 72 (Intérieur de cour au Kaire. Nous publions ce dessin : $1^{\circ}$ Pour les moucharaby ou cages en bois qui ferment l'ouverture des fenêtres. $2^{\circ}$ Pour la disposition du treillage qui, appliqué aux jardins de Paris, permettrait de s'isoler des maisons voisines), la planche 109 (Rosaces pour plafond, marqueterie, orfêvrerie, gravures de plateau, de vases, de coffres, broderies, de coussins etc.) ou encore la planche légendée Couronnements de portes, de murs et de grilles. Peut servir aussi pour des frises peintes ou sculptées, des dessus de glace, des broderies, passementeries etc. 
12. «Pendentifs en bois découpé ou en zinc pour garniture de toits, de balcons et de moucharaby ».

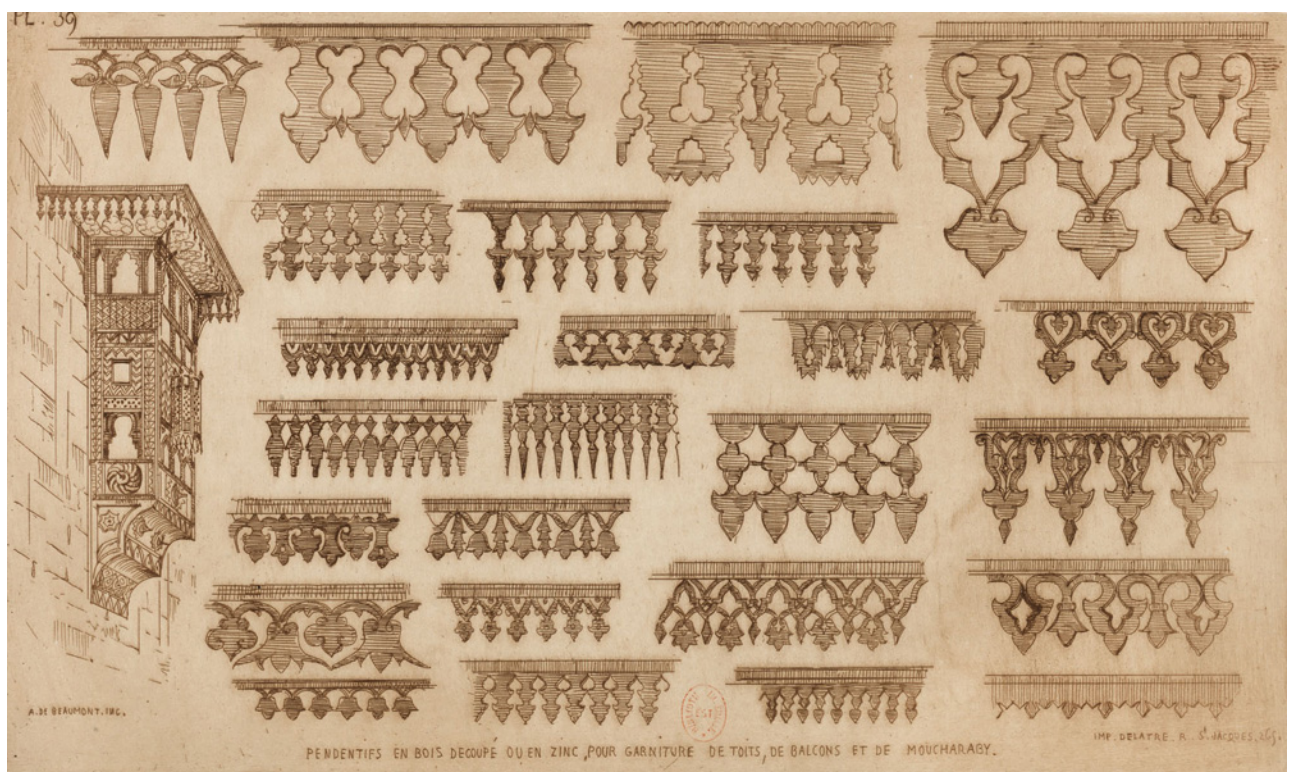

Source : Recueil de dessins pour l'art et l'industrie, 1859, pl. 39 reprise dans Ornements arabes, pl. 18. Paris (France), Bibliothèque nationale de France.

37 À travers ces exemples, l'artiste s'imprégnait du principe modulaire et sériel qui tapissait tous les supports pour bientôt les décontextualiser. Cette source féconde pouvait s'appliquer à la modernité ${ }^{6}$.

La réédition posthume, par Eugène Collinot ${ }^{70}$, du Recueil devenu Encyclopédie des arts décoratifs de l'Orient qui parut de 1880 à 1883 en six volumes avec des planches maintenant chromolithographiées (fig.13-15), s'enrichit d'une classification par grandes aires géographico-culturelles ${ }^{71}$ et les dessins du Recueil relatifs aux éléments architectoniques ou décoratifs relevés au Caire ou à des objets provenant du Caire sont classés dans les Ornements arabes ${ }^{72}$.

13. Côté opposé au sanctuaire de la Mosquée el-Ghoury [al-Ghawri].

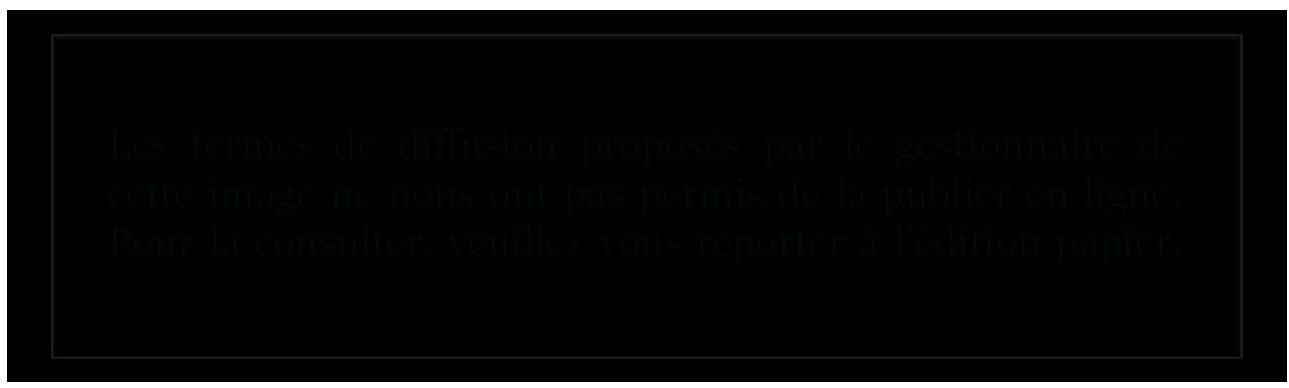

Source : Le Caire, 1844, graphite, aquarelle sur papier. Paris (France), musée des Arts décoratifs (4468 11a). 
14. Mosquée el-Ghoury [al-Ghawri], Le Caire, 1844, reprise dans le Recueil de dessins pour l'art et l'industrie, 1859, pl. 212.

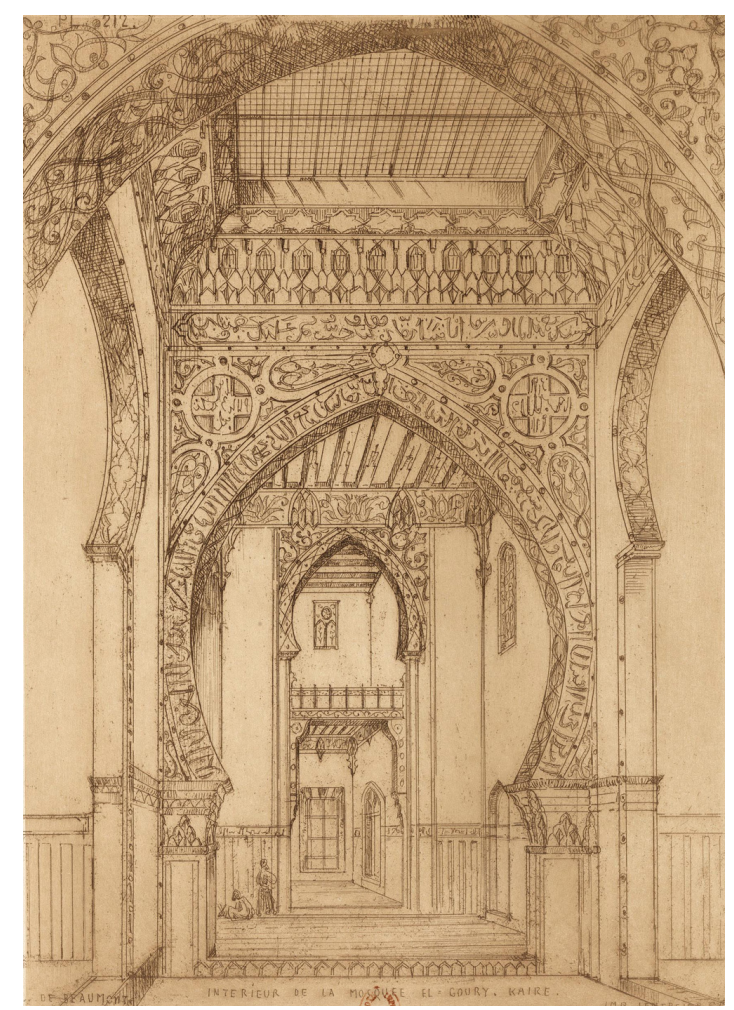

Source : Paris, BnF.

15. Mosquée el-Ghoury [al-Ghawri], Le Caire, 1844, reproduite dans Ornements arabes, 1883, pl. 24.

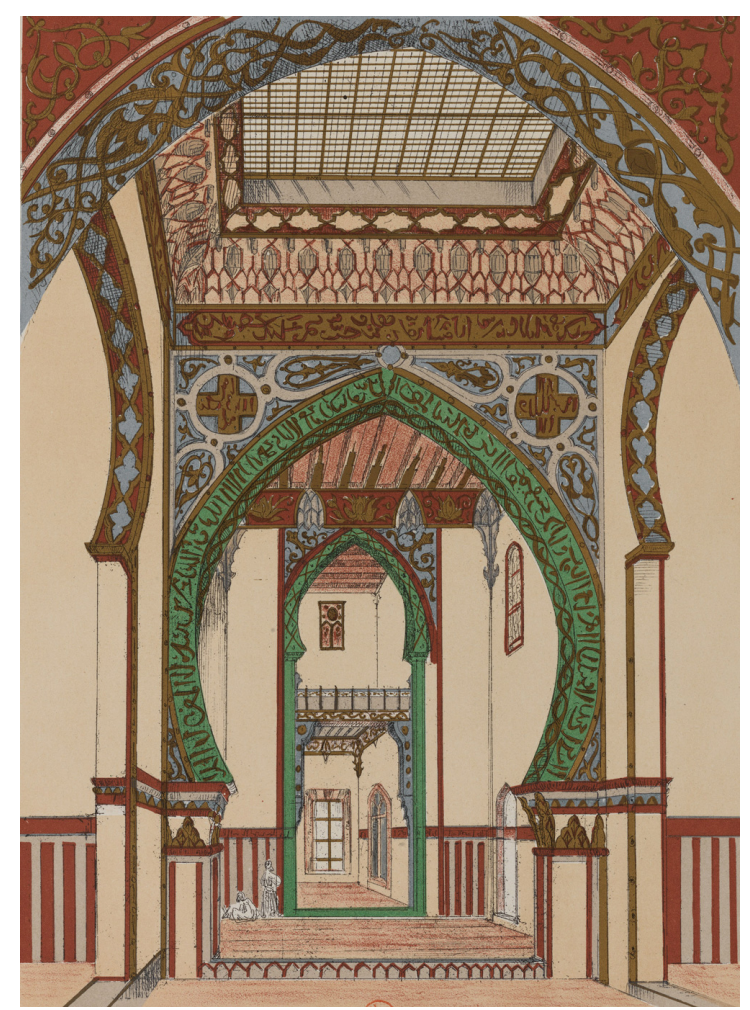

Source : Paris, BnF. 


\section{L'Orient et les arts industriels} Eugène Victor Collinot $^{80}$, et qui s'était spécialisée dans la technique des émaux cernés, était un des fruits de sa réflexion. Elle lui permit de mettre en application ses idées en privilégiant l'émail en relief, c'est à dire, favoriser la couleur franche au détriment du modelé où « Égypte, Inde, Japon et Chine fournissent les modèles.., la Perse servant de modèles pour la décoration céramique monumentale ${ }^{81}$.» Ce professionnalisme 
l'entraîna à concourir dans les expositions du Palais de l'industrie et à l'Exposition universelle de 1867 qu'il visita en rendant compte " du caravansérail des nations ${ }^{82}$ ».

L'étape du Caire fut essentielle pour l'expérience du voyageur Adalbert de Beaumont. Il découvrit par le dessin un répertoire formel et décoratif qui reflétait différentes cultures, favorisant paradoxalement un regard décentré d'une autre source, la référence antique. Le laboratoire qu'est la nature, au travers du coquillage ou de la fleur, joua un rôle fondamental dans la régénérescence de l'entrelacs et de l'arabesque " qui ne représentant rien de spécial peuvent s'appliquer à tout ${ }^{83}$ ». Par son rôle dans le discours sur l'ornement, l'artiste participa concrètement au renouveau esthétique du milieu du XIX ${ }^{\mathrm{e}}$ siècle dans une forme de vulgarisation de la connaissance liée à la création, essentiellement au travers des arts du feu, réservée plutôt à une élite.

\section{NOTES}

1. Adolphe JoAnNE, Voyage en Égypte et en Grèce, Ixelles-lez-Bruxelles : Delevingue et Callewaert, 1850, p. 66, qui reprend intégralement le texte publié dans Voyage illustré dans les cinq parties du monde en 1846, 1847, 1848, 1849, Paris : L'Illustration (s.d.). Il est à noter que les diverses citations empruntées à Adalbert de Beaumont dans cet ouvrage renvoient à une source qui n'a pas été identifiée ; Adalbert de Beaumont a séjourné au Caire en 1843-1844 d'après ses dessins, peut-être en 1834-1835 aussi.

2. Description de l'Égypte. État moderne, tome second, $\mathrm{II}^{\mathrm{e}}$ partie, Description abrégée de la ville et de la citadelle du Kaire, suivie de l'explication du plan de cette ville et de ses environs, et contenant des renseignements sur sa distribution, ses monumens, sa population, son commerce et son industrie, p. 581-584. Si Edme Jomard et Adalbert de Beaumont s'accordaient sur le nombre de mosquées, grandes ou petites, et sur celui des portes de ville, le reste diffère (Jomard recensait 53 quartiers, 4 places, 22 jardins principaux, 56 marchés, 31 bains principaux, 34 citernes principales, une vingtaine de ponts). Le Genevois Charles Didier (1805-1864), qui arriva au Caire en septembre 1853, donnait au chapitre III de son ouvrage Les Nuits du Caire (Paris : Hachette, 1860), le titre d'« Une page de statistique ». L'énumération qui y est faite s'achève par ces phrases non dénuées d'ironie : «Je demande grâce pour les trois pages qui précèdent et pour leur fastidieuse aridité ; mais les statisticiens n'ont jamais assez de chiffres, et j'ai voulu faire quelque chose pour eux. Il faut bien que tout le monde vive ".

3. Charles BLANC, Grammaire des arts du dessin: architecture, sculpture, peinture...Paris: Vve J. Renouard, 1867, p. 613.

4. En 1820, Marc-Antoine de Beaumont, était dit «demeurant à Paris en son hôtel, rue de Monsieur, Faubourg St Germain, $n^{\circ} 6 »$. Voir : http://www.souvenir-davout.com/spip.php? article46 (consulté le 22 mars 2011). Quant à la mère d'Adalbert de Beaumont, devenue veuve en 1830, elle résida 3, place du palais Bourbon, toujours dans ce quartier aristocratique de Paris. Sur l'histoire de la lignée, voir l'ouvrage de Jacques de BEAUMONT, Notice historique et généalogique sur la maison Bonnin de la Bonninière de Beaumont, marquis et comtes de Beaumont, marquis de la Chartre sur Loir, seigneurs Des Chastelliers, Beauvais, Le Fresne, Savary, Rezé, Rortre, Fontenay, Beaumont la Ronce..., pairs de France..., Tours : A. Mame, 1897, 146 p. et celui du Comte Charles de BEAUMONT, La maison Bonnin de la Bonninière de Beaumont, Vendôme: H. Chartier, 1907. La date de naissance exacte de Marc Adalbert de Beaumont ne se trouve que dans ce dernier ouvrage (p. 65). Adalbert de 
Beaumont, chevalier de la Légion d'honneur, mourut le 28 avril 1869 à Boulogne-sur-Seine (ou encore « au Parc-des-Princes (Seine) »).

5. Jules QUICHERAT, compte rendu d'Adalbert de Beaumont, Recherches sur l'origine du blason, et en particulier sur la fleur de lis, Paris: Leleux, 1853, 1854, p. 384-386 (Bibliothèque de l'École des chartes, vol. 15).

6. Journal de Eugène Delacroix, Paris : Plon-Nourrit, 1893-1895, tome 3, 1855-1863, p. 5.

7. Paris, musée des Art décoratifs, cabinet des Arts graphiques, CD 4458 à 4482, soit un corpus de quelque 59 dessins et aquarelles consacrés à l'Égypte sur les trois cent onze œuvres graphiques de Beaumont dans les collections du musée. Ces œuvres ont été données pour sept d'entre elles (inv. 979-985) en 1883 au musée des Arts décoratifs, puis passées à la bibliothèque en 1894, par Jeanne Elisabeth Marie de La Croix de Castries, comtesse de Beaumont (1843-1891), en mémoire de son cousin par alliance, Adalbert de Beaumont. Le reste, trois albums de dessins et d'aquarelles, fut donné en 1905 par Louise Adèle Mahot (1817-1909), épouse Collinot, veuve d'Eugène Victor Collinot (1824-1889), céramiste collaborateur et ami d'A. de Beaumont. Les deux ensembles furent réunis au musée lors de la création du cabinet des Arts graphiques en 1974.

8. Adalbert de BEAUMONT, «Les arts décoratifs en Orient et en France. Partie II. L'architecture moderne en Perse (1)», Revue des Deux Mondes, n 65, 1866, sept-oct, livraison du 15 octobre, p. 982.

9. Pour la bibliographie relative à A. de Beaumont, voir Chantal BOUCHON, «Adalbert de Beaumont (Paris 1809-Boulogne 1869), du cap Nord à l'aventure céramique ", Sèvres, 12, 2003, p. 33-43 ; ID., « Voyage, ornement, industrie : Adalbert de Beaumont saisi par l'Orient ", in Rémy LABRUSSE (dir.), Purs décors? Arts de l'Islam, regards du XIX siècle, Paris : Les Arts décoratifs/Musée du Louvre, 2007, p. 242-255.

10. Sur Joseph-Philibert Girault de Prangey, voir Joseph-Philibert GIRAULT DE PRANGEY, Monuments arabes d'Égypte, de Syrie et d'Asie-Mineure dessinés et mesurés de 1842 à 1845, Paris : chez l'auteur, 1846 ; Charles de SIMONY (comte), "Une curieuse figure d'artiste. Girault de Prangey 1804-1892 », Mémoires de l'Académie des sciences, arts et belles-lettres de Dijon, 1934, p.55-62). http:// gallica.bnf.fr/ark:/12148/bpt6k5613916m.r=.langFR. Consulté le 30 septembre 2010. Philippe QUETTIER (dir.), Sur les traces de Girault de Prangey 1804-1892. Dessins - peintures - photographies - études historiques, Langres: Musée de Langres/D. Guéniot, 1998; Frédéric HITZEL et Sophie MAKARIOU, «Girault de Prangey Joseph-Philibert (Langres, 1804-Courcelles-Val-d'Esnoms, 1892)», in François PoullLon (dir.), Dictionnaire des orientalistes de langue française, Paris: Karthala, 2008, p. 446-448.

11. Gérard de NERVAL, Voyage en Orient, Paris : Charpentier, 1851, $3^{\mathrm{e}}$ éd., tome 1.

12. Adalbert de BEAUMONT, «Les arts décoratifs en Orient et en France. Partie II. L'architecture moderne en Perse (1) », op. cit. (note 8), p. 990-991.

13. Le croisement de cette information avec d'autres sources contemporaines permet d'identifier ce personnage avec un certain Portier, marchand, naturaliste français, souvent mentionné comme actif à Livourne, et qui entreprit, à la fin de 1843, un voyage aux bords de la mer Rouge dans le but d'étudier les produits de la mer, voyage financé grâce à une souscription faite par plusieurs Européens résidant alors en Égypte. Émile Prisse d'Avennes rapporte dans ses notes (Paris, BnF, MS Nouv. acq. fr. 20420 fol. 65) que Portier, qui avait des " goûts antinaturels » et fréquentait les lieux où se réunissaient les pouchter [sic], fut assassiné à son domicile (vraisemblablement en 1848, selon Victor LOTTIN DE LAVAL, Voyage dans la Péninsule arabique du Sinaï et l'Égypte moyenne. Histoire, géographie, épigraphie, Paris: Gide et $C^{\mathrm{ie}}, 1855-1859$, p. 265). Nous remercions Mercedes Volait pour l'information trouvée dans les papiers Prisse d'Avennes.

14. "Minaret Ibrahim-Agha comparé à l'astrée polygonale», Recueil de dessins pour l'art et l'industrie (exemplaire de la BnF, département des Estampes et de la Photographie, Paris, 1859, pl. 
192-193 ; planches portant la date de dépôt légal 1866), cité dans Adalbert de BEAUMONT, «Les Arts décoratifs en Orient et en France ", op. cit. (note 8), p. 982-983.

15. «La Polynésie », Le Correspondant, 75, 1868, partie 5, p. 137.

16. Adalbert de BEAUMONT, « Les Arts décoratifs en Orient et en France », op. cit. (note 8), p. 984.

17. Dominique JACOBI (dir.), Pascal Coste, toutes les Égypte, Marseille : Parenthèses/Bibliothèque municipale de Marseille, 1998.

18. Jürgen EICHENAUER, Martin BOMMAS, Friedrich Maximilian Hessemer (1800-1860). Ein Frankfurter Baumeister in Ägypten [Ausstellung: 4-30.12.2001], Francfort-sur-le-Main: Kramer, 2001, 274 p. Voir supra, Maryse BIDEAULT, « "Mein Fritz geht nach Aegypten!" Friedrich Maximilian Hessemer sur les traces de l'arc brisé au Caire », p. 17-40.

19. Théophile GAUTIER, "Marilhat ", Revue des Deux Mondes, n²3, 1848, $1^{\text {er }}$ juillet, p. 56-75 ; ID., Portraits contemporains, Paris : Charpentier, 1874, p. 239.

20. Adalbert de BEAUMONT, « Les Arts décoratifs en Orient et en France », op. cit. (note 8), p. 988.

21. Paris, musée des Arts décoratifs, cabinet des Arts graphiques, CD 4458.

22. Paris, musée des Arts décoratifs, cabinet des Arts graphiques, CD 4459.

23. Paris, musée des Arts décoratifs, cabinet des Arts graphiques, CD 4467.

24. Paris, musée des Arts décoratifs, cabinet des Arts graphiques, CD 4468, "Côté opposé au sanctuaire de la mosquée El Goury. Le Caire, février 1844 ». Le dessin est repris dans le Recueil de dessins pour l'art et l'industrie (exemplaire de la BnF, 1859, pl. 212 (dépôt légal 1866) et dans Ornements arabes. Recueils de dessins pour l'art et l'industrie, gravés par Eugène CoLLINOT, et Adalbert de BEAUMONT, Paris : Canson, 1882, pl. 24.

25. Il est probable que le décollage de certaines feuilles encore collées en plein sur un type de papier kraft propre aux Albums Maciet, appartenant alors à la bibliothèque des Arts décoratifs, qui ont abrité jusqu'en 1974 les œuvres graphiques d'A. de Beaumont, révélerait, au dos des pièces, des esquisses et notes intéressantes.

26. Jean Joseph Sulpis (1826-1911), graveur d'architecture qui fut l'élève de Jean-Baptiste Bury et de Traversier, qui grava surtout pour les ouvrages de Jules Gailhabaud entre 1850 et 1858 mais aussi pour l'Encyclopédie d'architecture. Sur Sulpis voir l'article dans Allgemeines Lexikon der Bildenden Künstler von der Antike bis zur Gegenwart, Leipzig [1907-], 1938, vol. 32, p. 287.

27. Cet ouvrage devait être composé de six volumes subdivisés en 300 livraisons. Chaque livraison, au format grand in $-4^{\circ}$, était faite de huit pages de texte enrichies de vignettes sur bois, d'une planche gravée sur métal ou lithographiée, et d'une chromolithographie. La planche gravée par Jean Joseph Sulpis (1826-1911) n'est pas listée dans l'annonce des livraisons à venir publiée en quatrième de couverture de la première et unique livraison. Cette épreuve qui est, à l'heure actuelle la seule connue, se trouve dans le fonds Prisse d'Avennes de la Bibliothèque nationale de France (MS Nouv. acq. fr. 20442 (2) -27- VI-3, « Art arabe : Dessins : Monuments non égyptiens, 3 », f. 5). Seule la mention de cette estampe sous le $n^{\circ} 1767$ du Salon de 1853 (Explication des ouvrages de peinture, sculpture, gravure, lithographie et architecture des artistes vivants, exposés aux Menus-Plaisirs le 15 mai 1853, Paris : Vinchon, 1853, p. 296) permet de savoir que cette planche était destinée au Miroir de l'Orient. Nous remercions Maryse Bideault de nous avoir communiqué cette information.

28. Il est à noter que cette planche inédite est à la fois très proche et différente de la planche XIII (Mosquée de Mohammed-ben-Qalaoun, vue du mihrab ( $\mathrm{XI}^{e}$ siècle) gravée par Frédéric Sorrieu dans le volume 1 de l'ouvrage d'Émile PRISSE D'AVENNES, L'Art arabe d'après les monuments du Kaire depuis le VII siècle jusqu'à la fin du XVIII , Paris : J. Savoy \& Cie, [1869]-1877 (pour la $1^{\text {ère }}$ édition, tirage de luxe).

29. Paris, musée des Arts décoratifs, cabinet des Arts graphiques, CD 4449, 4469, 4470, 4471, 4472, 4473, 4474, 4475, 4476.

30. Adalbert de Beaumont cité dans Adolphe JOANNE, op. cit. (note 1), p. 67-68. 
31. Paris, musée des Arts décoratifs, cabinet des Arts graphiques, CD 4479, CD 4480.

32. Marseille, Bibliothèque de Marseille à vocation régionale, L'Alcazar, MS 1310, fol. 42.

33. Adolphe JOANNE, Voyage illustré dans les cinq parties du monde, op. cit. (note 1), p. 231 et gravures par M. Freeman d'après A. de Beaumont, p. 200-201, n 324-325.

34. The Florist, fruitist, and garden miscellany, vol.12, 1859, p. 260.

35. Georges Ville (1824-1897), botaniste, professeur au Muséum d'histoire naturelle, se rendit en Égypte en 1864 pour diriger les cultures de propriétés khédiviales. Les deux hommes se fréquentèrent au moins à partir des années 1855. Une correspondance d'A. de Beaumont avec $\mathrm{G}$. Ville est conservée dans: Paris, Archives MNHN, Ms 2642, pièces 1-201, Correspondance Ville. $\mathrm{N}^{\circ} 35$ : il évoque les travaux qu'il menait pour son Recueil, en cours d'élaboration : « Je suis dans le coup de feu de nos arrangements arabo=turco=Persico=Chimico=Indousta nico=fantasmagniki, ....Adio Salam alek we barakat alla !.. ».

36. Adalbert de BEAUMONT, "Les arts décoratifs en Orient et en France. Sèvres ", Revue des Deux Mondes, $n^{\circ} 39$, juin 1862, p. 832, note 1 . Voir Paris, musée des Arts décoratifs, cabinet des Arts graphiques, CD $6565 \mathrm{~A}$ [Deux personnages en costume traditionnel].

37. «Ayant rencontré près de chez moi un de ces hommes dont les haillons bizarres et l'atroce figure composaient un tout fort laid, mais certainement fort pittoresque, je le fis entrer afin d'en prendre un croquis. Il portait sur son dos un sac rempli de serpents qu'il déposa à terre ; puis, ayant fait entendre un léger sifflement, cinq ou six de ces animaux s'élancèrent du sac et se dressèrent autour de lui ", dans Adolphe JOANNE, op. cit. (note 1), p. 80.

38. Paris, musée des Arts décoratifs, cabinet des Arts graphiques, CD 4481 . Voir Rémy LABRUSSE (dir.), op. cit. (note 9), p. 345, cat. 247, reprod.

39. Paris, musée des Arts décoratifs, cabinet des Arts graphiques, CD 6565n.

40. Voir le prospectus inséré dans la première et unique livraison du Miroir de l'Orient ou tableau historique des croyances, mœurs, usages, sciences et arts de l'Orient musulman et chrétien.

41. Sur Prisse d'Avennes voir Marie-Laure PRÉvost (dir.), Visions d'Égypte. Émile Prisse d'Avennes (1807- 1879), Paris : BnF, 2011 ; Jean-Marie CARRÉ, Voyageurs et écrivains français en Égypte, vol. 1, Paris : Institut français d'archéologie orientale du Caire, 1932, p. 301-323 ; Mercedes volaIT, notice sur Prisse d'Avennes, in Dictionnaire critique des historiens de l'art actifs en France de la Révolution à la Première Guerre mondiale (http://www.inha.fr/spip.php?rubrique347 (mis en ligne le 25 mai 2011). 42. Adalbert de BEAUMONT, Recherches sur l'origine du blason et en particulier sur la fleur de lis, Paris: Leleux, 1853. Dans la table des planches, les figures 1 à 4 de la planche IV sont dites exécutées d'après des dessins originaux de M. Prisse d'Avennes.

43. Ibid., pl. IV, p. 9, fig. 1-4. Prisse émit des réserves quant à la démarche de Beaumont (voir Émile PRISSE D'AVENNES, L'Art arabe d'après les monuments du Kaire, Paris, [réed. L'Aventurine, 2002], p. 80 : «Quant à la fleur de lys, que M. de Beaumont a cru retrouver partout en Orient, nous n'en dirons qu'un seul mot : ...nous n'avons cru la reconnaître qu'une seule fois, dans une mosaïque où se trouvait un fleuron (fig. 4-5)».

44. Emmanuel HECRE, Les Orients de Charles Cournault, Malzéville : Éd. Serge Domini, 2004, p. 195. Beaumont mentionne un dessin provenant de Prisse dans le Recueil, 1859, pl. 178, «dessin du quart d'un des deux panneaux de la porte en érable sculpté de l'église de la Vierge, édifiée par sainte Hélène au Vieux Caire ", Ornements arabes, 1883, pl. 15.

45. Paris, musée des Arts décoratifs, cabinet des Arts graphiques, CD 4421. Il existe dans ce même ensemble d'œuvres graphiques, une autre aquarelle d'un intérieur de maison cairote (CD 4464). Il est toutefois impossible d'affirmer qu'il s'agit de la même demeure.

46. Daniel LANçON, L'Égypte littéraire de 1776 à 1882. Destin des antiquités et aménité des rencontres, Paris : Geuthner, 2007.

47. Le géographe genevois Paul Chaix (1808-1901) rapportait dans ses Lettres écrites sur les bords du Nil (publiées tout d'abord dans la Bibliothèque universelle de Genève et archives des sciences, 1847, 
vol. 6, p. 523) : «Enfin, le nombre des étrangers fixés au Caire, et la nature relevée des goûts de la plupart, ont permis la formation d'une Association littéraire égyptienne, anglaise principalement, et dont l'accès est une bonne fortune pour le voyageur qui peut y être introduit ».

48. Paris, musée des Arts décoratifs, cabinet des Arts graphiques, CD 6565 p. «Une cange contient deux chambres, élégamment peintes et dorées à l'intérieur, avec des fenêtres grillées donnant sur le fleuve, et encadrant agréablement le double paysage des rives; des corbeilles de fleurs, des arabesques compliquées décorent les panneaux; deux coffres de bois bordent chaque chambre, et permettent, le jour, de s'asseoir les jambes croisées, la nuit, de s'étendre sur des nattes ou des coussins. » (Gérard de NERVAL, Voyage en Orient, op. cit. (note 11), p. 258).

49. Voir la note 24 .

50. La première de ces contributions est consacrée aux « Méchitaristes. Notice sur le couvent des Arméniens à Venise et à Paris ", Revue orientale et algérienne, $\mathrm{n}^{\circ} 1,1852 / 1$, janvier, p. 71-84; la seconde à la «Restauration de Sainte-Sophie de Constantinople. Découverte des anciennes mosaïques », ibid. 1852/2, p. 160-175; la troisième, "Voyage en Asie Mineure. Brousse » paraît sous forme de trois articles (ibid., 1852/4, avril, p.478- 492; 2, 1853/1, mai, p.65-85 et ibid. p. 320-349).

51. Emmanuel HECRE, op. cit. (note 44).

52. Ibid., p. 104-133.

53. Lettre adressée par A. de Beaumont à Ch. Cournault en octobre 1861, dans ibid., p. 168.

54. Chantal BOUCHON, op. cit. (note 9).

55. Émile PRISSE D'AVENNES, op. cit. (note 28).

56. Alexis sоцтүкоғғ publia Voyages dans l'Inde, Paris: L. Cumer, 1851 et Voyage en Perse, Paris : L. Cumer et V. Lecou, 1851. L'exceptionnelle collection qu'il avait constituée fut dispersée à Paris en plusieurs vacations du 8 avril au $1^{\mathrm{er}}$ mai 1861 .

57. Voir Emmanuel HECRE, op. cit. (note 44), p. 140-141.

58. Lettre 21 juin 1863 signée Adalbert de Beaumont, adressée à «Mon cher et excellent directeur... Et sur ce je termine à la manière arabe par l'Essalam Alek we barakat Alla... » (Paris, Archives du Louvre et des musées nationaux, Z 61).

59. Jean-Noël MARCHANDIAU, L'Illustration 1843/1944. Vie et mort d'un journal, Paris : Privat, 1987, p. 30-31.

60. Adalbert de BEAUMONT, « De la magie et du magnétisme en Orient. Dessins de MM. Cournault et Adalbert de Beaumont ", L'Illustration, t. XI, 1848, n² 262, 4 mars, p. 11-15, reprod. p. 15. Le dessin au crayon sur calque est conservé à Paris, musée des Arts décoratifs, cabinet des Arts graphiques, CD 6566 D. Dans cet article, Beaumont, dont l'attrait pour le magnétisme est connu, cite une publication de Léon de Laborde : Recherches sur ce qu'il s'est conservé dans l'Égypte moderne de la science des anciens magiciens, Paris : J. Renouard, 1841. Cette même illustration est publiée concomitamment dans Adolphe JOANNE, Voyage illustré dans les cinq parties du monde... op.cit. (note 1), p. 205, gravure $\mathrm{n}^{\circ} 332$.

61. Adalbert de BEAUMONT, «El Tennour ", L'Illustration, t. XIX, 1852, $n^{\circ} 464,24$ janvier, p. 61-62. Il existe un dessin de cet objet par Charles Cournault précisant que son ami l'a acheté à Venise en 1845 (voir Emmanuel HECRE, op. cit. (note 44), p. 147) et Rémy LABRUSSE (dir.), op. cit. (note 9), p. 224, fig. 4, reprod.

62. Adalbert de BEAUMONT, Recherches sur l'origine du blason..., op. cit. (note 42), p. 2-5.

63. Ibid., p. 7-8.

64. Ibid., p. 17. Voir supra pour sa fréquentation du Jardin des plantes.

65. Jules QUICHERAT, op. cit. (note 5).

66. Jules Laurens (1825-1901) peintre, élève de Paul Delaroche, qui, après son échec au concours du Prix de Rome en 1845, partit en voyage en Orient en compagnie du géographe Xavier 
Hommaire de Hell. C'est un véritable périple qu'ils vécurent ensemble en parcourant la Grèce, la Moldavie, l'Anatolie et la Perse pendant plus de trois ans. Jules Laurens en rapporta plus d'un millier de croquis et les notes de voyage de son compagnon qui mourut à Ispahan (Iran) avant son retour. Voir Dictionnaire des orientalistes de langue française, op. cit. (note 10), p. 570.

67. Ceci est confirmé par l'exemplaire de la BnF qui porte la mention du dépôt légal 2558, 1873 (Pl. 248 : Lampe en verre émaillé d'une mosquée du Caire, $12^{e}$ siècle, collection Sheffer signé b.g. A de Beaumont inc, b.d.impr. Lemercier); or elle a dû être copiée en 1863 (voir Emmanuel HECRE, op. cit. (note 44), p. 175). Selon une lettre d'A. de Beaumont adressée à C. Cournault : « J'ai vu chez [Charles-Henri-Auguste] Schefer l'interprète de l'Empereur la plus belle collection d'objets d'Orient en tous genres! Plats en faïence de Perse, vases en cuivre, lampes en verre, en métal etc. C'est du plus haut intérêt, et j'espère bien y travailler ; du moins il me l'a offert, il est vrai, sur ma demande... » La planche 58 reproduit aussi une lampe de mosquée appartenant, elle, à la collection A. de Rothschild, planche portant 1862 comme date de dépôt légal, voir aussi : Emmanuel HECRE, op. cit. (note 44), reprod. p. 169 et p. 174.

68. [Prospectus] du Recueil de dessins pour l'art et l'industrie par Adalbert de Beaumont et E. Collinot. (coll. part.). Elles sont tirées en taille-douce par l'éditeur Rapilly bientôt relayé par l'imprimerie Delâtre puis par l'imprimerie Lemercier. Paris, Archives du Louvre et des musées nationaux, Lettre d'A. de Beaumont au comte de Nieuwerkerke datée de 1859: «Agréez comme œuvre qui n'a d'autre prétention que celle d'être utile à notre industrie fourvoyée. Je publie (ad vitam) 3 planches par mois. Rien n'est composé ; je ne fais que reproduire exactement ce qui m'a paru beau de par le monde... »

69. Rémy LABRUSSE, «Face au chaos: grammaires de l'ornement ", Perspective, 2010/2011, 1, p. $102-103$.

70. Sur Eugène-Victor Collinot (1824-1889), voir la notice de Chantal Bouchon dans Rémy LABRUSSE (dir.), op. cit. (note 9), p. 312.

71. Chantal воUchon, op. cit. (note 10), p. 245-246.

72. Adalbert de BEAUMONT et Eugène COLLINOT, Ornements arabes: Recueil de dessins pour l'art et l'industrie, Paris : Canson, 1883. On trouve dans cette publication une planche inédite (pl. 26) qui ne se trouve pas dans le Recueil entrepris en 1859. Quoique d'un dessin plus que malhabile et d'une mise en couleurs négligée, on peut toutefois reconnaître dans ce portail celui de l'okel de Qâytbây ( ${ }^{\circ} 75$ du Comité de conservation des monuments de l'art arabe).

73. Geneviève BRESC-BAUTIER, «Laborde, Léon-Emmanuel-Simon-Joseph (vicomte, comte puis marquis de)", in Dictionnaire critique des historiens de l'art actifs en France de la Révolution à la Première Guerre mondiale (http://www.inha.fr/spip.php?rubrique347 (consulté le 4 avril 2011).

74. Léon de LABORDE, "L'Orient et le Moyen-Âge », La France littéraire, 1833, octobre-novembre, p. 6, note 1. A. de Beaumont avait cité L. de Laborde en référence dans son article relatif à la magie en Orient : «Recherches sur la magie égyptienne », L'Illustration, t. XI, 1848, n² 262, 4 mars, p. 14.

75. ID., De l'union des arts et de l'industrie. t. 1 : Le Passé, t. 2 : L'Avenir, Paris : Imprimerie impériale, 1856,1, p. 241.

76. ID., op. cit.(note 75), t. 2, p. 229.

77. Adalbert de BEAUMONT, "De l'Union des arts et de l'industrie ", L'Illustration, t. 29, 1857, $\mathrm{n}^{\circ} 738,18$ avril, p. 246-247.

78. Revue des Deux Mondes, $\mathrm{n}^{\circ}$ 39, 1862, p. 947 et 949.

79. Paris, Archives du Louvre et des musées nationaux, Z 61, Paris, dossier Union centrale des Beaux-arts appliqués à l'industrie, 1864.

80. Sur l'activité de céramistes d'A. de Beaumont et d'E. Collinot, voir Chantal Bouchon, op. cit. (note 9). Voir aussi la notice consacrée à Collinot et $\mathrm{C}^{\text {ie }}$ dans Florence sLITINE, Sèvres, BoulogneBillancourt. La céramique indépendante, Luxembourg : Argusvalentines, 2007, p. 74-77. 
81. Adalbert de BEAUMONT, "Arts industriels en France et l'Exposition de 1863 ", Revue des Deux Mondes, $n^{\circ} 47,1863$, p. 1000. Charles Blanc qui, ayant voyagé en Égypte, eut un rôle important dans le développement de la décoration musulmane, souligna le rôle pionnier de Beaumont relatif aux lois de la couleur. Voir Charles BLANC, Grammaire des arts du dessin, Paris : Ensba, 2000, p. 539.

82. Il signale la collection du docteur Meymarie, au Caire, dont les objets proviennent de la mosquée Ibn Tulun. Voir «Les arts décoratifs en Orient et en France. Une visite en Orient à l'Exposition universelle ", Revue des Deux Mondes, $n^{\circ} 72,1867,1^{\text {er }}$ novembre, p. 143, et Mercedes volAit, Fous du Caire, excentriques, architectes et amateurs d'art en Égypte, 1863-1914, Montpellier : L'Archange Minotaure/CNRS/INHA, 2009, p. 198.

83. Adalbert de Beaumont partage le point de vue de Prisse d'Avennes quant à l'arabesque. Voir le paragraphe « Ornementation », dans PRISSE D'AVENNES, op. cit. (note 43), p. 238-243.

\section{AUTEUR}

\section{CHANTAL BOUCHON}

Conservateur honoraire, responsable du département des Arts graphiques, musée des Arts décoratifs, Paris. 


\title{
Visiter Le Caire en compagnie d'Émile Isambert, auteur de l'Itinéraire descriptif de l'Orient
}

\author{
Hélène Morlier
}

\begin{abstract}
Émile Isambert (1827-1876) fut le coauteur avec Adolphe Joanne d'un guide intitulé Itinéraire descriptif de l'Orient publié par la Librairie Hachette en 1861, dans le cadre de la collection des guides Joanne (fig. 1). Cette importante collection de guides de voyage affirmait la double vocation de s'adresser aux voyageurs, plus ou moins intrépides selon les destinations, et aux érudits qui consultaient l'ouvrage en chambre. Il rédigea ensuite la nouvelle édition dont les trois volumes parurent respectivement en 1873, 1878 et 1882 , les deux derniers volumes publiés à titre posthume.
\end{abstract}


1. Couverture du guide Joanne, Itinéraire de l'Orient.

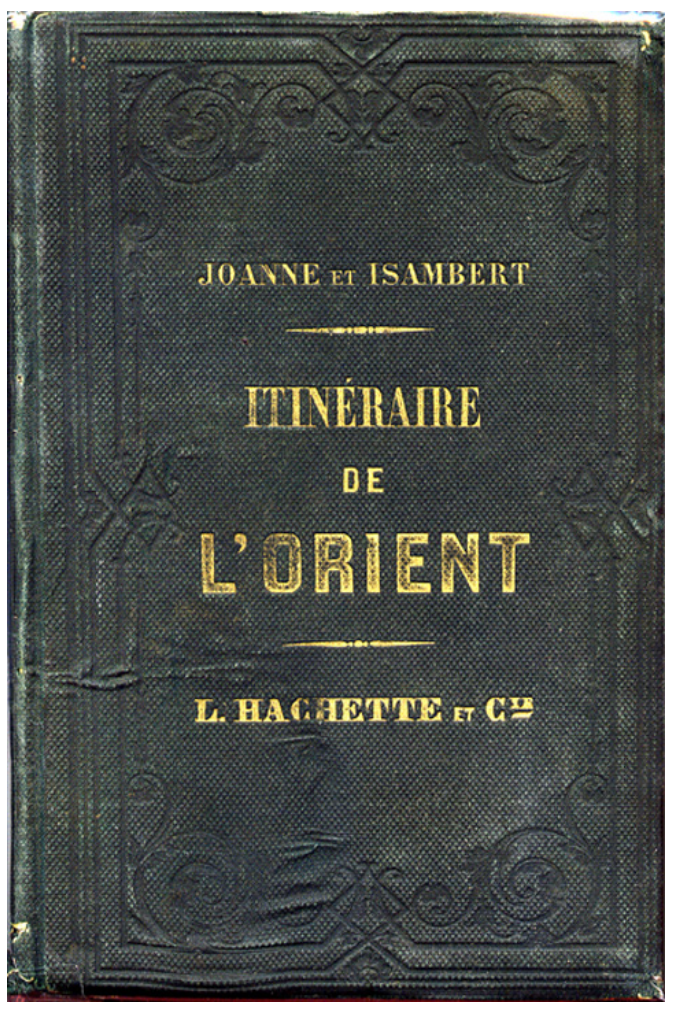

Source : Émile Isambert et Adolphe Joanne, Itinéraire descriptif de l'Orient, Paris : Librairie Hachette, 1861.

2 Émile Isambert était l'un des trois fils de François André Isambert (1792-1857), avocat qui s'illustra en particulier dans la lutte pour l'abolition de l'esclavage. Il fut l'un des fondateurs de la Société de géographie en 1821 et l'auteur de nombreux ouvrages juridiques de référence. Esprit très ouvert et érudit, il possédait une bibliothèque riche de nombreux ouvrages d'archéologie parmi lesquels l'ensemble des volumes de la Description de l'Égypte ${ }^{1}$. Son fils Émile était un médecin, fondateur notamment du service de laryngologie des hôpitaux de Paris à Lariboisière (IX ${ }^{\mathrm{e}}$ arrondissement). Il collaborait à plusieurs revues médicales et créa les Conférences cliniques sur les maladies du larynx et des premières voies, publiées à titre posthume. Ce médecin très actif était aussi un amateur d'art éclairé comme en témoigne le catalogue de vente de sa collection de tableaux le 9 mars $1877^{2}$, mais surtout un grand voyageur (fig. 2). C'est à ce titre qu'il collabora avec Adolphe Joanne, lui-même voyageur, pour rédiger le premier guide de l'Orient digne de ce nom en langue française. 


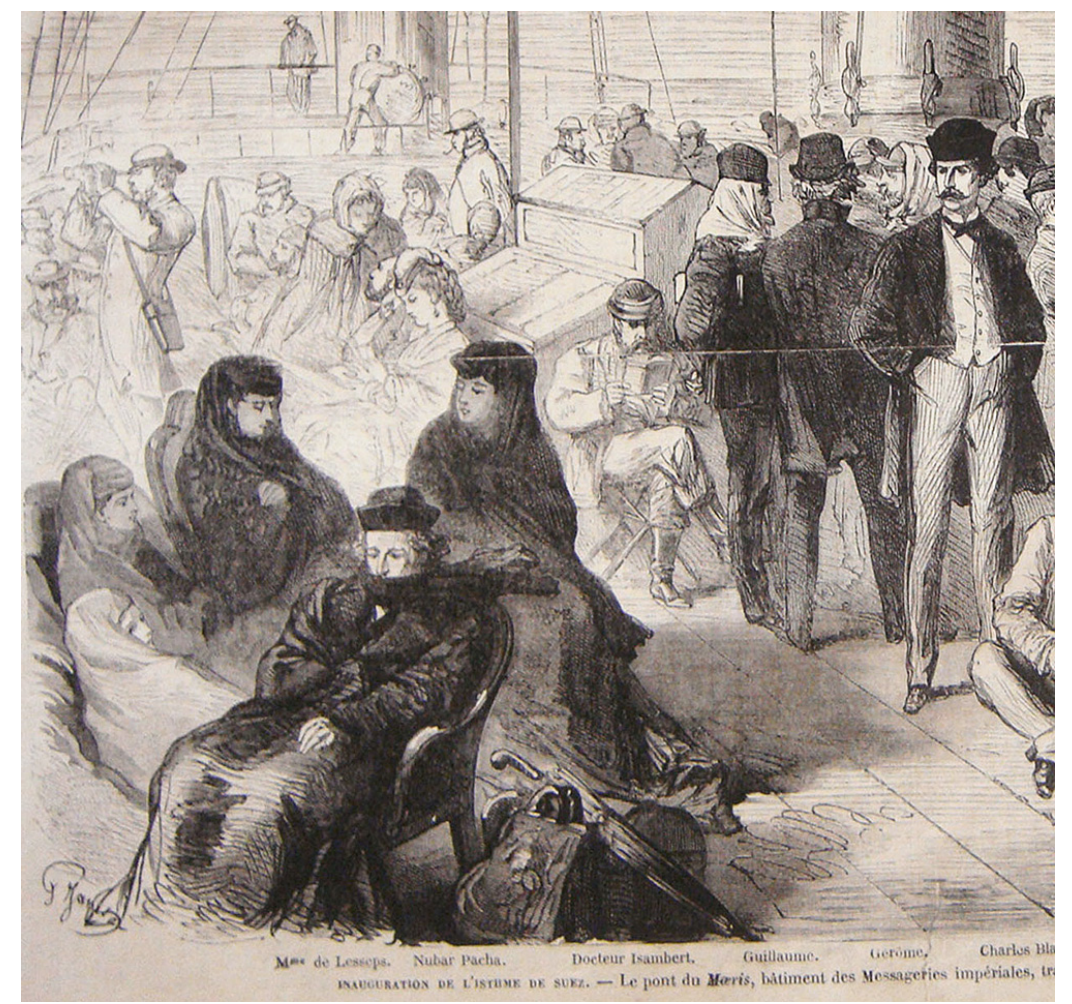

Le Moeris était un navire qui transportait des invités officiels pour les festivités d'inauguration du canal de Suez Isambert lit, assis en retrait, au second plan.

Source : Le Monde illustré, 15e année, 654, 25 octobre 1869, p. 265.

3 Isambert avait effectué un premier périple en Orient pendant l'hiver 1856, en compagnie de plusieurs voyageurs anglais dont $\mathrm{W}$. Coppinger, érudit protestant antiesclavagiste, qui participa ensuite à la description de la Grèce, de la Morée et de la Terre Sainte de l'Itinéraire descriptif de l'Orient. Le 18 juin 1858, Isambert fut présenté à la Société de géographie par Alfred Maury et Victor Malte-Brun ${ }^{3}$. Il signa le 15 juillet 1858 un contrat avec les éditions Hachette pour rédiger en qualité de coauteur un guide de l'Orient qui

«[...] contiendra la Grèce, les routes principales de la Turquie d'Europe et d'Asie, la Syrie, la Palestine et l'Égypte, en un mot toutes les localités visitées habituellement par les touristes qui font un voyage en Orient ${ }^{4} »$.

Isambert entreprit seul le voyage, alors que Joanne, retenu par ses tâches de directeur de la collection de guides, restait à Paris mais réunissait la documentation complémentaire. Au moment de sa parution, le guide fut l'objet d'un compte rendu élogieux rédigé par Victor Malte-Brun, pour le Bulletin de la Société de géographie ${ }^{5}$ :

«L'Orient, ce berceau de notre religion et de notre civilisation, cette contrée que l'imagination pare toujours de ses plus brillantes couleurs, conserve le privilège d'attirer chaque année un grand nombre de visiteurs de notre pays. C'était leur rendre un signalé service que de réunir en un seul volume les notions les plus indispensables qui peuvent rendre à tous ce voyage fructueux. MM. Adolphe Joanne et Émile Isambert l'ont tenté avec succès dans leur Itinéraire descriptif de l'Orient. La géographie et l'archéologie ont une grande part dans cet utile ouvrage, pour lequel les auteurs ont puisé aux meilleures sources et qu'ils ont enrichi de cartes d'une exécution remarquable ». 
5 géographie.

\begin{abstract}
De quels guides disposait le voyageur avant la parution de l'tineraire descriptif de lorient l'ensemble de l'Orient ${ }^{6}$; beaucoup de ces ouvrages étaient destinés aux voyageurs en route pour l'Inde et l'Extrême-Orient qui profitaient de leur traversée obligée de l'Égypte pour visiter le pays. Seul le guide Murray de l'Égypte, rédigé par Sir Wilkinson et paru en $1858^{7}$, était mentionné dans l'abondante bibliographie générale du guide Joanne qui répertoriait 151 titres sur l'Orient dont 27 pour l'Égypte. L'unique guide en langue française datait de 1851: Guide en Orient, Itinéraire scientifique, artistique et pittoresque, par Richard et Quétin ${ }^{8}$; Isambert possédait le Murray ${ }^{9}$. Il était donc temps de publier un guide qui corresponde aux attentes des voyageurs de plus en plus nombreux qui succombaient à la mode du voyage en Orient. Isambert allait-il s'inspirer directement des ouvrages existants ou faire preuve d'innovation pour la rédaction de son guide ? L'exemple de la visite du Caire permet de faire le point sur sa démarche.
\end{abstract}

\title{
Les « modèles » et les guides précurseurs de l'Itinéraire descriptif de l'Orient (1861)
}

\section{L'Aperçu de l'Égypte de Clot bey (1840)}

7 Publié en 1840 , ce livre ${ }^{10}$ n'est pas à proprement parler un guide au sens actuel du terme (fig. 3). Toutefois, Isambert avait une grande estime pour cet ouvrage qui figure dans la bibliographie de son propre guide ${ }^{11}$. Un double astérisque devant ce titre indiquait qu'il conseillait de l'emporter en voyage. 


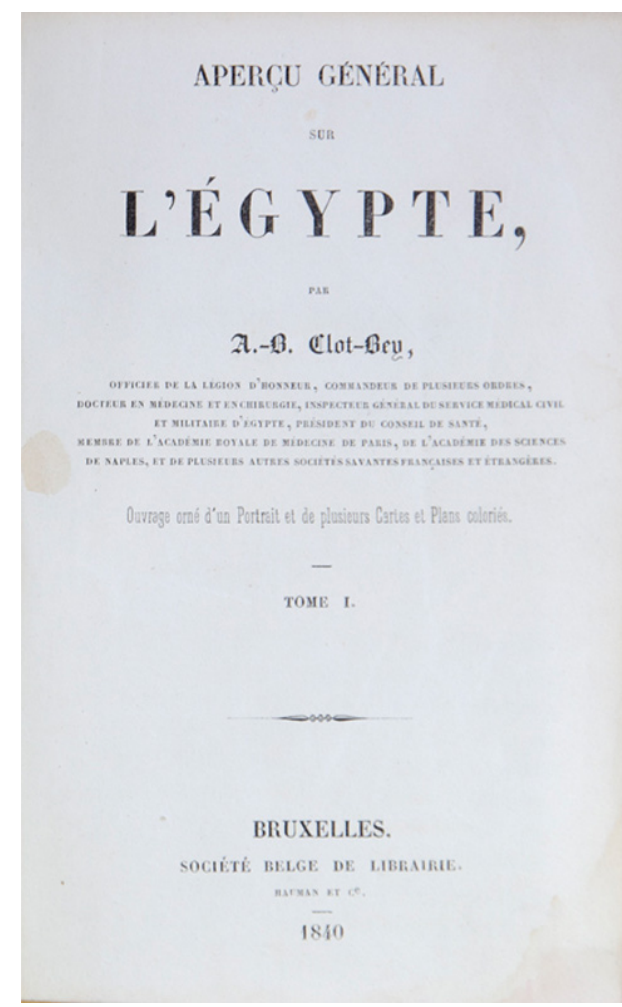

Source : Antoine Barthélémy cLot-BEY, Aperçu de l'Égypte, Ouvrage orné d'un portrait et de plusieurs cartes et plans coloriés, Bruxelles : Société belge de Librairie, 1840.

L'ouvrage d'Antoine Barthélemy Clot (1793-1868), médecin de Muhammad 'Ali et fondateur de l'école de médecine du Caire, est un condensé entre autres de connaissances géographiques, historiques, juridiques, religieuses ou sociologiques ainsi que d'observations de l'auteur qui passa de nombreuses années dans ce pays. Cette présentation des spécificités locales permet encore de nos jours d'appréhender l'Égypte de la première moitié $\mathrm{du} \mathrm{XIX}^{\mathrm{e}}$ siècle. Plusieurs sections sont consacrées à l'architecture publique et privée ainsi qu'à l'urbanisme - ou plutôt à son absence comme le souligne Clot bey ${ }^{12}$. La description des maisons citadines contient des remarques d'ordre général quant à leur distribution en relation avec les usages de la société musulmane ; l'auteur souligne l'existence des moucharabiehs et s'appesantit sur l'importance de la distribution de l'eau par les fontaines et de son usage dans les bains. La section dévolue aux édifices cultuels est plus détaillée : les particularités historiques et architecturales sont mises en exergue et reliées aux mœurs ou aux cérémonies locales. À propos de la mosquée de 'Amr, par exemple, Clot bey rapporte que :

«Lorsque la crue du Nil est tardive et qu'une disette est à craindre pour l'année prochaine, il est d'usage que le chef du gouvernement invite les ulémas, les cheiks, les rabbins, les prêtes cophtes, grecs et catholiques, à se rendre à la mosquée d"Amr, avec leurs coreligionnaires : chaque secte alors se réunit en groupe hors de l'enceinte de la mosquée pour implorer le secours du ciel, obtenir une bonne inondation et conjurer ainsi les malheurs qui menacent le pays ${ }^{13} »$.

Clot-Bey décrit les principales mosquées signalées ensuite par tous les guides: 'Amr, Ibn Tulun, al-Azhar, Barquq, Qalawun, Hasan, al-Mu'ayyad, Qaytbay. Il consacre un paragraphe aux minarets dont il indique la fonction et ajoute à ceux des mosquées déjà 
mentionnées celui de la mosquée d'al-Ghawri qu'il considère comme "les plus intéressants ».

Dans un dernier paragraphe intitulé «Tombeaux ", l'auteur décrit les deux groupes de sépultures réparties au nord-est et au sud du Caire.

Cet Aperçu est enrichi de cartes (l'Égypte avec l'indication des villes anciennes, le delta, les barrages du Nil) et plans de villes dépliants (Alexandrie, son arsenal, Le Caire [fig. 4]). Cette abondance de documents graphiques doit être soulignée, car elle est rare pour les ouvrages contemporains de synthèse et de petit format. Isambert $\mathrm{y}$ a certainement trouvé une source d'inspiration pour son guide.

\section{Plan du Caire inséré dans l'Aperçu de l'Égypte de Clot bey.}

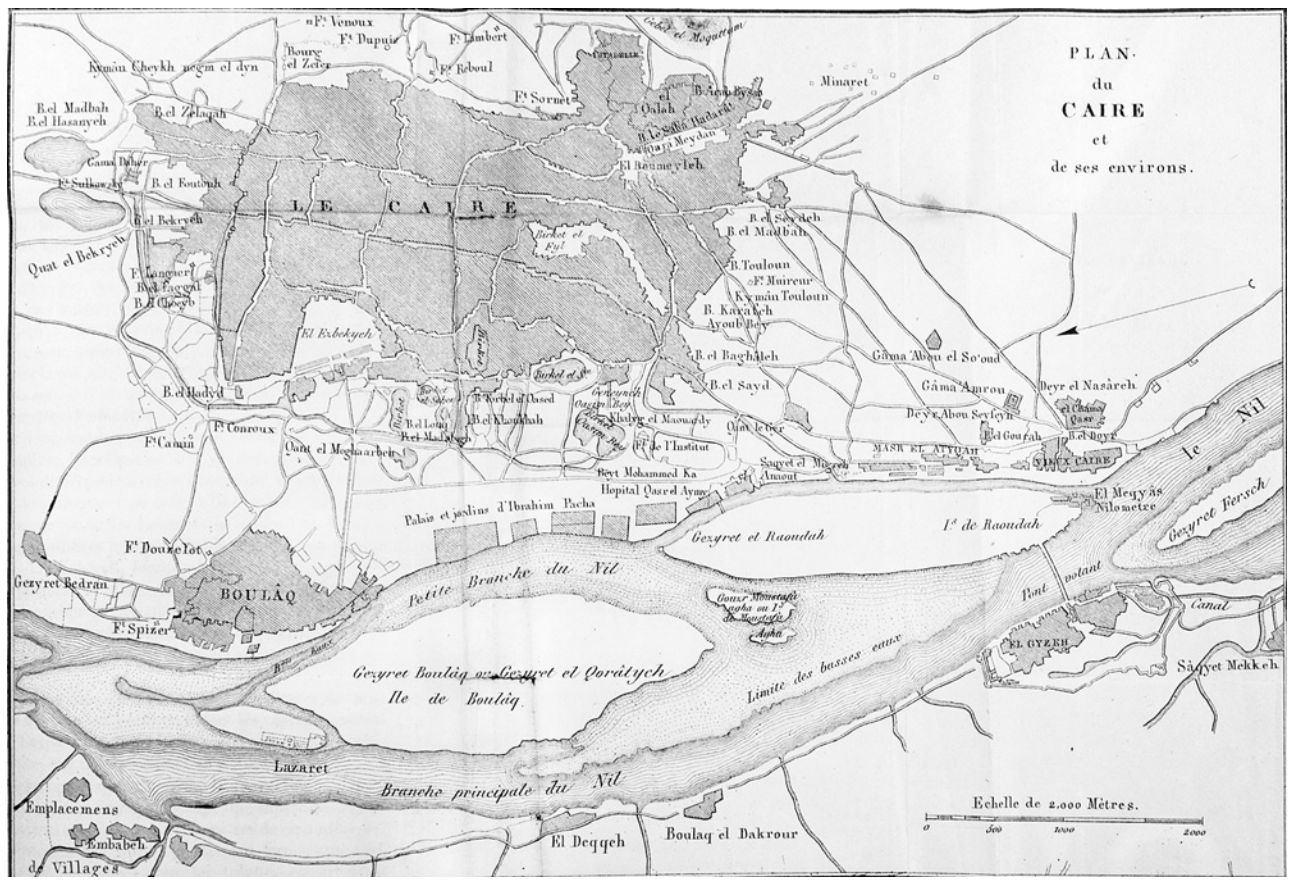

Source : Antoine Barthélémy cLOT-BEY, Aperçu de l'Égypte, Ouvrage orné d'un portrait et de plusieurs cartes et plans coloriés, Bruxelles : Société belge de Librairie, 1840.

\section{Le Guide en Orient de Richard et Quétin (1851)}

Richard est le pseudonyme de Jean-Marie Vincent Audin, auteur et éditeur de guides de voyage depuis 1823. Ces publications furent vendues au célèbre éditeur de guides Louis Maison, qui à son tour céda ses collections à la librairie Hachette. Louis Quétin est un auteur de guides de voyages, parfois rédigés en collaboration avec Richard.

Le guide rédigé par Richard et Quétin ${ }^{14}$ était certainement encore disponible en librairie ou au moins en bibliothèque quand Isambert prépara son voyage (fig. 5). Moins d'une dizaine de pages y sont consacrées à la ville du Caire, dont la majeure partie est constituée d'extraits de récits ou de considérations générales qui auraient dû être placées en tête de section ${ }^{15}$. Le texte parfois rédigé à la première personne - est-ce une citation non signalée d'un récit de voyage ${ }^{16}$ ? - donne des impressions personnelles banales (foule, bruit, etc.). 


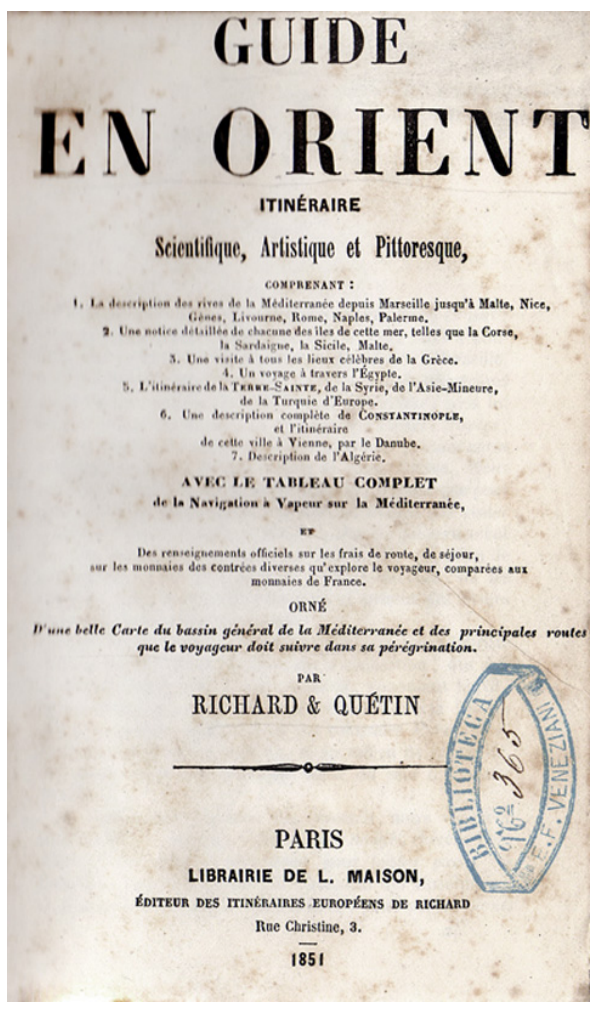

Source : RICHARD et QUÉTIN, Guide en Orient, Itinéraire scientifique, artistique et pittoresque, Paris : L. Maison, 1851.

Les habituels sujets mythiques du marché aux esclaves et des almées, objets de tous les fantasmes orientalisants des Européens, sont assez longuement traités ${ }^{17}$. Toutefois, l'ensemble du texte sur Le Caire est assez négatif (évocation des maladies, de la saleté, de la ruine des édifices, etc.) malgré une remarque d'ordre général :

«La beauté de la ville, comme dans les autres villes musulmanes, consiste plutôt dans les mosquées et les édifices isolés, que dans l'ensemble de la ville, qui n'offre aucune symétrie. ${ }^{18}$ »

Quant aux considérations sur l'art arabe, elles se limitent à constater l'absence de plan d'urbanisme de la ville, l'étroitesse des rues qui n'offrent aucune perspective :

«C'est aussi un effet singulier et frappant, que celui de ces énormes mosquées, près desquelles on passe sans en voir autre chose que les minarets élancés et les murailles bariolées, sans pouvoir saisir une idée de l'ensemble, un plan, une régularité quelconque. ${ }^{19}$ "

Aucune information structurelle sur l'architecture islamique ne sensibilise le voyageur à ce qu'il va découvrir. Seule la visite de la citadelle avec le puits de Joseph a réussi à intéresser l'auteur qui reste très général :

«La promenade le long des remparts est l'une des plus belles que l'on puisse s'imaginer, et d'où l'on a une des plus belles perspectives de tous les côtés, comprenant une immense quantité d'objets tant anciens que modernes. ${ }^{20}$ "

Une phrase comme celle-ci pourrait s'appliquer à n'importe quel panorama... Cette description du Caire qui n'est que la compilation de citations diverses n'a qu'un intérêt limité et ne peut être d'aucune utilité sur place. Elle contribue surtout au renforcement des imaginaires exotiques des Européens. 


\section{A Hanbook for Travellers in Egypt de Sir Wilkinson (1858)}

Sir John Gardner Wilkinson (1797-1875) était un voyageur anglais, considéré comme le fondateur de l'égyptologie par ses compatriotes. Il est l'auteur de nombreux ouvrages de référence dans ce domaine comme Topography of Thebes, and general view of Egypt ${ }^{21}$ publié en 1835 chez Murray. Son guide de l'Égypte est signalé comme “condensed from 'Modern Egypt and Thebes", ouvrage du même auteur paru en $1843^{22}$. Le guide publié par Murray en 1858 était alors le plus récent et Isambert l'avait probablement emporté sur place (fig. 6) ${ }^{23}$.

6a. Couverture et page de titre du guide Murray, rédigé par Wilkinson.

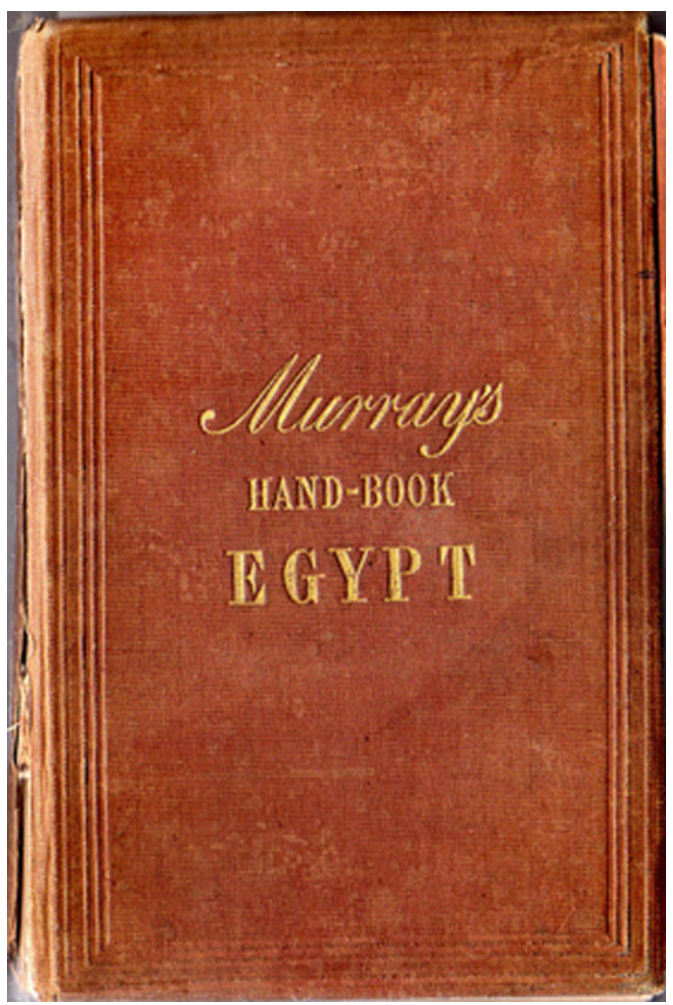

Source : John Gardner wILKInson, A Handbook for Travellers in Egypt, 1858. 
$6 b$. Couverture et page de titre du guide Murray, rédigé par Wilkinson.

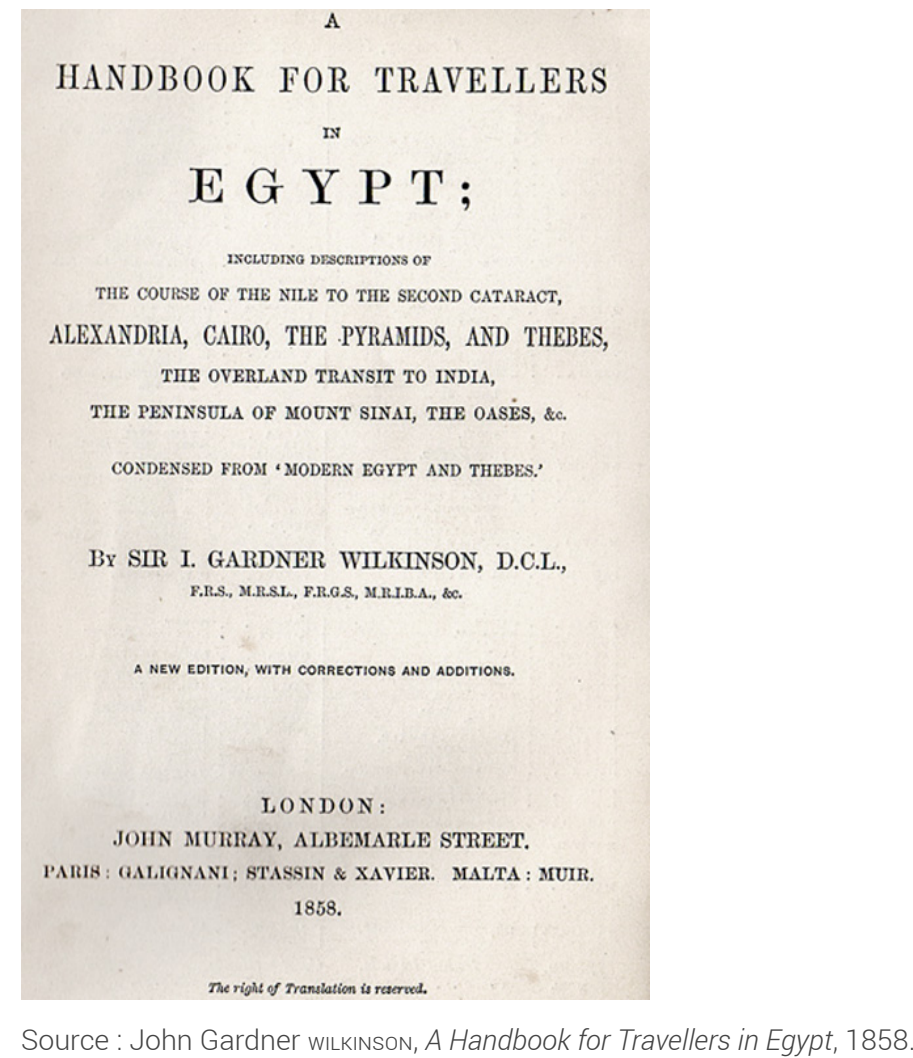

L'organisation des différentes sections pour la présentation et la visite du Caire reflètent la réduction d'un précédent ouvrage. En effet, l'ordre des rubriques est confus : les renseignements pratiques sont pourtant placés en tête de chapitre mais parfois mélangés avec d'autres informations. Ainsi la rubrique "Hotels", qui donne les adresses des hôtels convenant à une clientèle européenne, contient aussi la description du quartier de l'Azbakiyya ${ }^{24}$. L'enchaînement des rubriques semble aujourd'hui manquer de logique puisqu'il entremêle des descriptions de lieux avec des informations d'ordre général sur les habitudes locales ou des conseils au voyageur ${ }^{25}$. La partie "Quickest Mode of seeing Cairo [...]" aurait pu être suivie de la description des monuments concernés mais celle-ci est placée plus loin. Ici sont proposées plusieurs visites qui occupent six journées, dont la première est consacrée à Héliopolis et à quelques monuments rencontrés en route (Bab al-Futuh, le tombeau d'al-Ghawri), la seconde au Vieux-Caire et à l'île de Rôdah, la troisième permet enfin d'aborder le centre du Caire avec le bazar, puis une excursion à la citadelle, le quatrième jour est occupé par la visite d'autre mosquées et Shubra, le cinquième jour est consacré à la forêt pétrifiée ou au Muqattam. Il est indiqué que les trois journées précédentes peuvent être réduites à deux (sic!). Enfin, la dernière excursion, le sixième jour, concerne les pyramides et le Sphinx avec une extension possible à Saqqarah voire Memphis en une journée supplémentaire.

L'absence de plan de la ville dans le guide ne permet pas au visiteur de s'orienter, ni de repérer les monuments, encore moins de se rendre compte du manque de logique de ce programme, voire de son excessive densité. Les mosquées signalées dans la section "Mosk of Cairo - Early Pointed Arches" sont les plus représentatives : Ibn Tulun, alAzhar, Hasanayn, al-Hakim, Sultan Hasan, al-Ghawri et Qalawun, Sha'rawi, al- 
Mu'ayyad, Barquq, Sayyida Zaynab ; seule cette dernière est ajoutée à la liste de l'Aperçu de Clot-Bey. Les descriptions sont détaillées, peut-être trop, pour le visiteur non familiarisé avec l'art islamique : Wilkinson s'attache à l'étude critique d'une inscription en arabe reproduite dans le texte ${ }^{26}$ et qui ne s'adresse qu'aux spécialistes. Un court paragraphe traite des palais de la famille régnante, dont deux valent une visite (Shubra et Qasr al-Nil) ${ }^{27}$; un autre indique qu'il n'y a plus rien à voir au marché aux esclaves depuis l'abolition de l'esclavage ${ }^{28}$. Plus déconcertante pour le lecteur actuel est l'introduction de récits d'expériences personnelles de l'auteur: la séance chez le magicien $^{29}$ est révélatrice de l'intérêt des voyageurs anglais depuis la popularisation de ces pratiques par Edward Lane ${ }^{30}$. Si cette anecdote est riche d'intérêt - elle permet de connaître les participants à cette démonstration des pouvoirs supposés d'un magicien célèbre de la première moitié du XIX siècle -, elle n'avait plus d'utilité pour le voyageur de 1858 , mais continuait d'alimenter les imaginaires habituels sur l'Orient.

\section{L'ttinéraire descriptif de l'Orient, 1861 ou l'appropriation de l'espace et la formation du goût}

21 Pour Émile Isambert, il restait donc beaucoup à faire : sa tâche consistait en l'écriture d'un véritable guide de voyage aussi documenté, objectif et pratique que possible ${ }^{31}$. Ce n'est pas le texte du guide de Richard et Quétin qui a pu l'aider à rédiger sa description du Caire; en revanche l'ouvrage de Clot-Bey et le guide de Wilkinson lui ont certainement été plus utiles.

Selon l'habitude des guides Joanne qui structurent les informations, l'auteur donne d'abord des « renseignements généraux », nécessaires au voyageur qui doit commencer par se loger. Viennent ensuite l'histoire de la ville et une introduction topographique. L'auteur propose dix itinéraires certainement inspirés de Wilkinson. Toutefois, ces visites correspondent à des demi-journées combinables selon les désirs du voyageur et non pas à un programme statique réparti en six jours : la notion de rapidité pour visiter la ville a été abandonnée ${ }^{32}$. L'itinéraire le plus long est effectué le matin, le second assez court l'après-midi et en soirée ; cette organisation de la journée est adaptée au rythme local et à la température. Plusieurs matinées sont dévolues à des excursions dans les environs (Héliopolis, forêt pétrifiée, pyramides, etc.) ou dans des quartiers un peu excentrés de la ville (les cimetières, Fustat). Il est important de noter que cette manière de visiter Le Caire fut reprise par les guides suivants à quelques exceptions près, en particulier lorsque de nouveaux lieux étaient ouverts comme les grands musées. Avec ses itinéraires logiques mais souples, Isambert a fixé les principes de la visite de la ville.

La description des édifices ne suit pas l'ordre de ces tournées : l'intérieur de la ville est d'abord traité, puis sont ensuite proposées les excursions au dehors. Le visiteur est libre de s'organiser comme il l'entend, mais la structure du guide lui permet de retrouver facilement ce qu'il cherche dans la section «Édifices et lieux remarquables »: I. La citadelle ; II. Mosquées; III. Bazars, bains, fontaines ; IV. Places publiques, fêtes, etc.; V. Tombeaux, nécropoles. Ce classement par type de bâtiments était celui des premiers guides citadins de la collection de guides publiés par Hachette $^{33}$, qui ne proposaient pas d'itinéraires, mais des sections thématiques ${ }^{34}$. Si elle ne facilite pas forcément l'élaboration d'un itinéraire, cette disposition offre une approche synthétique et typologique qui permet aussi au lecteur en chambre de se documenter facilement sur un sujet. 

abondante pour l'époque ${ }^{35}$. Tout d'abord, le plan légendé du Caire, complété d'un plan des pyramides et d'une coupe de l'une d'elles, représentait un outil précieux pour le voyageur: depuis un point élevé duquel il pouvait contempler la ville, il pouvait repérer les sites et édifices numérotés et légendés sur le plan. Dans la préface de son guide, Isambert indique les sources de la cartographie : «Le plan du Caire est dressé d'après celui qui a été publié, en Égypte, par M. Szultz ${ }^{36}$, et que nous avons modifié et complété $^{37}$ " (fig. 7). Le plan gravé porte la mention "Dressé par A. Dufour, sous la direction de É. Isambert ${ }^{38}$ » (fig. 8). Jusqu'à la publication d'Isambert, les plans du Caire représentaient le Nil horizontalement: ceux de Clot bey et de M. Szultz, officier du Génie, n'échappent pas à cette règle. Sur le plan revu par Isambert, le Nil est orienté nord-sud selon les normes géographiques établies par la Commission de topographie en $1803^{39}$. Celles-ci étaient respectées par Adolphe Joanne qui, depuis son arrivée à la direction de la collection des guides à la librairie Hachette, avait remplacé des cartes «linéaires» qui suivaient horizontalement une ligne de chemin de fer, par de véritables cartes géographiques orientées et normalisées, utilisables sur le terrain ${ }^{40}$.

7. Plan du Caire rédigé par M. Bauer et complété par le lieutenant-colonel Szultz publié en 1846.

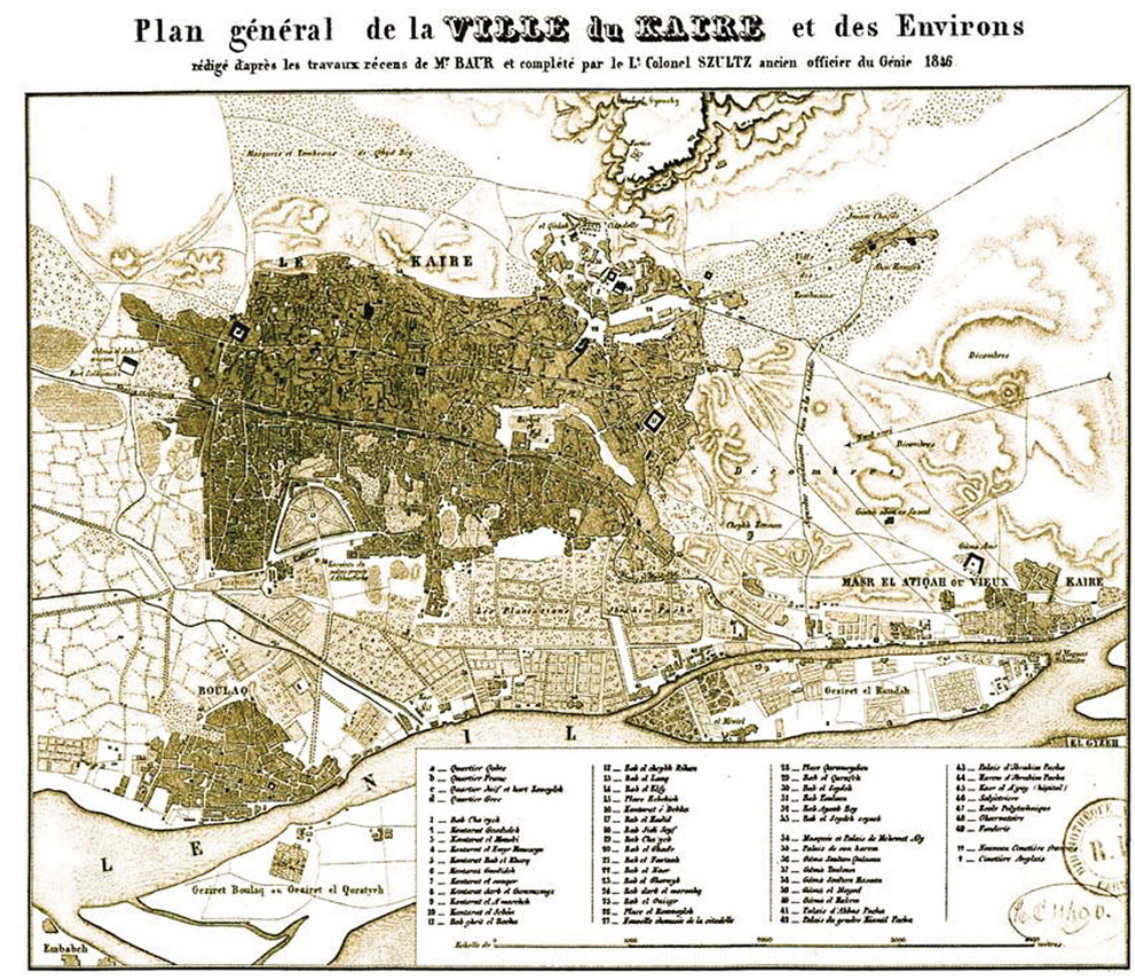

Source : collection privée. 


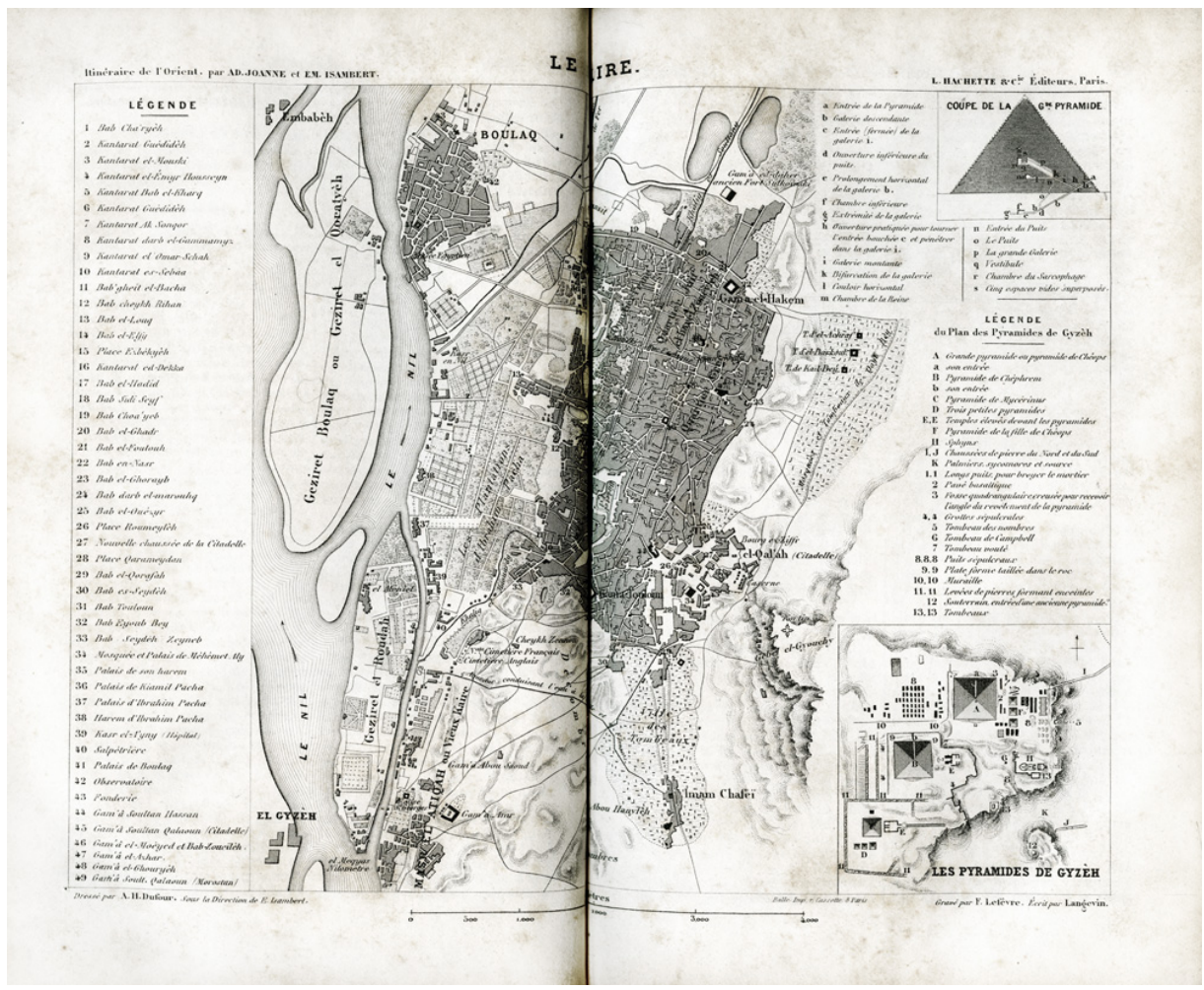

Source : paru dans le guide Joanne, Itinéraire de l'Orient, 1861

La visite de la ville commence par la citadelle et d'emblée le visiteur bénéficie d'un exposé critique de l'architecture de la mosquée construite sous Muhammad 'Ali :

«Au lieu de chercher des modèles parmi les charmants édifices sarrasins du Caire, on a voulu imiter les grandes mosquées de Constantinople. [...] c'est l'ancien plan byzantin, qui conserve toujours sa grandeur et sa beauté, même dans les plus faibles copies. [...] Les fenêtres sont de forme carrée à l'européenne, la décoration verte et or est de mauvais goût ${ }^{41}$.»

Isambert, critique d'art, décrit en quelques lignes acerbes un édifice pourtant admiré depuis sa construction : «la nouvelle mosquée de Mohamed Ali [...] passe au Caire pour une merveille d'élégance ${ }^{42} »$. Ainsi, le lecteur apprend rapidement à distinguer la copie d'inspiration ottomane de l'architecture authentique du Caire. Ce point est important, car l'introduction sur l'architecture islamique était fort brève ${ }^{43}$.

L'ordre descriptif des mosquées suit approximativement un itinéraire sud-nord avec un retour au centre de la ville : la Citadelle est suivie d'Ibn Tulun, puis de Sultan Hasan, alMaridani, al-Hakim, puis les ensembles situés autour des bazars : Qalawun, al-Ghawri et al-Mu'ayyad. Chaque notice est facile à repérer avec son nom imprimé en gras, suivi de la transcription de l'arabe en caractères latin italiques; les mosquées sont aussi indiquées sur le plan. Sept d'entre elles font l'objet d'une description spécifique, précédée d'une courte introduction historique.

La description d'Ibn Tulun, première mosquée " authentique » introduit adroitement le vocabulaire de base : si le visiteur suit le texte du guide, il peut identifier les éléments constitutifs essentiels d'une mosquée (mihrab, minbar) en les ayant sous les yeux. Isambert attire aussi l'attention sur les détails décoratifs des arcs des nefs, les inscriptions en caractère coufiques, autant d'éléments qui forment le regard du 
visiteur. À chaque occasion, il attire l'attention sur la spécificité d'un édifice : «AlAzhar est regardé comme l'université non seulement de l'Égypte, mais de tout l'Orient ${ }^{44}$ » et décrit l'organisation de l'enseignement, de l'accueil des étudiants, du système des waqf (fondations pieuses) et des secours dispensés aux pauvres; plus que l'architecture, c'est la présence d'un asile d'aliénés contre la mosquée du sultan Qalawun qui est soulignée. Il rapproche le décor du portail du style gothique européen et celui du minaret de l'ornementation de l'Alhambra, référence alors unique pour les historiens de l'art et de l'architecture de son temps.

L'auteur porte une attention particulière aux décors de sols ou pariétaux: les mosaïques des mihrab, les pavements de marbres de couleur, les frises sculptées, les lampes ou les arabesques des coupoles. Ces indications ne sont jamais détachées de l'histoire, de la présence de tombeaux et donc de vénérations particulières encore vivantes.

31 La visite des nécropoles est dominée par une vision presque romantique du délabrement général des édifices en accord avec la solitude du désert. Pourtant, Isambert parvient à extraire les éléments architecturaux les plus remarquables comme les subtils décors d'entrelacs des coupoles des mosquées (al-Ashraf) ${ }^{45}$.

La spécialité des bazars est présentée, sans aucune indication architecturale sur les okel $^{46}$. Un mythe oriental est détruit en une phrase lapidaire : «Le marché aux esclaves n'existe plus ${ }^{47}$ ». Pourtant, la disparition de ce lieu n'avait pas empêché Jean Léon Gérôme de continuer d'y situer certaines de ses toiles ${ }^{48}$. Isambert, par son ascendance et ses fréquentations, était évidemment très sensibilisé à la question de l'esclavage : sa remarque confirme celle de Wilkinson et a certainement pour but de couper court aux élucubrations des peintres et écrivains. Les bains échappent de même à toute rêverie inspirée par Ingres ou les peintres orientalistes : le mode d'utilisation actuel est indiqué sans autre précision architecturale.

En revanche, Isambert donnait des informations sur les sabil-kuttab, «fondations destinées à procurer de l'eau gratuitement à tout le peuple ${ }^{49}$ » et institutions purement cairotes: le bâtiment est composé d'une fontaine au rez-de-chaussée et d'une école gratuite à l'étage. Il indiquait ceux qui lui semblaient construits dans «l'ancien style sarrasin » et déplorait l'influence constantinopolitaine pour les plus récents.

L'intérêt pour l'Égypte antique apparaît au Caire dans l'excursion aux pyramides, considérée comme "l'excursion la plus importante de celles que l'on peut faire autour du Caire » puisque la visite de Gizeh est complétée par celle des sites archéologiques voisins ${ }^{50}$. Esprit ouvert et curieux, Isambert était aussi un connaisseur de l'Égypte antique qui savait déchiffrer les hiéroglyphes ${ }^{51}$.

Isambert, amateur de l'art musulman, même délabré, déplorait la modernisation architecturale de la ville et n'hésitait pas à l'écrire :

«Sauf les maisons à l'italienne, bâties autour de l'Ezbékiyèh [Azbakiyya], sauf ces palais et ces établissements nouveaux construits depuis Mohammed-Ali, qui n'appartiennent à aucun style, Le Caire est une ville tout orientale $[. . .]^{52}$ »

ou encore à propos du palais du vice-roi à la citadelle: «l'intérieur est vaste et magnifique, mais de cette fausse magnificence européenne que les Orientaux acceptent si facilement comme de bon aloi ${ }^{53}$ ». Il semble que l'auteur ait eu quelque animosité contre les architectes étrangers qui officiaient en Égypte : 
«Tout cela [le décor du palais de Shubra] est l'ouvrage d'architectes italiens, qui s'y sont livrés à tous les caprices de ce genre, moitié rococo, moitié oriental, que l'on prend en ce pays pour le progrès de la civilisation ${ }^{54}$ "

Le guide Orient, paru en 1861, fut d'après son éditeur un succès puisque « cette première édition fut promptement épuisée ${ }^{56}$ ». Adolphe Joanne expliquait que la mise à jour nécessaire pour l'édition suivante était tellement volumineuse qu'il avait fallu se résoudre à diviser le guide de l'Orient en plusieurs volumes ${ }^{57}$. L'Itinéraire descriptif, historique et archéologique de l'Orient comprend dorénavant les volumes suivants (fig. 9) :

- I. Grèce et Turquie d'Europe, paru en 1873, par É. Isambert ${ }^{58}$,

- II. Malte, Égypte, Nubie, Abyssinie, Sinaï, paru en 1878 par É. Isambert (terminé par Ad. (hauvet) $)^{59}$,

- III. Syrie, Palestine, paru en 1882, par Ad. Chauvet et É. Isambert ${ }^{60}$.

9a. Couverture du guides Joanne de l'Itinéraire de l'Orient, I. Grèce et Turquie d'Europe.

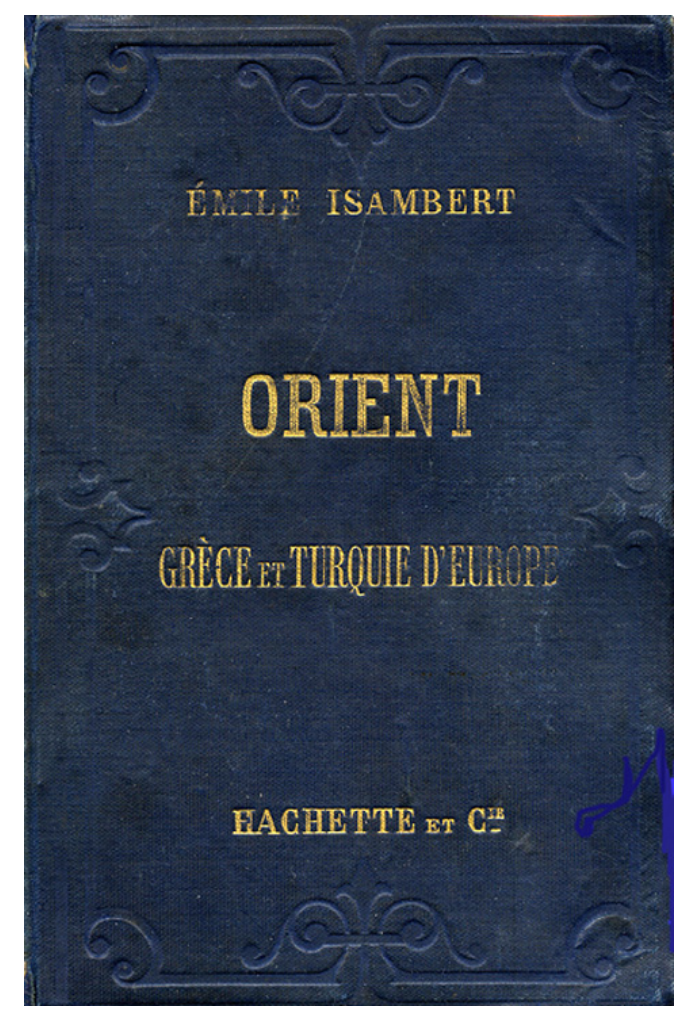


9b. Couverture du Joanne de l'Itinéraire de l'Orient, II. Malte, Égypte, Nubie, Abyssinie, Sinaï.

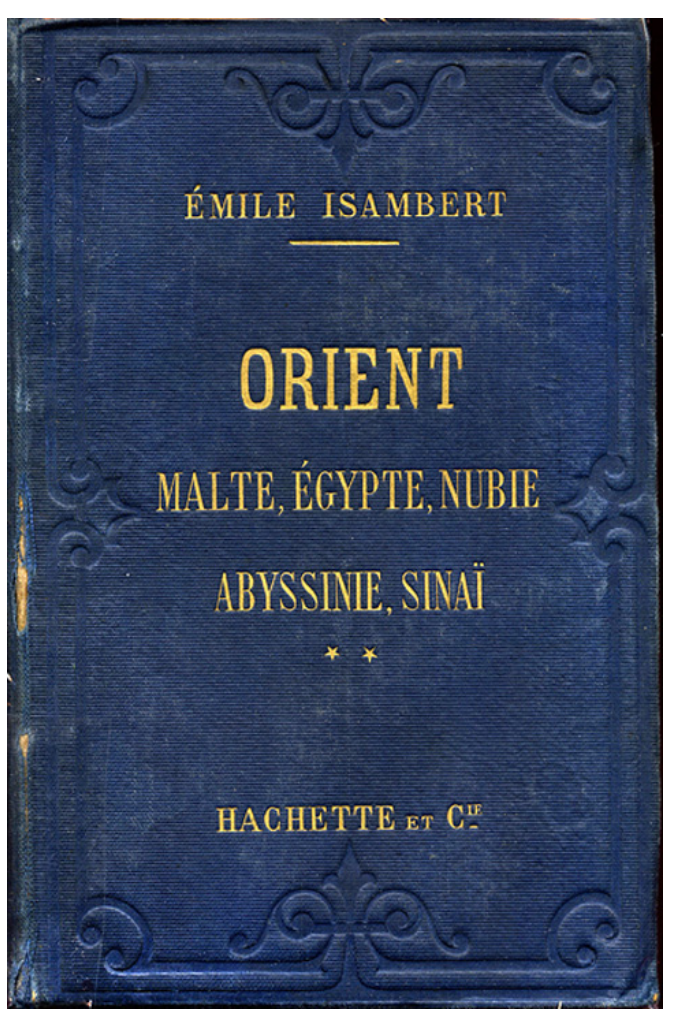

9c. Couverture du guide Joanne de l'/tinéraire de l'Orient, III. Syrie, Palestine.

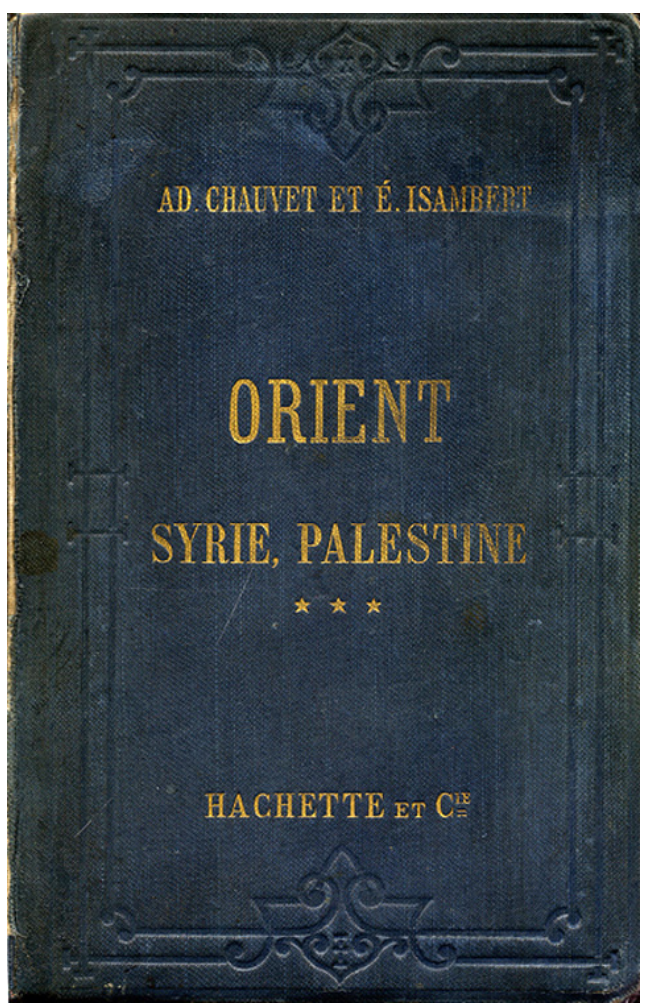



définitivement fixé. Une dixième visite intitulée «plusieurs visites aux bazars et au musée de Boulaq ${ }^{61}$ fut ajoutée : ce musée avait été ouvert à la visite en 1863 , soit deux ans après la parution du premier guide. Le texte reprend la structure, voire des paragraphes entiers, de l'édition précédente, avec de subtiles modifications et nuances, mais aussi plusieurs ajouts notables: les plans des mosquées et une très importante section introduite dans les "généralités» concernant l'Égypte. La "Section IV. Architecture arabe $»^{62}$ prend place après les longs développements sur l'Égypte ancienne. Les principaux traits de l'architecture des édifices cairotes sont répertoriés, après un historique et des interrogations bien contemporaines sur les origines de l'arc ogival. Deux illustrations commentées permettent d'apprendre à bien distinguer le plan à grande cour de la mosquée d"Amr (fig. 10), de celui en croix grecque de la mosquée du Sultan Hasan (fig. 11). Conscient de la vulnérabilité de ce patrimoine mal entretenu, l'auteur lance un appel :

«Il serait grand temps que le prince éclairé qui gouverne le pays nommât un conservateur général des monuments arabes de l'Égypte musulmane, comme son prédécesseur avait nommé un conservateur des monuments de l'Égypte antique ${ }^{63}$ ».

10. Plan de la mosquée d"Amr.

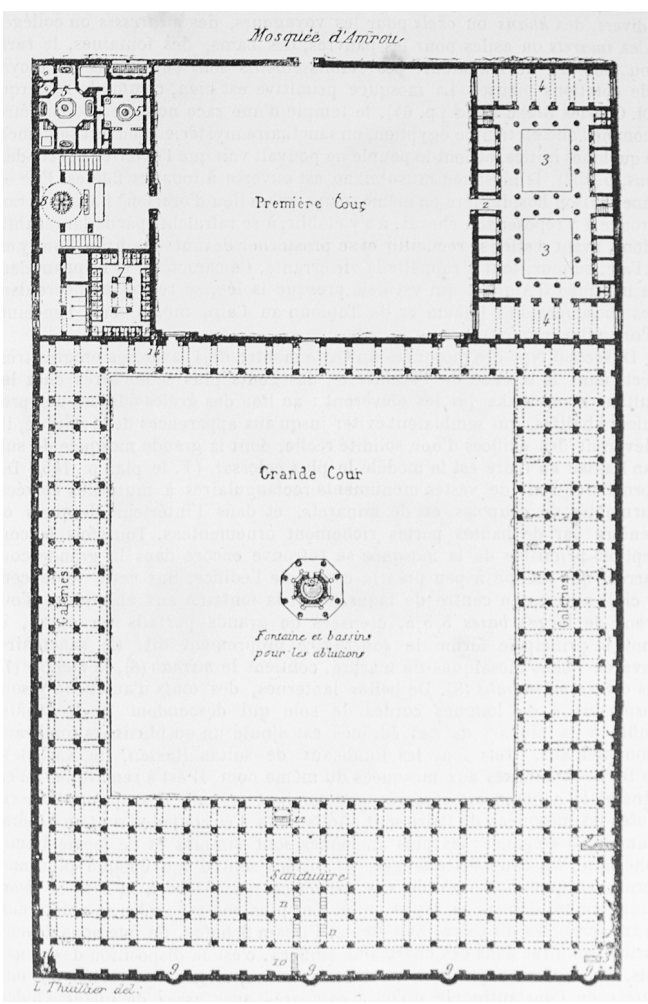

Source : Guide Joanne, Itinéraire de l'Orient, II. Malte, Égypte, Nubie, Abyssinie, Sinaï, Paris : Hachette, 1878, p. 143 


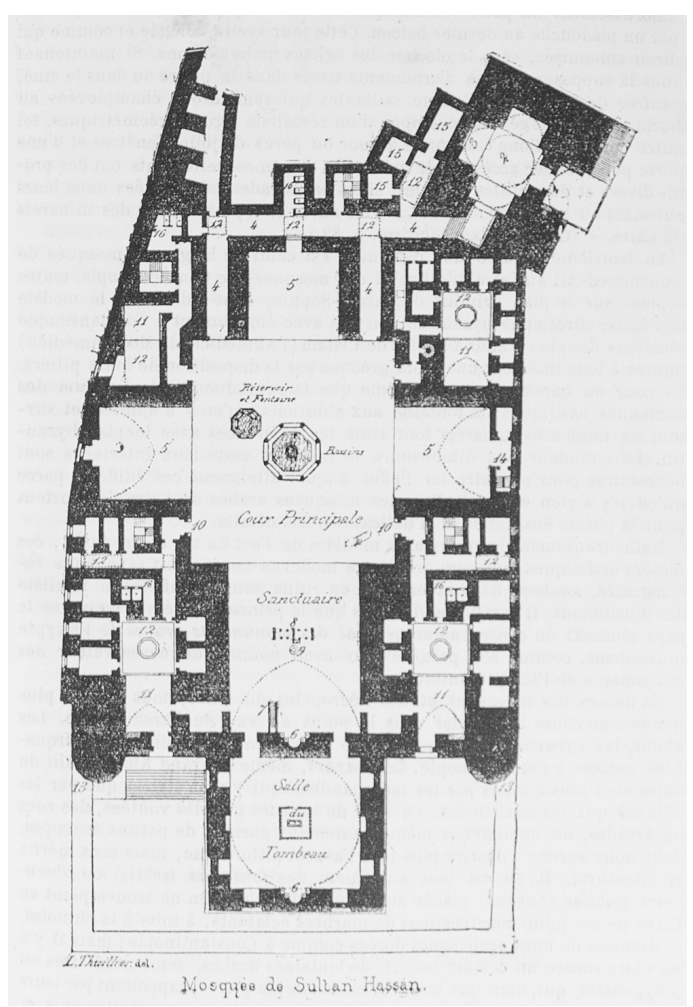

Source : Guide Joanne, Itinéraire de I'Orient, II. Malte, Égypte, Nubie, Abyssinie, Sinaï, Paris : Hachette, 1878, p. 145

Les considérations sur la modernisation du Caire et les emprunts à l'Europe réapparaissent dans le paragraphe intitulé «maisons, palais ». Après une description de l'architecture vernaculaire, on rappelle que les constructions récentes sont :

« d'un goût bizarre, lourd et disgracieux, qui fait un contraste désagréable avec l'architecture orientale. Ces constructions n'appartiennent à aucun style [...] nous n'avons donc pas à nous en occuper ici, si ce n'est pour exprimer nos regrets $[. . .]^{64}$ ».

Le plan du Caire paru dans l'édition précédente, si novateur en son temps, mais de taille relativement réduite $(19,5 \times 15 \mathrm{~cm})$ est remplacé par un autre, grand dépliant en couleurs $(33,5 \times 36 \mathrm{~cm})^{65}$. Ce plan a été dressé par $\mathrm{L}$. Thuillier d'après celui de Pierre Grand bey (1839-1918) : cet ingénieur en chef de la voierie du Caire l'avait levé en 1874 et continuait de représenter le Nil horizontalement ${ }^{66}$ (fig. 12). De nouveau, le plan est réorienté selon un axe nord-sud par les services cartographiques des guides Joanne (fig. 13). Outre l'apparition de la couleur dans le plan de Grand bey, reprise ici, 76 lieux remarquables y sont repérés contre 46 précédemment. Un détail pratique facilite l'orientation du voyageur: les descriptions des édifices renvoient aux chiffres mentionnés dans le plan. 


\section{Plan du Caire par Grand bey.}

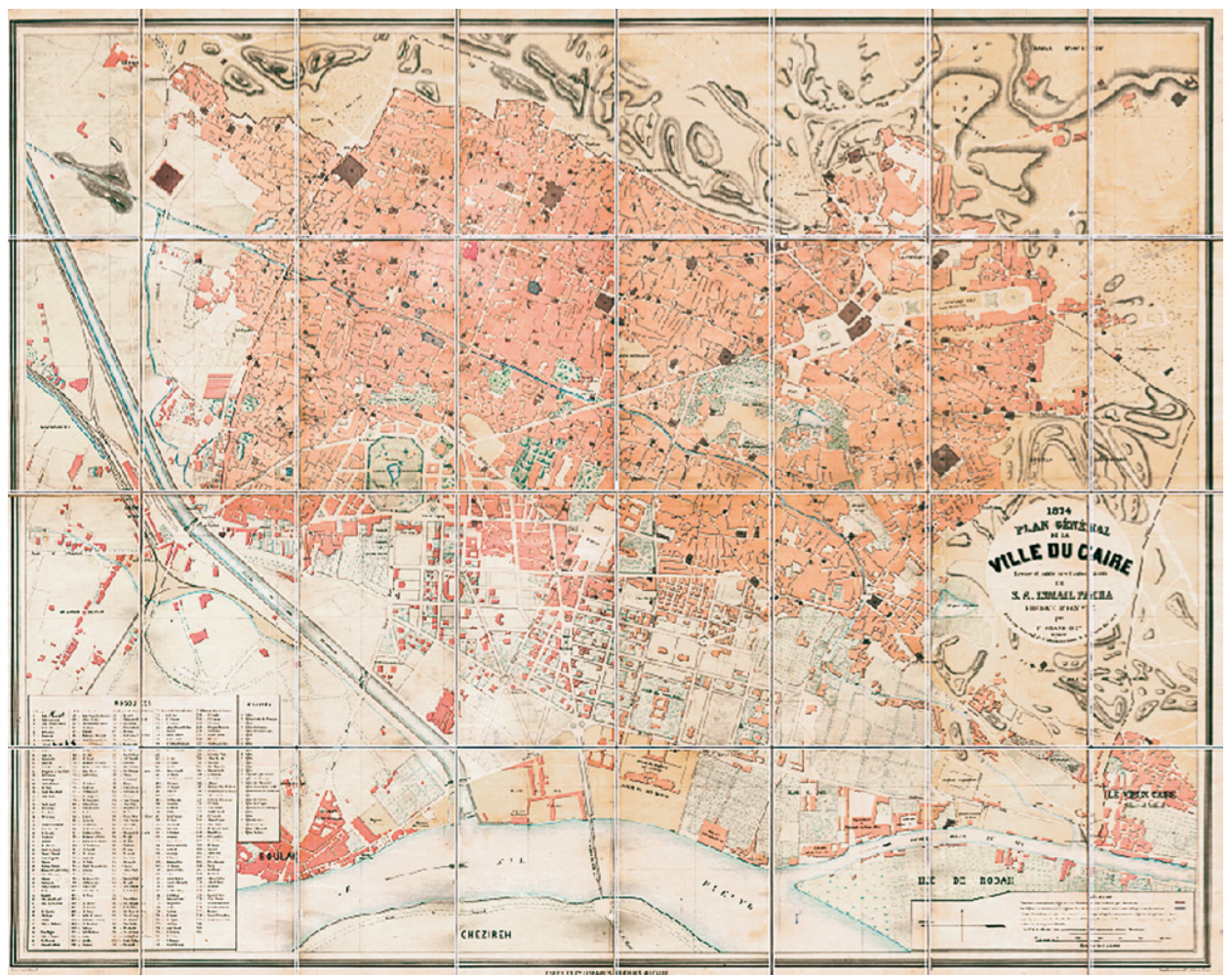

Source : collection privée.

\section{Plan du Caire.}

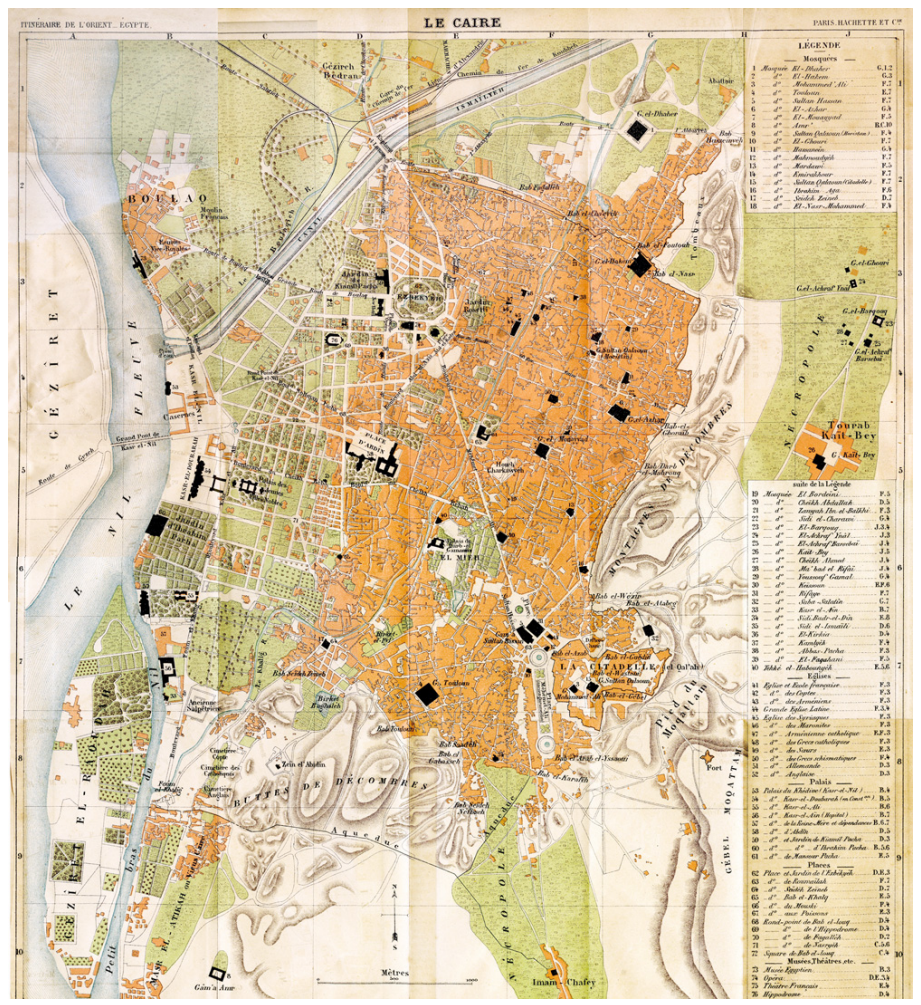

Source : Guide Joanne, Itinéraire de I'Orient, II. Malte, Égypte, Nubie, Abyssinie, Sinaï, Paris : Hachette, 1878 , p. 302-303. 
L'organisation thématique des sections a été conservée. Si les mosquées mentionnées sont pratiquement les mêmes que dans l'édition de 1861, les plans des plus importantes ont été ajoutés et les descriptions largement enrichies : dans la ville, Ibn Tulun, Sultan Hasan, al-Azhar, Qalawun et son maristan, et, dans les nécropoles Barquq, Qaytbay et enfin 'Amr dans le quartier proche du Vieux Caire ${ }^{67}$. Ces sept plans ont été gravés par l'habituel collaborateur de l'éditeur, L. Thuilier, à partir de ceux reproduits dans l'ouvrage de Pascal Coste, L'Art arabe ou Les Monuments du Caire, mesurés et dessinés de 1818 à 1826 $6^{68}$ (fig. 14-15). En bibliographie, le livre plus récent de Prisse d'Avennes, L'Art arabe d'après les monuments du Kaire, paru en 1877, est mentionné, mais c'est le travail de Coste qui a été privilégié. Est-ce parce que ses plans sont plus précis que ceux de Prisse d'Avennes ? Il est possible qu'il ne s'agisse que de la question financière de cession des droits de reproduction. En effet, Hachette était un éditeur très soucieux de la gestion de ses comptes et de la rentabilité de ses investissements. Le travail de Prisse d'Avennes est toutefois cité à propos de l'Égypte antique: Les Monuments égyptiens - bas-reliefs, sculptures, inscriptions, Paris, 1847. Ses travaux étaient donc connus, mais non utilisés directement dans le guide. À propos de l'état de la mosquée d'Ibn Touloun transformée en " asile pour les pauvres et les infirmes ${ }^{69}$ ", on lit dans le guide Joanne :

« ne pourrait-on pas, dans une ville où l'on a la manie de la construction, donner à ces infortunés un autre asile, et conserver à l'admiration de tous cette création du génie arabe, où l'on trouve encore dans les arcs ogivaux, dans les frises, dans les fenêtres découpées à jour, de si gracieux détails? Les pierres s'émiettent, le bois pourrit, et bientôt les derniers vestiges de ces chefs-d'œuvre auront disparu ».

Prisse d'Avennes était encore plus incisif :

«La mosquée de Touloun a été convertie en hospice pour les vieillards et les infirmes par Méhémet Ali [...] c'est à Clot bey, qui fut chargé de l'exécution de cette charitable fondation, qu'est due la ruine d'un aussi beau, d'un aussi ancien monument de l'art arabe [...] on ne peut s'empêcher de déplorer l'inutilité d'un tel acte de vandalisme, caché sous un masque de philanthropie ${ }^{70} »$. 
14. Plan de la mosquée al-Azhar reproduit d'après Coste.

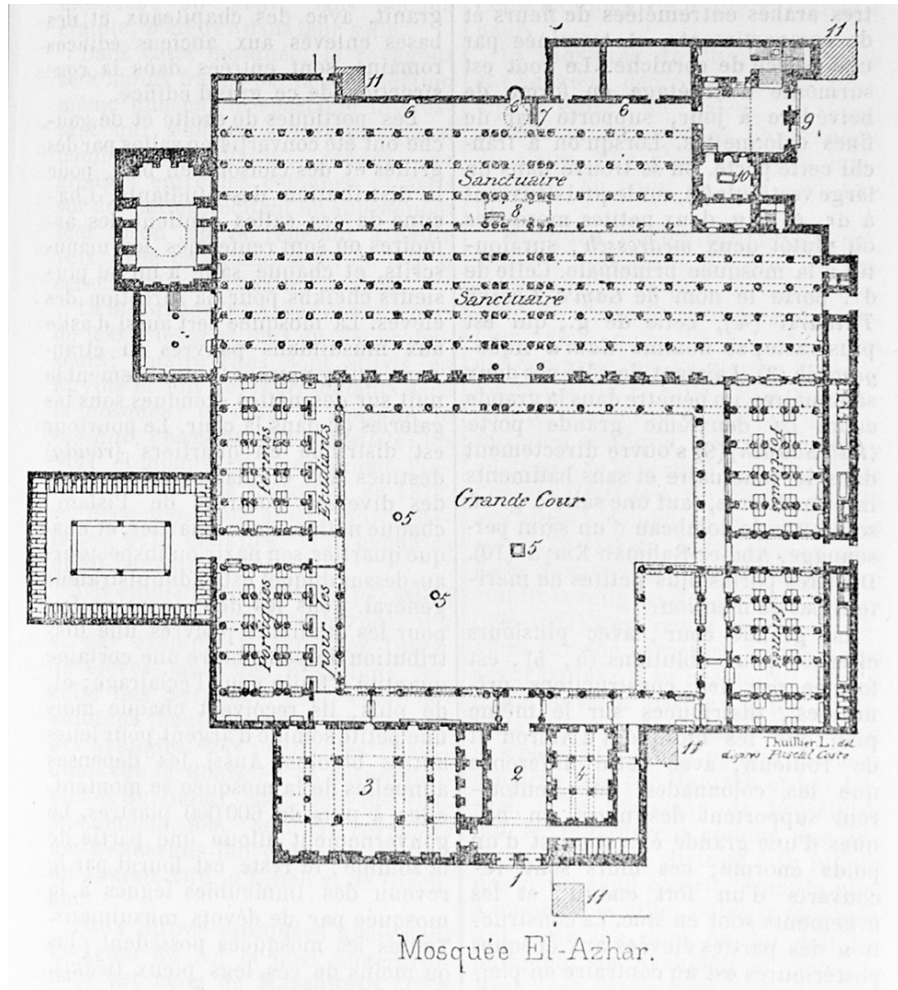

Source : Guide Joanne, Itinéraire de I'Orient, II. Malte, Égypte, Nubie, Abyssinie, Sinaï, Paris : Hachette, 1878 , p. 319 
15. Plan de la mosquée Qalawun et son maristan reproduits d'après Coste.

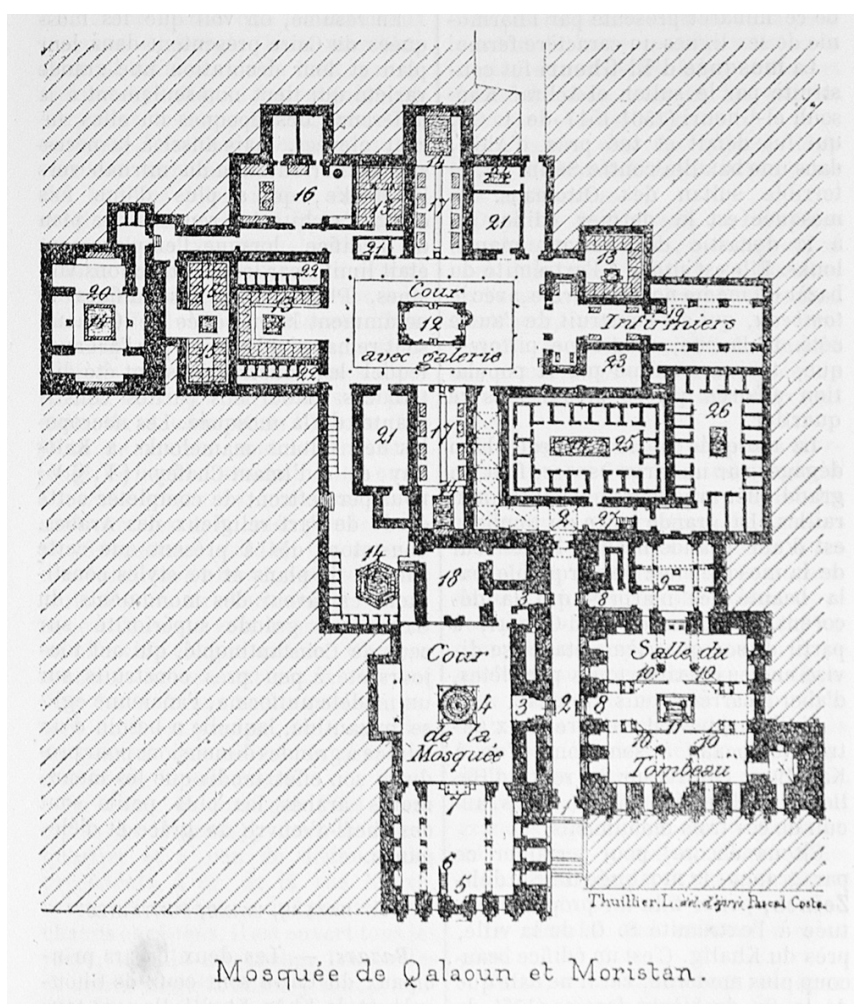

Source : Guide Joanne, Itinéraire de I'Orient, II. Malte, Égypte, Nubie, Abyssinie, Sinaï, Paris : Hachette, 1878, p. 325

Les descriptions des monuments des cimetières sont très largement enrichies $\left(\right.$ Barquq $^{71}$ ) et d'autres édifices importants inclus dans la visite: par exemple, les mosquées et tombeaux d'al-Ashraf Inal et d'al-Ashraf Barsbay ${ }^{72}$ et un développement nouveau concerne les tekke ${ }^{73}$. La visite des monuments de l'art arabe est limitée aux édifices religieux, alors que Prisse d'Avennes faisait une large part à l'architecture civile à laquelle il consacre un chapitre entier ${ }^{74}$, avec des illustrations et des plans, partie non reprise dans le guide. Si la visite des bains, okel et sabil-kuttab est conseillée voire encouragée par le guide, en revanche les demeures autres que les palais officiels ne sont pas indiquées.

L'architecture arabe devient aussi un sujet pour les photographes. Par exemple, la salle de prière de la mosquée est photogénique : «Lorsqu'on les [arcades] considère en se plaçant dans une position oblique, de manière que toutes ces travées et toutes ces colonnes s'entrecroisent sous le regard, on obtient un de ces effets de perspective qui ravissent les artistes, et fournissent aux photographes les motifs les plus heureux ${ }^{75} »$ : le guide est en adéquation avec les techniques nouvelles répandues parmi les voyageurs.

Un ajout concerne les « Églises, écoles, hôpitaux, bibliothèque, administrations " ${ }^{76}$ sans mention des styles architecturaux de ces bâtiments, qui reflète l'occidentalisation du Caire. De grands développements sur les places et les nouveaux quartiers ont été adjoints à la faveur des travaux entrepris sous le règne du khédive Ismaïl pour transformer l'Azbakiyya en un jardin d'agrément contenant de nombreuses espèces botaniques rares. Toutefois, ces travaux importants qui donnent un air européen au jardin ne sont pas du goût d'Isambert qui regrette l'ancien jardin plus grand et plus " couleur locale ». Il continuait de déplorer le goût des Orientaux pour l'architecture 
d'inspiration italienne bien trop présente à son idée ${ }^{77}$. Les autres aménagements du quartier sont décrits avec les nouveaux hôtels internationaux, les ministères, l'opéra où fut créée l'œuvre de Verdi Aïda commandée pour l'inauguration du canal de Suez ${ }^{78}$. Il notait aussi l'apparition de produits européens dans les bazars ${ }^{79}$. L'auteur semble ainsi regretter ces transformations qui font perdre à la ville son charme originel.

En stigmatisant les modernisations à l'européenne, Isambert mettait en valeur les aspects les plus intéressants, en particulier l'architecture et l'art islamiques ainsi que les quartiers plus populaires, sans sombrer dans le rêve oriental de pacotille. En notant des ajouts modernes parfois malheureux à l'architecture de la vieille ville, l'auteur sensibilisait son lectorat à l'art arabe authentique en l'opposant au pastiche moderne. Ce guide est un manifeste pour tenter de protéger un patrimoine menacé, sans critiquer ouvertement les actes et décisions du prince dirigeant d'un pays ouvert à l'influence française depuis des décennies.

49 Le nom d'Émile Isambert reste attaché aux deux éditions du guide Joanne d'Orient. Si aujourd'hui la proposition d'itinéraires de visites dans un guide est un passage obligé, cela ne l'était pas à la fin du XIX ${ }^{e}$ siècle. Il en fixa l'organisation pour Le Caire et celle-ci fut presque systématiquement adoptée par la suite. Il sut aussi s'inspirer des ouvrages précédents sans sombrer dans le plagiat.

50 Un autre aspect novateur, de nos jours tout aussi banal, est la cartographie moderne : les plans orientés avec une échelle et des légendes étaient alors rares (les guides Murray de 1847 et 1858 n'en possédaient pas), puis les plans d'édifices dressés par des architectes de renom, enfin la multiplication des cartes, véritable bilan des connaissances géographiques de la seconde moitié du XIX siècle.

51 À une époque où l'attrait principal de l'Égypte résidait dans ses monuments antiques, Isambert tenta d'intéresser son lectorat à un art alors peu connu, et le sensibiliser progressivement sans être trop disert. La distinction entre l'art islamique et les pastiches, l'authentique et l'architecture moderne d'inspiration européenne est un thème récurrent, transmis et développé d'une édition à l'autre.

52 Isambert souhaitait qu'un conservateur soit chargé de la protection des monuments de l'art arabe et il fut exaucé : Julius Franz pacha fut le premier conservateur du musée d'Art arabe. Son successeur, Max Herz bey, architecte en chef du Comité de conservation des monuments de l'art arabe en Égypte, dessina de nombreux plans qui furent publiés dans l'édition de 1900 du guide Joanne de l'Égypte ${ }^{80}$, rédigé en collaboration avec Georges Bénédite, conservateur des Antiquités égyptiennes au musée du Louvre.

53 Ces derniers développements sont la lignée des premiers guides d'Orient, qui contenaient depuis leur origine tous les éléments de sensibilisation à l'art arabe authentique. Le guide de voyage, instrument de divulgation des connaissances, remplit son rôle en instruisant des nouveaux sujets d'étude en Égypte un public élargi, tout en transmettant les dernières acquisitions géographiques. 


\section{NOTES}

1. Catalogue de livres composant la bibliothèque de feu M. Isambert, conseiller à la Cour de cassation, ancien député, membre de la Société de géographie, etc., etc. dont la vente aura lieu du 22 février au 2 mars 1858 à 7 heures précises du soir, Paris : Durand libraire, 1858, n 804 : Description de l'Égypte, Paris : Panckoucke, 1821, 24 tomes en 26 volumes.

2. $\mathrm{M}^{\mathrm{e}}$ ESCRIBE et HARO, Tableaux anciens et modernes de la collection de feu le Dr Isambert..., Vente à l'Hôtel Drouot le 9 mars 1877, Paris : imprimerie A. Quantin.

3. Bulletin de la Société de géographie, $4^{\mathrm{e}}$ série, vol. 15, 1858, p. 114 et 434.

4. IMEC, registres des traités de la librairie Hachette, traité $n^{\circ} 166$ du 15 juillet 1858. Je remercie chaleureusement Jean-Yves Mollier, professeur d'histoire contemporaine à l'université de Versailles Saint-Quentin-en-Yvelines, pour m'avoir signalé l'existence de ces registres.

5. "Rapport sur les travaux de la Société de géographie et sur les projets des sciences géographiques pendant l'année 1860 », Bulletin de la Société de géographie, 4 e série, vol. 20, 1860, p. 310-373, part. p. 316.

6. «Guides " parus de 1830 à 1860, inventoriés dans Oleg V. VoLKOFF, Comment on visitait la vallée du Nil: les «guides» de l'Égypte, Le Caire: IFAO, 1967 (Recherches d'archéologie, de philologie et d'histoire, 28).

7. John Gardner WILKINSON, A Handbook for Travellers in Egypt, Londres : Murray, 1858 (Murray's handbook).

8. RICHARD et QUÉTIN, Guide en Orient, Itinéraire scientifique, artistique et pittoresque, Paris : L. Maison, 1851.

9. Catalogue de livres de médecine, de voyages, de géographie et d'histoire de la bibliothèque de feu $\mathrm{Dr}$ Isambert, agrégé de la faculté de médecine, membre de la Société de géographie, dont la vente aux enchères aura lieu les mardi et mercredi 6 et 7 février 1877 à 7 heures et demies précises, Paris : Louis Leclerc, 1877 , lot de guides $n^{\circ} 56$.

10. Antoine Barthélémy CLOT-BEY, Aperçu de l'Égypte, Ouvrage orné d'un portrait et de plusieurs cartes et plans coloriés, Bruxelles : Société belge de Librairie, 1840, 2 tomes, $356+343$ p., in- $16^{\circ}$ et Paris : Fortin, Masson, 1840 , in- $8^{\circ}(\mathrm{BnF})$. Je remercie bien vivement Goulven Guilcher, spécialiste des guides et collectionneur, pour le prêt de son exemplaire.

11. Adolphe JOANNE et Émile ISAMBERT, Itinéraire descriptif, historique et archéologique de l'Orient, Paris: Hachette, 1861 (collection des guides-Joanne), $44+1104$ p., 11 cartes et 19 plans, ici p. XLIV.

12. Édition belge: tome premier, chapitre III, Population, habitations, villes et villages de l'Égypte, § II Maisons d'habitations édifices publics, p. 209- 217 et tome second, chapitre XV, Monuments et ruines, § II, Monuments arabes, p. 419-429.

13. Édition belge : tome second, chapitre XV, Monuments et ruines, § II, Monuments arabes, p. 422.

14. RICHARD et QUÉTIN, Guide en Orient, op. cit. (note 8).

15. Ibid., Climat et saisons, p. 342 et Hygiène, à la suite.

16. Sur les guides et les relations de voyages, voir Daniel LANçON, L'Égypte littéraire de 1776 à 1882, Destin des antiquités et aménité des rencontres, Paris : Geuthner, 2007, p. 257-258.

17. Ibid., Le Caire : p. 337-345 (9 pages); Marché aux esclaves : p. 340-341 (1 page); à la suite, respectivement un paragraphe pour Almées (Walmées), Bazars, Manufactures : p. 341-342.

18. Ibid., p. 338.

19. Ibid.

20. Ibid., p. 340. 
21. John Gardner WILKINSON, Topography of Thebes, and general view of Egypt,... With remarks on the manners and customs of the ancient Egyptians, etc, Londres : Murray, 1835.

22. John Gardner WILKINSON, Modern Egypt and Thebes: being a description of Egypt, including the information required for travellers in that country, Londres: [sans mention d'éditeur], 1843, 2 vol. in- $8^{\circ}$.

23. Voir Catalogue de livres de médecine, de voyages, etc., op. cit. (note 9), lot de guides $n^{\circ} 56$.

24. John Gardner WILKINSON, A Handbook for Travellers in Egypt, 1858 (note 7), p. 115. Je remercie Goulven Guilcher qui, en me prêtant son exemplaire, m'a grandement facilité cette étude.

25. Ibid., p. 115-123. Par exemple, la succession "Servants" avec des recommandations pour certaines personnes, "Horse - Asses - Carriages ", «Places of Public Resort - Libraries", "Quickest Mode of seeing Cairo and the Neibourhood" enfin « Boats"; cette dernière section contient des indications pour louer un bateau pour visiter la Haute-Égypte. On pourrait multiplier les exemples.

26. Ibid., p. 129.

27. Ibid., p. 133.

28. Ibid., p. 134.

29. Long récit détaillé et savoureux par ses anecdotes typiquement anglaises avec 3 illustrations : John Gardner WILKINSON, A Handbook for Travellers in Egypt, 1858 (note 7), p. 141-144. La même relation existe dans l'édition précédente: WILKINSON, A Handbook for Travellers in Egypt, 1847, p. 150-155. Je remercie chaleureusement Briony Llewellyn, historienne de l'art, pour la riche documentation qu'elle a bien voulu me communiquer, me permettant ainsi de saisir le contexte et l'intérêt de ces séances de magie : voir les dessins représentant les participants d'une séance : URL: http://collections.vam.ac.uk/item/0146226/drawing-the-egyptian-magician-holdinga/. Consulté le 25 novembre 2015 ; et le magicien: http://collections.vam.ac.uk/item/0126132/ watercolour-sheikabdul-kadir-mugrabi-the/. Consulté le 25 novembre 2015.

30. Edward W. LANE, An account of the manners and customs of the modern Egyptians, written in Egypt during the years 1833, -34, and -35, Londres : John Murray, 1860.

31. Daniel LANÇON, op. cit., (note 16), p. 286-289.

32. John Gardner WILKINSON, op. cit. (note 7), p. 117.

33. Guide de Londres (1853) depuis sa première édition ou de celui de Paris (1854) parus chez Hachette, voir Hélène MORLIER, Les Guides-Joanne, Paris: Les Sentiers débattus, 2007, respectivement $\mathrm{n}^{\circ} 608$ et $\mathrm{n}^{\circ} 2$.

34. Par exemple églises, théâtres, ministères, administrations, etc. Il faut attendre l'édition du guide de Paris en 1889 pour que le chapitre IV propose des visites de quartiers de Paris, mais la structure du guide reste inchangée.

35. 11 cartes et 19 plans. Pour des raisons d'économie, les plans sont souvent des encarts dans les cartes.

36. Ce plan est consultable en ligne : http://mapsof.net/cairo/static-maps/jpg/ cairo-map1847baur-szultz. Consulté le en 2012.

37. Adolphe JOANNE et Émile ISAMBERT, op. cit. (note 11), p. XXI.

38. Ibid. : plan inséré dans notre exemplaire entre les pages 974 et 975.

39. Je remercie bien vivement Marie-Vic Ozouf-Marignier, directeur d'études à l'EHESS, qui m'a indiqué cette date.

40. Voir Hélène MORLIER, op. cit. (note 33), p. 57-65.

41. Adolphe JOANNE et Émile ISAMBERT, op.cit. (note 11), p. 979-980.

42. Ibid., p. 979.

43. Ibid., p. 929-930.

44. Ibid., p. 983.

45. Ibid., p. 988. 
46. Ibid., p. 985.

47. Ibid.

48. Voir Laurence des CARS, Dominique de FONT-RÉAULX, Édouard PAPET (dirs.), Jean-Léon Gérôme (1824-1904). L'histoire en spectacle, catalogue d'exposition (Los Angeles, The J. Paul Getty Museum, 15 juin-12 septembre 2010; Paris, Musée d'Orsay, 19 octobre 2010-23 janvier 2011; Madrid, Musée Thyssen-Bornemisza, $1^{\mathrm{er}}$ mars-22 mai 2011), Paris : Skira Flammarion, 2010 : "Marché d'esclaves ", $\mathrm{n}^{\circ} 156$ et « Vente d'esclaves au Caire » $\mathrm{n}^{\circ} 157$.

49. Adolphe JOANNE et Émile ISAMBERT, op.cit. (note 11), p. 986.

50. Abouroach, Abousir, Sakkarah, sérapéum de Memphis, Dachour, ville de Memphis, Matanyeh et Meïdoum, Ibid., p. 996-1010.

51. $\mathrm{M}^{\mathrm{e}}$ ESCRIBE et HARO, op. cit. (note 2) : introduction signée de son ami le peintre Haro. Catalogue de livres de médecine, de voyages, op. cit. (note 9), n² 27 ; CHAMPOLLION, Précis du système hiéroglyphique des anciens Égyptiens, Paris : 1828 ; $n^{\circ} 14$, T. young, Rudiments of Egyptian Dictionary, 1836 ; ce livre portait le $\mathrm{n}^{\circ} 727$ lors de la vente de la bibliothèque du père d'Émile Isambert.

52. Adolphe JOANNE et Émile ISAMBERT, op.cit. (note 11), p. 976.

53. Ibid., p. 980.

54. Ibid., p. 993.

55. Ibid., p. 977.

56. Émile ISAMBERT et Adrien CHAUVET, Itinéraire descriptif, historique et archéologique de l'Orient, partie II, Malte, Égypte, Nubie, Abyssinie, Sinaï, Paris : Hachette et C ${ }^{\mathrm{ie}}, 1878$, LVI + 772 p., 6 cartes, 19 plans, 4 gravures : préface d'Adolphe JOANNE, p. XI.

57. Ibid., préface d'Adolphe JOANNE, p. XII.

58. $84+1084$ p., 11 cartes, 23 plans.

59. $56+772$ p., 6 cartes, 19 plans, 4 gravures.

60. $56+848$ p., 4 cartes, 62 plans et coupes, 5 vues avec le portfolio de 6 cartes.

61. Émile ISAMBERT et Adrien CHAUVET, op. cit. (note 56), p. 308.

62. Ibid., p.138-147. Cette section est divisée en "Origine et caractère du style arabe " (p. 138-142) et «Édifices arabes: mosquées, turbés, bains, bazars, khâns, fontaines, etc.» (p. 142-147, 2 plans). La partie III, Syrie, Palestine, 1882, contient aussi une section introductive à l'architecture arabe (p. 132-133) suivie d'une autre "Édifices arabes: mosquées, turbés, bains, bazars, khâns, fontaines, etc. » (p. 133-136). Les textes des deux guides sont adaptés aux régions traitées.

63. Ibid., p. 146.

64. Ibid., p. 147.

65. Encarté entre les pages 302 et 303 de notre exemplaire d'Émile ISAMBERT et Adrien CHAUVET, op. cit. (note 56).

66. Consultable en ligne http://www.ifao.egnet.net/uploads/images/archives/caire_grand_bey. Consulté le 25 janvier 2016.

67. Émile ISAMBERT et Adrien CHAUVET, op. cit. (note 56), respectivement Ibn Tûlûn : p. 313, Sultân Hassan : p. 317, al-Azhar : p. 319, Qalâwûn et son mâristân : p. 325 et dans les nécropoles Barqûq : p. 335, Qâtbây : p. 339 et enfin 'Amr : p. 347.

68. Pascal Coste, L'Art arabe ou Les Monuments du Caire, mesurés et dessinés de 1818 à 1826, Paris : Firmin Didot, 1839.

69. Émile ISAMBERT et Adrien CHAUVET, op. cit. (note 56), p. 315.

70. Émile PRISSE D'AVENNES, L'art arabe d'après les monuments du Kaire depuis le VII esiècle jusqu'à la fin du XVIII ${ }^{e}$ siècle, Paris : A. Morel et Cie, 1877, réédition Paris : L'Aventurine, 2002, p. 114-117.

71. Émile ISAMBERT et Adrien CHAUVET, op. cit. (note 56), p. 334-337 avec plan.

72. Ibid., p. 334 et p. 337-338.

73. Ibid., p. 329. 
74. Émile PRISSE D’AVENNES, op. cit. (note 70), réédition 2002, p. 159-192.

75. Émile ISAMBERT et Adrien CHAUVET, op. cit. (note 56), p. 314.

76. Ibid., p. 341-343.

77. Ibid., p. 330.

78. Ibid., p. 331.

79. Ibid., p. 327.

80. Georges BÉNÉDITE, Égypte, Paris : Hachette, 1900 (collection des guides-Joanne), voir les articles consacrés à Julius Franz pacha (https://inha.revues.org/4897) et à Max Herz bey (https:// inha.revues.org/4898).

\section{AUTEUR}

\section{HÉLÈNE MORLIER}

Éditrice, InVisu, USR 3103 du CNRS, Paris (France) ; doctorante à l'EHESS, Paris. 


\title{
Julius Franz-Pasha's Die Baukunst des Islam (Islamic architecture) of 1887 as part of the Manual of Architecture
}

\author{
Elke Pflugradt-Abdel Aziz
}

2010 saw the 130th anniversary of the Manual of architecture (Handbuch der Architektur), the most important encyclopedia of civil engineering. The first volume appeared as partial delivery in 1880, the last one in 1943. Over one hundred German, Swiss, and Austrian architects were involved in this fully comprehensive account of architectural knowledge available at the time of publication of each edition. This classical manual, until then essential in doctrine and practice, was no longer updated with the paradigm shift of modernism. Although the Manual still gives generally accepted descriptions, it met with a generalized historicist refusal lasting up to the seventies. The traditional continuity was therefore interrupted, but also the understanding of elder generations of architects as well as their educational concepts. The diversified implicit knowledge of the Manual's authors means that what they assumed was known at the time of writing is today no longer known. This is due to the fact that the large-scale industrialization applied to the building industry replaced the tradition of crafted products and their materials and techniques after 1945. More than 60 years of ignorance are not easily overcome, particularly in relation to the Manual of architecture. ${ }^{1}$

This study looks at how the Islamic architecture (ill. 1-2) came about in 1887 as part of the Manual of architecture and also at its historico-cultural intentions. For nearly half of a century, from the 1870s until the First World War, Julius Franz-Pasha played the role of a knowledge base between Western Europe and Cairo, which could no longer be the case in the modern world where professional expertise is changing fast and has to be adapted swiftly. 
1. Julius Franz-Pasha, photograph.

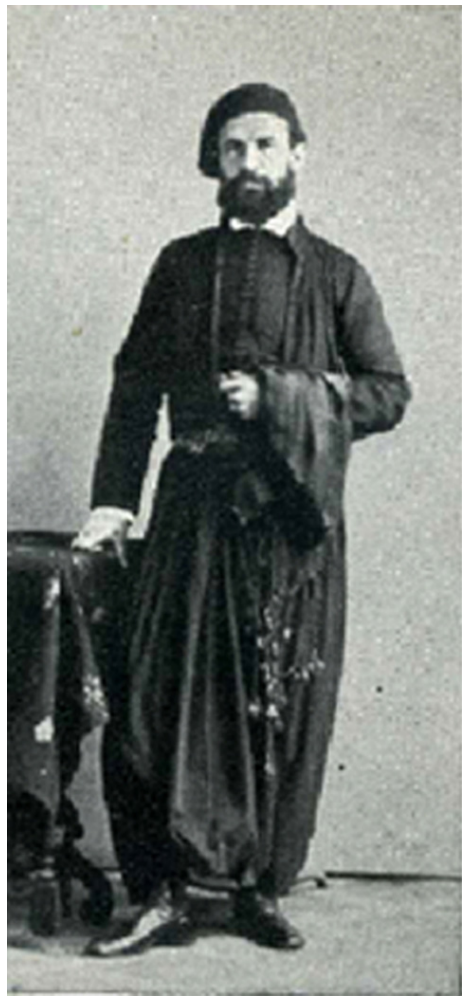

Source: Author's collection.

2. Front page of J. FRANZ-PASCHA, Die Baukunst des Islam, Darmstadt, 1896, II, 3.2.

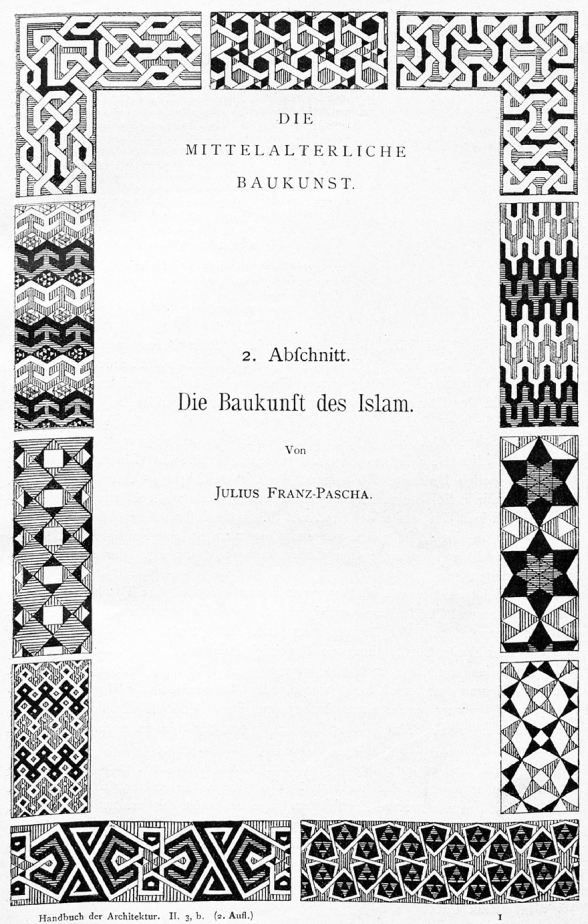

Source: Author's collection. 
Julius Franz-Pasha (1831-1915) is often identified as an Austrian, ${ }^{2}$ although he was actually born in Nassau, Germany, a son of a forest ranger called Wilhelm Franz. ${ }^{3}$ Presumably, he was thought to be of this nationality because he studied architecture in Vienna at the Academy of Fine Arts. But it was not the missing perspective of a career as an architect in Austria that made him search his fortune overseas: due to illness he left for Egypt as a patient of doctor Bilharz. In 1859 Franz joined Egypt's public services as an engineer. As court architect of Ismail Pasha, Khedive of Egypt and Sudan, he designed, constructed, and supervised many buildings for completion on the occasion of the opening of the Suez Canal in 1869. This included the most ambitious state commission at that time, the Palace and Kiosk on al-Gazira island (the Palace is today's Marriott Hotel in Cairo (ill. 3-4), as well as theaters, a comedy building and circus on the south side of al-Azbakiyya ${ }^{4}$ and hippodrome. For his services Ismail Pasha awarded him the title of "bey" in 1868. Even though Franz as a public servant was involved in the most radical transformation of al-Azbakiyya, the hub from which all new streets radiated in Cairo, he already felt very critical towards this development in 1871 . He describes his regretting the damage of traditional houses, including medieval monuments, in order to realize a modern urban concept after a French model. To his mind the new Cairo street net caused an irreplaceable loss in the arts. ${ }^{5}$ Afterwards, he worked in several different positions in Egypt such as professor, director of a spa, monument conservator, curator, until he retired in 1888 .

3a. Palace of al-Gazira, photograph by Bonfils.

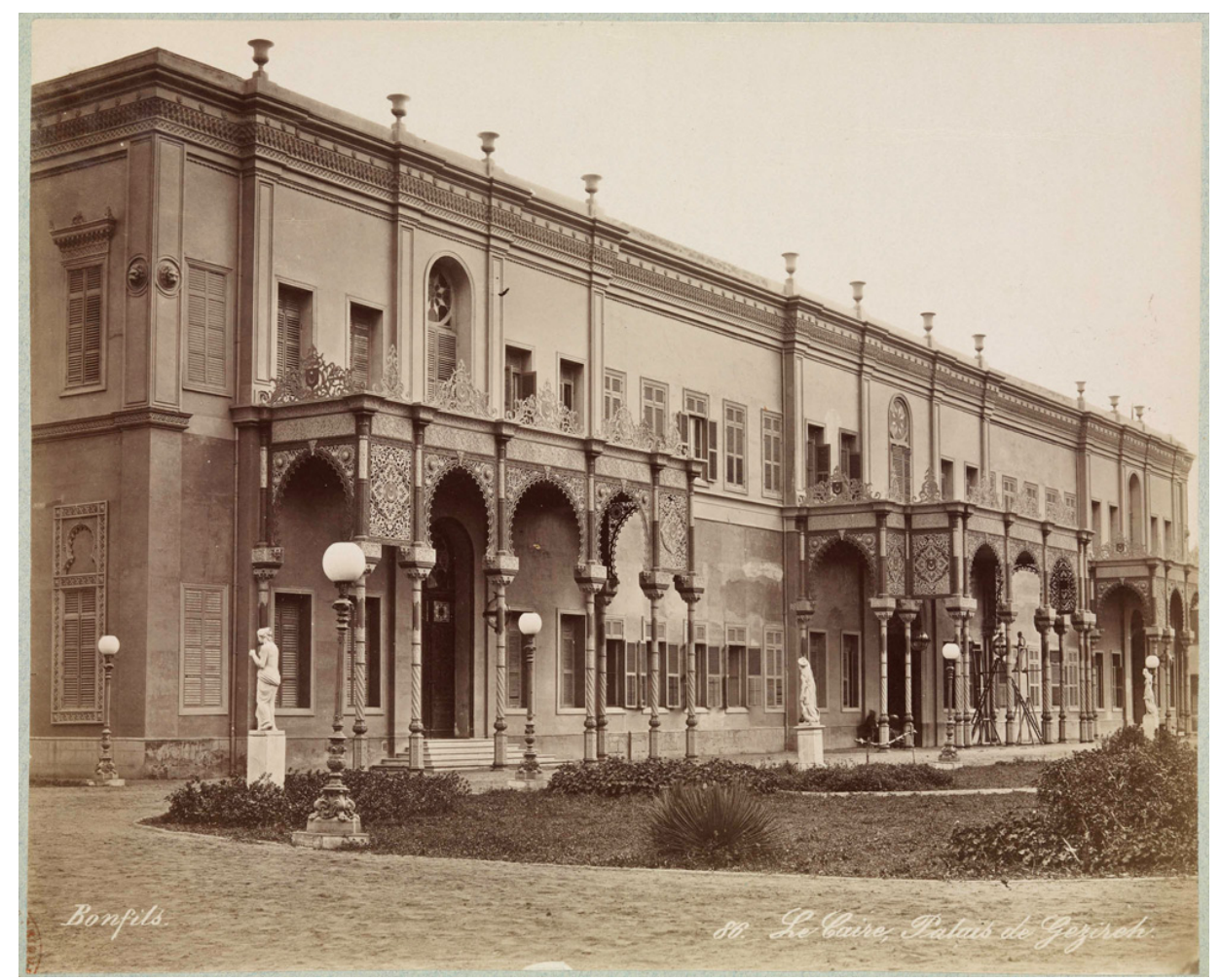

Source: Paris (France), Bibliothèque nationale de France, département des Estampes et de la Photographie. 
3b. Palace of al-Gazira, photograph by Bonfils.

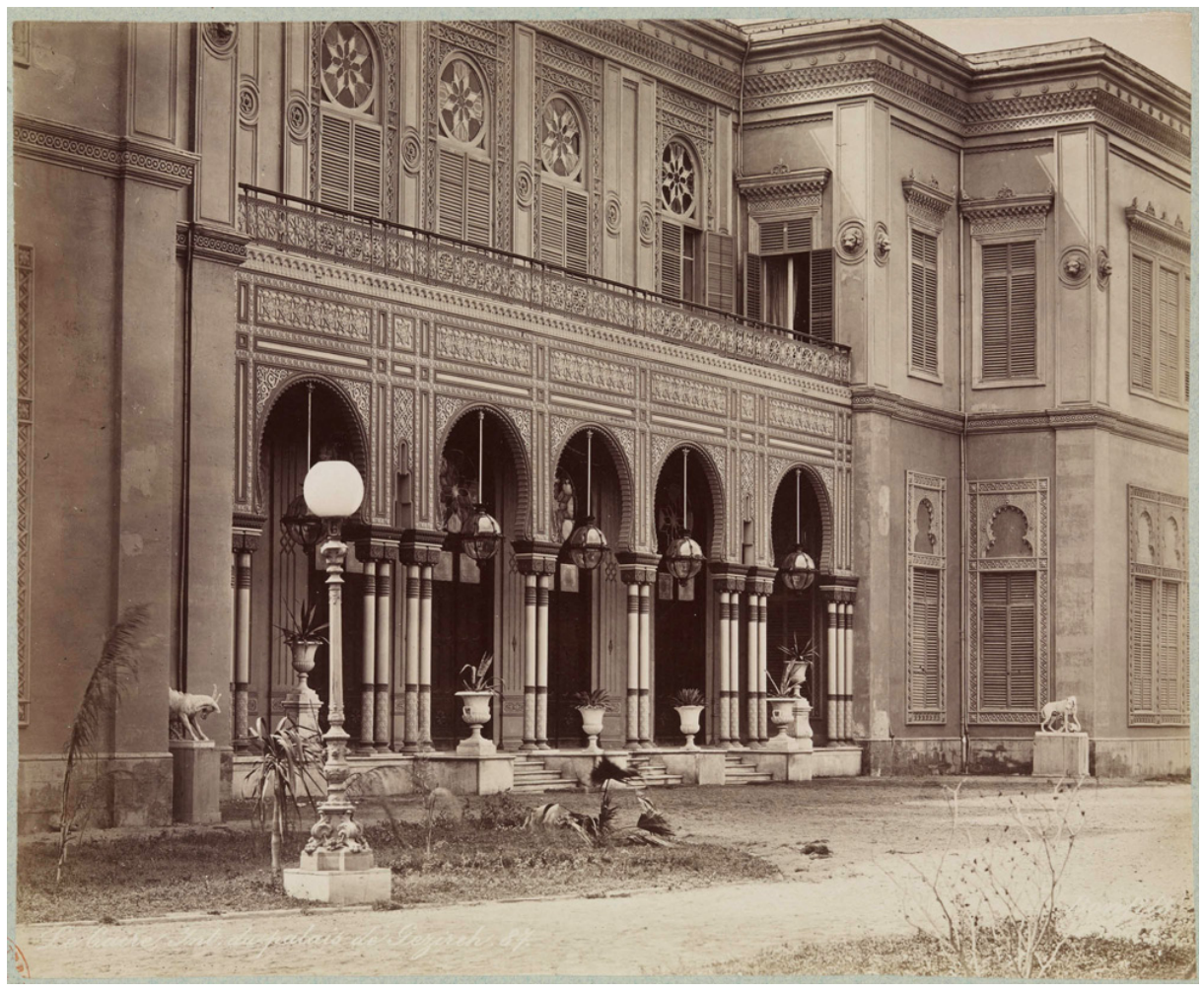

Source: Paris (France), Bibliothèque nationale de France, département des Estampes et de la Photographie. 
3c. Kiosk of al-Gazira, photograph by Bonfils.

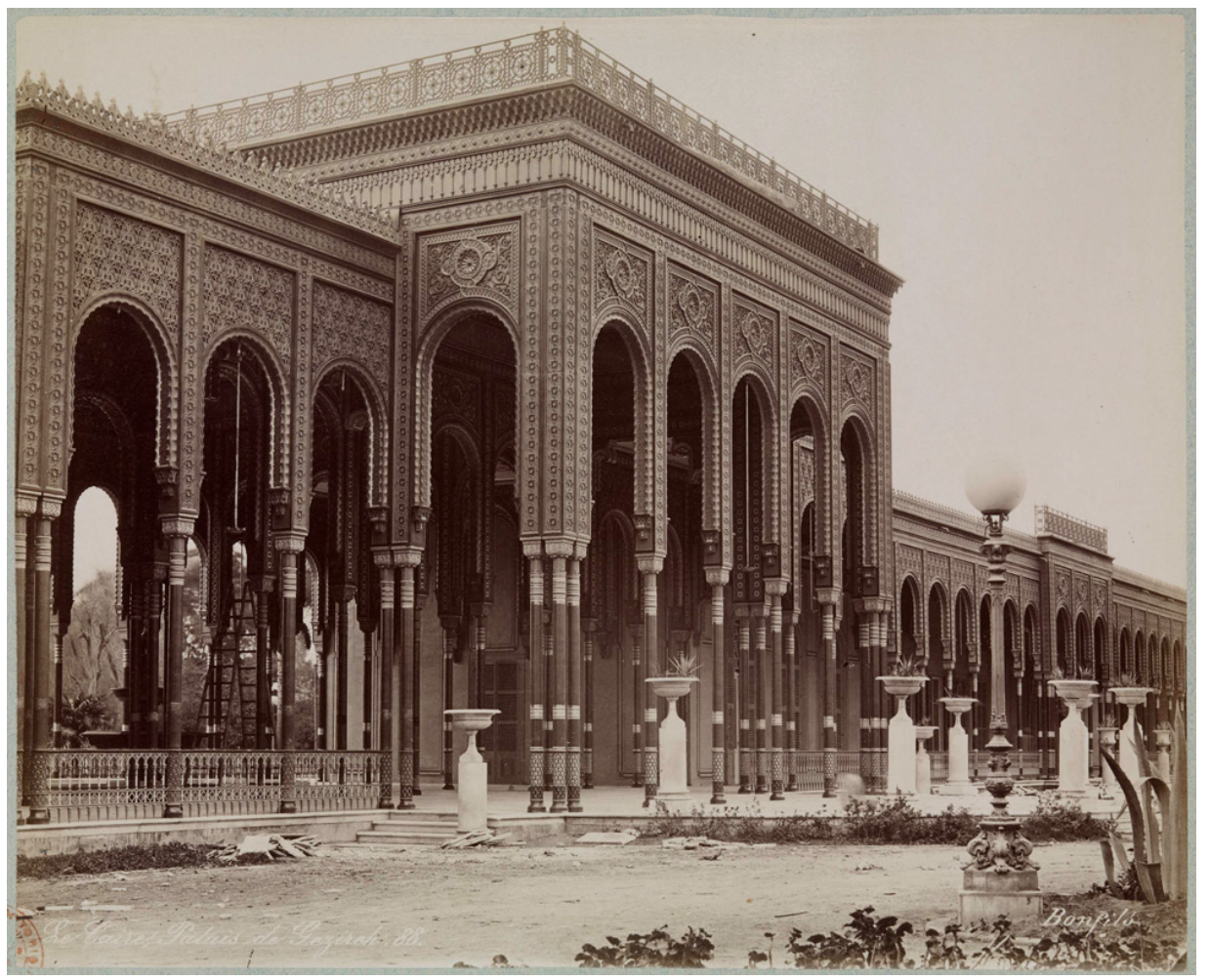

Source: Paris (France), Bibliothèque nationale de France, département des Estampes et de la Photographie. 
3d. Kiosk of al-Gazira, photograph by Bonfils.

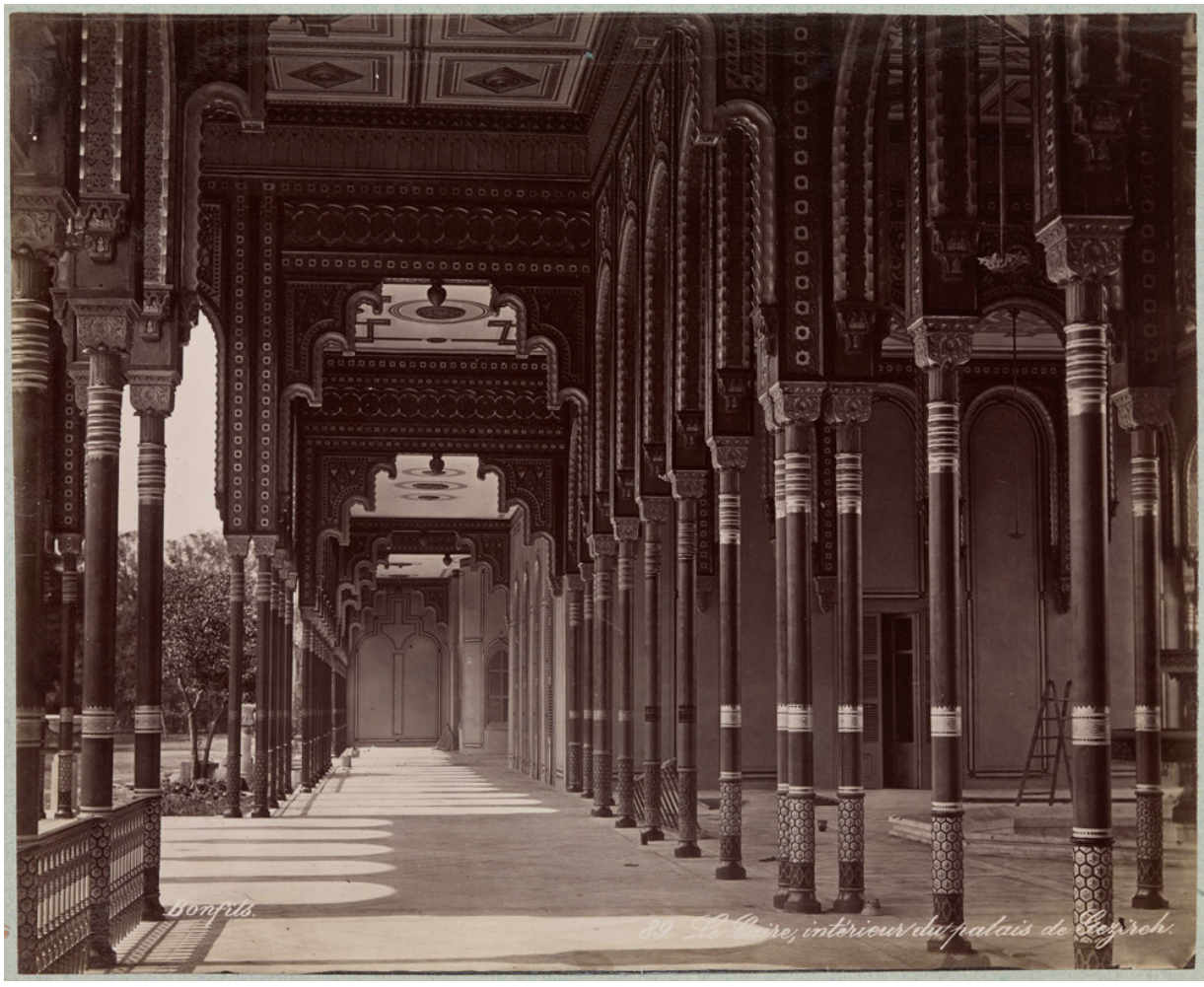

Source: Paris (France), Bibliothèque nationale de France, département des Estampes et de la Photographie. 


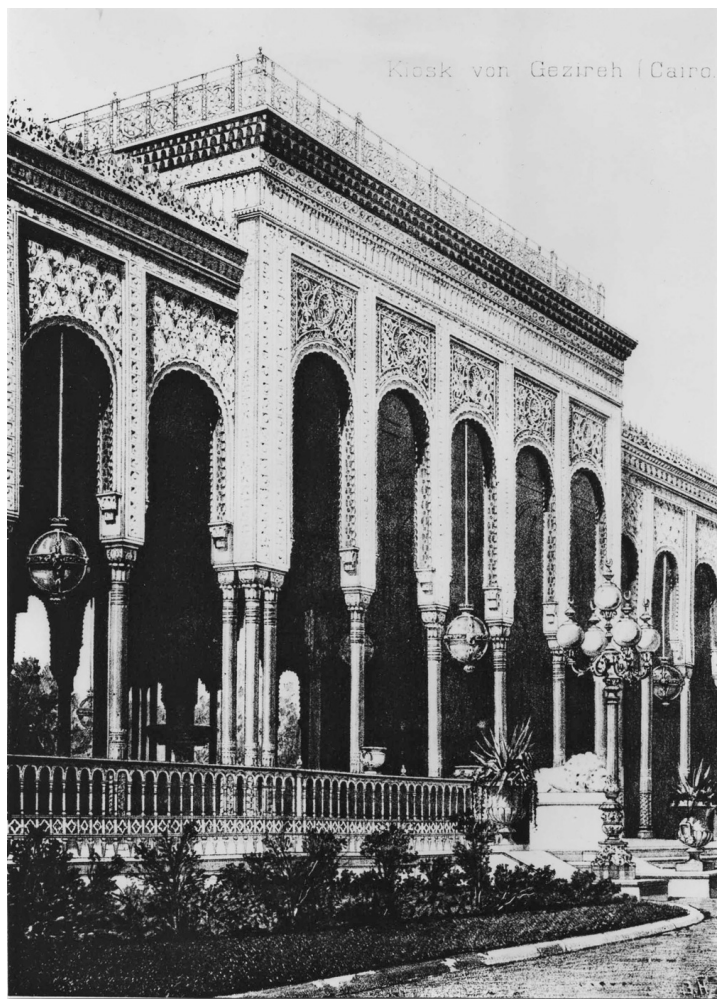

Source: J. Frant-Bey (variation in Julius Franz spelling), "Cairo's Neubauten", Zeitschrift für praktische Baukunst, 31, 1871, p. 193-198, p. 325-330, plate 22.

4 As professor he taught architecture in French language with Arabic translations according to a plan of lectures in Cairo's Serails Darb al-Gamamiz in $1871^{6}$. However, Franz' efforts do not seem to have been as successful as he intended. Indeed, 'Abd alRahman Zaki refers to the education of Egyptian architects who failed to contribute to Franz' aim to support the preservation of Islamic monuments ${ }^{7}$ by local architects. Foreigners only, especially the Hungarian Max Herz, who took on the role of Franz in the waqf ministry and the Islamic Museum, followed Franz' intentions. One could assume that Zaki's note refers to the fact that Franz' professorship was devoted to the preservation of monuments but it was not. The relevant Khedival Decree issues that students should be taught state-of-the-art architecture ${ }^{8}$. Probably, this document can be interpreted as the first one of modern Egyptian history referring to architecture as an autonomous discipline in an Egyptian institution. Franz as professor for architecture was closely involved in this development in Egypt, yet he had already left the Polytechnic Institute in 1875 becoming at first administrator and then director of the spa in Hilwan, southeast of Cairo'.

In his function as monument conservator, Franz was in charge of the preservation of very important Egyptian Islamic monuments as director of the Technical Waqf Department. The waqf administration was founded after 1850 to protect the waqf properties, although the Egyptian preservation of Islamic monuments (Comité de conservation des monuments de l'art arabe) was actually established in 1881 by a Khedival Decree and was consequently integrated in the Waqf Ministery. This was very possibly influenced by earlier European initiatives: according to Ludwig Borchardt, Franz played a major role in the founding history of the Comite ${ }^{10}$. His professor in Vienna, Eduard 
van der Nüll, was himself member of the Austrian Historical Heritage Preservation, which was constituted in 1851 . Franz therefore met the necessary requirements and sensitivity for such a position. Already, during his building activities (1859-1869) he had become aware that the concept of a historic monument embraces not only the architectural work itself but also the urban setting in which the evidence of the architectural heritage is found. Furthermore, Borchardt acknowledges Franz' high level achievements as a monument conservator:

"that he had stopped at the point where he could have applied his own work as an architect, and in this case moreover, that he had worked only in recourse to careful research of existing traditional settings." ${ }^{11}$

Borchardt explains how the conservator had to execute preservation work in 19th century Egypt: he had to teach himself every craftsman, even to execute simple work. In this way Franz found himself reviving old traditional craftsmanship. After some years of Egyptian preservation activities Franz recognized that it had been quite successful. He writes in one of his letters to the egyptologist Georg Ebers:

"that the so glorified Islamic monuments beautifully executed in your publication ${ }^{12}$ are not anymore so deserted as you have seen them when you have been visiting Egypt. ${ }^{13 "}$

7 As curator Franz founded the Islamic Museum in Cairo in 1880. Five years later he reflected on the current situation writing to Ebers as follows:

"also the Arabic Museum makes pleasingly progress which I had brought into being five years ago, and that the precious result has been achieved that the inhabitants were taught the relevance of their ancestor's art creations, preventing them from vandalism. ${ }^{14}$ "

The head of another letter dated only two months later shows an Arabic inscription with "Franz Pasha. ${ }^{15 "}$ At that time, when he was awarded the title "Pasha", he had reached the zenith of his career within the Egyptian services.

\section{Background to Die Baukunst des Islam (The Islamic architecture)}

Letters of Franz to the egyptologist Georg Ebers describe the troublesome joint venture of Karl Baedeker's first edition of Lower Egypt in 1877. The German 1906 edition of Baedeker's Egypt still mentions posthumously Georg Ebers in its preface as the one who provided the manuscripts for the first published Egyptian guidebook (ill. 5). Obviously the Baedeker dynasty felt obliged to this testimony after all those years. The founder Karl Baedeker designates both the man "Karl Baedeker" and "Baedeker" for his corporate successors. Ebers and Franz already dealt with one of Karl Baedeker's three sons who leaded the firm one after the other. Karl who succeeded his brother Ernst expanded the empire outward to Egypt.

In September 1873 Franz wrote to Ebers:

"today I send you the descriptions of the oldest monuments of Cairo and its surroundings in the south. In 8 days I hope to send the left ones. This work took much more effort than expected. For me as layman the writing is complicated, especially when you have collected all the material by yourself. Therefore I understand that you do not agree with my style of writing and that it is bad compared to your brilliant way of imagination. But I think, that the content is sufficiently scientific to provide a manual to the tourists... I take for granted that your changements of my paper may not lead to merge this large work into the general Baedeker. My efforts would not be rewarded at all like this. The honorarium which I am 
going to receive will not cover the fees for donkey, carriage, and translation. I hope B. (Baedeker) will pay for plans and sketches according to Egyptian taxes... Does B. own a map of Cairo? Otherwise I am going to highlight all the interesting spots on the photography of the water company and send it to him. The photography is not too bad perhaps a little bit pale. Please send me an answer. Such a map could be produced easily." 16

5. Book cover of Karl Baedeker, Ägypten und der Sudân. Handbuch für Reisende. 6. Auflage. Leipzig, Verlag von Karl Baedeker, 1906, including 38 maps, 59 floor plans, and 57 vignettes.

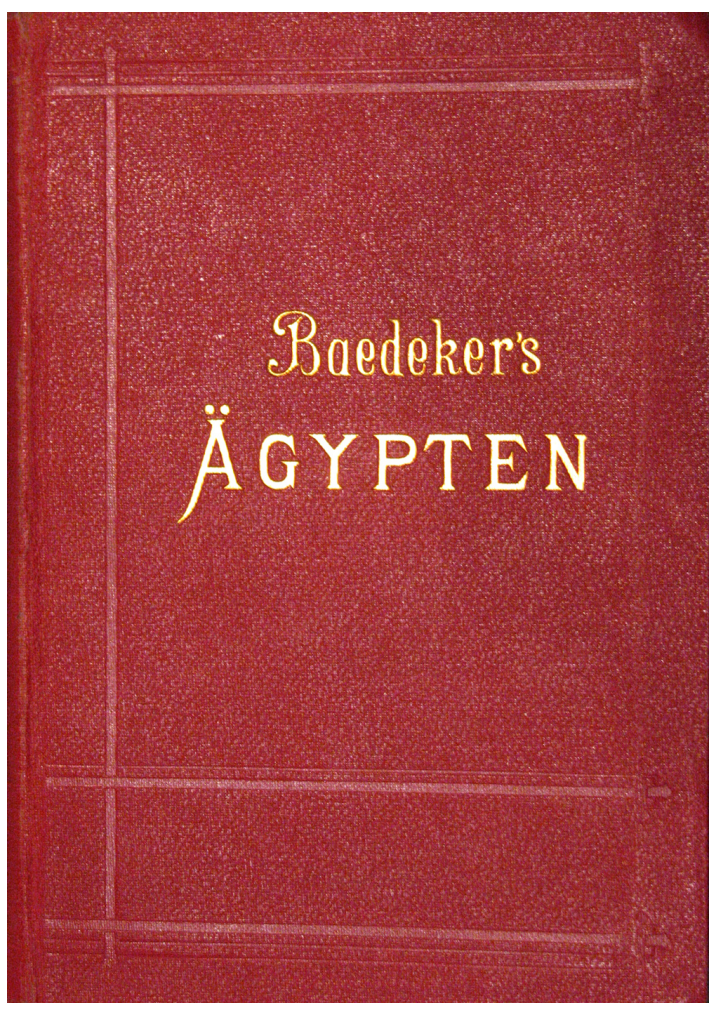

One month later Franz refers to the second route that he had worked out for the guidebook, which consisted of a general part about history, customs, religions, language, and literature, and another larger part illustrating the routes through the country:

"My dear friend, today I send you 18 pages with text, all including the second excursion. There is no possibility now to copy it, because otherwise I would miss to mail it. I beg you to excuse the stains on the paper... I own the copies of all plans. It will be followed by: alMuayyad, Mutani [?], Sultan Hassan Mosque, Citadel mosques of Muhammad Ali and Salah al-Din, fountain, Palace al Gazira, Shubra (Palace), Barrage." ${ }^{17}$

Reading these letters one gets the impression that Franz contributed much more to the publication than one would have expected after reading Baedeker's guidebook. He delivers the excursions for the Baedeker, most of the plans besides his part of the Islamic history and architecture. Corresponding to the proportion of this work, his efforts are not valued in the preface of the guidebook. It is not surprising, that Franz complains one year later:

"I did not spare any time or any money in order to meet your or Baedeker's wishes. But until today I have received neither the copy of my manuscript nor the printed sheets nor the honorarium for my works and plans." 18

13 On the one hand, an explanation of Baedeker's silence may have been that the firm was enlarging its territory: Baedeker sold the family's book shop in Coblenz and moved to 
an editorial office in Leipzig, editing now almost every year a new complete guide book. On the other hand, there was also an organizational change in the 1870s, from the younger son Karl Baedeker to the youngest one, Fritz. Karl Baedeker jun. resigned for health reasons. This could explain, even more reasonable, why Franz mentions in his letters Baedeker's lately strange and often inexplicable behaviour. However, the red bindings and gilt lettering became the familiar hallmark of Baedeker's guides (ill. 5), and the content became famous for its detail and accuracy. Baedeker's Palestine and Syria appeared in 1875, just in the time when Franz expected the appearance of Baedeker's Egypt which preparation had begun in 1873. It would not be published until 1877. Franz answered a letter from Ebers, in which he had cleared up the misunderstandings dating back two years:

"My dear friend, your letter from the 13th of May [1875] enjoyed me truly. It clarified what I felt before, and I understand now that the relationship between you and B. was the reason of our annoyance. According to B. he very urgently needed my work. I was a little overhasty... In this agonizing uncertainty I did not receive any letter, any answer or any notice of receipt. I thought that my work with all its mistakes would be send into the world. After B. delivered only one printed manuscript to me in Germany, I started to correct, what I have written, and I improved all incorrectnesses and changes that happened while time passed. I marked all details for the plans of Alexandria by myself and delivered new plans. I improved the article about the Nile, too. I did not touch your domain of history and hieroglyphics. I think B. is going to supply you with all of it. I did not get any news for month from him, and I don't know how far his work has progressed. His Syria is beautifully equipped and seems to be excellent." 19

Another two years later Franz comments on the published Aegypten, Theil 1. UnterAegypten (Lower Egypt) to Ebers:

"I think it was about time that the book was published. Even though it seems to be perfect and completed in its first edition, experience will teach us about the left issues. It was an enormous work. In Europe such work is relatively easy, because there are so many books to get prepared, and civilization has established comfortable conditions. How much different is Egypt, where changes happen in short intervals, where books about Egypt provide little substance and offer false, but entertaining information, so that it is difficult to decide whether the information is right or wrong. I talked and wrote about it to Baedeker. However, the book is the last and by far best one ever written about Egypt and offers a lot of material. It pleased me that B. became agreeable. The whole thing would have suffered damages..." 20

In the same letter he reassures Ebers that Egypt is still a rich country though England is lamenting about its currency, along with other European countries. He argues further on that they were the ones who exhausted Egypt. His attitude is therefore pro-Egyptian and not only in the context of this particular letter. From the beginning Franz knew that his manuscript for Baedeker would simply be his first publication to be followed by a more important one about Egypt and its Islamic architecture ${ }^{21}$. He comforted himself like this, knowing very well that Baedeker's Egypt would subsume his large work. In 1879 he asked Ebers to write a letter of recommendation for a well-known Leipzig bookseller's in order to buy new or antiquarian books about Islamic art. One can imagine what was written on his list: Prisse d'Avennes' L'Art arabe (1869-77), Bourgoin's Les Arts arabes... (1868-70), or later Le Bon's La Civilisation des Arabes (1883), Stanley LanePoole's The Art of the Saracenes in Egpyt (1886), and Gayet's L'Art arabe (1894). These publications are some of the references he used in his Islamic architecture in 1887 or in1896, the 2nd updated edition. 


\section{The origin of Die Baukunst des Islam} presumably, one could understandingly specify the arts which were meant by the authors. This understanding seems to date to the first half of the nineteenth century considering Coste's Architecture arabe ou Monuments du Kaire...(1824), or Girault des Prangey's Essai sur l'architecture des Arabes...(1842), which are also mentioned references in Franz' Islamic architecture. The term "Arab" was obviously related in the beginning to architecture, and then transferred to the arts, in general, in the second half of the 19th century. As Grabar stated, this term seemed "to have grown primarily among learned professionals associated with the community of Cairo." ${ }^{23}$ All the authors "shared more or less the same public in Egypt and in Europe". They felt obliged to use a title consecrated by usage. Therefore they accepted it, but as Grabar continues "with reluctance". Grabar sets Gayet as a good example to describe what he understands on Gayet's intentions, for "if there ever was a title empty of meaning, even in total opposition to whatever it defines, it is assuredly this one." Gayet elaborates his approach as follows: "The Arab has never been an artist". In his Islamic Architecture Franz dissociates himself from such an approach. For him it seems to be too adventurous to declare this race as fully untalented for architecture as Prisse d'Avennes $\mathrm{did}^{24}$. If Franz would have ever shared this approach he would have not been able to teach architecture to local students in the Polytechnic Institute in Cairo as he did for some years. Due to his lifelong experiences in different positions in Egypt's services he could draw other, very self-confident, conclusions, which differed radically from the generally accepted opinion represented by Prisse d'Avennes, Gayet and others.

In the above-mentioned article by Franz, which he wrote in 1894, he is already discussing the term "Arab", in fact, in the same way as Grabar did a hundred years later. The title of this article speaks for itself: "Studie über Namen und Entstehung der Kunst der Völker des Islams (study of names and genesis of the art of the Islamic people)". There he already points to his "high reluctance" to using the term "Arabic art" 25 , which resulted in the new heading of his article: "art of the Islamic people". His awareness of this matter is also apparent from the title of his Islamic architecture in 1887, though not discussed yet in his manual. Franz began to use the term "Islamic" very consciously and continuously. Ernst Diez (1878-1961), Austrian historian of Iranian and Islamic art, scholar of Strzygowski, follows him in heading his general art history on Islamic art of 1915: Die Kunst der islamischen Volker (Art of Islamic people). In his preface he writes:

"We admire Franz Pascha as senior figure (Nestor) of the German Islamic art research who was employed many years as governmental architect in Cairo and caused first mental stimulation by his manual Die Baukunst des Islam (Islamic Architecture) which recapitulates the most important known monuments as building types." 26 
19 study of forms and colours leaves him indifferent... and when he is obliged to become an architect, he merely borrows his material from Greek or Byzantine monuments. ${ }^{27 "}$ His understanding of Islamic art, fully shared by his contemporaries, appeared to be a static and linearly structured one, as an art adopted from ancient civilizations incapable of providing cultural autonomy. Franz displays a differentiated picture. He admits that the Islamic art developed otherwise but his statement is perhaps too cautiously verbalized at this early point of his study:

"Islamic architecture developed most beautifully and pure in Egypt. How much Arabs contributed to this development is not quite clear yet, because they were not so skilled craftsmen. But, on the contradictory, some solid achievements cannot be denied in very early times..."28

Then Franz quotes an Eastern authority in relation to the turning point when one can talk about Arab architecture in history to support his scientific approach. He selects the 14th-century Tunisian philosopher Ibn Khaldun who linked the beginning of Islamic art to the fall of the caliphate ${ }^{29}$. It becomes apparent that Franz' deep knowledge is based on both Western and Eastern sources. Sometimes he complains in his letters how much he has to pay for translation work, translating from Arabic into German. He undertook these efforts, he had to scrimp and save this amount of money from his comparatively small Egyptian officer's salary, because he knew that such a work demanded competent knowledge of the most important Arabic writer ${ }^{30}$. For him the Eastern sources were as precious as the Western ones. He comments in general that the same principles for the Arab monuments have to be applied for other earlier artistic developments: existing art forms are taken over, either changed or kept unchanged, into a new artistic style ${ }^{31}$. His approach differs much from the more or less racially motivated explanations of a Gayet, for example. Later in his study, Franz refers to a "genuine Arab invention without any doubt" ${ }^{2}$ : He describes in detail how different the transition from the cube to the dome constructed by the Arabs in opposition to the Romans and Greeks was, and notably the muqarnas in all its varieties used as a bridging element. He shows then impressive examples of a mausoleum and mosque in Cairo (ill. 7), which he drew himself. While focusing on the muqarnas as quintessentially Islamic he identified subsequently other Islamic structural designs, such as the mashrabiyya, a type of window or screen turned in wood. In relation to this, he published mashrabiyya images after his own drawings (ill. 6). Furthermore Gayet differentiates a new Arab art from Moorish, Turkish and Persian, whereas Franz affiliates emphatically with Le Bon's classification who differs the Arab monuments according to their location or to their related earlier art epochs. Franz considers this approach modern and rational, though he suggests adding the Arab-Ottoman period to Le Bon's classification ${ }^{33}$. 
6a. Plate from J. FRANZ Pascha, Die Baukunst des Islam, Darmstadt, 1896, II, 3.2, fig. 48-49.

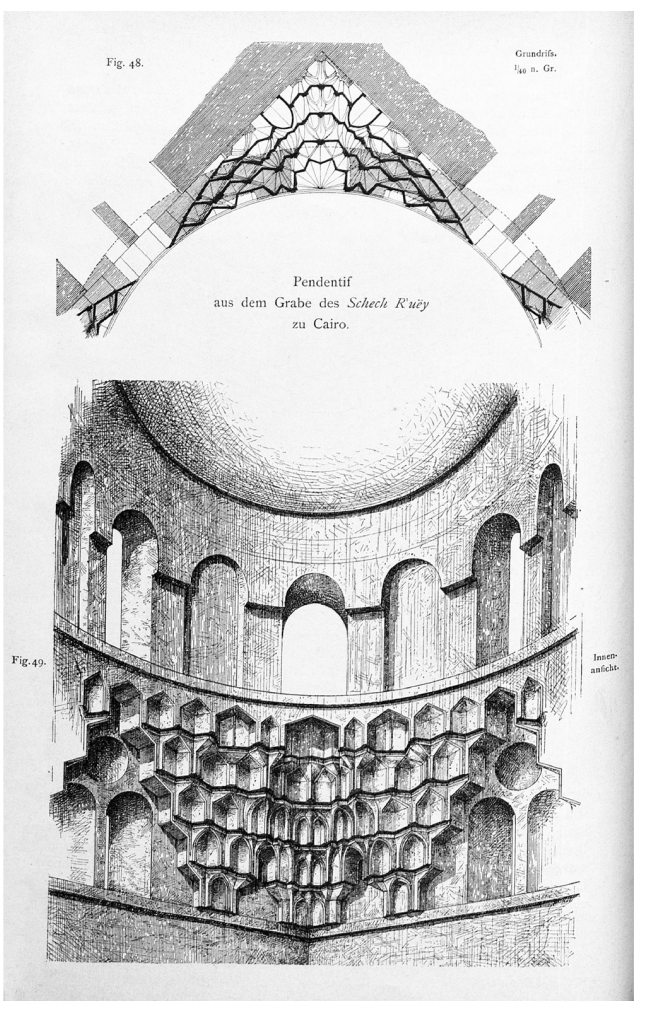

6b. Plate from J. FRANZ Pascha, Die Baukunst des Islam, Darmstadt, 1896, II, 3.2, fig. 104 à 107.

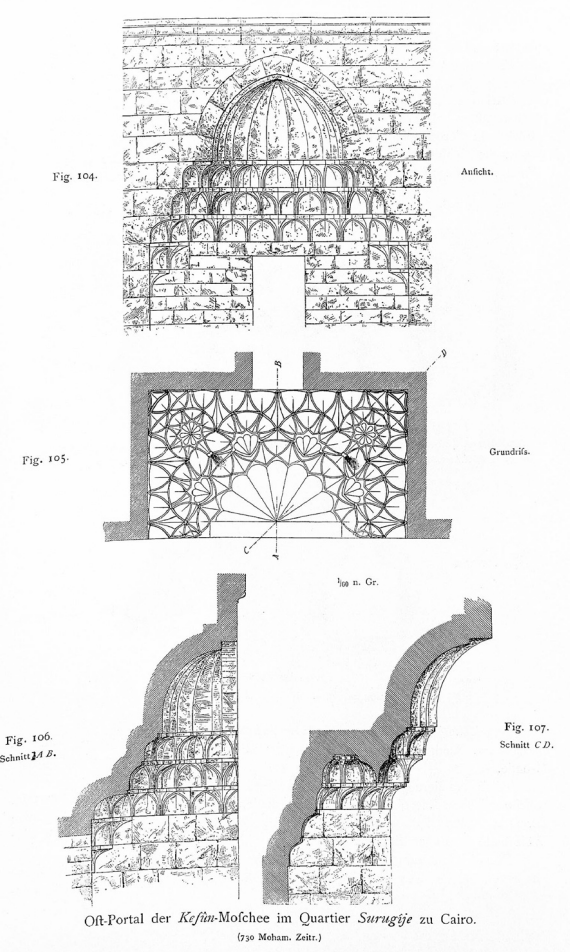

21 Diez thought it worth mentioning that Franz differentiated the known Islamic monuments according to their building types ${ }^{34}$. Franz had already classified the 
buildings in Baedeker's popular scientific guidebook into: mosques, tombs, and secular buildings. In Die Baukunst des Islam he extends his building types to more specific ones: sacred buildings, mausoleums, tombs for families and for single persons, tekke, sabil, madrasa, maristan, and finally secular buildings in general. Modern authors, for example Robert Hillenbrand in his Islamic architecture ${ }^{35}$, decided to classify the material according to building types as well as, rather than, to its chronology. Robert Hillenbrand proceeds in the same methodical approach more than one hundred years after Franz' Die Baukunst des Islam.

7a. Plate from J. Franz Pascha; Die Baukunst des Islam, Darmstadt, 1896, II, 3.2, fig. 81.
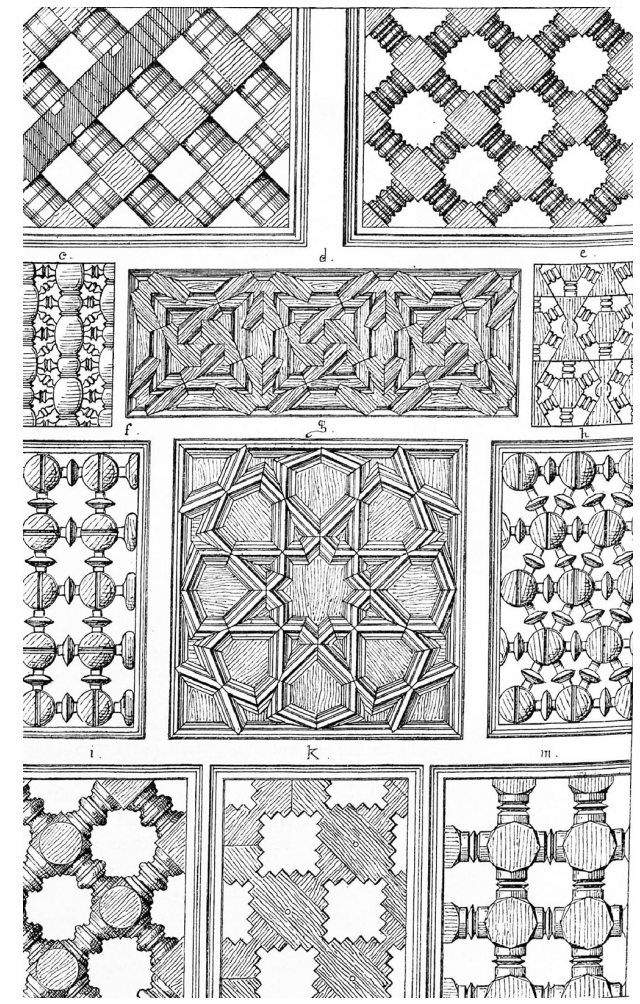

Source: Author's collection. 
7b. Plate from J. Franz Pascha; Die Baukunst des Islam, Darmstadt, 1896, II, 3.2, fig. 82.

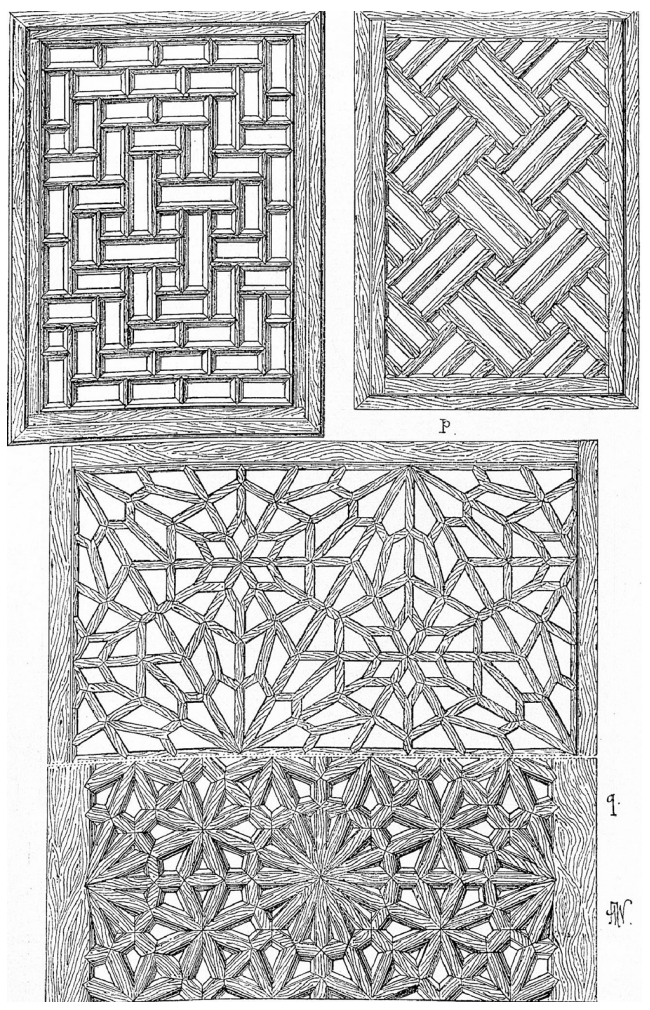

\section{The critical reception of Die Baukunst des Islam}

A second edition of the Die Baukunst des Islam became necessary in 1896. The updated edition received two positive reviews. Only one objection was voiced that the author admitted a priority of the art of the ancient world compared to the Islamic architecture ${ }^{36}$. The other reviewer was Josef Strzygowski ${ }^{37}$. Firstly, he drew the picture of the desolate situation of Arab art research, even Japanese and Mexican art were better explored than the Arab art. And secondly, he thanked Franz for putting pen to paper speaking from his own experiences as architect in Egypt's service for twentyeight years. He adds that the fact that it had needed a second edition would show the great demand. The new edition was now much more extended, especially the chapters concerning building materials and techniques. Illustrations with photographs and measuring views played the major part of the publication and were unsurpassed (ill. 6-7). Strzygowski's concern with Franz' manual has to be regarded as a milestone in Islamic art history. At the time, Strzygowski started to include Islamic art history into his field of research presumably because he felt that its research was still a vast unknown field. In the summer term of 1899 he had given his first lecture about "Christian and Muhammedan art in Asia Minor" at Graz University, followed then by "Egypt (Christian and Arabic monuments)" in 1903/4, and "Islamic art" in 1907/838. Later Stryzgowski became the head of the Art History Institute of Vienna University. In 1911 Diez became an assistant of Strzygowski and shared the opinion of his teacher about Franz-Pasha being the senior figure of German Islamic art history. In this way Franz had a wide ranging and significant impact on the historians of the Vienna school of Islamic art over decades. In this context it does not astonish that Franz bequeathed 
his library to the Vienna institute. Franz left for Graz after having retired. In 1904 he became honorary doctor of its university. This university has given rise to new scholarship on Islamic history by an award dedicated to Dr. Julius Franz-Pascha from 1917 to 1944 in order to encourage studies in the field of Islamic art.

Franz-Pasha is understood more as a practitioner than as a theoretician. He is to be regarded as German Islamic art "Nestor" as Diez refers to him. The term "Islamic" was used for the first time when he headed his most famous book Die Baukunst des Islam in 1887. Later "Islamic" was accepted in the Vienna school by Strzygowski, Diez, and others, either in their lectures or in their publications. In addition the Strzygowski scholar Diez participated in the preparations for the biggest exhibition for Islamic art ever organized in Munich in 1910. The exhibition was entitled: „Meisterwerke der Islamischen Kunst" (Islamic masterpieces). Officially, Islamic art objects have been covered by a religious aspect rather than by a racial one. The term "Islamic" has been worldwide taken for granted and had more or less substituted "Arab".

The Manual's influence on architects and monument conservators has been great as much as its influence on scientists and scholars. It was supposed to be a reference book for architects and engineers more than for librarians. Die Baukunst des Islam is indeed an architectural manual even making possible the creation of new and significant Islamic buildings. Franz himself was involved in creating modern Islamic buildings such as the celebrated Kiosk on al-Gazira island (ill. 3-4). The building theory of his publication is historical, scientific, and devoid of deliberate racism, based on historical materials and techniques. His methodical approach is a common one today but has to be considered pioneering in his time.

\section{NOTES}

1. See www.gtg.tu-berlin.de. Accessed on November 17, 2015 (Society for Technical History): one volume of the Manual of Architecture was implemented in a Wiki moderation system: the digital implementation without comments/context was only useful for the already informed user; the uninformed user could misinterpret the data.

2. Egyptian 19th century standard reference 'Ali MUBARAK, Al-Khitat al-Tawfiqiyya al-jadida li-Misr al-Qahira wa Muduniha wa Biladiha al-qadima wal-Shahira,20 volumes (Bulaq 1304/06; quoted edition from al-Qahira: Dar al-Kutub, 1969) vol. 1, p. 212, records Franz as an Austrian. In secondary sources this information is often repeated, see for instance Mohamed SCHARABI, Kairo. Stadt und Architektur im Zeitalter des europäischen Kolonialismus, Tübingen: E. Wasmuth, 1989, p. 83.

3. See for example the marriage registration of Julius Franz and his second wife Olga Lautner, mentioning that the architect was born in 25.08.1831 in Springen, Great Nassau, as son of the forest ranger Wilhelm Franz, Archive of the German Protestant church in Cairo.

4. See Julius FRANTZ, Régis de CUREL, "Cirque du Caire," Revue générale de l'Architecture et des Travaux publics, no.27, 1869, p. 276, plate 54; H. FRANTZ-BEY (variation in Julius Franz spelling), “Cairo's Neubauten," Zeitschrift fur praktische Baukunst, no.31, 1871, p. 193-198, 325-330, plates 21-22, 35-36: the author refers to himself as "Ober-Baudirektor des Khedive" reflecting his rank in the hierarchy of public servants in the field of civil engineering. Members of the architect 
Diebitsch' staff describe him as court architect, compare C. OHNESORGE, Orientalische Skizzen. Unsers Vaters Erinnerungen an sein Arbeiten und Wandern im Orient 1863-65 zu seinem siebzigsten Geburtstag, dem 17.07.1908, without statement of place 1908, 66, and W. Rose, letter 10. 12. 1863. Rose's letters are owned as copies by his daughter Elisabeth Reinbrecht, the mother of Dorothea v. Lübke. He was born in Gandersheim in 1842 and worked as engineering assistant for the Lauchhammer foundry.

5. Julius FRANTZ, op. cit.(note 4), p. 194.

6. Amin SAMI, Taqwim al-Nil (al-Qahira: Matba'at al-Amiriyya 1936), vol. 3, part 2, 929 and vol. 3, part. 3, 1287, where Sami writes that only one German named Franz Bek (or Bey as title of honour) was able to take the educational burden among 321 foreign teachers refering to files of the Department of Education from 1292/1875 to 1936. Mercedes VOLAIT, L'architecture moderne en Égypte et la revue Al-Imara 1939-1959, Le Caire: Cedej, 1988 (Dossier 4), p. 23 and footnote 9, identifies architecture as an autonomous discipline in Egypt with the 1886 reorganised Polytechnic Institute into the École d'irrigation et d'architecture in Cairo, but mentions also, that Franz gave architectural lectures there even before that date.

7. 'Abd al-Rahman ZAKI, Mawsu'at madinat al-Qahira fi alf 'Amm. Concise Encyclopaedia of the city of Cairo, al-Qahira, 1389 [1969], p. 170.

8. Amin SĀMI, op. cit. (note 6), vol. 3, part 2, p. 923.

9. Elke Pflugradt-ABdel Aziz, "La Cité d'Helwan en Égypte et son fondateur Wilhelm Reil-bey," Revue du Monde Musulman et de la Méditerranée (REMMM), vol.73, no. 1; 1994, p. 259-279. URL: http://www.persee.fr/doc/remmm_0997-1327_1994_num_73_1_1681. Accessed on November 17, 2015.

10. Ludwig BORCHARDT, "Franz Pascha", Zentralblatt der Bauverwaltung, no.35, 1915, p. 220.

11. Ibid.

12. Georg EBERS, Das Alte in Kairo und in der arabischen Kultur seiner Bewohner, Breslau: Schöttlander, 1882 (Deutsche Bücherei, 2, 11).

13. Franz to Ebers, Wiesbaden, 11.9.1885; Stiftung Preußischer Kulturbesitz, Staatsbibliothek, Manuscript Department, Literary Estate of Georg Ebers 21, Franz Pascha.

14. Franz to Ebers, Wiesbaden, 11.09.1885.

15. Franz to Ebers, 28.11.1885.

16. Franz to Ebers, Cairo, 20.09.1873.

17. Franz to Ebers, Cairo 17.10.1873.

18. Franz to Ebers, 01.06.1874.

19. Franz to Ebers, Cairo, 10.07.1875.

20. Franz to Ebers, 1877 (?).

21. Franz to Ebers, 1873 (?): “... My work for Baedeker has made progress so far. I have to read and to study much more than I have expected before I start writing, One believes to know so many things, but in case of putting it down you must overcome and eliminate these insecurities and scruples related to your work, or issues of translations, or even field investigation. However, this work is going to be a preliminary study of a large work."

22. Franz to Ebers, Cairo, 19.12.1894.

23. Oleg GRABAR, "What does 'Arab painting' mean?," in Anna CoNTADINI (ed.), Arab Painting. Text and image in illustrated Arabic manuscripts, Leiden: Brill, 2007 (Handbuch der Orientalistik, Erste Abteilung, Nahe und der Mittlere Osten, Bd. 90), p. 20.

24. Julius FRANZ-Pascha, Die Baukunst des Islam, 2nd edition (Darmstadt: Handbuch der Architektur, 1896), vol. II, 3.2, p. 8.

25. Julius FRANZ-Pascha, "Studie über Namen und Entstehung der Kunst der Völker des Islams", Monatschrift für den Orient, Wien, 1894, p. 73. 
26. Ernst DIEZ, Die Kunst der islamischen Völker, Berlin-Neubalelsberg: Akademische Verlagsgesellschaft Athenaion, 1915 (Handbuch der Kunstwissenschaft, 33) : "Als Nestor der deutschen Forschung auf dem Gebiet der islamischen Kunst verehren wir Franz Pascha, der viele Jahre als Regierungs-Architekt in Kairo tätig war und mit seinem Handbuch Die Baukunst des Islam, das die wichtigsten damals bekannten Denkmaler als Bautypen zusammenfasste, der weiteren Forschung erste Anregung gab."

27. Translated by Oleg GRABAR, op. cit. (note 23), p. 20.

28. Julius FRANZ-Pascha, Die Baukunst des Islam, op. cit. (note 24), p. 11.

29. Ibid., 11.

30. Ibid., 76.

31. Franz to Ebers, 20.09.1873.

32. Julius FRANZ-Pascha, op. cit. (note 25), p. 74.

33. Ibid., 74.

34. Ernst DIEZ, op. cit. (note 26)

35. Robert HILLENBRAND, Islamic Architecture: form, function, and meaning, New York: Columbia University Press, 1994.

36. H., Deutsche Bauzeitung, no. 31, 1897, p. 271.

37. Josef STRZYGowSKI, Dt. Literaturzeitung, no. 21, 1897, p. 848-849.

38. Gabriele Anna REISENAUER, Josef Strzygowski und die islamische Kunst, Master of Arts degree, Universität Wien, Wien, 2008, p. 82. URL: http://othes.univie.ac.at/ 917/1/2008-08-18_9105823.pdf. Accessed on November 17, 2015.

\section{AUTHOR}

\section{ELKE PFLUGRADT-ABDEL AZIZ}

Docteur ès lettres, spécialiste de l'architecture orientaliste. 


\title{
Max Herz Pasha on Arab-Islamic Art in Egypt
}

\author{
István Ormos
}

Having spent ten years in subordinate posts at the Technical Bureau of the Waqf Ministry, Max Herz (1856-1919; fig. 1) became chief architect to the Egyptian Comité de Conservation des Monuments de l'Art Arabe in $1890^{1}$. He occupied this position, which had been created for him personally, until the end of 1914. As chief architect, he played a key role in the conservation of Arab-Islamic architectural monuments in Egypt, in Cairo primarily ${ }^{2}$. The importance of the job was indicated by the fact that notwithstanding the losses in the course of previous centuries, Cairo was the world's richest city with regard to Islamic architecture. At the same time, Herz directed the Arab Museum in the city (also known as the "National Museum of Arab Art" at the time; it is currently the "Museum of Islamic Art"), considering this post ancillary to his main one. He was active as a private architect, too, personally preferring the Neo-Mamluk style, yet erecting buildings in other styles in addition. Owing to his long and continuous involvement with Cairo's architectural monuments, Max Herz Pasha, an accomplished architect by training as well as naturally, was regarded by many contemporaries as the foremost authority on the history of Arab-Islamic art in Egypt. For instance, D. S. Margoliouth, professor of Arabic at Oxford, in 1907 referred to Max Herz as "the highest authority on Moslem architecture"3. Herz was deeply interested in questions of architectural history in general and in those of Arab-Islamic architecture in particular, with special regard to the theoretical and practical problems he encountered in the course of a long career devoted to the conservation of architectural monuments. We are indebted to him for a number of publications in these fields. At the same time, it must also be said that Herz's regular workload was so heavy that he was unable to devote himself to scholarly tasks to the extent that he would have liked: in his letters to Ignaz Goldziher, he complains repeatedly that he has much interesting data, but never finds enough time to process it and write it up ${ }^{4}$. His letters to Goldziher and to Max van Berchem betray a certain insecurity in the field of scholarly publications: owing to work pressures, he evidently could not live up to his own high expectations. The present article endeavours to give 
an overview of Herz's most important works, with some emphasis on his writings in Hungarian, which may not be accessible to most readers ${ }^{5}$.

1. Max Herz. Undated photograph.

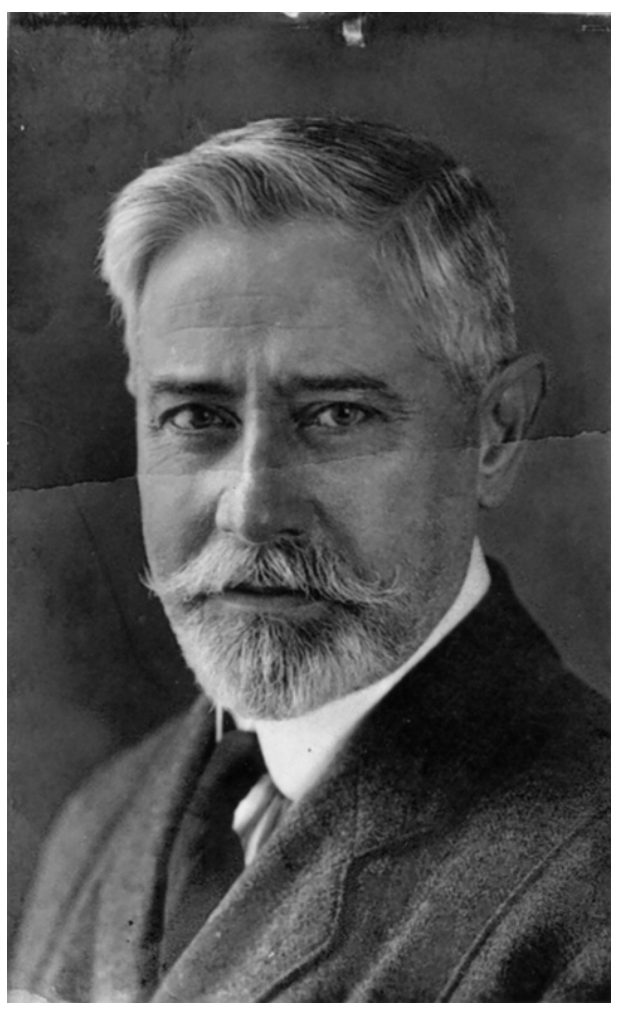

Source: Private collection.

During his term of office, Herz edited the annual reports (Bulletins) of the Comité. These consisted of the Comité's proceedings and of the reports of its Technical Bureau (Section Technique) also. Herz wrote the reports himself, beginning with no. 48 (29 November 1888) and ending with no. 485 (25 June 1914). From 1897 on, pithy descriptions of monuments written by Herz were added as appendices. It was planned to launch these as independent publications constituting a separate series, but only one volume ever appeared: this was Herz's fine short monograph on the mosque of Amir Ganim alBahlawan (883/1478; no. 129) ${ }^{6}$. The Bulletins contain a wealth of invaluable information on monuments. They are, however, not easy to use, mainly since, owing to the nature of the conservation work, information on individual buildings is scattered in many different places. Moreover, monuments often appear under different names. Published in 1914, the Index General by Herz Pasha up to the year 1910 is of great help in this respect ${ }^{7}$. The lack of a similar reference work for the post-Herz period is acutely felt ${ }^{8}$. Together with the Comité archives (now kept by the Supreme Council of Antiquities), the Bulletins allow us to reconstruct in very considerable detail the Comité's activities and its work on monuments. ${ }^{9}$. Comparable documentation for the period in question exists in no other Islamic country ${ }^{10}$. 
2a. Maison Bonfils, The old arab Museum in the Mosque of al-Hakim (380/990; no. 15).

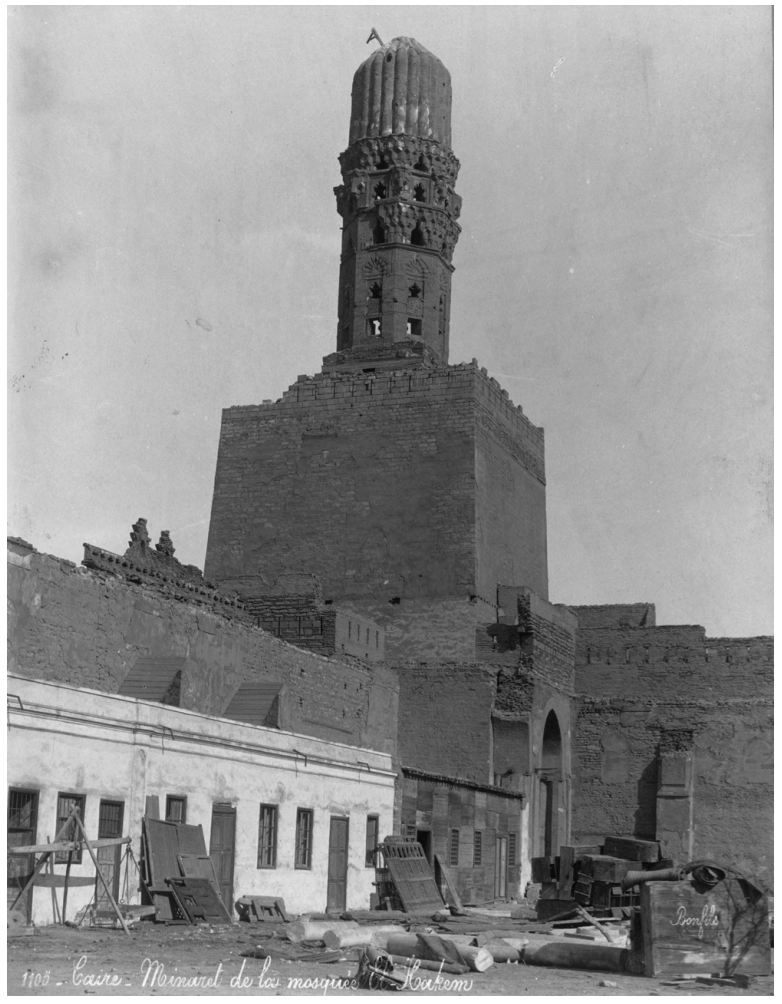

2b. Maison Bonfils, The old arab Museum in the Mosque of al-Hakim (380/990; no. 15).

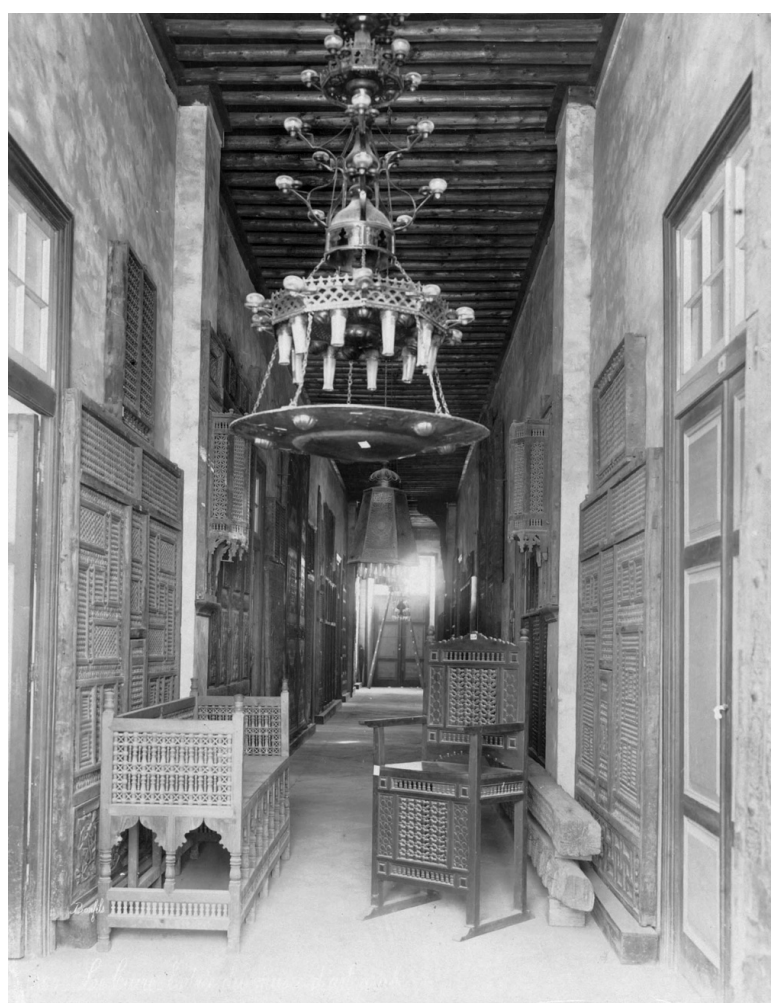


2c. Maison Bonfils, The old arab Museum in the Mosque of al-Hakim (380/990; no. 15).

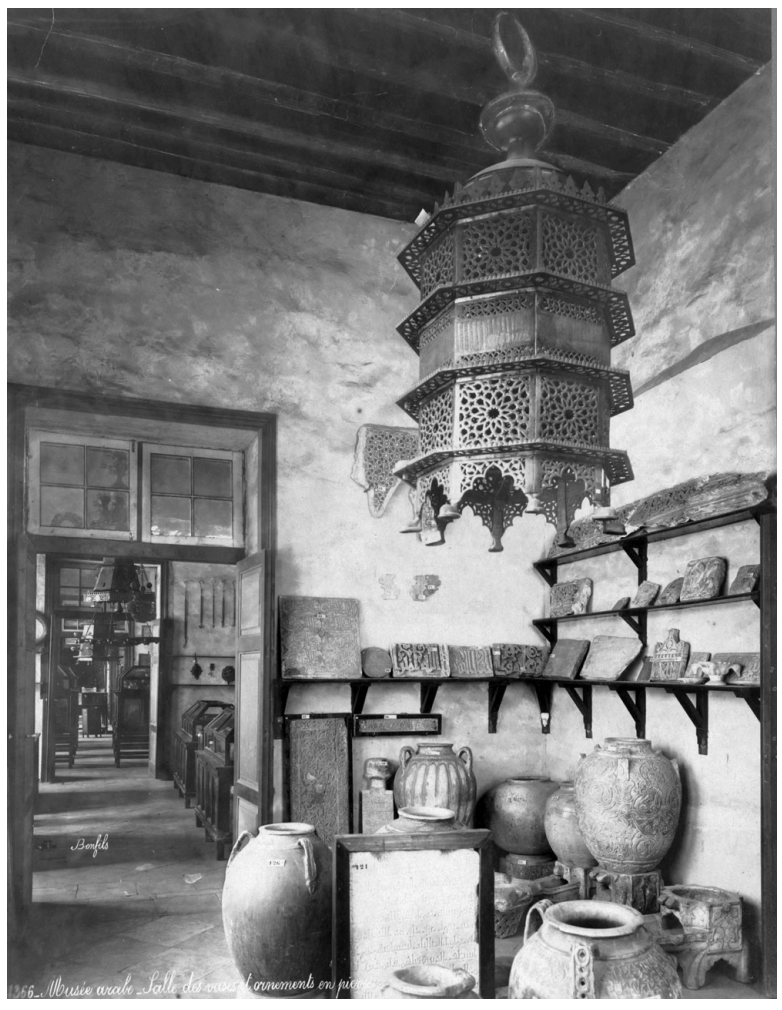

3 In connection with his tasks in the field of conservation, Herz was, from 1892 onwards, in charge of the above-mentioned Arab Museum, first with no special title and then, from 1901, with that of director. The latter appointment was connected to the erection and opening of a splendid new building designed to house the Museum and the Khedivial Library (1315/1898-1321/1903; U46; fig. 2-3) ${ }^{11}$. In this capacity, Herz published, in two editions, a French-language catalogue of the collections (fig. 4). Both editions appeared in English also, and the second in Arabic as well. Contemporaries praised these catalogues not just for the importance of the objects they featured and for the object descriptions they gave, but also on account of the essays that preceded each of the sections into which the catalogues were divided. These dealt individually with the different fields of Arab-Islamic art represented in the collections (plaster, stone, marble, mosaic, panelling, mashrabiyya, ivory, woodwork, metalwork, doors, glass, pottery, tissues, textiles, and leatherwork [book bindings]); the introductions to both editions offered concise accounts of the history of Arab-Islamic Egypt and of its architecture, too. The noted archaeologist, art historian, and islamisant Friedrich Sarre described the introductions and essays as "splendid presentations of the most diverse fields of Egyptian-Muhammadan art"12. Herz gave brief descriptions of the Arab Museum's collections in several other places also. One such piece, published in the Gazette des beaux-Arts, gave an interesting account of how qamariyyas were produced ${ }^{13}$. 
3a. The new Arab Museum. Postcard c. 1930.

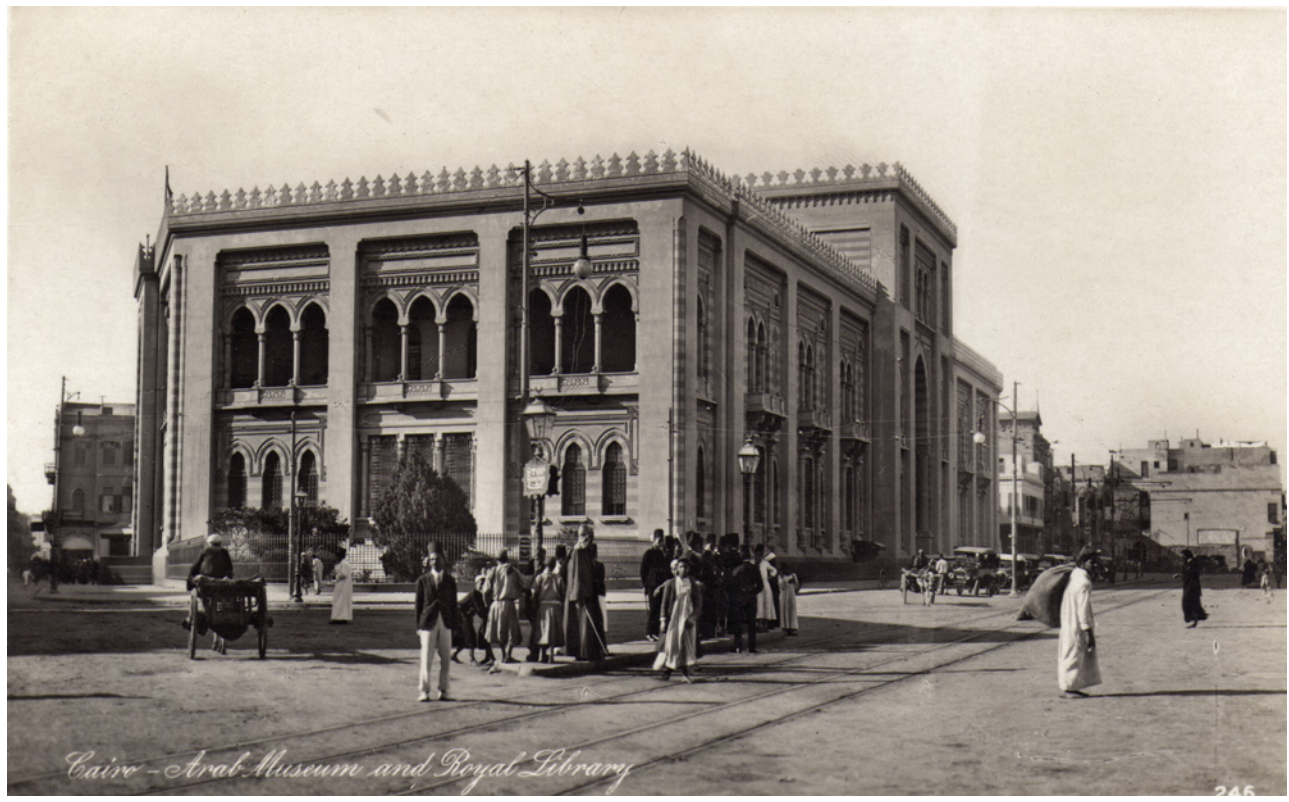

Source: Private collection.

3b. The new Arab Museum. Photographs, c. 1904.

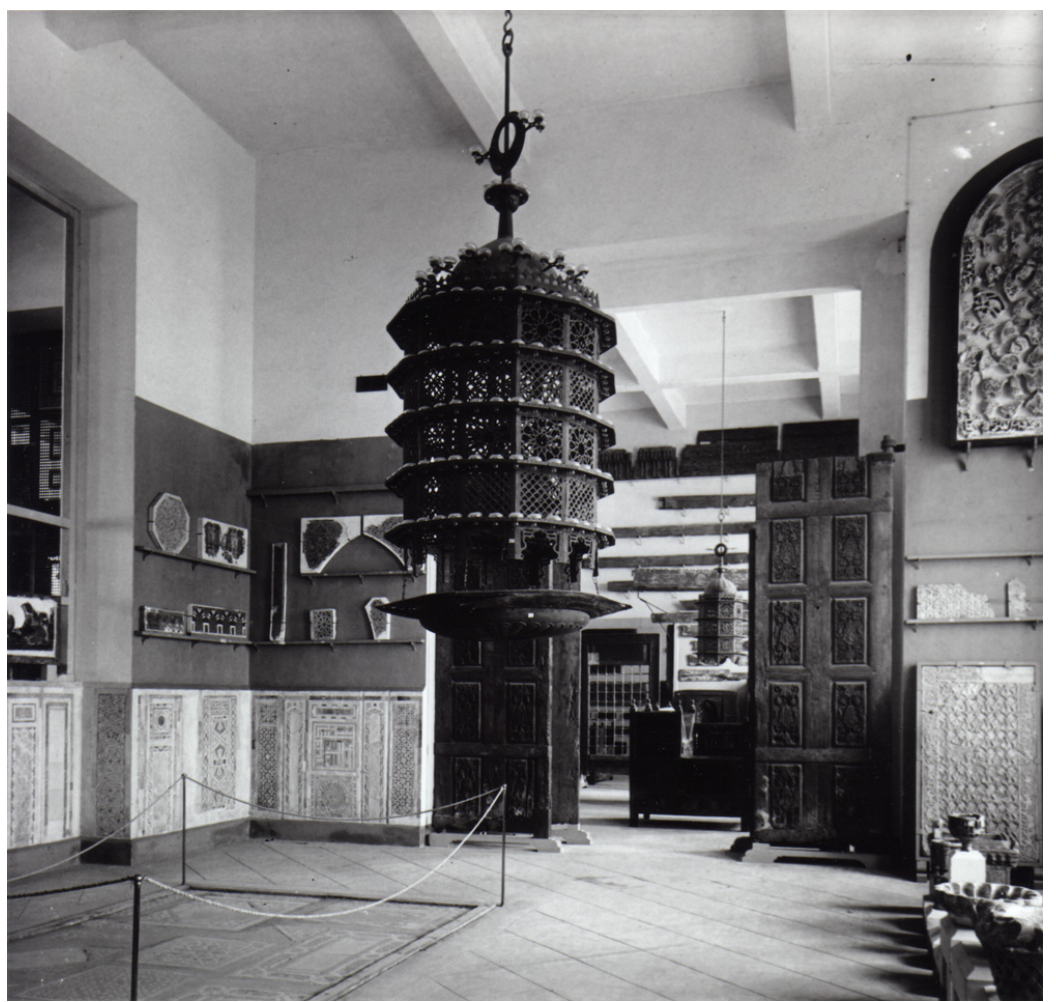

Source: Marburg an der Lahn (Germany), Bildarchiv Foto Marburg. 
3c. The new Arab Museum. Photographs, c. 1904.

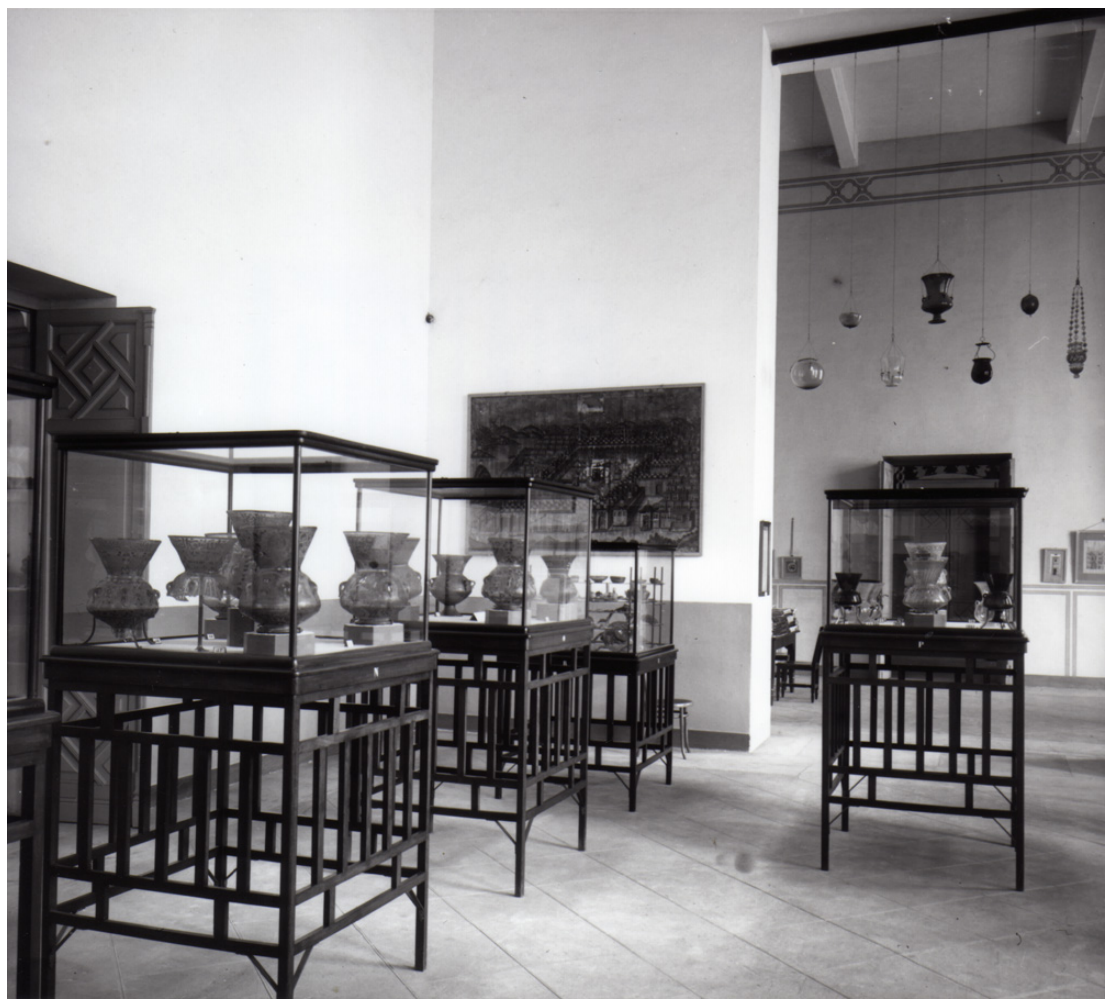

Source: Marburg an der Lahn (Germany), Bildarchiv Foto Marburg. 
4a. The first original French edition of Herz Pasha's catalogue of the Arab Museum.

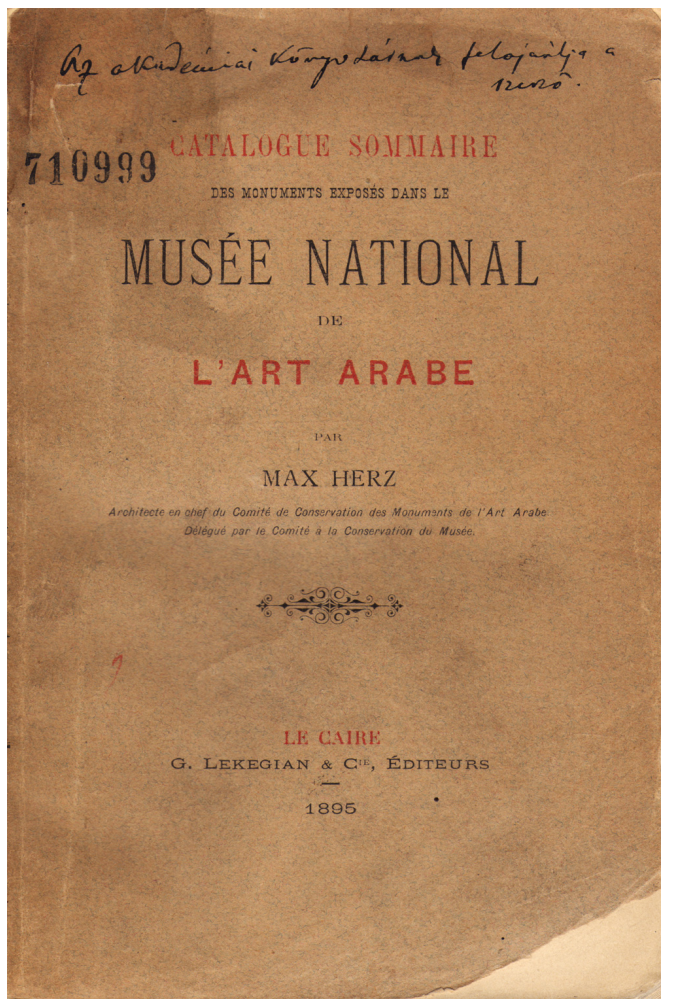

The dedication by "the author" to the Library of the Academy is in Ignaz Goldziher's hand, whom Herz asked to deliver the catalogue.

Source: Courtesy of the Oriental Collection, Library of the Hungarian academy of Sciences, Budapest (Hungary). 
4b. The second original French edition of Herz Pasha's catalogue of the Arab Museum.

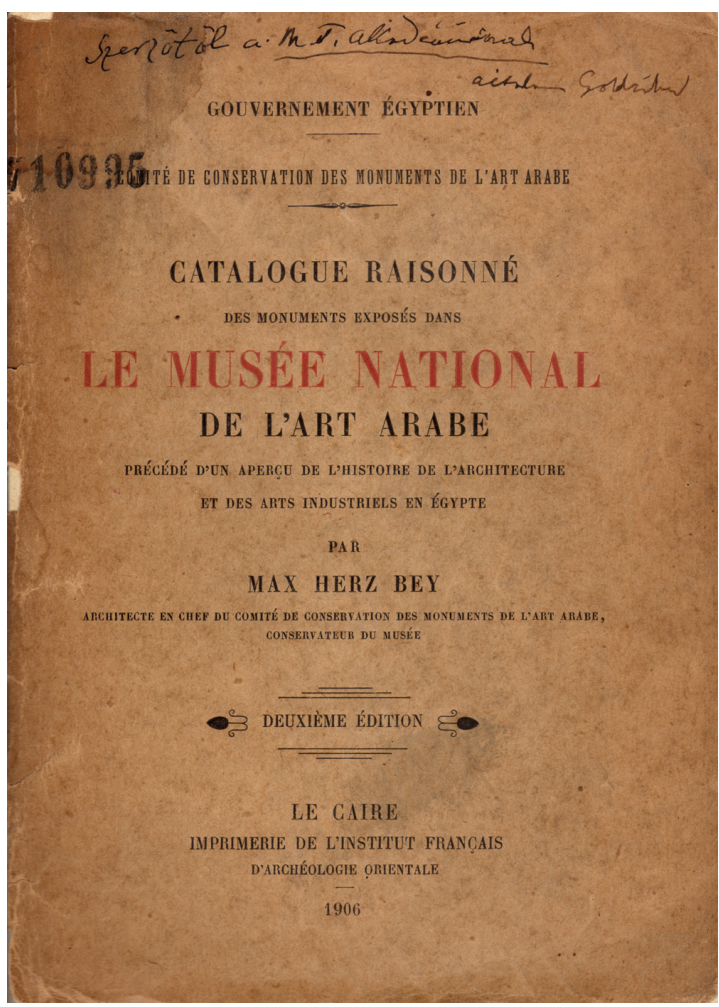

The dedication runs: "From the author to the Hungarian Academy of Sciences by me, Goldziher." Source: Courtesy of the Oriental Collection, Library of the Hungarian academy of Sciences, Budapest (Hungary).

In 1899, Herz published a monograph on what has always been regarded as the most important monument of Mamluk, and perhaps Arab-Islamic, architecture in general, the Madrasa of Sultan Hasan (757/1356; no. 133). The splendid and much admired madrasa had been in a poor state of repair for a long time and urgently needed restoration. However, the likely expenses were so high that for decades such a project could not even be considered. At the same time, the Comite also wanted to promote scholarly activity that would yield important publications in its own field of interest; this question was repeatedly discussed in its sessions. It was in this context that Herz published a lavish folio-size $(42 \times 52 \mathrm{~cm})$ monograph on the madrasa in 1899, partly with the aim of drawing attention to it, emphasizing the significance of the monument and of the necessary work, and thus helping to raise the funds required (fig. 5-6). ${ }^{14}$ Herz succeeded in this last respect: in 1902, he was able to begin the restoration project, which was to cost L.E. 40,000, an unprecedented amount in those days. He also managed to guide the project towards its completion: only minor work had to be finished by his successor Achille Patricolo after his expulsion from Egypt at the end of $1914^{15}$. This magnificent edifice has never failed to attract the attention of architectural historians, who have looked into various questions surrounding its details. Of these scholars, Keppel Archibald Cameron Creswell, Hasan 'Abd al-Wahhab and Michael Meinecke stand out. Yet in 1990, more than ninety years after the appearance of Herz Pasha's book, John Michael Rogers felt obliged to write: "The interpretation of its architectural history has not significantly advanced since the publication of Max Herz Bey's monograph. ${ }^{16 "}$ The next such study of Sultan Hasan's Madrasa appeared only in $2008^{17}$. Its author, 'Abdallah Kahil, summarizes the research achievements of the decades 
between, during which much new data on Islamic architecture has, of course, emerged. Although able to draw on the many new Arab sources - including waqfiyyas - brought to light since Herz Pasha's time, Kahil retains the method used by his predecessor: profound study of the monument itself, the consulting of written documents and pictorial representations, and comparison with parallel monuments in Cairo and elsewhere in the Islamic world. This last aspect is of paramount importance in the analysis of the monument, which was built in an age characterized by a great mobility of builders and artisans. However, the basic questions, "some of which still linger with us", as Kahil says, were formulated by Herz himself: the stylistic connections of the monument, the stylistic origin (Seljuq?) of the grandiose portal, the unusual placement of the mausoleum behind the qibla wall, the origins of the cruciform madrasa, and the possible identity - and origin - of the architect ${ }^{18}$. The only matter raised by later scholars that is new is the elusive question of the madrasa's interpretation; Kahil conveniently summarizes their opinions on this without, however, reaching a clear-cut and convincing conclusion. His approach differs from that of his predecessors in one fundamental respect: whereas in view of the madrasa's many unusual - sometimes innovative - characteristics art historians, Herz included, tended to scrutinize and trace the origins of these odd features, Kahil, without losing sight of the last mentioned, concentrates on the Mamluk traits of the edifice. His work offers a wealth of new data, analyses, and insights, and can justly be regarded as a major achievement in the history of research on the madrasa. Yet it neither supersedes nor replaces Herz Pasha's elegant monograph, as Kahil himself admits, stating that the last-mentioned study "remains indispensable"19. A part of Herz's data is not available elsewhere; his wise insights and considerations have not ceased to capture the attention of subsequent generations. Any serious study of this magnificent monument must start from his work: Herz Pasha's meticulous argumentation based on his thorough and intimate acquaintance with the monument cannot be overlooked. In addition, his superb large-size plans, drawings, and photographs documenting the madrasa's prerestoration state will always be of scientific value. 
5. The Mosque of Sultan Hasan. Detail of the main iwan. Watercolour by Max Rabesz (?).

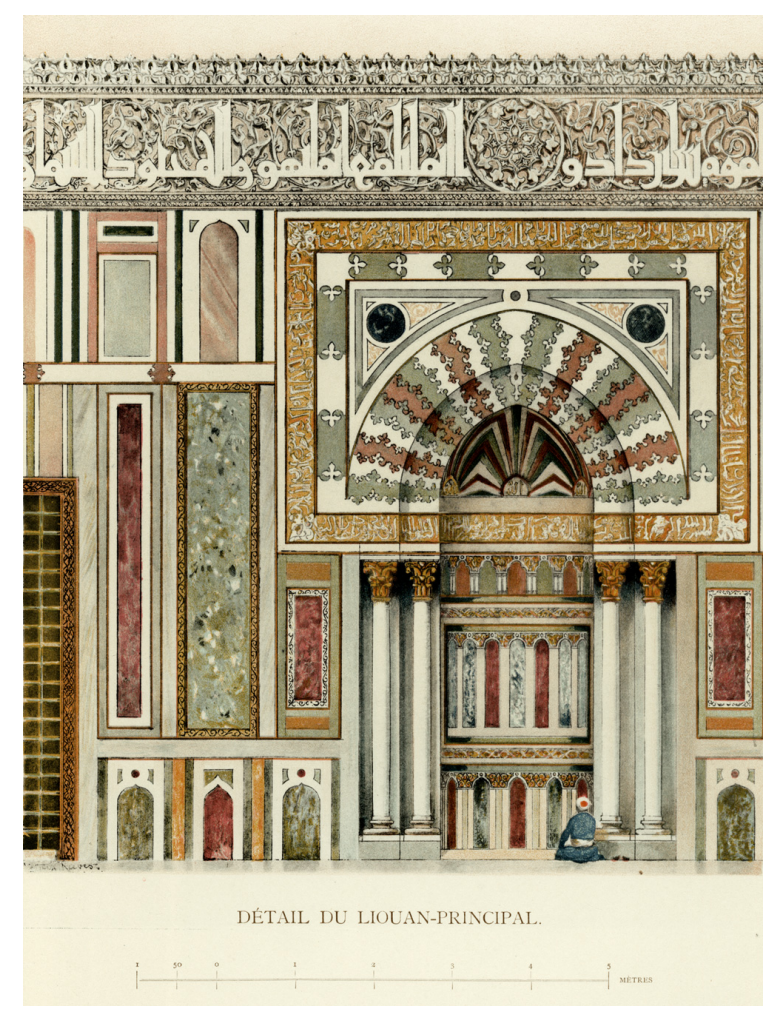

Source: MaX heRZ BEY, La Mosquée du Sultan Hassan au Caire, Cairo: IFAO, 1899, Plate XV, detail.

6a. The Mosque of Sultan Hasan. External façade of the mausoleum. Drawing by Eduard Matasek.

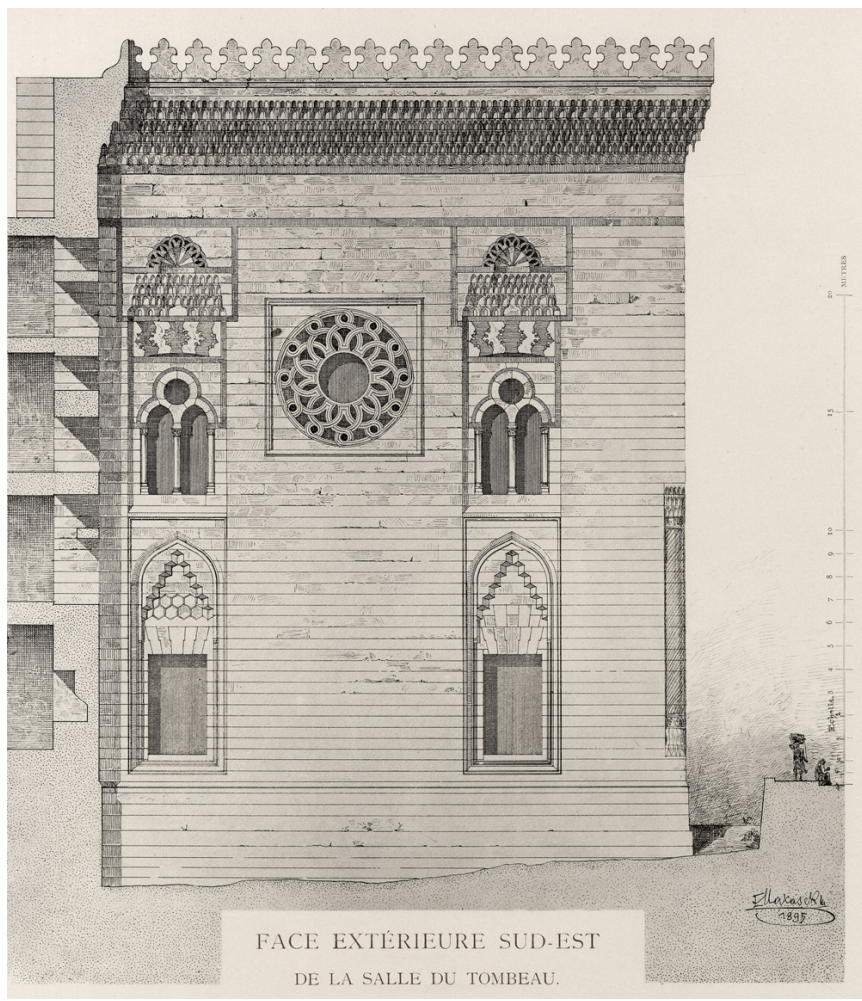

Source: MaX herz bey, La Mosquée du Sultan Hassan au Caire, Cairo: IFAO, 1899, Plate X. 
6b. The Mosque of Sultan Hasan. Cross-section of the Maliki school. Drawing by Carlo Virgilio Silvagni.

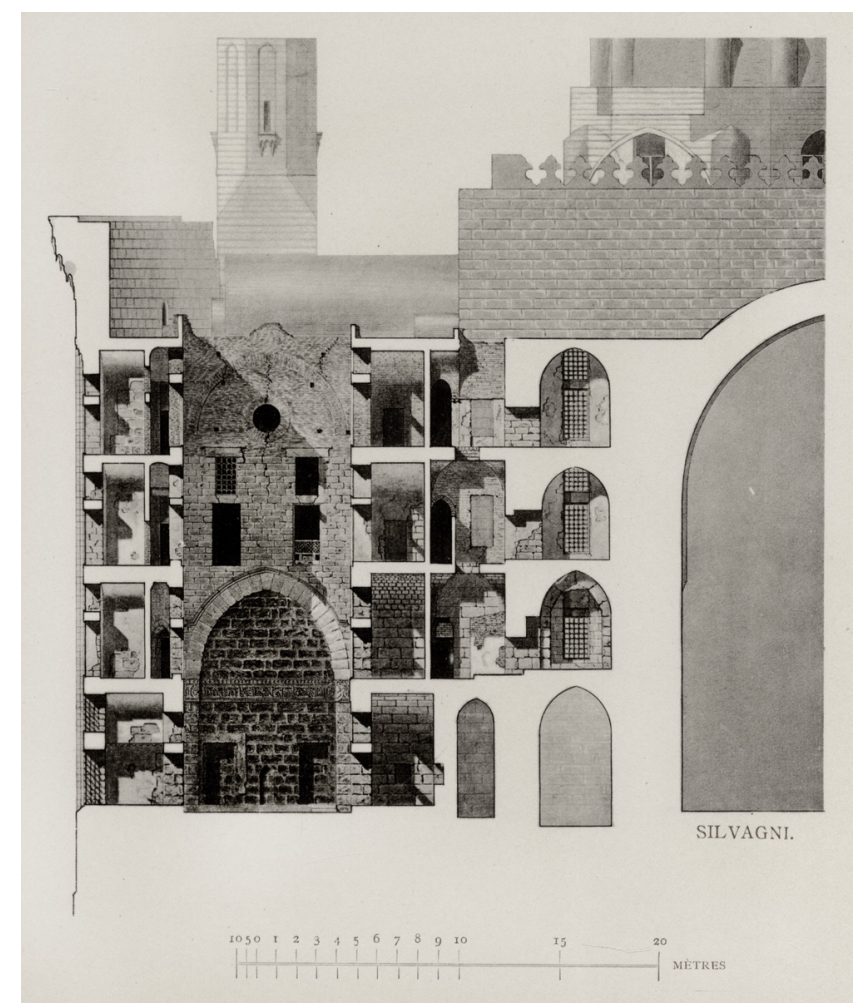

Source: Source: Max HeRz Bey, La Mosquée du Sultan Hassan au Caire, Cairo: IFAO, 1899, Plate X. 
6c. The Mosque of Sultan Hasan. Entrance door to the Maliki school. Watercolour by Max Rabesz (?).

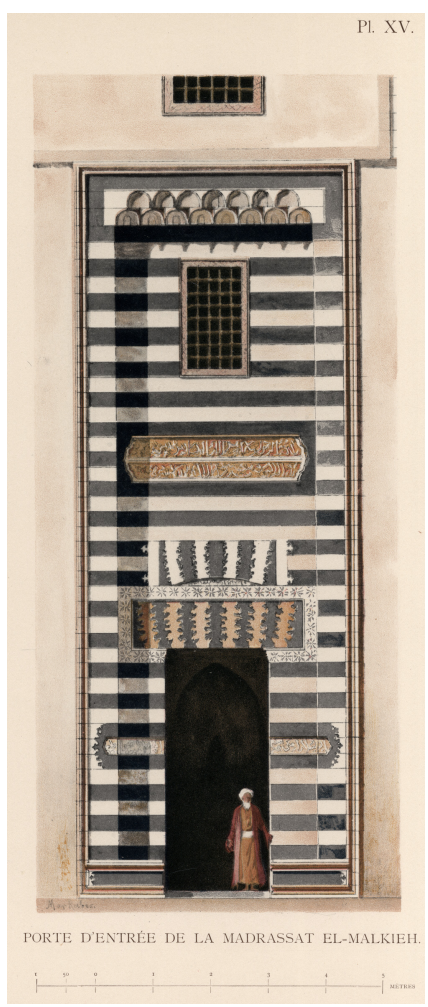

Source: Source: MaX heRz bey, La Mosquée du Sultan Hassan au Caire, Cairo: IFAO, 1899, Plate XV, detail.

5 Twelve years later, in 1911, Herz published a short article in Hungarian on the madrasa; the article dealt briefly with the Comite also $^{20}$. In the meantime, the restoration had been under way since 1902, as he himself wrote. Among others things, he repeated here what he had already written concerning the unusual traits of the madrasa and also the possible origins of the architect: he dealt with these subjects in Chapter Three of his monumental work. However, in the 1911 article Herz mentioned that since the publication of his monograph, which corroborated his hypothesis that ties existed between certain unusual characteristics of the madrasa and the architecture of the Rum Seljuqs, a new find had been made. This was a stone portal found in the Sultan Hasan madrasa in the course of work on the western wall that displayed a "real anomaly", namely that stalactites arranged horizontally served as the doorframe. It was possible to discover a related structure in the Sultan Han (626/1228) located between Konya and Aksaray in the erstwhile realm of the Rum Seljuqs. Herz discovered it in an illustration in Friedrich Sarre's account of his travels in Asia Minor, which had already served as a major source for similar conclusions concerning eventual Seljuq connections in Herz's monograph on the madrasa ${ }^{21}$.

In 1900, Herz contributed a short account of Arab-Islamic art to the "general section" of a three-volume guidebook to Egypt in the Collection des Guides-Joanne series (republished in 1905). It was not a history of Arab-Islamic art in the traditional chronological manner, but a description of characteristics, forms, materials, and building types under the following headings: "Theory of Architecture" (Materials; Forms - 1. Walls, 2. Coverings [Ceilings, Vaults]; 3. Supports; 4. Apertures [A. Doors, B. Windows]; Decoration), "Applied Art", and "Religious Art" (The Mosque, Its Description - 
Cruciform Mosques, Mosques with Central Domes, Madfan or Turba; Minarets, Furniture; Sabils, Wikalas, Baths, Drinking Troughs, Military Architecture). It was rounded off by a brief sketch of the history of Arab-Islamic art in Egypt. This part is illustrated with beautiful drawings (fig. 8-10), at least two fine examples of which were executed by Herz personally (fig. 9-10). Some of the plans prepared by Herz for this guide appear in later volumes of the Guides Bleus series, the successor to Guides-Joanne, too (fig. 7) ${ }^{22}$. The treatment of the subject reminds the reader of the approach chosen by Herz's mentor and predecessor Julius Franz Pasha in his book on Islamic architecture (which features many drawings by Herz [e.g., fig. 9, 11-14]), the second, enlarged, edition of which appeared in $1896^{23}$. In the "special section" of the GuideJoanne, Herz dealt with the various Arab-Islamic monuments one after another ${ }^{24}$.

\section{Plan of al-Azhar Mosque (359-/970-; no. 97) by Herz.}

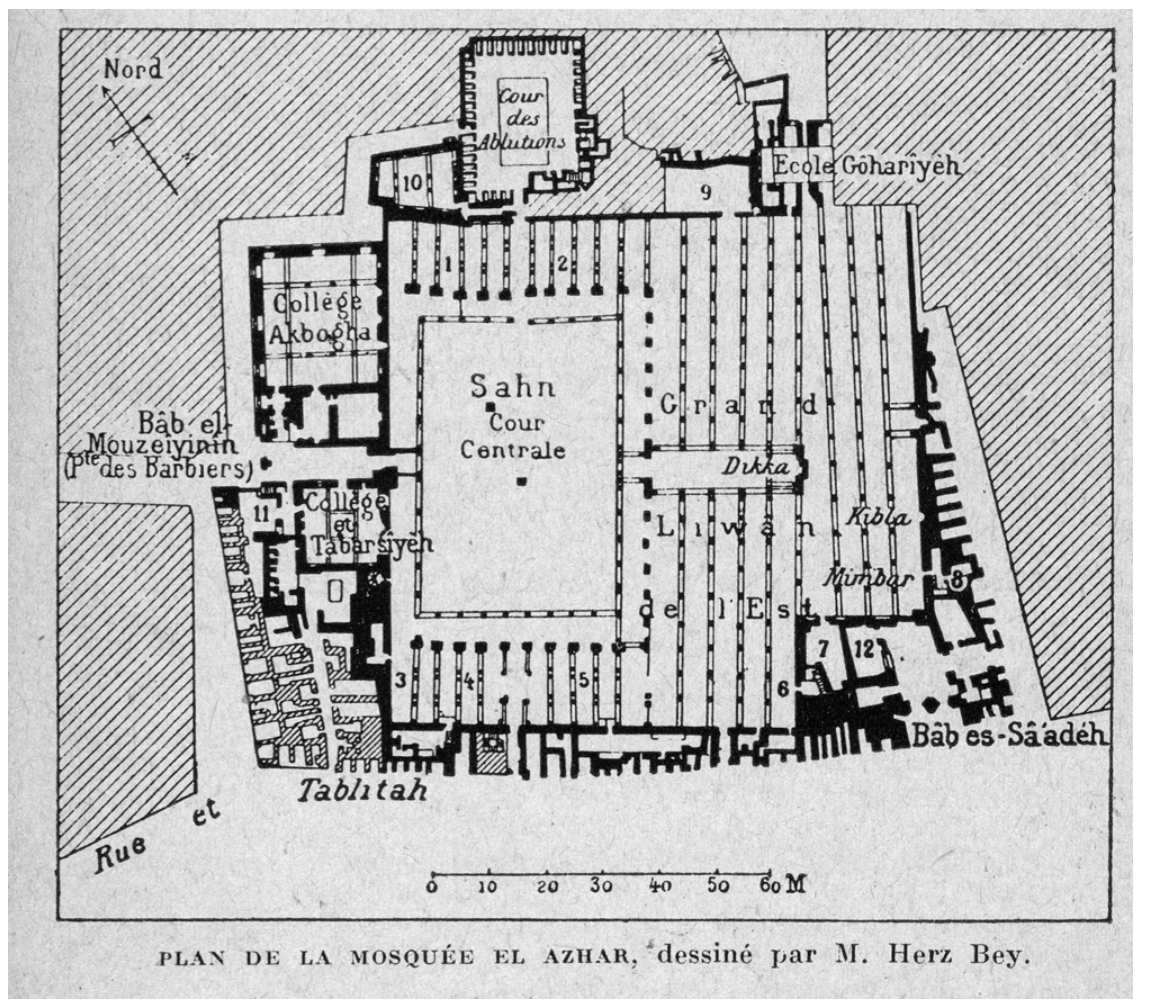

Herz's ground plans of al-Azhar are important testimonies for the significant transformations on this mosque in his time. Creswell pointed out this fact about the ground plans in Baedeker's guidebooks (without expressely mentioning Herz's name), stressing that there was a little else to be found in the Waqf and the Comité archives and even the originals of the plans could be traced in his time (The Muslim Architecture of Egypt, vol. I, p. 42, no. 6 and p. 47-48, fig. 12-13). The present plan belongs to this series. It comes from the Guide-Joanne of 1900/1905 and is a slightly modified version of the plan in Baedeker's third (1984), fourth (1897) and fifth (1902) German and fourth remodelled English editions (1898).

Source: Jean chaRDon (ed.), Méditerranée orientale. Guide du passage sur les itinéraires des croisières, Paris: Hachette, 1930, p. 223 (Les Guides bleus illustrés)25 


\section{Columns and capitals.}

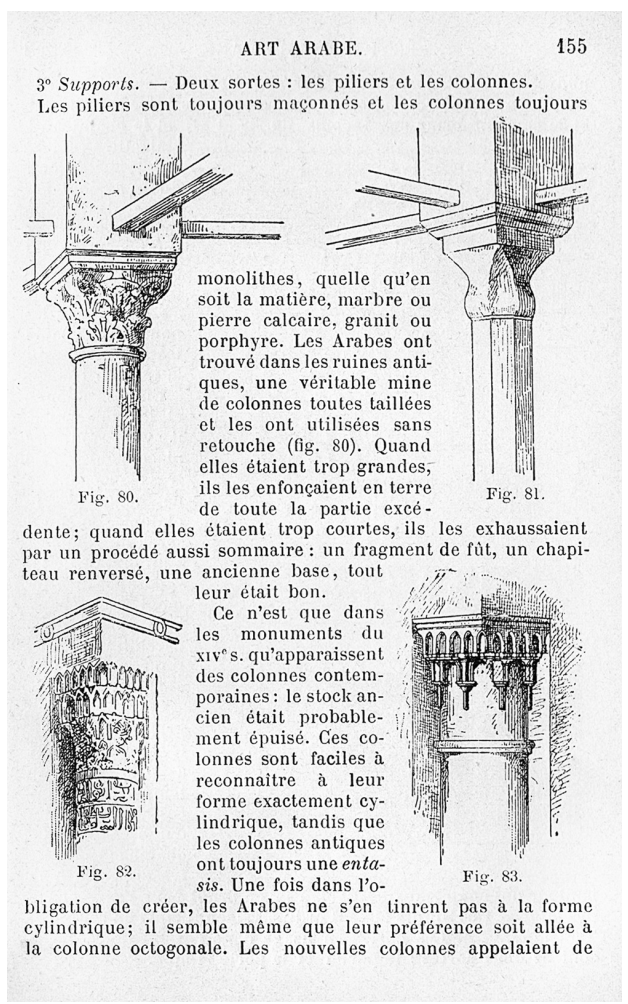

In all probability, these fine drawings to illustrate the chapter on supports are not by Herz but by a member of his staff.

Source: Max herz BEY, "Art arabe", dans Égypte, avec un appendice et des renseignements pratiques mis à jour pour 1905, Georges [Aaron] BÉNÉDITE (ed.), Paris: Hachette, 1905, p. 155 (Guides-Joanne). 
9. The sabil-kuttab (public fountain and elementary school) of Sultan al-Ghawri (909/1504; no. 67).

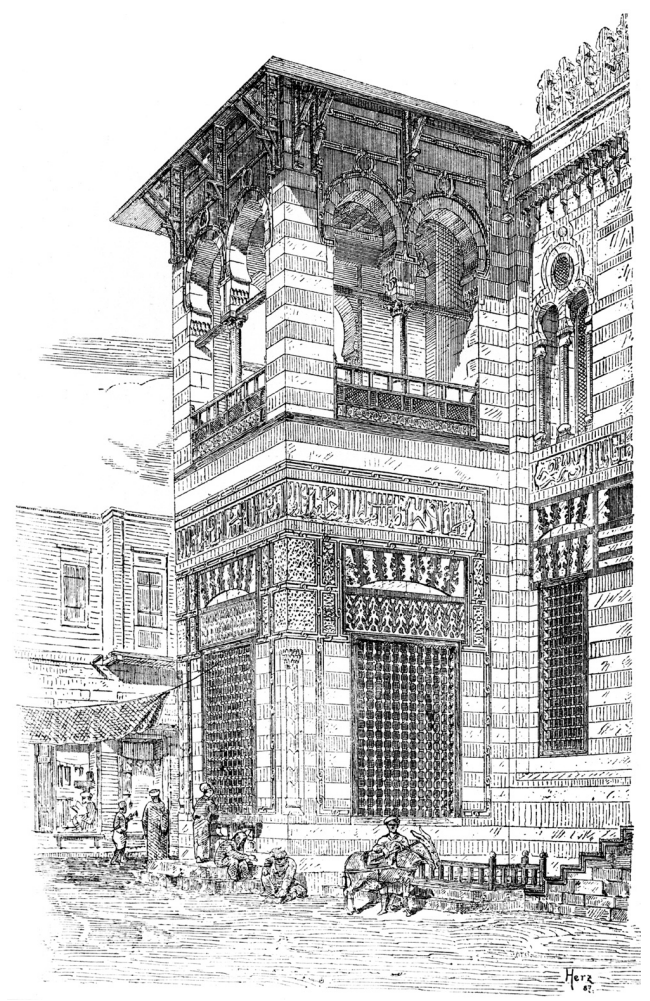

Herz published these fine drawings (fig. 9-10) in several places, among them in the volume on Egypt in the Guides-Joanne series as well.

Source: MaX herz, "Arab diszítmények III [Arab ornaments III]", Müvészi Ipar [Applied Art], 3, 1887, p. 200. 
10. The mansion of Gamal al-Din al-Dhahabi. Interior of the qa'a (hall). Drawing by Herz. Cairo, 1890.

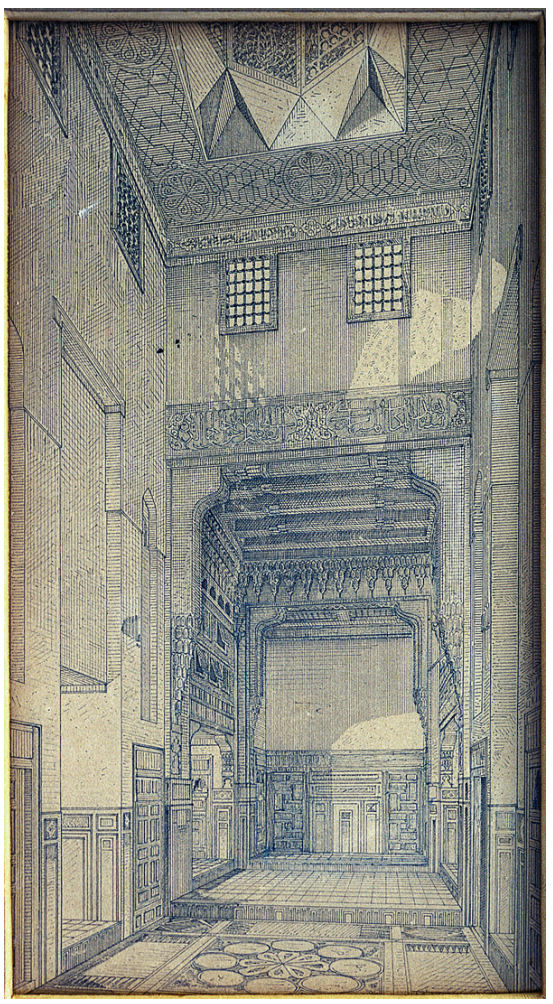

Source: Private collection.

7 In 1907, Herz published a concise history of Islamic art in Hungarian. It constituted a section in a comprehensive history of art in four volumes brought out under the auspices of Hungary's Ministry of Religious and Educational Affairs ${ }^{26}$. The work was meant to address the educated general public, with special emphasis on serving a need in the field of public education. Herz was very glad to be given this professional challenge, and regarded the task as a patriotic duty, too ${ }^{27}$. He laid great emphasis on placing the development of Islamic art in the proper historical setting, which he everywhere outlined succinctly. According to him, three basic areas, broadly speaking, could be differentiated within Islamic art in general: I. - The Egyptian Style; II. - The Persian-Arab Style; and III. - The Style of North Africa and Spain. For practical reasons, he chose to demonstrate the general traits of Islamic art in a detailed treatment of the Egyptian style, discussing the special characteristics of, and the differences between, the other styles in the second part of his contribution. The second part deals with the main characteristics of the "other" Islamic countries in general, too (fig. 15-16). The section on Egypt occupies 86 of the 154 pages, along with 105 figures and 6 plates ( 2 in colour) of the 167 figures and 18 plates ( 2 in colour), that the work contains. In Herz's approach, several aspects are especially prominent, the combination of which adds up to a remarkable achievement. In his treatment of styles and buildings, Herz's training as an architect comes to the fore repeatedly: for him, styles and stylistic elements are not merely decorations or aesthetic features determined by fashion and aesthetics, but regularly fulfil physical, architectural functions. On the other hand, he is not a dispassionate, "objective" chronicler of modifications and changes in style in history, but an enthusiastic connoisseur deeply attached to his field of work. He has very definite tastes and opinions, which he never tries to conceal: he regularly voices value 
judgments. These opinions and judgments are mostly convincing and demonstrate an exquisite taste. He worked and wrote with gusto: it is this feature of the account above all that captivates the reader and makes the reading of this work a refreshing intellectual adventure ${ }^{28}$. His low opinion of Ottoman architecture in general and of Ottoman architecture in Egypt in particular is expounded succinctly here, too. This view was based on professional grounds merely and was not politically or personally motivated $^{29}$. As a matter of fact, Herz sharply distinguished between Egyptian Arab art and Ottoman art, the second of which he considered alien to Egypt (fig. 13). Elsewhere he described the spread of Ottoman architecture as representing the "death agony" of Arab art in Egypt ${ }^{30}$.

11. Bevelled corner and cantilever on a house in Cairo. Quarter of Shari' Hulqum al-Gamal (behind Sultan al-Ghawri's Madrasa). Drawing by Herz.

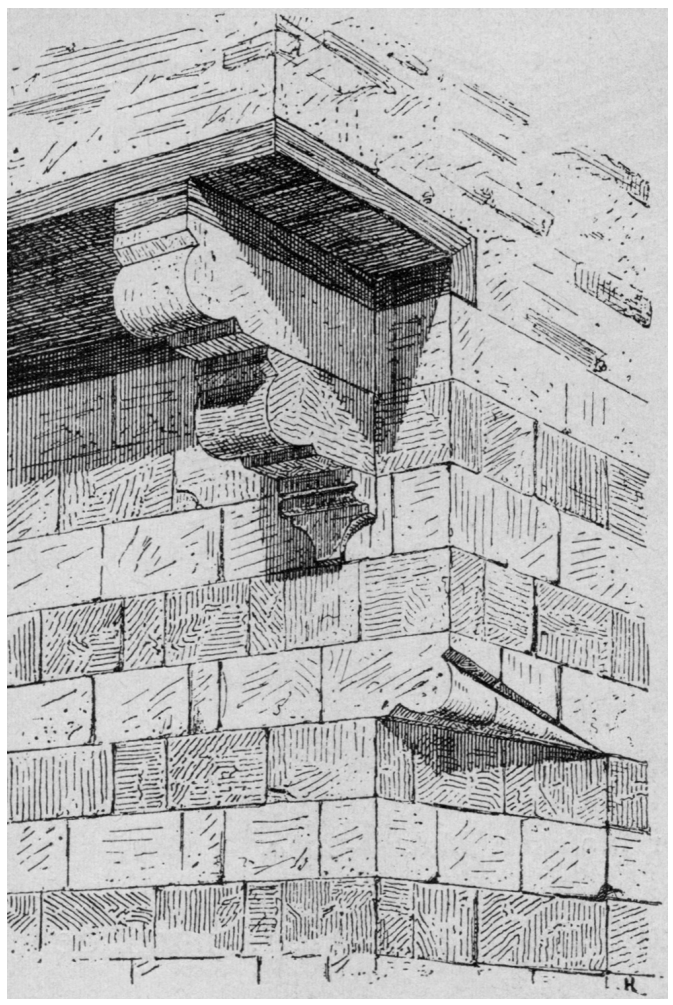

Source: Julius franz-PAScha, Die Baukunst des Islam, Darmstadt: Arnold Bergsträsser, 1887 (Die Baustile Historische und technische Entwickelung. Handbuch der Architektur II, 3/2); 2. [enlarged] ed., 1896, p. 84 (fig. 96). 
12a. Cross-section and plan of Sultan Barquq's funerary mosque (complex of Farag ibn Barquq; 803/1400; no. 149). Drawing by Herz.

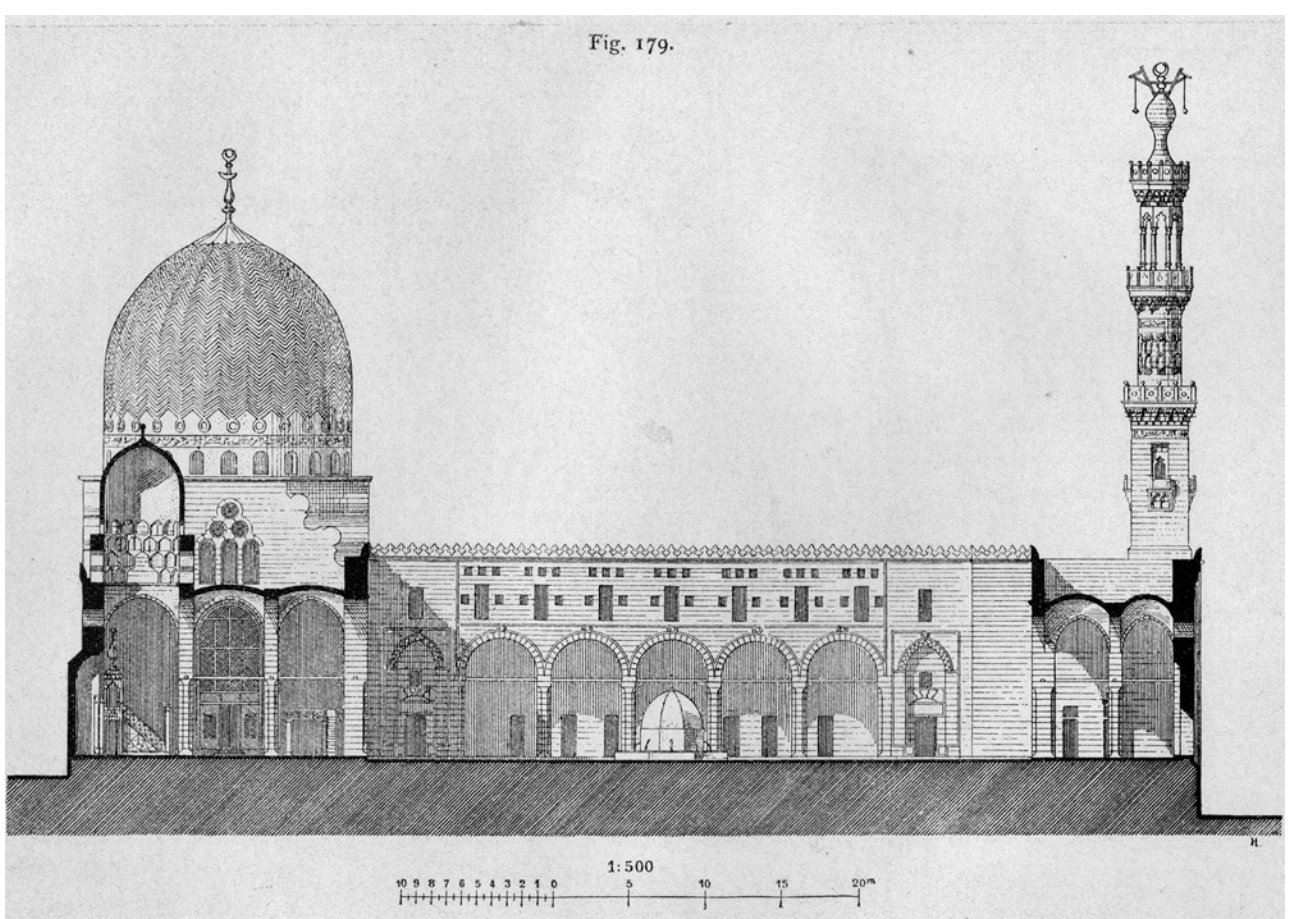

Source: Julius franz-PAScha, Die Baukunst des Islam, Darmstadt: Arnold Bergsträsser, 1887 (Die Baustile Historische und technische Entwickelung. Handbuch der Architektur II, 3/2); 2. [enlarged] ed., 1896, p. 130-131 (fig. 179).

12b. Cross-section and plan of Sultan Barquq's funerary mosque (complex of Farag ibn Barquq; 803/1400; no. 149). Drawing by Herz.

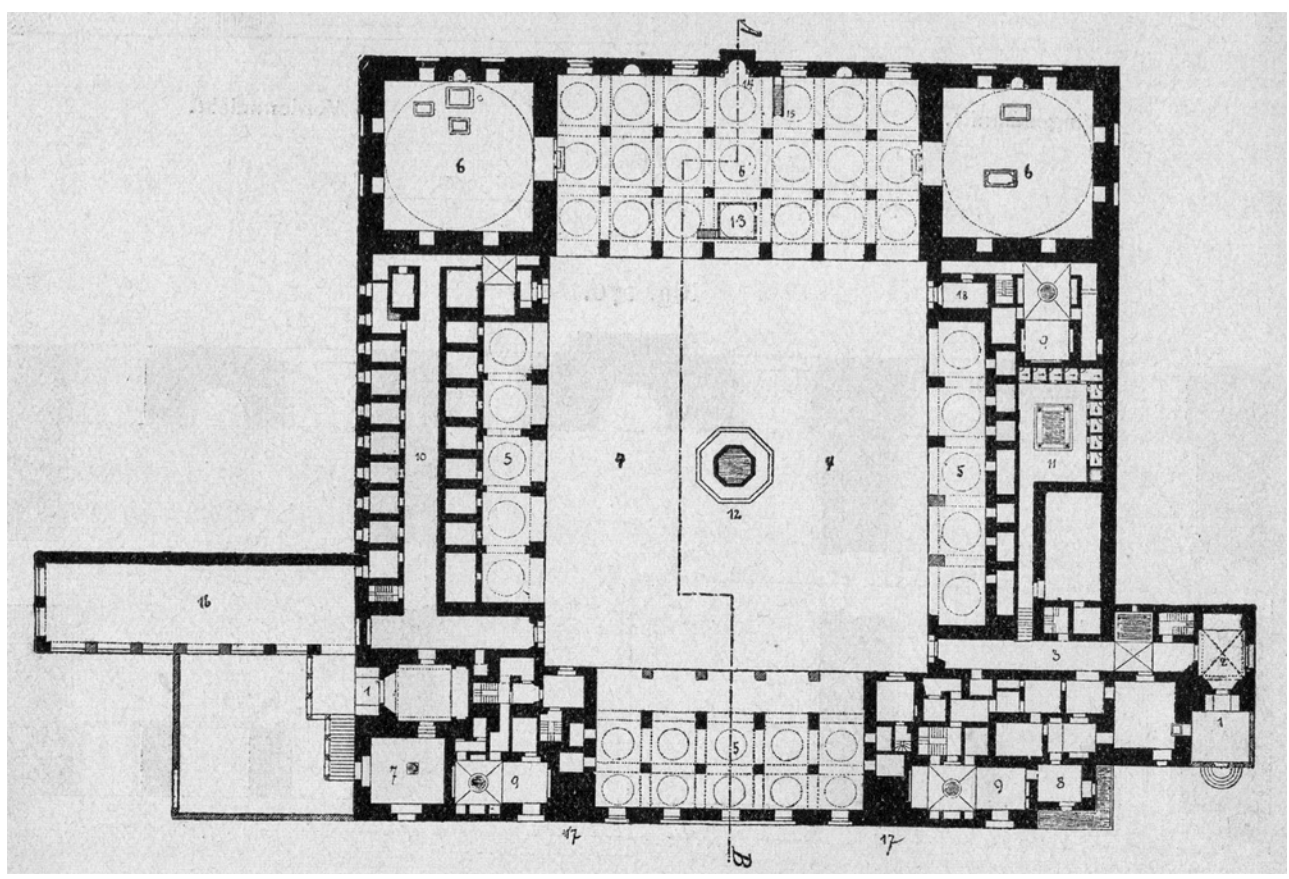

Source: Julius franz-PASChA, Die Baukunst des Islam, Darmstadt: Arnold Bergsträsser, 1887 (Die Baustile. Historische und technische Entwickelung. Handbuch der Architektur II, 3/2); 2. [enlarged] ed., 1896, p. 130-131 (fig. 178). 
13a. Cross-section and plan of Sinan Pasha's Mosque in Bulaq (now in Cairo; 979/1571; no. 349). Drawing by Herz.

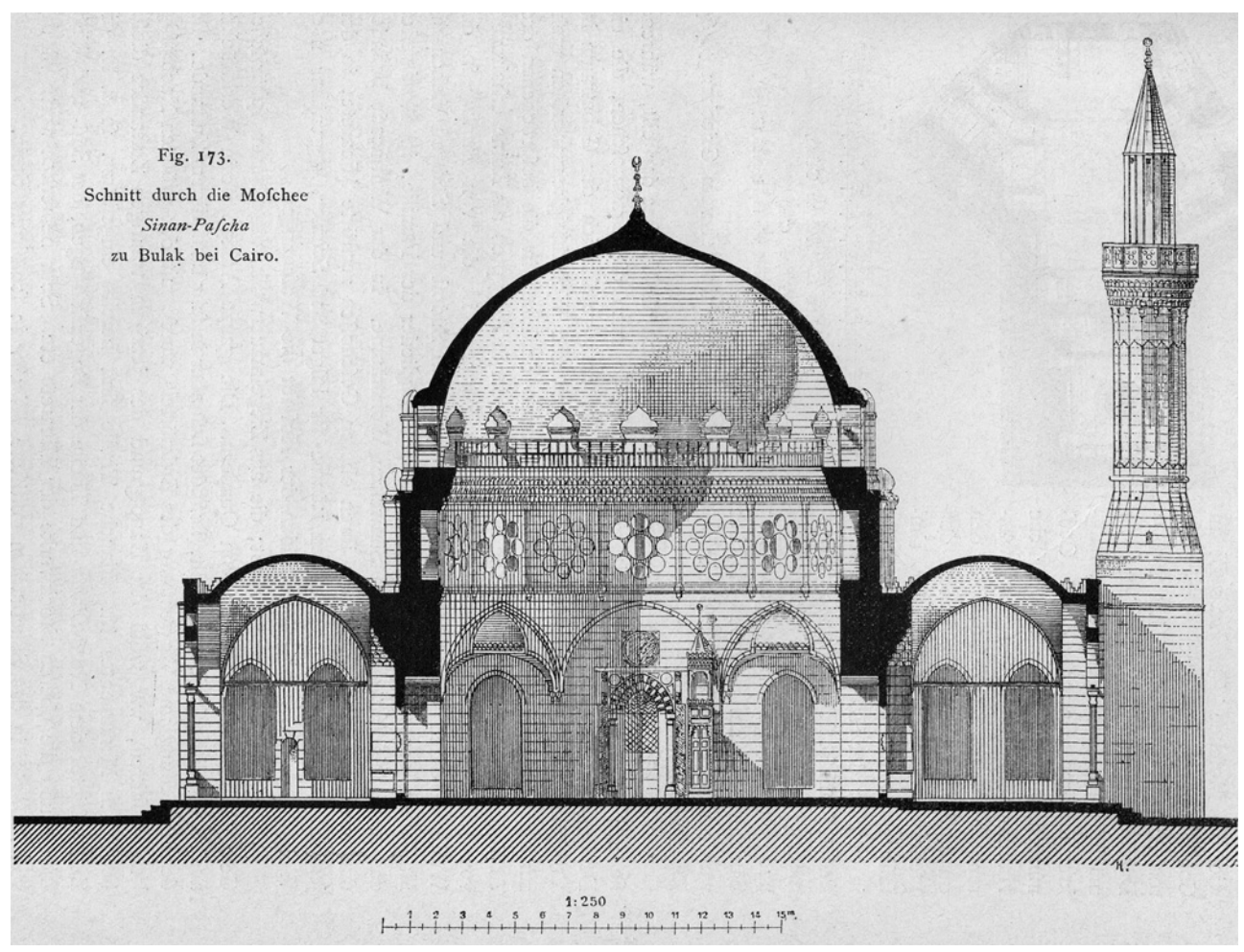

Source: Julius franz-PAScha, Die Baukunst des Islam, Darmstadt: Arnold Bergsträsser, 1887 (Die Baustile. Historische und technische Entwickelung. Handbuch der Architektur II, 3/2); 2. [enlarged] ed., 1896, p. 126-127 (fig. 173) 
13b. Cross-section and plan of Sinan Pasha's Mosque in Bulaq (now in Cairo; 979/1571; no. 349). Drawing by Herz.

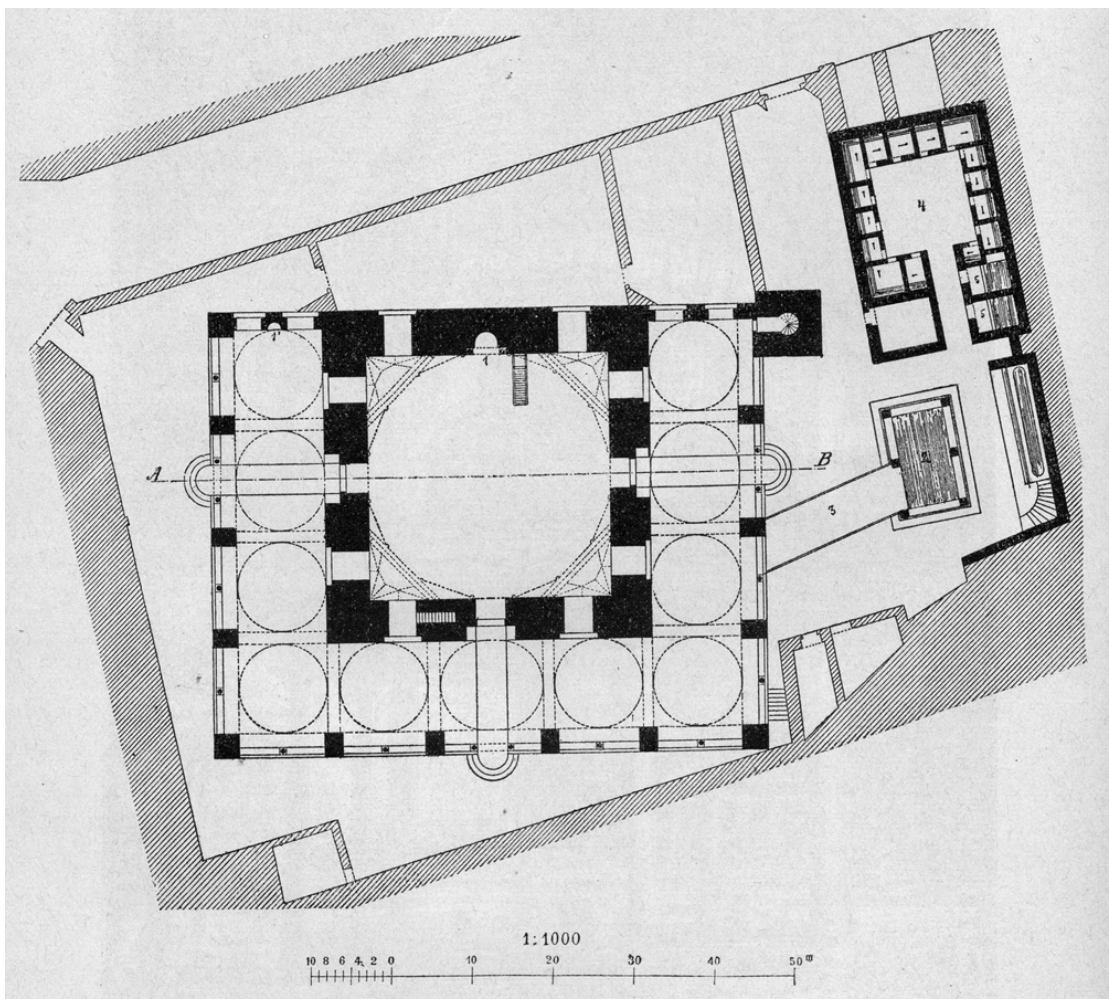

Source: Julius franz-PAScha, Die Baukunst des Islam, Darmstadt: Arnold Bergsträsser, 1887 (Die Baustile Historische und technische Entwickelung. Handbuch der Architektur II, 3/2); 2. [enlarged] ed., 1896, p. 126-127 (fig. 172)

His thorough familiarity with the subject shines through on every page: when Herz wrote this work, he had been engaged day and night on the monuments of Cairo and Egypt for more than a quarter of a century. Notwithstanding the concise nature of his work, Herz does not restrict himself to architecture, but devotes some space to applied art also; we find occasional references to painting and coinage, too. At the same time, his treatment of the subject is not confined to the core lands of Islam, but extends to such distant areas as Central Asia and India. There can be no doubt that this work is now dated in view of the exponential growth in Islamic art studies and of the information explosion that has taken place in this field ${ }^{31}$. Yet it offers data, minute observations, and thoughts, some of which would surely repay closer scrutiny. For instance, Herz comments on the origins of the cruciform madrasa. These he traces to Qasr Kharana (Syria at the time, Jordan today), which he regards as being of Sassanian (Iranian) provenance ${ }^{32}$. In 1900 already, Herz made a similar statement in his account of Arab art in the Egypt volume of the Guides-Joanne series, saying that Sultan Saladin ( $d$. 589/1193) had imported the cruciform madrasa from Syria ${ }^{33}$. In 1904, he again repeatedly advocated a Persian origin ${ }^{34}$. Earlier, in 1895 , he had expressed the view that this system had been "created" by the Ayyubids (564/1171-648/1250) ${ }^{35}$. The idea that the cruciform madrasa was introduced into Egypt from Syria had been voiced by Stanley Lane-Poole as early as 1886. Around 1901, Max van Berchem advocated the same idea, hinting at possible connections with areas further east as well ${ }^{36}$. In one place, van Berchem pointed to what is now known as the Reception Hall in the Palatial Complex in the Citadel of Amman as the cruciform madrasa's prototype; many regarded 
this monument as being of Sassanian provenance in those days ${ }^{37}$. Herz seems to have changed his mind later on. Towards the end of his life, he adopted the opinion that this madrasa type was not an importation from Syria, but that its origin could be found in local dwelling houses in Egypt. He intended to dedicate a separate article to this subject, but death prevented him from doing so ${ }^{38}$. In 1923, four years after Herz's untimely decease, Creswell voiced a similar idea, stating that the cruciform madrasa evolved in Egypt ultimately from the qa'as of dwelling houses. Creswell added that in 1920-1921 already he had presented his theory to Max van Berchem during the final visit to Egypt by that great epigraphist, who had seemed convinced by it ${ }^{39}$. Meinecke advocated an Iranian origin ${ }^{40}$.

14. Cross-section of the central part of the qa'a (hall) with the lantern in Gamal al-Din al-Dhahabi's mansion in Cairo. Drawing by Herz.

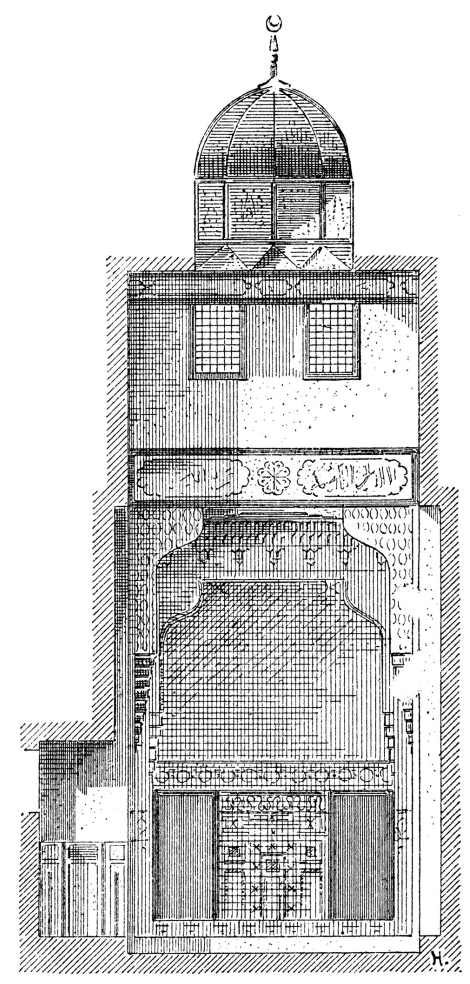

Source: Julius franz-PAScha, Die Baukunst des Islam, Darmstadt: Arnold Bergsträsser, 1887 (Die Baustile. Historische und technische Entwickelung. Handbuch der Architektur II, 3/2); 2. [enlarged] ed., 1896, p. 153 (fig. 207). 
15. Plan and cross-section of the mausoleum of Sultan Baybars al-Zahir in Damascus (676/1277). Drawings by Herz.

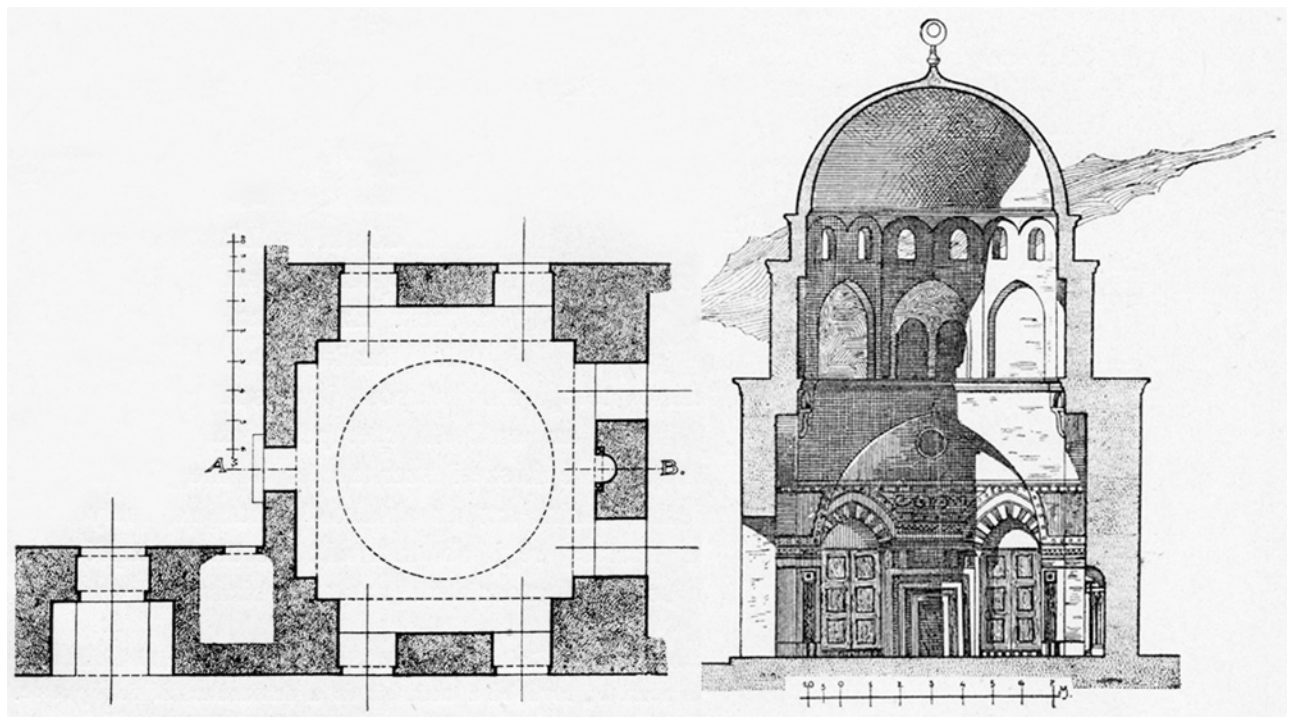

Source: Max herz, "Az Iszlám müvészete [Islamic art]", in A müvészetek története [The history of arts], Zsolt веӧтнr (ed.), Budapest: R. Lampel (F. Wodianer), 1906-1912, vol. II, p. 201 (fig. 235-236).

16. Cross-section of the palace of Amir Yashbak (738/1337; no. 266). Drawing by Herz.

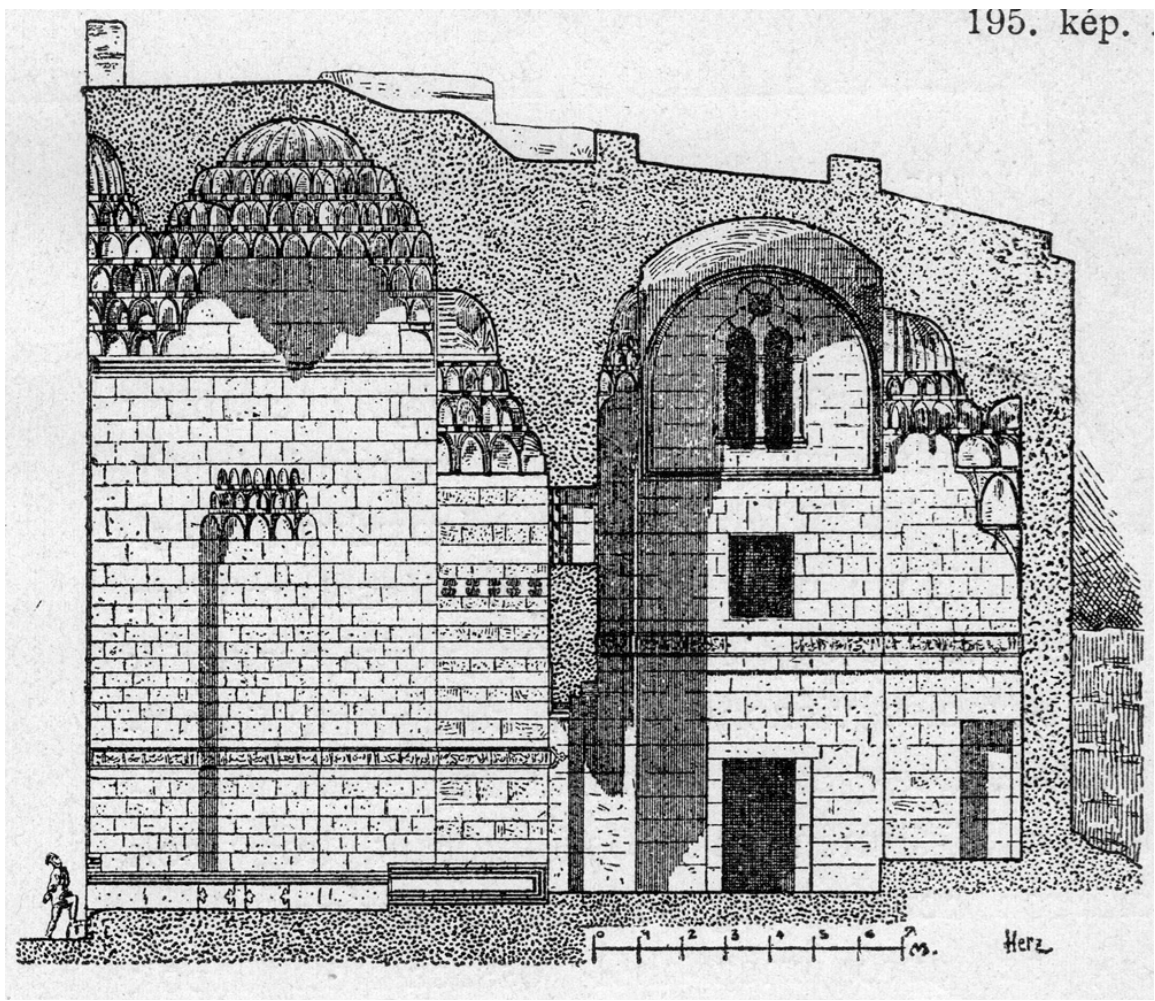

Source: Max HERz, "Az Iszlám müvészete [Islamic art]", in A müvészetek története [The history of arts], Zsolt веӧтну (ed.), Budapest: Lampel R. (Wodianer F.), 1906-1912, vol. II, p. 177 (fig. 195).

9 Herz deals with the origin of stalactites also ${ }^{41}$. There is some data - partly accompanied by illustrations - on Herz's donations of relevance to museum collections in Berlin, 
Budapest, and Cairo ${ }^{42}$. Acquaintance with this work is essential for students of the historiography of Arab- Islamic art in Egypt.

Chapter "G" of the last work (p. 147-189, including many illustrations; fig. 5, 9, 15-16, 21 top right-21 centre) dealt with "Art under the Mamluk Sultans", which was also the subject of a short article in Hungarian (6 pages) brought out by Herz three years earlier in a semi-popular periodical published by the Hungarian Academy of Sciences ${ }^{43}$. If we compare the two accounts, we find that the earlier article concentrates on theoretical questions first and foremost and that the book chapter is a traditional presentation of the subject with descriptions of a number of major monuments. Herz points out in the article that the Ayyubids (564/1171-648/1250) introduced the cruciform mosque (madrasa) type from Persia ${ }^{44}$ and that the next dynasty, the Turkoman Mamluks (648/1250-784/1382), initially avoided using it because it was connected to the memory of their immediate predecessors. Instead, they resorted to the traditional, primitive plan for mosques, which involved porticos or a combination of hypostyle halls. However, after the consolidation of their power, the Mamluks reverted to the new type introduced by the Ayyubids. This took quite a long time, Herz wrote, and they did so by adding an important new element, the column, to it, thus bringing about a considerable modification of the original idea. "The rows of columns opened up a wide and fruitful field for ingenious artistic combinations with respect to both construction and decoration, thus favourably contributing to the numerous foundations that were erected under the names of khanqa and ribat (convent): the core of these buildings remained a 'mosque' both literally and metaphorically." A real revolution took place in Arab-Islamic architecture in Egypt with the gradual replacement of brick by stone as building material. This necessarily led to solutions of structural problems that changed the direction of progress in architecture; at the same time, it was also the source of a highly favourable modification of the exterior arrangement of buildings. The results of this development can be studied on monuments from the fifteenth century. Domes and minarets are no longer haphazardly placed, but their location is determined by the requirements of harmony. In general, the overall effect of a building, its perspective view, is carefully and ingeniously calculated: "The harmony of the whole is surpassed only by the richness and purity of the details." The plain facades of earlier times yield to those elaborated with artistic care. In the interior, the appearance of plaster diminishes considerably while marble of all kinds and porphyry gain in importance. The overall application of columns leads to the neglecting of cumbersome vaults, with richly ornamented wooden ceilings replacing them. The preponderance of exquisite ornamentation characterizes applied arts, too. The late fifteenth century represents the apogee of Arab art in Egypt, achieving perfection in all its aspects, Herz declares, before the ensuing of its "death agony" after the Ottoman conquest $(923 / 1517)^{45}$.

In 1904, Khedive 'Abbas II Hilmi commissioned Herz to complete the Rifa'i mosque (1287/1870-1330/1912; U103). Responding to an order by Princess Khushyar Hanim, Khedive Isma'il's mother and 'Abbas II Hilmi's great-grandmother, the architect Husayn Fahmi began its construction according to his own design in 1870. Soon, though, work had to be suspended for financial reasons, and for a quarter of a century the edifice slumbered unfinished in the shadow of Sultan Hasan's splendid madrasa (fig. 17). Having completed the work, Herz privately printed a fine booklet on the mosque, which was distributed at its inauguration in $1912^{46}$. It remains our best source on this highly significant building, which is considered a milestone in the development of 
modern Arab-Islamic architecture not only in Egypt, but also in the Islamic world more generally (fig. 17 right-19). Herz also published an article on the mosque in Hungarian which contains data not found in the booklet, along with some interesting insights ${ }^{47}$. It is worth reading and comparing the two works, because even differences in the formulation of the same facts can sometimes help us better perceive the real state of affairs by illuminating aspects and nuances one would otherwise miss. For example, Herz's contribution to the mosque's exterior, and especially to the final design of the main entrance on the northwest facade, can be determined more precisely if the French booklet is read in the light of the Hungarian article. Also, the difference in the time of writing may be of interest in some respects. That is to say, Herz wrote the booklet before the mosque's inauguration, while he produced the article after it. Hence, the precise date of inauguration is the one given in the Hungarian article (19 April 1912); the date appearing in the booklet (New Year's Day 1330/22 December 1911), which is also often quoted in the scholarly literature, is wrong: evidently the inauguration was postponed, possibly because of delay with the building and other work $^{48}$.

17a. The Mosques of Sultan Hasan and al-Rifa'i.

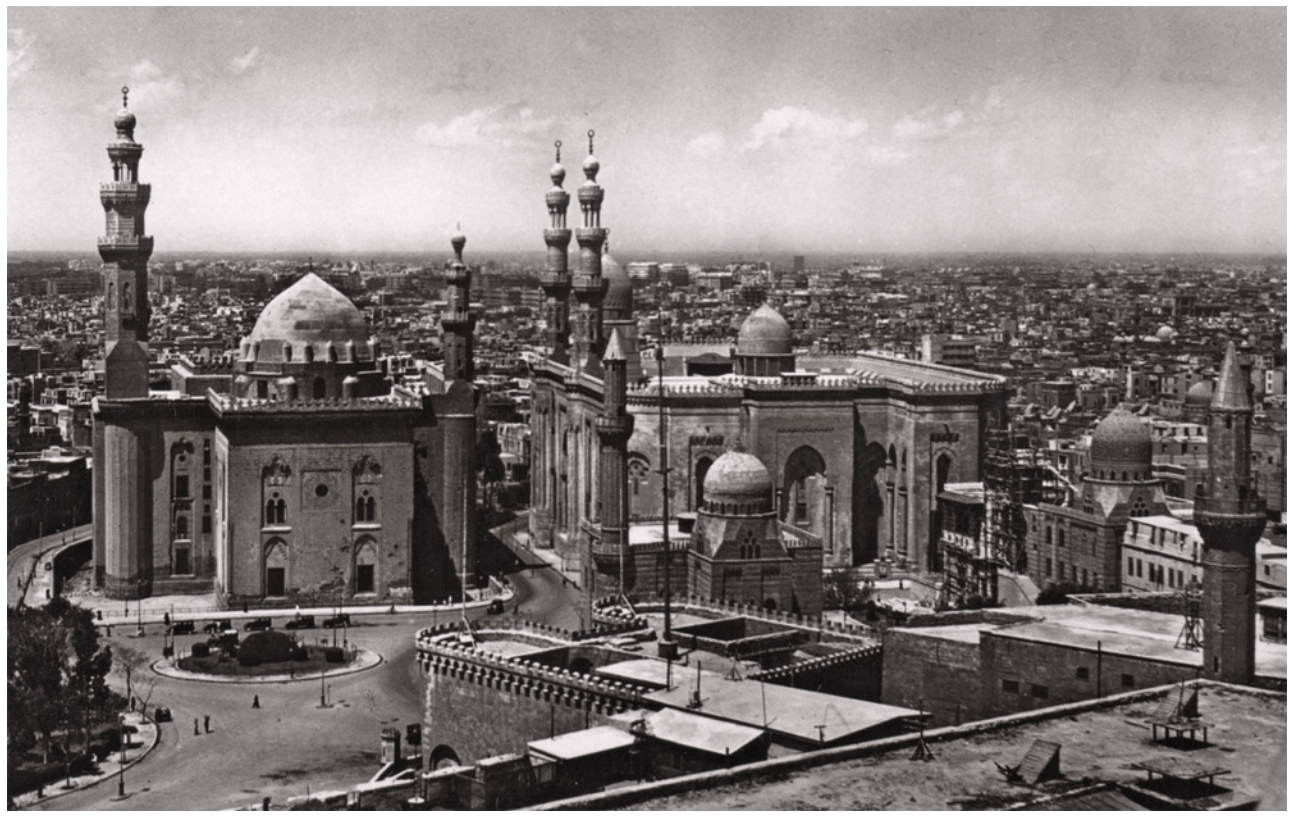

Postcard, 1937-1938. (The postcard can be dated on the basis of the reconstruction works in progress on the minaret of the Mosque of Qanibay al-Sayfi Amir Akhur [908/1503; no. 136]).

Source: Max herz, La Mosquée el-Rifai au Caire. Paru à l'occasion de la consécration de la mosquée, Milano: [Imp. Humbert Allegretti], s.d. [1911], p. 14 (fig. 3). 
17b. Plan of the immediate neighbourhood.

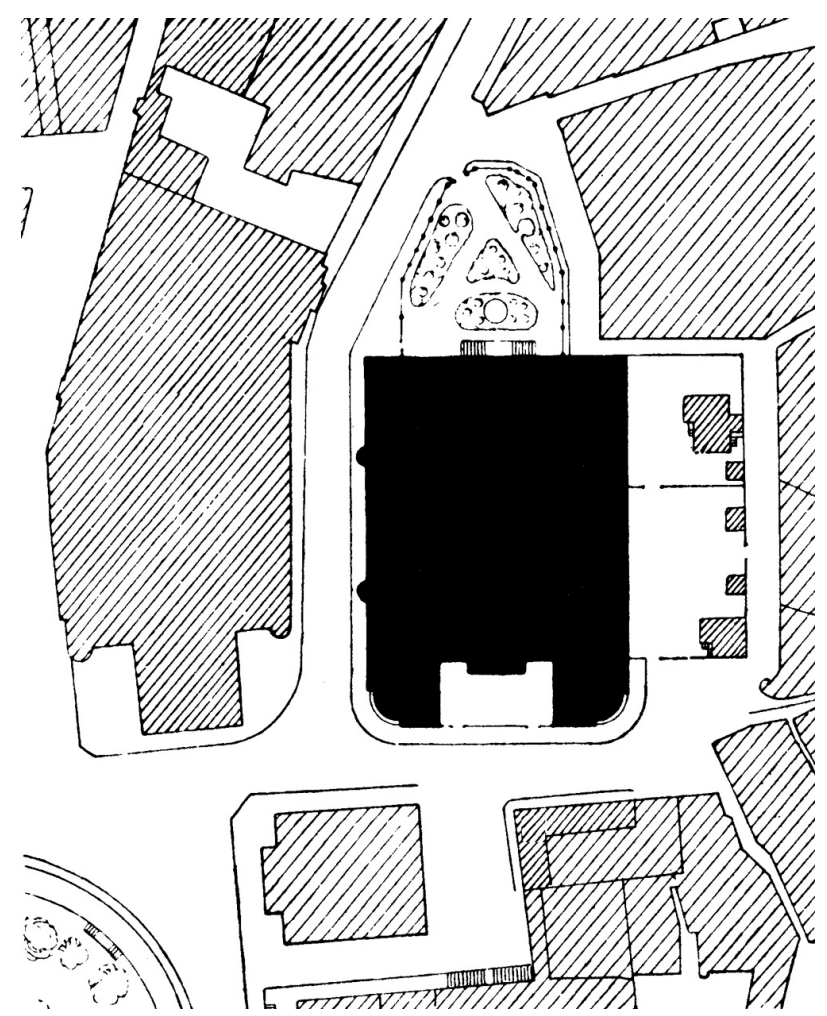

The orientation of the plan has been adjusted to that of the photograph.

Source: Max herz, La Mosquée el-Rifaï au Caire. Paru à l'occasion de la consécration de la mosquée, Milano: [Imp. Humbert Allegretti], s.d. [1911], p. 14 (fig. 3). 
18. The Mosque of al-Rifa'i. Husayn Fahmi Pasha's original plan and the final plan with Herz Pasha's modifications.

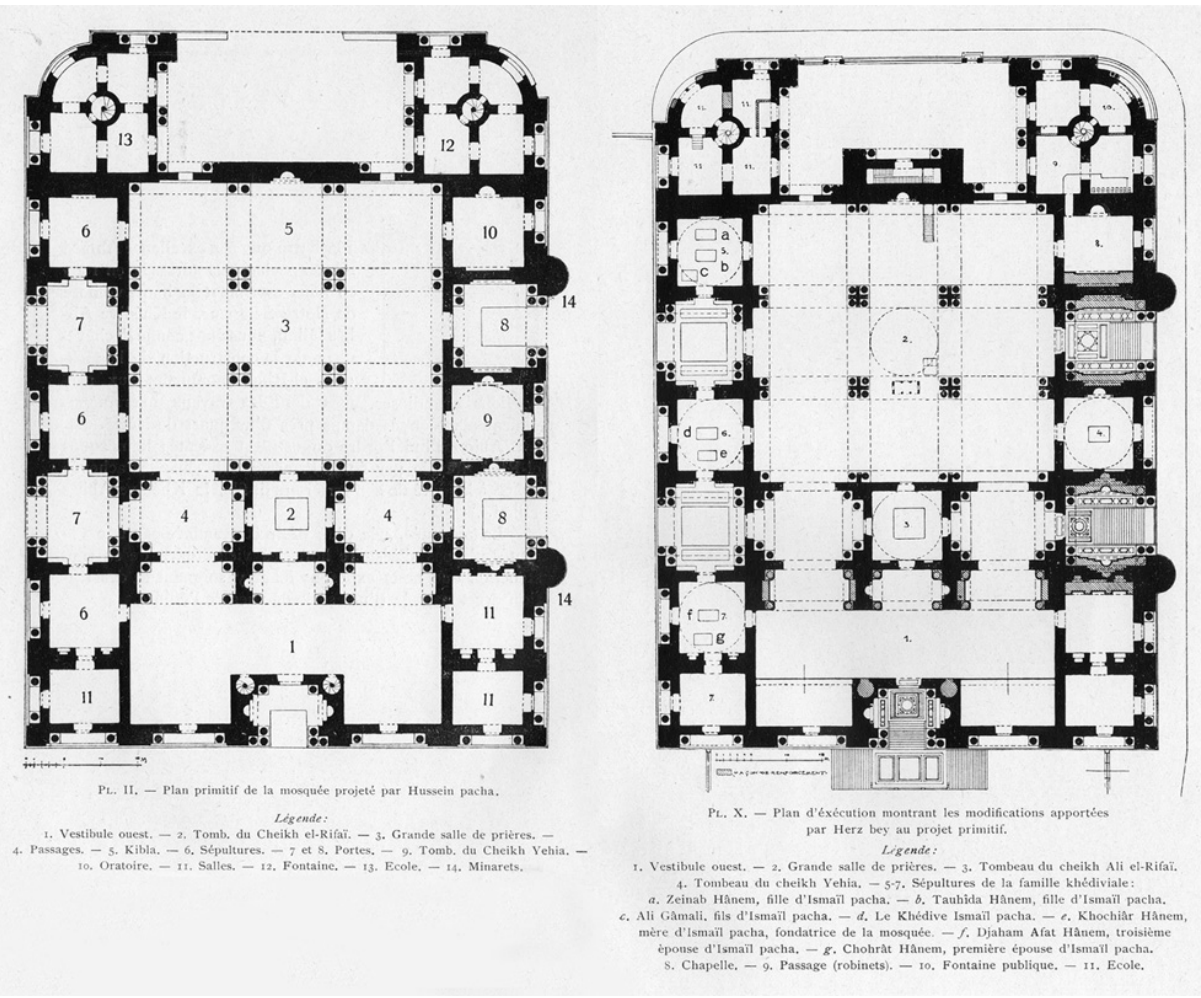

Source: MaX herz, La Mosquée el-Rifaï au Caire. Paru à l'occasion de la consécration de la mosquée, Milano: [Imp. Humbert Allegretti], s.d. [1911], p. 8 (plate II), p. 29 (plate X). 
19a. The Mosque of al-Rifa'i. Drawing showing Husayn Fahmi Pasha's original design for the southern façade.

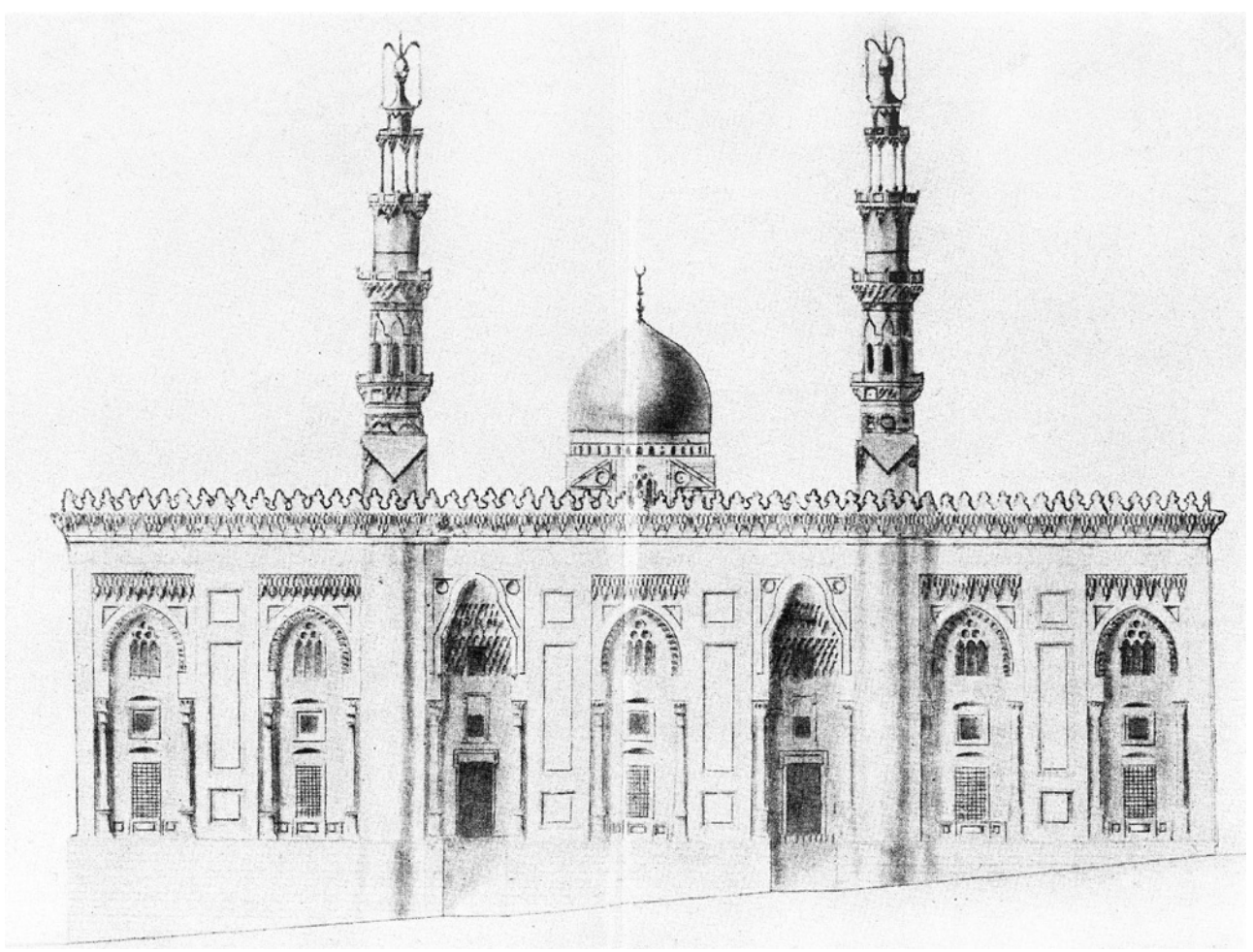

Source: Max herz, La Mosquée el-Rifaï au Caire. Paru à l'occasion de la consécration de la mosquée, Milano: [Imp. Humbert Allegretti], s.d. [1911], plate V.

19b. The Mosque of al-Rifa'i. The final design for the southern façade by Herz Pasha.
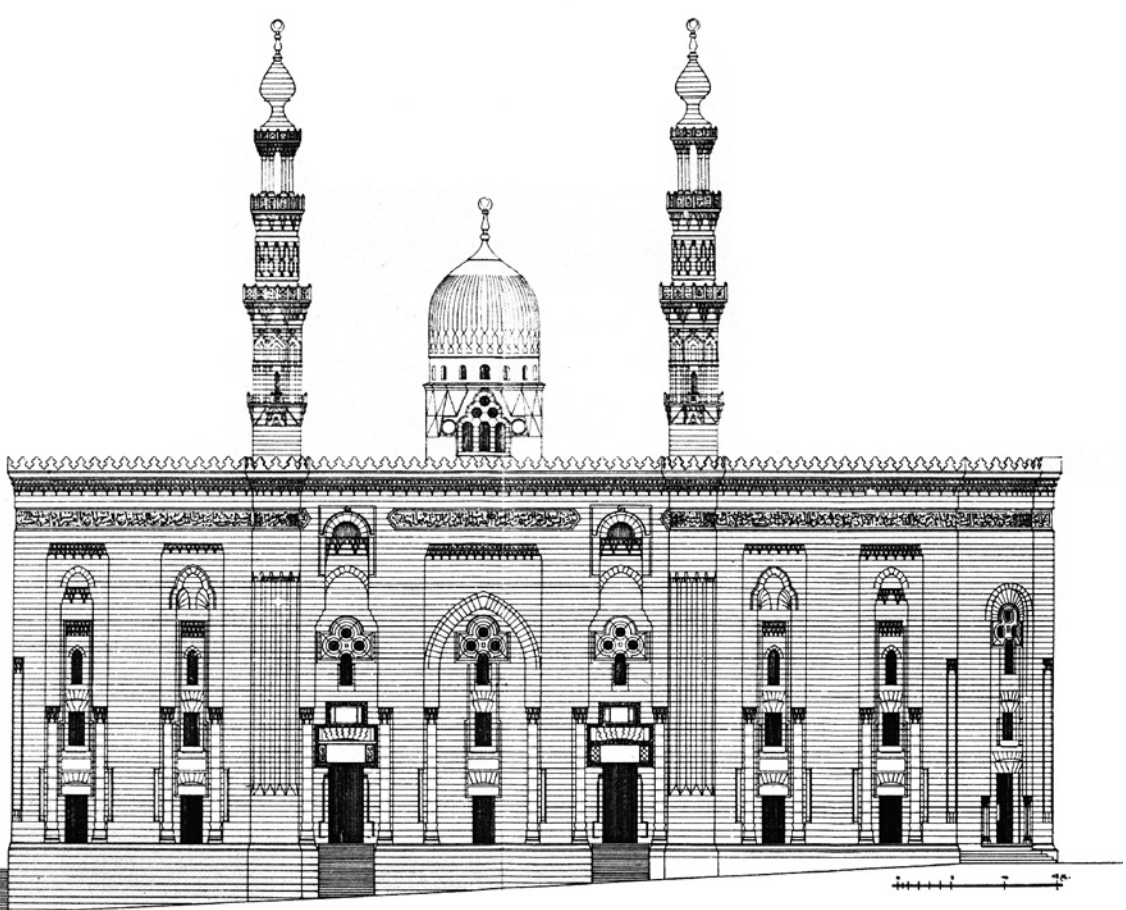

Source: Max herz, La Mosquée el-Rifaï au Caire. Paru à l'occasion de la consécration de la mosquée, Milano: [Imp. Humbert Allegretti], s.d. [1911], plate XIII. 
19c. The Mosque of al-Rifa'i. Longitudinal section. Drawing by Herz Pasha.

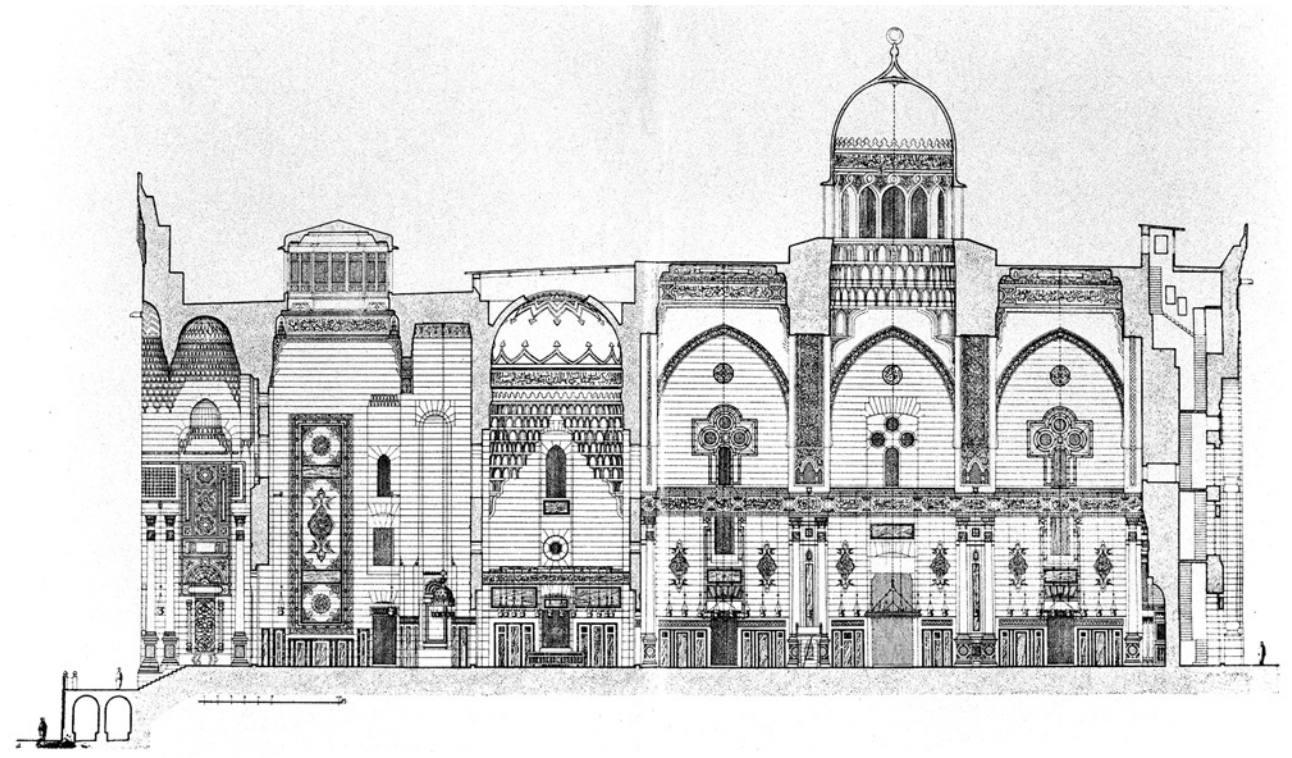

Source: Max herz, La Mosquée el-Rifaï au Caire. Paru à l'occasion de la consécration de la mosquée, Milano: [Imp. Humbert Allegretti], s.d. [1911], plate XVI.

19d. The Mosque of al-Rifa'i. Main prayer hall. Photograph. The interior decoration is Herz Pasha's work in its entirety because the original designs could not be found.

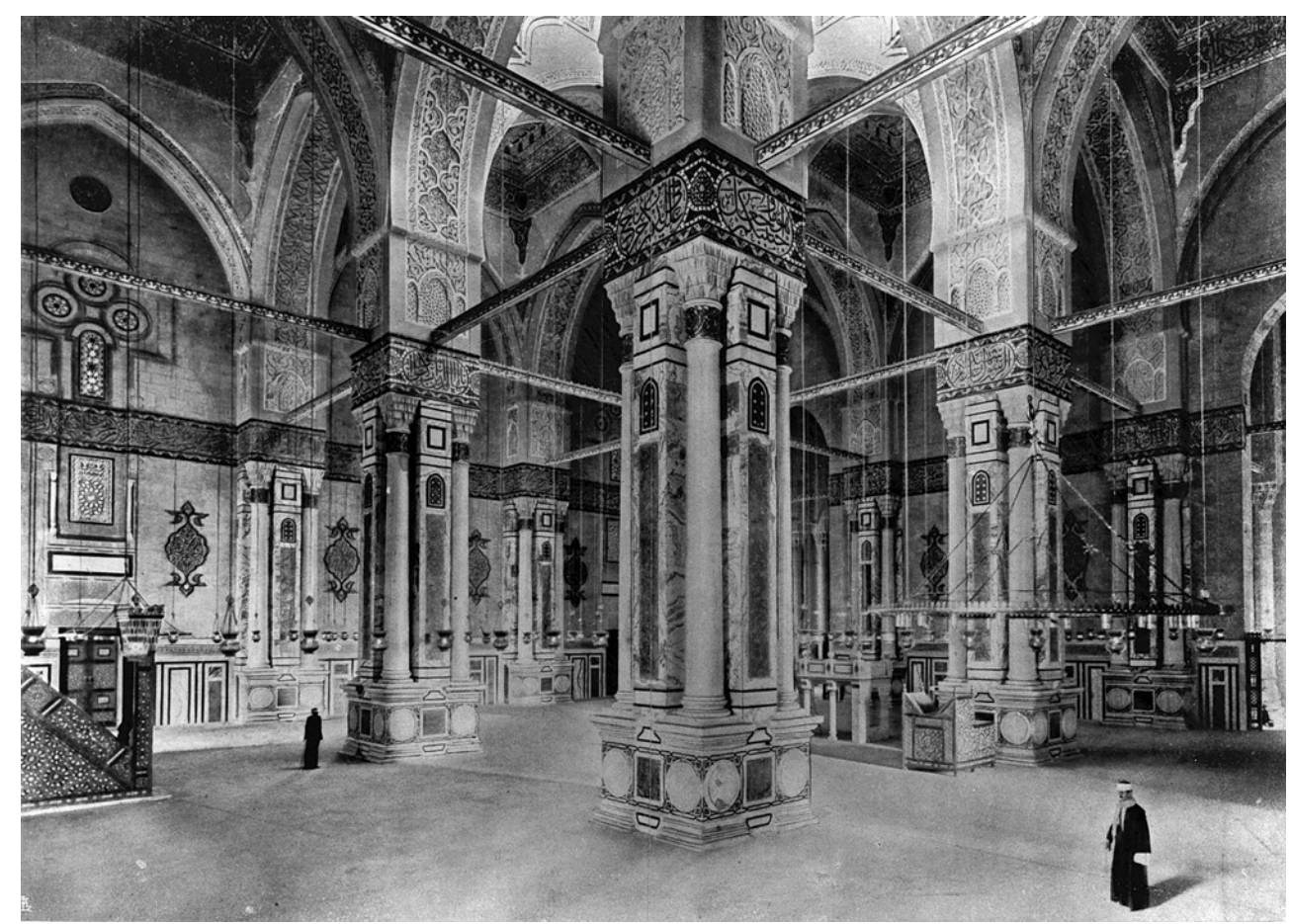

Source: Max herz, La Mosquée el-Rifaï au Caire. Paru à l'occasion de la consécration de la mosquée, Milano: [Imp. Humbert Allegretti], s.d. [1911], plate XVIII.

12 Herz devoted a number of shorter articles to various topics in Arab-Islamic art, mainly those with some bearing on his everyday work in the Comité. Some of these papers are of lasting value, while others have been superseded by later research. Yet others seem 
to have served day-to-day publicity or public relations purposes merely. Nevertheless, even those in the last two groups contain interesting pieces of information and are therefore a must for the historian of the Comité. To the third group belongs Herz's brief article on the Comité written in June 1890, after his appointment as chief architect but before the formation of its separate Technical Bureau ${ }^{49}$. A German version of the article appeared in 1891. In the meantime, significant changes had taken place in the Comité's structure, including the formation of the Technical Bureau within it. These changes were communicated in the German version. On the other hand, probably due to lack of space, certain important details were omitted from it ${ }^{50}$. Herz devoted part of a brief article in Hungarian to these details. It is no longer than an encyclopaedia entry, yet it may be of interest to historians of the Comité on account of the first-hand data contained in it, e.g. information concerning budgets and the numbers of monuments conserved, listed according to the sums spent on them ${ }^{51}$.

20a. The zawiya of Farag ibn Barquq (Zawiyat al-Duhaysha). Details of a window. Drawing by Herz.

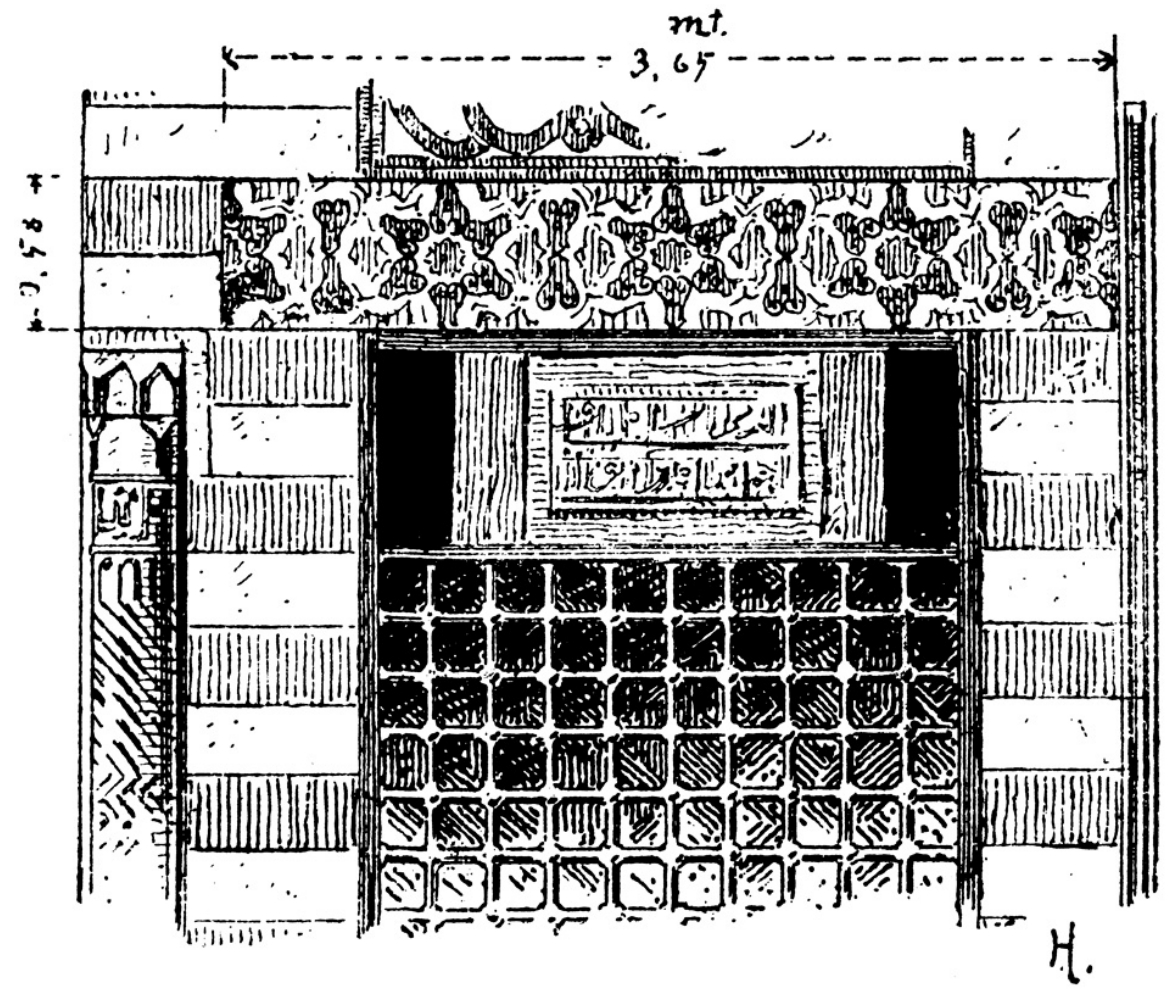


20b. The zawiya of Farag ibn Barquq (Zawiyat al-Duhaysha). Details of the mihrab. Drawing by Herz.

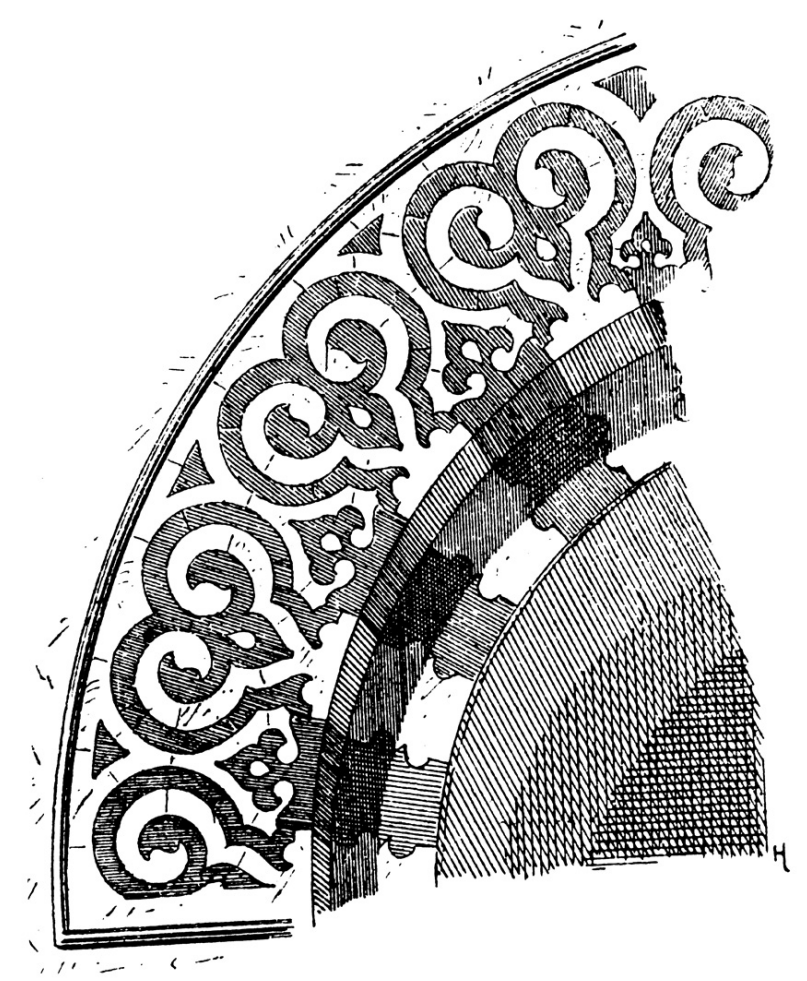

Source: Max HeRz, "Arab diszítmények II [Arab ornaments II]", Müvészi Ipar [Applied Art], 2, 1887, p. 99

20c. The zawiya of Farag ibn Barquq (Zawiyat al-Duhaysha). Details a band. Drawing by Herz.

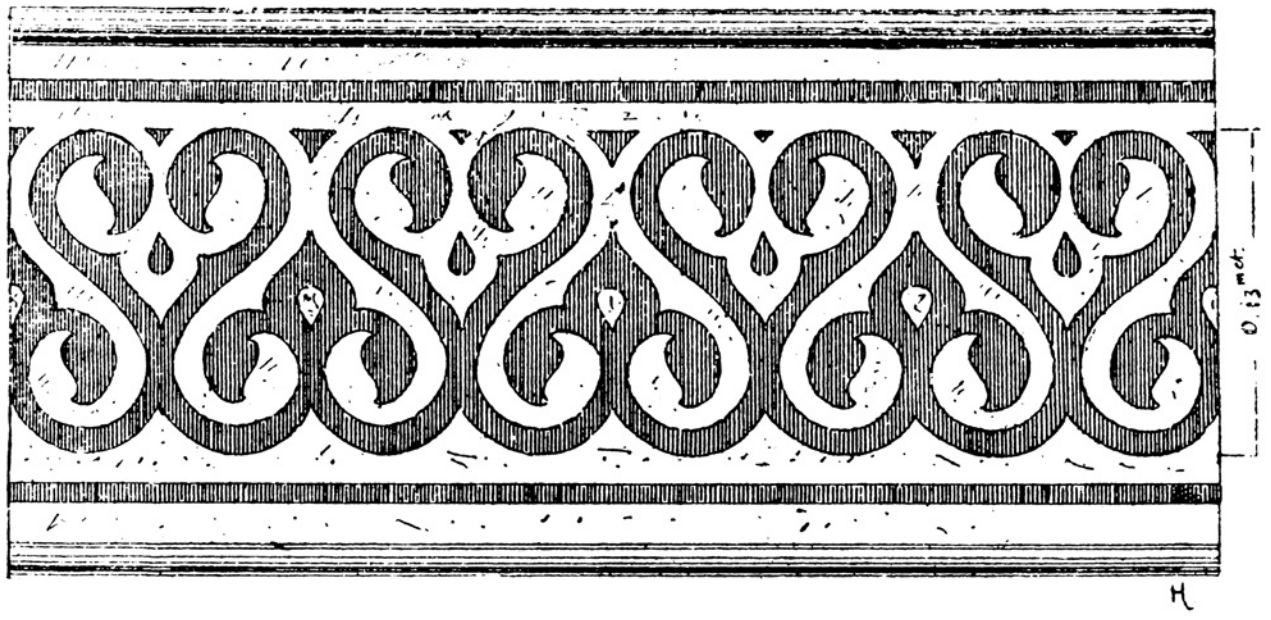

Source: Max herz, "Arab diszítmények II [Arab ornaments II]", Müvészi Ipar [Applied Art], 2, 1887, p. 99.

13 Herz had close ties to the Hungarian Museum of Applied Arts in Budapest. Together with the Hungarian Society of Applied Arts, this institution published a journal, to which Herz contributed a series of six short articles on Arab ornamentation between 1887 and 1890. He wrote that he had been in the "company" of Arab ornamentation for many years and had become very fond of it. However, this was not the primary reason for the presentation. Herz was convinced, as he wrote, that applied arts in the West could not afford to ignore Oriental art, especially Arab art, which was purely decorative 
in character. Rather, it was in the Westerners' "vital interest" to study it unceasingly. He considered the samples he was about to present not to be of primary importance on a world level. However, all were, he maintained, instructive as well as attractive to anyone familiar with the realm of forms. This was in accordance with the declared aims of the Society, which had been founded in 1884 with the goal of fostering the development of applied arts in Hungary. The first article dealt with woodcarvings and leather book bindings, while the second discussed the zawiya of Farag ibn Barquq (Zawiyat al-Duhaysha; 811/1408; no. 203) and its ornamentation. Herz mentioned (in 1887) that this used to be a place of execution with criminals being hanged on the northern grille of the sabil, and that the last execution had taken place "thirteen years ago". It was on this account, he maintained, that the monument was called the "Zawiya of Horror". This interpretation of the name is not accepted nowadays, but must have been the current one in Herz Pasha's time. Now it is generally believed that the word duhaysha, which also means "astonishment", "amazement", denotes a strikingly beautiful building in the present case ${ }^{52}$. Herz also discussed two faience plates from the collections of the Arab Museum. The subject of the third article was the sabil-kuttab of Sultan al-Ghawri (909/1504; no. 67). Article Four was devoted to ornamentation on hexagonal tables from mosques which had, in Herz's view, been used as stands for candlesticks (Ar. kursi [al-sham'a]) ${ }^{53}$, to ornamentation in the mosques of al-Mu'ayyad Shaykh (818/1415; no. 190), Khawand Baraka (Umm al-Sultan Sha'ban; 770/1318; no. 125), and to beautiful ornamentation from the sabil of Bashir Agha (1131/1718; no. 309). Article Five dealt with book bindings, a bronze grille in the courtyard of the mosque of Sultan Barquq (786/1384; no. 187) and a bronze door knocker from the mosque of Qigmas al-Ishaqi (885/1480; no. 114). Article Six dealt with Gamal al-Din al-Dhahabi's mansion (1047/1637; no. 72). The series included thirty-nine drawings by Herz, which were really exquisite and some of which have been published elsewhere, too (fig. 9-10, $20-22)^{54}$. 
21a. The Sabil-kuttab of Sultan al-Ghawri. Details of the northern window.

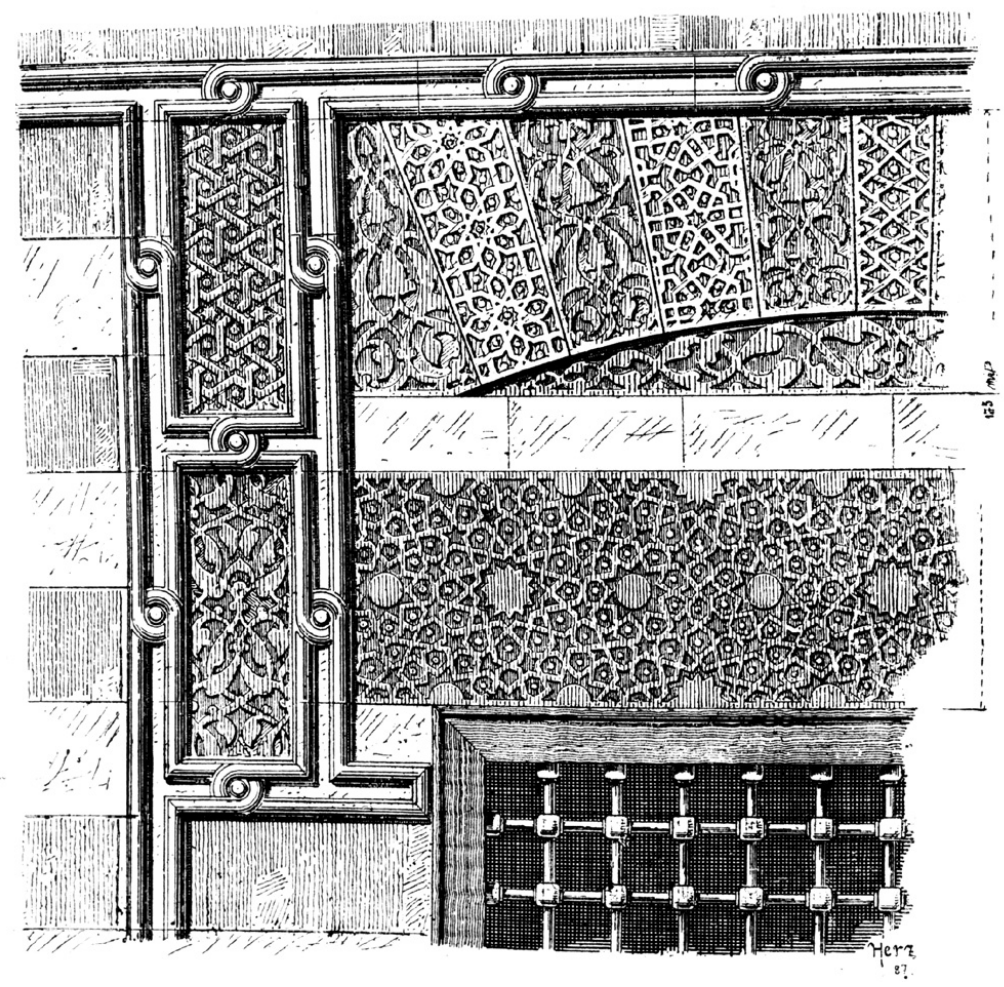

Salsabils were slanting rippled marble slabs in public fountains to cool the water which flowed over them. See ID., Catalogue of the National Museum of Arab Art, Stanley LANE-POOLE (ed.), London: Gilbert \& Rivington and Bernard Quaritch, 1896, p. 9, no.2.

Source: Max HeRz, "Arab diszítmények III [Arab ornaments III]", Müvészi Ipar [Applied Art], 3, 1887, p. 197. 
21b. The Sabil-kuttab of Sultan al-Ghawri. Details of the western window.

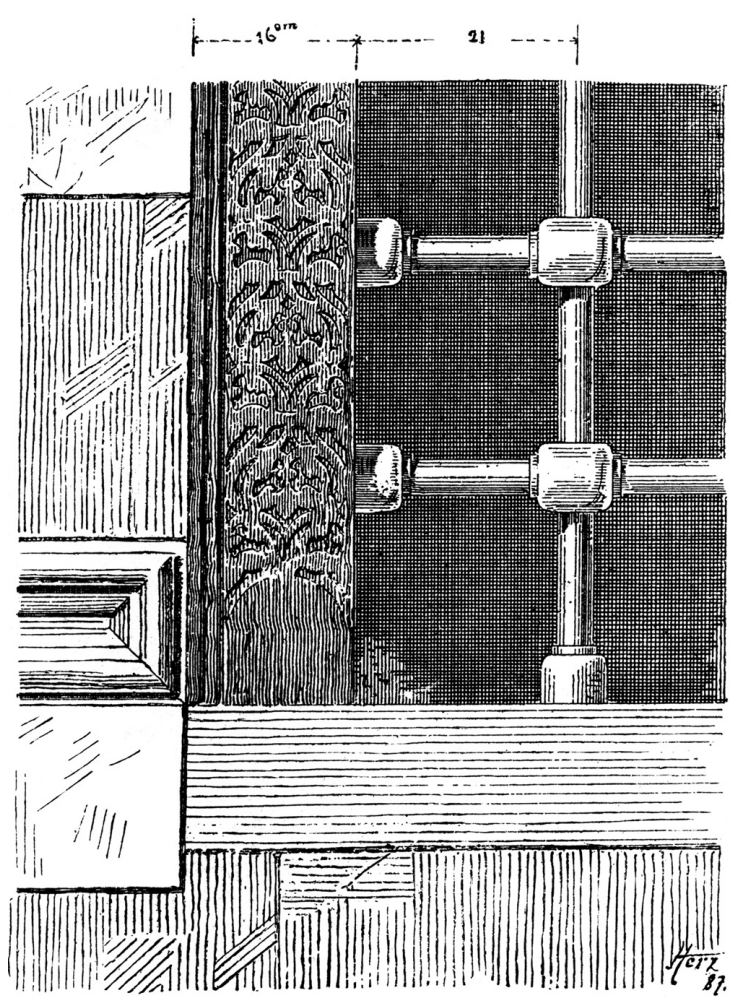

Source: Max HeRz, "Arab diszítmények III [Arab ornaments III]", Müvészi Ipar [Applied Art], 3, 1887, p. 199.

21c. The Sabil-kuttab of Sultan al-Ghawri. Details of the southern window.

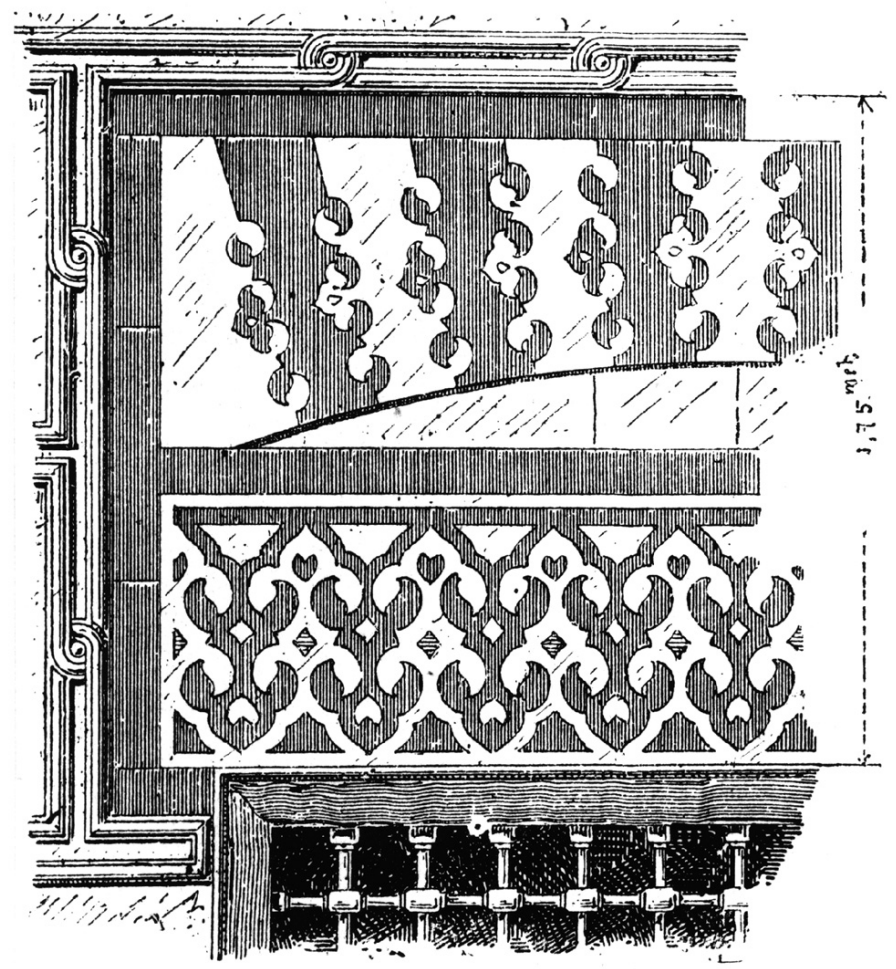

Source: Max HeRz, "Arab diszítmények III [Arab ornaments III]", Müvészi Ipar [Applied Art], 3, 1887, p. 201-202. 


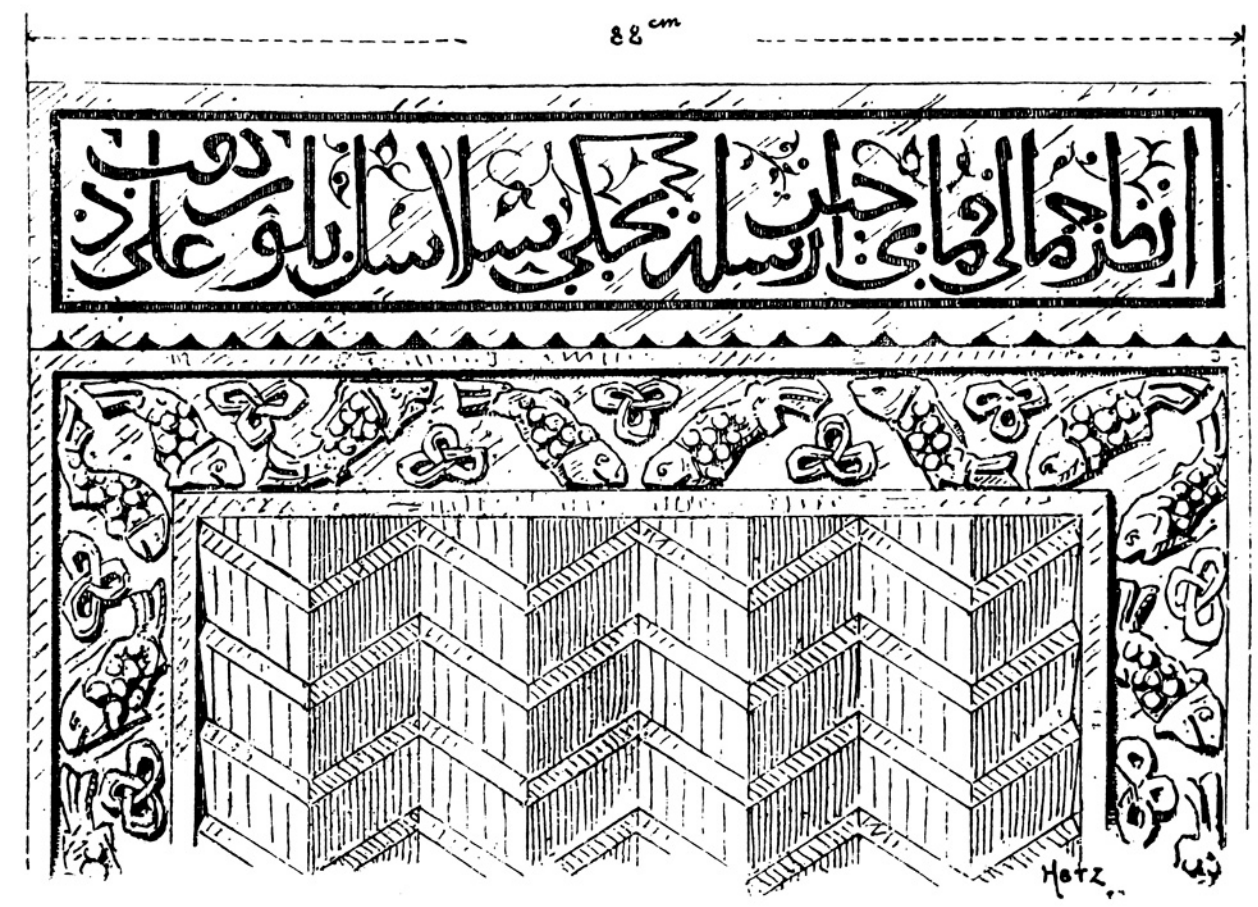

Source: Max herz, "Arab diszítmények III [Arab ornaments III]", Müvészi Ipar [Applied Art], 3, 1887, p. 201-202.

14 In Herz Pasha's day, numerous Mamluk monuments were painted in striped patterns and some in chessboard ones. The Comité did its best to rid them of this late "embellishment". At the same time, it was evident that in some cases the striped effect was original and had been achieved by the application of layers of stone of different colours or shades. To take a wider perspective, from the late eighteenth century onwards the idea gradually gained acceptance that classical Greek architecture had in fact been polychrome. It was in 1830 that the German-French architect Jakob Ignaz/ Jacques Ignace Hittorf published his discoveries, accompanying his work with an exhibition of watercolours giving hypothetical reconstructions of Greek temples in Sicily that showed how they might have looked in antiquity. Featuring vivid, bright, and sometimes even harsh colours in the Mediterranean sun, these pictures shocked purists accustomed to the "noble simplicity and silent grandeur" of classical monuments in the natural colours of their building material, which resulted in a puritanical appearance. As a matter of fact, the original painted colours had already weathered away when modern antiquarianism was born in the eighteenth century. A public outcry developed and a long controversy ensued that continued right up until the end of the nineteenth century. Slowly it became evident that polychromy had been an essential constituent of medieval architecture in Europe as well ${ }^{55}$. It was in this context that Herz published an article in two parts on polychromy in Arab-Islamic art. After enumerating various kinds of polychromy inherent in the natural coloration of building materials, he concentrated on painted polychromy. The monuments that were not newly striped in Herz's time were plain. Europeans were full of praise for the serene beauty of these monuments appearing in the pristine natural colour of the building materials used. In his article, Herz gave examples of traces of paint on various 
Arab-Islamic monuments in Cairo, inside and outside. In this way, he proved that originally they had been painted in colours, which had, however, disappeared in the meantime on account of weather effects, as was the case in Greece and elsewhere in Europe, too. Thus it was demonstrated that polychromy, including gilding, had in fact been an essential constituent of the aesthetic elements responsible for the overall effect of Arab-Islamic monuments in Cairo. Herz concluded the article with a brief discussion of painted objects made of wood ${ }^{56}$.

Herz wrote an intriguing article on the basins in the sahns of mosques ${ }^{57}$. Herz's thesis was that the fountains in the sahns of mosques like Sultan Hasan, Sarghatmish (757/1356; no. 218), or Barquq (in the Coppersmiths' Bazaar) originally served aesthetic purposes only, because these mosques possessed special ablution sections in secluded areas. It was, he maintained, as a result of the Ottoman conquest (923/1517) that the conquerors - who had been used to fountains in the courtyards of Ottoman mosques, where courtyards occupied a different place in the ground-plan of mosques as compared to Mamluk Egypt - turned the central parts of sahns into ablution areas. However, since they were followers of the Hanafi legal school (madhhab), who were obliged to use running water for ritual ablution, next to the central basin in the Sultan Hasan mosque they erected a special water tank with taps, as could be seen in Herz Pasha's time (fig. 23). (In original Ottoman mosques, the domed structure in the courtyard covered a device with taps, while in the Sultan Hasan mosque it covered a basin. In Cairo, the Muhammad Ali mosque [1265/1848; no. 503] in the Citadel may serve as a characteristic example of the Ottoman system in this respect.) The local Egyptian population followed suit, performing ritual ablution in the sahns. Egyptians, however, adhered to the Shafi'i legal school and thus could use the original basin for this purpose, because their prescriptions were less rigorous with respect to the purity of water. On this basis, on Herz's insistence, ablution was forbidden at the fountain in the sahn of the newly restored Barquqiyya mosque, because an original ablution court for this purpose existed there in impeccable condition. Herz Pasha's theory was highly plausible and elegant, but it has been refuted by the waqfiyyas of the respective mosques that have gradually become known since his death. It is clearly stated in them that the secluded ablution sections as well as the fountains in the central sahns were intended for ritual ablution ${ }^{58}$. However, the question remains: why was it necessary to install two such different systems for the same purpose? Was there any difference between their functions? "Abdallah Kahil uses the expression "ceremonial ablution" in connection with the fountain in the sahn of the Sultan Hasan mosque without comment. It is not clear whether he has something special in mind or whether he is using this expression simply as an equivalent for "ritual ablution". However, the waqfiyya has simply wudu' in the place referred to; the term proves nothing special in this respect ${ }^{59}$. To state matters more generally, once there was an ablution fountain in the sahn already, why was it necessary to add an extra secluded ablution section? Or to put them the other way round: if there was such a section already, why did the builder add an extra fountain in the sahn for the same purpose? Were they perhaps intended to serve different layers of society? There is no such hint in the waqfiyyas themselves and such an assumption contravenes the basic tenets of Islam prescribing the equality of the faithful. When describing certain large marble vessels (Ar. zir), Herz mentions that according to Prisse d'Avennes, these make it possible for persons of high rank to perform a superficial version of this religious duty without having to mix with the lower strata of society in the courts of ablution. In his later writings, Herz rejected this 
explanation: in his view, the vessels in question held drinking water. In my opinion, the inscription Herz cited to prove his point is not convincing. (Incidentally, no comment on this subject can be found in the first French edition of the catalogue of the Arab Museum. The English translation by Stanley Lane-Poole adds Prisse's view in a footnote. The description just referred to appears in the second French edition and in the subsequent English translation of this. Hence, there is a possibility that this note may have been added by Lane-Poole, who as a matter of fact is described on the titlepage as "editor" and not simply as "translator". However, it is difficult to imagine that he would have done this without Herz Pasha's consent..$^{60}$ ) On the other hand, we have to assume that Herz Pasha's statement reflected contemporary custom and beliefs, as did Prisse's, too: maybe they changed in the meantime? Or else, one of the two was wrong. If Prisse was right, here we would have a case of separate ablution areas for different strata of society, which might perhaps have been the reason for having different ablution areas in mosques, too. Such differentiation is not wholly unknown in Islamic countries. In his description of a bath in Cairo, 'Abd al-Latif al-Baghdadi (d. 629/1231) mentioned that there were "special cabinets for persons of distinction so that they do not mix with common persons, and do not appear naked in public. ${ }^{61 "}$ In his description of Cairene baths written in the years 1825-1828, Edward William Lane mentioned different arrangements for "the lower orders" also ${ }^{62}$.

22a. The mansion of Gamal al-Din al-Dhahabi. Detail of the façade of the maq'ad (loggia) with mashrabiyya-balustrade. Drawing by Herz. Cairo, 1890.

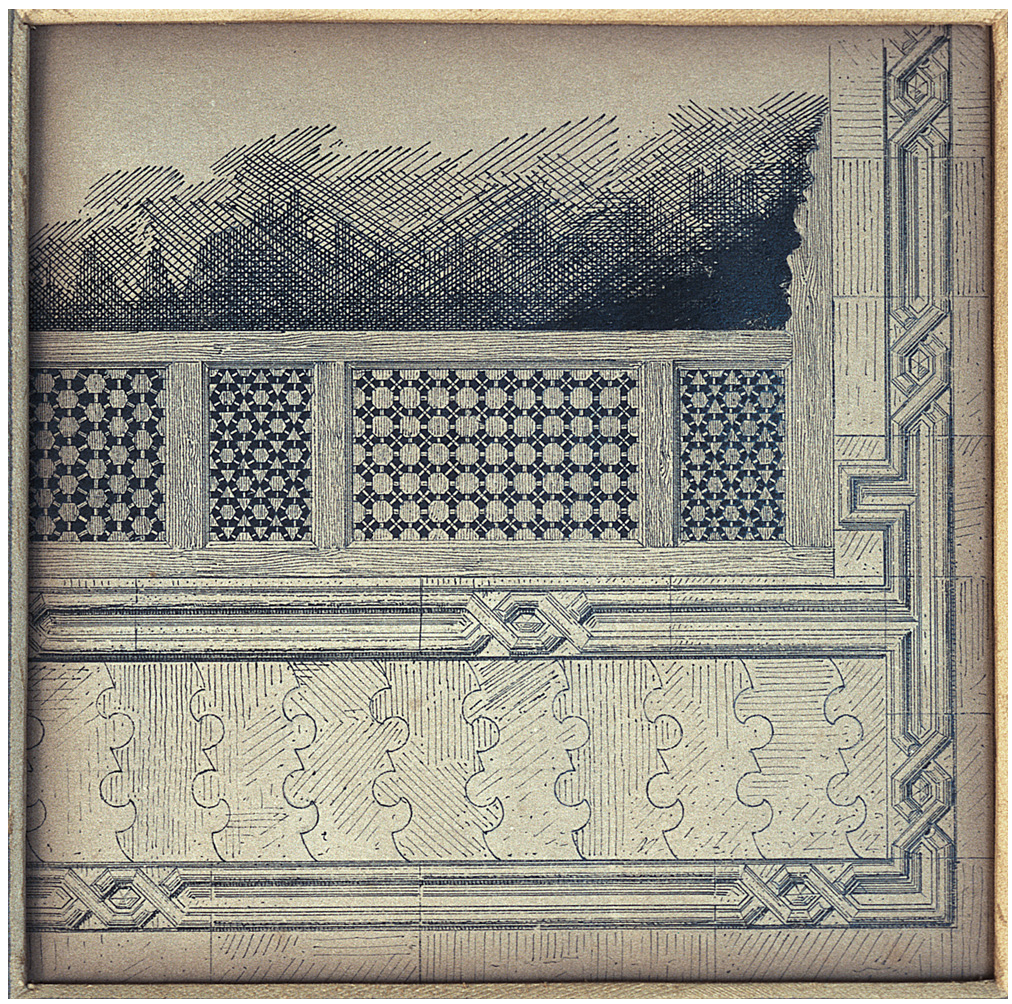

Source: Private collection. 
22b. The mansion of Gamal al-Din al-Dhahabi. Impost and capital in the maq'ad. Drawing by Herz. Cairo, 1890.

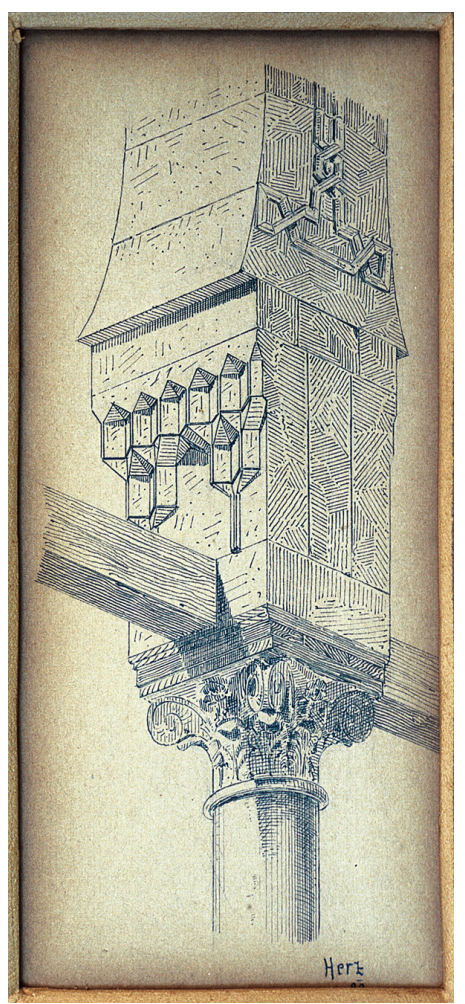

Source: Private collection. 
23. The sahn of Sultan Hasan in 1856. Drawing by Lajos Libay. Lithographed by Rudolf von Alt.

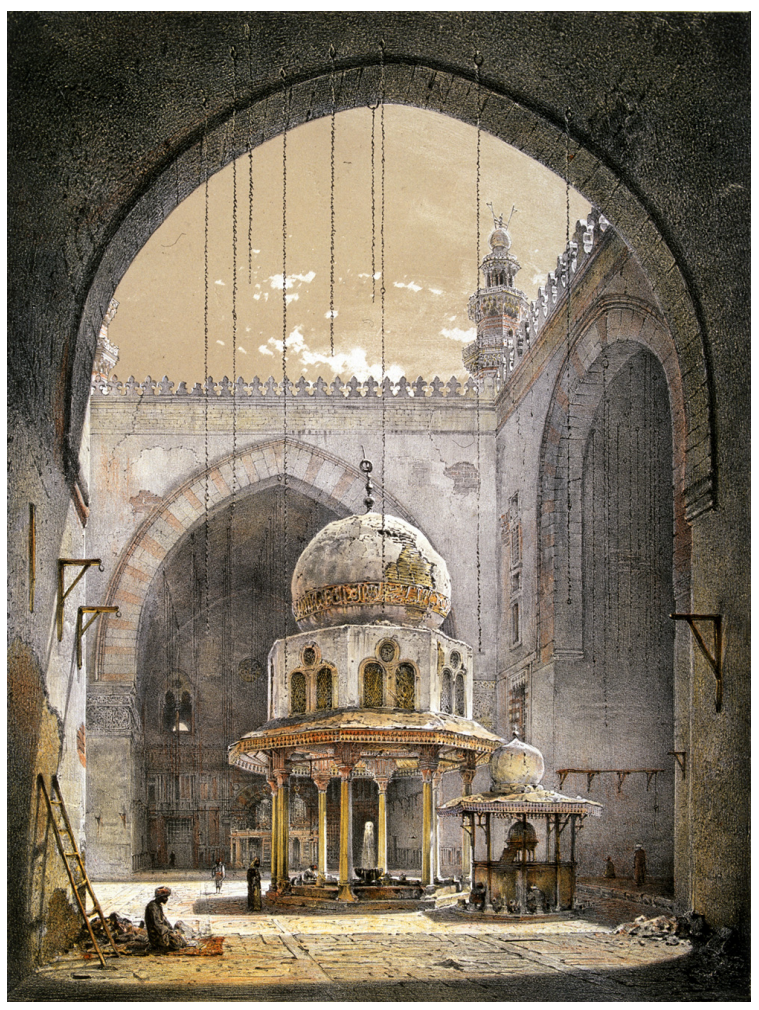

Source: Ludwig [Lajos] Libay, AEgypten. Reisebilder aus dem Orient, Vienna: L. Libay, 1857-1859, plate 12 (14).

From one particular point of view, secluded ablution sections were better suited for the purpose of ablution. Namely, the sound of splashing or running water induces men to urinate. Yielding to this physiological urge, they would relieve themselves into the basins of the fountains as is apparent from waqfiyyas which categorically forbid such behaviour ${ }^{63}$. This problem was easily solved in secluded ablution sections, because as a rule they contained latrines, too.

When Herz Pasha restored Sultan Hasan, he removed the Ottoman water tank with its domed canopy to the sahn of the Maridani mosque (739/1339; no. 120), which lacked a fountain. This step resulted in a public outcry: many protested against the destruction of the familiar picturesque view. However, after years of debate, during which even its return to Sultan Hasan was seriously considered, the Comite decided that the Ottoman tank should remain in the Maridani mosque, where it can be seen to this day (fig. 24)64. 
24. The sahn of the Maridani Mosque. Postcard, c. 1905.

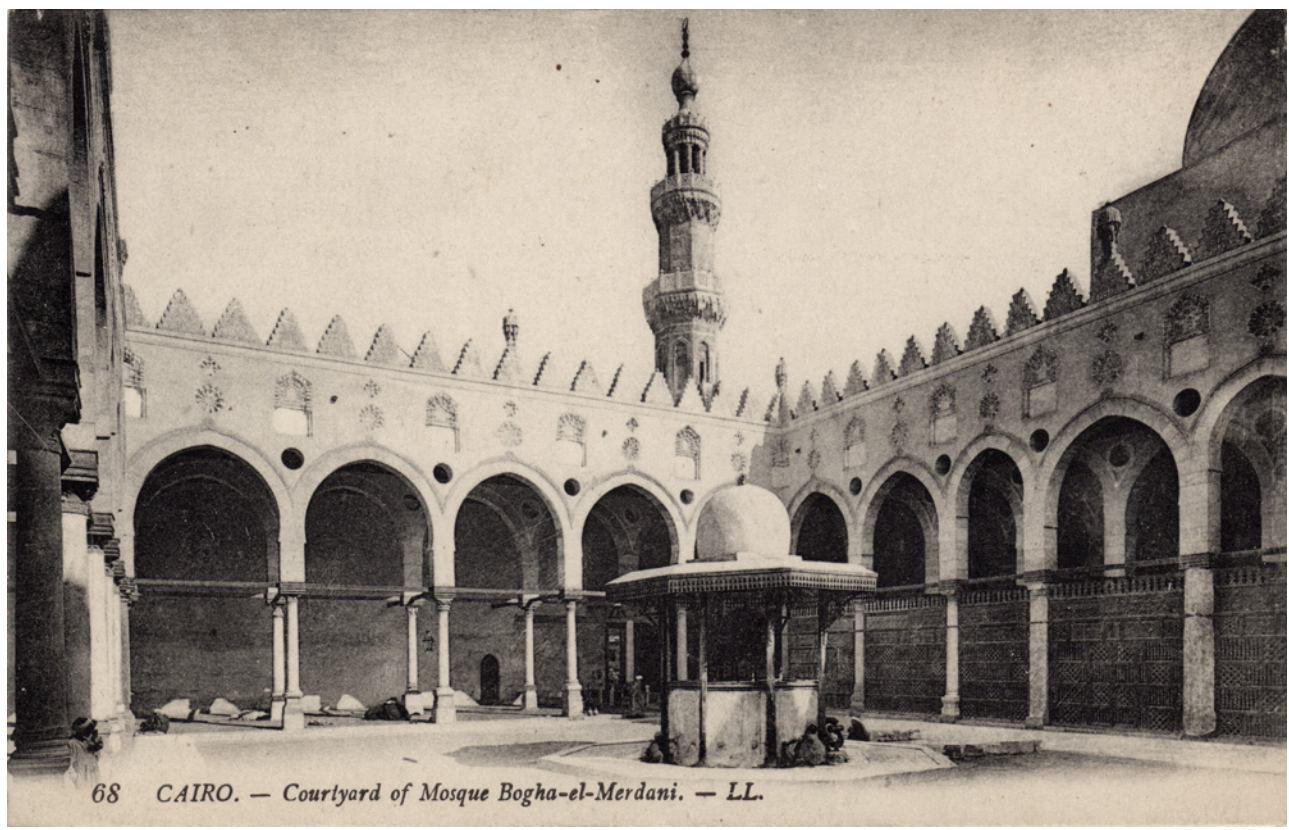

In an article which was in fact the text of a lecture given at the Institut egyptien on 1 April 1898, Herz voiced the idea of encouraging, or even enforcing, the adoption of the Arab style, with special emphasis on traditional projecting bay windows (mawardas) with mashrabiyya screens, in the construction of new buildings in native quarters, especially in the vicinity of architectural monuments. This idea was later adopted by Lord Kitchener, who envisaged the transformation of the neighbourhood of the Sultan Hasan and the Rifa'i mosques in an appropriate way. Nothing came of these efforts: only one building seems to have been erected in the Neo-Mamluk style. Similar efforts were also recorded in Istanbul ${ }^{65}$. As a matter of fact, this was not an original idea on the part of Herz. As he himself stated, he wanted to follow the example of Nuremberg in this respect. However, Nuremberg was not a haphazardly chosen German city. Having fallen into decline after mediaeval wealth and splendour, it was gradually rediscovered by protagonists of the romanticist movement from 1800 onwards - this process went hand in hand with a reappraisal of the Middle Ages and Gothic architecture, too, which had been the target of utter contempt since the Renaissance. Revered as the Protestant counterpart of Rome, soon Nuremberg was exalted into the glorified quintessence of German art and architecture, the foremost German city, which fully embodied Germany's spirit and soul at the time of the apogee of its power. Led by the desire to preserve the "old architectural physiognomy" of Nuremberg, from 1820 onwards there had been efforts to adapt the facades of new buildings to the traditional appearance of the city, within the framework of a "historicist city conservation". This meant that the Neo-Gothic style predominated in the first decades only to yield to Neo-Renaissance architecture later on. The idea seems to have gained acceptance fairly quickly, since even in the absence of an official statute many new buildings were erected in the characteristic local "Nuremberg style" (Nürnberger Stil), a Renaissance revival style, in the 1890s without apparent pressure from the municipal authorities. In 1899, a local police statute was passed to this effect. In a further extension of this idea, the city also served as a stage and backcloth for newly institutionalized historical processions. These were intended to conjure up the memory of its noble past, partly transforming it into a 
veritable lieu de mémoire in a symbolic sense ${ }^{66}$. The choice of tableaux represented a definitive programme: the aim was to keep historical tradition alive as an operative factor exerting a decisive influence on the shaping of modern society with the special aim of integrating the - often disturbing - corollaries of recent economic and social development within an accepted system of patriotic values. The ideal was an organically arranged society where the various strata coexisted in peaceful and mutually advantageous cooperation. At the same time, the adoption of the "Nuremberg style" was closely linked to the efflorescence of the modern industries of tourism and gastronomy, not only in Nuremberg itself but elsewhere, too. In addition to a certain similarity in cultural and political significance, Herz may have seen a close parallel between Nuremberg and Cairo in that, like the Egyptian capital, Nuremberg possessed architectural monuments, surviving in a relatively closed ensemble, in great abundance and concentration. In this regard, just as Nuremberg was unmatched in Germany, so, too, was Cairo unmatched in the Arab-Islamic world ${ }^{67}$.

Herz's last work, published posthumously, was devoted to the Qalawun complex (683/1284; no. 43) ${ }^{68}$. In view of his long involvement with this truly outstanding architectural ensemble, including the ongoing work aiming at complete restoration which he could not finish (fig. 25), there was at the time no-one more qualified to write such a monograph. Yet unhappy historical circumstances prevented him from accomplishing this task in accordance with his gifts and capabilities: he wrote the study in exile in Switzerland without access to his notes, photographs, or his books, or being able freely to consult a library specialising in Arab-Islamic art ${ }^{69}$. Still the monograph remains a basic reference work which has retained its relevance up to the present, notwithstanding the important contributions on this subject by later scholars such as Creswell, Meinecke, and Wolfgang Mayer ${ }^{70}$. 
25. Qalawun's Madrasa. Design for the reconstruction of the interior. Drawing by Herz. Zurich, 1919. The actual reconstruction carried out by Achille Patricolo after Herz Pasha's expulsion was based on a different conception.

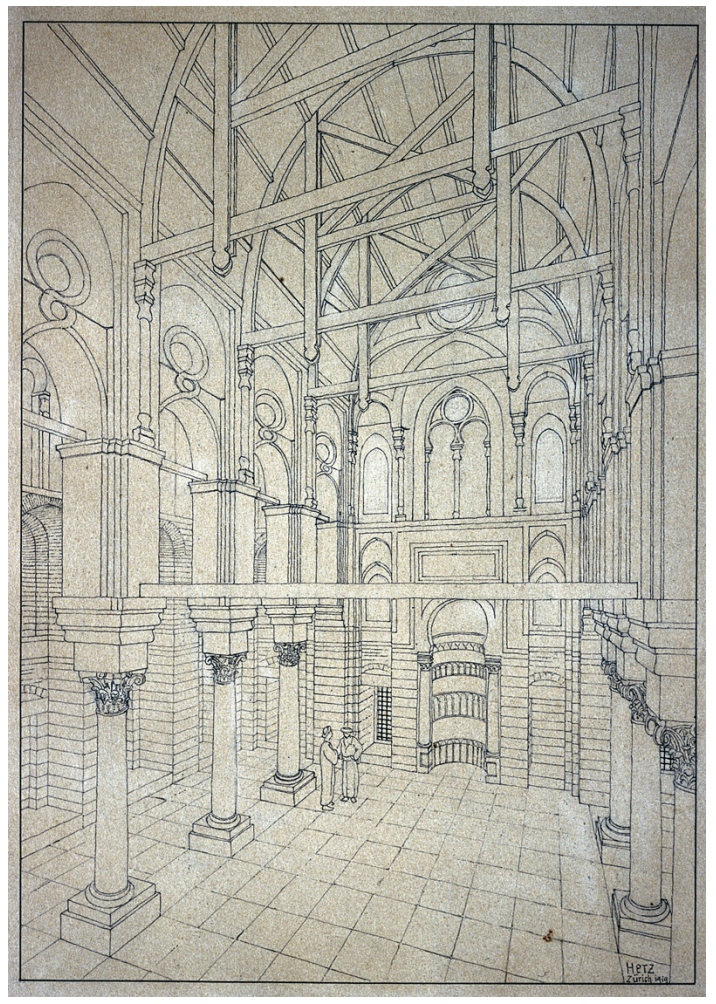

Herz published this drawing in his monograph on the Qalawun complex: Die Baugruppe des Sultans Qalāūn in Kairo, Hambourg: J. Friederichsen \& Co., 1919, pl. 27 (fig. 37) (Abhandlungen des Hamburgischen Kolonialinstituts, 42).

Source: Private collection.

It should be noted that Herz's letters to Max van Berchem also contain many references to art history ${ }^{71}$.

We know of a number of publications, among them a history of Arab-Islamic architecture in Egypt and several works on Coptic art, which Herz was planning to write, but could not, owing to his heavy workload in the Comite and to his enforced retirement and expulsion ${ }^{72}$.

Herz Pasha's scholarly activities in the field of art history were in fact ancillary to his conservation work in the Comité. He would have loved to devote himself to scholarly research on a much larger scale, but his daily workload prevented him from doing so. His scholarly publications represented the world standard at the time and played a considerable role in the evolution of Islamic art history. However, seen from a modern point of view, much of his output is now behind the times, the fate of most scholarly work eventually. There are some exceptions, though: his monographs on the Sultan Hasan mosque and the Qalawun complex, the Comite Bulletins together with the Index general, and the booklet on the Rifa'i mosque. These will never lose their relevance. On the other hand, owing to his long involvement with monuments and objets d'art in Cairo and in Egypt, all his writings, even his shortest articles, contain important data not to be found elsewhere and will serve as source material for subsequent generations of art historians which they will ignore at their peril. And let me conclude with a personal remark. Re-reading the entirety of Herz's publications now, I was struck once again by 
the gusto with which he worked, and also by the personal involvement - along with the commitment and love of his field - apparent from his elegant style. They made my present task an intellectual and emotional experience that was highly enjoyable.

\section{NOTES}

1. The numbers after monuments refer to the Index of monuments, Cairo, Survey of Egypt, 1951. In the case of-mostly late-monuments, which do not appear in this list, Nicholas Warner's numbers with a U-prefix (unnumbered) have been adopted. See Nicholas WARNER, The monuments of historic Cairo. A map and descriptive catalogue, Cairo: The American University in Cairo Press, 2005 (American Research Center in Egypt Conservation series).

2. On him see István oRMos, Max Herz Pasha (1856-1919). His life and career, Cairo: IFAO, 2009 (Études urbaines, 6).

3. David Samuel MARGoliouth, Cairo, Jerusalem and Damascus. Three chief cities of the Egyptian Sultans, London: Chatto \& Windus, 1907, p. 48.

4. István ORMOS, "The correspondence of Ignaz Goldziher and Max Herz," in Éva A POR, István ORMOS (eds.), Goldziher memorial conference, Budapest: Library of the Hungarian Academy of Sciences, 2005 (Keleti tanulmányok, 12), p. 196.

5. For Herz Pasha's bibliography see István oRMOS, op. cit. (note 2), p. 524-535.

6. Max HERZ, La mosquée de l'Emîr Gânem el-Bahlaouân au Caire, Cairo: Boehme \& Anderer, 1908.

7. Max HERZ, Index général des Bulletins du Comité des années 1882 à 1910, Cairo: IFAO, 1914.

8. Now Nicholas WARNER, op. cit. (note 1), fills this void to a great extent because he gives relevant data concerning every monument dealt with in this work. On the other hand his data are not exhaustive, as far as I can see, and in accordance with his work's concept, he does not cover monuments lying outside "Historic Cairo", e.g. those in the two cemeteries and in the vicinity of old Cairo.

9. Complete series are rare. Now an almost complete series is accessible on the internet. URL: www.islamic-art.org/comitte/Comite.asp. Accessed on November 17, 2015.

10. Ibid. (note 2), p. 356-358.

11. Ibid. (note 2), p. 318-322.

12. Friedrich SARRE, "Max Herz-Pascha†," Kunstchronik und Kunstmarkt, 54, 1919, p. 776.

13. Max HERz, "Musée de l'art arabe," in Georges [Aaron] BÉNÉDITE (ed.), Égypte, avec un appendice et des renseignements pratiques mis à jour pour 1905, Paris: Hachette, 1900, p. 638-640 (Collection des Guides-Joanne). Georges [Aaron] BÉNÉDITE, Max HERZ, Le Caire et ses environs, Paris: Hachette, 1909, p. 107-111 (Collection des Guides-Joanne). The latter book appeared a year later in English translation too. Max HERZ, "Le Musée National du Caire," Gazette des beaux-arts, vol. 28, 1902, p. 45-59, 497-505; vol. 30, 1903, p. 223-234: The production of qamariyyas is described on 52-53. ID., "National Museum of Arab Art, Cairo," in Arnold WRIGHT (ed.),Twentieth century impressions of Egypt, London: Lloyd's Greater Britain Publishing Co., 1909, p. 135-138.

14. Max HERz, La Mosquée du Sultan Hassan au Caire, Cairo: IFAO, 1899. An Arabic translation by 'Ali Bahgat came out in 1902 and a reprint edition of the latter was published in reduced size by the Egyptian National Library and Archives in Cairo in 2009.

15. István ORMOS, op. cit., (note 2), p. 228-229. 
16. J[ohn] M[ichael] ROGERS, "Al-Qāhira/Mamlūks," in Encyclopaedia of Islam, new edition, Leiden: Brill; London: Luzac, 1960-2004, vol. 4, p. 431.

17. Abdallah KAHIL, The Sultan Hasan complex in Cairo 1357-1364. A case study in the formation of Mamluk style, Beirut, Wurzburg: Ergon, 2008 (Beiruter Texte und Studien, 98).

18. Ibid., p. 14.

19. Ibid., p. 13.

20. Max HERZ, “Az arab műemlekek bizottsaga es a Hasszanmecset [The Comité of monuments of Arab architecture and the Hasan mosque]", Budapesti Szemle, no. 148, 1911, p. 210-215.

21. Ibid., p. 212-215. Friedrich SARRE, Reise in Kleinasien-Sommer 1895-Forschungen zur seldjukischen Kunst und Geographie des Landes, Berlin: D. Reimer, 1896. Herz must have had Plate (Tafel) XXXIII in mind, which depicts one of the two lateral recesses in the main portal crowned by horizontal stalactites. These last structures must be the "false stalactites" (stalactites employées à faux) which he describes in Max HERz, op. cit. (note 14), p. 25, too. This question must have occupied Herz's mind for some time because - with Sarre's permission - he reproduced the abovementioned Plate XXXIII in his own account of Islamic art too. Max HERZ, "Az Iszlam műveszete [Islamic art]", inZsolt вЕотну (ed.), A müveszetek tortenete [The history of arts], Budapest: R. Lampel (F. Wodianer), 1906-1912, vol. 2, p. 220 (fig. 253). He did not refer to this question in this last place. See the portal in Comité Bulletin 32, 1915-1919, part II, plate CXIV.

22. Max HERz, “Art arabe," in Égypte, op. cit. (note 13), 1900, p. 152-174. Cf. Jean CHARDon (ed.), Méditerranée orientale. Guide du passager sur les itinéraires des croisières, Paris: Hachette, 1930, p. 217232 (Les Guides bleus illustrés). The description of Cairo is based on Herz Pasha's earlier account, too. For the original plan of al-Azhar see Égypte (1900), p. 265. The plan of al-Azhar is an interesting and important testimony because it shows the mosque in its state before considerable transformations were executed on it towards the end of the nineteenth century. This also means however that the plan was slightly dated in 1900 already, when Hachette published the Egypt volume in question in the Guides-Joanne series. On the Guides Joanne in general see Hélène MORLIER, "Une série de prestige des guides Joanne: l'Itinéraire d'Orient," URL: http:// halshs.archives-ouvertes.fr/hal-00446195_v1/. Accessed on November 17, 2015.

23. Julius FRANZ-PASCHA, Die Baukunst des Islam, Darmstadt: Arnold Bergstrasser, 1887 (Die Baustile. Historische und technische Entwickelung. Handbuch der Architektur II, 3/2); 2. [enlarged] ed., 1896. For a list of Herz's drawings in this book see István oRMOS, op. cit. (note 2), p. 524-526.

24. Max HERZ, Égypte, op. cit. (note 13), (1900), p. 259-314.

25. Herz's ground plans of al-Azhar are important testimonies for the significant transformations on this mosque in his time. Creswell pointed out this fact about the ground plans in Baedeker's guidebooks (without expressely mentioning Herz's name), stressing that there was a little else to be found in the Waqf and the Comite archives and even the originals of the plans could be traced in his time (The Muslim Architecture of Egypt, vol. I, p. 42, no. 6 and p. 47-48, fig. 12-13). The present plan belongs to this series. It comes from the Guide-Joanne of 1900/1905 and is a slightly modified version of the plan in Baedeker's third (1984), fourth (1897) and fifth (1902) German and fourth remodelled English editions (1898).

26. Max HERZ, “Az Iszlam műveszete [Islamic art]”, op. cit. (note 21), p. 108-262. Volume 4 was never published - in all probability, because of the war.

27. Ignác GOLDZIHER, "Herz Miksa [Max Herz]," Budapesti Szemle [Budapest Review], vol. 179, 1919, p. 232-233. A German (French?) version must have existed too because Herz thanks Max van Berchem for reading the manuscript and for making useful comments. Max HERZ, op. cit. (note 21), 259 , n. 1. Herz seems to have kept working on the manuscript with the aim of drawing up an enlarged, expanded version for a later publication - before the outbreak of the war he already had a contract for a French edition. There is no trace of the manuscript(s?) now. 
28. Hillenbrand remarks: "the sense of gusto has unquestionably departed" from modern scholarship in this field. Robert HILLENBRAND, "Creswell and contemporary Central European scholarship," Muqarnas, no.8, 1991, p. 23.

29. See István oRMOs, "The attitude of Max Herz Pasha and the Comite de Conservation des Monuments de l'Art Arabe towards Ottoman architecture in Egypt at the end of the 19th century," in Géza DÁvID, Ibolya GERELYES (ed.), Thirteenth International Congress of Turkish Art. Proceedings, Budapest: Hungarian National Museum, 2009, p. 533-544. His views were also shared by others too. See, e.g., Ahmed zÉKI РACHA, "Le passé et l'avenir de l'art musulman en Égypte," L'Égypte contemporaine, vol. 4, no. 13, January 1913, p. 13-17. Also printed separately: ID., Mémoire sur la genèse et la floraison de l'art musulman et sur les moyens propres à le faire revivre en Égypte (Cairo: IFAO, 1913), p. 13-17. On the noted philologist and politician Ahmad ZÉKI PASHA (1867-1934), the "Dean of Arabism", see Arthur GOLDSCHMIDT, JR., Biographical dictionary of modern Egypt, Cairo: The American University in Cairo Press, 2000, p. 236-237.

30. Max HERZ, “Az arab műveszet Egyiptomban a turkoman es cserkesz mamluk-szultanok alatt (1250-1517.) [Arab art in Egypt under the Turkoman and Circassian sultans (1250-1517)]," Budapesti Szemle, no.120, 1904, p. 272. These two illustrations (figs. 13a and 13b) also appear in Herz Pasha's treatment of Ottoman influence on architecture in Egypt in his Hungarian account of Islamic art. Max HERZ, “Az Iszlam...,” op. cit. (note 21), p. 193 (fig. 223), p. 195 (fig. 225).

31. Cf. Robert HILLENBRAND, "Review of Keppel Archibald Cameron Creswell, A short account of early Muslim architecture, rev.James Wilson ALLAN, Aldershot: Scolar Press; Cairo: The American University in Cairo Press, 1989", British Journal of Middle Eastern Studies, no. 17, 1990, p. 86-87. Stephen VERNOIT, “The rise of Islamic archaeology," Muqarnas, no. 14, 1997, p. 1-10.

32. He describes the palace without mentioning its name. Max HERZ, op. cit. (note 21), p. 139, 209, 261. In modern times it was the Czech-Austrian explorer-Arabist, Prelate Alois Musil, who first drew attention to it in 1902. However, his description is so brief-mentioning a "quadrangular courtyard" merely in the relevant context-that it is most unlikely for Herz to have based his theory on it. It is to be assumed that he acquired the relevant data through personal channels. Musil published some more details about the Qasr, including a ground plan, in 1907. Alois MUSIL, "Kusejr 'amra und andere Schlösser östlich von Moab. Topographischer Reisebericht, I. Theil.," Sitzungsberichte der Philosophisch-Historischen Classe der Kaiserlichen Akademie der Wissenschaften, no. 144, 1902, part VII. Abh[andlung], 18-19, fig. 11. Kusejr 'Amra (Vienna, 1907), vol. 1, p. 38-40, 43-44 [fig. 36-37], 97-101 [fig. 82-86]. The ground-plan is on page 97 (fig. 82). On Kharana see now Heinz GAUBE, “'Amman, Harane und Qastal. Vier frühislamische Bauwerke in Mitteljordanien”, Zeitschrift des Deutschen Palästina-Vereins, no.93, 1977, p. 64-66. Cameron CRESWELL, A short account..., op. cit. (note 30), p 96-105.

33. Max HERZ, “Art arabe," in Égypte, op. cit. (note 13), 1900, p. 164.

34. Max HERZ, op.cit. (note 29), 266. ID., "Madrassat El-Kâmelieh. Appendice au $21^{\mathrm{e}}$ fascicule", Comité de conservation des monuments de l'art arabe. Procès-verbaux des séances. Rapports de la Section Technique [Bulletin], no.21, 1904, p. 98-99.

35. MaX HERZ, Catalogue sommaire des monuments exposés dans le Musée national de l'art arabe, Cairo: G. Lekegian, 1895, XXXVII and LIII in introduction.

36. Stanley LANE-POOLE, The art of the Saracens in Egypt, ([London: Chapman and Hall, 1886; reprint:] Beirut: Byblos, n.d.) p. 53. Max VAN BERCHEM, Matériaux pour un Corpus Inscriptionum Arabicarum, I. Égypte (Paris: Ernest Leroux, 1903): p. 254-269, 536. K[eppel] A[rchibald] C[ameron] CRESWELL, The Muslim architecture of Egypt, [Oxford: Clarendon Press, 1952-1959; reprint:] New York: Hacker Art Books, 1978, vol. 2, p. 106-107. Cf. also ibid., p. 104-133. Van Berchem's Matériaux appeared in instalments originally; Herz reported to Ignaz Goldziher in a letter dated 6th April 1901 that he had just received the fascicle containing p. 304 (no.197). The Goldziher Correspondence is preserved in the Oriental Collection, Library of the Hungarian Academy of Sciences, Budapest. 
37. MaX VAN BERCHEM, op. cit. (note 35), p. 536. Cf. Heinz GAUBE, op. cit. (note 31), p. 52-58. Cameron CRESWELL, op. cit. (note 30), p. 169-172.

38. Max HERZ-PASCHA, Die Baugruppe des Sultans Qalāūn in Kairo, Hamburg: J. Friederichsen \& Co., 1919, p. 25-26 (Abhandlungen des Hamburgischen Kolonialinstituts 42). On this subject cf. also Hazem I. SAYED, "The development of the Cairene Q Q⿳亠丷冖'a: some considerations", Annales Islamologiques 23 (1987), p.31-53. Bernard O'KANE, “Domestic and religious architecture in Cairo: mutual influences," in Doris BEHRENS-ABOUSEIF (ed.), The Cairo heritage. Essays in honor of Laila Ali Ibrahim, Cairo: The American University in Cairo Press, 2000, p. 149-182.

39. K. A. Cameron CRESWELL, "The origin of the cruciform plan of Cairene madrasas," Bulletin de l'Institut français d'Archéologie Orientale, no.21, 1923, p. 45. Creswell says he wrote this article in 1922. IDEM, op. cit. (note 35), vol. 2, p. 132. For van Berchem's acceptance of his theory see ibid., p. 128, n. 11. Cf. also Ernst HERZFELD, "Damascus: studies in architecture - II", Ars Islamica, no.10, 1943, p. 13-16 [The cruciform plan].

40. Michael MEINECKE, "Rückschlüsse auf die Form der seldschukischen Madrasa in İrān", Damaszener Mitteilungen, no.3, 1988, p. 185-202. ID., Die mamlukische Architektur in Ägypten und Syrien (648/1250 bis 923/1517), Glückstadt: J. J. Augustin, 1992, vol.1, p.26-28, esp. n. 61, 64 (Abhandlungen des Deutschen Archäologischen Instituts Kairo, Islamische Reihe, 5).

41. MaX HERZ, op. cit. (note 21), p. 128-130, 143-145.

42. Ibid., p. 116 (fig. 125), p. 117 (fig. 128), p. 117, n. 1, p. 124, n. 1, p. 126 (fig. 213).

43. Ibid., See also p. 230 sq. above. Max HERz, op. cit. (note 29), p. 266-272.

44. On this subject see the preceding section.

45. Max HERZ, op. cit. (note 29), p. 266-272.

46. MaX HERZ, La mosquée el-Rifaï au Caire. Paru à l'occasion de la consécration de la mosquée, Milano: [Imp. Humbert Allegretti], [1911].

47. Max HERz, "Ali el-Rifai sejk mecsetje Kairoban [The Mosque of Shaykh Ali al-Rifai in Cairo]", Budapesti Szemle, no.152, 1912, p. 249-257.

48. The date given in the Hungarian article is confirmed by contemporary Egyptian newspapers too. On the Rifa'i mosque in general see István ormos, op. cit. (note 2), p. 430-456.

49. Max HERZ, "Les monuments de l'art arabe. Le Comité de conservation en Égypte”, L'Ami des Monuments et des Arts, no.4, 1890, p. 193-195, 301-304.

50. Max HERZ, "Die arabischen Denkmale Ägyptens und das Komitee zu deren Erhaltung", Kunstchronik, N.F. [=New Series] 3 (1891-1892), no. 10, 31 December, col. 177-180.

51. Max HERZ, op. cit. (note 20), p. 210-215, esp. 210-211. For the convenience of the reader the amounts are given in crowns, the official currency of the Austro-Hungarian Empire at the time, but the exchange rate Herz applied can be calculated on the basis of data given on p. 214 .

52. István ORMOS, op. cit. (note 2), p. 450.

53. Cf. MaX HERZ, op. cit., (note 13), p. 54-58. IDEM, Catalogue raisonné des monuments exposés dans le Musée national de l'art arabe, [2 ${ }^{\text {nd }}$ ed.], Cairo: IFAO, 1906, p. 148.

54. Max HERZ, “Arab diszítmények I-VI [Arab ornaments I-VI]”, Művészi Ipar [Applied Art], no. 2 , 1887, p. 24-28, 98-100, 196-203; 3, 1888, 56-60; 4, 1889, 17-23; 5, 1890, 156-163. Cf. István ORMOS, op. cit. (note 2), 272, n. 665, 668; 278, n. 688; 305-306, fig. 199-206; 309, fig. 215; 310-311, fig. 217, 219-221.

55. Cf. "Polychromy (Architecture)", in Jane TURNER (ed.), The Dictionary of Art, London; New York: Grove, 1996, vol. 25, p. 171-174.

56. MaX HERZ, "La polychromie dans la peinture et l'architecture arabes en Égypte", Bulletin de l'Institut égyptien, $3^{\mathrm{e}}$ série (1893), no. 4, p. 49-58; $3^{\mathrm{e}}$ série (1894), no. 5, p. 387-392. Cf. István oRMOS, Max Herz Pasha..., op. cit. (note 2), p. 66-69.

57. Max HERZ, "Observations critiques sur les bassins dans les sahns des mosquées", Bulletin de l'Institut égyptien, $3^{\text {e }}$ série, 1896, nº 7, p. 47-51. 
58. István ORMOS, op. cit. (note 2), p. 121-122, 224-228. Cf. also Max HERZ, “Art arabe," inÉgypte, op. cit. (note 13), p. 164.

59. Abdallah KAHIL, op. cit. (note 17), p. 129.

60. Émile PRISSE D'AVENNES, L'Art arabe d'après les monuments du Kaire depuis le VII siècle jusqu'à la fin $d u X V_{I I I}{ }^{e}$, Paris: J. Savoy \& C Cie, 1877 , p. 200 [Text volume]. Max HERZ, op. cit. (note 13), p. 50-51. IDEM, op. cit. (note 52), p. 49. IDEM, op. cit. (note 34), p. 22-23. IDEM, Catalogue of the National Museum of Arab Art [Arab Museum], Stanley LANE-POole (ed.), London: Gilbert \& Rivington and Bernard Quaritch, 1896, vol. 12, n. 1. Julius FRANZ PASCHA, Kairo, Leipzig: E. A. Seemann, 1903, p. 76-77 (Berühmte Kunststatten, 21). See the vessel at right bottom, fig. 2 above. To date, the exact function of these vessels has not yet been clarified.

61. 'Abd al-Latif AL-BAGHDADI, The eastern key. Kitab al-ifadah wa'l-i'tibar, trans. Kamal Hafuth Zand, ed. John A. Videan, Ivy E. Videan, London: G. Allen \& Unwin, 1965, p. 183.

62. Edward William LANE, An account of the manners and the customs of the modern Egyptians. The definitive 1860 edition, Jason thOMPSON (dir.),Cairo: The American University in Cairo Press, 2003, p. 337.

63. István ORMOS, op. cit. (note 2), p. 122.

64. Ibid., p. 138, 224-225. Cf. also Julius FRANZ-PASCHA, op. cit.(note 23), p. 126.

65. Max HERz, "La protection de l'architecture arabe", Bulletin de l'Institut égyptien, $3^{\mathrm{e}}$ série (1898), $\mathrm{n}^{\circ}$ 9, p. 137-141. Cf. István ORMOS, op. cit. (note 2), p. 389-390, 412-416.

66. Pierre NORA, "Between memory and history: Les lieux de mémoire," trans. Marc Roudebush, in Special issue: Memory and counter-memory, Natalie ZEMON DAVIS, Randolph STARN (eds.), Representations, no.26, Spring 1989, p. 18-19. On the exact meaning of the term lieu de mémoire, see ibid., p. 25.

67. On Nuremberg, see Ludwig GROTE, Die romantische Entdeckung Nürnbergs, München: Prestel, 1967. Michael BRIX, Nürnberg und Lübeck im 19. Jahrhundert. Denkmalpflege, Stadtbildpflege, Stadtumbau München: Prestel, 1981, p. 89-106, 127-140.

68. Max HERZ, Die Baugruppe, op. cit. (note 37).

69. On the genesis of this monograph, see István ORMOS, op. cit. (note 2), p. 260, 486, 488.

70. K. A. Cameron CRESWELL, The Muslim architecture..., op. cit. (note 35), vol. 2, p. 190-212. Michael MEINECKE, op. cit. (note 39), vol. 1, p. 44-46. Wolfgang MAYER, "Feldstudien am Maristan des Sultans al-Mansur Qala'un in Kairo", Mitteilungen des Deutschen Archaologischen Instituts, Abteilung Kairo, no. 59, 2003, p. 289-304, pl. 49-51.

71. István ORMOS, op. cit. (note 2), p. 488.

72. Ibid., p. 359-364.

\section{AUTHOR}

\section{ISTVÁN ORMOS}

Professor, Eötvös Loránd University, Budapest ; spécialiste de l'œuvre de Max Herz Pacha. 


\title{
« Mudéjar » et identité nationale en Espagne au XIX siècle
}

\author{
Antonio Urquízar Herrera
}

1 Mudéjar a été et est encore un mot d'usage courant en espagnol. Le Tesoro de la lengua castellana de Sebastián de Covarrubias définissait en 1611 les Mudéjars comme «des Maures vassaux des chrétiens $»^{1}$. Le terme qui provenait de l'Arabe mudayyan, soulignait l'état de soumission et de tributaires. Les éditions actuelles du dictionnaire de la langue espagnole de la Real Academia prennent encore cette acception, étant mudéjar ce «musulman qui payait un tribut pour pouvoir vivre au milieu des vainqueurs chrétiens sans abandonner sa religion, en échange d'un tribut ». Cependant, un second sens a été ajouté à la première signification. Pour l'Académie, l'adjectif «mudéjar » qualifie le «style architectonique qui a fleuri en Espagne du XIII ${ }^{\mathrm{e}}$ siècle au $\mathrm{XVI}^{\mathrm{e}}$, style caractérisé par la conservation d'éléments de l'art chrétien et l'emploi de l'ornementation arabe $»^{2}$. Ce second sens correspond à la définition artistique proposée par José Amador de los Ríos en 1859.

2 Malgré la clarté du dictionnaire, la dénomination mudéjar entraîna un débat virulent dans le cadre de la critique historiographique espagnole pendant les cent cinquante ans d'existence de cette nouvelle acception.

Le débat prit en compte divers aspects :

- la discussion de la légitimité du concept comme catégorie stylistique,

- sa relation avec d'autres termes voisins du répertoire historico-artistique,

- la définition de ses caractéristiques formelles, matérielles, structurelles

- ou conceptuelles,

- la précision de sa filiation chrétienne ou musulmane,

- la proposition continuelle de nouveaux critères pour sa définition et son analyse.

4 Ces dernières années, l'histoire du terme et ses déplacements de sens en qualité d'«étiquette stylistique» ont été analysés dans quelques études ${ }^{3}$. Notre propos est 
d'approfondir la caractérisation politique et identitaire du terme chez José Amador de los Ríos et dans le débat qu'a engendré sa proposition.

5 Le sens artistique du mudéjar, comme on le trouve aujourd'hui dans le dictionnaire, pourrait être un terme banal du point de vue idéologique, puisque sa définition apparaît comme produite par la simple description d'un processus architectonique formel. Cependant, une analyse attentive des conditions de sa formulation originale montre que sa conception est née de la volonté d'une affirmation identitaire. La charge sémantique à caractère politique, social et culturel que revêtait le mot au départ, s'est maintenue en générant la nouvelle signification.

6 À partir de là, on a effectué une analyse idéologique de la genèse du terme mudéjar dans les premiers discours théoriques ${ }^{4}$. Il devient nécessaire d'examiner les composants idéologiques de cette récupération du Moyen Âge, en complément de la caractérisation générale du mudéjar comme une étiquette essayant de replacer l'histoire de l'art national dans une optique nationaliste et romantique. Cette analyse doit prendre place dans le cadre du débat historiographique et politique contemporain sur l'interprétation du passé islamique, ainsi que dans sa relation avec la construction de l'identité nationale espagnole. L'imprécision stylistique du terme chez Amador de los Ríos partiellement responsable de la virulence du débat postérieur - peut être replacée pour centrer le mudéjar dans le contexte d'un récit identitaire. Les pages suivantes essaieront d'analyser son discours et de proposer des réponses.

\section{Amador de los Ríos et El estilo mudéjar en arquitectura}

7 L'intérêt pour l'architecture médiévale avait favorisé l'élan historiciste du $\mathrm{xx}^{\mathrm{e}}$ siècle et la critique espagnole avait parlé des édifices visigóticos, románicos, bizantinos, árabes et ojivales. Ces adjectifs mêlaient des caractéristiques de nature culturelle et politique avec d'autres liées à l'analyse structurale des constructions. Ainsi, le terme arquitectura mozárabe avait obtenu un certain succès pour désigner les églises chrétiennes érigées en terres islamiques (conformément à l'acception historique du terme) et des édifices élevés par des musulmans soumis aux chrétiens (Mudéjars)5. Mudéjar était ainsi un mot d'usage courant dans l'historiographie politique et sociale du Moyen Âge espagnol.

8 Dans ce contexte intellectuel, il ne semble pas étrange que le déplacement du terme vers sa nouvelle signification artistique avait eu lieu lors d'un processus rapide et relativement raisonné. Sa première utilisation serait apparue dans le discours d'entrée à l'Académie des beaux-arts de San Fernando que José Amador de los Ríos avait lu le 19 juin 1859 , et qui portait le titre "El estilo mudéjar en arquitectura $»^{6}$ (fig. 1-2). Le texte contenait l'intention explicite d'imposer le concept et d'en promouvoir l'usage dans les lieux qui centralisaient la recherche en histoire de l'art en Espagne à cette époque. 
1. D. Martínez, portrait de José Amador de los Ríos, 1875.

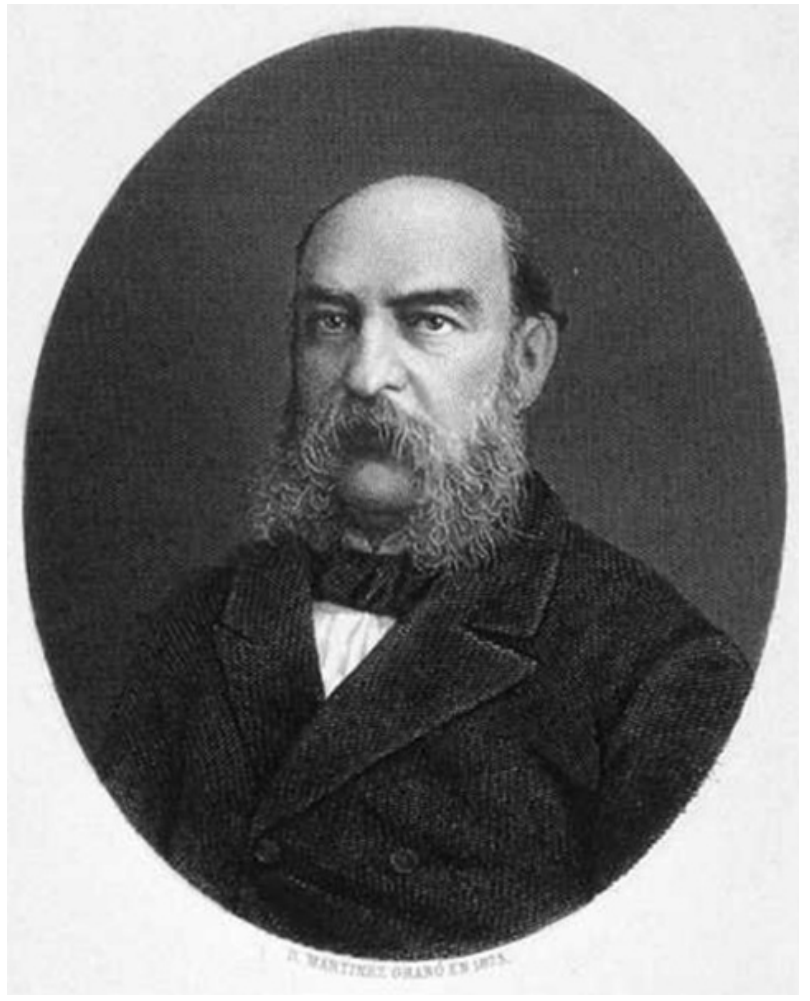

Source : Collection de l'auteur.

2. Page de titre du discours d'Amador de los Ríos à l'Académie sur le mudéjar.

\section{DISCURSOS}

REAL AGADEMII DE NOBLES ARTES

DE SAN FERNANDO,

EN LA RECEPGION PĹBLICA

DON JOSÉ AMADOR DE LOS RIOS.

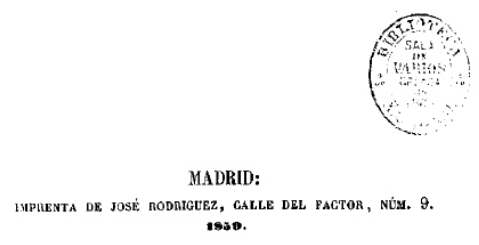

Source : Collection de l'auteur. 
Curieusement, Amador de los Ríos ne donna pas de définition précise des caractéristiques formelles du mudéjar architectonique, ni une argumentation théorique de sa catégorisation comme style. Au contraire, il disait « permettez que je ne m'arrête pas pour fixer minutieusement ses caractères [du style mudéjar], quand ils ne peuvent être ignorés par aucun de vous ${ }^{7}$. Cette absence d'intérêt pour la description physique des bâtiments est significative. Son discours recourait surtout à une caractérisation historique et culturelle du mudéjar, à partir de laquelle il analysait certaines constructions qui, selon lui, avaient été édifiées par des alarifes Mudéjars pour des seigneurs chrétiens. Ainsi, Amador commençait sa dissertation en se plaçant dans l'imbrication entre art et civilisation, pour présenter le mudéjar comme le « lignage de l'architecture » chrétienne qui rendait mieux l'esprit espagnol du Moyen Âge ${ }^{8}$. Après avoir exposé dans la première moitié du texte les relations politiques, sociales et culturelles entre chrétiens et musulmans, il commentait (de manière plus culturelle qu'esthétique) quelques édifices qui définissaient le style, comme les synagogues del Tránsito (fig. 3) et de Santa María la Blanca de Tolède, l'alcázar de Ségovie, le palais des Mendoza à Guadalajara (fig.4), et celui des Ayala de Tolède. On peut comprendre sa notion esthétique du mudéjar comme une combinaison de structures chrétiennes et d'ornements islamiques : une sorte de passerelle entre les deux religions. L'architecture était pour lui un territoire d'hybridation comme la littérature. Par exemple, la combinaison d'une structure chrétienne avec des arcs islamiques dans l'église Santiago del Arrabal de Tolède (fig. 5) était pour lui à mettre en relation avec les prédications évangélisatrices de San Vicente Ferrer dans la chaire?.

\section{Synagogue de Santa María del Tránsito à Tolède.}

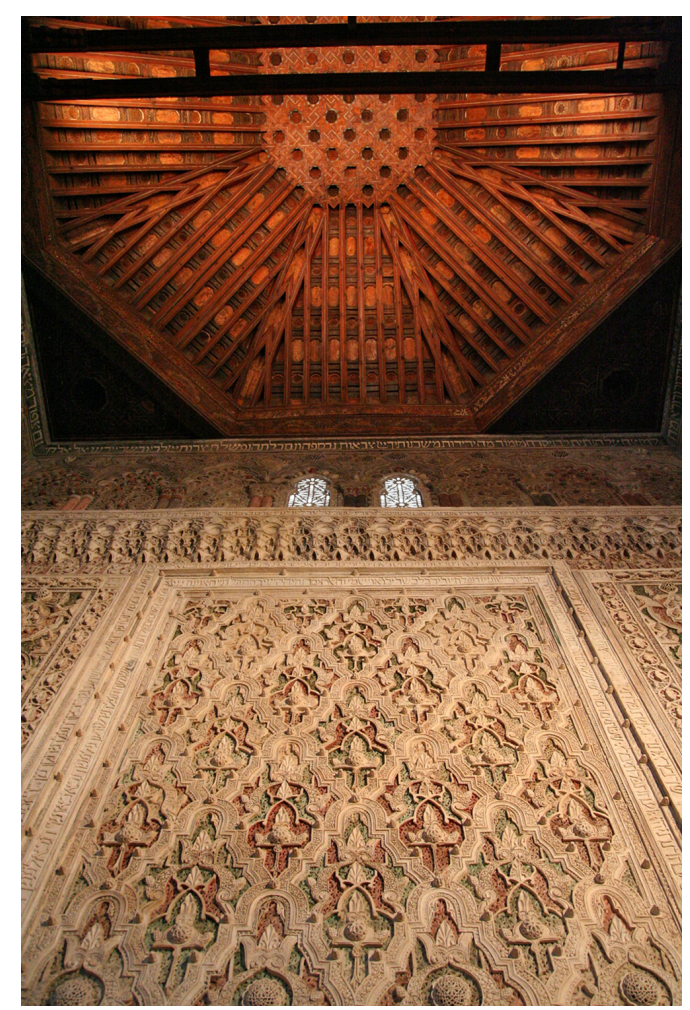

Source : Collection de l'auteur. 
4. Gustave Doré, Vue du patio du palais des ducs de l'Infantado à Guadalajara.

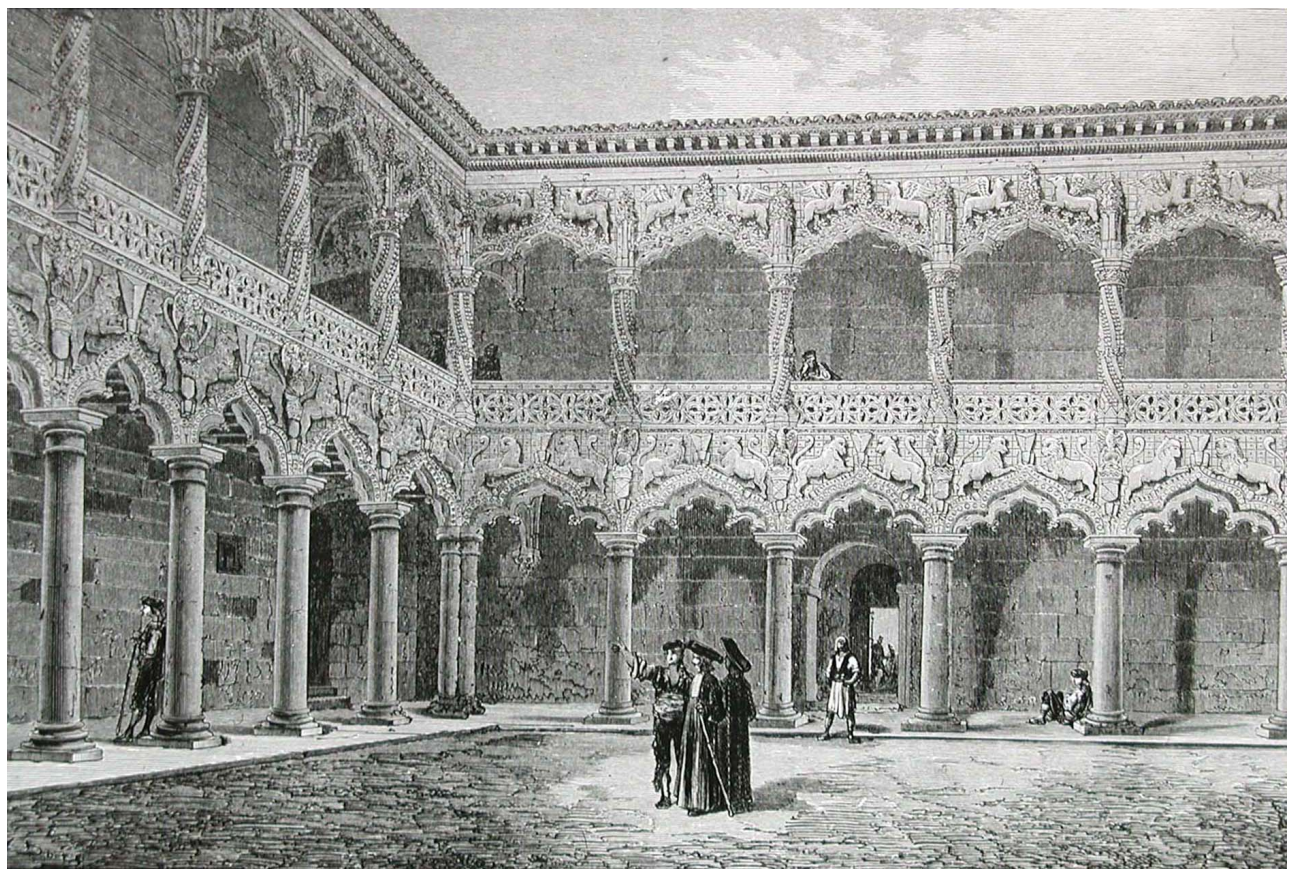

Source : Collection de l'auteur.

\section{5. Église de Santiago del Arrabal à Tolède.}

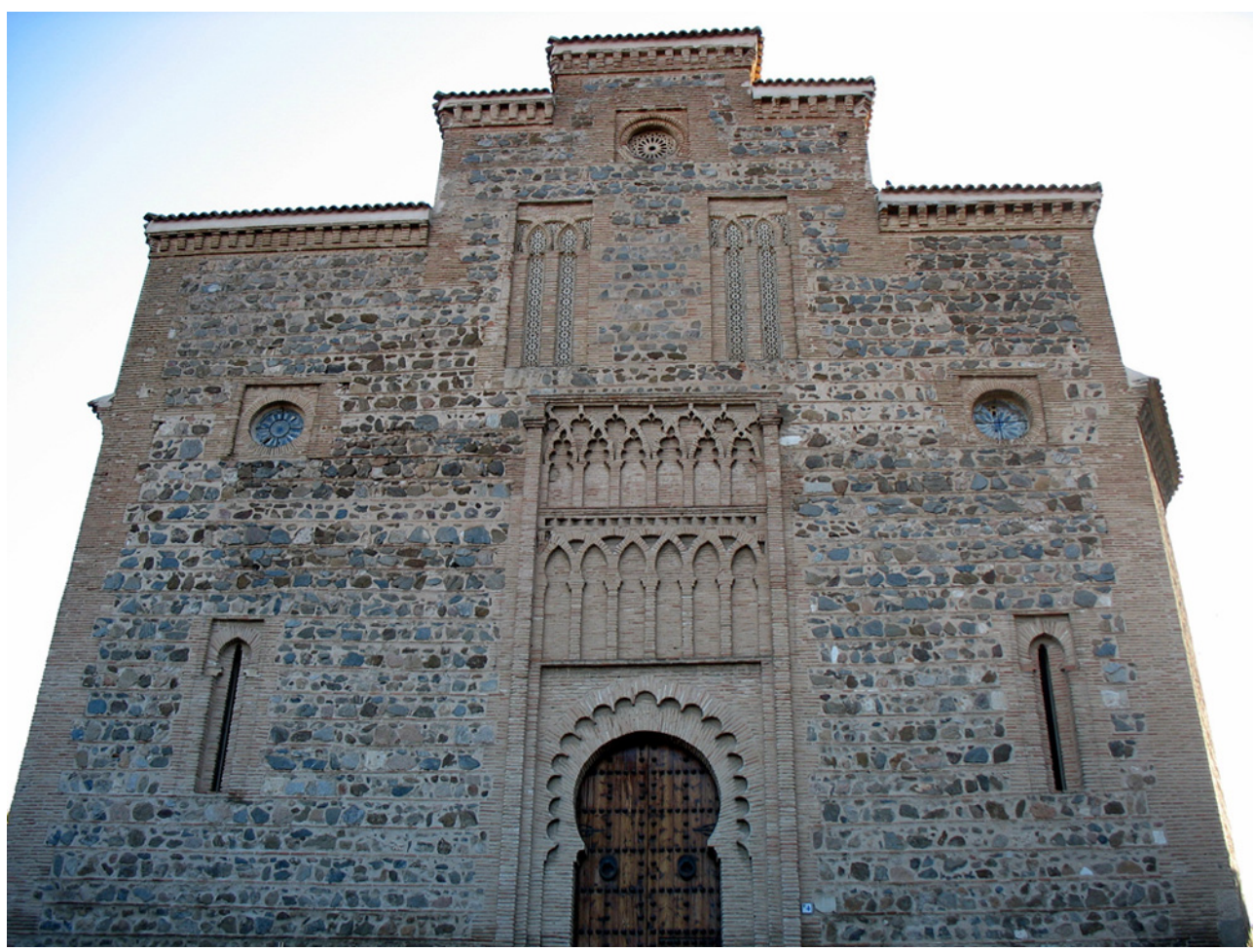

Source : Collection de l'auteur

10 Le concept fut repris de manière extraordinairement rapide. Quand Pedro de Madrazo critiquait ce terme en 1888 , à cette date " mudéjar » était déjà un mot à la mode chez les amateurs de la haute société ${ }^{10}$. Ce n'est pas étonnant car, pendant les trente années 
précédentes, il avait été fréquemment usité dans la presse généraliste ${ }^{11}$. Presque tous les journaux l'avaient repris avec enthousiasme pour les descriptions de monuments. Moins de dix ans après sa venue, il apparaissait déjà dans un cahier populaire de dessin ${ }^{12}$. Il fut aussi utilisé pour de nombreux travaux archéologiques ${ }^{13}$.

La position politique et académique d'Amador de los Ríos permit une institutionnalisation rapide du concept. C'est ainsi que le nouveau Museo Arqueológico Nacional posséda, depuis sa fondation en 1867 sous la direction d'Amador, une salle de "Arte hispano-mahometano y de estilo mudéjar» - remarquez l'insistance dans le mot " estilo ». Dans la description de son programme muséographique, Amador déclarait que le mudéjar, « unique et caractéristique de notre Espagne », ferait que le musée resterait sans «égal et [sans] rival $»^{14}$. Les programmes officiels des concours du corps de technicien de musées commencèrent à inclure une épreuve sur le mudéjar dans l'histoire de l'art espagnol ${ }^{15}$.

12 Cette première conceptualisation $d u$ nouvel usage du terme eut des origines historiques, en laissant de côté la variété des édifices. Ceci eut des conséquences importantes dans le débat technique sur la pertinence de son utilisation scientifique, ainsi que dans les implications identitaires de son emploi.

13 En premier lieu, cela créa un intéressant débat sur la pertinence de l'usage du terme à des fins de catégorisation stylistique ${ }^{16}$. Le sujet devint polémique dans la presse culturelle. Pendant les années 1860, 1870 et même 1880, nombre d'articles de fond prenaient parti en faveur ou contre le mudéjar comment «style » artistique ${ }^{17}$. Manuel de Assas reconnaissait qu'on pouvait parler d'une "arquitectura mudéjar», mais non d'un "estilo [un soi-disant goût] mudéjar », puisque les éléments architecturaux de ces édifices appartenaient à l'art musulman ${ }^{18}$. En 1862, dans le premier numéro de la revue El Arte en España, Fernández Giménez, utilisant les arguments historicistes d'Amador, promouvait l'emploi de la nouvelle étiquette «arquitectura cristiano-mahometana » qui englobait l'architecture des Mudéjars et des Mozarabes ${ }^{19}$ (fig. 6). 
6. Page de titre de l'article de Fernández Giménez « De la Arquitectura cristiano-mahometana », paru en 1862.

DE LA ARQUITECTURA

CRISTIANO-MAHOMETANA.

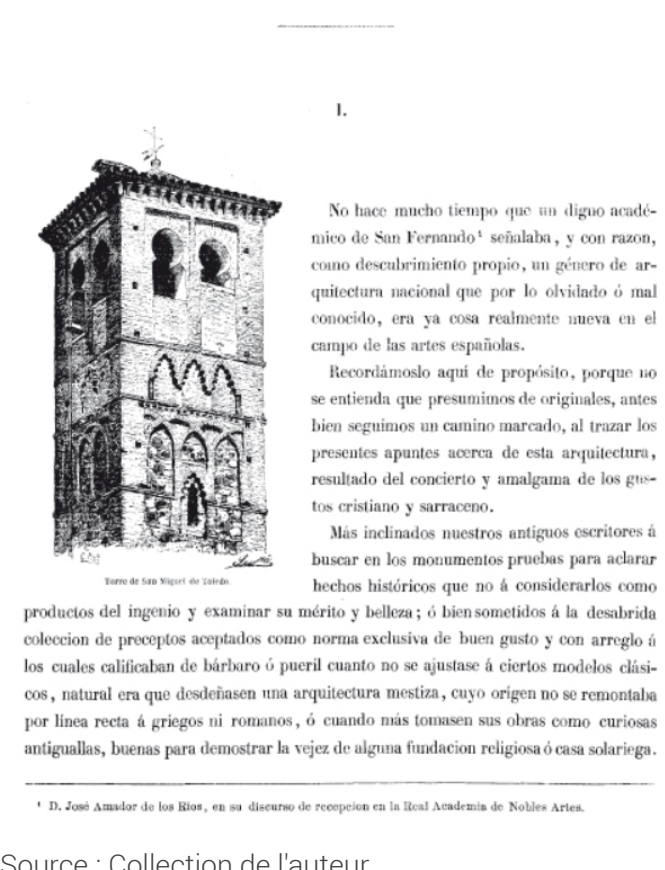

Le meilleur exemple des limites du cadre général qu'Amador avait fixé se trouve dans la réception du terme par Pedro de Madrazo. Ce dernier était l'académicien chargé de répondre à son discours de 1859 et, sans montrer trop d'enthousiasme pour le terme, il déclara que le concept était une "dénomination nouvelle mais plus rationnelle et philosophique, qui dépassait le terme 'mozárabe' par sa plus grande rigueur historique $»^{20}$. Cependant trente ans plus tard, Madrazo abandonnait Amador et insistait sur la totale inadéquation du terme pour nommer un style artistique : « on ne doit pas l'employer dans le domaine de l'art comme déterminant un style unique et particulier », ou " dire un style mudéjar, c'est ne rien dire de défini ». Alors qu'en 1859, il avait jugé selon les arguments historicistes d'Amador, en 1888, il analysait l'utilité du concept comme catégorie esthétique: «le qualificatif de mudéjar n'identifie pas un style spécifique, parce que l'un serait le mudéjar du Tolède, un autre le mudéjar cordouan ou sévillan, un autre le mudéjar aragonais, le dernier de Grenade, etc. ${ }^{21}$. Madrazo, parmi d'autres auteurs, soulignait le problème : la création historique par les Mudéjars ne correspondait pas aux aspects formels qui devaient définir un style, comme on le supposait alors. La question n'était pas banale. Deux ans auparavant, Rodrigo Amador de los Ríos, le fils de José, avait rédigé une longue série d'articles dans la revue La Ilustración española y americana pour définir précisément la nature du style mudéjar, sans toutefois apporter de nouveaux arguments au discours de son père ${ }^{22}$. Cependant, pour Madrazo, les constructions qualifiées de «mudéjar» étaient extrêmement variées d'un point de vue formel ${ }^{23}$. Madrazo $^{24}$ avait eu raison de souligner la contradiction entre la volonté d'Amador de placer le mudéjar dans la lignée architectonique chrétienne et la profonde imbrication de ses formes dans les variantes 
de l'art islamique péninsulaire. De même, ses doutes sur la nécessaire identification de formes décoratives mudéjares et l'intervention d'alarifes mudéjars se révélèrent adroites $^{25}$. Par exemple, nous savons que l'architecture des palais mudéjars n'est pas le résultat de l'hybridation sociale, mais de l'imitation de modèles prestigieux. On peut supposer que le style mudéjar d'Amador de los Ríos aurait pu exister sans population mudéjar ${ }^{26}$.

Les préventions de Madrazo furent reprises dans le débat terminologique sur le mudéjar qui continua durant la seconde moitié $d u x^{e}$ siècle ${ }^{27}$. Sa volonté de définir «les objets d'art par leur style, soit pur, soit bâtard, et non par la condition de l'artisan " s'est révélée vaine à court terme ${ }^{28}$. Dans son Historia de la arquitectura cristiana española en la Edad Media (1908), Vicente Lampérez supposait que, style ou non, "l'architecture mudéjar est faite pour les chrétiens et mêlait des éléments des arts mahométan et chrétien, à des doses plus ou moins fortes. C'est une œuvre de Maures mis au service des conquérants et, dans bien des cas, c'est aussi l'œuvre des uns enseignée par les autres ${ }^{29}$. La proposition d'Amador de los Ríos restait figée sur une définition concrète qu'il n'avait pas explicitée. Elle prenait la suite de son modèle fondé sur l'hybridation culturelle et la condition des artisans. La référence fondamentale pour les études médiévales de la première moitié $\mathrm{du} \mathrm{xx}^{\mathrm{e}}$ siècle était Lampérez, si bien que le concept servait encore de point de départ à de nombreux travaux, et de référence théorique pour l'architecture de l'époque. Des années plus tard, on s'est aperçu qu'une grande partie de l'architecture mudéjar n'avait pas été bâtie par des Mudéjars, mais les implications culturelles, politiques et idéologiques provenant du terme social et historique se sont maintenues.

\section{Mudéjar et identité nationale}

Lampérez trouvait important de considérer l'art mudéjar comme « un art national $»^{30}$. Il pensait que la question de la dénomination était futile. D'après nous, en cela, il manqua son $b^{3}{ }^{31}$. Le choix du terme mudéjar avait une forte charge sémantique et idéologique. Le choix du mot s'insérait dans le mouvement de récupération de l'histoire islamique et juive qui existait alors dans la pensée espagnole. La caractérisation de l'art mudéjar ne pouvait être séparée ni de la redéfinition et de la revendication nationaliste des études des premiers arabistas du XIX ${ }^{e}$ siècle, ni de la création de la première chaire d'Arabe en 1843 attribuée à Pascual de Gayangos, ni des études littéraires et historiques d'Amador de los Ríos ${ }^{32}$.

Onze ans avant d'entrer à l'Académie de San Fernando avec son discours sur le mudéjar, Amador avait été admis à l'Académie d'histoire avec une autre étude intitulée Influence des Arabes dans les arts et littérature des Espagnols ${ }^{33}$. Ce texte n'incluait pas de discussions terminologiques et ne parlait pas spécifiquement des Mudéjars, mais l'intention de souligner l'apport islamique à l'identité espagnole était claire : "parce que l'histoire écrite jusqu'à nos jours est uniquement l'histoire imparfaite du peuple chrétien, sans que tous les efforts possibles n'aient toujours pas été faits pour reconnaître et pour apprécier l'influence que les Juifs et les Arabes ont exercée dans la civilisation espagnole $\aleph^{34}$. Comme cela a été souligné, la valeur politique de sa position fut reconnue. Le discours lui valut une décoration du gouvernement et quand il obtint la chaire de l'Université centrale, cela fut considéré comme justement méritée ${ }^{35}$. 
18 Alors que la création de ce vocable artistique par Amador de los Ríos était essentiellement nationaliste, la question terminologique était teintée d'idéologie. Les légers changements qu'Amador avait introduits, de 1859 et 1872, dans les différentes éditions de son discours renforçaient le contenu politique du mudéjar et son nationalisme. Au lieu de préciser les questions esthétiques pour définir le mudéjar comme style, Amador préféra insister sur les significations politiques et nationalistes du terme. Comme l'a marqué Philippe Araguas, ce n'est pas un hasard si, d'une version à l'autre, il passe $\mathrm{du}$ « grey [nation] castellana » au «grey [nation] española $»^{36}$. Un des nouveaux paragraphes insérés faisait ressortir l'importance du mudéjar pour souligner celle de quelques édifices qui «donnaient au monde l'idée de ce que l'Espagne du Moyen Âge, loin de s'endormir dans la barbarie et l'ignorance comme cela fut injustement prétendu, figurait devant les autres nations d'Occident comme maîtresse d'un art inégalé et capable de satisfaire brillamment les nécessités les plus nobles de la vie $»^{37}$. Amador pensait que la meilleure défense de son appellation était la mise en valeur de son potentiel politique. Si bien que la signification historique du terme et ses nouvelles connotations allaient déterminer une importante charge politique capable de diriger la lecture symbolique des édifices jusqu'à nos jours. Bien que ces dernières années se soit produite une révision du mudéjar et de sa présumée singularité espagnole, l'historiographie du $\mathrm{xx}^{\mathrm{e}}$ siècle a affirmé presque unanimement, et au-delà des différences politiques, que le mudéjar était le style national par excellence.

Un Mudéjar était un musulman qui vivait parmi les chrétiens. Ce caractère semblait fondamental pour Amador parce qu'il s'intéressait en premier lieu à l'hybridation. Sa pensée nationaliste et libérale essayait de passer outre plusieurs siècles de perception négative de l'héritage hispano-musulman pour proposer une construction plus complexe: la prééminence des valeurs chrétiennes ne devait plus être opposée à l'assimilation d'une coexistence passée qui pouvait avoir enrichi l'identité espagnole. Le terme mudéjar doit être mis en relation avec le débat contemporain sur l'interprétation des relations entre les musulmans et les chrétiens de l'Espagne médiévale. Depuis l'Historia de la dominación de los árabes en España de José Antonio Conde (1820-1821, réédité en 1844), le nouveau lieu commun de la tolérance était à l'ordre du jour de l'historiographie nationaliste libérale. En 1866, l'Estado social y político de los mudéjares de Castilla de Francisco Fernández y González défendait l'hybridation culturelle avec un discours historiciste et culturel qui reprenait également le terme d'Amador. Les «fábricas mudéjares» restaient placées dans le contexte des apports de l'Islam à la nation espagnole ${ }^{38}$. Pour Amador de los Ríos, la littérature médiévale espagnole pouvait avoir produit une "fusion transcendante des caractères de l'Orient et de l'Occident, [qui] trouvait une réalisation analogue dans les sphères des arts dans le mélange annoncé de l'architecture chrétienne et de l'arabe, destiné à briller dans les siècles futurs avec une floraison croissante $»^{39}$. Dans son discours d'entrée à l'Académie, comme dans ses travaux historiques postérieurs, Amador défendait la (aujourd'hui déjà mythique) tolérance des rois médiévaux en opposition à la dureté de l'expulsion des Juifs et des Morisques à la Renaissance ${ }^{40}$.

20 Mais un Mudéjar était fondamentalement un musulman soumis aux chrétiens vainqueurs. Cette hybridation subodorée par Amador ne laissait aucun doute sur le binôme essentiel de cette identité. L'hybridation existait depuis le triomphe du christianisme. Quand Amador traça les bases historiques du mudéjar architectonique, il commença par déclarer que l'échec des Wisigoths à Guadalete était un «ignominieux 
désastre $\aleph^{41}$. En revanche, l'évocation de la Reconquista lui permettait de s'exclamer : «Le spectacle merveilleux offert en ces jours par la civilisation espagnole !42 " À son avis, le style mudéjar débuta «quand l'épée victorieuse de Ferdinand III (1199-1252) arracha à la religion mahométane l'ancienne ville de Médina Andalus [Cordoue] et plus tard Séville ${ }^{43}$. La Reconquista était une justification traditionnelle qui évacuait sept cents ans de vie commune pour établir l'identité catholique. L'hybridation apparaît comme le fruit de la clémence des rois chrétiens victorieux qui, dès Alphonse $\mathrm{X}$ (1221-1284), se montraient supérieurs par leur plus grande tolérance envers les Mudéjars $^{44}$. Dans un autre texte d'Amador, daté de 1873, l'architecture mudéjar était une œuvre "née de la tolérance et de la supériorité de la civilisation espagnole sur l'islam $»^{45}$. Fernández y González partageait une vision similaire de cette tolérance. Quand Pedro de Madrazo demandait à Amador "comment l'art des Maures est-il devenu la forme préférée des bâtisseurs, principalement civils, des magnats castillans après que furent vaincues Cordoue et Séville par Ferdinand le Saint ? ${ }^{46}$, il supposait que cette adoption des ornements exotiques pouvait seulement avoir été effectuée d'après une conception subordonnée de ces formes. Comme les Mudéjars, l'architecture mudéjar était tributaire des chrétiens. Pour Amador, la comparaison entre l'architecture de Grenade et le mudéjar des chrétiens andalous montrait que " les deux partaient de sources analogues et les deux conservaient le ton de la même idée originelle, tandis que le peuple de Mahomet, vaincu partout et partout poursuivi, apportait son savoir et son opulence aux contrées de Grenade, en les ornant sous le règne des Nazeritas de monuments merveilleux, où l'art parvient à obtenir la haute récompense de l'originalité [...] dans les domaines castillans [cet art] se soumettait à de nouvelles lois, en perdant une grande partie de sa fraîcheur originelle et de son courage $»^{47}$.

21 Ce déplacement terminologique, établi par Amador de los Ríos, de l'«architecture mozarabe » vers l'« architecture mudéjar » répondait sans doute à la stricte précision archéologique, mais il laissait entrevoir la symbolique, fondamentale pour cet auteur. Jusqu'à un certain point, l'existence d'un style mudéjar lié à l'art chrétien permettait de rendre visible la splendeur culturelle produite par l'hybridation, comme la grandeur des vainqueurs qui avaient accueilli les manifestations les plus brillantes de la civilisation vaincue. "Tout a changé d'apparence, quand les régions populeuses et riches qui s'étendent des gorges de Muradal à la mer de Cádiz sont tombées sous la domination castillane ", écrivait-il ${ }^{18}$. Bien qu'Amador ne l'eût pas expliqué directement, la nature du mudéjar architectonique et sociale restait caractérisée par sa contribution à la magnificence de l'Espagne chrétienne. Pour Amador, le mudéjar est national parce qu'il présente "à la critique une de phases les plus intéressantes de la civilisation espagnole » et par conséquent le mudéjar concerne le passé propre à l'Espagne ${ }^{49}$. La Reconquista et le Moyen Âge sont, d'après lui, les moments constitutifs de l'Espagne. Mais l'art mudéjar est aussi national parce qu'il signifie l'appropriation identitaire d'un passé musulman qui avait été (re)présenté, depuis le Moyen Âge sous le signe de l'altérité. Avec le mudéjar, Amador de los Ríos expliquait qu'après avoir opposé les Alcazars de Séville à l'Alhambra de Grenade, «cet art était déjà passé au domaine chrétiens, et [...] les croyances, les sentiments et les coutumes de ces derniers avaient substantiellement modifié sa nature $»^{50}$. Rodrigo Amador de los Ríos avait hérité de son père l'intérêt pour le concept de mudéjar, et aussi la direction de la salle dédiée à ce «style » dans le Museo Arqueológico Nacional. Ils étaient tellement persuadés de la réalité de ce déplacement culturel que, peut-être parce que le mudéjar se trouvait dans 
le musée situé à côté de l'art "hispanomahometano", Rodrigo le commentait ainsi : " le style mudéjar, comme manifestation très singulière de l'art chrétien, naît et vit, se développe et meurt, dans la culture proprement chrétienne de la Péninsule, sous la protection et au service de la chrétienté $»^{51}$. Dans un écrit similaire, Rodrigo Amador répétait que le mudéjar était chrétien "en étant une expression authentique de la vitalité des peuples et interprète fidèle de leurs croyances, aspirations et sentiments »; si cela n'était pas reconnu, c'était pour avoir posé «le regard dans l'accidentel et changeant $\aleph^{52}$. Dans cette image platonicienne, on doit supposer que l'«accidentel et changeant " seraient les formes qui liaient mudéjar et art islamique. Cette vision du mudéjar comme christianisation du passé musulman est une notion de base de la conceptualisation du mudéjar depuis Amador de los Ríos. C'est aussi la raison des problèmes liés à ce terme. En général, la révision du passé islamique a été (et est encore) une question controversée de l'historiographie espagnole. Dans ce contexte, l'interprétation du legs monumental musulman a été une source continuelle de conflit dans le processus de construction de l'identité nationale. Une partie de la tradition littéraire antérieure à Amador de los Ríos avait non seulement méprisé l'art médiéval, mais avait dénigré l'architecture islamique. Comme cela a été noté ailleurs, la pensée historiographique espagnole des $\mathrm{XVI}^{\mathrm{e}}$, $\mathrm{XVII}^{\mathrm{e}}$ et (partiellement) $\mathrm{xVIII}{ }^{\mathrm{e}}$ siècles avait tenté de minimiser l'impact du patrimoine islamique dans les lieux de mémoire nationaux et locaux ${ }^{53}$. Pour cela, les textes ont privilégié la narration de la conquête ou ont modifié l'interprétation par des appropriations narratives qui proposaient des origines romaines ou chrétiennes aux édifices. L'ouverture idéologique des Lumières et la découverte romantique de l'exotisme islamique ont changé la perception de ce patrimoine, le rendant attractif ${ }^{54}$. Cette revalorisation a certainement infléchi le regard des Espagnols sur l'art islamique national, mais sans résoudre les problèmes de symbolique. Le cadre d'une identité traditionnellement construite dans le contexte de l'assimilation entre catholicisme et nation était trop pesant - et l'est encore pour certains. Au-delà de l'historiographie, cette perception idéologique du mudéjar apparaît clairement dans les déplacements que l'architecture historiciste de la fin du $\mathrm{XIX}^{\mathrm{e}}$ siècle et $\mathrm{du}$ début $\mathrm{du} \mathrm{Xx}^{\mathrm{e}}$ a réalisés dans les divers revivals éclectiques ${ }^{55}$. À une époque où le neoplateresco pouvait représenter l'Espagne impériale de l'empereur Charles $\mathrm{V}$, le neomudéjar apparaissait logiquement comme un style plus national que l'exotique neoislámico ${ }^{56}$. Le mudéjar d'Amador de los Ríos offrait un moyen pour assumer le legs esthétique islamique sans renoncer à une identité chrétienne forte ${ }^{57}$. Ainsi, l'érection de quelques gares neomudéjars mettait en relief que le choix du style en faisait des "témoignages des traditions et du goût du pays " ${ }^{58}$. De même, un architecte qui choisissait ce style pour une église aurait eu "l'idée opportune de la construire en style mudéjar, éminemment espagnol, et qui rappelle la foi de nos ancêtres, jamais modérée pendant les siècles de la domination islamique ${ }^{59}$. Dans ce panorama, une grande partie du succès postérieur de la formule a sans doute découlé de la continuité de l'intérêt nationaliste pour l'histoire islamique de l'Espagne au $\mathrm{xx}^{\mathrm{e}}$ siècle ${ }^{60}$. D'une part, les idées de prééminence chrétienne et l'exaltation nationale qu' Amador avait placées dans le mudéjar servirent à nourrir des positions idéologiques ultraconservatrices. Ainsi, la revue réactionnaire Acción Española pouvait publier des textes de Benito Mussolini sur le fascisme avec des descriptions d'architectures de style mudéjar dans la même livraison, ou éditer un article de l'archevêque Gomá où le mudéjar était présenté comme l'un des grands apports nationaux à la colonisation de l'Amérique ${ }^{61}$. D'autre part, le terme nourrissait également l'historiographie 
progressiste. La composante libérale de récupération du passé islamique qui avait soutenu le mudéjar d'Amador pouvait aussi servir de modèle aux visions critiques de l'Espagne des rois catholiques et de la contre-réforme ${ }^{62}$.

\section{NOTES}

1. Sebastián de covarRubias OROzco, Parte segunda del tesoro de la lengua castellana; o española, Madrid : Melchor Sánchez, 1673, fol. 117r.

2. URL: http://lema.rae.es/drae/. Consulté le 16 novembre 2015.

3. Voir Maria Carmen fRAGA GONZÁLEZ, Arquitectura mudéjar en la Baja Andalucía, Santa Cruz de Tenerife : Gráficas Tenerife, 1977 ; Gonzalo BORRÁs, El arte mudéjar, Teruel : Instituto de Estudios Turolenses, 1990, p. 26 sq.; V. B. MANN, T. GLICK, J. D. DODDs (dirs.), Convivencia : Jews, Muslims and Christians in Medieval Spain, catalogue d'exposition, New York: Jewish Museum, 1992 ; Ana R. PACIOS LOZANO, Bibliografía de arquitectura y techumbres mudéjares 1857-1991, Teruel, 1993 ; Ana R. pacios lozano, Bibliografía de arte mudéjar. Addenda, [Teruel]: Instituto de Estudios Turolenses, Excma. Diputación Provincial de Teruel ; [Zaragoza?]: Gobierno de Aragón, Departamento de Cultura y Educación, 1993 (Estudios mudéjares); Rafael LóPEZ GUZMÁN, Arquitectura mudéjar, Madrid: Cátedra, 2000, et Juan Carlos RUIZ SOUZA, "Le "style mudéjar" en architecture cent cinquante ans après ", Perspective, 2009, n 2, p. 277-286. URL: https://perspective.revues.org/ 1384. Consulté le 16 novembre 2015.

4. Voir Rafael LóPEZ GUZMÁN, op. cit. (note 3), p. 23.

5. Selon Fernández Jiménez, Llaguno avait donné son aval au terme. José FERNÁNDEZ GIMÉNEZ, « De la arquitectura cristiano-mahometana », El Arte en España, t. I, 1862, p. 11-16.

6. Le discours fut édité une première fois (avec la réponse de Pedro de Madrazo) dans José AMADOR DE loS Ríos, Discursos leídos ante la Real Academia de Nobles Artes de San Fernando en la recepción pública de don José Amador de los Ríos, Madrid: Imprenta de José Rodríguez, 1859. Le discours fut réimprimé avec quelques changements dans José AMADOR DE LOS RíOS, Discursos leídos en las recepciones y actos públicos celebrados por la Real Academia de las Tres Nobles Artes de San Fernando desde 19 de Junio de 1859, Madrid : M. Tello, 1872. Une édition française (du texte de 1872) dans José AMADOR DE LOS RíOS (Pierre GUENOUN, éd.), El estilo mudéjar en arquitectura, Paris: Centre de recherches de l'Institut d'études hispaniques, 1965.

7. José AMADOR DE LOS RÍOS, op. cit. (note 6), 1859, p. 28.

8. "[...] los monumentos de las artes y las letras llevan impreso viva y profundamente el sello especial de las civilizaciones que los producen. Sus sentimientos, sus creencias, sus costumbres, su estado social y político, sus deseos y esperanzas, en el vario y contradictorio sentido de la vida, todo se halla revelado con sorprendente ingenuidad en las creaciones del arte, ora escriban el arquitecto y el estatuario en inmensas moles de piedra la historia de pueblos que ya no existen, ora confíen el pintor y el poeta a frágiles tablas e instables cantares los prodigiosos triunfos de sus héroes, la pacífica gloria de sus sabios, la justicia o la omnipotencia de sus monarcas. Ofrécenos la historia patria cabal comprobación de este principio trascendental de la crítica moderna, en cada una de sus páginas. Permitidme, no obstante, que fijándome por breves momentos en la grande Era de la Reconquista, período largo, difícil y glorioso, en que nace, se desarrolla y llega a colmada granazón el carácter nacional, ose señalaros entre todas las manifestaciones del arte cristiano cierto linaje de arquitectura, que reflejando de una manera inequívoca el estado 
intelectual de la grey española, desde mediados del siglo XII, es, en mi concepto, seguro comprobante de la verdad enunciada." José AMADOR DE LOS RÍOS, ibid., p. 6-7.

9. "Planta, distribución, proporciones, todo corresponde en el expresado templo [Santiago del Arrabal de Toledo] a las prescripciones del rito y de la liturgia, dando cumplida razón del estado de la cultura castellana : en cambio, arcos, ábsides, armaduras, portadas y torre seguían en sus formas la pauta de las construcciones mudéjares, estrechando los lazos que debían unir en las siguientes centurias los elementos de uno y otro arte. Prueba elocuentísima de esto ofrece en la misma iglesia el gracioso púlpito desde donde el ya citado San Vicente Ferrer evangelizó al pueblo toledano." José AMADOR DE LOS Ríos, ibid., p. 19.

10. Pedro de MADRAZO, "De los estilos en las artes ", La Ilustración española y americana, année 32, $\mathrm{n}^{\circ} 15,1888$, p. 262 sq.

11. Comme un exemple précoce entre plusieurs, voir La Correspondencia de España, 1040, 31 juillet 1861. Voir aussi les nombreux articles parus dans le journal El País dans la décennie 1880.

12. Voir « Tratado téorico y práctico de Dibujo con aplicación a las artes y a la industria de D. M. Borrel », La Ilustración española y americana, année 20, n 16, 1876, p. 295.

13. Quelques exemples intéressants, entre plusieurs: Eduardo de MARIÁTEGUI, «Arquitectura militar de la Edad Media en España ", El Arte en España, 1963, p. 142 (en parlant du mudéjar comme "estilo peculiar y exclusivo de nuestro suelo") ; Rafael conTRERAS, « Del arte árabe en España ", Revista de España, $\mathrm{n}^{\circ} 8,1868$, p. 513 et $\mathrm{n}^{\circ} 11,1869$, p. 111-125 (en soulignant que cette architecture mudéjar devait être source d'inspiration pour les architectes contemporains) et Francisco GINER, "Apuntes de un viaje a Portugal. », Revista de España, n 71, 1879, p. 307 et n 79, 1881, p. 350 (en commentant l'utilisation du mudéjar de Francisco Tubino pour décrire quelques peintures).

14. José AMADOR DE LOS RÍOS, «El Museo Arqueológico Nacional », Revista de España, n 4, 1868, p. 571-578.

15. Voir par exemple Anuario del cuerpo facultativo de Archiveros, Bibliotecarios y Anticuarios, 1881 (1882) et Gaceta de Instrucción Pública y Bellas Artes, 938, 1909.

16. Sur la première réception du concept, voir Maria Carmen FRAGA GONZÁLEZ, op. cit. (note 3).

17. «La cuestión de clasificar y denominar propiamente los estilos arquitectónicos, tornó a suscitarse en 1856 y 1857 en las reuniones celebradas por los Sres. D. Manuel Anibal Álvarez, D. Pedro de Madrazo, D. José Amador de los Ríos, D. Manuel de Assas, D. Enrique Ferrer, y no sabemos si alguien más, con el fin de trazar el plan general por el que había de publicarse la magnífica obra que lleva por título Monumentos arquitectónicos de España. En esas reuniones comenzaron las polémicas acerca del estilo artístico que D. José Amador calificó muy acertadamente de mudéjar, tesis sostenida luego y eruditamente apoyada por el mismo al tomar posesión de su plaza de número en la Academia de San Fernando en 1859, y que ha prevalecido. » José Ramón MÉLIDA, «La arqueología. Antecedentes históricos, concepto de la ciencia, método para su estudio », Revista de España, n 107, 1885, p. 66.

18. "Hay quien opina que los monumentos así construidos [por mudéjares] forman una clase que debe separarse de los tres gustos antes mencionados y que podría apellidarse mudéjar. Nosotros creemos que a tales construcciones, si con razón se las puede denominar mudéjares, no empero clasificarlas reuniéndolas en un gusto ; atendiendo a que las hay de dos gustos transitivo y andaluz ». Manuel de ASSAS, "Nociones fisionómico-históricas de la arquitectura en España. Artículo IX. Monumentos de estilo mahometano desde el siglo VIII al siglo XVI », Semanario Pintoresco Español, 8 novembre 1857, 45, p. 354. Étant donné que cet article est daté de 1857, un an avant le discours d'Amador de los Ríos, une polémique sur la paternité du vocable apparut. Aujourd'hui, il est reconnu que, bien que daté ultérieurement, le texte d'Assas était postérieur. Voir Gonzalo BORRÁs, op. cit. (note 3), p. 16.

19. José FERNÁNDEZ GIMÉNEZ, op. cit. (note 5), p. 11-16 et 21-23.

20. Réponse de Pedro de Madrazo dans José AMADOR DE LOS Ríos, op. cit. (note 6), p. 46.

21. "Comencemos por el mudejarismo. Ya aceptemos la traducción que de la palabra mudéjar nos da Mármol, el cual supone que se aplicaba como sinónimo de renegado al musulmán que hacía traición a su fe sometiéndose al yugo del conquistador cristiano ; ya admitamos la etimología de la Academia, según la cual 
mudéjar vale tanto como tributario, es lo cierto que, aun designando por extensión con este adjetivo todo lo perteneciente a los mudéjares, no cabe emplearlo en el terreno del arte como determinativo de un estilo único y peculiar. Es evidente que los constructores mudéjares que quedaron en Toledo, $y$ en algunas poblaciones de Castilla la Vieja sometidos al rey D. Alfonso en el siglo XI, no practicaban la misma arquitectura que los sometidos en Córdoba y Sevilla al rey D. Fernando el Santo en el siglo XIII, ni éstos usaban el estilo de los mudéjares granadinos obedientes a los Reyes Católicos en el siglo XV. [...] el calificativo de mudéjar no marca estilo determinado, porque uno sería el mudéjar toledano, otro el mudéjar cordobés o sevillano, otro el mudéjar aragonés, otro el granadino, etc." Pedro de MADRAzo, op. cit. (note 10), p. 262.

22. Rodrigo AMADOR DE LOS RÍOS, «El estilo mudéjar. Cartas al Sr. D. José Gestoso ». La Ilustración española y americana, année $29, \mathrm{n}^{\circ} 30$, p. 90 ; année $30,1886, \mathrm{n}^{\circ} 10$, p. 170 , et $\mathrm{n}^{\circ} 23$, p. 383-384.

23. Madrazo insistait encore dans un autre article de 1889 : "Que el estilo llamado mudéjar es en la mayor parte de los casos mauritano y morisco, y semejante denominación, mal que nos pese haber sido coautores de este calificativo, que hoy repudiamos por falso, no debe subsistir, porque los artífices mudéjares emplearon muchos estilos diferentes, y la calificación de mudéjar no determina nada fijo y característico. " Pedro de MADRAZO, «Penitencias. Errores biográficos », La Ilustración española y americana, année $33, \mathrm{n}^{\circ} 7$, février 1889 , p. 111.

24. Voir Gonzalo BORRÁs, op. cit. (note 3), p. 18.

25. Pedro de MADRAZo, op. cit. (note 10), p. 262 : «De otra parte, ¿tenemos por ventura la seguridad de que todo lo que se califica hoy de mudéjar es producto de manos mudéjares? ¿Acaso no adoptaron muchos alarifes cristianos el estilo de los arquitectos moros y moriscos que con ellos moraban?».

26. Si on accepte l'usage du terme mudéjar pour l'art américain, c'est sans doute le cas. Sur le style mudéjar et les Mudéjars, voir aussi Juan Carlos RuIz souzA, «Castilla y Al-Andalus. Arquitecturas aljamiadas y otros grados de asimilación ", Anuario del Departamento de Teoría e Historia del Arte, $\mathrm{n}^{\circ}$ 16, 2004, p. 34.

27. Une synthèse du débat terminologique, dans Gonzalo BORRÁs, op. cit., p. 26 sq. et une révision récente des relations entre l'art chrétien et l'art islamique dans Juan Carlos RUIZ SOUZA, op. cit. (note 26), p. 17-43.

28. Pedro de MADRAZo, op. cit. (note 10), p. 263.

29. Vicente LAMPÉREZ Y ROMEA, Historia de la arquitectura cristiana española en la Edad Media según el estudio de los elementos y los monumentos, Madrid : José Blass y Cía, 1908, vol. 2, p. 535-538.

30. Vicente LAMPÉREZ Y ROMEA, op. cit. (note 29), p. 540.

31. Ibid., p. 540 : «Sea hecha esta arquitectura por moros sometidos, por moros conversos o por cristianos aleccionados por los moros, ello es que hay un arte que muestra elementos de lo cristiano y mahometano y que debe tener un nombre; y tanto da el de mudéjar de Amador, como el cristianomahometano de Fernández Jiménez, como el morocristiano de un autor reciente [José Font y Gumá, Rejolas valencianas y catalanas, Barcelona, 1905], con la ventaja para el primero de ser más corto y más fonético. ».

32. Voir James T. MONROE, Islam and the arabs in Spanish Scholarship (Sixteenth Century to the Present), Leiden: Brill, 1970; Manuela MANZANARES DE CIRRE, Arabistas españoles del siglo XIX, Madrid: Instituto Hispano-Árabe de Cultura, 1971; Aurora RIVIÈRE GÓMEZ, Orientalismo y nacionalismo español. Estudios árabes y hebreos en la Universidad de Madrid (1843-1868), Madrid : Universidad Carlos III, 2000 et Cristina ÁLVAREZ MILLÁN, «Pascual de Gayangos y la historia medieval en España ». Espacio, tiempo y forma. Serie III. Historia Medieval, 2004, 17, p. 35-49.

33. José AMADOR DE LOS RÍOS, «Influencia de los árabes en las artes y literatura españolas », Boletín de la Real Academia de la Historia, $\mathrm{n}^{\circ} 33,1898$, p.539-552. Voir le texte original sur http:// www.cervantesvirtual.com. Consulté le 16 novembre 2015.

34. Ibid., p. 540.

35. Aurora RIVIÈRE GóMEZ, op. cit. (note 32), p. 65-66. 
36. Philippe ARAGUAS, «Le style mudéjar et l'architecture néo-mudejar dans l'idéologie nationaliste espagnole autour de 1900 ", in Carlos SERRANO (dir.), Nations en quête de passé. La Péninsule Ibérique (XIX ${ }^{e}-X^{e}$ siècles), Paris : Presses de l'université de Paris-Sorbonne, 2000, p. 77.

37. Ce texte était ajouté dans l'édition de 1872. Reproduit dans José AMADOR DE LOS RÍOS, op. cit. (note 6), p. 60.

38. Voir Aurora RIVIÈre GÓMEZ, op. cit. (note 32), p. 52 sq.; et Manuela MANZANARES DE CIRRE, op. cit. (note 32), p. 58 et 119 sq. José Antonio CONDE, Historia de la dominación de los Árabes en España, Madrid: Imprenta que fue de García, 1820-1821; Francisco FERNÁNDEZ y GONZÁLEZ, Estado social y político de los mudéjares de Castilla considerados en sí mismos y respecto de la civilización española. Madrid : Imprenta de Joaquín Muñoz, 1866, p. 224 et 231-32.

39. José AMADOR DE LOS RÍOS, op. cit. (note 6), 1859, p. 14.

40. Sur la position d'Amador de los Ríos en faveur de l'idée de la tolérance médiévale, voir Roberto LóPEZ-VELA, « De Numancia a Zaragoza. La construcción del pasado nacional en las Historias de España del ochocientos ", in Ricardo GARCíA CÁRCEL (dir.), La construcción de las historias de España, Madrid : Marcial Pons, 2004, p. 225-226.

41. José AMADOR DE LOS RÍOS, op. cit. (note 6), p. 7.

42. Ibid., p. 13.

43. Ibid., p. 15 : «Cuando la espada vencedora de Fernando III arrancó a la morisma la antigua ciudad de Medina Andalus y más tarde la ciudad de Sevilla, hallábase la arquitectura cristiana en uno de aquellos instantes supremos, en que, tras largas y difíciles elaboraciones, aspiraba a revestirse de nuevas formas, señalando así nuevo grado de progreso en el cuadrante de la civilización española. El arco ojival, que ya fuese natural y espontáneo desarrollo del arte de Occidente, ya derivación afortunada de otro arte de más lejano origen, comenzaba a dibujarse en las fábricas de la arquitectura castellana, fue transportado al suelo de Andalucía, apenas iniciado su futuro desenvolvimiento. Su presencia representaba allí la triunfante cultura de los vencedores. Mas en aquel mismo suelo había echado profundas raíces el arte de los vencidos; y Amires y Califas, walíes y cónsules se habían extremado, desde los tiempos de Abdul-aziz hasta los de Axataf, en dotar a Córdoba y Sevilla de portentosas aljamas y soberbios alcázares, en que brillando todas las galas de la arquitectura arábigobizantina, resplandecían en las más recientes construcciones los caracteres que distinguen la segunda edad de la historia de aquel arte, reconocida en ellos, no sólo la influencia de almorávides y almohades, sino también la menos duradera, aunque tal vez más brillante, de los príncipes abbaditas. He aquí, pues, Señores Académicos, los encontrados elementos que en tal instante se asociaban en la ciudad de San Fernando, si no para dar primer aliento al estilo mudéjar, ya antes engendrado y asociado no sin fortuna al estilo románico, para determinar de un modo inequívoco la senda que debía seguir en días venideros. ».

44. Ibid., p. 9.

45. José AMADOR DE LOS RÍOS, «Estudios monumentales y arqueológicos. Portugal. V. Monumentos de transición, apellidados manuelinos ", Revista de España, n 35, 1873, p. 212.

46. Réponse de Pedro de Madrazo dans José AMADOR DE LOS Ríos, op. cit. (note 6), p. 48.

47. Ibid., 1859, p. 17.

48. Ibid., p. 13.

49. Ibid., p. 7.

50. Ibid., p. 18.

51. Rodrigo AMADOR DE LOS RíOS, «La Sala de Arte hispano-mahometano y de Estilo mudéjar en la Sección segunda del Museo Arqueológico Nacional », Revista de España, n 122, 1888, p. 375-409. Voir aussi IDEM, «El Museo Arqueológico Nacional (notas para su historia) », La España Moderna, 170, 1903, p. 41-70. Autres références dans IDEM, «El estilo mudéjar. Cartas al Sr. D. José Gestoso », op. cit. (note 22).

52. Rodrigo AMADOR DE LOS RÍOS, «El estilo mudéjar. Cartas al Sr. D. José Gestoso », La Ilustración española y americana, année $30, \mathrm{n}^{\circ} 10,1886$, p. 170. 
53. Amador de los Ríos dénonçait: "Célebres filósofos, historiadores notables y eruditos literatos han formado un juicio poco exacto sobre el estado de cultura de los árabes cuando conquistaron la Península ibérica, y les han dado el nombre de bárbaros, llevados sin duda de las preocupaciones vulgares que por tanto tiempo han dominado entre nosotros, respecto á cuanto tenía relación con los sectarios del islamismo. La religión de los castellanos, y el odio que éstos profesaban a los musulmanes, contribuyeron en gran manera a que se les tuviese en un concepto tan equivocado y a que se les negase absolutamente el haber tenido influencia en los adelantamientos de la civilización española », José AMADOR DE LOS RÍOS, op. cit. (note 33), p. 540-541. Voir Victor NIETO ALCALDE, «El mito de la arquitectura árabe, lo imaginario y el sueño de la ciudad clásica », Fragmentos, 8-9, 1986, p. 132-155 ; Fernando MARÍAS, " Haz y envés de un legado : la imagen de lo islámico en la cultura del Renacimiento y el Barroco ", in VV. AA., La imagen romántica del legado andalusí, Barcelone ; Madrid : Lunwerg, 1995, p. 105-113 ; et Antonio URQUízAR HERRERA, «La memoria del pasado en la cristianización de la mezquita de Córdoba durante la Edad Moderna ", in Isidoro colomA, Juan Antonio SÁNCHEZ (dirs.), Actas del XIV Congreso Nacional del CEHA, Málaga : Universidad de Málaga, 2003, p. 523-531. Une vision complémentaire dans Barbara Fuchs, Exotic Nation. Maurophilia and the Construction of Early Modern Spain, Philadelphia, PA : University of Pennsylvania Press, 2009. Sur le rôle historique du mudéjar dans ce processus : p. 52 sq.

54. Voir Delfín RODRÍGUEZ RUIZ, La memoria frágil. José de Hermosilla y las antigüedades árabes en España, Madrid: Fundación Cultural Coam, 1992; La imagen romántica del legado andalusí, op. cit. (note 53) ; Francisco CALVo SERRALler, La imagen romántica de España, Madrid: Alianza, 1995 ; Luis MÉNDEZ, La imagen de Andalucía en el arte del siglo XIX, Séville : Centro de Estudios Andaluces, 2008 ; Antonio URQUízAR HERRERA et Noemi de HARO GARCíA, La escritura visual de Córdoba. Gramática de un imaginario colectivo, Cordoue : Universidad de Córdoba, 2006.

55. María José BUENO FIDEL, Arquitectura y nacionalismo (pabellones españoles en las exposiciones universales del siglo XIX), Málaga : Universidad de Málaga, 1987, p. 56 sq.

56. Ibid., p. 58.

57. Dans ce sens, les commentaires de Rodrigo Amador de los Ríos sur l'appropriation de la part des architectes de l'idée mudéjar proposée par son père Rodrigo sont significatifs : "Aunque no bien discernido en todos sus accidentes, y detalles, ni en sus fundamentos históricos y filosóficos, bajo el concepto de ser el referido estilo [mudéjar] intérprete genuino del genio nacional en la Edad Media, como elaborado dentro de la península y con medios y recursos propios, -apoderábanse los artistas de la idea, y, tratando de simbolizar en el arte arquitectónico la nacionalidad española, cuando el edificio era llamado a responder a necesidades privativas de España, o a representarla característicamente, no recelaban en imitar o reproducir lo más saliente del mencionado estilo, apellidando, en consecuencia, de mudéjares sus construcciones, cual acontece, por ejemplo, en la moderna Plaza de Toros de esta corte; pero alardeando de originalidad, no faltaba entre ellos quien, comprendiendo o no lo que en sí propio significaba el estilo mudéjar, tomaba de las fábricas muslimes granadinas los elementos principales desfigurándolos a capricho si bien en forma y condiciones artísticas aunque no rigurosamente arqueológicas, y dejándose llevar con el nombre de mudéjares, cual ocurría en la última Exposición Universal de Paris con el Pabellón de España, y como sucede con el Circo de Price, no ha muchos años construido en esta corte. » Rodriguo AMADOR DE LOS Ríos, «El estilo mudéjar. Cartas al Sr. D. José Gestoso », La Ilustración española y americana, année $29, \mathrm{n}^{\circ} 30,1885$, p. 90.

58. Note sur l'inauguration du chemin de fer Huelva-Séville, dans El Viajero Ilustrado Hispano Americano, 6, 30 de marzo de 1880, p. 1.

59. Manuel вољсн, «La nueva iglesia parroquial de Hortaleza », La Ilustración española y americana, année $24, \mathrm{n}^{\circ} 13,1880, \mathrm{p} .222$.

60. Une brève introduction à l'historiographie sur le Mudéjar de ces années dans Gonzalo BORRÁs, op. cit. (note 3), p. 26-36. 
61. Voir Isidro GOMÁ, "Apología Española », Acción Española, n 64-65, 1934, p. 202 et Acción Española, $\mathrm{n}^{\circ} 31,1943$.

62. Rafael LóPEZ GUZMÁN, op. cit. (note 3) p. 23 et Roberto LóPEZ-VELA, op. cit. (note 40), p. 225-226.

\section{AUTEUR}

\section{ANTONIO URQUÍZAR HERRERA}

Profesor titular de Historia del Arte en la UNED, Madrid. 


\title{
Ugo Monneret de Villard et la découverte de l'Oriente entre Croce et Strzygowski
}

\author{
Silvia Armando
}

\section{NOTE DE L'AUTEUR}

Ce texte résulte des recherches conduites grâce à une bourse d'études de la Fondazione per l'arte della Compagnia di San Paolo qui m'a permis de passer 12 mois (novembre 2007-octobre 2008) à Paris et de travailler sur Monneret de Villard et sur l'historiographie de l'art musulman au sein de l'INHA. Je tiens à remercier $\mathrm{M}^{\text {me }}$ Mercedes Volait pour avoir suivi mon travail et pour m'avoir associée à ce projet éditorial. Merci à Christian Omodeo pour avoir relu mon texte, et à $\mathrm{M}^{\mathrm{me}}$ Hélène Morlier pour le support éditorial, toujours valide et jamais envahissant. Je remercie particulièrement $\mathrm{M}^{\text {me }}$ Sabina Gavazzi, pour son témoignage sur son oncle, Ugo Monneret de Villard, et sa fille, Elisabetta Gavazzi, pour m'avoir envoyé des photos relatives à Monneret. Je suis également reconnaissante à l'Istituto Nazionale di Storia dell'Arte de Rome, à son directeur le professeur Adriano La Regina et à M. Massimo Pomponi, à la Biblioteca di Archeologia e Storia dell'Arte de Rome et à $\mathrm{M}^{\mathrm{me}}$ Francesca Zannoni pour de nombreuses illustrations publiées dans ce texte. L'Istituto (INASA) et la Biblioteca (BiASA) abritent respectivement les archives photographiques et documentaires (lettres, notes, etc.) ayant appartenu à Monneret de Villard. La bibliothèque personnelle du savant est conservée dans une section séparée de la BiASA. Pour une brève biographie et les principales références bibliographiques, voir Stephen J. Vernoit, « Monneret de Villard, Ugo », in The Dictionary of Art, vol. XI, Londres : Macmillan 1996, p. 888 et Silvia Armando, « Monneret de Villard, Ugo », in Dizionario biografico degli Italiani, vol. 25, Rome : Treccani, 2011.

1 Monneret de Villard naquit à Milan en 1881, année de fondation du Comité pour la conservation des monuments de l'art arabe, et vingt ans après l'unification de l'Italie. Il 
mourut à Rome en 1954 (fig. 1-2). Il existe donc un décalage évident entre son histoire et celles des autres personnages présentés dans ce volume, décalage que l'on pourrait qualifier d'historique : nous aborderons le point de vue d'un savant italien, originaire d'un jeune pays où le phénomène du colonialisme était plus récent et moins accentué que dans les autres nations européennes, pays où par conséquent la tradition d'études autour de l'Islam se développa tardivement, notamment dans le domaine des arts. Cet homme traversa des évènements historiques marquants comme les deux guerres mondiales. Les bouleversements politiques et culturels qui en découlèrent se reflètent de façon très nette sur sa production scientifique ainsi que sur les conditions et les moyens matériels dont il disposait pour travailler. Monneret de Villard représente un personnage-clé pour comprendre l'histoire particulière et différente des études sur l'art musulman en Italie.

1. Buste de Ugo Monneret de Villard.

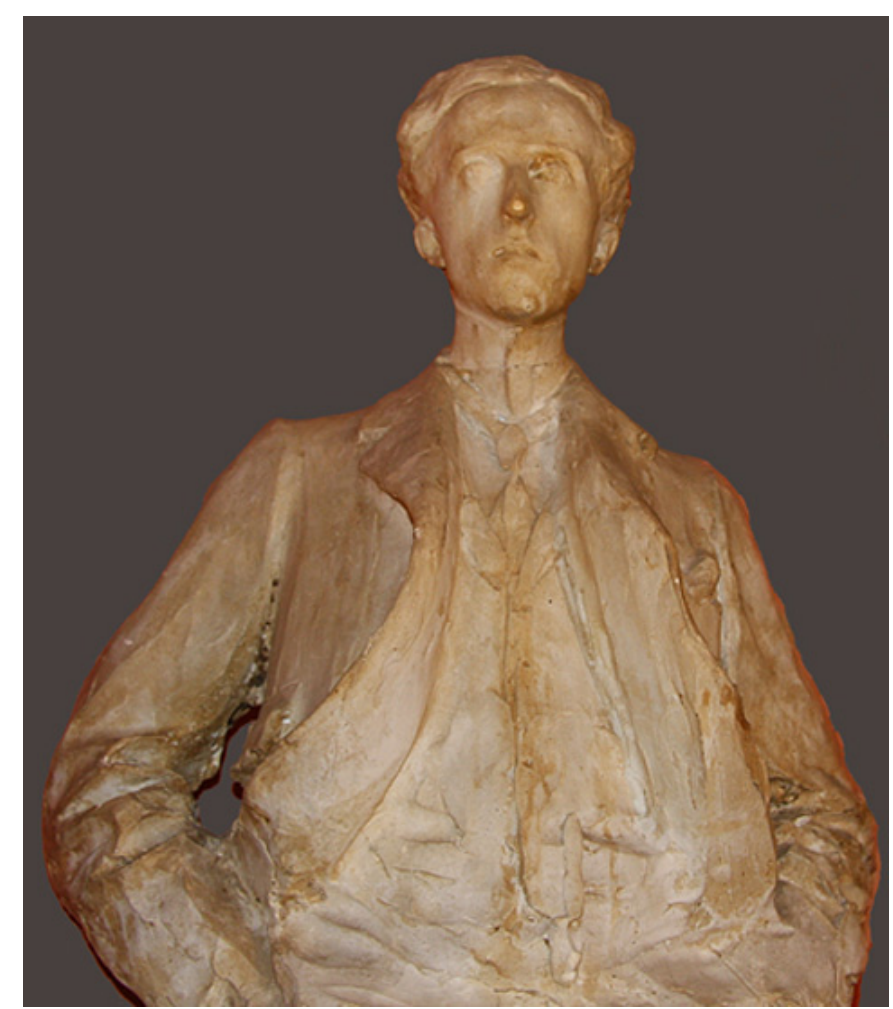

Source : Famille Gavazzi. 
2. La famille Monneret de Villard.

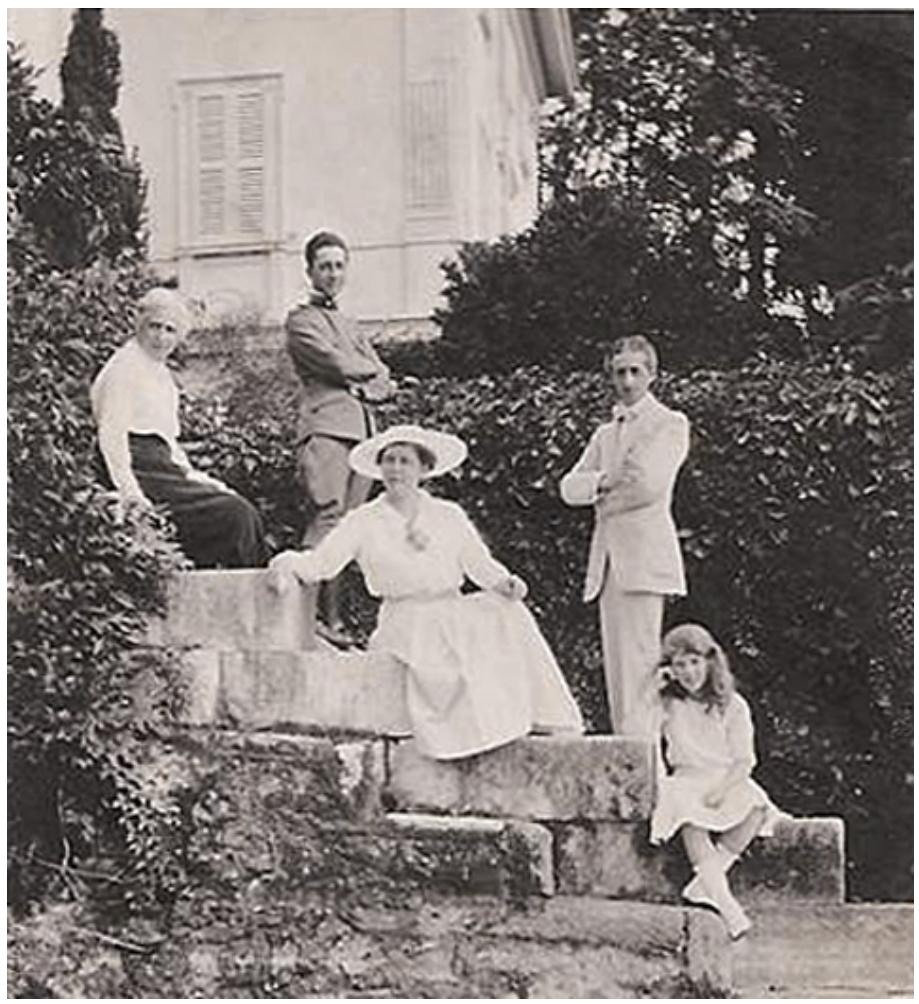

Source : Famille Gavazzi.

Bisogna ricordare che l'Oriente è paese dalle molte vite e dalle molte storie, e che in ogni località si sovrappongono strati di diverse civiltà; che l'archeologo deve scavarli tutti e studiarli con eguale amore e con eguale scienza ${ }^{1} \ldots$

2 Ugo Monneret de Villard traçait ainsi, dans le compte rendu d'une de ses missions archéologiques menées en Égypte entre 1921 et 1928, sa conception complexe de l'art de la région du Nil. Celle-ci reflétait son approche archéologique et sa condamnation de la pratique des fouilles sélectives :

non è più permesso oggi il vandalismo della vecchia scuola, di cui fortunatamente scompaiono anche gli ultimi rappresentanti o speriamo scompaiano presto, che riteneva lecito cercare in un dato terreno solo le vestigia di una certa epoca, distruggendo con una incoscienza bestiale i documenti d'interi secoli di storia ${ }^{2}$.

Son attaque virulente suggère un modèle scientifique qui s'engage à évaluer toutes les données et à fouiller les couches de toutes les époques, ainsi qu'une conscience historique et une méthode archéologique innovatrices, déjà relevées pour leur modernités.

4 Le compte rendu date de 1928. À cette époque, Monneret de Villard était âgé de quarante-sept ans et avait passé les sept dernières années principalement en Égypte. Sa formation, fruit de longues réflexions théoriques et d'expériences significatives sur le terrain, lui donnait une connaissance assez approfondie de l'histoire et des monuments locaux ${ }^{4}$. Sa première mission officielle au Caire date de février 1921 : Roberto Paribeni, directeur de l'Ufficio delle Missioni Scientifiche in Levante, chargea Monneret d'une mission archéologique, pour représenter le monde scientifique italien parmi la communauté d'archéologues et d'orientalistes français, anglais, allemands, américains, etc. installés en Égypte ${ }^{5}$. Probablement grâce à la médiation d'Eugenio Griffini qui était 
à cette époque le bibliothécaire du roi Fouad ${ }^{6}$, Monneret fut initialement engagé par l'Ufficio afin d'être candidat à la direction du musée d'Art arabe du Caire ${ }^{7}$. Il entretenait ses propres relations avec les institutions : un sentiment sincère d'orgueil national et une certaine velléité de pénétration culturelle apparaissent dans les mémoires envoyés au khédive et à Paribeni. Il rappelait sans cesse sa difficulté à lever des fonds et la nécessité de former du personnel italien compétent tout en proposant de nouveaux projets de missions ${ }^{8}$. Les institutions locales cofinançaient souvent les projets partiellement soutenus par le gouvernement italien et, alors que la question de la direction du Musée d'Art arabe était enlisée', Monneret rédigea en 1922 un catalogue du Musée copte à la demande de cette communauté ${ }^{10}$. Il signa également un accord avec le Comité pour la conservation des monuments de l'art arabe pour publier des monographies sur les monuments coptes au cours des cinq années suivantes ${ }^{11}$, en satisfaisant ainsi son intérêt pour le moyen âge chrétien. L'important volume Les Couvents près de Sohag ${ }^{12}$, consacré aux couvents Blanc et Rouge, est l'un des travaux les plus remarquables de cet ensemble. La réputation de Monneret de Villard s'accrut parallèlement. À partir de 1924, il obtint la direction des fouilles à Saint-Siméon, près d'Assouan (voir infra fig. 12-13), grâce à Pierre Lacau, chef du service des Antiquités ${ }^{13}$. Entre-temps, Monneret découvrait le Vieux Caire et entreprenait une étude topographique du Qasr al-Sham ' (fig. 3) ${ }^{14}$; il commençait à s'intéresser également aux monuments islamiques médiévaux, comme en témoignent les nombreux documents conservés dans ses archives à Rome (fig. 5$)^{15}$.

3a. Plan du Qasr al-Sham' dressé par Monneret.

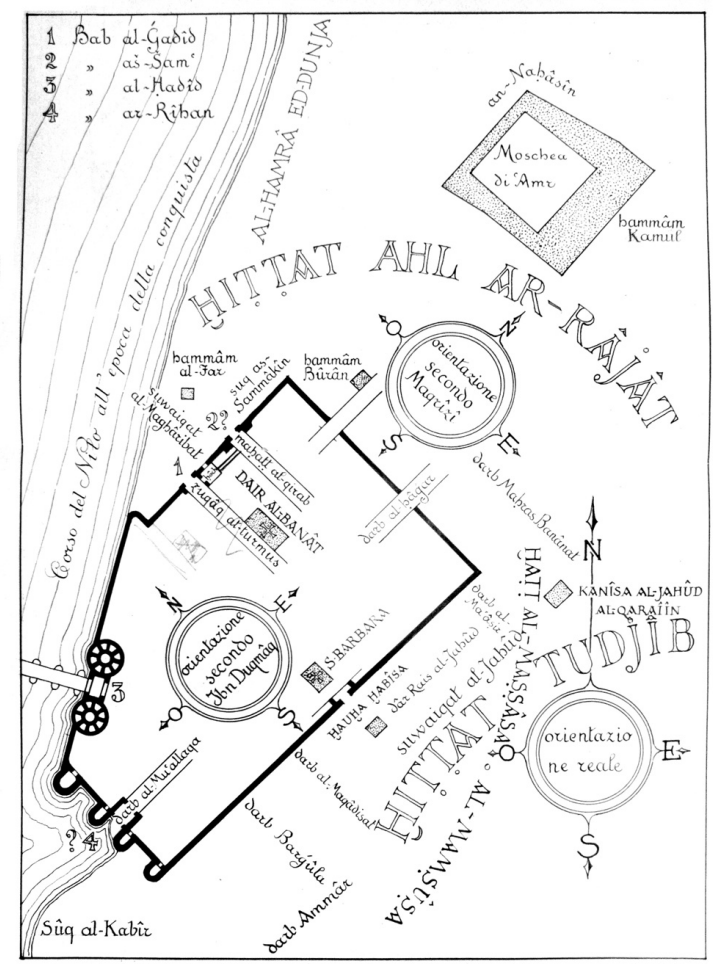

Source : Rome (Italie), Biblioteca di Archeologia e Storia dell'Arte, Fonds Monneret, boîte 11, carton 1 c 97. 
3b. Vue de Qasr al-Sham, Le Caire.

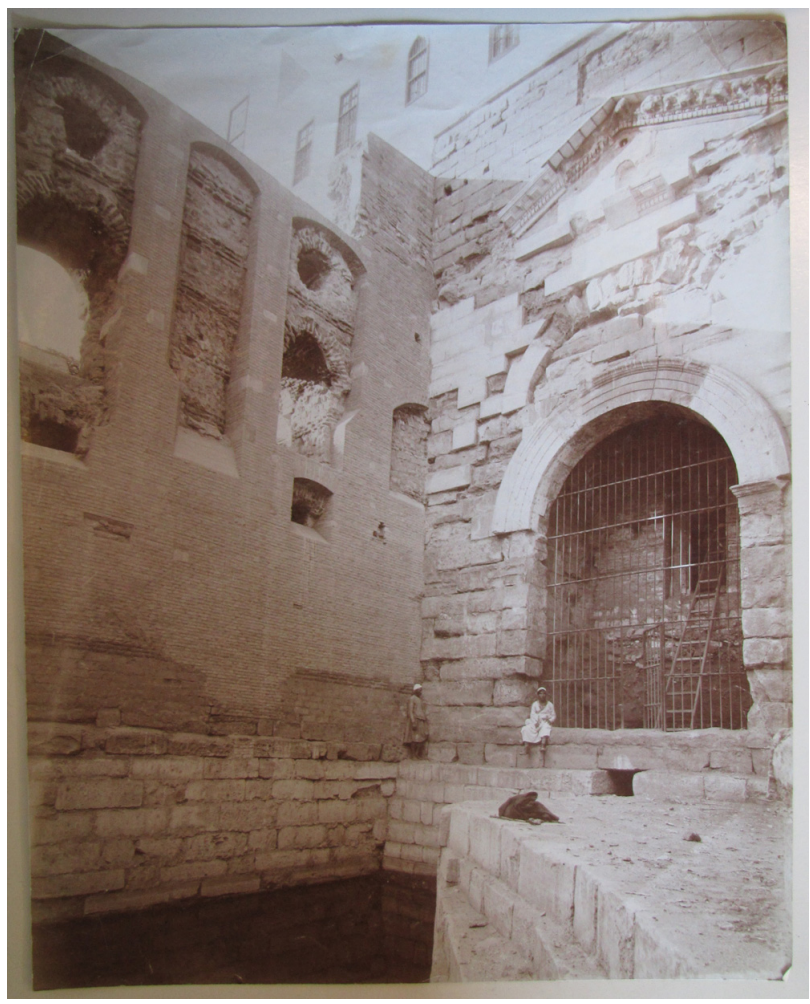

Source : Rome (Italie), Biblioteca di Archeologia e Storia dell'Arte, Fonds Monneret, boîte 11, carton 1 c 142. 
4. Vue d'Abu Sarga, Le Caire.

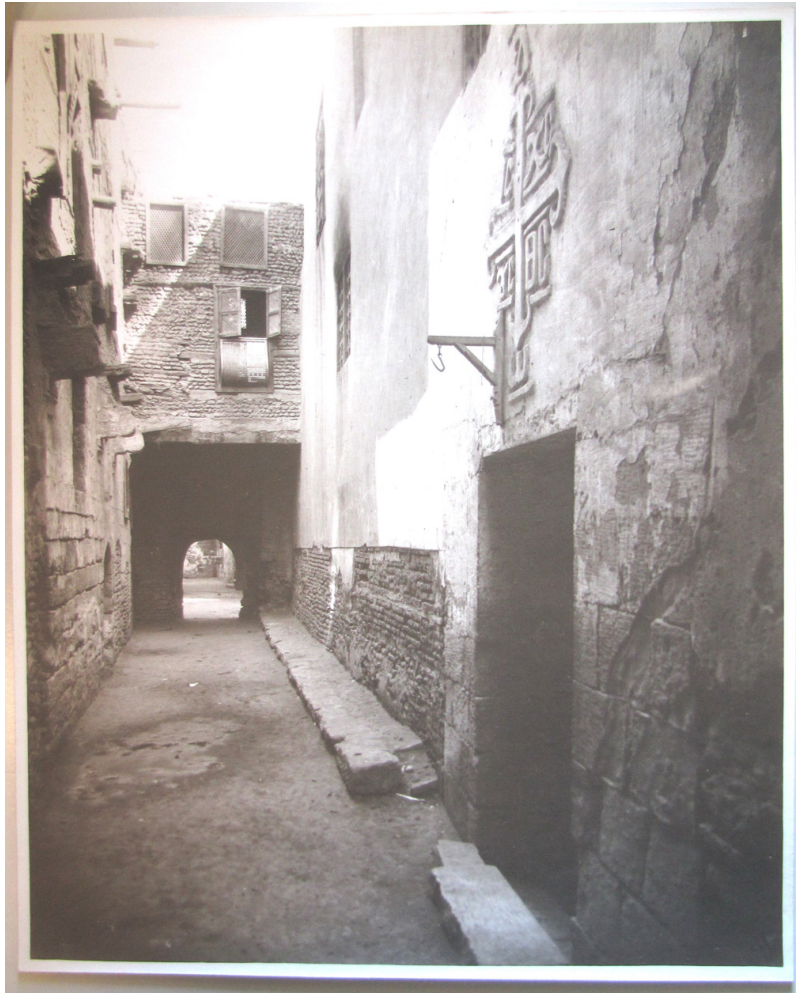

Source : Rome (Italie), Biblioteca di Archeologia e Storia dell'Arte, Fonds Monneret, boîte 11, carton 1 c 199.

5. Tombeaux de Muhammad al-Gafari, Sayyida 'Atika et Sayyida Ruqayya au Caire.

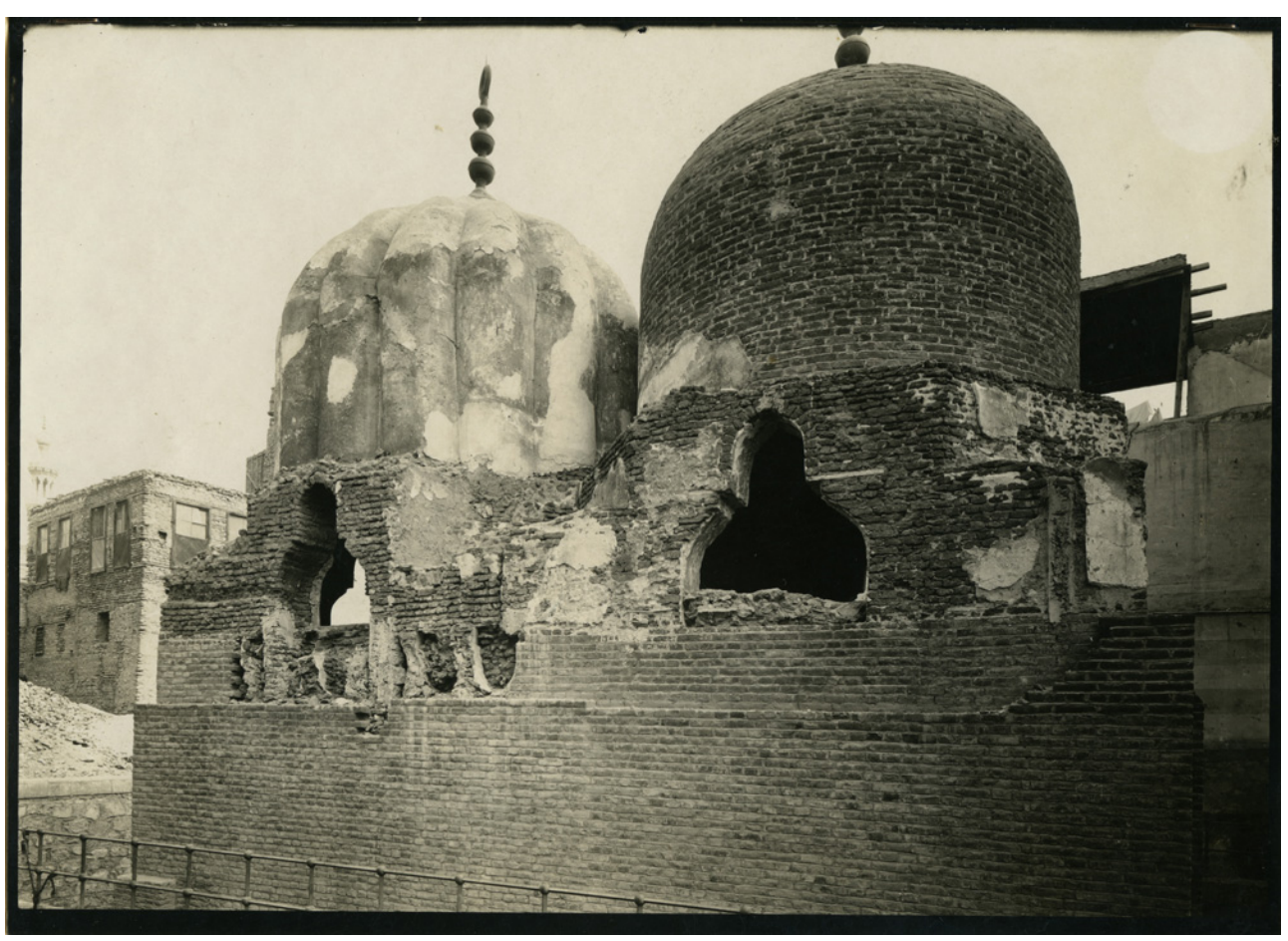

Source : Rome (Italie), Instituto di Archeologia e Storia dell'Arte, Photothèque, Fonds Ugo Monneret de Villard, $n^{\circ}$ inv. 66015. 
En 1927, il fut chargé de la direction des fouilles des monuments chrétiens d'Égypte ${ }^{16}$. Au milieu des années 1920, Monneret étendit ses recherches: il parcourut l'Afrique nord-orientale et remonta le Nil en direction de la $\mathrm{Nubie}^{17}$. Il ne pouvait pas négliger les monuments islamiques contemporains des bâtiments chrétiens qu'il étudiait :

queste ricerche non si sono limitate ai monumenti cristiani, avendo io ritenuto necessario estenderle anche ai monumenti arabi contemporanei, cioè dalla conquista al XIII secolo [...]. L'estensione delle ricerche è di una necessità evidente: arte copta e arte araba, vivendo $e$ sviluppandosi fianco a fianco nello stesso paese, non potevano rimanere e non sono rimaste punto estranee l'una all'altra; $i$ reciproci scambi sono stati quotidiani e profondi. La conoscenza di una delle arti presuppone e richiede la conoscenza dell'altra ${ }^{18}$.

6 Son approche de l'art islamique fut donc graduelle, mais inéluctable. La réputation de spécialiste d'art musulman de Monneret de Villard se constitua à cette époque et dure encore de nos jours ${ }^{19}$. Néanmoins, il faut relever que cette découverte arriva assez tard dans sa carrière scientifique : cela n'est que le résultat d'un parcours d'études long et cohérent, fait d'expériences sur le terrain et de réflexions théoriques.

Quelle a été la formation de Monneret de Villard? Quel chemin le mena à s'occuper d'archéologie en Égypte? Quels éléments ont concouru à structurer ses principes esthétiques ainsi que sa méthode de travail ? Pour répondre à ces questions, il est nécessaire de se plonger dans son passé, en examinant la formation de ce savant et sa participation précoce aux débats qui se tenaient autour de l'art et de l'architecture aux niveaux national et international. Deux figures éminentes et très éloignées influencèrent cette période : Benedetto Croce et Josef Strzygowski. On analysera donc non seulement l'impact des écrits de ces deux savants sur Monneret de Villard, mais aussi les rapports personnels que ce dernier entretint avec eux. Si les implications sont très fortes et ressortent dans ses écrits scientifiques pendant sa première décennie d'activité, ce bagage culturel demeure dans son approche de l'archéologie durant les missions menées en Afrique ; des vestiges significatifs peuvent même être repérés dans sa production tardive.

8 Il est curieux de découvrir que Monneret de Villard avait un diplôme d'ingénieur de la section chimique du Politecnico de Milan, obtenu en $1904^{20}$. Le jeune Monneret vivait parmi les ingénieurs et les architectes, plongé dans le milieu de la haute bourgeoisie milanaise, suivant le mythe de la productivité et du progrès scientifique, qui commençait à s'effondrer sous le poids de la crise imminente du positivisme ${ }^{21}$. Pendant ses années universitaires, Monneret assista aux cours dispensés au Politecnico par Camillo Boito. De là vient, vraisemblablement, sa fascination pour le Moyen Âge ${ }^{22}$, dont le dessin extrêmement soigné d'un pupitre, réalisé en 1905-1906, est un précieux témoignage visuel (fig. 6). 
6. Pupitre de San Bernardino (cathédrale, Pérouse) dessiné par le jeune Monneret.

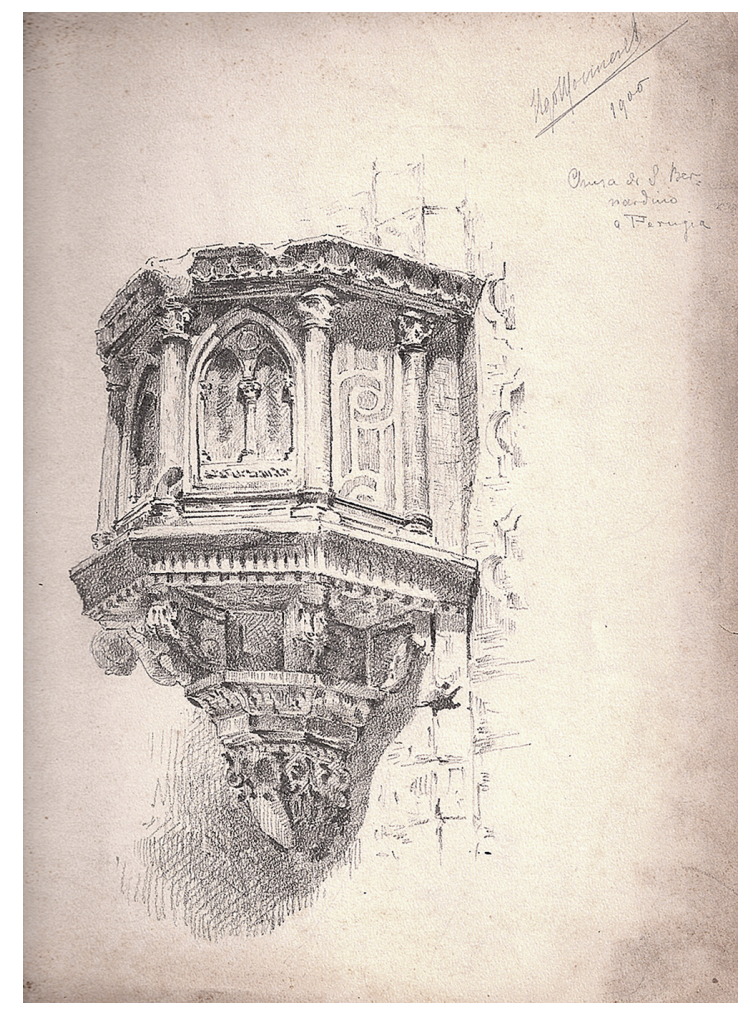

Source : Famille Gavazzi.

9 Monneret de Villard cultivait un intérêt précoce pour toute forme d'art ; il collabora à une série de revues, traitant les sujets les plus divers, des peintures de Giorgione à l'architecture contemporaine ${ }^{23}$. Le patrimoine historique était alors l'objet d'un nouvel intérêt en Italie et le jeune Monneret en fut imprégné2 ${ }^{24}$. Dans les cercles les plus "techniques», tel que dans le Collegio degli ingegneri e degli architetti (dont Monneret était membre $)^{25}$, des débats avaient lieu autour de la vie publique et de la ville. Il participa en qualité d'envoyé du Monitore tecnico et de La Perseveranza ${ }^{26}$ aux expositions et congrès internationaux, notamment à Vienne, Milan et Venise, où les premiers grands débats italiens concernant l'arte pubblica se tenaient. Les questions d'urbanisme essayaient de concilier l'agrandissement des villes avec la conservation du patrimoine historique ${ }^{27}$.

Les formulations théoriques de Monneret $^{28}$ trouvèrent bientôt une application pratique : en 1908, la Ville de Milan devait approuver un nouveau plan d'urbanisme et il fut parmi les membres de la commission chargée de l'examiner. Les enquêtes topographiques qu'il entreprit l'incitèrent à défendre le quartier de l'église San Lorenzo, en soulignant sa valeur archéologique face à un projet qui visait à rendre la ville plus fonctionnelle et à négliger ses aspects historiques ${ }^{29}$. Les études conduites autour de ce monument constituèrent un tournant fondamental : c'est à partir de 1909-1910 que Monneret se voua à la recherche archéologique, historique et documentaire ${ }^{30}$; l'architecture médiévale et ses relations avec le monde byzantin et le Moyen-Orient le fascinèrent. Dès 1908, il faisait référence aux monuments orientaux dans ses écrits ${ }^{31}$. En juillet 1909, il se rendit en Dalmatie puis passa deux mois en Grèce en $1912^{32}$. Le but de ce voyage était «quello di studiare i rapporti fra l'architettura e la decorazione bizantina dei secoli XI-XIII e l'italiana », comme il l'expliquait dans une lettre 
adressée à Adolfo Venturi ${ }^{33}$. En 1914, il passa l'examen de Libera Docenza en histoire de l'architecture et devint professeur d'architecture et d'archéologie médiévales ${ }^{34}$. Pendant dix ans, son attention se concentra essentiellement sur l'histoire et l'archéologie des monuments lombards; cette expérience de recherche sur les documents et sur le terrain, mêlée à une fascination constante pour l'Oriente, le conduisit, dès 1921, à entreprendre ses missions archéologiques en Égypte.

11 Voici rapidement tracées les étapes principales d'un parcours de formation complexe mais cohérent. Si la découverte de l'Orient doit beaucoup à la lecture des études de Josef Strzygowski, l'influence de Benedetto Croce sur la pensée de Monneret de Villard reste plus difficile à déceler. La question a déjà été abordée à plusieurs reprises sans pourtant apporter des réponses définitives et Monneret a été au fur et à mesure " étiqueté » comme positiviste ou « idéaliste-crocien " ${ }^{35}$.

La découverte de la correspondance entre les deux savants ${ }^{36}$ et une relecture des écrits de Monneret aident à aborder le problème, sans avoir la prétention de résoudre une question épistémologique délicate.

\section{L'influence de Benedetto Croce}

13 En 1902, la première édition de l'Estetica ${ }^{37}$ de Croce est publiée. Monneret perçut aussitôt la portée de cet ouvrage. En effet, l'Estetica était destinée à devenir assez rapidement un jalon de la culture italienne pour la première moitié du XX $\mathrm{XX}^{\mathrm{e}}$ siècle. Croce considérait l'œuvre d'art comme le résultat d'un acte intuitif qui s'accomplissait dans l'instant (fig. 7). La critique d'art avait pour but de recréer cet instant, devenant ainsi une intuition de l'acte créatif, qui était donc indépendant de la technique et de la réalisation pratique de l'œuvre. L'œuvre d'art devait être comprise en elle-même, ce qui excluait la possibilité d'une histoire universelle de l'art, qui n'aurait été que le fruit de systèmes de pensée abstraits. 


\section{Benedetto Croce.}

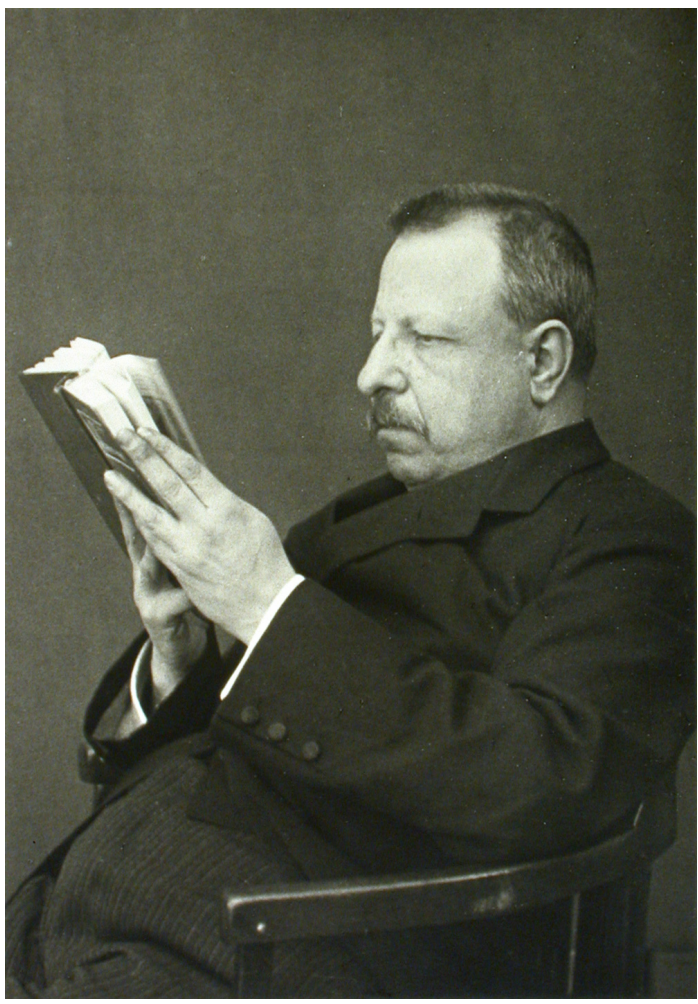

L'avis de Monneret à propos des théories de Benedetto Croce semble assez fluctuant : dans l'article "La supremazia della critica" publié dans le quotidien milanais La Perseveranza (17 août 1905) $)^{38}$, il adhérait avec enthousiasme à l'idée d'identifier l'acte créateur (génie) avec le jugement de l'œuvre (la critique) et alla jusqu'à soutenir que la critique était supérieure, tout en considérant que l'œuvre se composait de matériaux concrets et de l'existence réelle, alors que l'activité critique portait sur des matériaux déjà "purifiés »: les œuvres d'art. Cependant, dans d'autres articles traitant des relations entre l'architecture et la pensée de Croce, les commentaires de Monneret acquirent des nuances polémiques: juste après sa rencontre tant désirée avec le philosophe ${ }^{39}$, et malgré quelques hésitations ${ }^{40}$, le jeune ingénieur publiait « Per l'Estetica di Benedetto Croce e l'architettura $»^{41}$ dans la revue Leonardo ${ }^{42}$ : il y contestait l'idée que l'architecture, ainsi que les autres arts, puisse être considérée comme œuvre d'art quand le créateur rejoignait une vision instantanée - une sorte d'intuition - qui lui permettait d'accomplir la «sintesi artistica ${ }^{43}$ ». L'architecture était pour Croce un art complètement libre, indépendant de tout aspect pratique (presupposti) ${ }^{44}$. Or, Monneret proposait une série d'exemples pour démontrer que l'œuvre architecturale était le fruit d'expériences accumulées dans le temps, de considérations techniques et d'une connaissance des matériaux, qui concouraient à «la vera fase di creazione artistica ${ }^{45}$ ». L'intuizione de Croce se trouvait ainsi réduite à un «stato rudimentale del bisogno di creare $^{46}{ }^{\prime}$.

15 Cette mise en exergue des aspects pratiques est sans doute d'origine positiviste ${ }^{47}$. Pourtant, l'insistance qui émerge des lettres envoyées à Croce laisse penser que la polémique lancée par le jeune ingénieur représente une tentative pour attirer l'attention du philosophe, afin d'obtenir une prise de position publique de la part de ce dernier: "Spero ella avrà ricevuto il numero del Leonardo. Mi lusingo di avere io le Sue 
critiche le più acerbe e le più corrosive, poiché una polemica sull'Architettura molto mi piacerebbe e conto di non darmi per vinto troppo presto ", écrivait-il en décembre $1905^{48}$. D'ailleurs, Croce ne semble pas lui avoir accordé un tel honneur : dans la lettre envoyée par Monneret le 4 février 1906, on découvre que Croce n'avait pas apprécié le ton de l'article, et Monneret se dépêcha de s'excuser, en promettant d'écrire à nouveau sur ce même sujet :

Gentile amico,

La sua lettera mi getta in una vera costernazione. Si vede che la malattia mi ha molto rammollito, si che io credevo di dare un tono scherzoso all'introduzione del mio articolo ne ho invece dato uno offensivo. [...] Ma le annuncio [?] che io attaccherò ancora con violenza... Spero che l'equivoco sarà chiarito ed il malinteso dissipato. Ancora una volta la parola mi ha tradito e ne porto tutte le conseguenze. Scriverò ancora a proposito del medesimo soggetto e le manderò subito l'articolo. Non dispero di avere un giorno la sua risposta completa e dettagliata. Il soggetto mi sembra di grande importanza e di lunga portata. Ancora la prego di perdonarmi e mi creda suo dev. Ugo Monneret $\mathrm{D}^{49}$.

La même année Croce publia «Le antinomie della critica » dans La Critica ${ }^{50}$. Il analysait les courants opposés de storicismo et d'esteticismo en décrivant leurs différentes approches vis-à-vis de l'art. Si pour les historicistes, l'œuvre se comprenait (et se jugeait) à travers les éléments extérieurs, la position antithétique était que l'œuvre pouvait être comprise seulement par elle-même. Croce affirmait que seule la synthèse des deux options (antinomiques) était vraie et soulignait l'importance de la critique historique. Ainsi «la vera critica storica e la vera critica estetica coincidono ${ }^{51}$ ». La question de la sélection des faits historiques à considérer se posait alors; ceux-ci devaient être choisis au cas par cas.

Une fois de plus, Monneret entrait sciemment en conflit avec Croce en publiant un compte rendu, «Le antinomie della critica » dans $L a$ Perseveranza $^{52}$. Si dans son article sur l'architecture Monneret avait souligné la valeur des aspects pratiques et historiques, il dénonça ici la difficulté, voire l'impossibilité, de disposer de données historiques suffisantes surtout pour les œuvres anciennes. Il était possible, à son avis, de comprendre esthétiquement les œuvres (par exemple la Nikè de Samothrace) sans une connaissance effective de leur histoire. «Et tout le reste est littérature!», concluait Monneret en citant Verlaine.

Monneret modéra ses prises de position parfois agressives dans une lettre, en les justifiant par crainte que l'article de Croce ne puisse offrir une voie vers l'histoire de l'art tant « dédaignée ». En même temps, il distingua la compréhension de l'œuvre des questions d'influences et de dérivations qui intéressaient la Kulturgeschichte mais demeuraient sans intérêt pour la critique :

Il mio articoletto è spontaneo e sincero : se qualche frase è un po' librata [?] ne incolpi [?] la rapidità con cui fu scritto e la tema che la sua nota potesse a troppi aprire una via alla difesa della tanto esecrata storia dell'arte e simili cose.

Era mia intenzione ribattere una volta di più sulla teoria che l'opera d'arte si comprende in sé, e tutto quanto gli storici dell'arte vi [ ?] ricamano [ ?] intorno [?], influenze, derivazioni [?], ecc. non ha nulla a che vedere coll'arte: interessante tutto ammetto [?] per la Kulturgeschichte ma indifferente assolutamente alla critica d'arte ${ }^{53}$.

19 La critique, pour laquelle Monneret suggérait même le statut d'œuvre d'art ${ }^{54}$, assumait un rôle majeur par rapport à la Kulturgeschichte : cela explique peut-être certains de ses écrits sur la peinture des années 1903-1908, où la recherche historique, philologique et 
documentaire laissait entièrement la place à des lectures passionnées et esthétisantes des œuvres et des artistes ${ }^{55}$. C'est une démarche surprenante, si l'on connait ses écrits contemporains sur l'architecture médiévale et ses travaux successifs, toujours soutenus par une méthode systématique et par une attention constante aux données historiques et archéologiques. Monneret se plaçait à la fois aux deux pôles de l'esthétique de Croce, choisissant une approche esthétisante pour la peinture et pour la sculpture et une plus pragmatique ou historiciste pour l'architecture, et cela vraisemblablement sur les traces de la distinction hégélienne, reprise par son maître Camillo Boito, entre art en général (fruit des rêves des artistes) et architecture (activité pratique de l'esprit, supérieure parce qu'utile $)^{56}$.

À partir de 1908, avec son tournant historique et archéologique évoqué ci-dessus, ses écrits théoriques sur l'architecture manifestent une adhésion progressive aux théories de Croce. Si « Le forme architettoniche e la materia ${ }^{57}$ remettait partiellement en cause les contraintes des matériaux sur la création architecturale, telles qu'elles avaient été énoncées dans "Per l'Estetica di Benedetto Croce e l'architettura " ${ }^{58}$, l'année suivante "La libertà nell'architettura $"^{59}$ se présentait comme un véritable bouleversement de ce dernier ${ }^{60}$. Monneret soutenait qu'il était inexact d'associer l'architecture à un art non libre et jugeait la répartition entre moment pratique et moment artistique comme un "redoublement morbide» ("sdoppiamento morboso»), qui contredisait l'unité fondamentale de l'œuvre d'art. Les questions pratiques gardaient leur place, mais les finalités pratique et esthétique - auparavant distinguées - coïncidaient ${ }^{61}$. Il s'agit presque d'une auto condamnation, où l'ironie orgueilleuse des premiers textes laisse la place à une adhésion parfois pédante aux principes de Croce.

21 Presque toutes les lettres datées de 1905 à 1918 dévoilent la recherche constante d'une approbation, qui contraste avec la vis polemica des premiers textes. La plupart des articles sur ces sujets étaient envoyés à $\mathrm{Croce}^{62}$ : non seulement les écrits explicitement reliés à la pensée du philosophe, mais aussi ceux de caractère plus général. On apprend ainsi que ses articles "La libertà nell'architettura " ${ }^{63}$, «La teoria delle proporzioni

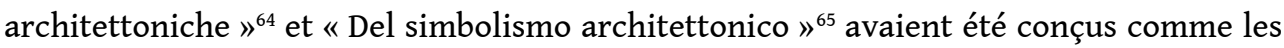
chapitres d'un ouvrage sur la méthode de l'architecture qui ne vit jamais le jour ${ }^{66}$.

L'influence de Croce se manifestait aussi dans le lexique : dans les premières pages de "Del simbolismo architettonico ", Monneret insistait sur les contingences matérielles en architecture, mais surtout sur " forme e procedimenti costruttivi, che non sono se non la traduzione di una speciale idea, di una particolare visione [...] Bisogna ciò̀ ricercare la visione fondamentale dell'artista $[. . .]^{67} »$. Un échantillon d'exemples pris de la France à l'Inde, de l'Amérique précolombienne à l'Étrurie, du Caire à La Mecque ${ }^{68}$, illustrait les manifestations possibles du symbolisme en architecture : il comptait leurs différents élans spirituels, les nombreuses contraintes religieuses, les décors. C'étaient les "imposizioni fondamentali che all'architetto hanno in principio delimitato il campo in cui poteva svolgersi la sua forza creatrice ${ }^{69}$ ». "Imposizioni»: Monneret amplifiait une fois encore les éléments capables de conditionner la création de l'œuvre architecturale...

Cette longue réflexion trouva sa forme définitive dans «Del metodo nello studio dell'architettura medioevale $»^{70}:$ après neuf ans de silence, Monneret ne manqua pas d'envoyer à Croce son nouvel article, consacré exclusivement au Moyen Âge. Sa correspondance apprend que ce texte était le résumé du cours d'archéologie médiévale tenu au Politecnico ${ }^{71}$. Monneret demandait à Croce de le relire afin qu'il puisse ensuite l'utiliser pour la préface des Studi di archeologia medievale, un autre livre (ou peut-être le 
même ? $)^{72}$ qui ne fut pas publié. Dans ce texte, les références à Croce sont continuelles et profitent d'une remise à jour, surtout sur les questions esthétiques et historiographiques ${ }^{73}$. On retrouve l'idée d'une intuition primitive ("fatto estetico», ce qui était autrefois la «visione fondamentale dell'artista » ou "l'epifania dell'opera d'arte »), élément premier duquel il faut partir pour comprendre l'œuvre d'art. Sur les traces de Croce, Monneret condamnait la recherche des lois de l'histoire et l'idée de progrès artistique; il déclarait l'impossibilité de faire une histoire générale de l'art, car seulement une juxtaposition des histoires particulières était possible ${ }^{74}$. L'objet réel de la critique artistique devait être le monument, fruit de la création individuelle ${ }^{75}$. L'architecte créateur devait suivre un rythme intérieur, complètement libre, et maîtriser l'étude technique jusqu'à la rendre instinctive ${ }^{76}$. Néanmoins, Monneret mettait l'accent sur des phénomènes d'ordre pratique, les presupposti de la création architecturale ou artistique en général ${ }^{77}$. La technique ${ }^{78}$, les aspects matériels et pratiques $^{79}$, ainsi que les problèmes chronologiques ${ }^{80}$, l'interprétation des sources documentaires ${ }^{81}$ et aussi des aspects proprement archéologiques tels que les traces des lapicides ${ }^{82}$, devenaient les protagonistes de sa pensée.

Même si le but déclaré était la sintesi artistica, saisie par la collecte de toutes les données, l'attention était de fait orientée vers ces dernières et dévoilait des échos positivistes. L'adhésion aux principes de Croce, qui revint dans plusieurs textes ultérieurs, semble claire et définitive dans "Del metodo nello studio dell'architettura medioevale ", mais elle y est traitée de manière superficielle. Ce rappel continu des éléments externes capables de concourir à la formation des œuvres laisse deviner la pensée rigoureuse de l'historien qui se retrouve dans ses œuvres postérieures.

\section{Josef Strzygowski et la quête des origines de l'architecture médiévale}

La pensée de Benedetto Croce ne fut pas la seule qui contribua à la formation de Monneret. On a déjà mentionné sa participation aux congrès et expositions internationaux à Milan, Venise, Vienne. Il côtoyait des milieux culturels internationaux, et connaissait les théories artistiques plus récentes ou d'avant-garde. Il avait notamment manifesté à plusieurs reprises sa préférence pour les artistes et les théoriciens autrichiens contemporains ${ }^{83}$. La culture artistique viennoise profitait, dès la fin du XIXe siècle, d'un rôle important dans la formulation de nouvelles conceptions esthétiques, tant dans le domaine des études théoriques, que dans la production artistique. Le nouveau siècle signa une rupture révolutionnaire avec les enseignements classicistes et winckelmanniens : en pleine époque coloniale, avec la découverte de mondes presque inconnus, grandissait une curiosité pour des formes d'art qui avaient jusqu'alors été négligées et regardées comme secondaires. L'art islamique, l'art byzantin, l'Antiquité tardive, le baroque, ainsi que les arts dits mineurs, l'ornement et la décoration suscitaient enfin l'intérêt des théoriciens et historiens de la Wiener Schule der Kunstgeschichte, ainsi que des artistes de la Sécession viennoise.

Telle une rupture dans la rupture, Josef Strzygowski proposait une orgueilleuse alternative à la grande académie viennoise ${ }^{84}$. Il bouleversa les interprétations traditionnelles des origines classiques de l'architecture du Moyen Âge avec son célèbre ouvrage Orient oder Rom (1901) ${ }^{85}$. 
27 Les relations directes et indirectes avec les milieux culturels viennois marquèrent la formation de Monneret ${ }^{86}$ et il n'est pas imprudent d'imaginer que son intérêt pour l'Orient en découle. Strzygowski (fig. 8) représenta pour Monneret une référence fondamentale et originale pour interpréter des formes architecturales médiévales italiennes qu'il découvrait alors. L'idée que l'architecture médiévale aurait trouvé son origine au Moyen-Orient toucha le jeune savant à un tel point que Monneret prit une position claire au sein du débat qui opposa les italiens Giovan Battista Rivoira et Gustavo Giovannoni - défenseurs de la Romanitas - aux théories de Strzygowski ${ }^{87}$. Monneret prit parti en faveur du professeur autrichien au cours des recherches sur la basilique San Lorenzo. Dans ses études en 1910, il attaqua les savants italiens et leur esprit nationaliste, qui leur faisait négliger les monuments hors d'Italie ${ }^{88}$. Monneret considérait San Lorenzo comme une œuvre byzantine du $\mathrm{VI}^{\mathrm{e}}$ siècle ${ }^{89}$. Sa quête de modèles ne s'arrêta pas à Constantinople: la recherche remonta - à travers d'abondantes comparaisons - aux édifices paléochrétiens à plan central avec coupole, localisés dans un Orient qui comprenait l'Égypte et la Palestine, la Syrie et la Mésopotamie, l'Asie Mineure et l'Arménie. Selon Monneret, les origines de ces expériences architecturales provenaient de ces régions, puis avaient atteint Byzance, pour finir en Italie et en Europe :

elementi manipolati, raffinati, resi quasi perfetti, in Siria, in Anatolia, in Palestina, sono importati a Costantinopoli, per infondersi in un unico concetto che durante l'epoca Giustunianea, si diffonde nuovamente per tutta l'orbe cristiana. [...] Gli architetti sono spediti ovunque, come le colonne ed i capitelli lavorati nelle cave del Proconneso. Il dominio artistico della capitale d'oriente non poteva mostrarsi più imperialmente universale.

Non si comprenderebbe dunque come a tale supremazia siano sfuggiti $i$ costruttori del $S$. Lorenzo e del S. Vitale [...]. Per questa via si dimostra insostenibile la tesi che vuole le due chiese prodotte da una scuola autocton $a^{90}$. 
8. Portrait de Josef Strzygowski.

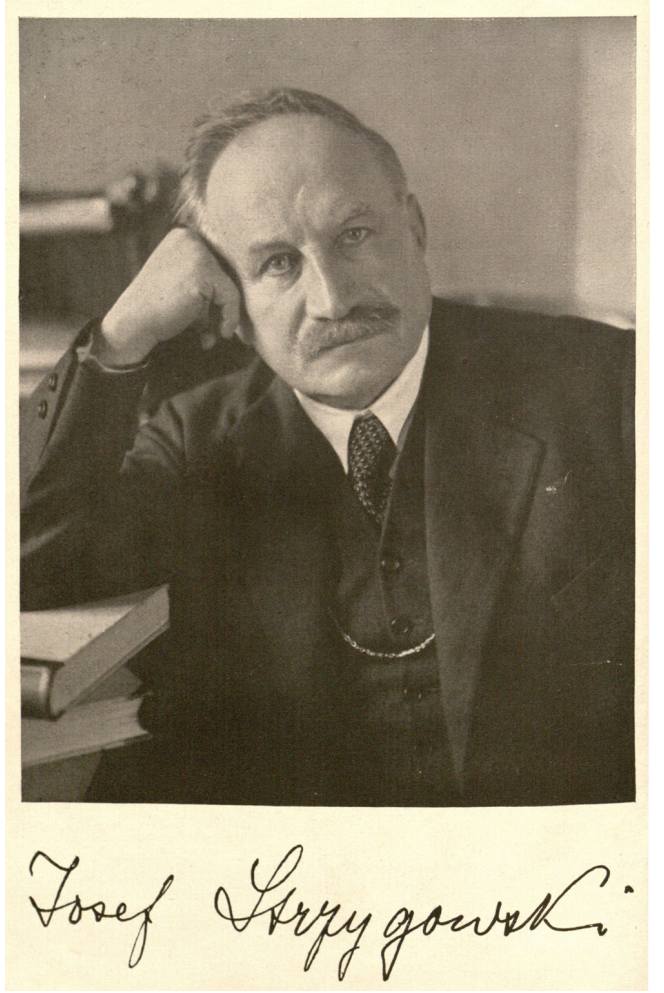

Source : Josef Strzygowski-Festschrift. Zum 70. Geburstag dargebracht von seinen Schülern, Klagenfurt : A. Kollitsch, 1932. refusait la comparaison d'œuvres lointaines dans l'espace et évaluait la question des influences comme un sujet très délicat ${ }^{96}$. Il condamnait surtout l'idée d'une influence du climat et de la race sur la production artistique : «Naturalmente è da condannare tutto il ciarpame della teoretica, tutte le considerazioni sulla razza e la loro importanza sulle forme 
$\operatorname{architettoniche}^{97} »$. Enfin, il réaffirma l'impossibilité de penser une histoire générale de l'art, qui ne pouvait se concevoir que «tutt'al più come una giusta posizione di molte storie particolari, ognuna delle quali ha per soggetto una singola opera ${ }^{98}$ ».

31 L'influence des principes de Croce est évidente, mais est compensée par une attention pour les aspects pratiques, provenant des expériences archéologiques de Monneret pendant ces mêmes années. Ce travail de terrain était lié à l'exégèse des documents ${ }^{99}$ et concourait à façonner une méthode transdisciplinaire, permettant de saisir les différentes facettes de chaque sujet d'étude. La complexité du réel articulait toutes les lectures monolithiques et morcelait le discours jusqu'à la fragmentation : remonter aux archétypes ne suffisait plus, parce que tout phénomène artistique devait être évalué selon sa propre spécificité. Cette conception et cette méthodologie furent le fondement de ses enquêtes sur les monuments égyptiens et contribuèrent à prendre une grande partie de l'œuvre de Monneret comme repère incontournable de l'historiographie.

9. Cahier de notes de Monneret pour le musée d'Art arabe du Caire.

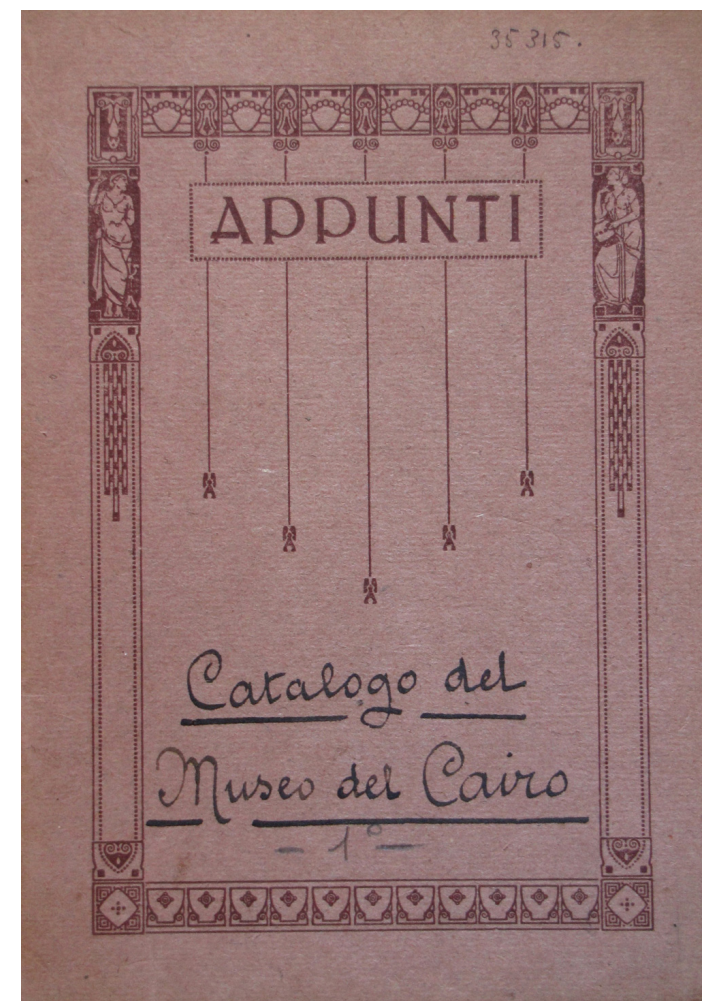

Source : Rome (Italie), Biblioteca di Archeologia e Storia dell'Arte, Fonds Monneret, ancienne boîte bleue, carton 8

Les études de Strzygowski demeurent néanmoins fondamentales pour la formation de Monneret de Villard. La lecture de ses ouvrages accrut sa connaissance de l'architecture médiévale, de Byzance jusqu'à la Syrie et à la Perse, et lui permit de découvrir des phénomènes artistiques peu connus. Il emprunta aussi à Strzygowski sa méthode comparative, ainsi que l'idée d'un Orient creuset de formes et de modèles ${ }^{100}$. Bien que progressivement délaissé au profit d'une recherche historique sérieuse, le thème de la "quête des origines ", "scientifiquement " fondée sur les évidences archéologiques, représenta un aspect fondamental de l'approche des monuments 
architecturaux, que paradoxalement Monneret et Strzygowski partageaient avec leurs adversaires Rivoira et Giovannoni ${ }^{101}$.

Strzygowski représentait une source d'inspiration pour les voyages, comme l'excursion en Dalmatie de $1909^{102}$ et ses premières missions en Égypte l'attestent. Le savant autrichien avait séjourné à plusieurs reprises au Caire pour étudier l'art chrétien d'Égypte ${ }^{103}$ et la rédaction du catalogue des objets du Musée copte, dont Monneret fut chargé en $1922^{104}$, constitua une sorte de pendant du Koptische Kunst que Strzygowski avait rédigé pour le Musée égyptien ${ }^{105}$. D'ailleurs, Monneret dédia à Strzygowski le premier volume de la série sur les monuments coptes, La chiesa di Santa Barbara al Vecchio Cairo (fig. 10-11) ${ }^{106}$. Dans ce texte, écrit à quatre mains avec Achille Patricolo, Monneret analysait les importantes décorations en bois de l'église, en localisant la source primitive d'inspiration au cœur de l'Asie, soit pour les panneaux qu'il considérait comme paléochrétiens, soit pour ceux datés du xII ${ }^{\mathrm{e}}$ siècle ${ }^{107}$. La même année, Monneret publia Saggio di una bibliografia dell'arte cristiana in Egitto ${ }^{108}$, où il collectait plusieurs centaines de références bibliographiques (réparties en sources historiques et études archéologiques), premier pas d'une recherche rigoureuse digne du Monneret ingénieur. La même rigueur se retrouve dans l'étude topographique du Qasr al-Sham', publiée en 1924 (voir supra fig. 3) : ici sources et documents anciens, arabes et latins, sont collectés et organisés de façon systématique, afin de retracer un contexte général des mosquées, des églises, des synagogues, mais aussi des portes et des routes, sur lequel fonder toutes recherches archéologiques (fig. 12-13) ${ }^{109}$.

10. Photographie de l'intérieur de l'église Sainte Barbara au Caire provenant des archives Monneret.

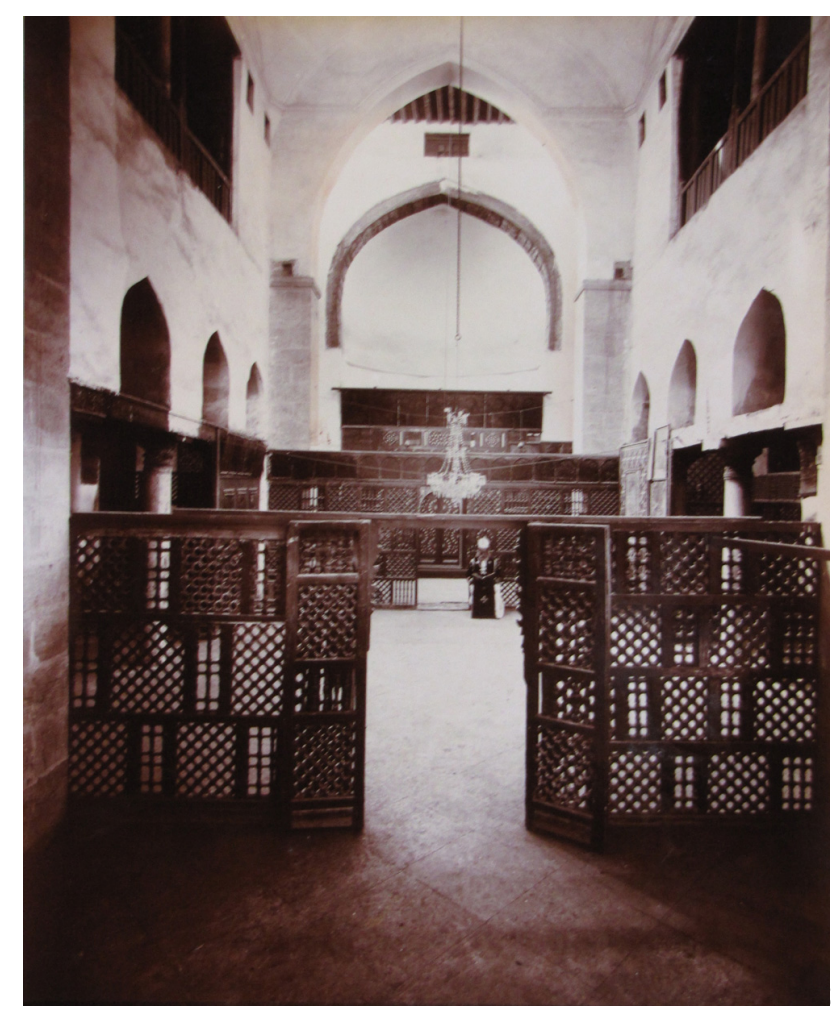

Source : Rome (Italie), Biblioteca

di Archeologia e Storia dell'Arte, Fonds Monneret, boîte 11, carton 1 c 178. 
11a. Achille PATRIColo et Ugo monneret de VILLARD, La Chiesa di Santa Barbara al Vecchio Cairo.

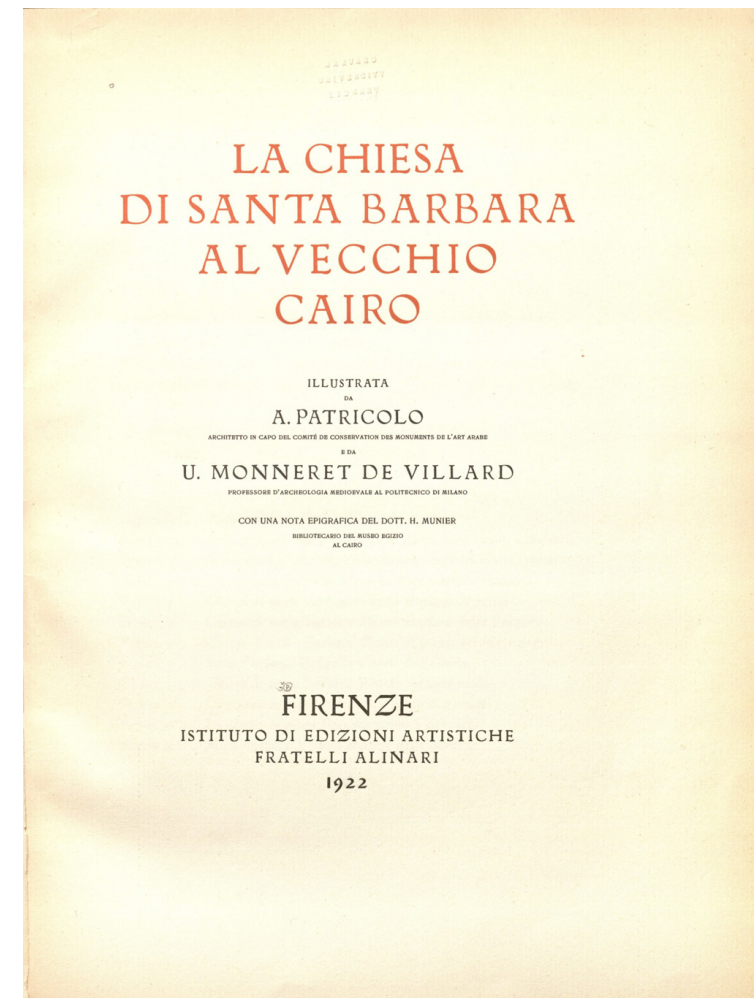

Source : Achille patricolo et Ugo monneret de VILLARD, La Chiesa di Santa Barbara al Vecchio Cairo, Florence : Instituto di Edizioni Artistiche Fratelli Alinari, 1922. 
11b. Dédicace à Strzygowski.

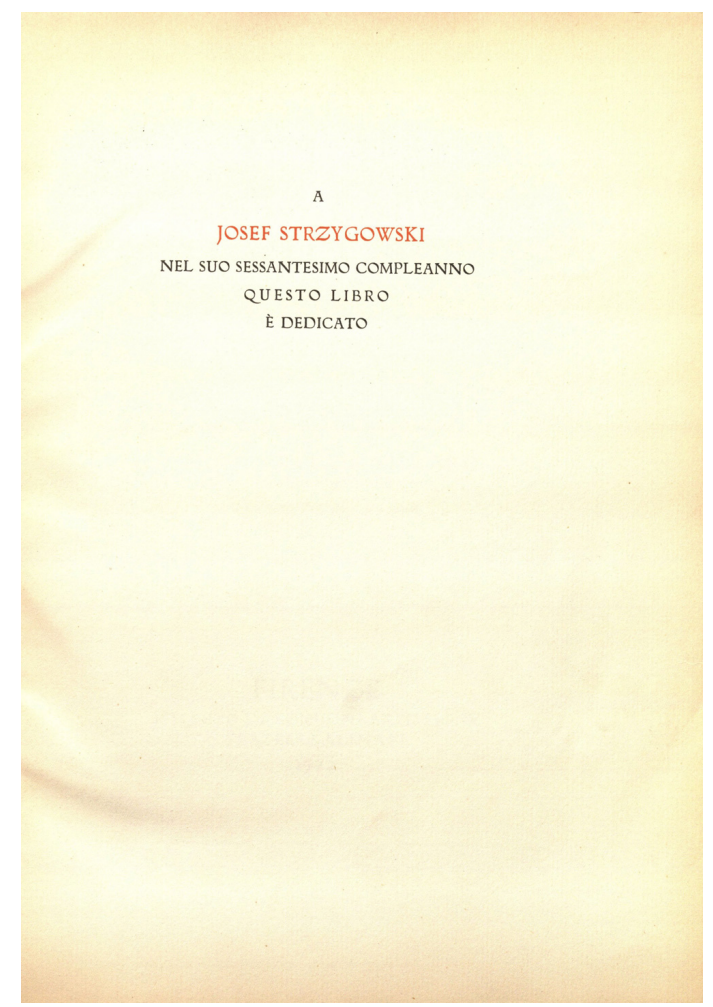

Source : Achille patricolo et Ugo monneret de VILlard, La Chiesa di Santa Barbara al Vecchio Cairo, Florence : Instituto di Edizioni Artistiche Fratelli Alinari, 1922. 
12. Assouan, monastère de Saint-Siméon.

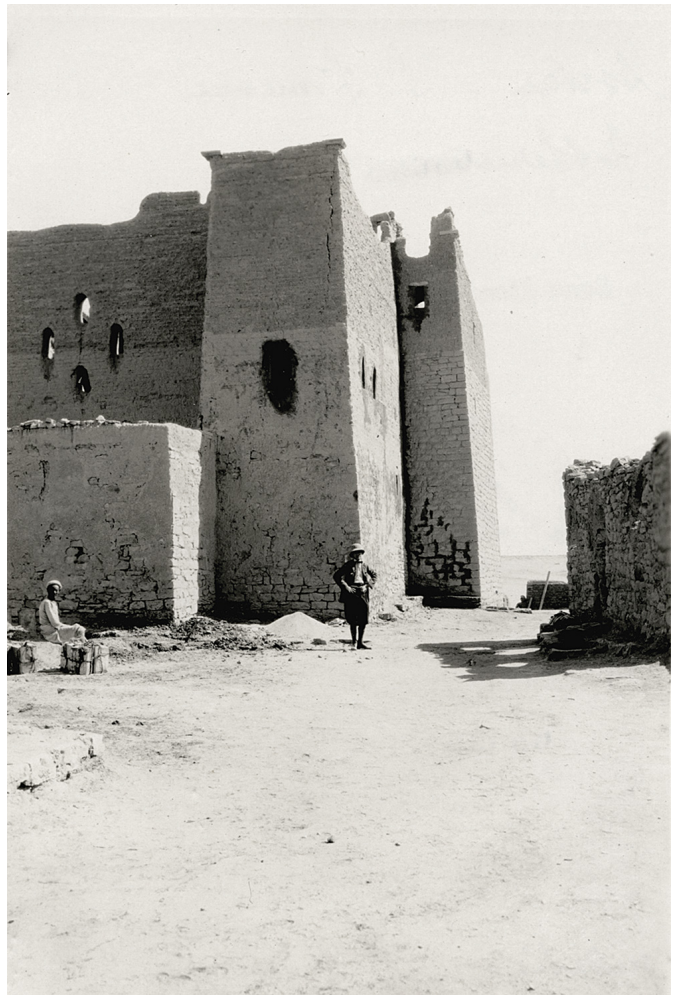

Source : Rome (Italie), Instituto di Archeologia e Storia dell'Arte, Photothèque, Fonds Ugo Monneret de Villard, $n^{\circ}$ inv. 65596.

13. Assouan, monastère de Saint-Siméon.

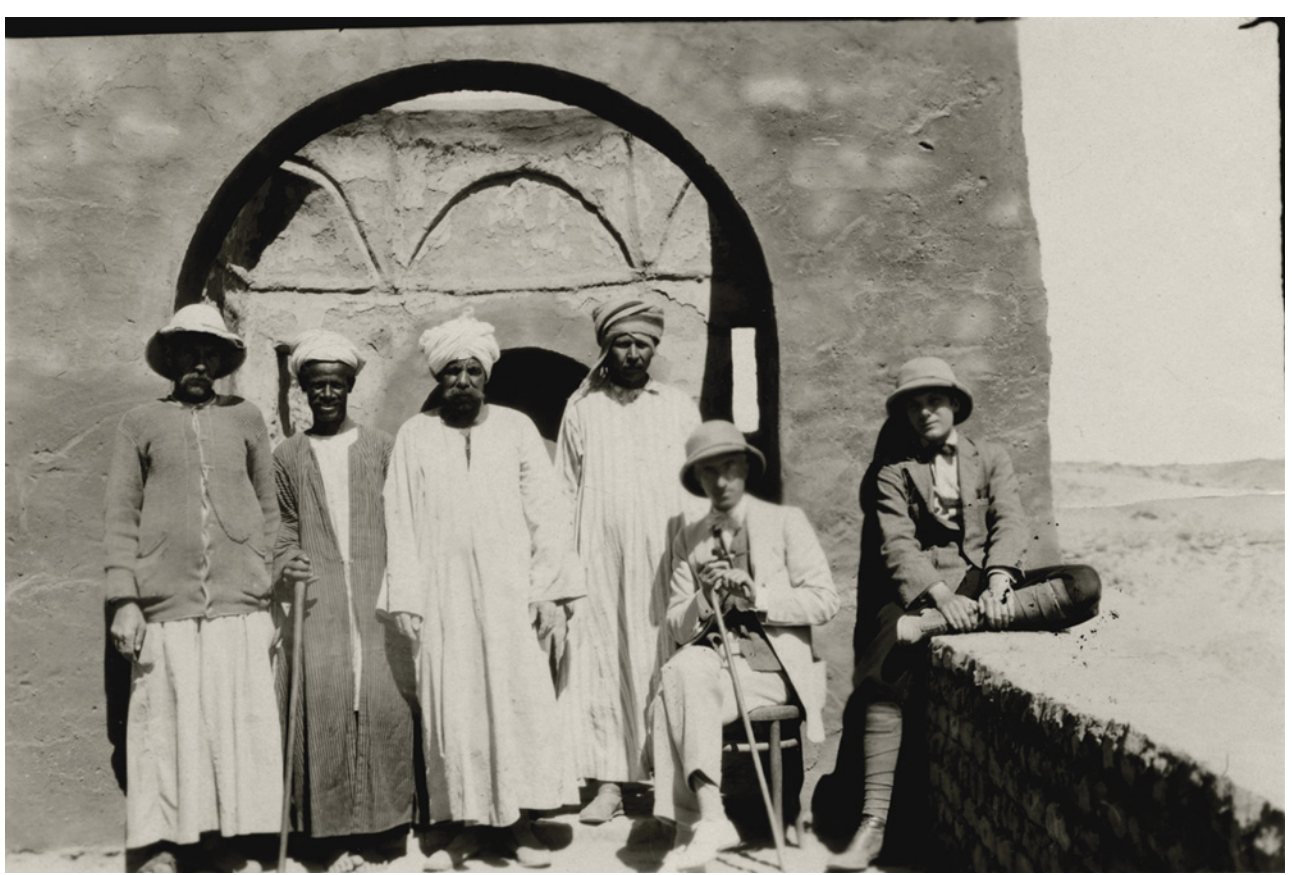

Source : Rome (Italie), Instituto di Archeologia e Storia dell'Arte, Photothèque, Fonds Ugo Monneret de Villard, $n^{\circ}$ inv. 65489 
identifiée grâce à sa mention dans cette lettre. Ce texte signé par Monneret permet de suivre l'évolution de ses positions par rapport à celles de Strzygowski. Monneret expliquait les différentes étapes parcourues par le "grande Maestro Giuseppe Strzygowski » à la recherche des origines de l'art religieux d'Occident, de Constantinople à la Syrie et à la Perse, de l'Arménie à la Transoxiane. Dans son dernier livre, Strzygowski soulignait l'importance des influences aryennes. Monneret déclarait l'impossibilité de suivre dans les détails un tel discours :

In quest'ultimo periodo della sua ricerca lo Strzygowski ha allargato notevolmente le sue tesi : se in origine (e dobbiamo risalire verso il 1900) non è stata se non una reazione alla tendenza romanistica, si è poi venuta evolvendo in una profonda esegesi delle forme artistiche dell'alto medioevo. [...] Certo l'attitudine che tiene il maestro viennese e certi sviluppi un po' paradossali prestano facilmente il fianco a critiche. Ma ben si sa come in una sì vasta ricostruzione non era sempre possibile conservare un olimpico equilibrio e una perfezione irreprensibile in ogni dettaglio [...] E allo Strzygowski dobbiamo essere sempre riconoscenti non solo degli elementi che egli ci ha preparati, ma anche e più della copia di idee fertilizzanti che egli ha gettato a piene mani nel campo dei nostri studit ${ }^{116}$.

Monneret ne manqua pas de souligner l'originalité de l'œuvre, ainsi que la richesse des nouveaux matériaux offerts à la communauté scientifique. Il mentionna la valeur de cette étude et de son analyse des éléments orientaux dans l'architecture romane italienne. Il perçut néanmoins le tournant pris par les écrits plus récents de Strzygowski et les limites d'une pensée trop rigide et souvent bâtie sans aucun 
fondement historique et documentaire. Au sujet de l'architecture romane et de son "évolution" gothique, Monneret écrivit ainsi : «ma anche qui solo l'idea generale è accennata e ne manca ancora la sua esemplificazione dettagliata e la dimostrazione della sua storicità ».

Le bagage positiviste et le poids des conceptions de Croce, opposées aux possibilités de filiation et d'histoire universelle, évitèrent peut-être à Monneret de s'engager sur la voie délirante de Strzygowski? Est-ce à cause de cette conception que l'histoire de l'architecture à travers les siècles de Monneret ne vit jamais le jour?

39 Si pendant sa période de formation, Strzygowski constitua un point de référence fondamental, les écrits les plus récents du professeur autrichien exercèrent une influence plus relative vers 1920. Christina Maranci ${ }^{117}$ a identifié le glissement idéologique de Strzygowski à partir de son ouvrage Die Baukunst der Armenier und Europa (1918) ${ }^{118}$, dans lequel l'étude des origines orientales de l'architecture médiévale faisait place à la recherche du génie du Nord et générait une lecture de l'histoire architecturale fondée sur la race. Monneret ne suivit pas la dérive proto-fasciste de son maître.

\section{L'archéologue Monneret de Villard}

40 Nonobstant les louanges exprimées à Strzygowski au tout début des années 1920, les études de Monneret étaient toujours - et de plus en plus - approfondies du point de vue archéologique et documentaire. Il en arriva même, quelques années plus tard, à critiquer ouvertement l'approche de Strzygowski et à opposer aux "pétillements des théories brillantes mais non démontrées et indémontrables comme les pages de Strzygowski [...] une recherche méthodique, peut-être pas très élégante mais, je l'espère, très sûre ${ }^{119}$ ".

41 Cette approche systématique est flagrante dans ses rapports de missions. Dans ses notes égyptiennes, Monneret présente ses huit années de travail comme un plan organique, articulé autour de différents niveaux progressifs : une première section est dédiée aux monuments ${ }^{120}$; une deuxième à une "esplorazione generale dell'archeologia cristiana d'Egitto ${ }^{121} »$. Le travail de terrain est accompagné par une lecture analytique des textes. Toutes les données sont collectées et classées, en donnant :

a) Una bibliografia generale dell'Egitto cristiano [...]

b) Un dizionario storico-topografico [...]

c) Un repertorio archeologico disposto secondo l'ordine geografico [...]

d) Una serie di fotografie e di disegni $[. . .]^{122}$.

Ce « Repertorio dell'arte cristiana in Egitto » constituait la «base sicura per ogni successiva indagine $^{123} »$.

Sa confiance en l'efficacité scientifique du croisement entre données concrètes et sources documentaires était inébranlable, et témoignait de la formation positiviste du savant. Mais Monneret ne s'arrêta pas à ce stade : il recherchait les influssi esteriori (de la Syrie et de la Mésopotamie, mais aussi de la Perse et de l'Inde) qui avaient contribué à la formation et au déploiement de l'art égyptien au Moyen Âge. Ce dernier niveau s'appuyait sur les phases précédentes de ses recherches, en les valorisant:

Se si vuole che tutti gli elementi raccolti nelle due prime serie di ricerche cessino d'essere inerti e sordi documenti e divengano materia viva di storia, sarà indispensabile determinare esattamente tali influssi, localizzarne e misurarne l'azione, chiarirne la reazione, sviscerare 
cioè tutta la dialettica interna [...] in poche parole, scriverne la storia. È questo lo scopo ultimo al quale debbono tendere le indagini, senza di che esse rimangono astratte alla vita, mera esercitazione erudita ${ }^{124}$.

accepter cette dernière tâche, mais il y était forcé ${ }^{136}$.
La quête des influences orientales reste présente, mais l'idée d'une histoire vivante et dialectique se ressent fortement de la leçon de Croce.

L'organisation structurée du travail apparaît à nouveau pour ses missions en Nubie (1929-1934), avant la construction du barrage d'Assouan ${ }^{125}$. C'est dans ce cadre que Monneret publia sa première étude consacrée exclusivement à des monuments islamiques, La necropoli musulmana di Aswan (1930) ${ }^{126}$ : cette correspondance géographique et chronologique n'est pas fortuite, car son intérêt pour l'archéologie musulmane datait de ses premières explorations de la Nubie ${ }^{127}$.

\begin{abstract}
national était accompagné d'une volonté de pénétration culturelle, alors que les recherches menées en Égypte et en Nubie relevaient d'un engagement scientifique sincère. Les rapports professionnels avec les institutions italiennes étaient fréquents entre 1921 et 1938, pendant l'époque fasciste ${ }^{131}$. La nature des travaux confiés à Monneret en Éthiopie (1936-1938) reste encore à éclaircir : ce n'est pas un hasard si les intérêts de Monneret se poussèrent jusqu'à l'Abyssinie ${ }^{132}$ juste avant la conquête de ces territoires par l'armée italienne et la fondation de l'Impero coloniale par Mussolini en 1936 (fig. 14). Pendant qu'Addis Abeba était conquise, Monneret effectuait une étude topographique de la zone archéologique d'Axoum, finalisée officiellement par la mise en place d'un programme de fouilles ${ }^{133}$. Le financement de recherches topographiques d'intérêt exclusivement archéologique dans des territoires conquis depuis peu par le gouvernement italien paraît étrange, alors qu'à partir de 1933 presque tous les fonds de l'Ufficio delle Missioni Scientifiche in Levante avaient été fortement réduits ${ }^{134}$. Monneret fut aussi chargé du transport de l'obélisque d'Axoum (fig. 15) ${ }^{135}$. Les descendants de Monneret rappellent qu'à son avis la stèle aurait dû rester en Éthiopie. Il eut du mal à

représente la concrétisation de sa méthode et l'aboutissement de ses enquêtes en Afrique. Monneret analysait les rapports économiques, les phénomènes d'immigration et de colonisation dans la péninsule arabe et sur les côtes africaines de la mer Rouge, sans négliger les routes commerciales. Un cadre historique et politique général, des Achéménides au moyen âge, structurait son approche. Alors que ses missions archéologiques se terminaient, il reliait les connaissances acquises à de nouvelles considérations historiques, archéologiques et philologiques. Il en tirait des conclusions originales et opérait une importante distinction entre la production artistique de 'Égypte et celle de l'Afrique nord-orientale ${ }^{129}$. Les données précédemment accumulées étaient valorisées et devenaient significatives grâce à la reconstruction historique.
Monneret parvint à anticiper des résultats archéologiquement confirmés à partir des

années 1950 seulement ${ }^{130}$. Les résultats scientifiques démontrent l'efficacité de sa Les missions archéologiques avaient été souvent conditionnées par les événements ou les stratégies politiques italiennes. L'analyse de l'activité de Monneret pendant cette longue période coloniale révèle un profil assez conflictuel: un véritable orgueil
\end{abstract}

$$
\text { Les }
$$ \\ d.}


14. Groupe avec des militaires à Axoum.

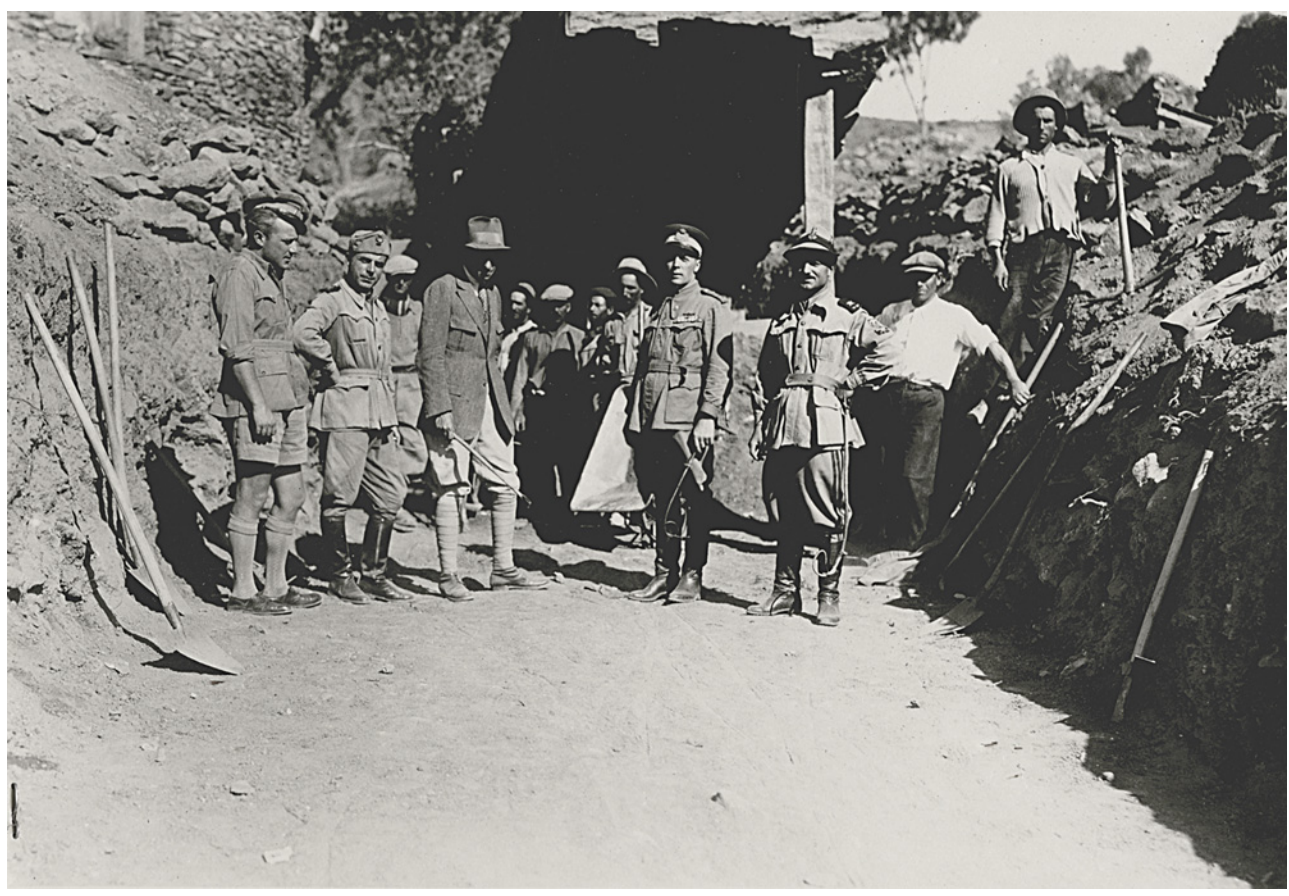

Source : Rome (Italie), Instituto di Archeologia e Storia dell'Arte, Photothèque, Fonds Ugo Monneret de Villard, $n^{\circ}$ inv. 65168.

\section{Stèle d'Axoum en place avant son transport à Rome.}

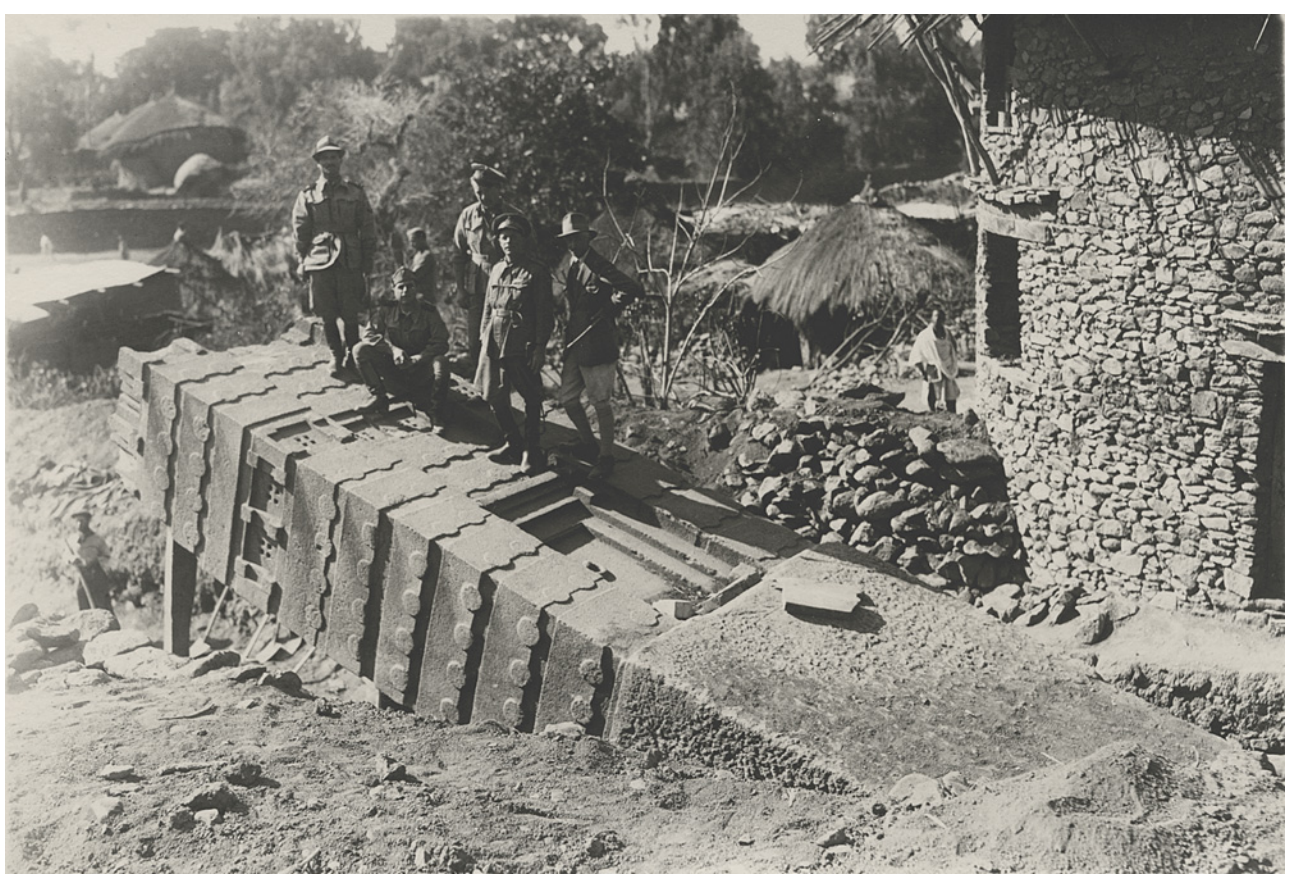

Source : Rome (Italie), Instituto di Archeologia e Storia dell'Arte, Photothèque, Fonds Ugo Monneret de Villard, $n^{\circ}$ inv. 65155

Quelle est donc la relation entre Monneret de Villard, le savoir et le pouvoir? Archéologue passionné, incapable de saisir les enjeux coloniaux de sa démarche? Pion d'un dessein plus vaste pour imposer l'hégémonie culturelle et territoriale italienne 
dans ces régions? Ou plutôt collaborateur conscient du gouvernement fasciste? La question reste ouverte, mais n'est pas le centre de notre réflexion. Comme Marcello Barbanera nous en avertit :

[...] Se bastasse inoltre, per giudicare il valore di un archeologo, verificare le sue aderenze più o meno aperte al fascismo $o$ ad altra ideologia politica, tracciare $\mathrm{i}$ lineamenti della storia dell'archeologia sarebbe oltremodo semplice, ma in gran parte disonesto ${ }^{137}$.

La valeur scientifique des études de Monneret n'a plus besoin d'être justifiée. Ses écrits ne semblent pas se ressentir de conditionnements politiques, voire idéologiques. Le savant paraît même imperméable au «culte de la Romanité » en vogue dans les milieux scientifiques italiens ${ }^{138}$. Il explora des pistes de recherches, telles que l'archéologie médiévale, l'art musulman et l'art chrétien oriental, peu exploitées par ses compatriotes. Ses méthodes de fouille s'opposèrent même aux pratiques aveugles d'autres archéologues travaillant dans les colonies ${ }^{139}$.

Un autre élément, tout à fait nouveau, nous aide à recomposer le contexte: la découverte de la correspondance de Monneret avec Umberto Zanotti Bianco, un antifasciste impliqué dans la question méridionale italienne. Elle révèle leurs rapports amicaux et une collaboration pour réaliser l'étude et la mise en valeur du patrimoine d'art musulman en Italie, ainsi que la fondation d'une chaire d'art islamique au sein de l'Université italienne. Dans les lettres préservées, rédigées par Monneret, il critique les institutions et la science officielle, qui ne s'intéressent pas à ce genre d'études. Ces documents (datés de 1934 à 1938) ont fait l'objet d'une étude parallèle à celle-ci ${ }^{140}$, mais déjà ces quelques éléments aident à rééquilibrer la possibilité de voir Monneret de Villard en collusion intime avec le fascisme, et en tous cas mettent en valeur l'authenticité de son engagement scientifique.

51 Les dernières missions de Monneret datent de la fin des années 1930; il fit de nombreuses tentatives infructueuses pour retourner en Afrique, jusqu'à $1949^{141}$. En 1937, il quitta Milan pour s'installer définitivement à Rome et mettre au point ses recherches précédentes; il désirait s'intéresser à d'autres sujets sur le Moyen âge et l'Orient. L'analyse de sa bibliographie révèle un intérêt croissant pour l'Islam et l'art islamique, souvent fondé sur l'étude d'objets conservés en Italie ${ }^{142}$. Il se consacra aussi à d'importants travaux de synthèse ${ }^{143}$.

52 Le texte posthume Introduzione allo studio dell'archeologia islamica (1966) ${ }^{144}$ est une référence pour l'art islamique, mais il faut aussi mentionner Le pitture musulmane al soffitto della Cappella Palatina in Palermo (1950) ${ }^{145}$. Dans cet ouvrage, aucun aspect de l'étude du monument n'est négligé. Un cadre historique de la peinture islamique et du contexte culturel de la Sicile normande sont mis en valeur, tout comme l'analyse des documents relatifs à la chapelle Palatine, les aspects techniques et structurels des plafonds et l'étude comparative des décorations et de l'iconographie. Tout cela reste néanmoins préliminaire à l'étude de l'œuvre d'art, qui doit être comprise au travers de son style :

Tutto quanto siamo andati sino ad ora dicendo si riferisce solo alla storia esterna delle pitture alla Cappella Palatina: dobbiamo ora entrare nel vivo dell'argomento, ed esaminarle come opere d'arte, intendere quale linguaggio parlano questi artisti, che cosa essi abbiano a 
dirci e ci hanno detto esteticamente, in parole povere ed usando un vecchio termine che trovo sempre ottimo, quale è lo stile di queste pitture ${ }^{146}$. l'idéalisme sur les courants positivistes pendant la première moitié $\mathrm{du} \mathrm{xx}^{\mathrm{e}}$ siècle, Marcello Barbanera définit ces derniers comme un "fiume carsico della cultura italiana", courant peut-être fragile du point de vue théorique, mais toujours présent ${ }^{147}$. S'il est vrai que l'archéologie est un domaine où les deux courants pouvaient facilement coexister ${ }^{148}$, il faut désormais abandonner toutes les étiquettes afin de constater la complexité de l'arrière-plan culturel de Monneret de Villard.

16. Portrait de Monneret de Villard âgé.

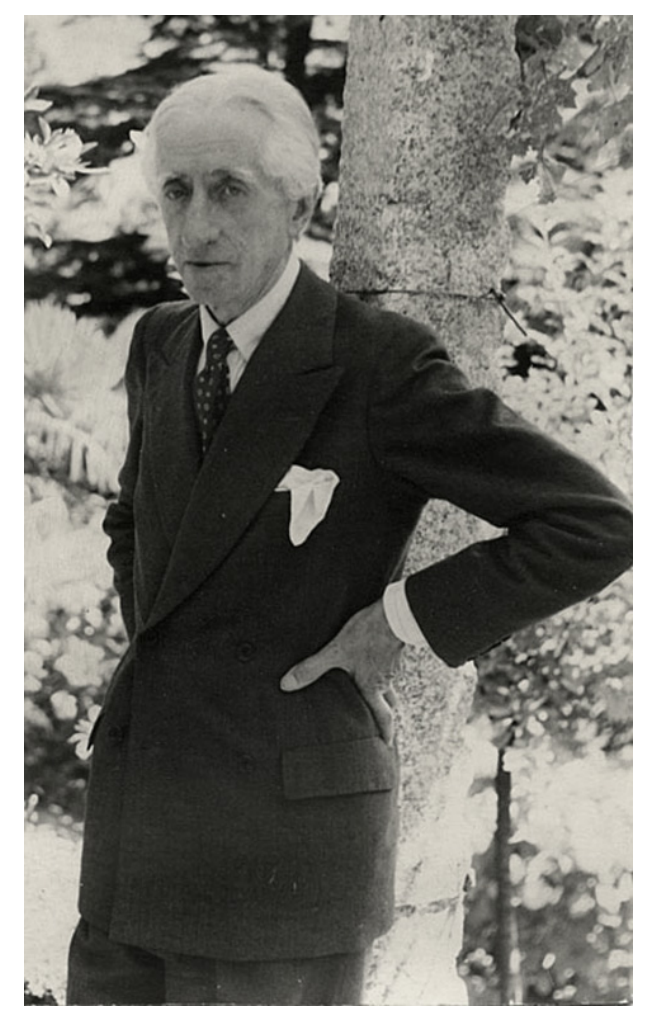

Source : Famille Gavazzi.

Ce cadre s'enrichit aujourd'hui de la figure de Strzygowski. Le savant autrichien représente une source d'inspiration fondamentale : prises d'abord comme modèles, ses études contribuèrent à déclencher l'attrait du jeune Monneret pour l'Oriente. Mais ce dernier s'écarte progressivement des thèses de Strzygowski et il ne le suit pas dans ses visions antihistoriques et racistes. Cette prise de distance doit beaucoup à la 
connaissance de Croce. Monneret et Strzygowski partagent toutefois un intérêt pour les données matérielles, ainsi qu'une attitude fièrement excentrique, irregolare ${ }^{149}$. Cette " irrégularité » Monneret la montre dès sa jeunesse dans sa manière d'apostropher Croce, dans ses lettres à Zanotti Bianco, mais aussi dans ses articles et dans le choix de ses champs d'étude.

Dans le contexte italien, l'intérêt de Monneret de Villard pour l'Oriente et pour les arts islamiques est un phénomène secondaire et original à la fois. Certes, Monneret est un homme de son époque, fasciné par diverses théories d'avant-garde, comme celles proposées par Benedetto Croce et par Josef Strzygowski. Il était " orientaliste », sans doute, et se positionnait à temps, souvent avec opportunisme, au sein des réseaux intellectuels et institutionnels. Pourtant, l'interprétation idéologique de son œuvre se laisse appréhender moins aisément que celles d'autres savants de son époque. Ce sont peut-être son approche interdisciplinaire et son intérêt pour des études subalternes qui lui ont valu son autonomie scientifique et lui ont apporté une grande reconnaissance jusqu'à nos jours.

\section{NOTES}

1. Ugo MONNERET DE VILLARD, «La Missione archeologica italiana in Egitto, 1921-28 ", Oriente Moderno, vol. 8, 1928, p. 270.

2. Ibid., La violence de l'attaque est remarquable surtout si l'on considère qu'au même moment le centre historique de Rome subissait les destructions archéologiques opérée au nom du mythe de la romanité et de l'empire. Voir à ce propos : Daniele MANACORDA, Renato TAMASSIA, Il Piccone del regime, Rome: Armando Curcio, 1985 et Marcello BARBANERA, L'archeologia degli Italiani, Rome: Editori Riuniti, 1998.

3. Voir Andrea AUGENTI, «Per una storia dell' archeologia medievale italiana : Ugo Monneret de Villard ", Archeologia Medievale, n 28, 2001, p. 8-19.

4. Quelques détails des missions peuvent être déduits des comptes rendus et des écrits scientifiques de Monneret. Pour reconstituer ses relations avec les institutions : Marta PETRICIOLI, Archeologia e Mare Nostrum. Le missioni archeologiche nella politica mediterranea dell'Italia 1898/1943. Rome: Valerio Levi Editore, 1990. Pour une bibliographie de Monneret de Villard, voir Angelo Michele PIEMONTESE, «Bibliografia delle opere di Ugo Monneret de Villard (1871-1954)», Rivista degli Studi Orientali, vol. 58, 1984 [1987], p. 1-12. La liste inclut 197 titres. Voir la mise à jour qui comprend 267 titres dans mon mémoire de maîtrise : Silvia ARMANDO, "L'Oriente è paese dalle molte vite e dalle molte storie... » Ugo Monneret de Villard e gli studi di arte islamica in Italia, sous la direction de Maria ANDALORo, Viterbo, Università della Tuscia, Facoltà di Conservazione dei Beni Culturali, 2007. Les nouvelles références bibliographiques ont été tirées principalement d'Alessandro PICCINELLI, Alle origini del Novecento: arte, architettura e città nell'opera di Monneret de Villard (1903-1921), mémoire de maîtrise sous la direction de Guido zucconI, IUAV Venezia, 1985-1986 ; Elisabetta SUSANI, "Gli “scritti rifiutati”. Indagando sui retroscena della formazione al collegio degli ingegneri e architetti di Milano e della damnatio memoriae di certi 'delicta iuventutis' di Ugo Monneret de Villard », in Maria Grazia SANDRI (dir.), L'eredità di Monneret de Villard a Milano, 
Atti del Convegno, Politecnico di Milano 27-29 novembre 2002, Florence : All'insegna del Giglio, 2004, p. 45-61.

5. Ugo MONNERET DE VILLARD, op. cit. (note 1), p. 268. Roberto Paribeni était coordinateur de la plupart des missions archéologiques à l'étranger entre 1919 et 1943 (voir Marta PETRICIOLI, op. cit. (note 4), p. 417). Voir Roberto PARIBENI, Italia e Africa mediterranea, Florence : Sansoni, 1942. Sur PARIBENI voir aussi Bollettino d'arte, $\mathrm{n}^{\circ} 139$, janvier-mars 2007, p. 3-16.

6. Cette connexion a été suggérée dans Maria Grazia SANDRI, «Monneret de Villard nell'archivio del politecnico di Milano », in Maria Grazia SANDRI, op. cit. (note 4), p. 12-13. Sandri propose aussi le nom d'Achille Patricolo. Entre 1908 et 1910, Griffini travailla à la Biblioteca Ambrosiana de Milan, fréquentée aussi par Monneret, ce qui confirmerait un lien possible (sur Eugenio Griffini voir Bruna SORAVIA, "Griffini, Eugenio », in Dizionario biografico degli Italiani, vol. 59, Roma: Treccani, 2002, p. 367-368).

7. Voir Marta PETRICIOLIop. cit. (note 4), p. 250-251.

8. Ibid., p. 252-253. Voir également le très significatif Programma per una missione storicoarcheologica italiana in Oriente (1925), rédigé pour le ministère, voir ibid., p. 256-257. Pour le problème des fonds, voir aussi Ugo MONNERET DE VILLARD, op. cit. (note 1).

9. Le problème du musée fut résolu seulement en 1926, lorsque Gaston Wiet fut nommé directeur: voir André RAYMOND «Bibliographie de l'œuvre scientifique de M. Gaston Wiet ", Bullettin de l'Institut français d'archéologie orientale, $\mathrm{n}^{\circ} 59,1960, \mathrm{p} .9$.

10. Bien qu'il fût terminé en 1924 (Marta PETRICIOLI, op. cit. (note 4), p. 255), je n'ai pas retrouvé d'autres notices concernant le catalogue.

11. Ugo MONNERET DE VILLARD, «Saggio di una bibliografia dell'arte cristiana in Egitto », Bollettino del R. Istituto di Archeologia e Storia dell'Arte, Anno I, 1922, p. 20-32. Marta PETRICIOLI, op. cit. (note 4), p. 254.

12. Ugo MONNERET DE VILLARD, Les Couvents près de Sohag (Deyr el-Abiad et Deyr el-Ahmar). Ouvrage publié sous les auspices du Comité de conservation des monuments de l'art arabe, Milan: Tipografia Editrice Arcivescovile S. Giuseppe, 1925-1926.

13. Marta PETRICIOLI, op. cit. (note 4), p. 255 ; Ugo MONNERET DE VILLARD, « Rapporto preliminare sugli scavi al Monastero di S. Simeone presso Aswan 1924-1925 ", Atti della Reale Accademia Nazionale dei Lincei. Rendiconti, cl. di scienze morali, série VI, vol. 1, 1925, p. 289-303 ; IDEM, "Descrizione generale del monastero di San Simeone presso Aswan ", Annales du Service des antiquités de l'Égypte, Le Caire, $\mathrm{n}^{\circ}$ 26, 1926, p. 211-245. À deux occasions Monneret fut aidé par son élève Ferdinando Reggiori : Marta PETRICIOLI, op.cit. (note 4), p. 255 et Ugo MONNERET DE VILLARD, op. cit. (note 1), p. 271.

14. Ugo MONNERET DE VILLARD, op. cit. (note 1), p. 375.

15. Ibid., p. 383, note introductive signalée par un astérisque.

16. Marta PETRICIOLI, op. cit. (note 4), p. 261.

17. Lors de ses précédentes missions en Égypte, Monneret fut frappé par les monuments de Nubie : Ugo MONNERET DE VILLARD, op. cit? (note 1), p. 275.

18. Ibid., p. 276.

19. Silvia ARMANDO, «Ugo Monneret de Villard (1881-1954) and the Establishment of Islamic Art Studies in Italy », Muqarnas, 2013, p. 35-71.

20. Maria Grazia SANDRI, op. cit. (note 4), p. 9.

21. Elisabetta SUSANI, op. cit. (note 4).

22. À propos de Boito (1836-1914) : Giuseppe MIANO, «Boito, Camillo », in Dizionario biografico degli Italiani, vol. 11, 1969, Rome: Treccani, p. 237-242; Guido ZUCCoNI, L'invenzione del passato. Camillo Boito e l'architettura neomedievale 1885-1890, Venise : Marsilio, 1997 ; Guido zUCCONI et Tiziana SERENA (dirs.), Camillo Boito: un protagonista dell'Ottocento italiano, Venise: Istituto veneto di scienze, 
lettere ed arti, 2002 ; Voir Alessandro PICCINELLI, op. cit. (note 4), p. 18-26, pour les rapports entre Monneret et Boito.

23. Pour avoir une idée de cette variété, voir la bibliographie du savant (voir supra, note 4).

24. Les sollicitations le plus importantes sur ce thème vinrent de Boito, mais aussi de Corrado Ricci : voir Nora LOMBARDINI, « Carteggio Corrado Ricci-Ugo Monneret de Villard (1904-1917) », in Maria Grazia SANDRI, op. cit. (note 4), surtout p. 23-25.

25. Elisabetta SUSANI, op. cit. (note 4), surtout p. 45-49.

26. Monneret collabora avec le Monitore Tecnico, revue des anciens élèves du Politecnico, de 1906 à 1913. Il publia dans La Perseveranza, quotidien de la droite libérale, de 1906 à 1910.

27. Voir particulièrement Ornella SELVAFOLTA, «Ugo Monneret de Villard e gli scritti di architettura moderna », in Maria Grazia SANDRI, op. cit. (note 4), p. 133-146 et Guido ZUcCoNI, «Sitte e l'arte di costruire la città ", ibid., p. 99-103.

28. Note sull'arte di costruire le città, Milan : Società Editrice Tecnico-Scientifica, 1907, représente un point focal de cette réflexion, fondée sur la connaissance de Camillo sITTE, Der Städtebau nach seinen künstlerichen Grundsätzen, Vienne, 1889. Voir Alessandro PICCINELLI, « Monneret de Villard e la versione italiana », in Franco ANGELI et Guido zUcCoNI (éds.), Camillo Sitte e i suoi interpreti, Milan, 1992, p. 29-33.

29. Andrea AUGENTI, op. cit. (note 3), p. 11 et n. 36, Agnese DIONISIO, « Monneret de Villard e la ridefinizione dell'arte dell'area di San Lorenzo », in Maria Grazia SANDRI,op. cit. (note 4), p. 117-122 et Guido ZUCCONI,op. cit. (note 27), p. 103.

30. La dernière contribution au domaine des arts contemporains est Ugo MONNERET DE VILLARD, Opere di architettura moderna, Milan: Società Editrice Tecnico Scientifica, 1909 (voir Ornella SELVAFOLTA, op. cit. note 27). La même année Monneret devint membre de la Società Storica Lombarda, voir Maria Grazia SANDRIop. cit. (note 4), p. 53.

31. La teoria delle proporzioni architettoniche (Milan, 1908) «concerne le architetture egizia, persiana achemenide, siriana, greca, islamica, omayyade, medievale cristiana » : voir Angelo Michele PIEMONTESE, op. cit. (note 4), p. 1.

32. Il s'agit des deux premiers voyages documentés : Nora LOMBARDINI, op. cit. (note 24), p. 26, 27 et n. 28.

33. La lettre, inédite, est conservée à la Scuola Normale Superiore di Pise (Bibliothèque, Collezioni speciali) ; je suis très reconnaissante à Sandra Di Majo, directrice de la bibliothèque, de m'avoir envoyé une copie du document.

Voici quelques extraits de la missive :

Da bordo/ Corfù 22.V.12/ [...] Il mio viaggio aveva uno scopo ben definito, quello di studiare i rapporti fra l'architettura e la decorazione bizantina dei secoli XI-XIII e l'italiana [...] Ma il materiale qui mi si è presentato così vasto, così numeroso, così interessante, che non mi è stato possibile, con i miei limitati mezzi di privato studioso, d'esaurirlo ed è un vero dispiacere, giacché tanto interessante sarebbe tale studio e ricco certamente di preziosi insegnamenti per la storia dell'arte italiana. [...]Sarebbe doloroso che in questo campo che tanto interessa la nostra arte ci lasciassimo avanzare dagli stranieri [...] Coi migliori saluti/ Ugo Monneret de Villard. Pour la correspondance d'A. Venturi, voir Giacomo AGosti (éd.), Adolfo Venturi. Introduzione al Carteggio, 1876-1908, Pisa: Scuola Normale Superiore, 1990; IDEM, Elenco dei corrispondenti, Pise : Scuola Normale Superiore, 1991 et IDEM, Introduzione al Carteggio, 1909-1941, Pisa : Scuola Normale Superiore, 1992.

34. Celui-ci était le premier dédié à l'archéologie médiévale en Italie. Il était renouvelé chaque année jusqu'en 1923-24 (Andrea AUGENTI, op. cit. note 3). Voir aussi Maria Grazia SANDRI, op. cit. (note 4), p. 12.

35. Alfonso воттI, «Giuseppe Prezzolini e il dibattito modernista » (Corrispondenza MonneretPrezzolini), Fonti e Documenti, Centro Studi per la storia del Modernismo. Istituto di Storia dell'Università di Urbino, 11-12, 1982-1983, p. 79-127 : l'auteur a pris en considération les opinions exprimées par 
Monneret à Giuseppe Prezzolini à propos de Croce. Selon Botti, l'image de l'illustre penseur se déprécie progressivement aux yeux de Monneret, qui serait insensible à la fascination de Croce, en révélant sa nature d'intellectuel à contre-courant (voir ibid., p. 91). Selon Alessandro PICcINeLLI (op. cit., note 4), Monneret se libère des processus généalogiques de l'histoire de l'architecture propres à Boito, grâce à l'adoption de quelques principes de l'Estetica de Croce. Notamment, la considération de l'acte créatif comme activité spirituelle de l'individualité de l'artiste est un élément indispensable pour la réalisation des œuvres d'art. Amedeo BELLINI, «La critica d'arte di Monneret de Villard al primo apparire del crocianesimo; un nuovo restauro architettonico?", in Maria Grazia SANDRI, op. cit. (note 4), p. 37-43 : l'auteur a analysé les écrits de Monneret qui abordent ouvertement les nouvelles théories esthétiques en relation à l'architecture. Il croit y lire un parcours qui part de positions positivistes et qui arrive à une adhésion totale aux thèses de Croce (ibid., p. 38, note 1). Santino LANGÉ, « La teoria artistica di Ugo Monneret de Villard : un testamento previo », in Maria Grazia SANDRI, ibid., p. 33-36: l'auteur analyse d'autres textes de Monneret autour de la même question, en concluant que les réflexions de jeunesse représentent une " sintesi di pensiero anticipata ", à laquelle Monneret restera toujours fidèle (ibid., p. 33). Il met également en évidence la difficulté de concilier l'attitude pratique de l'ingénieur-architecte avec l'idéalisme de Croce. Andrea AUGENTI (op. cit. note 3) a analysé la figure de Monneret surtout par rapport à ses activités archéologiques. Il a pris en considération l'attraction du jeune Monneret pour l'idéalisme de Croce, mais il insiste surtout sur l'approche positiviste qui se manifeste dans l'activité des fouilles.

36. J'ai repéré cette correspondance dans les archives de la Fondazione Biblioteca Benedetto Croce (Napoli) : il s'agit de douze unités d'archives datées des années 1905 à 1922.

37. Benedetto CROCE, Estetica come scienza dell'espressione e linguistica generale, Bari : Laterza, 1902. Des réflexions autour des mêmes sujets allaient être publiées dans la revue La Critica, fondée par Croce en 1903.

38. Ugo MONNERET DE VILLARD, « La supremazia della critica », La Perseveranza, 17 août 1905.

39. Monneret avait en vain espéré rencontrer le philosophe à l'Exposition de Venise. Il fit finalement sa connaissance à Milan en octobre 1905 (Alfonso BOTTI, op. cit. (note 35), lettre 16, p. 108 et lettre 20, p. 111).

40. Monneret écrivait à Prezzolini «Appena la salute me lo permetterà mi metterò all'Architettura. Annunci pure a Croce un attacco in piena regola", mais aussi : "Prego [...] di vagliare bene il valore dell'Architettura prima di pubblicarlo. L'ho scritto in un cattivo momento e dubito molto " (Alfonso Botti, op. cit. (note 35) : lettre 15, p. 106 et lettre 18, p. 110).

41. Ugo MONNERET De VILLARD, «Per l'Estetica di Benedetto Croce e l'architettura », Leonardo, Rivista critica di Fatti e di Idee, vol. 3, ottobre-dicembre 1905, II s., p. 174-176. Voir Alfonso BELLINI, op. cit. (note 35), p. 38-39; d'autres commentaires se trouvent dans Santino LANGÉ, op. cit. (note 35), p. 33-34.

42. La revue fondée en 1903 par Giovanni Papini et Giuseppe Prezzolini, était conçue comme un pendant de La Critica de Croce ; voir Mario QUARANTA, «Il Leonardo nel giornalismo italiano del primo Novecento ", Leonardo, t. I, 1903-1905 ; t. II, 1906-1907, riletto da Mario Quaranta e Laura Schram Pighi, Sala Bolognese : Arnaldo Forni Editore, 1981. Papini et Prezzolini étaient dans l'orbite des mouvements catholiques du Modernismo, auquel Monneret de Villard participa de manière occasionnelle. Tous les trois coopéraient à un projet pour la publication d'une série dédiée aux auteurs mystiques. Le projet n'aboutit jamais à cause des divergences avec les deux promoteurs Tommaso Gallarati Scotti et Umberto Pestolazza (Alfonso вотTI, op. cit. (note 35), surtout p. 85-91). Des références à la question se trouvent aussi dans les premières lettres envoyées à Croce par Monneret.

43. Ugo MONNERET DE VILLARD, op. cit. (note 41), p. 174. 
44. Monneret faisait référence à l'Estetica, mais aussi à Benedetto CROCE, «Di alcune difficoltà concernenti la storia artistica dell'architettura », La Critica, vol. 2, 1904, p. 412-417.

45. Ugo MONNERET DE VILLARD, op. cit. (note 41), p. 175-176.

46. Ibid., p.176.

47. Alfonso BELLINI, op. cit. (note 35), p. 39.

48. Naples, Fondazione Biblioteca Benedetto Croce, Archivio privato di Benedetto Croce, Cor 707, lettre datée du 23 décembre 1905. Dans la lettre du 30 octobre 1905 (ibid., Cor 706), Monneret avait déjà annoncé qu'il allait publier dans Leonardo un article à propos de l'Estetica. L'échange continua après la sortie du texte : le 21 janvier 1906 (Naples, Fondazione Biblioteca Benedetto Croce, Cor 691) Monneret mentionnait un article par De Rinaldis qui lui avait été envoyé par Croce et annonça sa réponse. Malheureusement je n'ai pas trouvé l'article mentionné : pour les années 1905-1906, le texte ne figure ni dans La Critica ni dans Napoli Nobilissima (autre revue liée à Benedetto Croce et dans laquelle Aldo De Rinaldis publie plus tard).

49. 4 février 1906 (Naples, Fondazione Biblioteca Benedetto Croce, Archivio privato di Benedetto Croce, Cor 692). Le 7 février, Monneret se plaignait avec Prezzolini: " $E$ Croce non risponde!» (Alfonso BоTтI, op. cit. (note 35), lettre 26, p. 117); le 14 février 1906, il écrivait de même à son ami Alessandro Casati: "Io sono in gran dibattito con Croce per la questione dell'Architettura. Croce forniva le risposte con lettere ma promette una risposta pubblica che attendo con molto desiderio ». La correspondance Monneret-Casati a été repérée dans les archives de la Biblioteca Ambrosiana (Milan) (Casati 42 busta 16). Il s'agit de 54 unités datées de 1906 à 1948.

50. Benedetto CROCE, « Le antinomie della Critica », La Critica, vol. 4, 1906, p. 325-328.

51. Ibid., p. 326. D’ailleurs déjà dans le programme de La Critica, Croce avait insisté sur l'importance de la méthode philologique et historique, qui nécessitait pourtant d'être complétée par un retour à l'idéalisme (Benedetto CROCE, « Programma de La Critica rivista di storia letteratura e filosofia » ensuite publié dans IDEM, Conversazioni critiche, serie II, Bari : Laterza, 1918, appendice).

52. Ugo MONNERET DE VILLARD, «Le antinomie della critica », La Perseveranza, 2 janvier 1907.

53. 6 janvier 1907 (Naples, Fondazione Biblioteca Benedetto Croce, Archivio privato di Benedetto Croce, Cor 805).

54. Ibid., "Per concludere mi sembra ora [?] che l'opera di critica d'arte sia anch'essa un'opera d'arte. Forse prendo un grosso abbaglio !».

55. Voir en particulier les commentaires des écrits sur Giorgione, Pietro Longhi et Anglada dans Elisabetta SUSANI, op. cit. (note 4), p. 56-57.

56. Ibid., p. 49 et note 45.

57. Ugo MONNERET DE VILLARD, «Le forme architettoniche e la materia », Monitore Tecnico, vol. 22, 10 août 1908 , p. 433-435.

58. Ugo MONNERET DE VILLARD, op.cit. (note 41), p. 175-176. Notamment, Monneret revenait sur l'idée que "l'artista pensa in una data materia ", avec une série d'exemples qui démontrait que les mêmes formes étaient souvent réalisées avec des matériaux différents. Il ne fallait donc pas penser le rapport entre architecture et matériaux comme déterminé a priori, mais non plus nier l'influence de ces derniers sur l'art de bâtir (Ugo MONNERET DE VILLARD, op. cit. note 57).

59. Ugo MONNERET DE VILLARD, « La libertà nell'architettura », Monitore Tecnico, vol. 15, 20 mai 1909, p. 268-270.

60. Dans Alfonso BELLINI, op. cit. (note 35), p. 40, on identifie ce moment comme « svolta crociana».

61. Ugo MONNERET DE VILLARD, op. cit. (note 59), p. 268-269.

62. Parmi les textes de Monneret de Villard préservés dans la bibliothèque de Benedetto Croce, il est opportun de mentionner: «La supremazia della critica » et «Le antinomie della critica d'arte» (dans les coupures de La Perseveranza); «Per l'Estetica di Benedetto Croce e l'architettura » (Leonardo était régulièrement envoyé au philosophe). Une lacune significative est «Le forme architettoniche e la materia» (Monitore Tecnico); l'article ne fut pas envoyé par 
Monneret, si l'on en croit le vide de la correspondance entre le 6 janvier 1907 et le 29 novembre 1909.

63. Ugo MONNERET DE VILLARD, op. cit. (note 59) ; voir aussi Santino LANGÉ, op. cit. (note 35), p. 34-35.

64. Ugo MONNERET DE VILLARD, op. cit. (note 31) ; Santino LANGÉ, op. cit. (note 35), p. 35-36.

65. Ugo MONNERET DE VILLARD, «Del simbolismo architettonico », Il Rinnovamento, anno II, 1908, p. $125-174$.

66. Lettre (Naples, Fondazione Biblioteca Benedetto Croce, Cor 912), 29 novembre 1909 : « Mi sono permesso di inviarle un $\mathrm{N}$ del Monitore Tecnico con un mio articoletto che non è se non il rapido riassunto della prima parte di un grosso, troppo grosso! volume a cui lavoro da anni [...] Intanto mi permetto di sottoporle la tesi della Ia parte, pregandola di volermi, se il tempo glielo permette, farmi tutte le osservazioni e le critiche che crederà ». Le sujet de la préparation d'un ouvrage important dédié à l'architecture revient souvent dans les lettres de Monneret. Voir par exemple Alfonso воттI, op. cit. (note 35) : lettre 38, p. 126-127, datée de janvier 1911.

67. Ugo MONNERET DE VILLARD, op. cit. (note 65), p. 128.

68. Les nombreuses références à l'architecture musulmane dévoilent un intérêt précoce. Les œuvres mentionnées sont les manuels d'Albert GAYET, L'Art arabe, Paris : Librairies-imprimeries réunies, 1893 et Henri SALADIN, Manuel d'art musulman, Paris : A. Picard, 1907.

69. Ugo MONNERET DE VILLARD, op. cit. (note 65), p. 164.

70. Ugo MONNERET DE VILLARD «Del metodo nello studio dell'architettura medioevale », Atti del Collegio degli Ingegneri ed Architetti di Milano, anno LI, juillet 1917-décembre 1918, p. 22-62.

71. Lettre du 11 novembre 1918 (Naples, Fondazione Biblioteca Benedetto Croce, Archivio privato di Benedetto Croce, Cor 950) : « Mi permetto mandarle un opuscoletto nel quale ho pubblicato, più che altro per utilità dei miei scolari, un sunto del mio corso di archeologia medioevale, tenuto al Politecnico nel 1917-1918. » Cela confirme que Monneret concevait l'archéologie médiévale comme une section de l'architecture (Andrea AUGENTI, op. cit. (note 3), p. 9).

72. Voir supra (note 66).

73. À côté de l'Estetica, citée tout au long du texte, on retrouve aussi des références à Problemi di estetica (1911) et à Teoria e storia della storiografia (version définitive 1917).

74. Ugo MONNERET DE VILLARD, op. cit. (note 70), p. 24 -25.

75. Ibid., p. 43.

76. Ibid., p. 32.

77. Ibid., p. 33.

78. Ibid.

79. Ibid.

80. Ibid., p. 26.

81. Ibid., p. 48-55.

82. Ibid., p. 56-60.

83. Voir Ornella SELVAFOLTA, op.cit. (note 27), p. 134-141; pour les écrits villardiens relatifs à Vienne : Elisabetta SUSANI, op. cit. (note 4), p. 51 ; voir aussi supra (note 27).

84. Voir en particulier Suzanne MARCHAND, "The Rhetoric of Artifacts and the Decline of Classical Humanism: The Case of Josef Strzygowski », History and Theory, 33, 1994, p. 106-130. Voir aussi Edwin LACHNIT, "Josef Strzygowski », in The Dictionary of Art, London : Macmillan, 1996, vol. 29, p. 795-796.

85. Josef STRZYGowsKI, Orient oder Rom. Beiträge zur Geschichte der spätantiken und frühchristlichen Kunst, Leipzig : Hinrichs, 1901.

86. Les rapports intellectuels entre la capitale viennoise et Milan étaient encore intenses à cette époque (Ornella SELVAFOLTA, op. cit. (note 27), p. 138).

87. Gustavo Giovannoni avait confirmé en 1902 les théories proposées l'année précédente par Giovanni Teresio Rivoira: Gustavo GIovANNONI, «Recenti studi sulle origini dell'architettura 
lombarda ", Nuova Antologia, vol.37, juillet 1902, p. 773 ; Giovanni Teresio RIVoIRA, Le origini dell'architettura lombarda e delle sue principali derivazioni nei paesi d'oltralpe, Rome : Loescher, 2 vol., 1901-1907. Pour une synthèse sur la question : Annabel Jane WHARTON, Refiguring the Post-Classical City, Dura Europos, Jerash, Jerusalem and Ravenna, Cambridge : Cambridge University Press, 1995, p. 4-11.

88. Ugo MONNERET DE VILLARD, «La chiesa di S. Lorenzo in Milano. Studio del tracciato planimetrico », Il Monitore Tecnico, vol. 16, 1910, p. 388-390; IDEM, « Intorno al S. Lorenzo di Milano. Note sull'origine del tipo planimetrico », ibid., [1910], p. 591-593, 631-634, 651-654. Les œuvres de Strzygowski les plus citées par Monneret sont Josef stRZYGowsKI, Kleinasien, ein Neuland der Kunstgeschichte, Leipzig: Hinrichs, 1903 et Max VAN BERCHEM, Josef STRZYGOWSKI, Amida, matériaux pour l'épigraphie et l'histoire musulmanes du Diyar-Bekr, Beiträge zur Kunstgeschichte des Mittelalters von Nordmesopotamien, Heidelberg : C. Winter, 1910.

89. Ugo MONNERET DE VILLARD, «La chiesa di S. Lorenzo in Milano. Studio del tracciato planimetrico ", op. cit. (note 88), 1910, p. 388. Le monument est aujourd'hui généralement daté au $\mathrm{V}^{\mathrm{e}}$ siècle, c'est-à-dire avant l'âge d'or de Justinien à Ravenne. Voir Angiola Maria ROMANINI (dir.), Il Medioevo, Florence : Sansoni, 1988, p. 70-72 et 96-98. Sur l'architecture lombarde en général, mais sur San Lorenzo en particulier, Rivoira et Giovannoni reconnaissaient leur origine dans l'architecture romaine.

90. Ugo MONNERET DE VILLARD, «La chiesa di S. Lorenzo in Milano. Studio del tracciato planimetrico », op. cit. (note 88), 1910, p. 389.

91. Ugo MONNERET DE VILLARD, «Intorno al S. Lorenzo di Milano. Note sull'origine del tipo planimetrico », op. cit. (note 88), p. 653.

92. À propos de la méthode comparative de Strzygowski : Maurice S. DIMAND, «In memoriam Josef Strzygowski (1862-1941)», Ars Islamica, vol.7, 1940, p. 177 et Ernst HERZFELD, Wilhelm Reinhold KOEHLER, Charles Rufus MOREY, « Josef Strzygowski », Speculum, vol. 17, 1942, p. 460-461.

93. La mise en évidence d'analogies et de différences dans les plans d'édifices parfois très variés donne l'impression d'être un jeu qui permet à Monneret de supposer des influences, par exemple : «Se alla S. Sofia di Adrianopoli immaginiamo aggiunta la cupola centrale ed un deambulatorio circolare otteniamo S. Giorgio di Etschmiadsin. Se le quattro nicchie non sono, come qui, tangenti fra di loro, ma occupano la parte centrale dei lati di un recinto rettangolare, ed il tracciato esterno del deambulatorio non è più circolare ma parallelo al primo, con le esedre corrispondenti, si genera l'edificio di Rusafa (491-501), identico al S. Lorenzo di Milano, salvo che il secondo ha forma quadrata mentre il primo l'ha rettangolare. » (Ugo MONNERET DE VILLARD, «Intorno al S. Lorenzo di Milano. Note sull'origine del tipo planimetrico », op. cit. (note 88), p. 653.)

94. Ibid.

95. Ugo MONNERET DE VILLARD, «L'architettura romana negli ultimi secoli dell'impero », Atti del Collegio degli Architetti e degli Ingegneri di Milano, vol. 48, Milan, 1915, p. 9-10 (cité par Alessandro PICCINELLI, op. cit. (note 4), p. 52).

96. Ugo MONNERET DE VILLARD, op. cit. (note 70), p. 46.

97. Ibid., p. 48.

98. Ibid., p. 24-25.

99. Dans l'étude sur San Lorenzo, l'analyse du plan était accompagnée de la recherche de dessins anciens. Ensuite, la recherche archéologique était très souvent étayée par l'étude philologique.

100. Voir supra (note 90).

101. Annabel Jane WHARTON, op. cit. (note 87), part. p. 2-4.

102. Voir supra p. 366. Josef STRZYGowSKI, Spalato, ein Markstein der romanischen Kunst bei ihrem Übergange vom Orient nach dem Abendlande, Freiburg, 1906. Ugo MONNERET DE VILLARD, « Il Palazzo di Costantino e di Giustiniano », Il Monitore Tecnico, vol. 16, 1910, p. 530-531; ID., « Studi sull'arte di costruire le città. Spalato ", Il Monitore Tecnico, vol. 19, 1913. 
103. Strygowski était en Égypte en 1894-1895 et de nouveau autour de 1900. Sur cette mission, voir Gabriele MIETKE, Petra LINSCHEID, «Josef Strzygowskis Erwerbungen in Ägypten », Museum Journal, vol. 15, n 1, 2001, p. 86-87.

104. Voir supra, p. 363.

105. Josef STRZYGowsKI, Koptische Kunst (Catalogue général des antiquités égyptiennes du Musée du Caire), Wien, 1904.

106. La chiesa di Santa Barbara al Vecchio Cairo illustrata da A. Patricolo e da U. M. de V., Florence : Istituto di Edizioni artistiche Fratelli Alinari, 1922.

107. Ibid., p. 51-54.

108. Ugo MONNERET DE VILLARD, « Saggio di una bibliografia dell'arte cristiana in Egitto », Bollettino del R. Istituto di Archeologia e Storia dell'Arte, anno I, 1922, p. 20-32.

109. Ugo MONNERET DE VILLARD, "Ricerche sulla topografia di Qasr es-Sam », Bulletin de la Société royale de géographie d'Égypte, vol. 12, 1924, p. 205-232 ; vol. 13, 1924, p. 73-94.

110. Sont exemplaires les cas de Benedetto Croce, Corrado Ricci, Adolfo Venturi...

111. Je tiens à exprimer toute ma gratitude à Annegret Plontke-Luening pour m'avoir envoyé une copie de cette lettre, conservée dans les Archives de l'Institut für Kunstgeschichte à Vienne (Autriche).

112. Monneret accusait réception de fascicules non identifiés et envoya en échange son étude sur les vitraux de la cathédrale de Milan (Le vetrate del Duomo di Milano. Ricerche storiche, Milan: Alfieri \& Lacroix, 3 vol. 1918-1920).

113. Le livre en préparation sur l'histoire de l'architecture est mentionné une fois de plus. Une attention spéciale est donnée aux rapports entre Lombardie et Arménie, et Monneret fait référence à Josef sTRZYGowsKI, Die Baukunst der Armenier und Europa, Vienne: Kunstverlag A. Schroll \& Co, 1908.

114. D'autres sujets sont abordés dans cette lettre : notamment Monneret annonçait un article sur le calice d'Antioche (jamais paru). En outre, Monneret mentionnait une recension de Strzygowski à propos de Ugo MONNERET DE VILLARD, « Note di Archeologia lombarda », Archivio Storico Lombardo, anno XLI, 1914, p. 5-70 (Josef Strzygowski dans Byzantinische Zeitschrift, 23, 1919). Monneret justifia le manque de références à l'architecture arménienne dans son livre par le fait qu'il n'avait pas pu consulter Die Baukunst der Armenier à cause de la guerre.

115. Ugo MONNERET DE VILLARD, « Rec. di J. Strzygowski, Ursprung des Christlichen Kunst, Berlin, 1920 », Architettura e Arti Decorative, vol. 2, 1921, p. 210-211.

116. Ibid.

117. Christina MARANCI, Medieval Armenian Architecture: Constructions of Race and Nation, Louvain : Peeters, 2001, part. p. 120.

118. Josef STRZYGOWSKI, op. cit. (note 113).

119. Ugo MONNERET DE VILLARD, op. cit. (note 12), p. 48.

120. Ugo MONNERET DE VILLARD, op. cit. (note 1), p. 272-274.

121. Ibid., p. 274.

122. Ibid., p. 275.

123. Ibid.

124. Ibid., p. 276-277.

125. Voir Ugo MONNERET DE VILLARD, «La missione italiana nella Nubia Cristiana ", Bollettino dell'Associazione Internazionale di Studi Mediterranei, anno II/3, août-septembre 1931, p. 19-23. Une fois de plus, Monneret s'opposait à ceux qui, à la recherche des monuments plus anciens, détruisaient les vestiges médiévaux. (Ugo MONNERET DE VILLARD, La Nubia Medioevale: Volume Primo, Inventario dei Monumenti; Volume Secondo, Tavole I-C; Volume Terzo, Origine e sviluppo delle forme monumentali ; Volume Quarto, Tavole CI-CCIII, Le Caire : Imprimerie de l'IFAO, 1935-1957). 
126. Ugo MONNERET DE VILLARD, La necropoli musulmana di Aswan, Le Caire : Imprimerie de l'IFAO, 1930.

127. Voir supra p. 364.

128. Ugo MONNERET DE VILLARD, « Note sulle influenze asiatiche nell'Africa orientale ", Rivista degli Studi Orientali, vol. 17, 1938, p. 303-349.

129. Voir aussi Giorgio LEVI DELLA VIDA, « Ugo Monneret de Villard (1881-1954) », Rivista degli Studi Orientali, vol. 30, 1955, p. 175.

130. Les enquêtes archéologiques menées en Afrique orientale ont confirmé l'existence de colonies islamiques, la présence d'éléments persans, somaliens et indiens et le rôle fondamental du commerce pour la propagation desdits éléments : Stephen J. VERNOIT, "The Rise of Islamic Archaeology ", Muqarnas, $\mathrm{n}^{\circ}$ 14, 1997, p. 7-8.

131. Marta PETRICIOLI, op. cit. (note 4).

132. Le premier texte sur le sujet est «Un tipo di chiesa abissina ", Africa Italiana, Rivista di storia e d'arte a cura del Ministero delle Colonie, vol. 6, 1935, p. 83-91.

133. Ugo MONNERET DE VILLARD, Aksum. Ricerche di topografia generale, Rome : Pontificium Institutum Biblicum, 1938 (Analecta Orientalia, Commentationes scientificae de rebus Orientis antiqui, 16).

134. Marta PETRICIOLI, op. cit. (note 4), p. 306 -310.

135. Monneret dirigea le transport jusqu'à Massaoua. Ugo MONNERET DE VILLARD, op. cit. (note 128), p. V; Francesca ZANNONI, «Il carteggio e l'archivio di studio di Ugo Monneret de Villard nella Biblioteca di archeologia e storia dell'arte di Roma ", in Maria Grazia SANDRI, op. cit. (note 4), p. 17-18.

136. L'information m'a été aimablement communiquée par $M^{\text {me }}$ Sabina Gavazzi, nièce de Monneret de Villard. Apparemment Monneret accepta la tâche sur l'insistance d'Amedeo, Duca d'Aosta, qu'il estimait beaucoup, mais il aurait préféré laisser l'obélisque sur place et en approfondir l'étude, pour comprendre aussi les raisons historiques pour lesquelles il gisait à terre en morceaux.

137. Marcello BARBANERA, op. cit. (note 2), p. 85.

138. Sur le culte de la Romanitas à l'époque fasciste et préfasciste, ibid., p. 144-154.

139. Ibid., p. 154.

140. Silvia ARMANDO, op. cit. (note 19).

141. Francesca ZANNONI, op. cit. (note 135), p. 18.

142. Voir aussi Silvia ARMANDO, op. cit. (note 19).

143. Monneret collabora notamment à l'Enciclopedia Cattolica. Autre importante contribution générale: Ugo MONNERET DE VILLARD, "Arte cristiana e musulmana del Vicino Oriente ", in Giuseppe TUCCI (dir.), Le Civiltà dell'Oriente, Rome : Gherardo Casini editore, 1962, vol. 4, p. 451-462.

144. Ugo MONNERET DE VILLARD, Introduzione allo studio dell'archeologia islamica. Le origini e il periodo Omayyade. Venise-Rome : Istituto per la collaborazione culturale, 1966 (Civiltà veneziana. Studi, 20).

145. Le Pitture musulmane al soffitto della Cappella Palatina in Palermo. Rome : La Libreria dello Stato, 1950.

146. Ibid., p. 49.

147. Voir Marcello BARBANERA, op. cit. (note 2), p. 85.

148. Voir Sergio ROMANO, "Prefazione ", in Marta PETRICIOLI, op. cit. (note 4), p. XI.

149. Giorgio LEVI DELLA VIDA, op. cit. (note 129), p. 98 ; Suzanne MARCHAND, op. cit. (note 84). 


\section{AUTEUR}

\section{SILVIA ARMANDO}

Docteur en histoire de l'art, Università della Tuscia, Viterbo ; spécialiste de l'œuvre de Monneret de Villard. 